\title{
Southeast Asia in the ancient Indian Ocean
}

\section{World}

Combining historical linguistic and archaeological approaches

\author{
Tom Hoogervorst \\ Linacre College \\ tomhoogervorst@hotmail.com
}

Thesis submitted to the University of Oxford for the degree of D.Phil in Archaeology

\author{
Supervised by \\ Dr. Nicole Boivin (University of Oxford) \\ Prof. Chris Gosden (University of Oxford)
}




\section{Abstract}

This thesis casts a new light on the role of Southeast Asia in the ancient Indian Ocean World. It brings together data and approaches from archaeology and historical linguistics to examine cultural and language contact between Southeast Asia and South Asia, East Africa and the Middle East. The interdisciplinary approach employed in this study reveals that insular Southeast Asian seafarers, traders and settlers had impacted on these parts of the world in premodern times through the transmission of numerous biological and cultural items. It is further demonstrated that the words used for these commodities often contain clues about the precise ethno-linguistic communities involved in their transoceanic dispersal.

The Methodology chapter introduces some common linguistic strategies to examine language contact and lexical borrowing, to determine the directionality of loanwords and to circumvent the main caveats of such an approach. The study then proceeds to delve deeper into the socio-cultural background of interethnic contact in the Bay of Bengal and the Indian Ocean as a whole, focusing on the oft-neglected Southeast Asian contributions to the cultural landscape of this region and addressing the nature of pre-modern contact between Southeast Asia and the different parts of the Indian Ocean Word. Following from that, the last three chapters look in-depth at the dispersal of respectively Southeast Asian plants, spices and maritime technology into the wider Indian Ocean World. Although concepts and their names do not always neatly travel together across ethno-linguistic boundaries, these chapters demonstrate how a closer examination of lexical data offers supportive evidence and new perspectives on events of cultural contact not otherwise documented.

Cumulatively, this study underlines that the analysis of lexical data is a strong tool to examine interethnic contact, particularly in pre-literate societies. Throughout the Indian Ocean World, Southeast Asian products and concepts were mainly dispersed by Malay-speaking communities, although others played a role as well. 
Table of contents

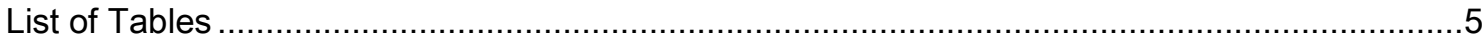

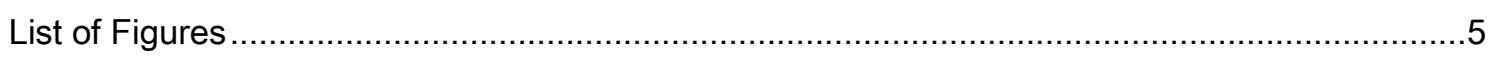

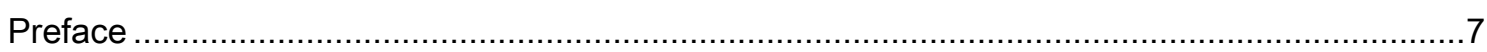

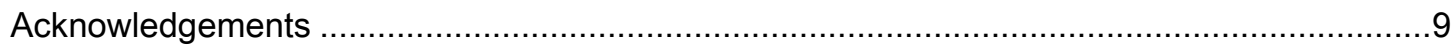

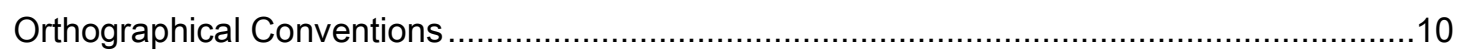

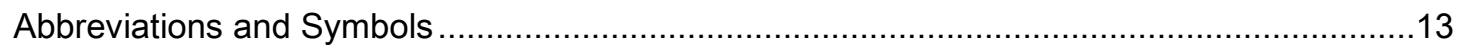

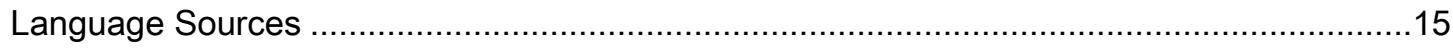

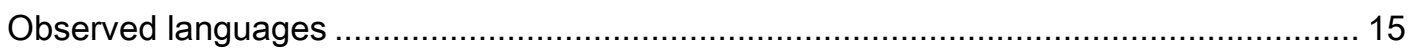

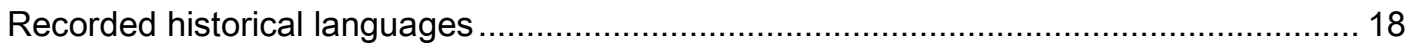

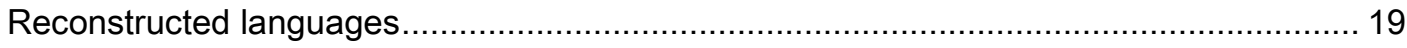

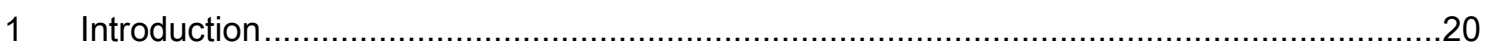

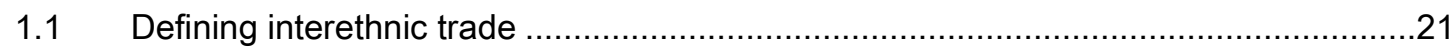

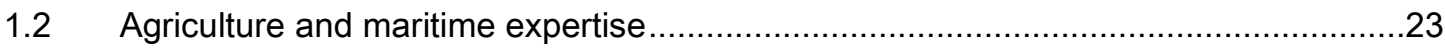

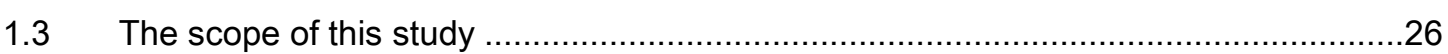

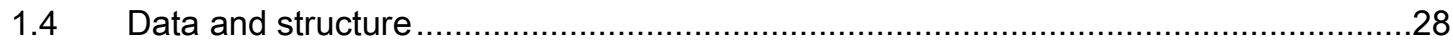

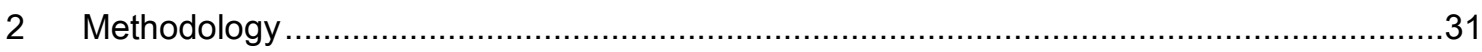

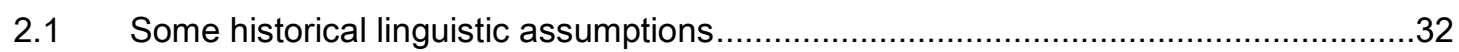

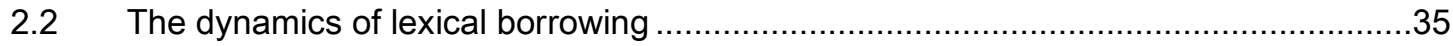

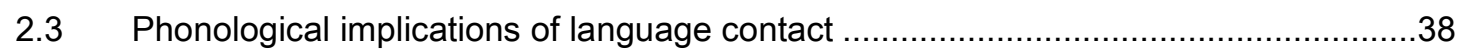

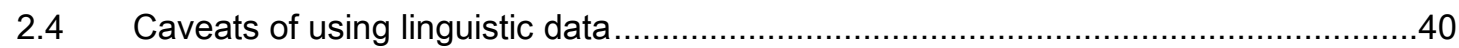

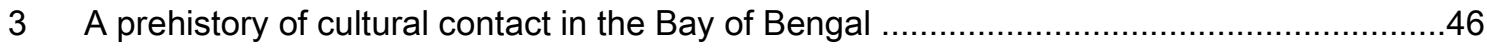

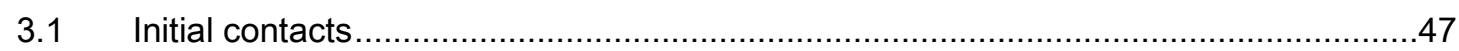

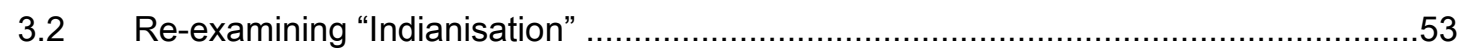

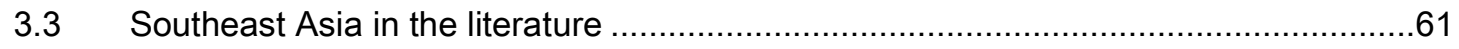

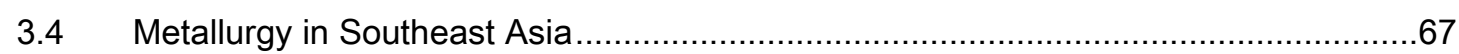

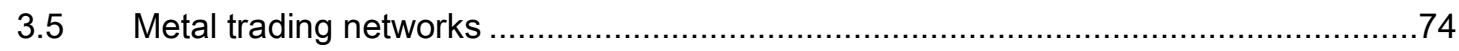

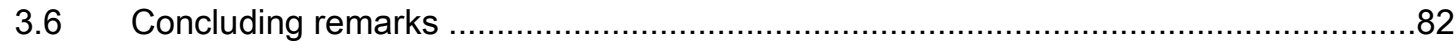

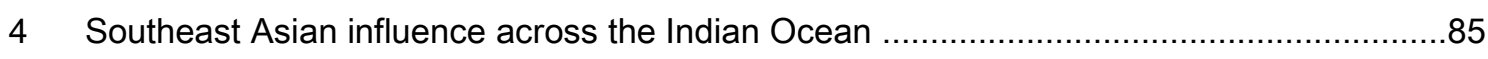

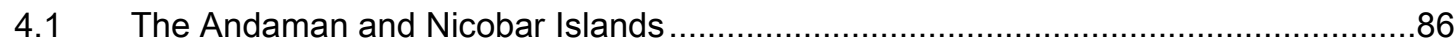

4.2 India

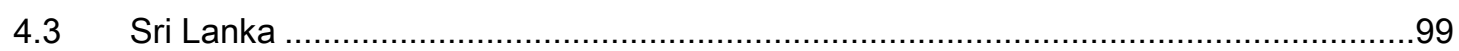

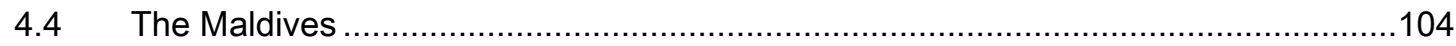

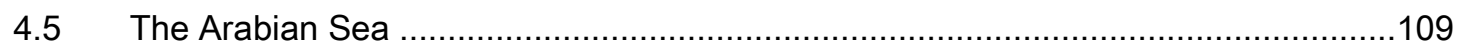

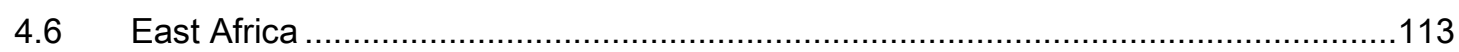

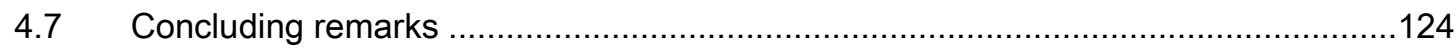

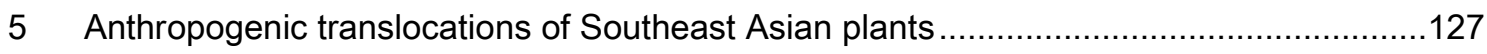

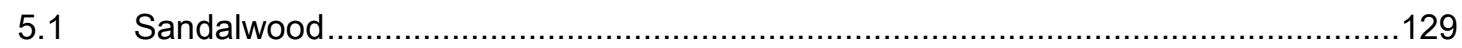

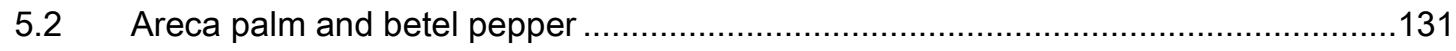

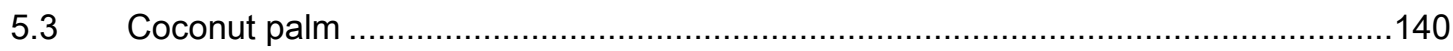




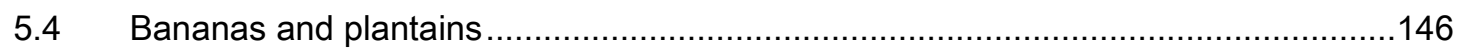

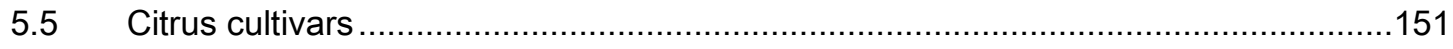

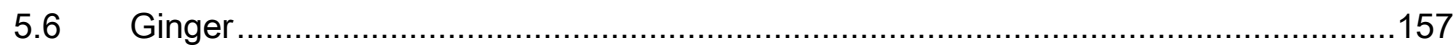

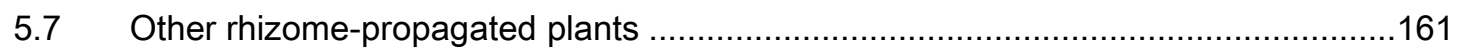

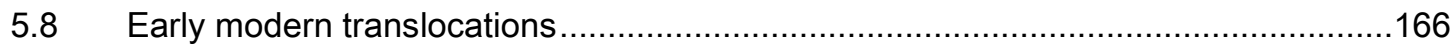

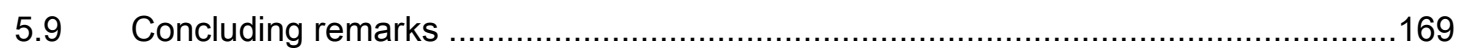

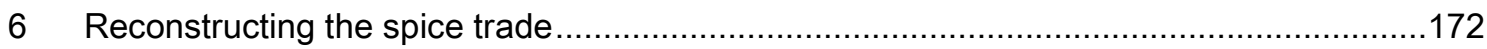

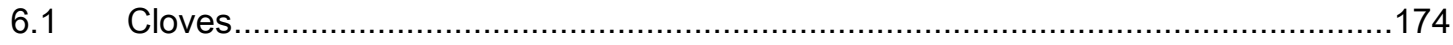

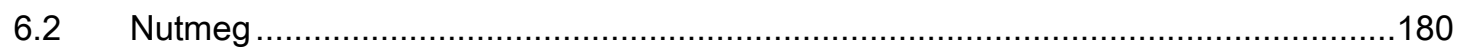

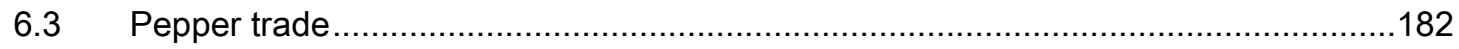

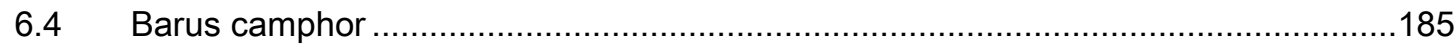

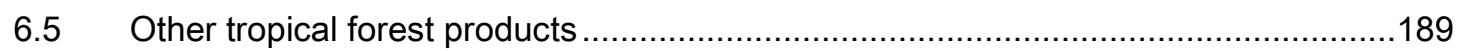

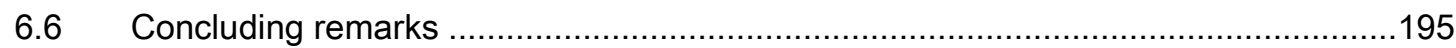

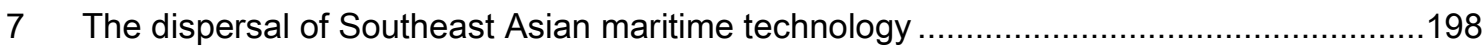

7.1 Nautical traditions across the Indian Ocean.......................................................202

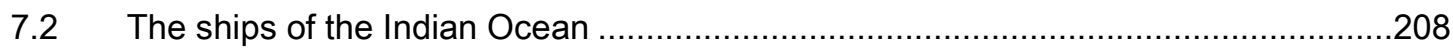

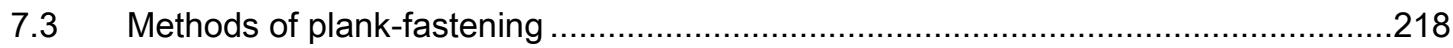

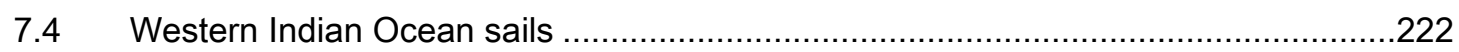

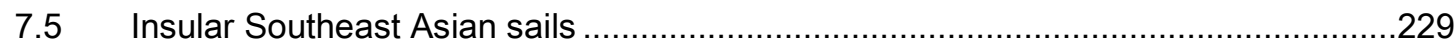

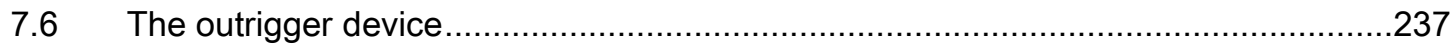

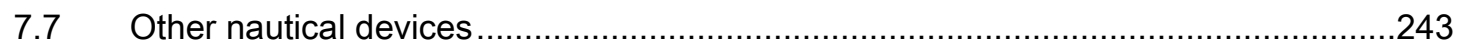

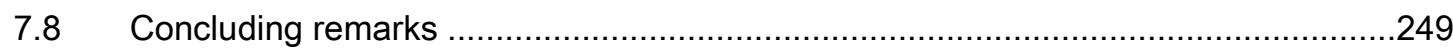

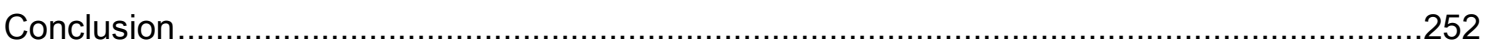

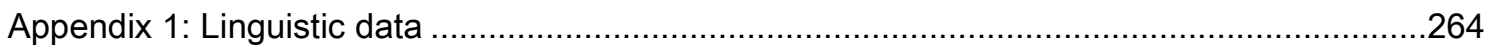

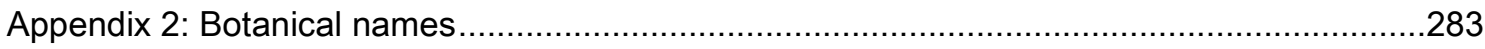

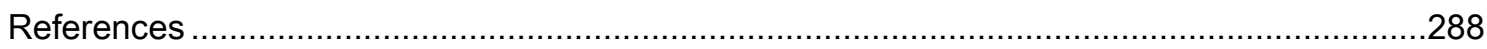

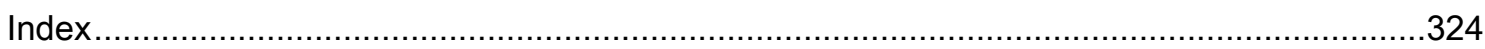




\section{List of Tables}

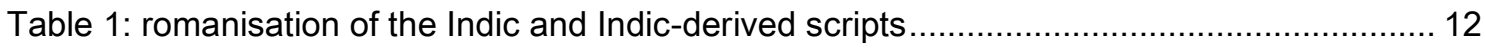

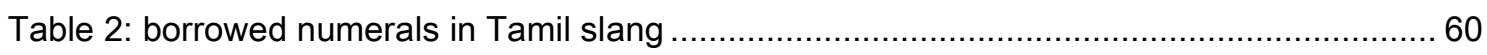

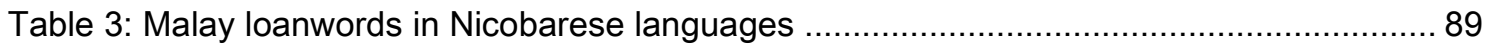

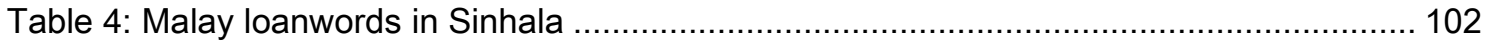

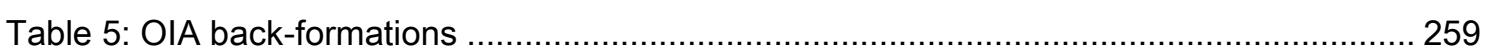

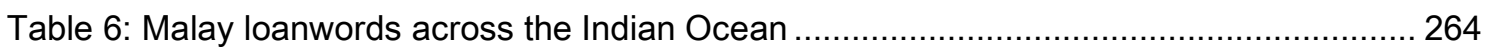

Table 7: other Malayo-Polynesian loanwords across the Indian Ocean ................................... 273

Table 8: South Asian mineral and metal terms in Southeast Asia .......................................... 276

\section{List of Figures}

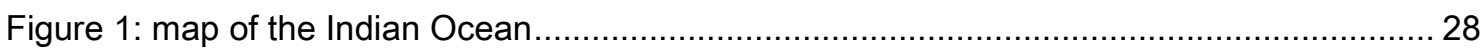

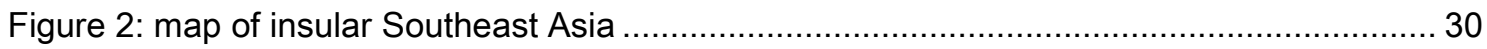

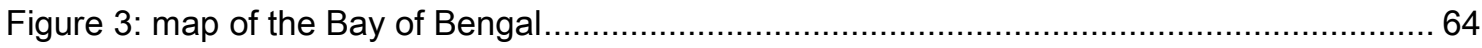

Figure 4: takkola kakkola and its meanings across the Indian Ocean ................................... 65

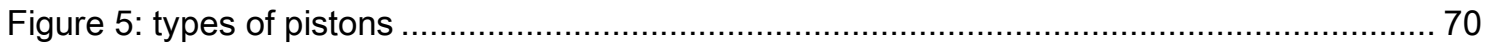

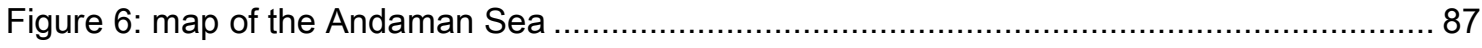

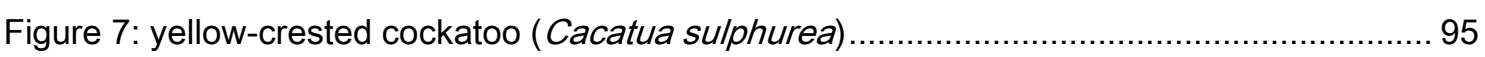

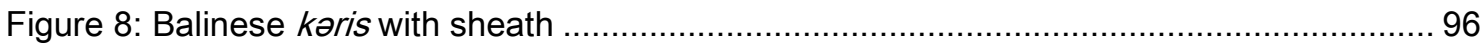

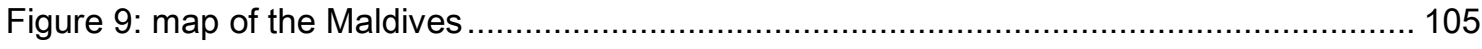

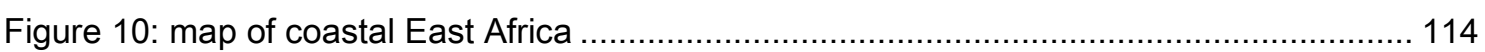

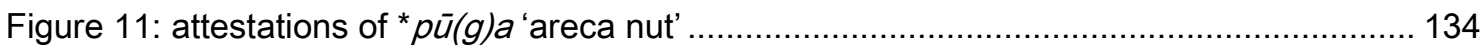

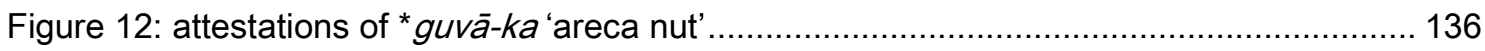

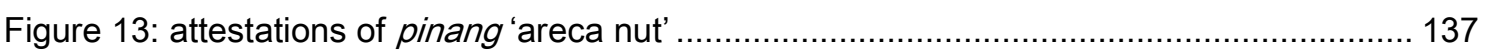

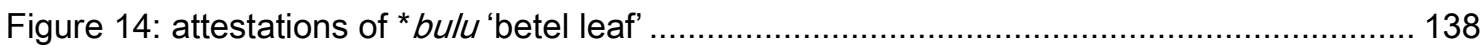

Figure 15: attestations of *tāmbūla *tāmbōla 'betel leaf'...................................................... 139

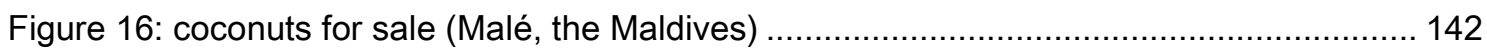

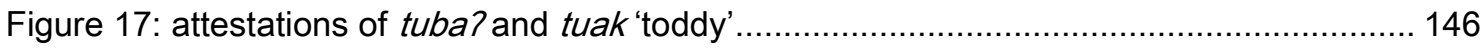

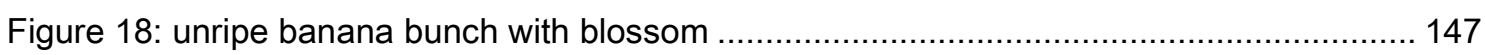

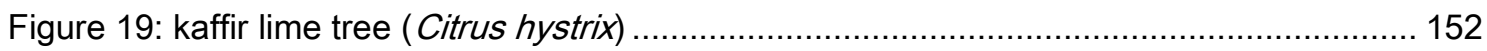

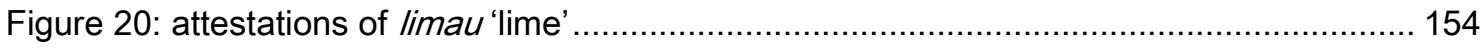

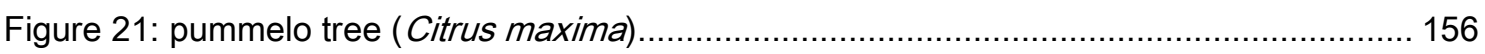

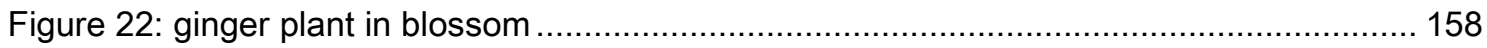

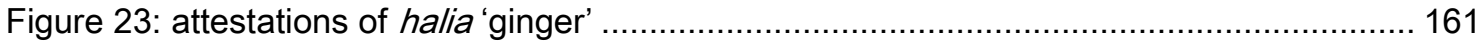

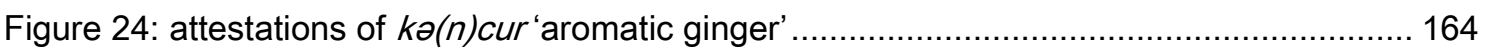

Figure 25: ginger (left), galangal (right), aromatic ginger (front) ......................................... 165

Figure 26: attestations of bəlimbing 'bilimbi' ................................................................... 166

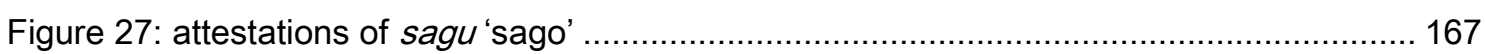


Figure 28: attestations of 'mangosteen' 169

Figure 29: map of North and Central Maluku 173

Figure 30: half-dried cloves (Neniari Teha, Maluku, Indonesia). Photo courtesy of Nicky Lumatalale 175

Figure 31: attestations of 'clove' across the Indian Ocean ........................................ 177

Figure 32: attestations of lawang 'clove'

Figure 33: fresh nutmeg drying in the sun (Ullath, Maluku, Indonesia). Photo courtesy of Ebed

Litaay 180

Figure 34: black pepper plant (Piper nigrum) 182

Figure 35: attestations of 'Java long pepper' 183

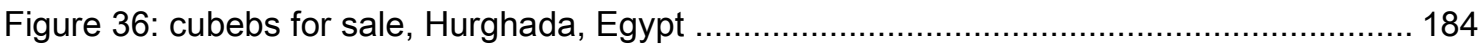

Figure 37: attestations of barus '(camphor from) Barus' ............................................ 188

Figure 38: attestations of damar 'dammar' ........................................................ 189

Figure 39: attestations of kəmənyan 'benzoin' ..................................................... 191

Figure 40: single outrigger boat (front) and lateen-rigged dhow (background), Mafia Island,

Tanzania. Photo courtesy of Ania Kotarba-Morley 206

Figure 41: attestations of * $p[\partial a] D a H u$ '(sailboat for) long-distance navigation' ...................... 213

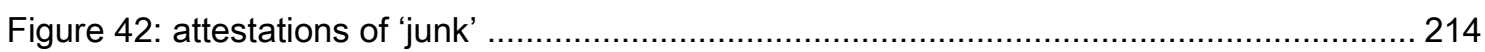

Figure 43: attestations of 'sambook', 'sāmvau' and 'sampan' ....................................... 217

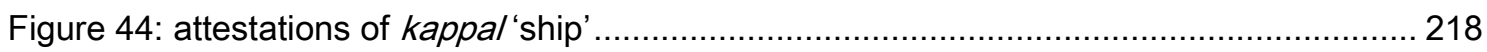

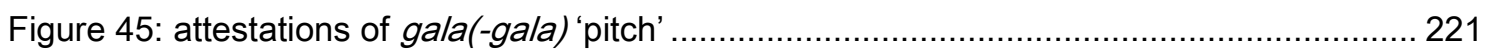

Figure 46: edge-dowelled planks (Kota Kinabalu, Sabah, Malaysia) .............................. 222

Figure 47: attestations of 'yard' across the Indian Ocean ......................................... 226

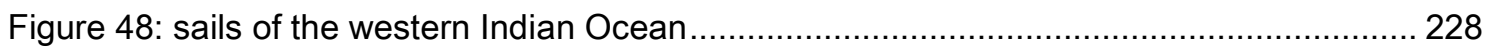

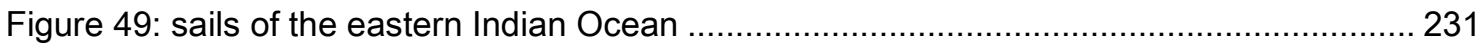

Figure 50: Oceanic spritsail (Pulau Sapondan, Sulawesi, Indonesia) ............................... 233

Figure 51: Oceanic spritsail (left) and western Indian Ocean lateen sail (right) ................... 233

Figure 52: double outrigger canoe (Tuktuk, Sumatra, Indonesia) ................................... 238

Figure 53: small single-outrigger boat (Baotere, Sulawesi, Indonesia) ............................. 240

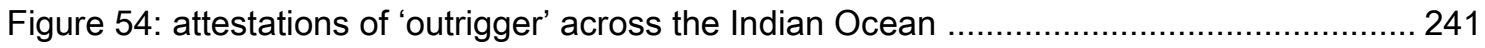

Figure 55: attestations of *baRat '(outrigger) crossbeam' ............................................... 242

Figure 56: lateral steering oar on a fishing vessel known as mādæl-pāru 'large net boat' (Negombo, Sri Lanka). 


\section{Preface}

The Indian Ocean, with its favourable sea currents and seasonal monsoon winds, has enabled maritime trade and interethnic engagement since the development of ocean-going watercraft. Many of the world's earliest civilisations, including those of Mesopotamia and the Indus Valley, have developed in the vicinity of its shores and river deltas. Consequently, the Indian Ocean occasioned one of the world's first trans-regional economies and, arguably, the first instance of globalisation. This manuscript grew out of an initiative to bring together various scholars from several disciplines working on the Indian Ocean to cast a new light on the complex social processes underlying this area's unique history. The resulting monograph is the first of a number of studies under the auspices of the Sealinks Project (Principal Investigator Dr. Nicole Boivin), an interdisciplinary project which aims to increase our understanding of the world's earliest maritime movements, the role of regional communities in these developments, and their social, economic and environmental impact on global history. My own focus within this project is the analysis of linguistic data and the resultant new insights into the diffusion of agriculture and material culture across the societies of the Indian Ocean, in particular the dispersal of plants, spices and maritime technology.

This study synthesises new evidence and existing ideas, bringing together archaeological, archaeobotanical, linguistic and epigraphic data. In particular, it focuses on the role of Southeast Asia and its inhabitants in the maritime networks that have emerged along the shores of Indian Ocean. Hence, the present work has two aims: to highlight the often overlooked Southeast Asian element in the prehistory of the Indian Ocean, and to fine-tune our understanding of pre-modern interethnic trade and cultural contact in a more general context. In writing this manuscript as a scholar specialised in the languages of Southeast Asia, it has been a daunting challenge and an enriching experience to immerse myself into the highly interdisciplinary character of this research, and to combine data and insights from such a wide range of disciplines into a study accessible to scholars in each one of them. I hope that the 
archaeologist, the anthropologist, the linguist and the historian will all be able to glean some profit from it.

Conventional wisdom has it that interethnic trade in Southeast Asia was predominantly initiated by merchants from China, South Asia and the Middle East. Therefore, the notion of a distinct Southeast Asian influence sphere expanding from the Asian mainland all the way to coastal East Africa seems beyond the imagination of many. Whenever I discussed the nature of my fieldwork - collecting and analysing linguistic data to reconstruct patterns of cultural contact and examine the influence of Southeast Asia on other regions - I was immediately "corrected" by my South and Southeast Asian consultants, as it was consistently assumed that the influence exclusively took place in the opposite direction. Indeed, preconceptions of one-way acculturation from India (and the Middle East) to Southeast Asia are persistent and deeply rooted into both western and Asian scholarship, frequently resonating in the media, national historiographies, political discourse and other semi-credible narratives. On the other hand, many people from North Sumatra seem perfectly aware of the historical importance of their mineral-prolific region, proclaiming - facetiously - that the camphor used to embalm the body of Jesus Christ originated from their village. Likewise, people from South Sulawesi carry with them proud notions of the annual voyages of their ancestors to the furthest corners of the known world. The framework in which to place such isolated inferences, however, is still largely incomplete. Southeast Asian agency in pre-modern interethnic trade networks is poorly understood; the evidence is scattered geographically and across the disciplines of archaeology, linguistics, history, the natural sciences and others. The evidence, one might say, is out there, but needs to be brought together comprehensively and critically. I can only hope that this study is able to surmount this challenge and provide a much needed counterbalance to the underrepresentation of Southeast Asia in global history.

\section{Tom G. Hoogervorst}

Oxford, 20 November 2011 


\section{Acknowledgements}

This study would never have been completed without the generous assistance of supervisors, professional colleagues and friends. The Sealinks Project was carried out in the wider context of teamwork and it was a privilege to work alongside the highly qualified, amiable scholars involved, who have supervised me, read and commented on early drafts of this thesis and offered numerous suggestions for improvement. In the first place, I would like to thank Nicole Boivin, for giving me the opportunity to be a part of this exciting project, for her unbroken enthusiasm and for her inspiring supervision. My gratitude also goes to my second supervisor Chris Gosden, for his deep understanding of my topic and for the many refreshing and stimulating occasions on which I could benefit from it. I am also extremely thankful to Waruno Mahdi, who spared neither time nor trouble in providing helpful comments throughout the writing process of this manuscript, sharing his valuable insights into the languages and cultures of the Indian Ocean, and sending me books and journal articles not available in Oxford. Furthermore, this study would not have attained its present form without the generous and consistent support of Alexander Adelaar, whose vast knowledge, humour and unflagging good spirit continues to be an inspiration to me. I am grateful to my examiners, George van Driem and Robert Barnes, for their encouraging, constructive and detailed feedback. This work has also greatly benefitted from the conversations and correspondence I have had with Andrea Acri, Phillippe Beaujard, Mahidas Bhattacharya, Roger Blench, Robert Blust, Amy Bogaard, Dorian Fuller, lan Glover, Dominic Goodall, B. Gopinathan Nair, Arlo Griffiths, David Henley, Hedi Hinzler, Jiří Jakl, Philip Jenner, Keng We Koh, Pierre-Yves Manguin, Charlotte Minh Hà Pham, Damian Robinson, Thilo Schadeberg, Rick Schulting, V.I. Subramoniam, G. Vijayavenugopal and Martin Walsh. Needless to say, final responsibility for all views expressed and any remaining errors or shortcomings rests entirely with the author.

It is a privilege to carry out research in another country and it is an even greater privilege to do so in a variety of countries. The European Research Council, the Linacre House 
Trust and the William Waldren Fund have enabled this through their financial support. I am also indebted to the many people in India, Sri Lanka, the Maldives, Thailand, Malaysia and Indonesia who made my fieldwork experience a pleasant one. Although a complete list of those who helped is practically impossible to provide, I wish to express my sincere gratitude to the enthusiastic and helpful staff at the libraries and institutes where I conducted my research: the Royal Netherlands Institute of Southeast Asian and Caribbean Studies (KITLV), Bodleian Oriental Institute Library, Balfour Library, African Studies Centre, Central Institute of Indian Languages, École française d'Extrême-Orient, Pondicherry Institute of Linguistics and Culture, International School of Dravidian Linguistics, Bangalore State Central Library, University of Colombo Library, National Library of Sri Lanka, National Library of Maldives, Maldives National Centre for Linguistic and Historical Research, and Institut Linguistik SIL Cawangan Malaysia. I should also emphasise that I owe a great debt to the numerous people whom I have consulted with during my fieldwork in South and Southeast Asia, for their time, patience and kind interest in my research. At the University of Oxford, too, I was extremely fortunate to be amongst great minds and dear friends, encouraging me to develop my ideas and advising me throughout the writing process; I am grateful to Wijerathne Bohingamuwa, Alkiviadis Ginalis, Ilaria Grimaldi, Kyungkyu Kim, Eric Makinen, Yukihiro Nomura, Shams ur Rahman, Venkatesh Rao and Greg Votruba. Finally, I express my heartfelt gratitude to my family, in-laws and especially my wife Renate, whose love, encouragement and support have been my source of inspiration.

\section{Orthographical Conventions}

The lexical data compiled in this study is intended to facilitate further research on cultural contact in the Indian Ocean. Hence, it is necessary to elaborate on the data presentation and orthographical conventions used. Foremost, in a study that deals with data from a great variety of languages from different language families, it is important not to obfuscate the overall picture. Maintaining the spelling from the original dictionaries or wordlists would lead to the incorporation of outdated transcriptions and a confusing amount of symbols representing the same sounds, 
whereas neglecting standardised or generally accepted orthographies would lead to rejection by specialised scholars and native speakers. Hence, a middle ground is chosen according to the guidelines below. For the sake of accessibility, the glosses of the lexical attestations have been translated into English if originally in French, German, Indonesian, etc. Obsolete botanical names in the original sources have been adjusted according to the present scientific consensus (see Appendix 2). Finally, the toponyms, ethnonyms and glossonyms referred to in this study are those currently in use, e.g. "Fuvahmulah" instead of "Fuah Mulaku", "Maluku" (including the northern, central and southern island groups) instead of "the Moluccas", "Makhuwa" instead of "Macua" and "Southern Min" instead of "Hokkien". In the light of this study's pre-modern focus, however, I prefer general geographical terms such as "insular Southeast Asia", "South Asia" and "East Africa" over the names of modern, postcolonial nation states.

For languages without a written tradition, this study uses the phonetic representation according to the guidelines of the International Phonetic Association (IPA). The transcription of Austronesian languages, however, is linked to several well-established conventions, which will be used here (cf. Blust 2009a:546-7), e.g. /c/: voiceless palatal affricate, /j/: palatalised voiced velar stop, ${ }^{*}$ S: (reconstructed) voiceless alveolar fricative, and ${ }^{*} \mathrm{R}$ : (reconstructed) alveolar or uvular trill. For Chinese dialects, the traditional characters (not their modern, simplified correspondents) are given along with the Pīnyīn transliteration or - in the case of early textual attestations - their (reconstructed) pronunciations in Middle Chinese. The Pèh-ōe-ji transliteration is used for Southern Min, the Quốc ngữ alphabet for Vietnamese (both with tone diacritics). The International Organization for Standardization (ISO) 233 guidelines are used for the Arabic script and its derivatives. For Indic and Indic-derived scripts, including those of written Southeast Asian languages and Dhivehi, the conventional Indological system of romanisation is used as indicated in Table 1. Inevitably, this means that diachronic or dialectal variation is not always accurately reflected, especially in diglossic languages such as Tamil, Arabic and Burmese. The standard orthographies of such languages as Malay, Vietnamese and Swahili, too, circumvent regional variety and differences in pronunciation. That being said, 
standard languages and received pronunciations tend to be based on the dialect of a nation's capital or perceived cultural centre, not necessarily on the most archaic variety. In support of my choice to represent several of the Southeast Asian languages involved in this study based on their Indic-derived orthographies - paradoxical as this may seem in a study that aims to take distance from Indocentric perspectives - it needs to be borne in mind that we are dealing with historical languages, not their present-day descendents. Often, the orthography of literary languages contains clues to earlier pronunciations (as is certainly the case with many words in

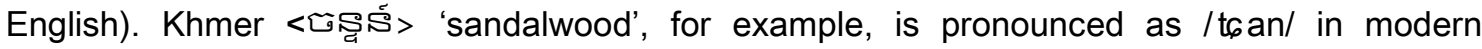
parlance. Its orthography, however, points to an earlier ${ }^{*}$ candan $^{\circ}$ (with inherent /a/ and unpronounced word-final vowel), which demonstrates beyond doubt that it is ultimately derived from Old Indo-Aryan *candana 'sandalwood'. In modern Thai, furthermore, the akșaras representing $\langle\mathrm{c}\rangle,\langle\mathrm{j}\rangle,\langle\mathrm{t}\rangle,\langle\mathrm{th}\rangle,\langle\mathrm{d}\rangle,\langle\mathrm{d} h\rangle,\langle\mathrm{t}\rangle,\langle\mathrm{th}\rangle,\langle\mathrm{d}\rangle,\langle\mathrm{dh}\rangle,\langle s \dot{s}\rangle,\langle\mathrm{s}\rangle$ and $\langle\mathrm{s}\rangle$ are all pronounced as /t/ in a word-final position, whereas $\langle y\rangle,\langle$ n $\rangle,\langle n\rangle,\langle 1\rangle,\langle$ l $\rangle$, and $\langle$ r $\rangle$ are realised as $/ \mathrm{n} /$ at the end of a word. The modern standard pronunciation of Thai, therefore, does not necessarily tell us much about earlier pronunciations of loanwords and inherited vocabulary, while several clues persist in its orthography. For this reason - and at the risk of underexposing modern pronunciations - I will use the "Indic" transliteration, accompanied by the orthography, to represent the mainland Southeast Asian languages at the tentative period of pre-modern cultural contact.

Table 1: romanisation of the Indic and Indic-derived scripts

\begin{tabular}{ll}
\hline $\mathrm{k}$ & voiceless velar stop \\
$\mathrm{kh}$ & aspirated voiceless velar stop \\
$\mathrm{g}$ & voiced velar stop \\
$\mathrm{gh}$ & aspirated voiced velar stop \\
$\dot{\mathrm{n}}$ & velar nasal \\
\hline $\mathrm{C}$ & voiceless palato-alveolar affricate \\
$\mathrm{ch}$ & aspirated voiceless palato-alveolar affricate \\
\hline $\mathrm{j}$ & voiced palato-alveolar affricate \\
$\mathrm{jh}$ & aspirated voiced palato-alveolar affricate \\
\hline$\tilde{n}$ & palato-alveolar nasal \\
\hline$\underline{t}$ & voiceless retroflex stop \\
\hline$\underline{t h}$ & aspirated voiceless retroflex stop \\
\hline
\end{tabular}

\begin{tabular}{ll}
\hline$d$ & $\begin{array}{l}\text { voiced retroflex stop (voiced alveolar implosive } \\
\text { in Mon, Khmer and Cham) }\end{array}$ \\
\hline$d h$ & aspirated voiced retroflex stop \\
\hline$n$ & retroflex nasal \\
t & voiceless dental stop \\
th & aspirated voiceless dental stop \\
d & voiced dental stop \\
dh & aspirated voiced dental stop \\
\hline n & dental nasal \\
\hline p & voiceless bilabial stop \\
ph & aspirated voiceless bilabial stop \\
b & voiced bilabial stop \\
bh & aspirated voiced bilabial stop \\
\hline
\end{tabular}




\begin{tabular}{|c|c|}
\hline y & palatal approximant \\
\hline $\mathrm{r}$ & alveolar flap \\
\hline I & dental lateral approximant \\
\hline v & labiodental approximant \\
\hline ś & voiceless palato-alveolar sibilant \\
\hline ș & voiceless retroflex sibilant \\
\hline$s$ & voiceless alveolar sibilant \\
\hline $\mathrm{h}$ & voiceless glottal fricative \\
\hline$\underline{n}$ & alveolar nasal \\
\hline$\check{n}$ & prenasalised consonant \\
\hline b & voiced bilabial implosive \\
\hline$\underline{r}$ & alveolar trill \\
\hline r & retroflex flap \\
\hline$r$ & syllabic rhotic (in Sanskrit) \\
\hline$\underline{1}$ & retroflex approximant (in Tamil) \\
\hline$!$ & retroflex lateral approximant \\
\hline$æ$ & near-open front unrounded vowel \\
\hline$\partial$ & mid-central vowel \\
\hline o & close-mid back unrounded vowel \\
\hline
\end{tabular}

\begin{tabular}{|c|c|}
\hline$\dot{y}$ & $\begin{array}{l}\text { silent or short close-mid front unrounded vowel } \\
\text { (in Bengali) }\end{array}$ \\
\hline$\dot{\mathrm{m}}$ & anusvāra (marks a type of nasalisation) \\
\hline h & visarga (allophone of /r/ and /s/ in pausa) \\
\hline . & ok mrac (marks creaky tone in Burmese) \\
\hline : & vacca pok (marks high tone in Burmese) \\
\hline 0 & $\begin{array}{l}\text { daṇlaghāta (marks unpronounced vowels in } \\
\text { Khmer and Thai) }\end{array}$ \\
\hline ll & $\begin{array}{l}\text { mūsikadanta (marks sound in loanwords in } \\
\text { Khmer) }\end{array}$ \\
\hline $\bar{\delta}$ & $\begin{array}{l}\text { combining macron (marks long vowels; marks } \\
\text { neutral tone in Thai and Lao) }\end{array}$ \\
\hline$\tilde{\sigma}$ & combining tilde (marks nasalisation) \\
\hline $\mathrm{d}$ & $\begin{array}{l}\text { combining grave accent (marks first tone in } \\
\text { Thai and Lao) }\end{array}$ \\
\hline 0 & $\begin{array}{l}\text { combining circumflex (marks second tone in } \\
\text { Thai and Lao; marks short vowel in Khmer) }\end{array}$ \\
\hline 8 & $\begin{array}{l}\text { combining acute accent (marks third tone in } \\
\text { Thai and Lao; marks short vowel in Khmer) }\end{array}$ \\
\hline
\end{tabular}

\section{Abbreviations and Symbols}

BCE

before Common Era

C

consonantal phoneme

c.

century

CE

Common Era

coll.

colloquial

EMC

Early Middle Chinese

fig.

figure

gen.

generic

id.

identical gloss (as the one just given)

I.

line

lit.

literally

LMC

Late Middle Chinese

MIA

Middle Indo-Aryan

mill.

millennium

N

nasal phoneme 
n. noun

OIA Old Indo-Aryan

PAN Proto-Austronesian

PCEMP Proto-Central-Eastern-Malayo-Polynesian

pl. plural

PMK Proto-Mon-Khmer

PMP Proto-Malayo-Polynesian

POC Proto-Oceanic

PWMP Proto-West-Malayo-Polynesian

V vowel phoneme

v. verb

precedes a reconstructed protoform

precedes an incorrect reconstruction

precedes a tentative or problematic reconstructed form

precedes an intermediate stage of innovation

precedes a not inherited quasi-protoform, possible early loan

$\dagger \quad$ precedes an extinct or obsolete form

$\sqrt{ } \quad$ precedes the root of a word

$<\quad$ developed from

$>\quad$ became

$>$ ? $\quad$ undetermined directionality or possible genetic affinity

$\neq \quad$ is a different form

$\quad$ doublets or alternations between two variant words or sounds

$\varnothing \quad$ zero phoneme

(...) encloses an optional phoneme

/.../ encloses a phonemic representation

[...] encloses a phonetic transcription 
encloses a semantic meaning or translation

$<\ldots>\quad$ encloses an orthographic representation

precedes a condition under which a phonological innovation takes place

position of a sound to which a phonological rule applies

word boundary

affix boundary

\section{Language Sources}

\section{Observed languages}

1. Acehnese

2. Alas

3. Angkola-Mandailing Batak

4. Arabic

5. Bajau

6. Bajuni

7. Balinese

8. Baluchi

9. Bengali

10. Bikol

11. Bugis

12. Burmese

13. Car Nicobar

14. Cebuano (Bisayan)

15. Central Nicobarese

16. Cham

17. Chamorro
Djajadiningrat 1934 ,

Akbar et al. 1985

Eggink 1936

Wehr 1976

(fieldwork)

Nurse 2009

Barber 1979

Dames 1922, Collett 1986

Biswas 2000

Mintz 2004

Matthes 1874

Myanmar 1996

Whitehead 1925, Das 1977

Mentrida 1841, Wolff 1972

Röepstorff 1884, Man 1888-89

Aymonier \& Cabaton 1906

Topping et al. 1980 
18. Chaura

19. Chinese

20. Chong

21. Comorian

22. Dairi Batak

23. Dhivehi

24. Farsi (Persian)

25. Gayo

26. Great Andamanese

27. Hindi (Hindustani)

28. Hindi (Laskari dial.)

29. Iban

30. Ilokano

31. Jarawa

32. Javanese

33. Kannada

34. Kapampangan

35. Karbí (Mikir)

36. Karo Batak

37. Khasi

38. Khmer

39. Lao

40. Makasar

41. Makhuwa

42. Malagasy

43. Malagasy (Antankarana dial.)

44. Malagasy (Betsimisaraka dial.) Richardson 1885
Röepstorff 1884, Man 1888-89

Giles 1892:282

Baradat 1948

Ahmed-Chamanga 1992

Manik 1977

Reynolds 2003

Steingass 1892

Hazeu 1907

Manoharan 1989, Abbi 2012

Shakespear 1834

Small 1882

Richards 1981

Rubino 2000

Blevins 2007, 2009

Robson \& Wibisono 2002, Albada \& Pigeaud 2007

Kittel 1894

Buenaobra 2004

Neighbor 1878

Prinst 2002

Singh 1906

Headley et al. 1997

Kerr 1972, Patterson 1995

Cense 1979

Rankin 1886, Prata 1990

Richardson 1885

David 1952 


\begin{tabular}{|c|c|}
\hline 45. Malagasy (Mayotte dial.) & Gueunier 1986 \\
\hline 46. Malagasy (Sakalava dial.) & Thomas-Fattier 1982 \\
\hline 47. Malagasy (Tañala dial.) & Beaujard 1998a \\
\hline 48. Malay & Wilkinson 1932 \\
\hline 49. Malay (Ambon dial.) & Clercq 1876 \\
\hline 50. Malayālam & Gundert 1962, Subramoniam 2008 \\
\hline 51. Manipuri & Primrose 1888 \\
\hline 52. Mara (Lakher) & Lorrain 1951 \\
\hline 53. Maranao & McKaughan \& Al-Macaraya 1996 \\
\hline 54. Marāṭ̂̄ & Molesworth 1857 \\
\hline 55. Minangkabau & Moussay 1995 \\
\hline 56. Mizo (Lushai) & Lorrain 1940 \\
\hline 57. Moken & Lewis 1960, Larish 1999 \\
\hline 58. Mon & Shorto 1962 \\
\hline 59. Nepāli & Turner 1961 \\
\hline 60. Ngaju & Hardeland 1859 \\
\hline 61. Nias & Sundermann 1905 \\
\hline 62. Onge & Ganguly 1966, Blevins 2007, 2009 \\
\hline 63. Oriyā & Praharaj 1931-40 \\
\hline 64. Pacoh & Watson 2009 \\
\hline 65. Palaung & Milne 1931 \\
\hline 66. Pañjābī & Singh 1895 \\
\hline 67. Raluana & Lanyon-Orgill 1960 \\
\hline 68. Rejang & Hamidy et al. 1985 \\
\hline 69. Santali & Campbell 1899 \\
\hline 70. Shan & Cushing 1881 \\
\hline 71. Shom-Pen் & Röepstorff 1884, Man 1888-89 \\
\hline
\end{tabular}


80. Tamil (Sri Lanka dial.)

(fieldwork)

81. Tani (Abor-Miri)

Lorrain 1910

82. Tausug

Haynes 1885-86, Hassan et al. 1994

83. Telugu

Brown 1903

84. Temiar

Means 1998

85. Teressa

Röepstorff 1884, Man 1888-89

86. Tetum

Manhitu 2007

87. Thai

Haas 1951-

88. Tangkhul

Pettigrew 1918

89. Tibetan

Das 1902

90. Toba Batak

Warneck 1977

91. Tulu

Männer 1886

92. Vietnamese

Hyde 2008

\section{Recorded historical languages}

93. Aramaic

94. Old Javanese

95. Old Khmer

96. Old Malay
Löw 1881

Tuuk 1897-1912, Zoetmulder 1982

Jenner 2009

Cœdès 1930, Casparis 1950, 1956 
97. Old Mon

98. Old Sundanese

99. Pali

100.

Sanskrit
Shorto 1971

Noorduyn \& Teeuw 2006

Rhys Davids \& Stede 1966

Monier-Williams 1899

\section{Reconstructed languages}

\begin{tabular}{|c|c|c|}
\hline 101. & ${ }^{*}$ Early Middle Chinese & Pulleyblank 1991 \\
\hline 102. & ${ }^{*}$ Late Middle Chinese & Pulleyblank 1991 \\
\hline 103. & ${ }^{*}$ Middle Indo-Aryan & Turner 1966 \\
\hline 4 & ${ }^{*}$ Old Indo-Aryan & Turner 1966 \\
\hline 105. & ${ }^{*}$ Proto-Austronesian & Blust 1995 \\
\hline 106. & *Proto-Bantu & Bastin \& Schadeberg 1992 \\
\hline 107. & ${ }^{*}$ Proto-Chamic & Thurgood 1999 \\
\hline 108. & ${ }^{*}$ Proto-Katuic & Sidwell 2005 \\
\hline 109. & ${ }^{*}$ Proto-Malayo-Polynesian & Blust 1995 \\
\hline 110. & ${ }^{*}$ Proto-Moken-Moklen & Larish 1991 \\
\hline 111. & ${ }^{*}$ Proto-Mon-Khmer & Shorto 2006 \\
\hline 112. & *Proto-Muṇḍā & Zide \& Zide 1976 \\
\hline 113. & ${ }^{*}$ Proto-Oceanic & Blust 1995, Ross et al. 2008 \\
\hline 114. & ${ }^{*}$ Proto-Sama-Bajaw & Pallesen 1977 \\
\hline 115. & ${ }^{*}$ Proto-South-Sulawesi & Mills $1975 b$ \\
\hline 116. & ${ }^{*}$ Proto-West-Malayo-Polynesian & Blust 1995 \\
\hline
\end{tabular}




\section{Introduction}

The Indian Ocean has been a commercial nexus from time immemorial, allowing maritime communication between Asia, Africa and the Middle East. During the summer, the Southwest Monsoon facilitates seafaring voyages from East Africa and the Middle East to the Indian subcontinent and thence to Southeast Asia, whereas the Northeast Monsoon enables journeys in the opposite direction during the winter. The resultant tradition of interregional maritime trade goes back for millennia and opens many questions from different disciplines. This study aims to examine the extent to which the use of linguistic data can shed new light on cultural contact in the Indian Ocean, focusing especially on the role of the Southeast Asian participants in the maritime trading networks of pre- and protohistoric times. The temporal focus of this study begins with the mid-2nd mill. BCE, when the first plant cultigens from Southeast Asia start to appear in the archaeological record of South Asia (Asouti \& Fuller 2008:91, 114-5), and ends with the late $1^{\text {st }}$ mill. CE, when the Islamic expansion began to mark a completely new episode of interethnic commerce and cultural contact.

Through the analysis of specialised vocabulary and lexical borrowings in the domains of material culture, plants and spices, this study offers new perspectives on the different speech communities engaged in the interregional trade networks of the Indian Ocean, the reputation they enjoyed among their neighbours, the products they imported, exported and transported, and the linguistic and cultural impact they asserted on each other. This study does not assume that products and their names always neatly travelled together and, therefore, additionally explores the concepts of lexical borrowing and the underlying social processes that make societies "open up" towards foreign influence, either culturally, linguistically or genetically. In doing so, this study provides an interdisciplinary framework to explore and synthesise the evidence for cultural and linguistic influence from Southeast Asia on the other civilisations of the Indian Ocean littoral. Hoping that it will contribute meaningfully to the "scattered interdisciplinary 
puzzle pieces" that form the basis of our understanding of the "jigsaw puzzle of Indian Ocean prehistory" (Fuller et al. 2011a:553), this introductory chapter will first call attention to the emergence and dynamics of interethnic trade. Next, it will briefly address the agricultural and maritime traditions of Southeast Asia, whose impact on the neighbouring societies of the Indian Ocean forms the red line of the subsequent chapters. The following section outlines the scope of this study and defines what delimits it from previous scholarship. Finally, attention is given to the methods of data acquisition and the outline structure of this study.

\subsection{Defining interethnic trade}

Although this study draws heavily on linguistic data, it seeks to answer questions of an interdisciplinary nature. This is the only sensible approach, since Southeast Asian communities left but few traces of their ancient presence in the western sections of the Indian Ocean. Of these traces, the language, culture and genetic admixture of the Malagasy people are by far the most extensively documented, while there is less conclusive evidence elsewhere. The Southeast Asian wealth in export products and prominence in seaborne navigation are important reasons to suspect, a priori, an active and frequently overlooked participation in Indian Ocean trading networks. This study incorporates archaeological perspectives on the development of the world's earliest maritime trade networks, the sequential dispersal of material culture, and the dating of these dynamic processes. Archaeobotanical evidence is employed to reconstruct the anthropogenic dispersal of plant species, including tree crops, tubers and spices. These biological translocations, after all, can profoundly affect the agricultural landscape of societies at a relatively early stage of development, hence transforming their history and culture. The transmission of technology, including metallurgy and ship-building, is approached through the lens of ethnography. From the late $19^{\text {th }}$ century, this discipline has provided us with valuable insights into the numerous ethnicities inhabiting the Indian Ocean World and their often strikingly similar material cultures. While the diffusionist hypotheses of earlier ethnologists were imbued with somewhat obsolete notions of cultural transmission - leaving little room for the 
possibility of independent evolution (polygenesis) of the objects under scrutiny - their studies left us with a large corpus of documented metallurgical artefacts, boat types and other cultural items now largely sunk into oblivion.

This raises the question of why, and by what dynamics, interethnic trade emerged along the Indian Ocean littoral. The development of commercial networks seems to have been fuelled by several social processes. Often, the introduction of food-stuffs from afar was motivated by desire, rather than basic needs for subsistence. Ever since the first societies developed social stratification, socio-economical distinction became closely linked to the consumption of luxury foods. Throughout the world's civilisations, it is observed that luxury foods have often been consumed during communal feasts, providing local aggrandisers with ample opportunity to display their wealth and social status (Hayden 2003, Leach 2003, van der Veen 2003). Indeed, the very concept of feasting may have been a key contributor to the emergence and development of long-distance commerce in food products (Hayden 2003). Religion is another social institution facilitating the movement of (agri)cultural items. In many societies around the Indian Ocean, the function of aromatic spices, gums and resins is highly ritualised. There is solid archaeological evidence that certain spices made their way to the Red Sea coast from at least the $1^{\text {st }}-3^{\text {rd }}$ C. CE (van der Veen 2011), appearing even earlier in the Graeco-Roman literature. As is generally the case with religious items, those brought in from afar often possessed a higher spiritual value - combined with more expensive price tag - than native equivalents. In this light, we should also view the distinctive function of European pottery in nomadic indigenous American communities (Marshall \& Maas 1997), Indian Buddhist paraphernalia in ancient China (Bentley (1996:753-4) and the interethnic "commerce" of rituals and religious items in Melanesia (Harrison 1993), among others.

It follows from this that the acquisition of religious exotica is related to the control of wealth and political power. This explains why some of the most valued items of insular Southeast Asian export - such as cloves, nutmeg, sandalwood and agarwood - were rarely used domestically, catering an almost exclusively foreign clientele. Nevertheless, these 
products became the backbone of many local economies in Southeast Asia, facilitating the development of multifaceted patron-client relations between the foraging or semi-sedentary communities who obtained these commodities and the more cosmopolitan, maritime-oriented communities who incorporated them into wider commercial networks. In these encounters, the Malay language was normally resorted to as a means of interethnic communication. We may expect to find this reflected in the linguistic data collected in this study. The presence of Malay vocabulary, however, does not necessarily imply the involvement of people belonging to a "Malay ethnicity", inasmuch as we can speak of such a concept within the pre-modern timeframe of this study. Rather, it needs to be borne in mind that this language was shared by people of several backgrounds, as continues to be the case at present. In the absence of skeletal or material culture remains, we may never know for sure what the agents in the premodern trade networks of Southeast Asia and the Indian Ocean World looked like or which socio-cultural niche they were part of, but we do possess the tools to reconstruct what language they spoke.

\subsection{Agriculture and maritime expertise}

Southeast Asia, with its green fertility, great rivers and vast island chains, has developed unique agricultural and maritime traditions. The study of agriculture and plant origins in this part of the world has a relatively longstanding history (e.g. Vavilov 1926, 1927, Li 1970, Chang 1970), predating the development of molecular phylogenetic methods. Earlier still, scholars looked at plant names to determine the geographical origins of the Malayo-Polynesian and Austro-Asiatic language families (Kern 1889a, Schmidt 1906). More recently, it has been argued that a series of plants, known as the Austronesian "Neolithic package", was dispersed anthropogenically from Taiwan across insular Southeast Asia (e.g. Bellwood 2002:26). While it is beyond the scope of this study to contribute to the ongoing debate over whether the first speakers of Austronesian languages were primarily agriculturalists and how they may have influenced the Southeast Asian Neolithic, discussions of this type provide useful case studies of 
interdisciplinary research and its caveats. Initially, the debate concerning agricultural origins in Asia was predominantly shaped by linguistics.

It has been argued early on that there is a Southeast Asian substrate in South Asian agriculture introduced by speakers of Austro-Asiatic languages, based on the observation that several agricultural terms distributed across the linguistic boundaries of the Indian subcontinent are not attributable to either proto-Indo-Aryan or proto-Dravidian. This theory, popularised by Lévi et al. (1929) and Gonda (1932), resonates in the work of numerous scholars (e.g. Kuiper 1948, Mayrhofer 1956, Masica 1979, Burrow 2001[1955]:379-80, Southworth 2005). Examples of Sanskrit vocabulary conventionally attributed to this tentative Austro-Asiatic lexical substrate include kadala 'banana', marīca 'pepper', nimbū(ka) 'lime', alābu 'bottle-gourd', tumba 'dried bottle-gourd', karpāsa 'cotton' and lārigala 'plough'. ${ }^{1}$ Some later publications, however, treated the subject more critically (Zide \& Zide 1976, Kuiper 1991, Mahdi 1998, Osada 2009). Indeed, our understanding of Austro-Asiatic languages and linguistic history remains too fragmentary to permit conclusions about South Asian agricultural prehistory of such a wide-ranging nature.

Southeast Asia, including the south of China (Ling 1970:229-37, Li 1979:13-5, Solheim 1980), has developed a maritime tradition sophisticated enough to eventually enable the colonisation of Remote Oceania and Madagascar. Several early $1^{\text {st }}$ C. CE shipwrecks found in Southeast Asia show complex techniques of plank-fastening (Manguin 1996:186). An advanced knowledge of seafaring is also substantiated by the linguistic record: the occurrence of various cognate words for nautical terms in such languages as Malay, Tagalog, Māori and Hawaiian implies protoforms appertaining to proto-Malayo-Polynesian (Zorc 1994, Pawley \& Pawley 1994, Pawley 2000). That is to say, Austronesianists generally assume that a considerable quantity of

\footnotetext{
${ }^{1}$ An Austro-Asiatic origin of OIA */ā'rngala 'plough' is certainly plausible from the perspective of Mon-Khmer linguistics, cf. Old Mon lanigur 'pair, yoke' and Old Khmer añgāl añgāla 'plough'. The latter may consist of gāl 'to raise' and the prefix /?əN-I, hence '[earth-]raiser' (Jenner 2009 s.v.). Shorto (2006:448) reconstructs the Mon-Khmer protoforms */ngal * $\mathrm{ggal}$ (and, by dissimilation, *Ingu[ə]r and *Inguur), cf. Khasi IIko.r 'plough; anchor'. These Mon-Khmer forms presumably stood at the head of a series of loanwords in Malayo-Polynesian languages, e.g. Cham langar (Ewn) langal (5w) 'plough', Acehnese langay, Gayo nung(g)ul, Toba Batak ninggala tinggala, Malay tənggala, Makasar nangkala and Bugis rakala id. Similar words are found in Dravidian languages (e.g. Burrow 1943:131, Witzel 1999:2930).
} 
maritime terms was known and used by the common (linguistic) ancestors of these speech communities. While an increasing number of communities in insular Southeast Asia have ultimately lost these seafaring skills, maritime navigation remained the primary way to sustain commercial contacts, obtain sufficient foodstuffs and maintain viable populations until recent times. In this light, it is not surprising that some authors believe insular Southeast Asians were able to reach South Asia earlier than South Asians were able to make the reverse journey (Sarkar 1970:14, Marschall 1980:15-7). While the presence of Malayo-Polynesian languages throughout Southeast Asia and the Pacific is testimony to the ability of their speakers to sail enormous distances and successfully colonise new areas, the Indian Ocean west of Sumatra with exception of Madagascar and Mayotte - lacks Malayo-Polynesian speech communities other than those established there during or after colonial times. Nevertheless, the extensive work of James Hornell (see References), an authority on traditional watercraft, demonstrates that the outrigger boats of South Asia and East Africa are derived from insular Southeast Asian prototypes, suggesting that Southeast Asians did reach the western regions of the Indian Ocean and introduced their produce and technology in a largely undocumented past. Island groups between Southeast Asia and East Africa, such as the Seychelles and the Chagos Archipelago, were probably too isolated or deprived of fresh water to ensure successful colonisation or continuous navigation, as they were unpopulated upon their European discovery. If, on the other hand, Madagascar was settled from insular Southeast Asia in shore-hugging watercraft, some relatively small pockets of westward migrating Southeast Asian communities may have been assimilated into pre-existing populations of South Asia, the Middle East and East Africa (e.g. Mahdi 1999b:163), a scenario supported by recent phylogenetic research (Hurles et al. 2005, Ducourneau 2010). Studies on Middle Eastern philology, too, suggest that insular Southeast Asian seafarers remained a familiar sight in the Indian Ocean into medieval times (Ferrand 1910, Allibert 1999). 


\subsection{The scope of this study}

Before the development of archaeological dating methods, scholars relied predominantly on linguistics and philology to analyse cultural contact in the Indian Ocean World, focusing on the names of trade items and their geographical dispersal. As early as the mid-19th century, several well-known philologists examined linguistic clues to early maritime trade in the Arabian Sea, highlighting the presence of tentative South Asian loans in the Middle East and classical Europe (Benfey 1840, Lassen 1847-61/1:537-9, Caldwell 1875, Sayce 1887:137-8, Müller 1899). This tradition was sporadically pursued in later times (e.g. Legrand 1954, Rabin 1968, 1994, Rathnavel 1973), but these studies display an unfortunate tendency to exaggerate the Tamil element in these lexical exchanges beyond the bounds of objective scholarship. My work differs from previous studies in two ways. First, this study incorporates a wide range of linguistic data from primary (fieldwork) sources and secondary sources (dictionaries, wordlists, epigraphic sources, etc.). Second, it brings together the latest insights from archaeology, linguistics and the natural sciences. Inferences from each of these disciplines are intended to complement, corroborate or correct each other in an attempt to enhance our knowledge of the complex social processes that have shaped the pre-written past of the Indian Ocean. Since recent technological developments in the field of archaeology have provided better dating methods and an increased understanding of Southeast Asia's prehistory - especially prior to the period of "Indianisation" that began in the early $1^{\text {st }}$ mill. CE - the unidirectionality of cultural contact with South Asia also came under question. On the one hand, new insights suggest that several socio-cultural phenomena - including interregional trade, rice cultivation, relatively large-scale settlements and metallurgy - were of indigenous (mainland) Southeast Asian origin, not of foreign introduction. On the other, we are still confronted with a considerable lack of archaeological evidence for reciprocal influence across the Bay of Bengal. As a result, the impact of Southeast Asia on India is still poorly understood. As Southeast Asia did not export durable products on a scale comparable to South Asia, its people show up in the archaeological 
record as little more than the recipients of trade goods. This study is a preliminary attempt at the rectification of this imbalance. It focuses on the products that were exported from Southeast Asia in return for South Asian manufactured goods. It also touches upon the ways in which these commodities reached the subcontinent, the people who transported them and the watercraft in which they were conveyed.

This study predominantly deals with maritime trade. Overland trade networks between South and Southeast Asia merit a study on their own. The exact dispersal patterns of bananas (Musa spp.), the areca palm (Areca catechu), the betel pepper (Piper betle) and several yam varieties (Dioscorea spp.) into the Indian subcontinent are still poorly understood (cf. Fuller 2007:427). Possibly, the arrival of these food crops into the South Asian agricultural setting was concomitant with the westward dispersal of Austro-Asiatic speech communities from the Southeast Asian mainland. While it is known that the Muṇā tribes possessed knowledge of agriculture (e.g. Zide \& Zide 1976), their exact role in the prehistory of South Asia remains to be further determined. In addition to this Munḍā element, there potentially exists an ancient link between the megalithic traditions and other cultural practices of Northeast India and those of Southeast Asia, including swidden or shifting cultivation ("jhooming"), head-hunting, tattooing, communal houses, ceramic traditions, massive funeral ceremonies and boat-shaped coffins (cf. Logan 1848, Banerjee 1965:51-2, Mahdi 1999a:165-7, 1999b:175, 181-3, van Driem 2001:290, 411-7, Gupta 2005, Hazarika 2006). The current inhabitants of Northeast India and the surrounding states are predominantly of Tibeto-Burmese linguistic affiliation. Marrison (1967:1/206-29) provides some tentative examples of Mon-Khmer, Malayic and other Southeast Asian loanwords in their languages, but the used methodology is not up to current standards and further research is necessary to verify these claims. Finally, since the geographical focus of this study is on the Indian Ocean, the prehistoric contacts between Southeast Asia and China will not be addressed, except in passing. I will also not touch upon the southern parts of present-day China, which were - and partly continue to be - part of the Southeast Asian cultural 
sphere in pre-modern times (cf. Schafer 1967). Nevertheless, some valuable Chinese textual sources are used to illustrate the use of certain products and cultural items.

Figure 1: map of the Indian Ocean

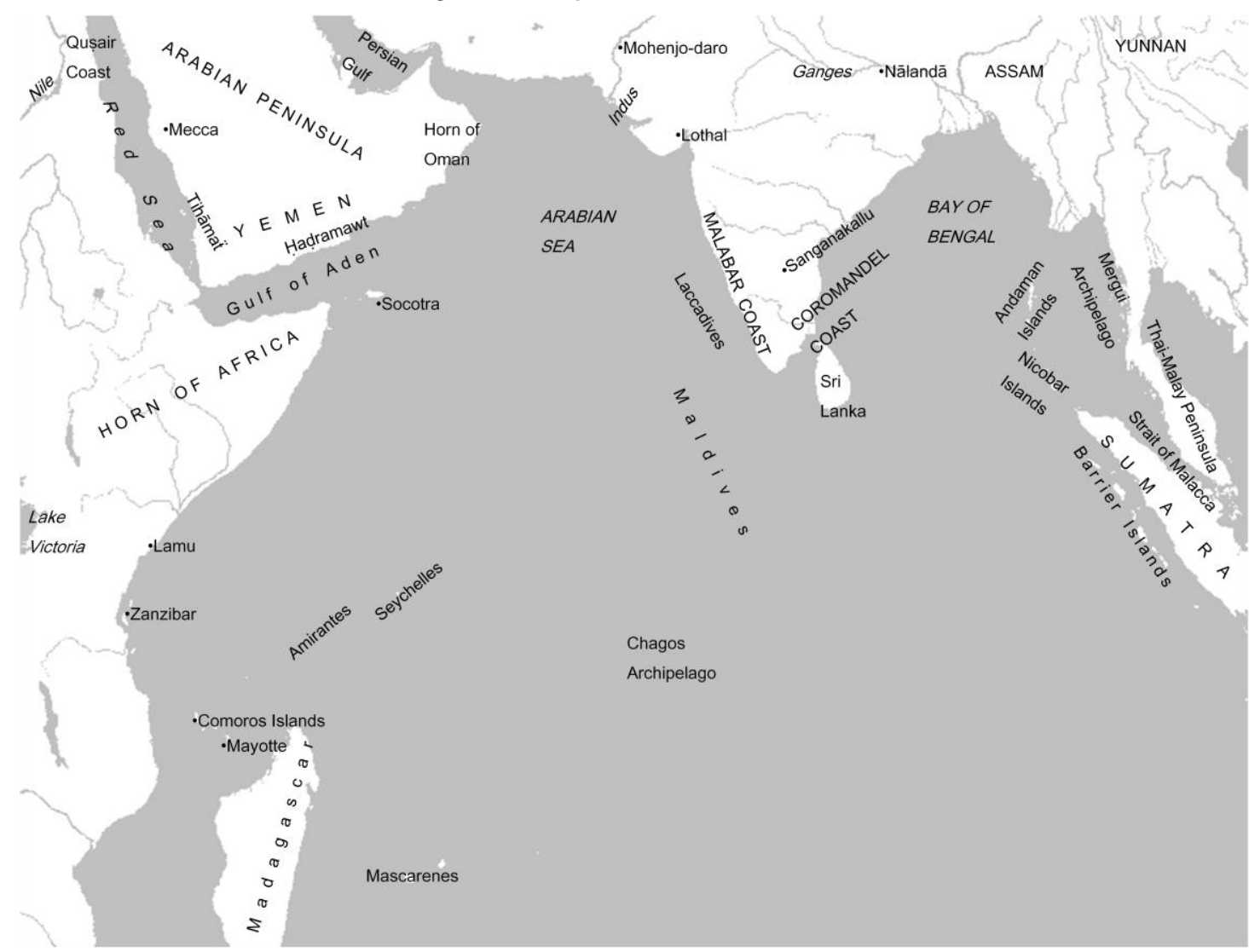

\subsection{Data and structure}

One of the most significant components of this work is the lexical data collected during fieldwork trips to southern India, Sri Lanka and the Maldives (January - March 2009), Malaysia (November - December 2009) and Indonesia (July - August 2010). In essence, this fieldwork can be characterised as a journey along the same routes taken by the ancient seafarers who form the focus of this study. In a broader perspective, it provided several opportunities to consult with local experts, cross-check information and enhance my knowledge of the regional languages. My key sources of data were the consultants from whom I elicited specific cultural and agricultural vocabulary in their native language. To increase my knowledge of maritime technology, I confronted the helpful fishermen of southern India, Sri Lanka, Indonesia and 
Malaysia with detailed sketches of local boat types. To elicit the names of spices and plants, I mainly used photos and drawings from my personal collection. For cultural reasons, all my consultants were male. In India, Sri Lanka and the Maldives, English was used for communication, whereas I spoke Malay in Indonesia and Malaysia. All data have been doublechecked using the dictionaries listed under Language Sources. Partly for this purpose, extensive library research in India, Sri Lanka and the Maldives was carried out in addition to linguistic fieldwork, enabling me to access numerous local publications not well distributed abroad. In addition, it can be observed that I make occasional use of $19^{\text {th }}$ or early $20^{\text {th }}$ century sources. This has several benefits. In the first place, many of the authoritative lexicographic and philological works include words that are no longer known to native speakers and contain a minimum of neologisms and recent loanwords. In the second place, interdisciplinary research inherently bears the danger of misinterpreting research results from disciplines other than one's own. To minimise the risk of introducing a string of erroneous assumptions into the wider literature, it is particularly important to trace back the original source of an idea, theory or finding, so that it can be verified. A more general truth revealed by this approach is that a great deal of scholarship considered to be innovative is in fact much older than commonly assumed.

Including this introductory chapter, this study is divided into seven chapters united by a single question: to what extent can historical linguistics shed new light on the ancient presence of insular Southeast Asian communities in the Indian Ocean? In Chapter 2, I will expand on the methodology used in this study. Bringing together data from archaeology, linguistics and natural sciences is a relatively recent practice, requiring a considerable degree of caution regarding the caveats of this approach. This chapter also introduces some methodological conventions from the field of historical linguistics. After the methodology chapter, the study proceeds to explore how this interdisciplinary approach works out with concrete data. Chapter 3 offers new perspectives on the development of interethnic contact and trade networks across the Bay of Bengal, focusing on the nature of these interactions, the communities involved and the products exchanged. The impact of Southeast Asian sailors and merchants on the different regions of the 
Indian Ocean will be discussed in Chapter 4. Chapter 5 is dedicated to anthropogenic translocations of Southeast Asian plants into other parts of the Indian Ocean littoral, since the earliest line of evidence for contacts across the Bay of Bengal was found in an archaeobotanical context (i.e. the finding of sandalwood remains). Chapter 6 deals with the trade in and westward dispersal of Southeast Asian spices. The development and transoceanic distribution of the Southeast Asian boat- and ship-building traditions is examined in Chapter 7. In the conclusion, I return to the research questions addressed here and consider the extent to which interdisciplinary research can provide new perspectives on the prehistory of the Indian Ocean. A reconstructed history of the insular Southeast Asian element in the Indian Ocean World is formulated based on the findings of this study, followed by a brief treatment of topics of interest for future research. Appendix 1 comprises a tabulated list of loanwords from Malayo-Polynesian sources into other languages of the Indian Ocean World. It encompasses three tables: "Malay loanwords across the Indian Ocean", "other Malayo-Polynesian loanwords across the Indian Ocean" and "South Asian mineral and metal terms in Southeast Asia". Appendix 2 lists the authorities for the botanical names used in this study.

Figure 2: map of insular Southeast Asia

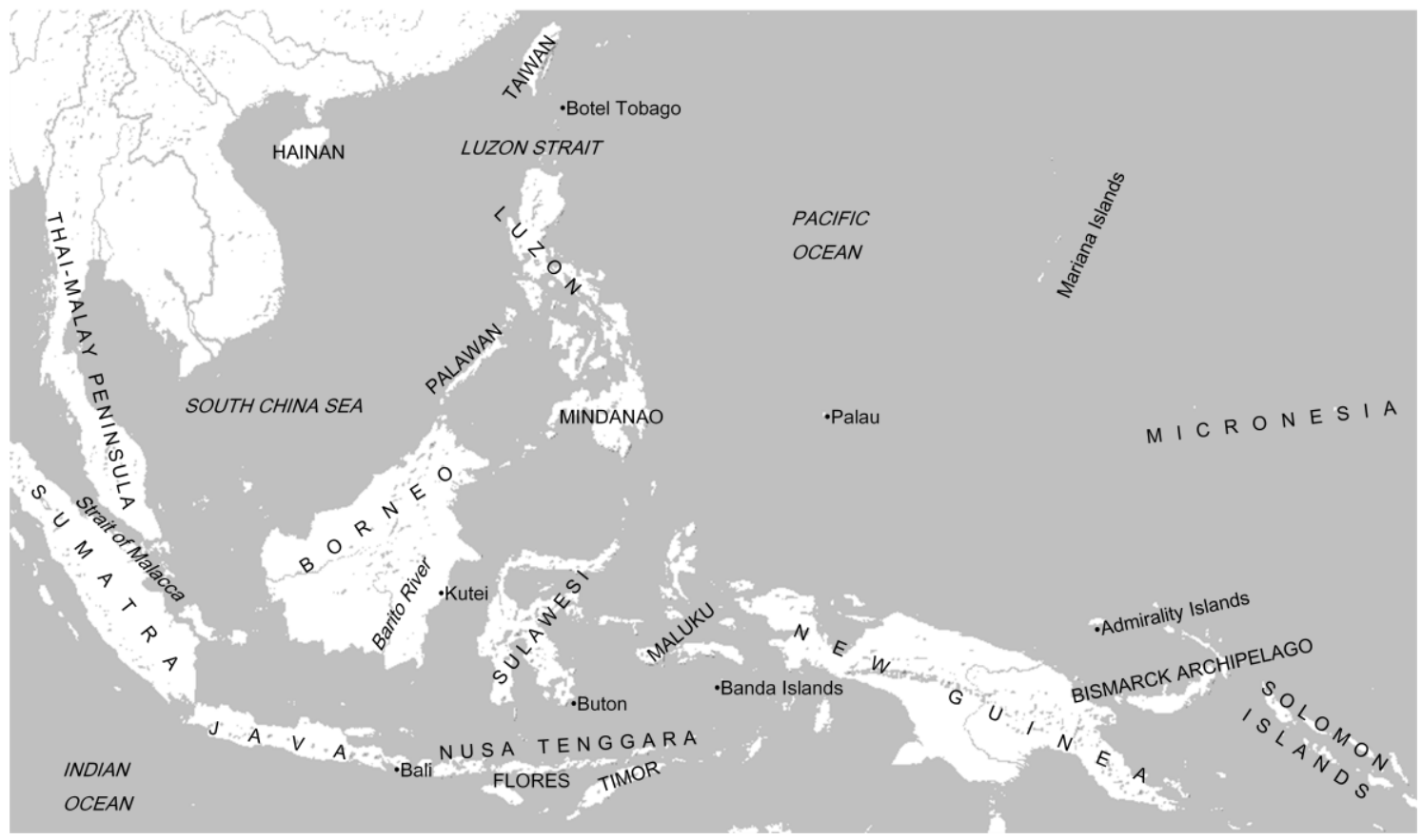




\section{Methodology}

As one of the oldest sciences dealing with culture, linguistics provides a useful framework for exploring cultural contact, interaction and transmission. Although I have done my best to make this study accessible to non-linguists, the use of certain field-specific methods and technical terms is inevitable for an appropriate treatment of the processes involved. This chapter introduces the relevant concepts and analytical methods employed throughout the subsequent chapters. Where necessary, they are illustrated with examples from my own fieldwork. The chapter addresses to a non-linguist readership the relevance of historical linguistics, the ways in which archaeological research can benefit from the use of lexical data and the limitations of such an approach. Foremost, it is simplistic to assume that lexical borrowing is always an indication of foreign introduction, while borrowed concepts cannot be designated with indigenous vocabulary. In fact, the meaning of an indigenous word is often expanded to include an introduced concept, while the adoption of a foreign word can obscure or eradicate preexisting indigenous vocabulary. Therefore, this chapter gives special attention to the underlying socio-linguistic processes of lexical borrowing.

The first section introduces the methodology of historical linguistics, addressing several frequently used terms, linguistic palaeontology and contact linguistics. The second section elaborates on lexical borrowing. It examines why words are borrowed and sheds light on the sociolinguistic factors determining whether languages are susceptible or hostile towards loanwords. The third section focuses on phonological analysis to propose a chronology of lexical borrowing, the importance of sound changes, and the accommodation of foreign vocabulary in recipient languages. The fourth section addresses the challenges of bringing together data from historical linguistics and archaeology, highlighting the benefits of such an interdisciplinary approach and addressing the caveats of doing so. 


\subsection{Some historical linguistic assumptions}

Language, material culture and biological lineages are rarely inseparable. Nevertheless, languages can contain important clues to a past not otherwise documented. There are two ways in which the study of linguistics can help us to understand the past of speech communities: through linguistic palaeontology and contact linguistics. The field of linguistic palaeontology is concerned with the study of the nature of ancient societies through their vocabulary, either reconstructed or attested in the literature. It is inferred that the lexicon of a language contains clues about the society in which it is spoken, providing a picture of its technology, social hierarchy and relations with the environment. In linguistic theory, languages are perceived to be genetically related if they are descended from a common ancestral language, the protolanguage. Through comparing cognate forms in related languages, historical linguistics aims to establish regular sound correspondences to allow the (partial) reconstruction of this ancestral language. In the case of the Romance languages, the protolanguage (Vulgar Latin) is partly documented in the literary corpus, while the existence of classical Latin provides a wealth of comparative material to test the reconstructed vocabulary. In most other cases, however, the lexicon of a tentative protolanguage can only be reconstructed based on regular sound changes in its daughter languages. Such protoforms have not been directly observed in either spoken or written form and are conventionally marked with an asterisk $\left({ }^{*}\right)$. Hence, the reconstructability of proto-lexicon is predominantly hypothetical. A wide distribution of reflexes (i.e. forms directly transmitted from an earlier form - reconstructed or attested) often hints at - but is no guarantee for - a considerable antiquity of the word in question. In relation to each other, those words that have developed from a common ancestor are known as cognates. Malay layar 'sail', for example, is cognate to Moken layan id.; both forms are attributable to proto-Malayo-Polynesian *layaR id.

The second important inference in historical linguistics is that a speech community is typically in contact with its neighbours, taking over ideas of technology, trade, religion and other 
socio-cultural aspects. As a result, the vocabulary of any language partly consists of elements accounted for by language contact. In many but not all cases, the name of an introduced concept is adopted from the same source as the concept itself. Historical linguistics provides a useful tool to reconstruct the spread of cultural elements from one society to another. Even today, the evidence for cultural contact in pre-literate societies is often largely based on linguistic inferences in the absence of corroborative historical data. The analysis of loanwords has revealed contact between insular Southeast Asia and northern Australia (Walker \& Zorc 1981, Evans 1992, Cooke 1999) and between Polynesia and the Andes (cf. Langdon 2001), to name but a few examples. Prolonged language contact normally results in the transmission of linguistic elements; not just lexical, but also grammatical material can be borrowed (Campbell 2004:62).

Change in vocabulary is known as lexical innovation. It takes place, among others, through the process of importation, i.e. borrowing words from other languages or creating new words influenced by other languages. Evolution in the usage of existing words is known as substitution or semantic shift. A loanword is a word imported from another language, e.g. Central Nicobarese powan 'onion' from Malay bawang id. Some cases display semantic narrowing or specialisation, e.g. Malay təmbaga 'copper' yielding Tagalog tumbaga 'copper-gold alloy', whereas others display semantic widening or extension, e.g. Malay perak 'silver (coin)' yielding Tausug pilak 'money'. A loanword is distinct from a loan translation or calque, which is an element-by-element translation of word or phrase from one language into another, e.g. Tamil vāl-millaku 'tailed pepper' from Malay lada bərekor id., both denoting the 'cubeb pepper (Piper cubeba)'. As a result of lexical borrowing (or other linguistic processes), languages may display two words which are historically from the same source, but underwent different stages of development. These are known as doublets, e.g. Tamil cāntam 'sandalwood' alongside cantanam id. (from Sanskrit candana, ultimately from a Dravidian source).

Based upon the premises that loanwords indicate cultural contact and are normally taken from the same source as the objects they refer to, identifying lexical borrowing and 
determining its directionality are the next steps in reconstructing the nature of cultural contact. Loanwords can demonstrate what communities have learned from each other in terms of trade, culture, technology and organisational change. Upon determining the directionality of lexical borrowing, the general rule of thumb is that a concept not present in the original geographical setting of a speech community is likely to be borrowed, e.g. Sinhala ran̆butan 'rambutan (Nephelium lappaceum)' is from Malay rambutan id. and not the other way around, since the fruit originates from insular Southeast Asia. Various factors can hint at a foreign acquisition, as opposed to inheritance. Every language has its own system of permissible phonetic units (phonotactics), such as tones, consonant clusters, vowels sequences and syllable structures, which determine the form of its words. Lexical units that violate these rules are likely candidates for lexical borrowing. Illustratively, Tamil lankar 'anchor' exhibits a word-intial /I/, which is "forbidden" in Tamil phonotactics, hinting at a foreign provenance (from Farsi langar id.). Another strategy to determine the original source of a borrowed word is the recognisability of morphemes - the grammatical units smaller than words, such as plural markers, articles, etc. which may have been adopted as a whole into the recipient language. The name of the famous durian fruit (Durio zibethinus), for example, is extremely likely to be from Malay or a closely related language on account of its composition of the elements duri 'thorn' + -an (a suffix), so that Sinhala dūriyan must be a Malay loanword. Finally, we may look at the sister languages to find out whether a word is borrowed or inherited. If a word is reflected in a set of genetically related languages, corresponding with regular sound changes, these forms are most likely inherited from a common protoform. Nevertheless, caution is required: a seemingly regular protoform could still be an early loan (in which case it is conventionally marked with a superscript x). "Proto"-Indo-Aryan ×lavariga 'cloves', for example, is in fact an early loan from Malay (bunga) lawang id. (cf. Section 6.1). 


\subsection{The dynamics of lexical borrowing}

The primary motivation for lexical borrowing is to designate new things, concepts, people and places (Weinreich 1974:56ff). This explains why culture words are more frequently borrowed than basic vocabulary. It is further believed that infrequently used vocabulary, such as specialised technological devices, is susceptible to replacement. Common concepts, on the other hand, are typically designated with indigenous terms. While borrowing is a considerably more efficient process than inventing native terms to accompany the acquisition of new concepts, it is pointed out in this section that some languages are less susceptible to foreign influence than others. If the conveying culture is considered worthy of imitation, foreign loans are often regarded as more refined than indigenous vocabulary. In particular, the vocabulary of languages associated with intellectual thought, such as Latin, Sanskrit or Arabic, tends to quickly enter the learnèd stylistic stratum of vernaculars, embellishing otherwise plain sentences. In this regard, it would make perfect sense for languages in a socially stratified society to adopt "luxury loans", "snobbish vocabulary" or "elitarian expressions" from such prestigious languages (hence the infusion of French loans into English). These loans may even include terms for existing concepts, such as body parts and family members (Wild 1970:127, Campbell 2004:645). Along similar lines, the semi-accessible "ritual languages" of shamans and other magicoreligious practitioners also draw from foreign languages as a source of inspiration. In yet other cases, foreign lexicon is borrowed for the opposite purpose. The less elegant, lower speech registers of a language, which tend to be spiced with slang terms, abusive idioms and affective words, need to be constantly innovated to maintain their expressive force and, in some cases, incomprehensibility towards outsiders (Weinreich 1974:56-8, Campbell 2004:64-5).

Not many scholars have examined how lexical borrowing is influenced by sociolinguistic attitudes. Languages, even those in close geographical proximity, tend to display great variety in their affinity to loanwords. Modern Japanese, for example, has a high tolerance towards loanwords, whereas Korean has not. In the same way, languages such as English, 
Spanish and Malay are known to be quite receptive to foreign influence, whereas French, Chinese and Modern Standard Arabic are particularly unaccommodating to lexical borrowing and exhibit various alternative ways to deal with new vocabulary. These strategies - carried out consciously, through literary formulations, or spontaneously, through vernacular expressions include the creation of full or semi-calques and other neologisms. Upon examining the discrepancy in socio-linguistic attitudes towards loanwords, susceptibility to foreign influence, and general openness of speech communities, we frequently encounter somewhat irrational fears of so-called "bastardisation" and linguistic impurity. From an objective point of view, languages are continuously evolving, expanding and adapting to new environments and social developments, notwithstanding the existence of different degrees of linguistic conservatism and the universal habit of the older generation to condemn the language of young people. Nevertheless, many speech communities that experience a perceived threat by culturally prestigious or otherwise influential languages develop a defensive reluctance towards borrowing, often resulting in systematic attempts to "purify" undesirable elements. Such enterprises tend to be politically charged and a correlation between nationalism and the "need" to guard the language against foreign infiltration is not difficult to imagine.

In a study of the Arabic language, Issawi (1967:128-31) gives various reasons for its reluctance towards lexical borrowing, many of which are transferable to other linguistic settings as well. An important factor is the social prestige of Arabic; as a widely used classical language with an extensive literary-religious tradition, a higher degree of conservatism is conceived and expected by those who use it. Such sentiments are fuelled by persistent folkloristic notions that some languages are "richer" than others and that loanwords are essentially impure. In addition, Issawi notices that Arabic has a relatively high quantity of abstract terms, making the language better equipped to create indigenous neologisms for new concepts. Finally, there appears to be a correlation between linguistic and cultural conservatism. The Arabs have been relatively conservative towards social change and zealous to preserve their cultural and religious identity, frowning upon cultural, political or linguistic identification with European societies. These and 
other differences in socio-linguistic hierarchy often lead to imbalanced reciprocity between a "high" and a "low" language in contact, as illustrated, among others, by the relatively small quantity of Malay loanwords into Arabic or Hindi loanwords into English.

As mentioned previously, speech communities display various motives to adopt foreign vocabulary, including the need to fill up gaps in the lexico-semantic system, the cultural status of another speech community, the desire to show off to the less educated and (aspired) affiliation with a religious or socio-political network. A prominent example of "opening up" to foreign influence is presented by the prolonged Francophone hegemony in England, which radically changed the attitude of the English speech community towards accepting foreign loanwords. Evident extra-lingual reasons can also play a role. Hindi and Urdu, effectively two varieties of same language, are open to respectively Sanskrit and Perso-Arabic influence on account of political and religious reasons. In both cases, confusion in usage between original and borrowed synonyms can lead to the disappearance of one of the forms or the survival of both forms with specialisation in content (cf. Weinreich 1974:54-5). Another important incentive to open up to foreign influence and lexical borrowing, I would argue, is the facilitation of interethnic commerce. This is one of the reasons that languages used by mercantile communities occasionally adopt loanwords from speech communities in contact when perfectly applicable indigenous synonyms are available. This, perhaps in combination with the desire to align oneself with specific social or ethnic groups, would explain why the Malay language frequently adopts foreign vocabulary unimpeded by notions of linguistic purism. ${ }^{2}$ It displays the word pauh 'mango (Mangifera spp.)' (< proto-Malayo-Polynesian *pahuq) alongside məmpəlam (< Tamil māmpalam id.) and mangga (< Portuguese manga < Tamil mānikāy /ma:nga:/ id.) (Mahdi 2007:46-7). Such loanwords are typically adopted from languages associated with a cosmopolitan allure or high socio-economic prestige. It has also been pointed out that the

\footnotetext{
2 The best documented attempts at Malay linguistic purism took place after the Malaysian independence, partly aimed to delimit the Malaysian variety from its Indonesian counterpart (cf. Altehenger-Smith 1990:122-3). Post-independent Indonesia has witnessed similar processes. Since the 1970s, however, Indonesia, Malaysia and Brunei Darussalam have tried to monitor the development of the Malay language collaboratively.
} 
adoption of a word into a wide variety of languages increases its likelihood to be borrowed into even more languages (Thomas 1991:86). This idea casts a revealing light on the existence shared cultural vocabulary in highly interconnected geographical areas. To a large extent, the modern languages of the Indian Ocean form no exception and display a common set of economically and culturally significant terms (cf. Dalgado 1913, 1919), a process that may have commenced millennia ago.

\subsection{Phonological implications of language contact}

A deeper understanding of the dynamics of linguistic borrowing requires some insights into the sound systems of languages (phonology). The sounds of loanwords are usually adapted to the phonology of the recipient language. After prolonged and intensive contact, new sounds can be introduced from one language into another. In such cases, we can observe a distinction between older loans (prior to intensified contact) accommodating to the phonology of the recipient language and more recent loans reflecting phonetic influence of the donor language (Campbell 2004:67-79). Illustratively, Tamil phonology originally forbade a word-initial ///, allowing us to infer that the Farsi loanword larikar 'anchor' is of relatively recent acquisition, whereas the Malay loanword ilavarikam 'clove-tree' (< lawang) reflects an earlier developmental stage. For technical reasons, languages with complex phonotactics may be less susceptible to loanwords and favour calques instead (Weinreich 1974:61, Hoffer 2005). In addition to the sociolinguistic factors mentioned previously, these restrictions also play a role in the observed hostility of Modern Standard Arabic towards lexical borrowing, since its morphology is largely based on trilateral word roots that are seldom compatible with multisyllabic European loanwords (cf. Issawi 1967:128-31, Campbell 2004:68).

As pointed out above, knowledge of regular diachronic sound correspondences can shed some light on the stage of development of the donor language and the recipient language at the time of a lexical transmission. The innovation of * $s>h$ in Sinhala, for example, leads us to expect $/ \mathrm{h} /$ instead of $/ \mathrm{s} /$ in all loanwords transmitted prior to intensified contact, e.g. hambāna 
'large boat' (from Malay sampan 'shoe-boat'). This example additionally demonstrates another linguistic mechanism: the addition of a word-final vowel (paragoge). Sinhala shares this phonotactic rule with Swahili, Malagasy, Makasar and many other languages, as can be observed with numerous examples given in this study. Along similar lines, early borrowings into Swahili regularly display the loss of $/ /$ between vowels ( ${ }^{*} \mid>\varnothing / V_{-} \vee$; cf. Nurse \& Hinnebusch 1993:103-4), e.g. Gujarātī phophal 'dry areca nut' > Swahili popoo id. (< +popolo), giving us an indication of the time depth of transmission; if a loanword into Swahili displays a "forbidden" intervocalic /I/, it must have been transmitted after this sound change took place. In yet other cases, loanwords are accommodated to the existing word structures of the recipient language. In Tamil, loanwords ending in /a\#/ are often provided with the female, male or neutral gender suffixes (respectively /ai\#/, /an\#/ and /am\#/; cf. Ronkel 1902:102). In the same way, Sinhala often adds the singular suffix - va to foreign loans, whereas Swahili uses the prefix $k i$ - for the same purpose.

The integration of loanwords and the phonological features involved in this process trigger various analogy patterns, in which words are reinterpreted as meaningful compounds in the recipient language and hypercorrected accordingly (Weinreich 1974:28). There are numerous examples of "wrong division". The English word 'cherries' goes back to the French cheris but was subsequently analysed as a plural form based on what was perceived to be the word-final plural marker $-s$, eventually yielding the "incorrect" singular form 'cherry'. Likewise, Malay bəniaga 'to trade' is often interpreted as having the prefix $b \partial(r)-$, while the form actually goes back to Sanskrit vanijaka 'a merchant, trader'. If the phonological history of a language is understood, such analogy patterns can be used to "correct" loanwords into native-sounding forms. Sanskrit, for example, shows several pseudo-forms (apabhramśa) created through backformation of local or foreign vernacular vocabulary (e.g. Wackernagel 1903, Mazumdar 1927:211-3, Pelliot 1959:532). Examples include vadāma 'almond' from Farsi bādām id. and dinnāra 'a gold coin or a certain weight of gold' from Arabic dīnār, itself from Greek dēnárion 


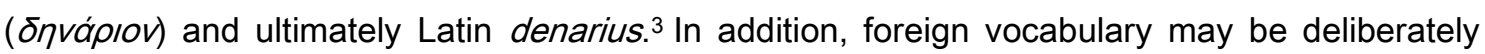
adjusted to resemble actual or potential words in the recipient language (Weinreich 1974:48), a process known as 'folk-etymology'. For example, it has been documented that speakers of Hindi display a tendency to equate foreign names with familiar sounding indigenous names to remember the former correctly (phonetic matching), turning Newberry into Lomrī (also meaning 'fox') and Grongerham into Gangā Rām (Bonavia 1890:30, Mazumdar 1927:2). The linguist Ghil'ad Zuckermann (2003:49) gives similar examples in Israeli, Mandarin and other languages, naming this process 'folk-etymological nativisation'.

\subsection{Caveats of using linguistic data}

Due to the interdisciplinary character of this study, it is difficult to fit it into a familiar category. On the one hand, combining inferences from different academic disciplines, each entitled to its own conventions, terminology and methodology, is an exceedingly difficult enterprise. On the other, the wider, macro-historical picture of a region cannot be reconstructed through a single discipline. A renewed and growing interest in the past of specific ethnolinguistic groups and the search for their origins has brought about a relevant change in archaeological thought. Facilitated by theoretical, methodological and technical developments - and despite a dark history of misuse and questionable validation of political and nationalistic claims archaeologists have become gradually more interested in the shared prehistory of linguistically related populations and the incorporation of data from the natural sciences, linguistics and anthropology to help reconstruct their past (e.g. Trigger 1989:376). This combination has proven to be a powerful one in developing new perspectives on the prehistory of Europe (Renfrew 1987), insular Southeast Asia (Bellwood 1997), South Asia (Southworth 2005) and Africa (Blench 2006). Since the publication of Colin Renfrew's pioneering work Archaeology and Language (1987) and of four volumes edited by Roger Blench and Matthew Spriggs under the same title $(1997,1998,1999 a, 1999 b)$, interdisciplinary research has been gradually gaining

\footnotetext{
${ }^{3}$ Kusuba \& Pingree (2002:219-59) give more examples of pseudo-Sanskrit forms with Perso-Arabic origins.
} 
ground among archaeologists, yielding several more edited volumes devoted to this issue (e.g. Terrell 2001, Bellwood \& Renfrew 2003, Sagart et al. 2005, Petraglia \& Allchin 2007, SanchezMazas et al. 2008).

A well known strategy to measure the antiquity of a speech society or a group of related languages in a geographical area is to look at the linguistic diversity. As is the case in biology, phylogenetic diversity tends to be greatest where a population has been the longest, barring large-scale extirpation or assimilation. That being said, this study underlines the view that language, culture and ethnic affiliation are non-coterminous and often profoundly influenced by interethnic contact. The Austronesian languages, spoken by people of great cultural and biological diversity, illustrate this point clearly. Most linguists believe Taiwan to be the homeland of this language family on account of the remarkable internal linguistic diversity on that island. ${ }^{4}$ Nevertheless, the distribution of a word in both Taiwan and insular Southeast Asia does not automatically guarantee proto-Austronesian antiquity or reconstructability. Several words attested on both sides of the Luzon Strait are in fact secondary distributions transmitted during historical contacts between Taiwanese and insular Southeast Asian populations, even though their sound correspondences may be identical to those of regularly inherited reflexes (cf. Mahdi 1994/1:172-3). Indeed, the considerable quantity of insular Southeast Asian loanwords in Formosan languages (e.g. Tsuchida 1977:111-2, Adelaar 1994a, Jen-kuei Li 1994:245-7, 1995:964-5) must be placed in the context of interethnic contact in historical times, through maritime trade and/or, perhaps, the short presence of Philippine household personnel and soldiers during the Spanish occupation of North Taiwan in the early $17^{\text {th }}$ century (Ferrell 1969:19-20). Only when a regularly inherited reflex occurs in Taiwan, insular Southeast Asia and the Pacific do we have a virtual guarantee that the word is indigenous and not borrowed from a non-Austronesian language.

\footnotetext{
${ }^{4}$ Dyen (1965), on the other hand, perceives the linguistic diversity between Austronesian languages to be the greatest in New Guinea. His hypothesis of a New Guinean homeland has not found wide acceptance among Austronesianists.
} 
The use of hypothetical protoforms to reconstruct the past of speech communities presents several other difficulties. Regular reconstructions in the agricultural domain suggest that the earliest people speaking Austronesian languages were familiar with pigs, dogs, cultivated rice, millets, sugarcane, the giant taro (Alocasia macrorrhizos) and yams (Wolff 1994, Zorc 1994, Bellwood 1997:241-2). Such wide-ranging inferences are not necessarily supported by the archaeobotanical record, although difficulties in frequency, durability, identification, etc. make it difficult for archaeobotanists to "catch" all the agricultural items used in a given society. Various plants reconstructable to high-order branches of Austronesian, such as rice, sorghum, bananas, mangos, taro, cucumbers, gourds, melons, sesame, eggplants, garlic and ginger, are not indigenous to Taiwan (cf. Jen-kuei Li 1994). Nonetheless, the traditional Out-of-Taiwan hypothesis formulated by Peter Bellwood (1979, 1991, 1995, 1997, Bellwood \& Diamond 2003, Bellwood \& Dizon 2008) assumes a strong connection between agricultural developments - in particular the cultivation of rice and millets - and the dispersal of the Austronesian languages from Taiwan into insular Southeast Asia and eventually into the Pacific. A demic movement from Taiwan into the northern Philippines is further supported by similarities in pottery excavated in these two regions (cf. Chang 1969). It follows from this that the identification of Taiwan as the Austronesian Urheimat is largely based on linguistic inferences, while our still limited understanding of the agricultural prehistory and archaeobotany of the island cautions us to identify it, a priori, as a major centre of agricultural and demic dispersal. It is unclear whether rice was as important in Taiwan as it was in coastal and riverine mainland China, although there is mounting archaeological evidence of rice cultivation on the island from $\pm 3500 \mathrm{BCE}$ (Tsang 2005). This lends support to the view that the crop was introduced from the Chinese mainland, concomitant with the arrival of Austronesian speech communities. On the other hand, one of the earliest European accounts of Taiwan mentions that the indigenous communities obtained their rice from the Chinese (Blussé \& Roessingh 1984:70), which contradicts the presumed importance of this crop as a driving factor of the Austronesian "Neolithic dispersal". 
It may also be pointed out that the "sticky" japonica variety of rice, from which most insular Southeast Asian cultivars have evolved, was initially unsuitable for equatorial latitudes (Garris et al. 2005, Poonyarit et al. 2007). This would suggest that it was only cultivated on a small scale, perhaps as a secondary source of nutrition, at the time of the Austronesian ethnolinguistic dispersal into Southeast Asia (cf. Mahdi 1994b:435, 438, Paz 2002:280). Even today, rice is often intercropped with other cereals, tubers, sago or bananas in the less densely populated areas of insular Southeast Asia. Archaeological remains of rice in insular Southeast Asia usually co-occur with red-slipped pottery (Paz 2002:278-9), which implies that the product was being stored and perhaps traded in long before it was widely cultivated in irrigated or dryland fields. Conversely, the importance of rice appears to have been much greater in the more temperate uphill regions of the Southeast Asian mainland, where historical linguistic research reveals a thorough familiarity with rice cultivation among the speakers of Hmong-Mien and, especially, Austro-Asiatic languages, making their (linguistic) ancestors the world's most likely first rice cultivators (van Driem 2001:324-7, 2012, Sagart 2003, Diffloth 2005, Ferlus 2010). In insular Southeast Asia, rice monocropping and the resultant prominence of its famous terraced paddy fields were much later developments, presumably around the first centuries CE (cf. Anshari et al. 2004). As this agricultural system is more demanding of its environment, susceptible to climatic variations and pests, prone to seasonal hunger, and in need of higher labour availability compared to other sources of carbohydrates, the predominance of wet rice cultivation in parts of insular Southeast Asia must be connected to political centralisation, population growth and increased opportunities of exchange (Henley 2004). The availability of cast iron tools, domesticated ungulates to pull ploughs and fast-growing rice varieties may also have accelerated this process. Although neither is absolutely indispensible to rice cultivation, it is worth calling attention to the fact that Austronesian languages display no inherited words for 'plough' and 'water buffalo'. That being said, there is no reason to assume that rice was not included in the diversified farming systems of Southeast Asia prior to these introductions, in particular through swidden cultivation or the management of wild rice in uphill regions or 
naturally swamped areas (pond fields). While there is as yet little firm, systematically collected archaeobotanical evidence on the cultivation systems of Southeast Asia, the levels of atmospheric methane indicate a significant transition between dry-cropping systems and wet field cultivation after 1000 BCE (Fuller et al. 2011b).

The distribution of reflexes for 'millet' ('zawa) and 'water buffalo' ('karabaw) in the languages of Taiwan (e.g. Ferrell 1969:125, 141, Jen-kuei Li 1994:242, 1995:964) and insular Southeast Asia illustrate the caveats of reconstructing agricultural prehistory through linguistic data. Although these attestations appear to go back to regularly inherited Austronesian protoforms, Mahdi (1994/1:200 fn.5, 2:431ff.) points out that the former is in fact an early IndoAryan borrowing, whereas the latter goes back to an Austro-Asiatic source. ${ }^{5}$ In addition, the same word for 'plough' is attested in Austronesian, Austro-Asiatic, Indo-Aryan and Dravidian languages (e.g. Witzel 1999:29-30), demonstrating how easily (agri)cultural vocabulary can spread across linguistic boundaries. For a deeper understanding of these transmissions, contacts between mainland and insular Southeast Asia in particular merit further research. The names of agricultural items such as 'sesame (Sesamum indicum)', 'dog', 'buffalo', 'ox', 'goat', 'cassumunar ginger (Zingiber montanum)', 'eggplant (Solanum melongena)' and 'rakum palm (Salacca wallichiana)' and their attestation in both Mon-Khmer and Malayo-Polynesian languages (cf. Shorto 2006:\#34, \#41, \#103, \#119, \#126, \#216, \#587, \#1312a) are testimony to the strong ties between the mainland and the islands in a pre-documented past, regardless of the exact ways in which these words have spread. The situation becomes even more complex if we take into account semantic shifts; often a loanword does not refer to the same object as its precursor in the donor language. The Sanskrit word jambu 'rose-apple (Syzygium cumini), for example, is borrowed as Malay jambu, which is used for 1) the "Indian" rose-apple, 2) endemic

\footnotetext{
${ }^{5}$ Reflexes of ‘zawa 'millet' go back to Middle Indo-Aryan *jāva 'barley (Hordeum vulgare)', Old Indo-Aryan * yáva id. and ultimately to proto-Indo-European *yewo- 'grain'. Presumably, the Middle Indo-Aryan form was also borrowed as "proto"Mon-Khmer `d[b]aw 'millet'. Reflexes of “karabaw 'water buffalo' go back to proto-Mon-Khmer *[kr]puh *krpiiw *krpi? *krpu?, cf. proto-Muṇạā *oreXj 'drought animal, cow', Burmese kyvai (nj) 'water buffalo', Thai khvāy (ควาย) id. and many other related forms listed by Mahdi.
} 
species such as $S$. malaccense and $S$. jambos and 3) New World species such as the 'guava' (Psidium guajava) and 'cashew' (Anacardium occidentale). ${ }^{6}$ Finally, one should be prepared to encounter similar looking words due to chance resemblance. Upon initial inspection, Sinhala oruva 'boat, canoe' strikingly resembles Polynesian reflexes such as Māori hourua 'double canoe' in both form and meaning. The fact that Sri Lanka and parts of Polynesia both exhibit single outrigger canoes has made it tempting to interpret the Sinhala form as a Polynesian loan (e.g. Wijesekera 1949:45 fn. 4). However, the Sinhala form is probably connected to Old IndoAryan uḍpa 'raft, float' and related forms (Kuhn 1883:15, Turner 1966 \#1695), whereas the Māori attestation goes back to proto-Eastern Oceanian * paqurua 'double canoe' (Pawley \& Pawley 1994:340). This example demonstrates an important rule: historical linguistics should always be based on regular sound correspondences, not on superficial similarities.

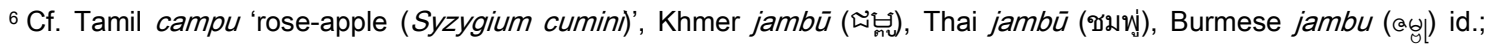
Tagalog yambu 'rose-apple (S. malaccense)' (Madulid 2001/2:295) and perhaps Swahili (Zanzibar dial.) m-zambaru 'rose-apple (S. cumini)' (Williams 1949:252). 


\section{A prehistory of cultural contact in the Bay of Bengal}

Scholars have long been aware of the interconnectedness of the Indian Ocean and its littoral regions, linked to each other by natural harbours, monsoon winds and sea currents. Since Sumerian and Akkadian times, we have literary evidence of maritime trade in timber and copper (Hourani 1995:6). However, textual evidence on commercial activities between these state-level societies only reveals the culmination of much older networks. In order to understand how these networks emerged, it is crucial not to overlook the role of small-scale maritime oriented societies operating in a pre- or proto-urbanised setting. In the Middle East, such communities played a pioneering role in establishing the first foundations of maritime trade in the region from at least the $7^{\text {th }}$ mill. BCE (Horton 1997, Boivin et al. 2009). In the early Bronze Age, contemporaneous with the formation of the first civilisations, the intensification of these maritime contacts led to advanced commercial networks connecting the shores of the Middle East with those of East Africa and South Asia (Ratnagar 1981, Boivin et al. 2009).

A second boost in Indian Ocean trade was assisted by the Roman expansion and subsequent acquaintance with and demand for silk, spices and other exotic luxuries. Overland trade between the Roman Empire, India and China, which had been carried out on large scale from the $2^{\text {nd }} C . B C E$, was highly dependent on the intervening Central Asian populations and their often unstable internal and external relations. Sea trade was less precarious, but still required the services of foreign intermediates, as neither the Greeks nor the Romans possessed accurate knowledge of the monsoon winds. ${ }^{7}$ From the various Graeco-Roman texts on the Indian Ocean (cf. Cœdès 1910), we may infer that the Romans and especially the Hellenised Egyptians of post-Augustinian times had a relatively clear picture of the Middle East, East Africa and South Asia, while notions of the areas beyond these regions remained vague and often contradictory. All of their information on Southeast Asia seems to have been obtained

\footnotetext{
${ }^{7}$ The linguistic data suggest that the Arabs played an important role in spreading this knowledge across the Indian Ocean; Arabic mausim 'monsoon' was adopted as Farsi mausim, Swahili msimu, Hindi mausim, Sinhala mosama,

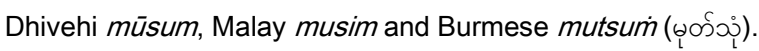


through Indian informants, as the Graeco-Roman accounts contain less detail than the Indian accounts but list similar place-names (Lévi 1925, Ray 1994:111-3). In the same way, Arabic authors initially often drew on Nestorian, Graeco-Roman and Indian sources (Tibbetts 1979:2). Under the Islamic expansion, the nations of the Indian Ocean became even more interconnected and began to converge to the same laws, culture and religion, as had happened earlier under Buddhism (e.g. Wheatley 1961:48, Kulke 1990:10). This study's focus, however, is on the pre-Islamic trade networks.

This chapter addresses cultural contact between South and Southeast Asia from the mid-2 ${ }^{\text {nd }}$ mill. BCE until the first centuries CE. The first section deals with the earliest encounters between the populations of the Indian subcontinent and Southeast Asians. Among the concepts Southeast Asian sailors brought back from the subcontinent are notions of urbanism and religion. The second section addresses religious, political and commercial influence from the subcontinent on the early kingdoms of Southeast Asia, underlining that these transoceanic networks were spear-headed by merchants. The third section examines how this intensification of contacts between South and Southeast Asia was reflected in the literary corpus of South Asia and, to a lesser extent, China and the Middle East. The fourth section addresses the (pre)history of metallurgy in Southeast Asia and argues that transoceanic networks were instrumental in reinforcing and reshaping the use of metal in insular Southeast Asia. The fifth section demonstrates that the trade in metals and the diffusion of metal technology became important components of both regional Southeast Asian as well as wider Indian Ocean exchange networks.

\subsection{Initial contacts}

We have no means of dating the first period of contact between the populations of South and Southeast Asia. As a starting point we may take the second half of the $2^{\text {nd }}$ mill. BCE, when charcoal remains of insular Southeast Asian sandalwood (Santalum album) start to show up in a South Indian Neolithic context (Asouti \& Fuller 2008:135). Other Southeast Asian 
introductions into the Indian subcontinent include the sweet banana (Musa x paradisiaca), areca nut (Areca catechu) and possibly the coconut (Cocos nucifera) and orange (Citrus aurantium) (Fuller 2007:427). If the identification and dating of the sandalwood finding are correct, the sailors who introduced this valuable commodity across the Bay of Bengal would have been insular Southeast Asians who obtained the tree from present-day Nusa Tenggara, a chain of arid islands east of Java and north of Western Australia. The timeframe roughly corresponds with that of the initial settlement of Remote Oceania by speakers of Malayo-Polynesian languages, leaving little doubt that they could have sailed equal distances in the opposite direction. There is little evidence of comparable maritime skills among South Asian populations by that time, although the Harappans were most likely involved in westward maritime trade with Mesopotamia, the Horn of Oman and possibly East Africa (Kennedy 1898, Sastri 1938:25ff., During Caspers 1965, Ratnagar 1981, Meyer et al. 1991, Ray 1994:12, Cleuziou \& Tosi 1995, Boivin et al. 2009:11-3). However, the documentation of Indian ships in the waters of the Red Sea and Southeast Asia - archaeological, textual or other - is of much later date (Warmington 1974:4, Ray 1994:107).

With the exception of carved paddle impressed pottery (cf. Selvakumar 2011) and bronze with a high tin-content (Rajan 2011:188-90), there is little solid archaeological evidence pointing at Southeast Asian elements in South Asia prior to the first centuries CE. In an exploration of the earliest contacts across the Bay of Bengal, Mahdi (1994/2:451, 1999b:181ff.) postulates that the megalithic traditions in South and Northeast India have incorporated several Southeast Asian elements. He argues that both the boat-shaped coffins in Northeast India and the burial urns in South India represent funeral traditions introduced from insular Southeast Asia. A Southeast Asian origin of the Sri Lankan urn burial tradition - involving a secondary postexcarnation burial in an urn or jar - is also suggested by Solheim \& Deraniyagala (1972). ${ }^{8}$ However, the urn burial tradition was quite widespread and of considerable time-depth in South

\footnotetext{
8 From insular Southeast Asia, this tradition has also spread to the Southeast Asian mainland and to Japan in prehistoric times (Bellwood 1997:272-3, Gupta 2005:22), but was subsequently eradicated by later practices in each of these regions.
} 
Asia itself, so that its tentative Southeast Asian derivation raises more questions than it answers at this stage of knowledge.

Conversely, cultural contact across the Bay of Bengal is reflected by socio-cultural changes that took place in Southeast Asia. Although recent archaeological insights support an indigenous, Southeast Asian origin of concepts previously treated as foreign introductions including metallurgy, irrigated rice agriculture and semi-urbanisation (Glover 1996:130) - we may safely assume that such processes were occasionally reinforced by external stimulus. An example of a wide-ranging agricultural development in Southeast Asia fuelled by contact with South Asia is the adoption of sorghum (Sorghum bicolor), both the plant and its name, from an Indo-Aryan source (Mahdi 1994/2:431ff.). Other plants that moved from South to Southeast Asia in the $1^{\text {st }}$ mill. BCE include the mungbean (Vigna radiata), Indian rice (Oryza sativa subsp. indica), cotton (Gossypium arboreum), oilseed sesame (Sesamum indicum), tamarind (Tamarindus indica), mango cultivars (Mangifera spp.) and horse gram (Macrotyloma uniflorum) (Castillo \& Fuller 2010:95-6). ${ }^{9}$ The diffusion of new concepts from South Asia also becomes evident from a closer look at the geographical distribution of urban settlements and "Indianised" polities across Southeast Asia, which is restricted to those regions situated within the wider transoceanic trade networks of western Southeast Asia (Wheatley 1983:263). It would be tempting to conclude that trade with India generated the economic advantages that facilitated the formation of cities and states in Southeast Asia, as previous scholars often did. However, recent scholarship has proved these notions incorrect: a closer look at Southeast Asian archaeology prior to contact with India reveals outstandingly rich elite burials and the existence of agricultural settlements and proto-urban centres (cf. Wheatley 1983, Slamet-Velsink 1995, Higham \& Higham 2009:134). The occurrence and wide distribution of words such as datu - "a

\footnotetext{
9 This is (partly) corroborated by linguistic data: Old Khmer (pre-Angkorian) mudgā 'mungbean', Old Javanese mudga id. (< OIA *mudgá id.); Old Khmer kalamva 'a variety of rice' (< Sanskrit kalama id.); PMK ‘kpaas 'cotton', Old Javanese kapas id. (< OIA *karpā'sa id., possibly a non-Indo-Aryan word); Old Khmer tila 'sesame', Old Javanese tila id. (< OIA *tilá id.); PMK `m[b]il 'tamarind', Old Khmer amivil, Old Javanese amla id. (< MIA *amibiliyā < OIA *āmlā id.); Old Javanese cūta 'mango tree' (< OIA * cūta id.).
} 
priest charged with the guardianship of the sacred paraphernalia of his lineage and of customary law, with the conduct of public rituals and ceremonies, and with the preservation of genealogical knowledge, among other things (Blust 2007:47)" - across the languages of insular Southeast Asia also points towards indigenous notions of social complexity and political organisation.

Nevertheless, the first sensu stricto cities emerged after trade with South Asia was wellestablished. With an urban tradition dating back to Harappan times, the diffusion of South Asian concepts of urbanism and statehood to Southeast Asia would be a natural development after contacts between these regions intensified. As is the case in East Africa (cf. Horton 1996, Boivin et al. in press), urbanisation in Southeast Asia has indigenous roots, which have been somewhat overshadowed by later, more cosmopolitan elements. While the initial emergence of Southeast Asian urban settlements was facilitated by local socio-economic developments, the region exhibits significant strata of South Asian influence. The linguistic record displays numerous examples of Indo-Aryan settlement and state-related vocabulary spreading across the western regions of insular Southeast Asia. Examples include Malay kota 'fortified place, stronghold' (< Sanskrit koț(t)a 'fort, stronghold'); 10 Malay nəgara 'country, (capital) city', Burmese naguir (ฐกิ๊์) 'city', Khmer nagar (ङณฐ) 'kingdom, empire, etc.' and Thai nagar (นคร) 'city, town' (< Sanskrit nagara 'town, city'); Malay pura 'city, town' (< Sanskrit pura 'fortress, city, etc.'); Malay desa 'region, country (village)' and Khmer des (โSূ) 'country, land' (< Sanskrit deśa 'province, country, etc.'); and Malay bumi 'earth, world', Old Mon bhum 'world', Khmer bhümi (รูษิิ) 'village, country, place, etc.' and Thai bhümi (ภูมิ) 'earth, place' (< Sanskrit bhümi

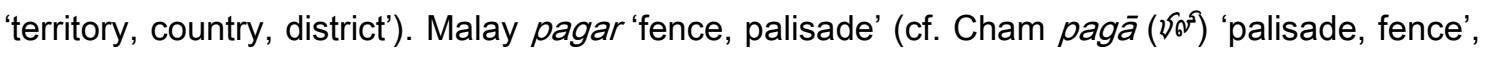
Old Javanese pagər 'hedge, fence, enclosure', Malagasy fahitra 'a cattle-fold') appears to be an early MIA borrowing related to Bengali pagār 'trench, ditch, etc.' and Hindi pagār 'mound, bank',

\footnotetext{
10 Originally from a Dravidian source (Burrow \& Emenau 1984 \#2207). Also compare Swahili mkuta 'stone wall', Comorian kura 'boundary, border, limitation, fence', uhura 'brick wall' and Malagasy (Mayotte dial.) kòra 'wall' (cf. Section 4.6).
} 
both of which go back to an earlier pragadda 'ditch' (Turner 1966 \#8464). ${ }^{11}$ Some lexical transmissions specifically point to South India as a locus from which notions of urbanism were disseminated to parts of Southeast Asia. As first suggested by Zoetmulder (1982/1:1298), a set of attestations including Malay pərigi 'well, spring', Old Javanese parigi 'low encircling wall of stones, paved bank or slope' and Malagasy farihy 'a pool, a pond, a lake' appear to go back to Tamil parikai 'moat, ditch; mound within a rampart', 12 itself borrowed from Sanskrit parikhā 'ditch'. In addition, Malay pəkan 'marketplace' (> Old Javanese pəkən 'market') appears to be a borrowing from Tamil pākkam 'town, village' (Omar 1966:556), while the word urung 'union of villages with the same ancestry' in the Batak languages of North Sumatra appears to go back to medieval Tamil ūrōm 'village assembly' (Edwards McKinnon 1996:93, cf. Stein 1965:54). The multifaceted relation between South India and North Sumatra will be addressed in more detail in the following section.

Several scholars have pointed out that these contacts did not remain undocumented in the rich literary tradition of South Asia. Hornell (1920d:215-46) was the first to claim that the Parava, Cānār and Illavan castes of coastal South India were of partly Polynesian (sic!, presumably Malayo-Polynesian) descent. He associated these incoming maritime people with the mythical serpent-demons of the Indian literature, known as Nāgas. This argument is further expanded by Mahdi (1999b:174ff.), who calls attention to similarities between the semi-divine

\footnotetext{
11 < OIA *gadda 'hole, pit' (Turner 1966 \#3981). The similarity was first pointed out by Chatterji \& Bagchi (1929:xxix), who supported a westward dispersal of the word based on a small set of Southeast Asian attestations. Blust (1995 s.v.), likewise, reconstructs PMP * pager 'enclosure; palisade around a village; fence', but all examples cited are found within the influence sphere of the Malay language and may be early borrowings.

12 The pronunciation of Tamil parikai (பரிகை) was presumably /perige/. The innovation ${ }^{*} \mathrm{k}>\mathrm{g} / \mathrm{V}_{-} \mathrm{V}$ is regular in colloquial Tamil. The colloquial Tamil course of Asher \& Annamalai (2002), for example, gives such transliterations as magan 'son', adigam 'much' and samuugam 'society' for the literary forms makan (மகன்), atikam (அதிகம்) and camükam (சமூகம்) respectively. The voicing of the velar stop in Tamil is also evident from loanwords in Malay, e.g. bagai 'kind, species, variety' (< vakai 'division, branch, section'), logam 'mineral; stone or metal' (< lōkam 'metal') and maligai 'palace' (< mālikai id.). Meanwhile, Mahdi (1994/2:441ff.) proposes a completely different etymology. He argues that the form, which he reconstructs as *parigi? 'ditch around a stone fortification', developed out of a reflex of PWMP * parij 'ditch, canal', presumably through a language in the Sulawesi-Sangir region (on account of the atypical ${ }^{*} \mathrm{j}>\mathrm{g}$ innovation and the postglottalised vowel). This sequence of borrowing would also explain the otherwise irregular Maranao attestation paridi? 'well; spring'. Blust (1995 s.v.), on the other hand, attributes * paRigi 'artificially enclosed catchment for water: well, ditch' to PWMP.
} 
literary Nāgas and the traditional insular Southeast Asian populations, including a maritime orientation, serpent worship (ophiolatry), a sacred tree cult surrounding Ficus species, the worship of megaliths and the practice of the buffalo sacrifice. Mahdi also points out that the Nāgas were occasionally associated with piracy in the literature, e.g. in the $11^{\text {th }} \mathrm{C}$. CE Bodhisattvāvadāna Kalpalatā poem by Kșemendra in an account on King Aśoka's Marine Edict (cf. Mookerji 1957:79-80). ${ }^{13}$ Piracy was indeed documented extensively in the earliest textual sources on Southeast Asia (Maspéro 1928:68-74, Wolters 1967:152, Schafer 1967:61ff.). Nevertheless, other features attributed to the legendary Nāgas strongly plead against a Southeast Asian identification. The Sri Lankan Mahāvamisa implies that the Nāgas were preAryan, pre-Dravidian inhabitants of that island. Especially in the early Tamil literature, they were depicted as extremely hostile and warlike (Kanakasabhai 1904:42-3). In the early Hindu literature, they developed into mythical half-human half-snake creatures inhabiting the regions below the earth (Pātāla). The early Buddhist texts and iconography, on the other hand, depict Nāgas as wise serpents watching over the Buddha (cf. Hewitt 1888:325-7).

On account of these and other characteristics of the literary Nāgas, Mahalingam (1965) concludes that it is impossible to identify them with a single ethnicity. The literary term Nāga, as Mahdi (1999b:180) argues, was probably not restricted to Malayo-Polynesian communities, but covered a wider scope of non-Hindu ethnicities. Their relation with the Tibeto-Burman Nāgã populations (note the different spelling) of Northeast India and Myanmar and with the "nude people" (nagna) described in the Rg Veda (cf. Lubotsky 1997:786) - if any - remains uncertain. Despite these difficulties, several lines of evidence assure us that Southeast Asians were certainly among the people referred to as Nāgas. First, early Southeast Asian Hindu dynasties often create or retrofit founder myths involving Indian princes marrying into local Nāga families (e.g. Przyluski 1925, Subrahmanian 1977:12), implying that "Indianised" Southeast Asians took over the habit of referring to pre-Hindu populations as Nāgas. Second, there is linguistic evidence suggesting that Nāga refers to 'Southeast Asian' in certain contexts. One of the

${ }^{13}$ Other scholars identify these Nāga pirates as Andamanese (cf. Abbi 2012:xxxv). 
meanings of nāga(ja) in Sanskrit is 'tin', which was obtained from Southeast Asia (see below). In Sinhala, meanings of the term nāga include 'tin' and 'betel' (Clough 1892:282), both of which presumably reached the island as a result of contacts with Southeast Asia.

\subsection{Re-examining “Indianisation”}

The early $1^{\text {st }}$ mill. CE Chinese accounts on Southeast Asia unmistakably describe "Indianised" kingdoms, i.e. kingdoms that adopted Hinduism or Buddhism and often used Indian names, while contemporaneous Southeast Asian epigraphy was predominantly in Sanskrit (cf. Ferrand 1919a, Maspéro 1928, Cœdès 1968). Through these textual accounts, our picture of Southeast Asia in the first mill. CE is centred on Hindu-Buddhist kingdoms such as Funan, Campā, Dvāravatī, Śrī Vijaya and others. The political structure, religion, art, architecture and language of these Southeast Asian kingdoms underwent profound influence from the subcontinent, a process known as "Indianisation" or "Hinduisation". Early European scholars, with Indian nationalists in their pursuit, approached the large-scale cultural transmissions from India through a framework of perceived political dominance and cultural superiority of the incoming South Asians. This model has been subject to severe criticism (Bosch 1956, 1961, Cœdès 1968, Casparis 1983), resulting in new modes which leave room for indigenous agency, complicated interethnic relations and cultural hybridity. Sunil Gupta's recent theory of a "Bay of Bengal interaction sphere" has a lot to recommend itself (Gupta 2005). In view of the fact that the perishability of the Southeast Asian spices, aromatic woods and other export products accounts for a significant imbalance in the archaeological record, we are challenged to ask ourselves, as one scholar put it, "to what extent should the Indonesians be pictured as simple folk, fascinated by foreigners and delighted to have the chance of bartering their minerals and jungle wealth for Indian manufactured goods? (Wolters 1967:64)"

It may be observed that the religious and linguistic influence from the subcontinent, i.e. the actual "Indianisation" of Southeast Asia, is predated by centuries of commercial contacts. This becomes clear when we look at the large quantities of imported South Asian carnelian and 
glass beads at the late $1^{\text {st }}$ mill. BCE sites of Óc Eo in southern Vietnam and Khao Sam Kaeo in southern Thailand (Solheim 1967, Peter 2002, Bellina 2003, 2007). Such commercial contacts also led to the diffusion of South Asian pottery and metal artefacts into Southeast Asia, a development first evidenced in Bali around 150 BCE (Ardika \& Bellwood 1991). Of relevance here is that the large-scale South and Southeast Asian commercial networks of the first centuries CE appear to reflect deliberate import by local communities, with Indian traders tapping into pre-existing networks. Some of the Indian merchants and artisans involved in these networks settled in Southeast Asia. A human tooth found in a $1^{\text {st }}$ mill. BCE archaeological context in Bali, whose Y-chromosomal haplogroup A sequences strongly support the hypothesis that it belonged to an individual of north-east Indian ancestry, forms the first available genetic evidence for the presence of Indian traders in the region (Lansing et al. 2004). From that time, it is beyond doubt that there was demic diffusion, in addition to cultural diffusion, from South Asia to parts of insular Southeast Asia. This was accompanied by substantial levels of gene flow; recent $\mathrm{Y}$-chromosome analysis of $\mathbf{5 5 1}$ males from different parts of the island Bali reveals that eight different haplogroups - making up approximately $12 \%$ of the Balinese paternal gene pool - can be traced back to the Indian subcontinent (Karafet et al. 2005). It is of great interest to the question of "Indianisation" to investigate whether other Southeast Asian populations display similar patterns.

Facilitated by the rising demand for Southeast Asian products in South Asia and further west, the concentration of wealth and power in the former region resulted in larger urban settlements, as argued in the previous section, but also in the desire among local chiefs to underline their paramountcy with the help of a wide array of rituals and symbols. In other words, intensified interregional contacts stimulated the Southeast Asian leaders to appropriate a more cosmopolitan culture, including religious symbolism, architecture and literature from abroad. This is echoed in early palaeography, such as the Võ-cạnh inscription near Nha Trang (Vietnam) and the yüpa stone inscriptions near Kutai (Indonesia). These inscriptions document the presence of large numbers of Brahmins at the Southeast Asian courts (as do several early 
Chinese accounts on Southeast Asia), welcomed with great generosity by the local rulers in an attempt to legitimate their authority and dynastic interests in a new, advanced way (Leur 1934:127, Casparis 1983:5, Kulke 1990:17-21). In this regard, it has been pointed out that essentially the same process of "guided Hinduisation" took place in the south and east of India, where Brahmins settled near the courts of local rulers to consolidate the latter's regional authority (Leur 1934:120-2, Kulke 1990:27-8). Thus, we can observe the manifestation of a "high" culture throughout the courts of South and Southeast Asia, in particular through the adoption of Sanskrit as "the cosmopolitan language of elite self-representation (Pollock 2006:129)". It may be pointed out that the Chinese, with whom Southeast Asia maintained equally vital commercial contacts, never asserted a comparable cultural influence. Unlike Japan and Korea, the Chinese political system had limited appeal to indigenous rulers and was rarely adopted into Southeast Asia other than through conquest (e.g. in Vietnam).

The wealth, sophistication and advanced material culture of the South Asian participants in these trade networks must have been impressive. Indian textiles and other manufactured products enjoyed great esteem in Southeast Asian cultures and were often exchanged for expensive spices (e.g. Maxwell 2003). South Asia's geographical position ensured an important and firmly established position for its traders throughout the Indian Ocean littoral. In the first centuries $\mathrm{CE}$, Indian traders frequented the Abyssinian city of Axum (Warmington 1974:13), while the Perip/us documents their presence in Socotra. ${ }^{14}$ Indian trading communities emerged as a result of the growing prosperity and private ownership of land in the middle valley of the Ganges during the mid-1st mill. BC, after which wealthy landowners (grhapatı) began to form specialised trading guilds such as the setthis and vanijas (Ray 1989:42-3, Glover 1996:131). As elsewhere, the long-distance commercial contacts with the east and west were preceded by local networks (cf. Lahiri 1992). Concomitant with the rise of new religious ideologies such as Buddhism and Jainism, South Asian society grew gradually

\footnotetext{
14 This observation is corroborated by the recent findings of Brahmi inscriptions in the Hoq Cave on that island (Geest 2006).
} 
less averse to trade, maritime and overland, with outsiders. These tendencies were especially reinforced during the dissemination of Buddhism under King Aśoka (imperabat ca. 270-230 BCE). From this period onwards, the profitable journey to Southeast Asia also found its way into the rich Indian literature (e.g. Wheatley 1961, Meulen 1974).

As mentioned previously, the transfer of religious ideas across the Bay of Bengal postdates centuries of trade contacts. Commercial networks facilitated interaction between different regions in South and Southeast Asia to such a degree that priestly elements began to play an increasingly important role. As indicated previously, religion was used for the consolidation and justification of power, as it had been throughout most of mankind's history. Many Southeast Asian dynasties trace their origin back to semi-mythical Indian lineages (Subrahmanian 1977, Ray 1994:87). The linguistic evidence also portrays India as a source of political and spiritual inspiration. For instance, such common Sanskrit words as sakti 'power' and putra 'son' were adopted into Malay as sakti 'supernatural power' and put(ə)ra 'prince'. On the other hand, there is insufficient evidence to assume de facto political dependency or military subjection to the subcontinent. Whereas the adoption of an Indo-Aryan and a Dravidian vernacular (i.e. Sinhala and Tamil) in Sri Lanka indicates large-scale demographic movements and the subjugation of pre-existing populations, we see a relatively percentage of vernacular influence reaching ancient Southeast Asia. Instead, the largest number of loanwords is of Sanskrit or Pali etymology, for reasons not so different from the adoption of Latin in medieval Europe. Bosch (1961:7) and others have quite convincingly pointed out that the Brahmanical religion, Sanskrit language, refined architecture and iconography, political concepts and other examples of "higher" culture could not have been transmitted by kṣatriyas or vaiśyas, leaving Brahmins as the most likely agents of "Indianisation". While it is believed that the latter faced strong prohibitions against crossing the "dark waters" (kāla pāni) out of fear for ritual pollution, contamination by foreigners (mlecchas), and the loss of religious purity (Subrahmanian 1977:11, Dhal 1999, Ray 1994:2-3, 153, Bayly 2004:720), their well documented presence in Southeast Asia cautions us to assume a one-to-one correspondence between the ideologies constructed 
in the Brahmanical śāstras and actual social practices during the first centuries CE. That being said, Brahmins were by no means the earliest Indian settlers in Southeast Asia. They were almost certainly preceded by generations of traders, as well as artisans skilled in the manufacture of beads (cf. Bellina 2007).

Occasionally, the linguistic data unambiguously reveal the identity of the agents involved in the "Indianisation" of Southeast Asia. We may call attention to the eastward spread of royal seals. Not the original Sanskrit word mudrā 'seal, signet-ring, etc.', but its Tamil counterpart muttirai 'seal, signet, etc.' was adopted into Malay as mətərai 'seal, stamp'. This word seems to have been misinterpreted as a verb in Malay, which has a verbalising circumfix $m ə(N)-\ldots-i$ in the meaning 'to apply ... on st.', leading to the hypercorrected form təra 'royal seal, etc.' (cf. Gonda 1973:442). This Malay word was subsequently introduced into the mainland, cf. Cham trā (Wֵ stamp; note') and Thai trā (ตรา) 'brand, trademark, seal'. As pointed out by Tadmor (2009:694), there are several more words shared by Malay, Khmer, Thai and other languages, underlining once again the importance of looking at pre-modern contact between mainland and insular Southeast Asia. We may call attention to one such example that travelled in the opposite direction: a term for a traditional gesture of respect or salutation by placing the open hands together with the fingers pointed up, the so-called añjali of the Hindus. This gesture was known in Old Khmer as sambah sambah, reflected as Khmer sambah (ஸ்m:) and Cham sambah (๕์V?). ${ }^{15}$ It spread to insular Southeast Asia through Malay səmbah, with the additional meaning of 'obeisance', yielding Old Javanese səmbah sambah 'worship, veneration, reference, etc.', Toba Batak somba 'worship, homage', Malagasy sambasamba 'a word used in greeting the queen', Tagalog sambá 'worship', Kapampangan samba 'adore, worship', Bikol sambá 'to venerate or worship; to adore' and Cebuano simba 'regard with respect and affection'. These

\footnotetext{
15 Presumably from the root bah 'to touch, meet, join' (Jenner \& Pou 1980-81:207). Also compare Old Mon sumbup sumbip 'hands with palm joined together, raised as a gesture of respect'.
} 
examples, however, stand in isolation and in most cases it is difficult to reconstruct how words have spread from one language into another.

The significant role of South Indian traders in the networks with Southeast Asia and beyond is supported by the distribution of rouletted ware bowls, which appear to have originated from the Coromandel Coast (Ardika \& Bellwood 1991:223-6, Smith 1999:7), the presence of Tamil Brahmi inscriptions in China, Southeast Asia and the Qușair Coast (Sastri 1932, 1949, Ray 1994:72, 107, Edwards McKinnon 1996:85, Christie 1998, Kulke et al. 2009) and iconographic and architectural evidence (Guy 2011). Linguistic research reveals a considerable quantity of Tamil loanwords in Malay (Ronkel 1902, Hamilton 1919, Omar 1966, Jones 2007). In addition, Manickavasagom (1986:125-38) gives a preliminary analysis on Tamil loanwords in Thai, a topic that merits a much more comprehensive study. Based on certain phonological characteristics, some Sanskrit vocabulary was apparently also introduced into China and Southeast Asia by speakers of Tamil (Gonda 1973:161-6, Wheatley 1983:124-5, Tadmor 2009:694). The South Indian evidence is especially strong in Sumatra. Its rainforest was famed for its valuable tree resins, rhinoceros horns, ivory and other products. From Śrī Vijayan times, the island maintained close relations with India and especially with the Cōla Dynasty. There is palaeographic documentation of Sumatran kings donating precious goods to temples in the Tañcāvūr district and in Nāgappațtinam during the early $11^{\text {th }}$ C. CE, while the Nālandā monastery in Bengal maintained contacts with Śrī Vijaya at least a century earlier (Cœdès 1918:4, Sastri 1940:264, 280-3, Chhabra 1956-57:58, Parkin 1978:50-1, Casparis 1983:13). In addition, Śrī Vijaya was known as an important centre of Buddhism, attracting famous Buddhist scholars such as Yijìng (cf. Takakusu 1896) and Atîśa (cf. Schoterman 1986).

In the case of North Sumatra, the agents of "Indianisation" were not restricted to Brahmins, but also included members of influential vaiśya trading guilds. In this region, Indian influence had permeated several aspects of society, including the names of the days, creation myths, the calendar, divination books, the horse sacrifice ritual and the game of chess (Tideman 1936, Parkin 1978, Edwards McKinnon 1996, Andaya 2002:391-3, Lukas 2003). Although 
preliminary research on the Tamil element in the Batak languages did not yet yield an impressive corpus of loanwords (cf. Ronkel 1918), we may expect to find more Tamil loans in North Sumatra upon closer inspection. For instance, Edwards McKinnon (1996:95) suggests that the Karo Batak word cingkəru 'Job's tears (Coix lacryma-jobl)' may be from Tamil. ${ }^{16}$ We may also note that the Batak languages adopted various Sanskrit loanwords unattested in other insular Southeast Asian languages (Gonda 1973:126-7, Parkin 1978:107-15). In addition, Tamil inscriptions in the South Indian grantha script have been identified in West Sumatra (Oudheidskundig 1912:46) and North Sumatra (Sastri 1932, Schnitger 1937:17), implying the physical presence of a Tamil merchant community in medieval times. In addition, there are remarkable cultural similarities between North Sumatra and South India. The Mərga Səmbiring, a subgroup of the Karo Batak, presents a clear case of a mixed South Indian - North Sumatran community. Both their funeral rites and family names exhibit distinct South Indian elements (Joustra 1902, Kern 1903, Ronkel 1918, Edwards McKinnon 1996). Another possible clue to the South Indian contacts with North Sumatra from at least medieval times is the Tamil word cāmpirāni, denoting 'benzoin' and various other aromatics, but also a Southeast Asian region famous for its horses (cf. Malayālam sāmbrāṇi 'benzoin, olibanum', Telugu sāmrāṇi 'benzoin; a steed, a fine horse'). This region was most likely North Sumatra, known for both its aromatic tree resins and sturdy horse breeds. The Tamil word may be from Malay səmbərani səmburani, which refers to a semi-legendary horse breed of reddish or sorrel colour. If so, it would be a case of re-borrowing, since the Malay word itself appears to go back to Tamil cempurani 'red-skinned' (Ronkel 1905, Gonda 1941:164). ${ }^{17}$ Interestingly, Tamil also features the

\footnotetext{
16 Cf. Tamil cikkuru 'horse-radish tree (Moringa oleifera)' (< Sanskrit śigru id). Based on its form, Old Javanese cikru id. must also be of Tamil rather than Sanskrit derivation (Tuuk 1897-1912 /1:606). The tentative connection between Karo Batak tiga 'market' and Tamil kațikai-t-tāvalam 'periodic fair' seems less convincing on phonological grounds (pace Edwards McKinnon 2011:143).

17 Others have favoured a Persian origin of the word, i.e. sum-parrān 'having winged hoofs' (Brown 1952:237-8 n. 412, Hill 1960:196 n.137, Jones 1978:81, 2007:281). However, such a compound is not attested in the Persian literature and neither do the Malay texts describe "Pegasid" wings on these legendary horses.
} 
word cāran 'a breed of horse', presumably adopted from Javanese jaran 'horse', although Java was never known for its quality horses. ${ }^{18}$

Linguistic research demonstrates that the commercial contacts between North Sumatra and South India left their traces in the colloquial Tamil language. The specific slang used by marginal communities of the Tamil-speaking world is rather poorly documented. We have a small corpus of data on the secret languages of the Paraiyar community in Jaffna (Lewis 1890) and the merchants inhabiting the Coromandel Coast (Pandit 1894), used to keep transactions incomprehensible to the non-initiated. Kern (1894) was quick to notice that several of the numerals given by Pandit resemble their equivalents in Malayo-Polynesian languages and were presumably adopted into the Tamil merchant slang as a result of interethnic trade. While Philippus Samuel van Ronkel, the renowned Dutch expert on Asian languages, remains unconvinced of these perceived similarities and rejects the Malayo-Polynesian etymology (Ronkel 1933:42), a closer inspection of the relevant numerals shows that this rejection has been premature. Table 2 features the numerals given by Lewis (1890) and Pandit (1984), with the addition of examples I have found in the Tamil Lexicon (1924-36) and correspondences in Karo Batak and Malay.

Table 2: borrowed numerals in Tamil slang

\begin{tabular}{|c|c|c|c|c|c|}
\hline $\begin{array}{l}\text { Jaffna Tamil } \\
\text { (Lewis 1890) }\end{array}$ & $\begin{array}{l}\text { Indian Tamil } \\
\text { (Pandit 1894) }\end{array}$ & $\begin{array}{l}\text { Tamil lexicon } \\
(1924-36)\end{array}$ & Karo Batak & Malay & \\
\hline$s \bar{a}-$ & śā- & (vịtu) & sada sə- & satu sə- & 'one' \\
\hline tuvā- & $t \overline{-}-$ & (vinai) & dua & dua & 'two' \\
\hline tilu & tiru- & tilu & təlu & (tiga) & 'three' \\
\hline pāttu & pātt- & pāttu & әmpat & әmpat & 'four' \\
\hline (tadda) & (kulaccu) & (tatțal) & (lima) & (lima) & 'five' \\
\hline (taḍava) & (kirāti) & (tațaval) & (әпәт) & (әnam) & 'six' \\
\hline (nulaicca) & рісси & (nulaiccal) & pitu & (tujuh) & 'seven' \\
\hline
\end{tabular}

\footnotetext{
18 The innovation ${ }^{\mathrm{j}} \mathrm{>} \mathrm{c}$ is regular in Tamil. The similarity between these attestations was first noticed by Amrit Gomperts (forthcoming), who assumes that the Javanese form is a Tamil loan. However, Old Javanese displays the earlier form (h)ajar-an 'horse (lit. 'trained animal')', which was adopted as Bugis anyarang, Ngaju (ha)jaran and Toba Batak hajaran id. In addition to its tentative adoption into Tamil, the truncated form seen in modern Javanese has been borrowed into Makasar as jarang, Manggarai jarang, Ngadha zara jara, Sawu jara, Kambera njara and various other attestations in East Indonesia (Verheijen 1967:100).
} 


\begin{tabular}{|c|c|c|c|c|c|}
\hline $\begin{array}{l}\text { Jaffna Tamil } \\
\text { (Lewis 1890) }\end{array}$ & $\begin{array}{l}\text { Indian Tamil } \\
\text { (Pandit 1894) }\end{array}$ & $\begin{array}{l}\text { Tamil lexicon } \\
(1924-36)\end{array}$ & Karo Batak & Malay & \\
\hline- & vali- & valu & waluh & (dəlapan) & 'eight' \\
\hline - & tāyā- & tāyān & siwah & (səmbilan) & 'nine' \\
\hline - & puli- & pulu & (sə)puluh & səpuluh & 'ten' \\
\hline
\end{tabular}

In addition to these numerals, Tamil tarikān 'half' is probably also borrowed from a MalayoPolynesian source (Kern 1894), cf. Malay təngah(an) 'half'. ${ }^{19}$ Judging from this juxtaposition, it becomes clear that several numbers in peripheral varieties of Tamil are indeed from a MalayoPolynesian source and were adopted as an in-group code against the background of trade networks between South India and Sumatra. In the case of Indian Tamil slang, the donor language was in all likelihood a Batak language. The Jaffna data are too incomplete to determine the source of the loanwords, but - if not the residue of a now-extinct trading language - the transmission of the tabulated numerals could be related to the short Malay presence on that peninsula in pre-modern times (see Section 4.3), cf. Old Malay sa 'one', dua 'two' and t/u 'three' (the Old Malay word for 'four' remains unattested). Unfortunately, we have no way of dating these lexical acquisitions, as slang words rarely enter literary texts. On the other hand, they do tell us something about the commercial nature of contact. Thefact that numerals (alongside many other lexical items) have also spread in the opposite direction is better known and reflected by Malay juta 'million' (< Sanskrit *ayuta 'ten thousand'), kəti 'hundred thousand' (< koți 'ten million'), laksa 'ten thousand' (< lakșa 'hundred thousand') and tiga 'three' (< MIA *tiga 'triple'). ${ }^{20}$

\subsection{Southeast Asia in the literature}

As a result of the intensified contacts between South and Southeast Asia and the emergence of commercial, and later, religious networks, literary notions of the different Southeast Asian regions and kingdoms became less vague and several different locations were distinguished in

19 On the other hand, the Tamil weight unit pikkal, based on the final vowel, must have entered the language through English 'pecul', rather than directly from Malay pikul 'to carry a load on the shoulder, a weight equal to 133 pounds'.

20 This similarity was already noticed by Ronkel (1903), who dismissed it as chance resemblance. These and other examples of Indo-Aryan numbers in languages of Indonesia are further addressed in Dyen $(1946,1952)$ and Gonda $(1973: 313-7)$ 
the Indian textual corpus. One of the oldest references to Southeast Asia is found in the Kiṣkindhākānda, the fourth book of the Rāmāyana, which mentions the Southeast Asian lands of Yāvadvīpa and Survarnarūpyakadvīpa in a list of countries (Kern 1969b:640, Wheatley 1961:177, Eliot 1998:152 fn. 2). Later texts make allusions to the mythical 'Golden Land' (Suvarnabhümi), presumably also located somewhere in mainland Southeast Asia. ${ }^{21}$ Such accounts seldom contained specific information on these semi-mythical kingdoms and their precise locations. More detailed information became available after - or, perhaps, as a result of - the rise of Buddhism. Such early Buddhist texts as the Niddesa, Brhatkathā-Śloka-Sangraha and Milindapañho display a considerable quantity of Southeast Asian toponyms, including Takkola, Yãva, Survarnadvīpa and many others (cf. Lévi 1925).

The aforementioned "Yāva Island" (Yāvadvīpa) of Sanskrit literature is reflected as Tamil Yāvattīivu, several different renderings in Chinese (e.g. Mahdi 2008a) and Ptolemy's labadíu. ${ }^{22}$ The Sanskrit word Yãva refers to 'barley (Hordeum vulgare)', but since this cereal was not traditionally cultivated in Southeast Asia, the name must instead have referred to the indigenous 'foxtail millet (Setaria italica)' (Lassen 1847-61/2:1042, Kern 1871b:120) or the introduced 'sorghum (Sorghum bicolor)' (Mahdi 1994/2:433). According to indigenous traditions, 'foxtail millet' lent its name to the island of Java, where it may have been a principal subsistence crop before the introduction of wet rice cultivation (Klerck 1862:27 fn. 2, Rouffaer 1905:364, 364 fn.1, Raffles 1978/1:2, 2/67, 83). However, the original "Yãva Island" of the Indian literary accounts was probably a Malay-speaking kingdom in south Sumatra, rather than present-day Java (Kern 1871b, Mahdi 1995, 2008a, Laffan 2005). The geomorphological features of ancient eastern Sumatra may have easily led to the assumption that Sumatra consisted of two islands

\footnotetext{
21 This place is traditionally identified with the Satum Kingdom in present-day Myanmar (Shorto 1971:384). As mentioned previously, the Indian accounts of Southeast Asia probably stood model for the descriptions by Ptolemy and several Middle Eastern authors. More on this can be found in the wider literature (cf. Kern 1869b, Obdeijn 1941a, Wheatley 1961, Meulen 1974 and Ray 1994:87).

22 Actually labadíos, if we interpret labadíu nēsos '/abadíos Island' of the original text as displaying a genitive case ending (Rouffaer 1905:365). Ptolemy also lists the nearby Sabadeĩbai islands, which, since his geographical information was most likely obtained from secondary sources, may have been the same toponym.
} 
(Obdeijn 1941a) and several Arab geographers, Marco Polo and Nicolò Ponti indeed distinguished Greater Java and Lesser Java. In due course, the former came to refer to our present-day Java, while the latter continued to denote a part of Sumatra before it fell out of use (cf. Mahdi 2007:73). The fact that the term Jawa originally referred to 'Malay' or insular Southeast Asia in general is reflected in two sets of attestations: 1) Acehnese Jawa 'Javanese, Malay', Nias Dawa 'foreigner, Malay', Bugis Jawa 'Javanese; other ethnicities outside Sulawesi; Malay', Makasar Jawa 'all civilised people west of Southwest Sulawesi', Cham Javā ( Javanese', Old Khmer Javā Java 'Java, with or without Sumatra; Śrī Vijaya'23 (> Khmer Jvā (్ํ) 'Javanese, Malay', Thai Javā (ชวา) 'Java', Lao Javā (२ะอๆ) id.), Vietnamese Chà và 'Malay', Sinhala Jāvā 'Malay', Dhivehi Jāva id. and Arabic †Ǧābaẗ †Ǧāwä̈'a Sumatran-Malay kingdom',24 2) Pali Jāvaka 'Malay' (Kern 1896), Tamil Cāvakam 'the Archipelago, Sumatra-Java or Java', Arabic †Zābağ 'a Sumatran-Malay kingdom' and Armenian †Zapech id..$^{25}$

${ }^{23}$ Or, rather, the name of a Sumatran Malay kingdom with historical ties to Cambodia (Mahdi 2008a:129).

${ }^{24}$ See Laffan (2005) for an elaborate discussion on Yãva-related names in Middle Eastern sources.

25 This kingdom has also been connected to the influential Śailendras in $8^{\text {th }}$ C. CE Java (e.g. Cœdès 1968:108, Tibbetts 1979:107), a dynasty known for their active promotion of Mahāyāna Buddhism and the issuing of inscriptions in Sanskrit, Old Javanese and Old Malay. However, in later accounts, including the Description of Cities, Indian and Persian - an anonymous Armenian work dated to the early $12^{\text {th }} \mathrm{C}$. CE - the toponym / ethnonym (Zapech) unambiguously refers to Sumatra (Braginsky 1998:371). These inferences are not irreconcilable, especially in view of the fact that the insular Southeast Asian thalassocracies were much more dynamic than their land-based counterparts. In fact, the Śailendras are often regarded as a foreign (i.e. non-Javanese) dynasty, possibly of Sumatran Malay ancestry (cf. Mahdi 2008a:127-8). Cumulatively, the available evidence strongly supports a primary meaning of 'Malay' for Jāvaka and its derivatives. 
Figure 3: map of the Bay of Bengal

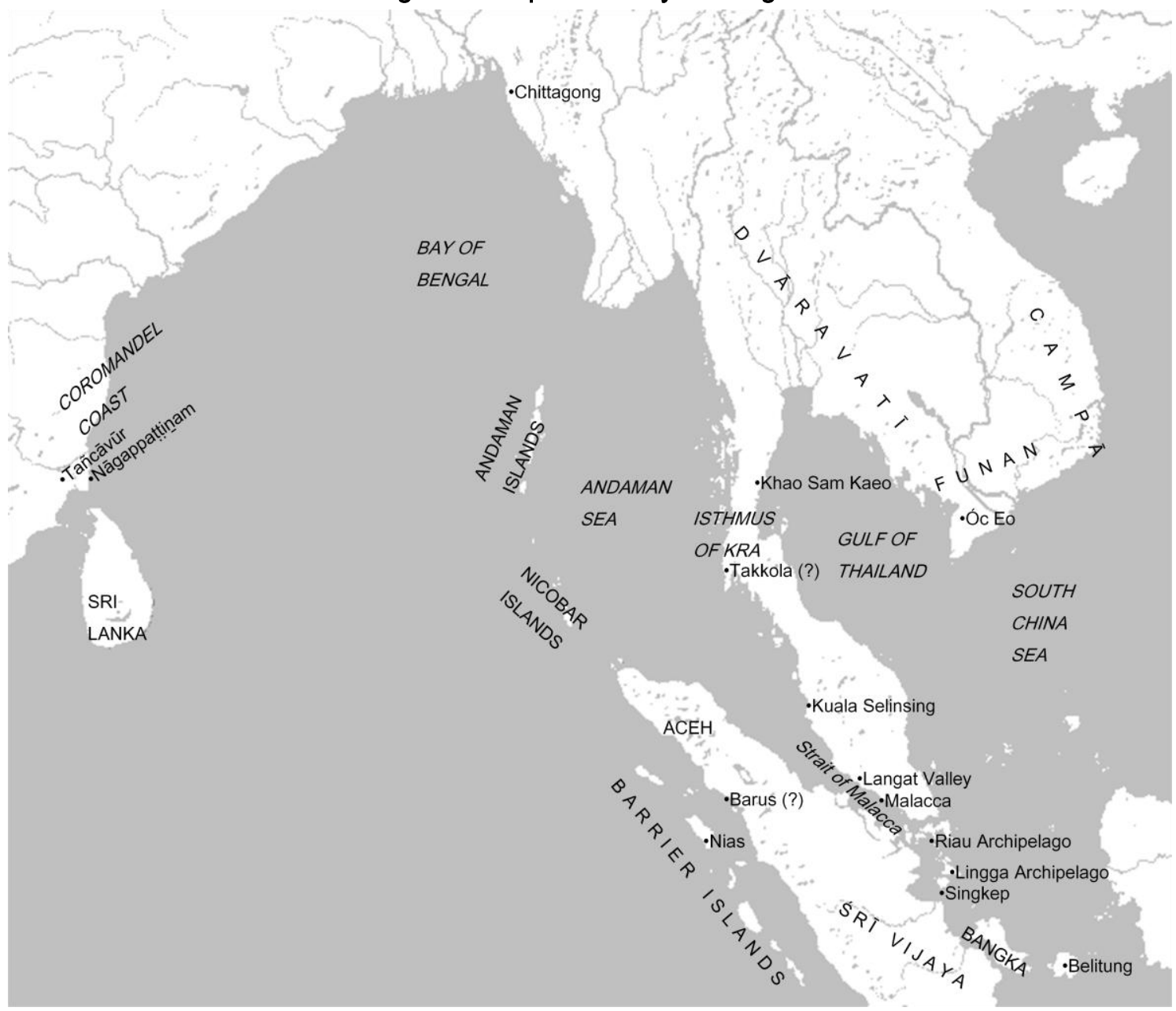

Another famous Southeast Asian commercial entrepôt was known as Takkola. The name of this harbour, and its apparent doublet Kakkola, is mentioned in various Indic, Chinese and Middle Eastern sources. ${ }^{26}$ The place was presumably situated somewhere on the Thai-Malay Peninsula and is often identified as the present-day region of Tākū’a Pā' (ตะกั่วป่า). Archaeological research in this region points to early $1^{\text {st }}$ mill. CE contacts with other regions in Southeast Asian and India (Lamb 1960). In the $9^{\text {th }}$ C. CE, a Tamil inscription indicates the presence of a residential South Indian community in Tākū'a Pā' (Sastri 1949:28-9, Cœdès 1961). By that time, the harbour had become one of the main gateways to insular Southeast Asia, a position it shared with the Isthmus of Krā (กระ), which also features prominently in

${ }^{26}$ Many scholars have attempted to determine its exact location (cf. Schlegel 1899, Yule \& Burnell 1903:139, Rouffaer 1905:381-2, Gerini 1897:572-3, 1909 passim, Ferrand 1913-14/1:iv, 1919/14:56 n.1, Sastri 1949, Boeles 1966, Tibbetts 1979:128-35). The discrepancy in the word-initial consonant (Takkola vs. Kakkola) may indicate an Austro-Asiatic origin of the name (Lévi 1923:11-8). 
Sanskrit, Tamil and Chinese literature on Southeast Asia (cf. Obdeijn 1943:714, Sastri 1944:26,

Wheatley 1983:268). As a result, several spices, aromatics and other Southeast Asian products were distributed across the Indian Ocean from this region. Consequently, the name of the harbour (both Takkola and Kakkola) has been applied to various products of Indian Ocean commerce. ${ }^{27}$ The corresponding words are found in the pre-modern literature of India (Turner 1966 \#2586), the Middle East (Löw 1881:349, Laufer 1919:193) and China. ${ }^{28}$ Further attestations are encountered in insular Southeast Asia (Tuuk 1897-1912/2:291, Heyne 1927/1:485) and other parts of the Indian Ocean. Figure 4 presents an overview.

Figure 4: takkola kakkola and its meanings across the Indian Ocean

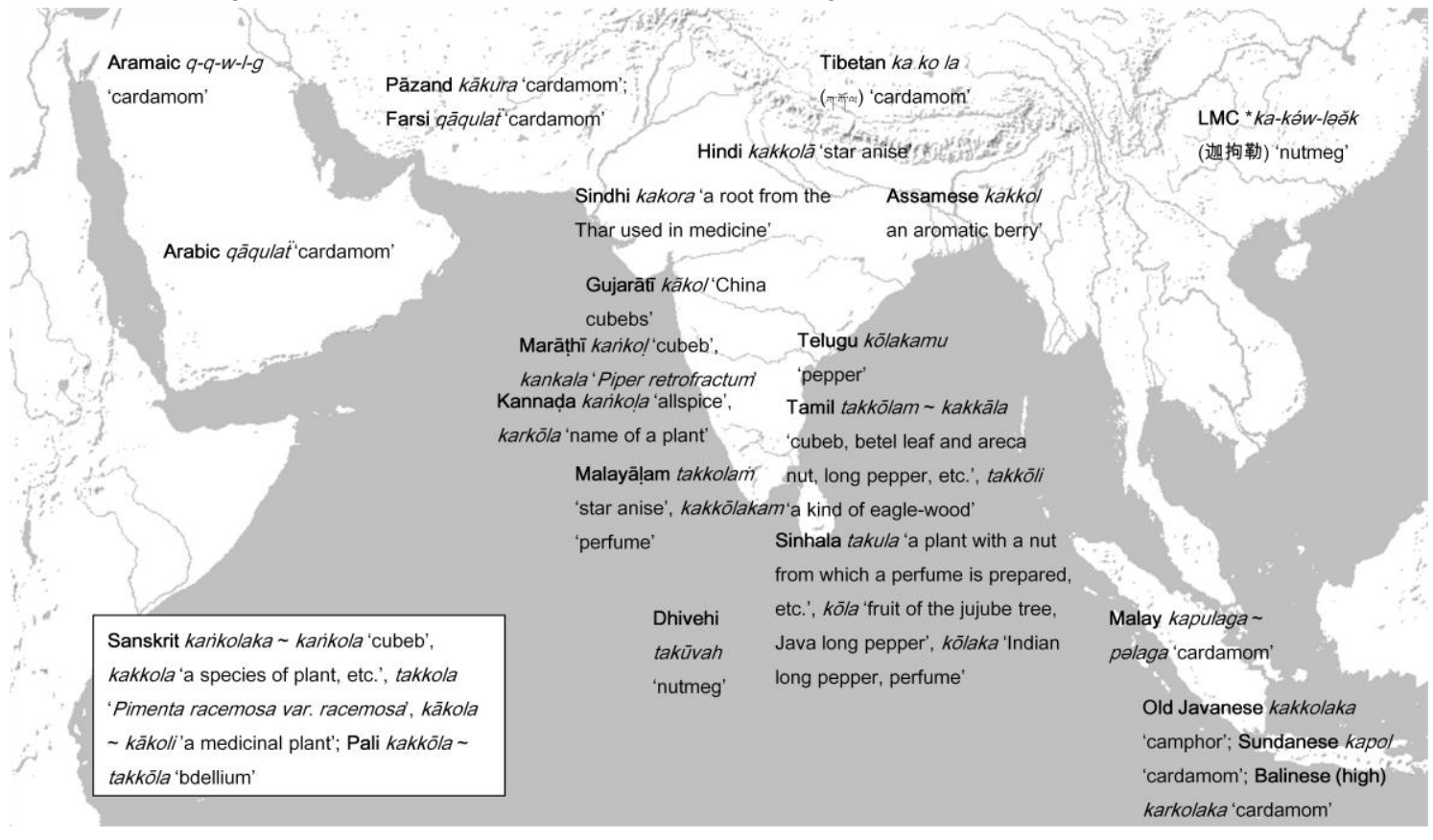

Another important source of information on Southeast Asia is the detailed Chinese literature (cf. Groeneveldt 1880, Hirth \& Rockhill 1912, Ferrand 1919a, Pelliot 1925, Lévi 1931, Mills 1937, Schafer 1967). The earliest Chinese accounts of Southeast Asia are concerned with the mainland, bordering to the southernmost territories of the Han Chinese. Voyages to the less easily accessible regions of insular Southeast Asia were documented centuries later. Based on

${ }^{27}$ In general, it is quite common to name a product after the place from which it is obtained. Tamil displays several analogies pertaining to other Southeast Asian regions, e.g. cilyam 'madar juice (Calotropis gigantea)' (lit. 'Siam'), kițāravan 'agarwood' (lit. 'Kedah') and arumanavan 'elephant' (lit. Rāmañña).

${ }^{28}$ Attested as LMC *ka-káw-ləăk (迦拘勒) 'nutmeg' in the $8^{\text {th }}$ C. CE Supplement to Materia Medica by Chén Cángqì, who marks it as a foreign word (Hirth \& Rockhill 1912:210-1 n.). 
the findings of Chinese pottery and bronze items in East Java and Sumatra, Bellwood (1997:137, 316 n.2) argues that the trade between China and insular Southeast Asia started during the Han Dynasty (206 BCE - 220 CE). This is complemented by the description of cloves in the Former Han Annals (Hirth \& Rockhill 1912:209, Burkill 1966/1:976-7, Purseglove et al. 1981/1:229) and early 1 st mill. CE textual accounts of embassies sent from different Southeast Asian kingdoms to the Chinese emperor, the first in 132 CE (Ferrand 1919a/14:5-6). Chinese accounts referred to the maritime communities of Southeast Asia as Kun-/un (崑崙),,29 probably reflecting an indigenous word (cf. Ferrand 1919a/13:290, 310, Christie 1957:351-2, Mahdi 1999a:164).

Medieval accounts present a more detailed record of the trade oriented regions of Southeast Asia. Again, Sumatra features prominently and is well known by merchants and geographers from China, the Middle East and the Indian subcontinent. From the $7^{\text {th }} \mathrm{C}$. CE, we come across Chinese reports of the Sumatran kingdom *Muâ-lâ-iäu (摩羅游), arguably one of the first literary attestations of the people now known as Malays (cf. Ferrand 1918:477). The same name found its way into Tamil inscriptions as Malaiyūr (Krom 1931:249-50), presumably a rationalisation of malai 'mountain' + ür 'city'. The Sumatran harbour of Barus, famous for its export of high-quality camphor, is also well documented and is mentioned by Ptolemy (Baroũsai Pénte 'Five Barus Islands') and in late Sanskrit works under the names Vārūṣa, Vārușa and Vrșa (cf. Obdeijn 1941a, Prakash 1964:85, Paranavitana 1966a:19ff., Wolters 1967:186). The toponym is also found under different renderings in Chinese and Middle Eastern accounts. ${ }^{30}$ It might be the same place as Karpūradvīpa 'Camphor Island', mentioned in the Kathāsaritsāgara (Wheatley 1983:268). Finally, the region of Aceh, especially its harbours Pasai and Lambri, also

\footnotetext{
29 This form has various other renderings (cf. Hirth \& Rockhill 1912, Ferrand 1919a/1:241-63, Lévi 1931:621, Mahdi 1999a:164).

30 It is beyond the scope of this study to comment on the precise location of Barus and its alleged synonym Fanșūr; a topic that has interested various scholars (cf. Tuuk 1866:132 fn.4, 1894:33, Hirth 1896:499 n., Gerini 1909:427ff., 445-6, Ferrand 1913-14/2:652, 671, 1919a/13:298 fn. 1, 14:56-8 n.3, Schoff 1922b, Obdeijn 1941a:239, 326ff., Wolters 1960, 1967:186ff., Tibbetts 1979:140-3, Drakard 1989, Ptak 1998, Donkin 1999:131). The archaeological site of Barus, which does not show signs of settlement prior to the $9^{\text {th }}$ C. CE (Perret \& Surachman 2009), may be a different location than the place described under the same name in the earliest textual accounts.
} 
obtained a prominent place in medieval Tamil, Chinese and Middle Eastern accounts (Gerini 1909:434, 698-705, Ferrand 1907, Krom 1931:249-50, Obdeijn 1941a:326-7, Pelliot 1959:87, Tibbetts 1979:138-40, Braginsky 1998).

\subsection{Metallurgy in Southeast Asia}

Metallurgy marked a new phase in human history. Metal tools and weapons could be shaped more accurately than their stone or flint predecessors and have greatly enhanced the efficiency of hunting, agriculture and warfare. The resultant new patterns of human life enabled larger settlements and more complex societies, but also led to social inequality and communal violence based on uneven distribution of raw materials. In most cases, people became acquainted with metal objects through neighbouring communities, although there are arguments for independent invention of metal technology in several parts of the world. Metal objects became valuable trade commodities, not in the least since the art of metal smelting, forging and processing was often shrouded in mystery and magico-religious practices. Artistic styles and cultural perceptions often shed light on the history of metal in a particular region, as do the names given to metals. These are often descriptive in nature and carry meanings such as 'strong', 'shining', or 'yellow'. Many European words for 'gold', for example, go back to the protoIndo-European root $\sqrt{ }$ ghet 'yellow, green'. In other cases, the names for metals reveal their place of origin, such as (late) Latin cuprum, hence English 'copper', which implies a Cyprian provenance. Names for metals may also contain clues about the people who introduced the commodities into a society or demonstrated their economic value. If we look at Swahili dhahabu 'gold' and fedha 'silver', it is not difficult to see that these words are derived from their Arabic counterparts: dahab and fidquät. In addition, etymological analysis can help us to understand in what form a metal first entered a region. Several languages of Mozambique display ndalama for 'gold', which goes back to a widespread word denoting a certain golden coin, e.g. Arabic dirham (pl. darāhim), Old Greek drachmé (Meinhof 1900), as well as the word d(r)amma found in South Indian temple inscriptions (Subramaniam 1957:xii, xiii). The linguistic data thus strongly suggest 
that the inhabitants of south-eastern Africa became acquainted with gold through commercial networks and the introduction of bullion. Semantic shifts between types of weapons, coins and other utensils and the metals from which they are manufactured are quite common crosslinguistically and can prove very useful to reconstruct the ways in which metal was introduced into a given geographical area.

Several parts of Southeast Asia are rich in metal deposits. Tin and gold were exported from the Malay-speaking world from antiquity onwards. Some parts of the Thai-Malay Peninsula with abundant tin and gold deposits display elements of a maritime tradition, evidenced by the boat burial site at Kuala Selinsing and the finding of wooden paddles in the Langat Valley dated to the $1^{\text {st }}$ mill. BCE (Ray 1989:49). Of older age is a set of bronze artefacts found in northern Thailand and Vietnam, suggesting a sophisticated Southeast Asian bronze-working tradition including alloying (bronze is an alloy of copper and tin), casting and spanning. Since Solheim (1968) and Bayard (1972) first wrote about these bronze artefacts and placed them in an early or mid-3rd mill. BCE context, there has been much controversy surrounding the early dating and the possibility of independent invention of Southeast Asian metallurgy, neither of which are currently supported (Higham \& Higham 2009:138, Pryce et al. 2011:156). Instead, the picture we get is one of interaction networks between copper-producing and -consuming societies within and beyond Southeast Asia covering a timeframe from c. 2000 BCE to c. 500 CE (Bellwood 1997:269, Pryce et al. 2011). This eventually formed the basis of a cultural complex coined the "Đông Sơn Culture" - characterised by bronze drums, high-status burials and the first Southeast Asian appearance of iron - which spread from the mainland to insular Southeast Asia between 500 and 300 BC. The archaeological record of insular Southeast Asia reveals that there was no separate bronze age in this region and that the earliest metal findings correspond with the mainland Southeast Asian type, rather than Chinese or Indian inspired assemblages (Bellwood 1997:268-9).

Since copper metallurgy was a mainland Southeast Asian development spreading to insular Southeast Asia in the $1^{\text {st }}$ mill. BCE, no protoform for 'copper' can be reconstructed for 
Malayo-Polynesian. Due to its limited copper ore deposits, Indonesia has only developed a very small-scale copper industry, in which it is mostly the by-product of gold and silver (Bemmelen 1949:146-7). Most insular Southeast Asians words for 'copper', including Old Javanese tambaga, Malay təmbaga and Acehnese tumaga, go back to an Indo-Aryan source. These forms are unrelated to similar looking attestations for 'tin', on which I will elaborate in the following section. The above words for 'copper' appear to be from a MIA vernacular, rather than directly from Sanskrit tāmraka 'copper' (Casparis 1988:63-4). Although not nearly as common as pure Sanskrit loanwords, this example of an early "Prakritism" in Indonesia does not stand in isolation. ${ }^{31}$ An important semantic shift took place in the Philippines, so that Tagalog tumbaga (< Malay təmbaga), came to refer to a 'copper-gold alloy', yielding Spanish tumbaga, Portuguese †tambaca, English 'tombac', Sinhala tambakkka ('pinchbeck'), Tamil tampākku and Arabic tambāk in the same meaning (Blust 1992:443). The substitutionary Tagalog word for 'copper' is tansô, apparently from Southern Min tâng sek (銅色) 'copper-coloured', cf. Malay tangci 'copper money' from tâng chîn (銅錢) id. In all likelihood, the Chinese played a considerable role in the dispersal of copper artefacts and possibly copper-forging techniques across Southeast Asia. Other copper-related Chinese borrowings into Southeast Asia include Khmer dán (马ُّ่) 'bronze, red copper', Thai dorं (ทอง) 'gold', Lao dọn் (ยภง) 'copper' and Vietnamese đồng 'copper, brass, bronze', presumably all borrowed from a Chinese source (cf. Pou \& Jenner 1973:31), cf. EMC *dəwך (銅) 'copper', hence Korean dong (동) and Japanese $d \bar{o}$ (銅). ${ }^{32}$

The prehistoric presence of iron in insular Southeast Asia provides a compelling case study of the ways in which archaeological and linguistic methodologies complement but also contradict each other. There is no firm evidence regarding the origins (i.e. indigenous, Chinese or Indian) of Southeast Asian ferrous metallurgy. As argued before, most archaeologists believe that iron reached insular Southeast Asia as part of a cultural assemblage traditionally

\footnotetext{
31 Several other examples are given in Kern (1869a:10), Tuuk (1881:46), Gonda (1973:79-81) and Casparis (1988). This fascinating topic merits a study on its own, as it may further deconstruct existing notions of "Indianisation".

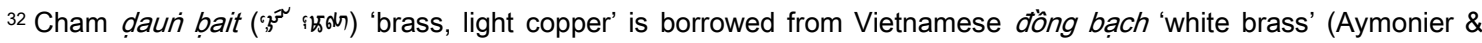
Cabaton 1906:239).
} 
associated with the "Đông Sơn Culture". Iron objects have not been unearthed anywhere in insular Southeast Asia before 500 BCE (cf. Higham \& Higham 2009:137), although iron-working appears to have been conducted on a very limited scale on the mainland, possibly as a result of Chinese stimulus (Bellwood 1997:271). About 500-400 BCE, iron starts to appear in many sites in mainland Southeast Asia, concomitant with more regular contacts with India (Glover forthcoming). There is less evidence for similar developments in insular Southeast Asia. It should also be pointed out that there has been a tendency to regard archaeological sites with laterite deposits as possible locations of pre-modern iron-working, whereas the percentage of iron in laterite bricks is in many cases too small to extrapolate local iron production (Pryce \& Natapintu 2010). Therefore, the presently available data remain too sparse to propose broad scenarios for the origins and spread of Southeast Asian iron-working traditions.

As in most other regions, pre-modern Southeast Asian iron-workers used a bloomery smelting furnace. Fire pistons, used in the smithing process to reach sufficiently high temperatures, are found abundantly and in different forms throughout the region (cf. Balfour 1907). Both Chinese and Southeast Figure 5: types of pistons Asian metallurgy involve a construction of double piston bellows, which are pushed alternatingly to maintain a constant stream of air. While the Chinese developed this prototype into their famous horizontal box bellows (Needham 1965:135-55), the Southeast
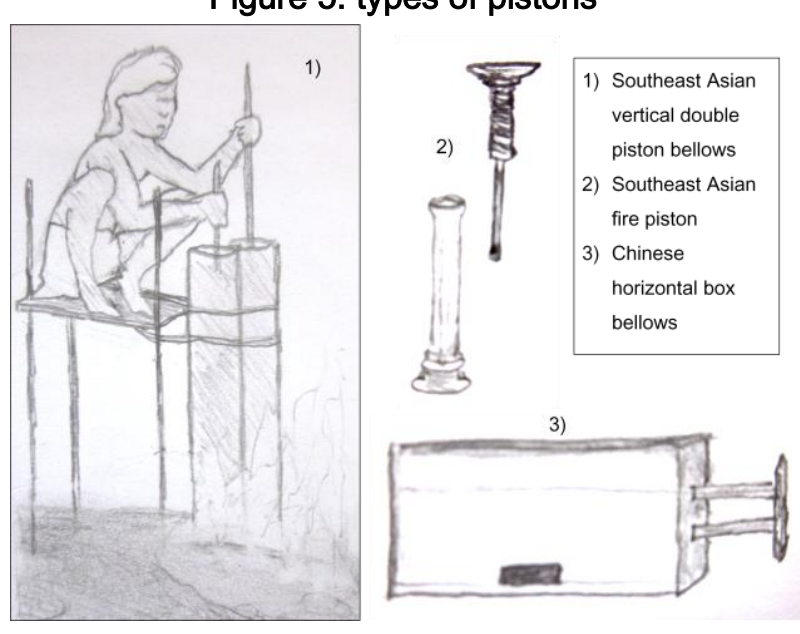
Asian version consisted of two vertical cylinders made of bamboo or wood into which a piston was entered from the top and rapidly forced down (cf. Figure 5). ${ }^{33}$ The cylinder and piston were made as air-tight as possible, so that the compression of air generated a temperature sufficient

\footnotetext{
33 The two prototypes may be related. Needham (1965:141) proposes that the Chinese bellows are derived from the Southeast Asian bellows, while Mahdi (1994/1:179) argues that they were invented independently in relative proximity to one another.
} 
to ignite a small quantity of tinder placed on the piston. The latter type of bellows has been documented throughout Southeast Asia and Madagascar (Balfour 1907, Forbes 1971), Yunnan (Needham 1965:139), Northeast India (Stonor 1975) and possibly in South India (Raghavan 1935, cf. Rea 1915:16), although the Indian subcontinent generally features other types of bellows (cf. Wijesekera 1949:126, Forbes 1971:116-7, Stonor 1975:838, Juleff 1996).

Moving to the linguistic data, Blust (1976:27-9) postulates the reconstruction of a protoAustronesian word for 'iron' with reflexes in Taiwan and insular Southeast Asia, implying acquaintance with the metal much earlier than indicated in the archaeological record. In a later publication, Blust (1999) clarifies that knowledge of iron, including unworked meteoric iron ore, does not necessarily imply knowledge of iron-working. Three iron-related protoforms are of direct concern to us: ${ }^{*}$ bəsi, ${ }^{*}$ badi? and ${ }^{*}$ bari ${ }^{34}$ The form ${ }^{*}$ bəsi is widely reflected in insular Southeast Asia, but almost all forms appear to be direct borrowings from Malay. In an article dedicated to this protoform, Blust (2005) addresses several important issues. Southwest Borneo, he argues, was an important centre of early iron production based on the iron terminology attested in this region and the fact that it was inhabited my cosmopolitan Malay speech communities. Knowledge of iron-working may have triggered the expansion of speakers of Malayo-Chamic languages from Borneo into the Southeast Asian mainland during the first two or three centuries BCE. On the mainland, the Malayo-Chamic word for 'iron' was borrowed into Old Mon as birsey, cf. Mon basai (๖ò) 'iron; nail, spike'. Interestingly, the word was borrowed twice into some languages of west Borneo, which therefore display lexical doublets; the older borrowing denoting an iron object 'spear, small axe, etc.' and the newer one referring to 'iron' in a generic sense (Blust 2005:33). Similarly, reflexes of the form ${ }^{*}$ badiq denote a 'short iron utensil or weapon' (Mahdi 1994/1:174). There is little reason to assign an ancient pedigree to

\footnotetext{
34 In addition, we find that some reflexes of the PWMP reconstruction *wasay 'axe' carry the generic meaning of 'iron' in several languages of North Sulawesi (Mahdi 1994:177). Wolff (2010/2:1023) reconstructs * wacay 'axe', an apparent secondary borrowing that he speculatively connects to Malay bəsi 'iron'. Based on the word-final diphthong, we may alternatively envision a connection with Cham basəi ( $\left.v_{\alpha}\right)^{x}$ id. or Mon basai (๖ò) 'iron; nail, spike', on which I elaborate below.
} 
this form and most of its reflexes go back to Malay badik 'k.o. dagger' (Blust 1995 s.v.). ${ }^{35}$ The form * bari is reflected in the Philippines, northern Borneo and Taiwan. Rather than attributing this form to proto-Austronesian, Mahdi (1994/1:171-5 contra Blust 1976:29) argues that the Formosan reflexes may be secondary borrowings from a Philippine source and outlines the possibility that all forms ultimately go back to a southern Philippine reflex of * badiq. 36

None of these forms present a clear origin. In the light of the prehistoric interethnic networks that form the basis of this study, we are compelled to compare the terms for 'iron' in regions in contact with Southeast Asia. Some languages of Mindanao and Taiwan exhibit reflexes of *putəu 'axe, iron' (cf. Mohring 1973:27, Mahdi 1994/1:178-9), which, together with Khmer būthau (ตูโษ્\}) 'axe, hatchet', appear to be borrowed from LMC fuə̆'-thəw (斧頭) 'axe'. ${ }^{37}$ This corresponds with the hypothesis that the Chinese played a role in the dispersal of metallurgy into Southeast Asia. On the other hand, I am not aware of any Chinese forms resembling *bəsi, " badi? and *bari. A possible connection with Near Eastern attestations, such as Hebrew barzel 'iron' and Arabic firzil 'fetters', is equally misleading and raises more questions than it answers. The Indian subcontinent is a likelier region from which ideas of iron metallurgy could have spread to insular Southeast Asia. Central and South India are rich in iron ore deposits and have an iron-working tradition dating back to the $2^{\text {nd }}$ mill. BCE - possibly independent from other centres of ferrous metallurgy (Chakrabarti 1976, Tewari 2003) although most Iron Age sites in South Asia yield much later dates (e.g. Maloney 1975:6, Juleff

\footnotetext{
35 Probable cognates not listed in Mahdi (1994) and Blust (1995) include Sundanese badi(-badi) 'k.o. cut-and-thrust weapon (from Sumatra)' and Old Javanese (?) kadivaḍi 'splinted open', attested in the Kuñjarakarna, possibly a corrupted form (Kern 1901:51 n. 31). Mahdi (1994/1:174-5) also proposes an etymological relation with Malay baji '(splitting) wedge' based on the fact that some Malay dialects are known to postfix a word-final glottal stop to words ending in a vowel. Alternatively, I would explain Malay baji as a loanword from Tamil vācci 'adze' (cf. Ronkel 1902:103, Lafeber 1922:98), further reflected as Acehnese baci 'axe (small type)', Gayo baji 'wedge', Toba Batak baji 'splitting wedge' and Makasar banci 'a tool to cut stones'. The presence of a geminated consonant and a long vowel in the tentative Tamil precursor make an acquisition in the opposite direction unlikely.

36 This does, however, not explain the word-final consonant in some of the Formosan attestations (cf. Ferrell 1969:90);

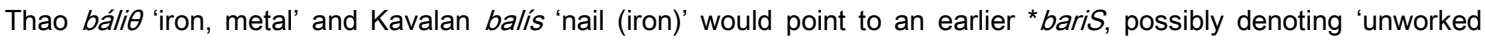
meteoric iron ore' (cf. Blust 1999).

37 Alternatively, Ferrell (1982:206) derives the Taiwanese attestation from Chinese pōdāo (朴刀) 'long-bladed sword wielded with both hands' or a regional pronunciation thereof. Based on the discrepancy in meaning, this etymology strikes me as less likely.
} 
1996, Raghunatha Rao \& Sasisekaran 1997). Since the bulk of palaeometallic sites in insular Southeast Asia are coeval with the earliest period of trade with India (Bellwood 1997:275), the scarcity of written research on metal-related vocabulary travelling across the Bay of Bengal is somewhat surprising.

The possible derivation of the Malayo-Polynesian protoforms for 'iron' from a South Asian source has been overlooked in the literature known to me. Both in form and meaning, the reconstructed protoform *bəsi 'iron' corresponds to OIA *vā'śi 'sharp pointed knife or adze', cf. Pali vāsi 'sharp knife, adze', Bengali bāsi 'axe' and Sinhala væhæ id., all originally from a Dravidian source (Burrow 1948:393, Southworth 2005:93). The voiceless palato-alveolar sibilant $<$ ś> of the OIA precursor has been preserved in the Vietnamese variety of written Cham, which exhibits the form biśi ( $\left.\mathcal{V}^{\top} \boldsymbol{F}^{\top}\right)$ 'iron', corresponding to basəi $\left(\mathcal{V}_{\alpha}{ }^{\gamma}\right)$ in Cambodia. The word-final diphthong attested in some Chamic reflexes (cf. proto-Chamic *bəscy, presumably yielding the Old Mon attestation) regularly reflects an earlier /i\#/ (Thurgood 1999:115-7). Furthermore, if the protoform * bari indeed goes back to *badiq, both forms may be connected to yet another set of South Asian attestations. At the dawn of intensified contacts between southern India and Southeast Asia, the Tamil word vați 'sharpness', Telugu vāọi 'sharpness of weapons or instruments' or a related form (cf. Burrow \& Emenau 1984 \#5349) may have been adopted as Malay badik in an earlier meaning of 'sharp iron utensil'. These two tentative lexical transmissions suggest that relations between India and the Malay World were much more instrumental to the spread of iron and iron-working across the Bay of Bengal than previously realised. Notwithstanding the indigenous iron-working tradition with vertical double piston bellows, two words for 'iron' in Malay and other Malayo-Polynesian languages appear to be from South Asia. This supports a scenario in which the earliest acquaintance with this metal, in particular among the Malay-speaking communities inhabiting coastal southwest Borneo, may have been through the iron utensils used by their South Asian trading partners, presumably by the early $1^{\text {st }}$ mill BCE. The introduction of sharp iron utensils provided the maritime oriented trading communities of Southeast Asia with enormous advantages over their forest- and 
mountain-dwelling neighbours in terms of agriculture, hunting and warfare. As the iron smelting techniques of the Malay World are largely similar to those of mainland Southeast Asia, we must assume that contact with Indians and their advanced knowledge of iron-working intensified and revamped the pre-existing local practices of ferrous metallurgy. As was the case in South Asia, this powerful new technology continued to be shrouded in secrecy and was exclusively practiced by specialised guilds, as will be argued in the following section.

\subsection{Metal trading networks}

As pointed out previously, certain Southeast Asian regions - or perhaps Southeast Asia as a whole - were eulogised in Chinese and Indian texts as the "Golden Land" or "Golden Island". This was probably more than just a euphemistic allusion to its abundant natural resources. Instead, archaeological and historical studies point towards the presence of a considerable indigenous gold mining industry in Sumatra and the Thai-Malay Peninsula (Obdeijn 1943:707, Bemmelen 1949:106, Burkill 1966/1:1112-3, Freeman 2003:59). It is generally believed that the ancient Indians obtained gold from Southeast Asia from the $2^{\text {nd }}$ C. BCE, when hostile Central Asian populations drew a close to the former's access to Siberian gold deposits. ${ }^{38}$ Before the establishment of large-scale industrial gold mines in colonial times, Southeast Asian gold was traditionally obtained by "panning" it in a circular tray known as dulang in Malay. Several Malayo-Polynesian languages display reflexes of *bulawan 'gold', related to *bulaw 'golden colour', which appears to be the original word. In west and central Indonesia, this term was largely replaced by words resembling Malay əmas 'gold' (e.g. Mahdi 1994/1:191-2), presumably a borrowing from Old Khmer mās(a) 'gold, a weight of gold, etc.' (> Khmer mās (ษ)ญิ) 'gold', Thai māś (มาศ), Cham mợ (ห३) id.). In the Malay word, too, the word originally designated a weight unit (Yule \& Burnell 1903:530, Wilkinson 1932/2:110), which makes Sanskrit māṣa 'a bean; weight of gold; etc.' a plausible ultimate precursor.

${ }^{38}$ Smaller gold deposits were also found in South India (cf. Krishnan 1951 passim). 
Silver is less common in the Malay World and found mostly in an alloy with gold (cf. Burkill 1966/2:2067). In an article on pre-colonial Malay coins, Dakers (1939:2) observes that local coins were mostly made out of gold or tin, while silver coins were of foreign provenance. In Java, silver has been used to manufacture local coins from the $8^{\text {th }}$ century onwards (Wicks 1992:248-50). Mahdi (1994/1:185-6) points out that the Malay word perak 'silver' (from Old Khmer prāk(a) 'silver') ${ }^{39}$ and cognate forms were disseminated along similar lines of commercial interaction between the Malay World and the Southeast Asian mainland. He demonstrates that reflexes of perak substituted an earlier word for 'silver' reflected as Malay səlaka, Old Javanese salaka and several related forms. This word, he argues, is probably a borrowing from Sanskrit śalākā 'chip, splinter, etc.', testimony to the pre-monetary stage of insular Southeast Asian history during which small pieces of silver were used as a medium of exchange. This practice is described in the History of the Song Dynasty (960-1279): "they cut leaves of silver and use them as money (Groeneveldt 1880:16)." The above lexical transmissions suggest that political and commercial relations between the Malay World and mainland Southeast Asia, particularly the Mon-Khmer speaking kingdoms, played an important role in the acquisition and distribution of bullion throughout insular Southeast Asia in the first centuries CE. 40

Next to gold, the most valuable metal of Southeast Asian commerce was tin. As mentioned in Section 3.4, tin is alloyed with copper to produce bronze. It was known to the ancient Greeks, traded in by the Phoenicians and extensively used by the Romans, who obtained it from Lusitania, Gallaecia, Cornwall and Ireland (Warmington 1974:269). Other important known sources of tin in the ancient world were the mines of West Asia, northern China and the Thai-Malay Peninsula (Shrimali 1976:89, Muhly 1985). In South Asia, which never had many tin deposits, this metal was mainly imported and used for the minting of copper coins (Ray 1989:47); a higher tin percentage results in harder coins. Linguistic evidence

\footnotetext{
39 Cf. Khmer prâk (โธฺุ่) 'silver, money', Thai parak (ปรัก) 'silver'); proto-Chamic * pirak 'silver, money', proto-Katuic *pra? *prakid.

40 Similarities between Malayo-Polynesian and Mon-Khmer words for 'gold', 'silver' and 'iron' have been noticed earlier, but the acquisition was previously assumed to have taken place in the opposite direction (e.g. Luce 1965:147).
} 
suggests that part of the tin imported into the subcontinent came from the west. The late Sanskrit word kastīra 'tin' (> Hindi kathïr 'tin, pewter') is evidently related to Old Greek kassiteros 'tin', Arabic qazdīr qașdīi id., Farsi qistīir 'tin, pewter' and several Middle Eastern and West Asian attestations. ${ }^{41}$ As mentioned previously, Southeast Asia was another source of imported tin, with deposits of cassiterite tin ores in present-day Myanmar, the Thai-Malay Peninsula and the Sumatran islands Bangka, Belitung and Singkep. Archaeological assemblages identified with the "Đông Sơn Culture" include bronze bowls with a high tin content, confirming that the commercial exploitation of the mineral was known in Southeast Asia prior to regular trade with the outside world. These bowls are found in various sites in South India and Sri Lanka (cf. Ray 1994:103, Rajan 2011:188-90). The Malays had access to these rich tin deposits from the moment they first settled in Sumatra and the Thai-Malay Peninsula - perhaps triggered by this area's abundant natural resources - and used the word for 'lead' to refer to this new metal (see below). The Aslian communities, indigenous to the Thai-Malay Peninsula, took their words for 'tin' from Malay (Skeat \& Blagden 1966/2:739), which suggests that tin metallurgy in this region was the monopoly - and possibly the invention - of Malay-speaking craftsmen. Large-scale tin-mining started in Bangka and Belitung under the colonial powers in 1710 , eventually making it the backbone of the regional economy and the most valuable mineral resource aside from oil (Bemmelen 1949:92-3). In pre-modern times, however, tin was already obtained from alluvial (secondary) deposits in these regions. As one of the few non-perishable trade commodities exported by Malay seafarers, we have ample documentation of an extensive trade in tin between the Malay World, China, South Asia and the Middle East from in the first centuries CE (Wheatley 1959:115-6, Rajan 2002:90). The metal was used domestically as a means of exchange. Thus, we read in a medieval Chinese description of Malacca that "in all their trading transactions they use pieces of tin instead of money" (Groeneveldt 1880:124), an

\footnotetext{
41 Many of the palaeographic attestations for 'tin' are controversial and will therefore not be treated here, but cf. Schliemann (1881:479), Muss-Arnolt (1892:132-3) and Schrader (1917-23/2:699). In any case, the Old Greek and

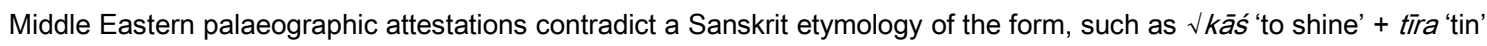
proposed by Monier-Williams (1899:266).
} 
observation confirmed by the finding of pre-Portuguese tin coins in this area (Dakers 1939:1). The Malay agency in the dispersal of tin coins is also reflected in the Malagasy language, whose word for 'tin, pewter' (firaka) probably goes back to Malay perak in the meaning of 'silver', but more specifically 'coin' (Mahdi 1994/1:186). Such a semantic shift also occurs in Philippine and Formosan borrowings of Malay perak 'silver' to a more general meaning of 'money' (cf. Mahdi 1994/1:171-2) and perhaps also in the name of the Malaysian state of Perak, which was traditionally a tin-mining and therefore a coin producing area.

The (partly) insular Southeast Asian origin of South Asian tin is reflected in the linguistic record. According to Blust (1999a:138), reflexes of PMP *timeRaq 'lead' were applied to 'tin' in the tin-prolific areas of Southeast Asia. Modern Malay, for example, has timah 'tin', timah hitam 'lead (lit. 'black tin')' and timah putih 'tinned iron (lit. 'white tin')'. .2 The clear similarity between Malayo-Polynesian attestations for 'tin' and the Sanskrit equivalent tī(v)ra has not gone unnoticed and has been interpreted in different ways. Gonda (1973:129) suggests a Sanskrit origin, while Lafeber (1922:138-40) and Mills (1975a/2:901) postulate an acquisition in the opposite direction. In fact, the Sanskrit reflex is only attested in later works (Monier-Williams 1899:449, Shrimali 1976:88). In addition, Blust (1982:287-8) demonstrates that a Sanskrit origin is implausible on account of the consonant clusters in the Philippine attestations (e.g. Tagalog tingâ, 'lead', Bikol timgá', Cebuano tinggà id.) and that Malay timah goes back to an earlier ${ }^{+}$timrah (< PMP *timeRaq 'lead'). ${ }^{43}$ This strongly supports the second scenario, in which early Malay 'tim(ə)rah or a related reflex (cf. Old Javanese timbrah 'tin', Minangkabau timbarah id.) was the precursor of Sanskrit $t \bar{T}(v)$ ra 'tin, steel, iron', Sinhala tīvra 'tin' and Dhivehi timara 'tin, lead'. The $/ \mathrm{v} /$ in the Sanskrit attestation may be the result of folk-etymological association with tīvra 'strong'. Other lexical transmissions are also in support of a scenario in which speakers of Malayo-Polynesian languages exported tin across the Bay of Bengal. Bugis tamara? 'tin', cognate to Malay timah, appears to be the precursor of late Sanskrit tamara 'tin', which was

\footnotetext{
42 The semantic overlap between 'tin' and 'lead' is well documented cross-linguistically; cf. Arabic al-rașāṣ al-qaliT'tin (lit. 'the white lead') (Tibbetts 1979:124) and Pliny's plumbum album 'tin' vis-à-vis plumbum nigrum 'lead'.

${ }^{43}$ Adelaar (1992a:110) reconstructs proto-Malayic timerah 'tin'.
} 
subsequently adopted into a number of Dravidian languages. ${ }^{44}$ In addition, another MalayoPolynesian form, possibly Makasar tumbera 'lead', may have yielded Sinhala tun̆ba 'lead'. 45 Another set of synonyms for 'tin' allude to the region from which the mineral was procured. As first pointed out by Obdeijn (1943:707), the island of Bangka - perhaps through the Malay compound timah bangka 'tin from Bangka' - has lent its name to Tamil vankkam 'lead, tin, zinc, etc.' and late Sanskrit vaniga 'tin or lead'. ${ }^{46}$ Several more attestations go back to the same source, e.g. Malayālam vanigam 'lead, tin, tincal', Kannaḍa vaniga 'tin, lead', Sinhala variga 'tin' and Hindi bang 'calx of tin given internally as an aphrodisiac'. It is most likely that the Indian languages obtained their words from Malay and not the other way around, as a reverse transmission would have yielded Malay ${ }^{*} \operatorname{bangga}(\mathrm{m})$ instead of bangka. ${ }^{47}$ Finally, as mentioned previously, the Southeast Asian "Nāga" origin of the metal is revealed by such forms as Sanskrit nāga(ja) and Sinhala nāga, both of which can be used for 'tin' (cf. Tamil nākam 'black lead, zinc'). Cumulatively, the above lexical transmissions point towards a flourishing export of tin from Southeast Asia to India by the first centuries CE, in which the main agents were speakers of different Malayo-Polynesian languages.

By now, it has become clear that metal trade in Southeast Asia involved both regional and transoceanic commercial networks. During the first centuries CE, contacts between the Malay World and mainland Southeast Asia were of such nature that considerable quantities of silver (perak) and gold (əmas) were distributed across insular Southeast Asia. By this time, contacts with South Asia were firmly established and the Southeast Asian wealth in tin and gold was recounted in the Indian literature. As argued in the previous section, I believe that contacts

\footnotetext{
44 Tamil takaram 'tin, white lead, etc.', Malayālam takaram 'tin, tinned iron plate', Kannaḍa tagara tamara tavara id., Tulu tamarů tamara tavara id., Telugu tagaramu tamaramu $\sim$ tavaramu id. and other forms. The Tamil attestation is already found in the Cankkam literature (Lehmann 1992:211). The intervocalic velar stop in the Dravidian attestations may be under influence of Sanskrit tagara 'borax'.

45 Central Nicobarese tumba 'lead', on the other hand, appears to be from Portuguese chumbo id. (< Latin plumbum id.)

${ }^{46}$ Malay Bangka > Tamil vankam is regular. The Sanskrit form could be a Tamil loan. Alternatively, it has been argued that tin entered South Asia via Bengal, known as Variga in Sanskrit, so that this toponym came to refer to the product (Shrimali 1976:89).

47 The relation between these forms and Iban bangkang 'lead, to solder' remains somewhat obscure.
} 
with South Asia accounted for innovations in Southeast Asian metallurgy. The linguistic evidence supports a considerable South Asian element in the iron-working traditions of insular Southeast Asia. This is further corroborated in the lexicon pertaining to steel production, an advanced development in ferrous metallurgy in which iron is alloyed with carbon to produce a much harder metal. Two insular Southeast Asian terms for 'steel' point specifically to South India, which was known for its high-quality steel ('wootz') from Alexandrian times onwards (Srinivasan 1994). Malay kəluli 'steel', I would argue, is borrowed from Tamil kalluli 'stonecutter's chisel', cf. the compound kalluli-y-urukku 'a kind of very hard steel used for cutting stones'. Another example is Old Javanese malyāla 'a country in South India and its people; steel (a partic. kind of steel)', which yielded Javanese malelo 'steel', Sundanese malela 'shining (steel)', Malay məlela 'dark, undamasked steel', Acehnese mulila 'steel', Toba Batak malela id. and Karo Batak malela 'a word often used in mantras'. From this inference, we may deduce that the Malabar Coast (Malayāla) exported steel to insular Southeast Asia from at least the first centuries CE.

The most common word for 'steel' in insular Southeast Asia is Malay baja, Old Javanese vaja, Karo Batak baja, Bugis baja?, etc. This word is also used in the meaning of a certain preparation applied to the teeth, e.g. Old Javanese vaja 'teeth; the pieces of steel inserted in the mouth of a corpse as teeth, to get him beautiful teeth in a later incarnation' (Tuuk 1897-1912/3:599), Malay baja 'an oily preparation made from burnt coconut-shell and used to stain the teeth black', Acehnese baja 'a type of blacking to stain the teeth black', Karo Batak baja 'name of a small-leaved tree with very hard trunk, its oil can be used as shampoo and to blacken filed teeth', Angkola-Mandailing Batak baja 'blacking for the teeth' and Toba Batak baja 'a tree with hard wood, from its juice is prepared a black dye, which is used as ink and to blacken the teeth (Planchonia valida)'. Zumbroich (2009:391) demonstrates that iron-containing solutions are often used for the purpose of teeth-blackening in Southeast Asia, a notion that may help us to understand the presumed semantic shift from 'steel' to 'teeth'. A third meaning of this word is reflected by Malay baja 'fertiliser' and Acehnese baja 'manure'. Therefore, it has 
been argued that the ultimate source of these sets of word is Malay baja in the meaning 'to temper or enrich', which can be said of iron (as to produce steel), fertilizers and teeth blacking concoctions (cf. Wilkinson 1932/1:67). I would argue that Malay baja is another Indian loanword for 'steel'. As was first suggested by Rigg (1862:364), it may go back to Sanskrit vajra, which denotes a 'thunderbolt' or other extremely powerful weapons, but also other hard things such as 'a diamond', 'a kind of hard mortar or cement', 'a kind of hard iron or steel', etc. (Monier-Williams 1899:913). The Sanskrit literature also displays granthivajraka, śaivālavajra, śonavajra and svarnavajra as names for steel types. We may further point out that OIA * vájra would yield MIA *vajja (cf. Turner $1966 \# 11204$ ), which resembles the Malay attestation even closer.

The transmission of Indian words for 'steel' does not stand in isolation. Malay reflects various loanwords for metal names, such as Sanskrit kañcana 'gold' (> Malay kəncana), kamsa 'brass, bell-metal, etc.' (> gangsa 'bronze'), rasa 'mercury, quicksilver' (> rasa), rājasa 'tin' (> rəjasa), ritit 'yellow or pale brass, bell-metal' (> †riti 'brass, bronze'), ${ }^{48}$ rūpya 'silver, stamped coin, rupee' (> rupiyah 'rupee'), sindūra 'red lead, minium, vermilion' (> sindura 'minium, red-lead') and svaccha 'an alloy or amalgam of silver and gold' (> suasa 'gold alloyed with copper'). ${ }^{49}$ Malay pat(ə)ri 'solder; borax' may be a borrowing from a vernacular Indo-Aryan source, cf. Hindi pațri`a narrow slip of iron, etc.' (Gonda 1973:139), while Malay kərsani 'iron from Khorasan'50 _ cf. Old Javanese purasani 'a kind of iron' and Javanese purosani 'high-quality iron or steel used for making kərises, royal carriage etc.' - appears to be an early borrowing from Farsi h̆orāsānī 'from the Khorasan region' (Tuuk 1897-1912/4:99). Five loanwords from Tamil - cătilinkam 'vermilion, red sulphurate of mercury, etc.' (> Malay sədəlinggam 'minium; red-lead'), lōkam 'metal' (> logam id.), pañcalōkam 'the five kinds of metal' (> pancalogam 'multicoloured or

\footnotetext{
48 Although the word is not attested in modern Malay, it was apparently transmitted to several insular Southeast Asian languages through an early Malay variety (cf. Mahdi 1994/1:181), cf. Old Javanese riti 'certain metal (brass, bronze?)'.

49 The etymology of suasa is uncertain and several other tentative precursors have been proposed (cf. Maxwell 1882:15, Ronkel 1902:109, Gonda 1973:136-7 fn. 26, Jones 2007:300). Even more metal- and mineral-related Sanskrit borrowings are found in Southeast Asian epigraphy. The Old Javanese literature, for example, displays ayah 'iron' (< Sanskrit ayas id.), cāmikara 'gold' (< cāmikara id.), nila 'sapphire' (< nīla id.), rajata 'silver' (< rajata id.), sotya 'jewel, gems' (< śauca 'purity'), tāmra 'copper, bronze' (< tāmra 'copper'), etc.

50 Marsden's Malay dictionary (1812:125) gives khorasānī(خرساني) 'fine tempered steel of Khorāsān'.
} 
"composite" metal or stone'), turuci turucu 'blue vitriol' (tərusi 'copper vitriol; copper sulphate; bluestone') and tuttam 'a prepared arsenic, vitriol, sulphate of zinc or copper' (> tutam $~$ cutam 'niello') - again point particularly to the Coromandel Coast as a place from which the early Malays acquired new ideas of mineral and metal technology (cf. Table 8 in the appendix). This is also reflected in North Sumatran oral traditions, which attribute the magical art of metallurgy to the deity Tuan Banua Koling (Neuman 1926:23-4), whose name reminds us of the Malay, Javanese and Karo Batak word kəling 'South Indian'. ${ }^{51}$

The insular Southeast Asian words for 'smith', too, appear to hail from the Indian subcontinent. A class of Brahmins known in Bengali as Pã̃re, Oriyā Pāṇta and Hindi Pã̃ de (cf. Turner 1966 \#7718) appears to have lent their name to the blacksmiths guild in a number of Malayo-Polynesian languages (Gonda 1973:170-1, Casparis 1988:61), cf. Old Javanese pande panday 'skilled worker, smith, goldsmith, etc.', Balinese pande 'a maker of likenesses, artist, craftsman, smith, worker in metal', Malay pandai 'artist-craftsman, expert, specialist', Acehnese pande 'blacksmith', Toba Batak pande, Karo Batak pande, Makasar panre, Tagalog panday id., and Cebuano panday 'blacksmith, carpenter'. ${ }^{52}$ In Bali, moreover, Pande is still used as the clan name for metallurgists (Goris 1960, Guermonprez 1987). This case of lexical borrowing presents an interesting analogy with Sanskrit kauśala 'skilfulness, cleverness, experience', which was adopted, via Old Javanese guśalī 'blacksmith', into Javanese as gusali 'blacksmith', Sundanese gosali 'smithy', Lampung †kasali id., Nias osali 'council, church', Bugis †gosali 'cemetery, residence of the deceased' and Tagalog gusali 'building' (cf. Tuuk 1897-1912/2:199,

\footnotetext{
51 Cf. Sanskrit Kalinga (Tamil Kalinkam), the name of an historical kingdom in coastal Orissa that appears to go back to an Austro-Asiatic source (cf. Lévi 1923). The Chinese monk Yìjing mentions a Southeast Asian kingdom under the same name, i.e. EMC * xa-lin (訶陵). Also compare Old Mon kālin, Old Khmer khlin and Khmer kling (芯占) ('Indian').

52 Alternatively, we may connect Malay pandai 'expert, specialist, etc.' with Tamil panțai/pande/ 'knowledge, learning' (< Sanskrit paṇ̂̄ā 'wisdom, knowledge, learning). In my opinion, the tentative Indo-Aryan (or, perhaps, Tamil) etymology is plausible based on the evident similarities in form and meaning (pace Brandstetter 1925:6-8). It would not be the only example of an Indian class name that came to refer to a profession in a Southeast Asian context. Sanskrit Vanijaka, a caste of merchants, has been borrowed into Malay as bəniaga 'trade' (< Old Malay baniaga 'trader') and Malayālam Panikkar, a family name used by teachers of martial arts, as Acehnese panika 'skilled, master of fence', Malay pəndekar 'master of fence' and Javanese pandekar 'champion of a cause, skilled fighter' (pace Casparis 1988:61-2). Tsouic pxatxi '(black)smith' is unrelated and goes back to Southern Min phah-thih (撲鐵) 'iron-worker' (Tryon 1995/3:354).
} 
4:733, Lafeber 1922:135-6, Gonda 1973:548, Casparis 1988:58). Also related is Balinese hasta kosali 'title of a book of measurements for houses' (hasta = 'hand'). Analogously, three Khmer

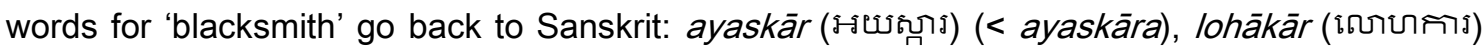
(< lohakāra) and byokār (เต็กการ) (< vyokāra). The word for 'carpenter' has also spread from

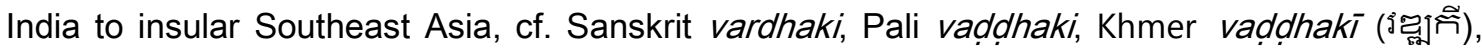
Lao vaddhakī(อัถทะภึ), Old Javanese unda(ha)gi, Sasak bəndagi, Lampung †dahagi †duhagi, Tagalog anlu(w)agi alwagi, Bikol anluwagi anduwagi, llokano allawági, Kapampangan aluwaggi(cf. Tuuk 1897-1912/1:35, Casparis 1988:64-5).

We may also call attention to the presence of Sanskrit words for specific metal ornaments in Southeast Asian languages, e.g. makuța (= mukuța) 'diadem' > Old Javanese makuța, Old Khmer makuța, Thai makuț (มกุฎ) manikuț (มงกุฎ), etc.; kuṇ̦ala 'ear-ring', > Old Javanese gonḍala, Old Khmer kundala, Thai kuṇ̦al (กุณฑล); and valaya 'bracelet' > Old Javanese valaya, Old Khmer vala(i)ya, Thai valai (วลัย). As is seen from these examples, premodern metallurgy was not restricted to the manufacture of agricultural, hunting and warfare items, but also contributed to the consolidation of social hierarchy. As in many other parts of the world, smiths in Southeast Asia were assumed to possess magical powers. This would explain why many of the Southeast Asian words for 'smith' also denote skilfulness, i.e. kauśala. These attitudes towards blacksmiths, as one scholar put it, "would be strengthened by the fact that the art of metallurgy is so often practiced by outsiders, men of strange speech and habits, who keep the secrets of their crafts strictly to themselves and form a guild or caste apart (Webster 1948:165)." If this was the case in insular Southeast Asia, and the linguistic data seem to be in support, it further strengthens the idea that prehistoric contacts with South Asia considerably influenced the role of metal and its usages in the societies of insular Southeast Asia.

\subsection{Concluding remarks}

The linguistic evidence brought together in this chapter implies earlier and more frequent interethnic contacts across the Bay of Bengal than assumed in the wider literature, fuelling 
developments on both sides as a result. In insular Southeast Asia, the language of the sailors and merchants involved in these interactions was predominantly Malay, although isolated examples of other West-Malayo-Polynesian languages influencing both the vernacular and literary languages of South Asia are also encountered. The westward directionality of some of the cultural and lexical transmissions addressed in this chapter support a scenario of active participation of insular Southeast Asian traders in the commercial networks linking their archipelago with the Indian subcontinent and other regions of the Indian Ocean. The strong links between South India and North Sumatra - and perhaps other Southeast Asian regions are particularly in need of further research, as they may challenge our understanding of the interaction and reciprocal influence between Indian and Southeast Asian communities throughout pre-colonial history.

Notwithstanding the vast quantity of cultural and religious concepts from India adopted by the early Southeast Asian kingdoms, the foundations of interethnic networks across the Bay of Bengal display a strong commercial element. In many cases, the trade networks connecting South and Southeast Asia were continuations of small-scale local systems. The trade in gold and silver, for example, seems to have been a predominantly regional phenomenon involving Mon-Khmer and Malayo-Polynesian speaking societies and largely excluding participants from South Asia. Although there is little evidence of Indian political or military dominance over Southeast Asia prior to the Cōla expansion (early 11th $\mathrm{C}$. CE), we do see that new techniques and ideas of urbanism, religion and metal-working were readily taken over by Southeast Asian societies in contact with South Asia and other regions, providing the former with significant advantages over their neighbouring societies. As argued, the acquaintance of Malayo-Chamic populations with iron may have fuelled their socio-economical hegemony across insular Southeast Asia and their expansion to the Southeast Asian mainland.

On the other hand, the Southeast Asian rulers appear to have been very deliberate in picking the elements of Indian society that they felt would benefit them in terms of material, economic and political proficiency. The decision to manoeuvre themselves into the orbit of 
"Indianisation" must be interpreted along these lines, instead of political or religious dominance. Innovative "Indian" notions of statehood, architecture, religion, arts and language (Sanskrit) were proudly upheld by Southeast Asian dynasties - albeit in a localised form - rather than being imposed on them. The process of "Indianisation" in Southeast Asia, therefore, was not that different from the treatment of Graeco-Roman culture throughout medieval Europe. Essentially, the rise and predominance of Islam in large parts of Southeast Asia can be explained along similar lines. Following up on this general historical overview of cultural contact and diffusion between South and Southeast Asia, the next chapter presents a more specific survey of the Indian Ocean regions under the influence of insular Southeast Asia. 


\section{Southeast Asian influence across the Indian Ocean}

The focus of this chapter is on the cultural elements from insular Southeast Asia that found their way into broader avenues of the Indian Ocean World, emerging from the commercial networks that developed across the Bay of Bengal by the $1^{\text {st }}$ mill. BCE. In general, the evidence supporting a cultural impact from Southeast Asia on any of its adjacent regions is at best scattered and has rarely been approached in a comparative, interdisciplinary way, making it rather difficult to get an overall picture of the complicated social processes at play. Nevertheless, it is underlined that data specific to one region provide us with useful comparative material to study other regions, whereas inferences from one discipline may corroborate, fine-tune or challenge theories or perspectives from other fields. The aim of this chapter, accordingly, is to explore the impact of sailors, traders and - presumably - settlers from insular Southeast Asia on neighbouring societies in the Indian Ocean World. Drawing on archaeological data and textual sources, the chapter aims to reconstruct the nature and dynamics of cultural exchange between Southeast Asia and other parts of the Indian Ocean. Subsequently, the extent will be examined to which this impact is reflected in loanwords or other linguistic inferences. Plant translocations, spices and maritime technology all merit separate chapters (respectively Chapter 5, 6 and 7) and will not be dealt with here.

This chapter focuses on region-specific characteristics of interethnic contact in the Indian Ocean World, elaborating on the similarities and differences between these regions in their commercial and cultural ties with insular Southeast Asia. A complicating factor in reconstructing large-scale models of Indian Ocean prehistory is the lack of archaeological evidence for pre-European human settlement or activity in the Seychelles, the Mascarenes, the Chagos Archipelago and other island groups - all uninhabited upon initial European contact leaving us without any clues as to the possible role of these islands as a transit point between 
Southeast Asia, the Arabian Sea and Madagascar. ${ }^{53}$ The complex interrelations between cultural regions of the Indian Ocean notwithstanding, the chapter addresses - in the order of geographical proximity to Southeast Asia - the Andaman and Nicobar Islands, India, Sri Lanka, the Maldives, the Arabian Sea and East Africa separately. Our knowledge of these regions, their historical relationship with Southeast Asia and the resultant cultural and lexical transmissions will be synthesised and analysed. On a more general level, this chapter addresses the nature and dynamics of interethnic contact between Southeast Asia and the aforementioned regions.

\subsection{The Andaman and Nicobar /slands}

The Andaman and Nicobar Islands, situated in the Andaman Sea at the southeast end of the Bay of Bengal, occupy a strategic position between India, Myanmar and Sumatra. The islands have been continuously populated for several millennia and are linguistically diverse. Both island groups feature in geographic works of antiquity as a location inhabited by naked, savage cannibals, although it is unlikely that many of the Hellenistic, Arabic and other authors responsible for these accounts had actually set foot on the islands. ${ }^{54}$ In all likelihood, frightening tales of the islands and their inhabitants were deliberately disseminated by Malay freebooters in order to keep intruders and fortune-seekers away from their headquarters (Portman 1899:53; Śâstrî 1927:242-4). Historically documented slave-raiding activities by Malay-speaking sailors help us to understand the deeply rooted and pervasive resentment of the Andamanese towards foreigners (e.g. Mouat 1863:21-2). In Islamic times, the Andamanese (as well as African) slaves were known to the Malays, among others, as kafir. ${ }^{55}$ Those not involved in slave-raiding, such

\footnotetext{
53 Ongoing research by Prof. Atholl Anderson, Dr. Geoffrey Clark and Dr. Simon Haberle is expected to bolster our knowledge on remote island colonisation in the Indian Ocean in the foreseeable future.

54 Whether the islanders were genuinely cannibals seems to be of secondary importance; the correlation between "barbarians" and "cannibals" was quickly established. The early descriptions of the Andaman and Nicobar Islands have been made accessible by previous scholars (cf. Lassen 1847-61/3:250-1, Yule 1871:250ff., Hirth 1888, Gerini 1909 passim, Hirth \& Rockhill 1912:147-8, Śâstrî 1927:236-8, Devic 1928:112-3, Obdeijn 1941b:479, Mathur 1968, Tibbetts 1979:152-6).

55 Cf. Acehnese kaphe and Moken (Myanmar var.) kape?, ultimately from Arabic kāfir 'infidel, unbeliever'. Burmese kappali (mự) 'black person' appears to go back to the older Malay †kapiri 'African negroes' (Marsden 1812:260),
} 
as Malay birds' nests collectors, made all possible efforts to avoid the hostile Andamanese communities (Watt 1889-96/ii:505-6). On a lesser scale, slave-raiding by Malay freebooters also took place on the Nicobar Islands, where hostile encounters were reported during the colonial period (Colebrooke 1807:125 fn.). However, while the Andamanese groups all share a history of animosity towards outsiders, as well as each other, their Nicobarese neighbours have predominantly been welcoming towards foreigners and eagerly bartered their coconuts, ambergris and other products for iron from at least the first centuries CE (Yule 1871:250, Takakusu 1896:xxx).

Two language families are found on the Andaman Islands: Great Andamanese and Angan (Onge-Jarawa). They do not appear to be closely related to other language families or to each other (Manoharan 1989, Abbi 2009). ${ }^{56}$ Very little is known about the language of the inhabitants of North Sentinel Island, who continue to refuse any contact with the outside world and rebuff all strangers they encounter, including aid-workers following the devastation of their island as a result of the 2004 Indian Ocean tsunami. All Great Andamanese languages are either extinct or moribund. In the mid1970s, the Indian government issued a compulsory relocation of the remaining indigenous Andamanese to Strait Island (a small island east of Great Andaman). Subsequently, the few remaining speakers of Great

\section{Figure 6: map of the Andaman Sea}
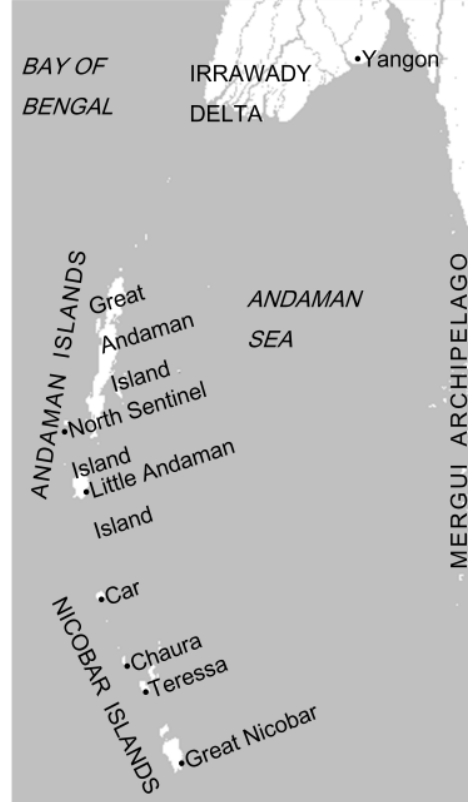
SUMATRA Andamanese languages developed a lingua franca known as "Great Andamanese", which at present has almost completely been replaced by a local variety of Hindi (Abbi 2012:xxiii-iv). The

whereas Tagalog kapre kapré 'savage, inhuman' may have been borrowed from Spanish cafre 'savage' (also borrowed from Arabic).

56 See Zide \& Pandya (1989) and van Driem (2001:205-16) for an overview of scholarship on Andamanese languages and linguistics. 
Nicobarese languages form a subgroup of the Austro-Asiatic family. Pinnow (1959:4) lists the following Nicobarese languages and their indigenous names: 1) Car Nicobar (Pu:), 2) Chaura

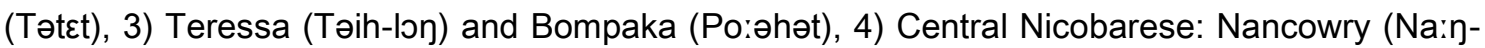
kəuri), Trinkat (La:fu:l) and Kachel (Te:hnu), 4) South Nicobarese: Great Nicobar (Lo-oๆ), Little

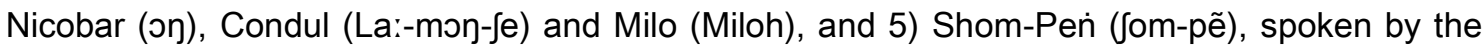
inland populations of Great Nicobar. Unfortunately, it is nearly impossible to obtain research permits for the islands, leaving their languages rather poorly documented. The only Nicobarese languages that have been studied in post-colonial times are Car (Braine 1970, Das 1977) and Nancowry (Radhakrishnan 1981).

During the British presence on the Nicobar Islands, trade was dominated by Malays and Chinese (Sen 1962:188) and many Nicobarese were reported to speak Malay (Man 1888-89:Ix fn.1). Therefore, we would expect to find Malay influence on the Nicobarese languages. While some cultural and linguistic parallels between the Nicobarese and the Malay World are drawn in Man (1888-89) and Mathur (1968:229-30), both authors describe rather superficial typological features quite common across Southeast Asia in general, leaving the extent of direct Malay influence unexplored. Morphological similarities between Nicobarese and Malayo-Polynesian languages are pointed out by Reid (1994). These, too, are not indicative of Malay-Nicobarese contact, but may demonstrate a relation of much greater time depth: between the Austronesian and Austro-Asiatic languages. Unable to personally conduct fieldwork on the Nicobar Islands, I have made an impressionistic analysis of lexical influence from Malay on the Nicobarese languages - as documented in the available dictionaries (Röepstorff 1875, 1884, Man 1888-89, Whitehead 1925, Das 1977) - yielding a list of several tentative loanwords from Malay or closely related languages (Table 3). Some of these may, however, be of relatively recent acquisition, since they are loanwords int Malay as well (cf. Appendix 1). 
Table 3: Malay loanwords in Nicobarese languages

\begin{tabular}{|c|c|c|c|c|c|c|}
\hline Malay & $\begin{array}{l}\text { Central } \\
\text { Nicobarese }\end{array}$ & $\begin{array}{l}\text { South } \\
\text { Nicobarese }\end{array}$ & Teressa & Car Nicobar & Chaura & Shom-Peń \\
\hline ayam & & & haijom & haijam & & \\
\hline 'chicken' & & & 'chicken' & 'chicken' & & \\
\hline $\begin{array}{l}\text { bawang } \\
\text { 'onion' }\end{array}$ & powan 'onion' & powan 'onion' & & & & \\
\hline cabai' 'pepper' & $\begin{array}{l}\text { komeanta- } \\
\text { tfape } \\
\text { 'Capsicum } \\
\text { baccatum' }\end{array}$ & & & & & \\
\hline $\begin{array}{l}\text { cangkeh } \\
\text { 'cloves' }\end{array}$ & $\begin{array}{l}\text { fis-tfingi } \\
\text { 'cloves' }\end{array}$ & & & & & \\
\hline $\begin{array}{l}\text { duit 'copper } \\
\text { coin, money' }\end{array}$ & $\begin{array}{l}\text { rut' 'copper, } \\
\text { copper coin' }\end{array}$ & & & & & \\
\hline hanyut 'coat' & kanut 'coat' & kanut 'coat' & & enut 'coat' & hanut 'coat' & \\
\hline jarum 'needle' & tfarum 'needle' & tadup 'needle' & $\begin{array}{l}\text { kiarum } \\
\text { 'needle' }\end{array}$ & tfarum 'needle' & tfarum 'needle' & \\
\hline $\begin{array}{l}\text { jung 'sea- } \\
\text { going ship' }\end{array}$ & tfoワ 'ship' & & $\begin{array}{l}\text { kion ton } \\
\text { 'ship' }\end{array}$ & to:ク ‘ship' & & \\
\hline $\begin{array}{l}\text { kapur } \\
\text { '(slaked) lime' }\end{array}$ & & & & & & $\begin{array}{l}\text { kabeu } \\
\text { '(slaked) lime }\end{array}$ \\
\hline $\begin{array}{l}\text { kəmənyan } \\
\text { 'benzoin' }\end{array}$ & $\begin{array}{l}\text { kaminan } \\
\text { 'gutta-percha' }\end{array}$ & & & & & \\
\hline $\begin{array}{l}\text { kərbau 'water } \\
\text { buffalo' }\end{array}$ & kapo 'cow' & & krebo 'cow' & & & \\
\hline kucing 'cat' & kotfin 'cat' & & & & & tin 'cat' \\
\hline labu 'gourd' & lapu 'pumpkin' & & & & & \\
\hline lada 'pepper' & $\begin{array}{l}\text { lara 'black } \\
\text { pepper' }\end{array}$ & $\begin{array}{l}\text { lara 'black } \\
\text { pepper' }\end{array}$ & & & & \\
\hline $\begin{array}{l}\text { mangkuk } \\
\text { 'small bowl' }\end{array}$ & monko 'cup' & & & & & \\
\hline $\begin{array}{l}\text { Məlayu } \\
\text { 'Malay' }\end{array}$ & Malaju 'Malay' & & & & & \\
\hline $\begin{array}{l}\text { nangka } \\
\text { 'jackfruit' }\end{array}$ & $\begin{array}{l}\text { nanka } \\
\text { 'jackfruit' }\end{array}$ & & & & & \\
\hline pənyu 'turtle' & & & & penut 'turtle' & & \\
\hline $\begin{array}{l}\text { pinang 'areca } \\
\text { nut' }\end{array}$ & & & $\begin{array}{l}\text { hinan 'areca } \\
\text { nut' }\end{array}$ & & $\begin{array}{l}\text { hinaク 'areca } \\
\text { nut' }\end{array}$ & $\begin{array}{l}\text { nay 'areca } \\
\text { nut' }\end{array}$ \\
\hline pinggan 'plate' & & & & pinã:/'plate' & & \\
\hline $\begin{array}{l}\text { pulau pulo } \\
\text { 'island' }\end{array}$ & & & pulo 'island' & & & \\
\hline $\begin{array}{l}\text { rupiyah } \\
\text { 'rupee' }\end{array}$ & rupia 'rupee' & & & rupia 'rupee' & & \\
\hline $\begin{array}{l}\text { təmbikai } \\
\text { təmekai 'water } \\
\text { melon' }\end{array}$ & $\begin{array}{l}\text { tamikaj } \\
\text { 'melon' }\end{array}$ & & & & & \\
\hline $\begin{array}{l}\text { timun } \\
\text { 'cucumber' }\end{array}$ & $\begin{array}{l}\text { temon } \\
\text { 'cucumber' }\end{array}$ & & & $\begin{array}{l}\text { timun } \\
\text { 'cucumber' }\end{array}$ & & \\
\hline
\end{tabular}




\begin{tabular}{lllllll}
\hline Malay & $\begin{array}{l}\text { Central } \\
\text { Nicobarese }\end{array}$ & $\begin{array}{l}\text { South } \\
\text { Nicobarese }\end{array}$ & Teressa & Car Nicobar & Chaura & Shom-Pen் \\
\hline $\begin{array}{l}\text { tong 'tub, tun, } \\
\text { cask, etc.' }\end{array}$ & ton 'wooden & & & & \\
tuak 'toddy' & toak 'toddy' & & & \\
\hline
\end{tabular}

In addition to these loanwords from Malay, we may also explore the influence of Moken languages, spoken in the Mergui Archipelago about $700 \mathrm{~km}$ northeast of the Nicobar Islands. Similarities in the boat-building techniques of these contiguous regions have been pointed out by Sopher (1965a:197-8). In addition, Lewis $(1960: 55,62,93)$ suggests three possible Moken loanwords in Nicobarese: 1) Central Nicobarese hifua 'European boat' (cf. Moken (Myanmar var.) tøepau 'boat'), 2) Car Nicobar kupok 'a rowing boat, or very small yacht' (cf. Moken kabān 'houseboat'), and 3) Central Nicobarese powah 'a paddle', South Nicobarese pawwə, Car Nicobar pajjuə id. (cf. Moken (Myanmar var.) pewa 'oar, paddle'). In the absence of regular sound correspondences, the first two tentative borrowings should be treated with scepticism, but the word for 'paddle' appears to be a genuine borrowing from Moken. The role of Moken sailors in the wider Southeast Asian trade networks is conventionally believed to have been rather marginal and early $20^{\text {th }}$ century ethnographies depict them as extremely timid people (Sopher 1965a:71, Ivanoff 1989, Sather 1997:323-4, Andaya 2008:176, Hoogervorst 2012:13). This was presumably different in earlier times. The Old Mon literature depicts them as fearsome pirates frequently attacking the Dvāravatī kingdom that existed in the late $1^{\text {st }}$ C. CE (Luce 1965:145-7, Mahdi 1999b:177-8). In addition, some nautical terms seem to have reached the Southeast Asian mainland through a Moken language (see Section 7.5). A significant role of Moken seafarers in the pre- and protohistoric trade networks in Southeast Asia is also envisioned by Mahdi (2009), who provides linguistic and literary evidence for their believed involvement in the dispersal of products and concepts across the region.

The Andaman Islands show less compelling evidence of linguistic contact with Malay or other Southeast Asian speech communities, especially since the encounters with foreign sailors were predominantly of hostile nature. Blevins $(2007,2009)$ has made a somewhat daring 
attempt to link Onge and Jarawa (labelled the "Ongan" family), spoken in the southernmost Andaman islands, to the Austronesian language family. This is rather problematic from a macrohistorical point of view and the methodology of this research has been subject to criticism (e.g. Blust 2009a:707-8). Nevertheless, it is conceivable that some of the given forms are genuinely related, though better explained as loans than common inheritance, e.g. Onge beruge 'outrigger' (< PWMP ?*bilug 'type of boat (dugout with outrigger)'; possibly also the precursor of Great Andamanese bil(I)u 'ship'), Jarawa kulu 'jackfruit (Artocarpus heterophyllus)' (< PMP *kuluR 'breadfruit (Artocarpus altilis)'), Jarawa paraw 'raft' (< PMP ?* paraqu ?*padaw 'boat'; further analysed in Section 7.2) and Jarawa ububu 'fish-keeping vessel' (< PAN *bubu'conical bamboo basket trap for fish'). These forms may indicate early stages of cultural contact, predating the problematic relations between the Andamanese and the outside world documented in historical times.

\subsection{India}

The presence of a shared set of words in the vernacular languages of South and Southeast Asia is not a new observation. Early scholars such as Marsden (1812b:xxxvi) and Bonavia (1890:289) already pointed out that the Malays and Indians have several lexical items in common, although the exact history and directionality of these transmissions was not very well understood. In other cases, cultural items and their names were adopted during colonial times, such as Tamil catinki 'clew-line' from Malay sətinggi (ultimately from Portuguese estingue 'brails'). In an article devoted to this particular instance of lexical borrowing, the famous Indologist F.B.J. Kuiper (1962) argues that this word is the only Malay loanword adopted into Tamil. In his etymological dictionary of the Tamil language, Prakasar (1999) fails to notice any Malay influence. In her research on Tamil loanwords in the Philippine languages, Ariokaswamy $(2000: 125)$ proposes four tentative instances of borrowing in the opposite direction, none of 
which strike me as convincing. ${ }^{57}$ On the whole, no scholar has hitherto made a thorough study or compiled a corpus of Malayo-Polynesian loanwords in Tamil and other South Asian languages, although isolated instances of Malay vocabulary adopted into Indian languages can be found scattered across the literature (e.g. 'camphor', 'clove' and 'lime', all addressed in the following chapters). Nevertheless, the multitude of examples given in this and the next chapters compel us to critically rethink the impact of Malay on Tamil and other South Asian languages. As will be demonstrated, numerous names for plants, fruits, spices, aromatic woods and boat terms in the languages of South Asia are pre-colonial borrowings from a Malayo-Polynesian source.

As mentioned in Section 3.1, the first unambiguous archaeological evidence for contact between South and Southeast Asia was the trade in various types of beads. This is supported by linguistic evidence; the Malay word mani(k) 'bead' goes back to Sanskrit mani 'a jewel, gem, pearl'. ${ }^{58}$ In addition, we find various other Malay terms for precious stones and other materials borrowed from Sanskrit, e.g. baiduri 'beryl, opal' (< Sanskrit vaiḍūrya 'a cat's-eye gem'), †galuh 'silver, gem' (< galū 'sort of gem'), guliga 'talismanic or curative bezoar; snake-stone' (< gulikā 'globule; pearl'), intan 'diamond' (< hïra id.), ${ }^{59}$ kaca 'glass' (< Sanskrit kāca id.), kəmala 'luminous bezoar' (< kamala 'rose-coloured'), məstika 'bezoar' (< sphațika 'crystal, quartz'), 60 mutia 'pearl' (< mutya id.), mutiara 'pearl' (< *mutyahāra 'a string of pearls'; Gonda 1973:493), pərmata 'jewel' (< paramatā 'highest position or rank'), rajawardi 'lapis lazuli; pale blue enamel'

\footnotetext{
57 The words given are dilis 'anchovy' (Tamil nettili id.), pala 'fruit' (Tamil palam id.), tulak 'push away' (Tamil tulakku 'to move') and dalan 'road, way' (Tamil tatam id.).

58 Cf. Tamil mani 'gem, precious stone', Old Mon mani 'gem', Old Khmer mani manī 'jewel, gem', Thai manī (มณี)

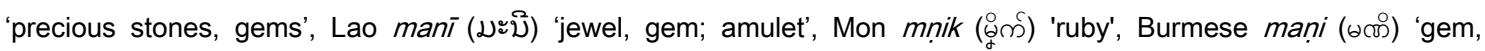
precious stone, jewel', Old Javanese mani(k) 'jewel, gem, pearl; crystal', Balinese manik 'jewel', Acehnese mane? 'coral, beads, cord made of corals', Karo Batak manik 'a long necklace made of beads', Tagalog †manik 'pearls, glass beads'. ${ }^{59} \mathrm{Cf}$. Old Javanese hira 'diamond'. The innovation *Cira\# > Cintan\# is not unique in Malay, cf. jintan 'cumin' (< Sanskrit jira id.). Analogous examples are given in Adelaar (1992a:52 fn. 95).

60 Probably via Old Javanese pastika 'a (powerful) gem' > a-mastika 'like a pastika' (Gonda 1973:493), cf. Sundanese mustika 'prime jewel, the best thing, etc.'.
} 
(< rājāvarta 'lapis lazuli; a kind of diamond or other gem') $)^{61}$ and ratna 'jewel' (< ratna 'a jewel, gem, precious stone'). Several other lexical borrowings point to the Coromandel Coast in particular as a place from which knowledge and ideas of precious minerals reached the Malay World. This is exemplified by several Tamil loanwords, e.g. Malay †beram 'red diamond' (< Tamil vairam 'diamond'), biramani 'coral beads' (< vayira-mani 'bead of gold; diamond'), manikam 'precious stone' (< mānikkam 'ruby, carbuncle'), mutu 'pearl' (< muttu id.), nilam 'sapphire' (< nilam id.), podi 'the dust of gems; very small gems mounted in large numbers to make a glittering show' (< poți 'dust; magical powder; small gem') and pualam 'marble' (< pavalam 'red coral, stony axis of the stem of a gorgonian'). ${ }^{62}$ See Table 8 for an overview of these borrowings.

In return for the precious beads and other exotica from South Asia, the Southeast Asians of pre-modern times had various valuable forest products to offer, including aromatic spices and resins (see Chapter 6), rattan, beeswax and hornbill casks. In addition, the tropical rainforests of insular Southeast Asia housed an enormous variety of brilliant feathered birds. Especially New Guinea and the Maluku Islands are home to an unparalleled variety of parrots and cockatoos. Some of these species were exported to other parts of insular Southeast Asia and beyond. Parrots from Southeast Asia were held at the Chinese court during the Song Dynasty (Wheatley 1959:122-3) and were present in India upon initial European contact (Yule \& Burnell 1903:521-2). Of particular interest were the so-called 'lories', insular Southeast Asian birds known in Malay as nuri luri 'parrot, lory', cf. Javanese nori 'k.o. parrot', Makasar nuri(?) 'k.o. small, red parrot', Bugis nuri 'k.o. parrot', Khmer ṇūrī (ถูกิ) norī (โร็าริ) 'kind of large red

\footnotetext{
${ }^{61} \mathrm{Cf}$. Old Javanese rājāvarta 'a kind of diamond or other gem'. The earliest attestation of Sanskrit räjāvarta is in the Bālarāmāyana, written by the late $9^{\text {th }}$ - early $10^{\text {th }} \mathrm{C}$. CE poet Rājaśekhara. It appears to be a back-formation of the Farsi equivalent läžuward - the same source as our 'lazuli' (< Medieval Latin lazulum) and 'azure' - ultimately from the toponym Lājward (Badahšān Province, Afghanistan), where the stones were mined from antiquity. Malay lajuardi 'lapis lazuli' appears to go back to Farsi lāžuwardī 'of a blue colour, of the colour of lapis lazuli' and may have influenced its doublet rajawardi. Also compare Gonda (1973:427-30) and Casparis (1988:53) on the innovation *Ca\# > Ci\# in IndoAryan borrowings in Malay and Javanese, cf. Malay biji 'seed, grain' (< Sanskrit bija id.), orti 'meaning, significance' (< artha 'sense, meaning, notion'), sunyi 'Ionely, desolate' (< śūnya 'empty, desolate; wholly alone or solitary'), etc. 62 The earliest Malay dictionary has †pawalam 'coral' (Edwards \& Blagden 1931:745).
} 


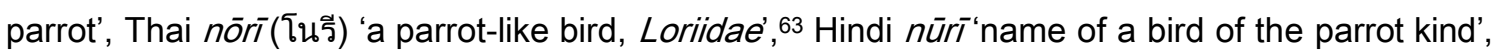
Marāthī nurī'a bird of the parrot kind', Dhivehi nūrī ‘k.o. parrot, lory’ and Farsi nūrī ‘a kind of red parrot; a kind of apricot'. The form does not occur in the epigraphic record of South or Southeast Asia. Judging from the above glosses, the parrot in question can be identified with a reasonable degree of safety as the red lory (Eos bornea) of the Psittacidae family endemic to the northern Maluku Islands. In light of the insular Southeast Asian origins of this bird, it seems reasonable to assume that the languages on the Asian mainland borrowed their words from Malay. As seen above, Malay displays both nuri and luri, the latter most common in the northern Maluku Islands (Oemar 1896:20, Mahdi 2007:192). Mahdi (2007:192) argues that the Malay form may have been adopted from a North Maluku source (e.g. Ternate /uri), where the bird is endemic. ${ }^{64}$ Both forms are attested in European accounts of the colonial period, in which the form /uri gradually replaced nuri (cf. Scott 1897:84, Yule \& Burnell 1903:521-2, Mahdi 2007:192). Cockatoos (Cacatuidae spp.) were also exported from the eastern archipelago to the Asian mainland. Their Malay name kakaktua, which appears to be an onomatopoeic imitation of the bird's call (cf. Kern 1889b:1215-6), was adopted as Javanese kakaktuwak, Thai kratûa (กระตั้ว), Bengali kākātuỳā, Hindi kākātūā, Oṛiyā kākatuā, Marāṭī kākākavvā, Tamil kākkattuvān and Dhivehi takatuvā.

\footnotetext{
63 This word is not in daily use, but common in Thai poetry (cf. Hartmann 196:181).

64 There is probably no etymological relation with the homophonous Arabic word nūr-ī 'luminary, luminous, like light', since the parrot in question is, in most cases, of red plumage. Anecdotally, the phrase nür-i-Muhammad 'the Light of Muhammad' used in Persian Sufism had at one point been misinterpreted as nuri Muhammad 'Muhammad's parrot' in the Malay dialect of Patani, so that the parrot became a symbol of religious conscience (Annandale 1906:334-5).
} 
Since a considerable number of the insular Southeast Asians who ventured into the Bay of Bengal were accomplished sailors, nautical terminology is an important other domain to search for Malayo-Polynesian loanwords in South Asian languages. Chapter 7 deals with the dispersal of boat- and ship-building techniques and demonstrates a certain degree of insular Southeast Asian influence on local traditions. With regard to marine life and fishing techniques,

Figure 7: yellow-crested cockatoo (Cacatua

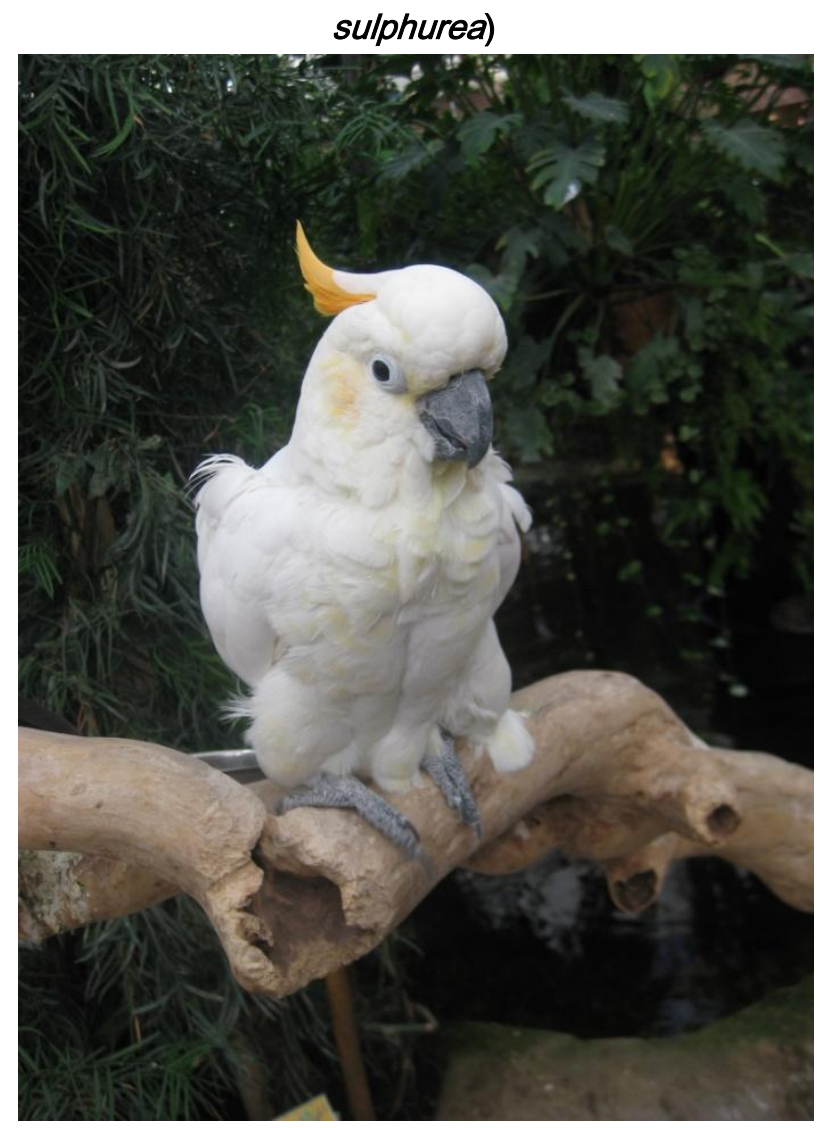

the lexical evidence is less compelling. I have not encountered a great deal of similarity between the fish names of South and Southeast Asia, which is understandable in view of the fact that knowledge about fishing predated cultural contact between these regions. One example worth attention, as first pointed out by Allibert (1984:191), is the Malay word malung 'conger eel', which appears to have been borrowed as Tamil malanku 'true eel' (pace Burrow \& Emenau 1984 \#4737) and Malagasy amalona 'an eel'. 65 The Malay language

also features two fish names borrowed from Tamil, as has been pointed out by Maxwell (1921:57, 66); bawal 'pomfret' (< Tamil vavvā/id.) and kalui' 'a freshwater perch (Osphronemus olfax)' (< Tamil kalavai 'Indian rock-cod'). In addition, Hornell (1924b:326, 334) highlights the South Indian practice of catching fish by means of a blowgun, known as tūmbitān in Malayālam and cerikuttān in Tamil, arguing that this name goes back to Malay sumpitan (also səmpitan) and that the practice is a Southeast Asian introduction. In several regions of Southeast Asia,

65 Allibert also assumes an Asian etymology for several African attestations, cf. Swahili mhunga 'eel', Comorian mhunga 'eel, conger', etc. but these forms go back to proto-Bantu * kúngá 'eal'. 
most notably the island of Borneo, blowguns and dart poison are used to hunt small game and in warfare. Indeed, the Sri Lankan Cülavamisa chronicle specifically accounts that Malay invaders of the island used poisoned arrows during their assault (Kern 1896:245, Geiger 1952/2:151-3). Since bamboo and other vegetal products yielding hollow reeds are abundant across Southeast Asia (as well as southern China and Northeast India), it would be very difficult to determine from which region the blowgun was introduced into South India without the corroborative linguistic data. Fortunately, in this case, we can safely attribute the introduction of a certain type of blowgun, or perhaps all blowguns, to Malay-speaking communities. The Malay word sumpitan has also been borrowed into several insular Southeast Asian languages (Blust 1976:34-5) and into Arabic as zabațānaẗ 'blowgun', Farsi zabtānaẗ id. and several European languages (cf. Yule \& Burnell 1903:795, Hornell 1924b:334 n. 2).

Another well-known weapon manufactured in and exported from the Malay World is the famous kəris or 'kris'. The kəris is an asymmetric, double-edged dagger consisting of parallel, alternating strips of iron alloy. The highest valued types of kəris incorporate layers of meteoric

Figure 8: Balinese kəris with sheath

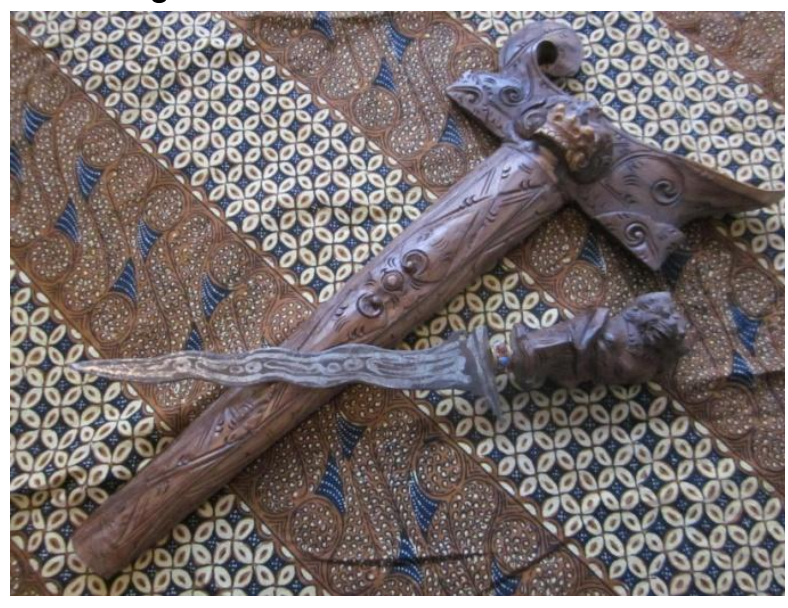

iron and are hence attributed with celestial and magical properties. Such legendary weapons can take years to complete and are expensive rarities. The name of the weapon may go back to either Old Javanese $k(\partial)$ ris or Malay kəris, 66 from which it was borrowed as Tausug kalis, Toba Batak horis, Makasar kurisi, Khmer

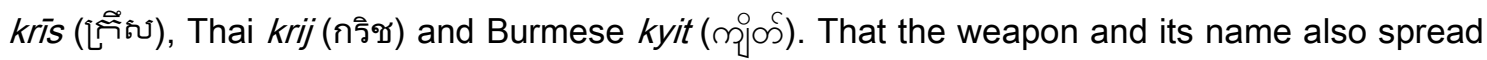
across South Asia is testified by Sinhala kiriccaya kinissa 'poniard, dagger', Dhivehi kiris 'dagger', Tamil kiricu 'Malay dagger, small double-edged sword', Malayālam kiriśu kiricu

\footnotetext{
66 There may be a semantic relation with Old Javanese iris 'to cut', garis 'stripe, graze', laris 'straight line' or baris 'line' (cf. Malay (h)iris 'to slice', garis 'scratch, line', laris 'in demand', baris 'line'). In fact, we do not know what kind of weapon or utensil the original kəris had been and its present shape may be relatively modern.
} 
'creese, dagger', Telugu kirusu 'a small double edged sword', Oṛiyā kiric 'small straight sword hanging from the belt; dagger', Hindi kir(i)c 'a sword, especially a straight one to thrust with' and Pañjābī kirc 'a sword, especially a rapier'.67 The /c/ in some of the South Asian languages suggests that the transmission took place via Tamil, in which ${ }^{*} \mathrm{~s}>\mathrm{c}$ is regular. The word is unattested in Sanskrit literature, so that it is safest to assume a relatively late transmission.

An important trade-related term attested widely across the Bay of Bengal is the word for 'warehouse' or 'godown': Malay gudang, Thai kudan் (กุดัง) kōdan் (โกดัง), Lao kudan் (รุถัง)

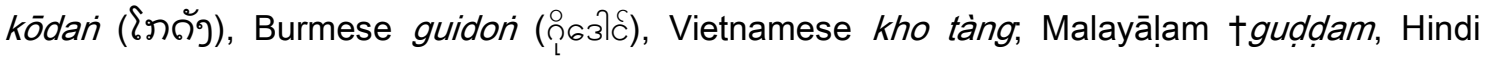
†gudām, Bengali †gūdam, Końkaṇī †gudãv (Dalgado 1913:87); Dhivehi gudan, Nepāli godām, Sinhala gudama, Tamil kutām and Swahili godoni (the latter perhaps from the English). It has been argued that this form is essentially the Portuguese rendering (†gudão) of Malay gədung 'stone building' (cf. Schuchardt 1891b:288, Jones 2007:99), but this theory leaves unexplained the occurrence of gudang in pre-Portuguese Malay literature. ${ }^{68}$ The superficial similarity between these forms and Farsi humdān 'a repository for jars; a wine-vault; a potter's or brick maker's kiln' appears to be due to chance resemblance. The word is not attested in the palaeographic record of Sanskrit or other languages and a scenario of distribution during the colonial period appears most likely. Yule \& Burnell (1903:381) suggest that the ultimate precursor may be a Dravidian form, cf. Tamil kițaniku kițtaniki 'warehouse, storehouse, etc.', Malayāḷm kițaninu, Kannaḍa gaḍaniga gaḍanigu giḍ̣anigi, Tulu gaḍanigů and Telugu giḍ̣anigi id. (Burrow \& Emenau 1984 \#1525). However, the degree of fluctuation in the wordfinal vowel in these attestations also suggests borrowing. We further find Old Khmer ghläna glāin glan் 'storehouse, repository', rendered as Khmer ghlāmin (พ̛ํํำ), Thai glan் (คลัง), Lao

\footnotetext{
${ }^{67}$ These forms are unrelated to Turkish kılıç 'a sword' (cf. Scott 1879:67-70 contra Yule \& Burnell [1886]1903:274), for the latter goes back to proto-Altaic *kăle 'knife, to cut' (Starostin et al. 2003/1:636).

68 According to lan Proudfoot's Malay Concordance Project (http://mcp.anu.edu.au/ s.v., accessed Feb 2011), the word is first attested in the Hikayat Bayan Budiman (cf. Winstedt 1920), dated 1371. Needless to say, surviving copies of this manuscript may contain "corrections" based on the scribes' understanding of the text, so that the word gudang might not be pre-colonial after all.
} 
gari (ถั)) and Cham galan் (๘ธ์). I have no means of saying which attestation preceded the others, but their similarity in form and meaning is striking and merits further research.

The Malays also asserted some culinary influence on parts of the subcontinent, presumably in more recent times. A certain type of sweetmeat known in Hindi as gulgulā 'sweet cakes fried in butter' appears to be a borrowing from Malay gula-gula 'sweets' ${ }^{69}$ Likewise, the name of a layered pudding known in Konkkan̄i as bebinika comes from Malay (bə)bingka 'cake made of rice flour, coconut-milk, egg and palm-sugar'.70 The word dodol, found in Końkaṇi and Sinhala, refers to a toffee-like sweetmeat taken from Malay dodol in the same meaning. The limited distribution of these three terms for confectionary strongly suggests that the transmission took place during colonial times. We may also call attention to the spicy seafood dish known as

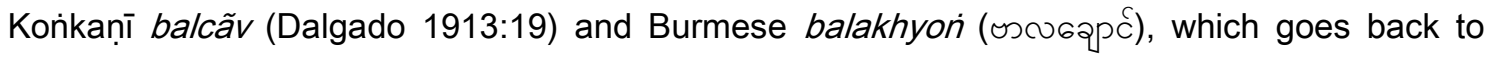
Malay bəlacan 'shrimp-paste', presumably through Portuguese bal(i)chão. In the same way, Malay sambal 'chilli-based spicy sauce or paste' was borrowed as Tamil cāmpal and Sinhala sambōla id. ${ }^{71}$ The predominance of (South American) chillies (Capsicum spp.) in all versions of this dish again supports a relatively late transmission. We know that the Dutch frequently "shanghaied" Indonesian ship crew during the early colonial period, some of whom ended up in India (Raffles 1978/2:201-2 fn.). This may account for some of the lexical transmissions mentioned in this section, although other instances of borrowing are clearly pre-modern. Nonetheless, the difficulties in periodising cultural contact become abundantly clear upon examining the relations between India and Southeast Asia, which cover a time span of three millennia.

\footnotetext{
69 This is the reduplicated form of Malay gula 'sugar', which ultimately goes back to Sanskrit guda gula 'raw or unrefined sugar, molasses' (> Hindi gur id.). Hence, Hindi gur and gulgulā are lexical doublets, the latter (re)introduced via Malay.

70 Cf. Javanese wingko, Tagalog bibingka, Cebuano bibingka, Bikol bibíngka, llokano bibíngka and Chamorro bibenka, all referring to types of rice flour desserts.

71 This Malay word is itself of somewhat obscure origin. Neither the Malay form nor its Old Javanese cognate sambəl, of uncertain meaning, are attested in early literature.
} 


\subsection{Sri Lanka}

With its abundance of valuable export commodities, such as precious stones, turtle shells, ivory and spices (e.g. black pepper and cinnamon) and a myriad of bays and natural harbours, Sri Lanka functioned as an important and strategically situated nexus of Indian Ocean trade. The island is well documented in Graeco-Roman and Middle Eastern literature (cf. Weerakkody 1997) and was also known to Southeast Asians. During colonial times, commercial and Islamic connections between Sri Lanka, southern India and the Malay World were well-established (cf. Sopher 1965b:17), although we do not know the extent to which these formed a continuation of older networks. Archaeological evidence for prehistoric contacts between Sri Lanka and Southeast Asia is as yet largely negative. However, the findings of carved paddle impressed pottery have been interpreted as the result of interethnic contact with Southeast Asia (Solheim \& Deraniyagala 1972, Selvakumar 2011). Other elements occasionally claimed to be premodern Southeast Asian introductions include burial urns, terraced rice cultivation and outrigger canoes (e.g. Wijesekera 1949:22, 45). However, there is need for caution against simplified scenarios of diffusion and the transmission of these elements cannot be seen in isolation from South India. In later, better documented stages of Sri Lankan history, we see that contacts with Southeast Asia were established and maintained by virtue of the Buddhist religion. The famous $4^{\text {th }}$ C. CE Chinese pilgrim Făxiăn used Sumatra as a stopover to travel from India and Sri Lanka back to China and is the first to document the strong ties across the Bay of Bengal. From that period onwards, Sri Lanka appears to have played an important role in the proselytisation of Theravāda Buddhism in Southeast Asia. The late $8^{\text {th }}$ C. CE Ratu Baka inscription in Java, for example, mentions contacts between local Buddhist monks and their Sri Lankan colleagues at a time when the former appear to have regularly visited the Abhayagiri monastic centre at Anurādhapura to receive teachings (Casparis 1961:247-8).

These commercial and religious networks were followed by political contacts. Since at least the mid-9th $C$. CE, the Sinhalese kings maintained friendly relations and marital bonds with 
the Sumatran Śrī Vijaya Empire (Nicholas \& Paranavitana 1961:150, Paranavitana 1973:13). There is $10^{\text {th }} \mathrm{C}$. CE epigraphic evidence documenting a continued tradition of intermarriage between Sinhalese and Malay royalty (Paranavitana 1966b). Later contacts between Sri Lanka and Śrī Vijaya and other regions in Southeast Asia were revitalised under the Polonnaruva kings (cf. Sastri 1962). All of this raises questions over the extent to which the relations between Sri Lanka and Southeast Asia were also of an expansionistic nature. After all, the $10^{\text {th }} \mathrm{C}$. CE Arab historian and geographer al-Mas'ūdī goes so far as to call Sri Lanka a Malay (Zābağ) colony, a claim resonating in the work of the early $13^{\text {th }} \mathrm{C}$. CE Chinese author Zhào Rǔguā (Hirth \& Rockhill 1912:73). As mentioned briefly in the previous section, two Malay military invasions of Sri Lanka took place in the late $13^{\text {th }}$ C. CE. The Sri Lankan Cülavamsa chronicle and the Tamil Jațāvarman Vira Pāndya inscription document an unsuccessful raid by Malays (Jāvaka, Tamil: Cāvakaṇ) under king Candrabhānu (believed to hail from the state of Tāmbralinga on the Thai-Malay Peninsula), ${ }^{72}$ who was defeated by the Sinhala king Parākramabāhu II, fled to the city of Jaffna and ruled there for several more years (cf. Kern 1896, Cœdès 1927, Sastri 1937:261, Geiger 1952/2:151-3, Majumdar 1963:133-4). Place names such as Cāvakaccēri 'Malay settlement' and Cāvankōț̣ai 'Malay fort' in Jaffna and Jāvakakōtțē 'Malay fort' on the Sri Lankan mainland still attest to the pre-colonial Malay presence on the island (Codrington 1994:78). On the other hand, a series of claims that the famous Sri Lankan Kalinga dynasty was of Malay origin (Paranavitana 1960, 1966a, 1966b) has been received with a considerable degree of scepticism and regarded as premature and methodologically unsound (e.g. Gunawardana 1967, Indrapala 1967, Sirisena 1971, 1978, Wolters 1979:9).

The pre-colonial contacts between Sri Lanka and the Malay World are not as clearly reflected in the linguistic data as one would expect. In his monumental work on Sanskrit and other South Asian loanwords in the languages of insular Southeast Asia, Gonda (1973:80-1) only proposes Malay bəlanja 'disbursement, expenditure, etc.' as a possible Sinhalese loan through Pali valañja 'trace, use, that which is spent or secreted', the latter being regarded as a

\footnotetext{
72 The state of Tāmbralinga is presumably identical to Mā-Damālingam in the Tamil Tanjore inscription (Lévi 1923:45).
} 
dialectal form under the influence of Sinhala (Rhys Davids \& Stede 1966:603). I propose three tentative additions. Malay kapuk 'tree cotton' appears to go back to Sinhala kapu 'silk cotton tree; cotton', itself derived from OIA *karpā'sa 'cotton' through +kapaha (cf. Turner 1966 \#2877). Malay rəbana 'tambourine' may be related to Sinhala rabāna id., whose ultimate origins appear to be Arabic 'arabānaẗ 'a drum, a tambourine'.73 Malay karabu 'ear-stud' is presumably from Sinhala $k(a) r a ̄ b u$ 'clove, earring'. In Dutch, this ear ornament was known as †oor-krab (oor = 'ear') (Oemar 1896:20, Gonda 1941:166); cf. Minangkabau kurabu 'earrings', Acehnese krabu 'ear stud', Toba Batak kurabu 'a golden ear ornament' and Angkola-Mandailing Batak kurabu 'ear ornament'. Based on the peculiar shape of this ear ornament, the Sinhala meaning of 'clove' was the original one, presumably borrowed from Portuguese cravo id. (see Section 6.1). Hence, this clove-shaped ear ornament must have spread from Sri Lanka to the Malay World during colonial times. Finally, we may call attention to Malay muara 'estuary, river-mouth', which Adelaar (1992a:52) reconstructs to an earlier muhara(?) 'river-mouth' (cf. Old Javanese muhara 'river-mouth, estuary'). ${ }^{74}$ Jonathan Rigg (1844:244-6, 1862:286) connects this word to Sinhala, which indeed displays the lookalikes muvadora mōdara mōya 'mouth of a river, place where a river disembogues'. The Sinhala attestations regularly go back to OIA *mukhadvāra 'mouth opening', cf. Tamil mukattuvāram 'mouth of a firth or river'. Instead of a Sinhala origin of the Malay and Old Javanese attestations, I would argue that the latter go back to MIA * muhavāra id. ${ }^{75}$

\footnotetext{
${ }^{73}$ Southeast Asianists sometimes explain this word as a derivation of Arabic rabbanā 'our Lord', a vocative used at the commencement of an Islamic prayer ( $\left.d u^{\prime} a \bar{a}\right)$ or a religious hymn (našĩd) accompanied by this type of percussion (e.g. Kunst 1973/1:218). This etymology is implausible on account of several South Asian attestations; cf. Farsi 'arabānä̈ 'tambourine', Tamil îravānam and Malayālam arabana id. The word has also been borrowed as Cham rapbana (5Mv̌̌s)

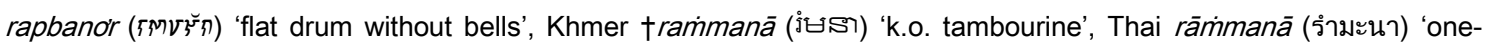
sided drum with shallow body', Minangkabau rabana 'tambourine', Malay (Brunei dial.) rəpana and Makasar rabana id. Tambourines and their (related) names have also been documented in the Maluku Islands (Nixdorff 1971:117). Judged from its form, the word may have been introduced into Arabic as well, but its ultimate source is unknown to me (but cf. Somali durbaan 'drum'). At present the instrument is mostly associated with devotional Islamic music in both South and Southeast Asia.

${ }^{74}$ The more common Malay word for 'river-mouth, estuary' is kuala.

75 Not found in Turner (1966), but regular according to the Indo-Aryan sound innovations.
} 
Lexical transmissions in the opposite direction have received only slightly more attention. Despite a currently disproven claim that Sinhala should be classified as a MalayoPolynesian language (Lassen 1867:553, 557), the lexical similarities between MalayoPolynesian languages and Sinhala remained unnoticed by the earlier philologists, with the notable exception of Jonathan Rigg (1844:244-6). The etymological dictionary of Sinhala by Geiger (1941) only marks the word for 'sail' (ravala, pl. ruval) as Indonesian in origin (cf. Section 7.5). Later scholars present more detailed lists of Malay loans in Sinhala (Gunasékara 1962:382, Sannasgala 1976:96-107, Hussein 2001:146, Jayasuriya 2002:54-7). Many of the proposed loanwords, however, are borrowed into Malay as well from languages such as Tamil, Hindi, Farsi, Arabic or Portuguese. Therefore, they reflect interethnic contacts in a wider Indian Ocean sense, but shed little light on the direct contacts between Sri Lanka and the Malay World. Other tentative etymologies, such as the oft-cited derivation of Sinhala varāya varāva 'sea port' from the Malay toponym Barus, are methodologically unsound. ${ }^{76}$ The remaining Malay loanwords in Sinhala are listed in Table 4:77

Table 4: Malay loanwords in Sinhala

\begin{tabular}{l|l}
\hline Sinhala & Malay \\
\hline bilin 'bilimbi (Averrhoa bilimbı)' & bəlimbing id. \\
\hline dodol 'k.o. sweetmeat' & dodo/ id. \\
\hline dummala 'k.o. resin; a tree yielding resin' & damar 'dammar, resin, torch' \\
\hline dūriyan 'durian (Durio zibethinus)' & durian id. \\
\hline gætissi 'young girl' & gadis 'marriageable girl' \\
\hline hambāna 'large boat, Malabar vessel, dhóney' & sampan 'shoe-boat, boat for harbour use' \\
\hline kiricca-ya kinissa 'poniard, dagger' & kəris 'the well-known Malayan dagger' \\
\hline lādā 'betel pepper (Piper betle)' & lada 'pepper (gen.)' \\
\hline mærigus 'mangosteen (Garcinia x mangostana)' & †manggus id. \\
\hline olu-va 'head' & hulu 'head, upper portion' \\
\hline $\begin{array}{l}\text { pāru-va 'flat-bottomed boat', paḍavva 'boat, } \\
\text { lighter' (further analysed in Section 7.2) }\end{array}$ & pərahu 'undecked native ship' \\
\hline pīha-ya 'knife, chopper' & pisau 'knife' \\
\hline
\end{tabular}

\footnotetext{
${ }^{76}$ This form is attested as varaya in medieval Sinhala texts and may go back to Dvārakā, the name of a famous north Indian port (Paranavitana 1973:13).

77 Attempts to derive Sinhala bān 'word used in addressing equals or inferiors' from Malay bang 'elder brother or cousin' and han̆bā 'haste, speed, rapidity' from hambat 'to pursue' (Disanayaka 1978:56) seem less convincing. As for grammatical influence, Disanayaka (1978:56-7) suggests that reduplication and the use of the imperative suffix -la in Sinhala may be of Malay origin, but both examples are relatively widespread cross-linguistically and more research is needed to verify these claims.
} 


\begin{tabular}{ll}
\hline puka 'anus' & pukas 'nudity, improper or indecent exposure' \\
\hline pukkī'indecent word for females' & puki 'female genitals' \\
\hline $\begin{array}{l}\text { ran̆butan 'rambutan (Nephelium lappaceum)' } \\
\text { sambōla 'chilli-based spicy sauce or paste' }\end{array}$ & rambutan id. \\
\hline $\begin{array}{l}\text { saroma 'native dress made of cloth the } \\
\text { ends of which are joined together' }\end{array}$ & sarung 'the typical Malay long kilt or skirt' \\
\hline
\end{tabular}

I would tentatively add the following Sinhala words to this series: kankun 'water spinach (Ipomoea aquatica)' (< Malay kangkung id.), katta-kumancal 'frankincense' (< kəmənyan 'benzoin'; Sinhala katța = 'piece of wood'), lavanga 'cloves' (< bunga lawang id.; Malay bunga = 'flower'), lima-dehi 'citron (Citrus medica)', (< Malay limau 'citrus fruit'; Sinhala dehi = 'citrus fruit'), namnam 'namnam (Cynometra cauliflora)' (< namnam id.), sau-hāl 'sago' (< Malay sagu id.; Sinhala hāl = '(unboiled) rice'), sēra 'vegetable plant used especially with beef' (< sərai 'citronella grass, Cymbopogon spp.'), siribō 'betel variety' (< (dial.) †sirih buah 'betel variety, (Piper betle var. Siriboa)'), ${ }^{78}$ tīvra 'tin' (< timah 'tin'; further analysed in Section 3.5) and variga 'tin' (< Bangka 'name of an island famous for its tin'; further analysed in Section 3.5). In addition, Sinhala underwent some influence from regional insular Southeast Asian languages. Sinhala mæliyam 'gum, glue, any glutinous substance exuding from trees or plants on incision' appears to go back to Javanese mənyan 'benzoin'. If this is true, it is a doublet of the Malay loan kattakumancal 'frankincense' mentioned above. Further, the famous textile fabric known as Javanese batik (Malay: batik) was borrowed as Sinhala batik batik, Javanese bocah 'child' was adopted as $b \bar{o} c \bar{a} \sim ~ b u \bar{c} c \bar{a}$ 'appellation for little child' and Minangkabau girek-girek 'areca nut pounder' became Sinhala gira-ya girē 'k.o. knife used especially for cutting areca nuts' (Sannasgala 1976:104-5).

It is very difficult to determine whether the transmission of these Malay loanwords took place before or during the colonial period. Since the mid-1 $7^{\text {th }}$ C. CE, the Dutch introduced large numbers of Malay-speaking mercenaries, exiles, convicts and slaves from insular Southeast Asian regions - particularly the eastern islands - to Sri Lanka, who have presumably introduced the vast majority of the Malay loanwords into Sinhala. The Sinhala word tē 'tea' is an obvious

78 Dutch sources cite this form for different vernacular Malay varieties (cf. Scott 1897:123, Mahdi 2007:108). In all likelihood, its transmission took place during the colonial period. 
example of a colonial-era transmission, cf. Malay teh and Dutch thee, ultimately from Southern Min tê (茶) (cf. Mahdi 2007:216). One example that predates the colonial period is the use of the suffix - $n d a$ in Sinhala to address kinship members, which is found in $13^{\text {th }}$-century literature such as the Saddharma-Ratnāvaliya and Butsarana (Ariyapala 1956:307-8). This is essentially the politeness suffix -nda used in Malay and related languages for the same purpose (e.g. Tuuk 1862:120 n.1). The presence of /s/ in certain loanwords, e.g. in san̆bōla, saroma and gæțissi 'young girl', hints at a relatively recent acquisition. Originally this consonant would have changed into /h/, as demonstrated by hambāna, piha-ya and perhaps puka (< ${ }^{+}$pukah). Further research on literary Sinhala could shed more light on the periodisation of the Malay lexical influence, but very little in that direction has hitherto been carried out. In the meantime, it is safest to assume that most Malay words in Sinhala have been transmitted during the colonial era.

\subsection{The Maldives}

Like Sri Lanka, the Maldives played an important role in the commercial networks of the Indian Ocean. Situated southwest of the Malabar Coast, the Maldives (including the island of Minicoy, which presently belongs to India) form a double chain of island atolls extending almost $1000 \mathrm{~km}$ from north to south. Traditionally, the Maldivians were famed for their skills in fishing, ropemaking, weaving, boat-building and coconut cultivation. The capital of Malé, situated on the northernmost island of the Kaafu Atoll, was an important entrepôt frequently called on by foreign ships for trade and provisions. The Maldives formed an important link in the maritime routes connecting Southeast Asia to the Arabian Peninsula during the southwest monsoon winds in the winter. As the southeast monsoons in the summer enabled direct eastward journeys from the Middle East to the South Asian mainland, missing the Maldives, the shipping on these islands was almost exclusively westbound (Forbes 1981:78-81). Therefore, the Maldives could have been used as a stopover for Southeast Asian sailors on the way to Madagascar, as envisioned by Shepherd (1982). The Maldives have been continuously inhabited for at least two millennia 
(Mohamed 2002). From the very beginning of human settlement, the islands were in contact with Sri Lanka; the Dhivehi language is most closely related to Sinhala. In addition to a strong Sinhalese element, the islands underwent profound influence from the Malabar Coast and the Middle East, which eventually resulted in the large-scale conversion to Islam in $1153 \mathrm{CE}$, supplanting earlier Buddhist and animist beliefs. ${ }^{79}$

Although most scholars see little reason to assume a direct cultural impact from Southeast Asia on the Maldives, there are scattered pieces of evidence reflecting a history of interaction. As argued before, the Maldives are

Figure 9: map of the Maldives easily reached from Sumatra during the southwest monsoon, an observation also made by early travellers such as Mǎ Huān, Tomé Pires and Pyrard de Laval (e.g. Manguin 2010:270-2). In the early $16^{\text {th }}$ C. CE, Duarte Barbosa documented ships from various Southeast Asian Muslim nations in the harbour of Malé (Gray 1887/1:479, Forbes 1981:80). In historical times, the Maldives were frequently visited by Javanese, Malay and Acehnese traders. On the island Fuvahmulah, Southeast Asian slave raiders were notorious for kidnapping young children, leading the population to settle inland (Mohamed 2005:41). The Maldives also feature on a 19th $\mathrm{C}$. CE Bugis sea chart (Roux 1935:707), 80 but since this chart situates the islands near the Nicobar archipelago, it is uncertain

\footnotetext{
79 Some of these earlier beliefs may still be alive. Leyden (1808:216) calls attention to the Maldivian practice to turn adrift a small bark loaded with offerings to their deities, a ritual also carried out by the Bajau and several other groups in insular Southeast Asia.

80 This chart uses the name Maladiwa, cf. Malay Baldewa, (Indonesia) Malədewa, Acehnese Pulo Diwa (pulo = 'island') and Sinhala Maldiva.
} 
how accurately the $19^{\text {th }}$-century Bugis knew the Maldives. The pre-Islamic / la Galigo poem of Bugis mythology, however, contains references to the Seychelles as the end of the world, suggesting at least some knowledge of this part of the Indian Ocean in pre-modern times. ${ }^{81}$ The presence of Malay communities in the Maldives is also reflected in the toponymy. The easternmost islands of the present-day Lhaviyaani Atoll are known as Jãva Kara 'the Malay coast', a name evidently connected to trade with Southeast Asia (Bell 1882:71, Mohamed 2004:67). The Chagos Archipelago south of the Maldives is known in Dhivehi as Fölavahi, the first element of which might go back to Malay pulau pulo 'island' (cf. Gray 1887/1:296, Maloney 1980:113). Although archaeological research has not yet yielded any supportive data, Manguin (2010:270) outlines the possibility that the Chagos Islands were used as a stopover during the seaborne journeys from insular Southeast Asia to Madagascar. Such contacts may also have led to the adoption of Southeast Asian maritime technology in the Maldives (see Chapter 7). It remains unclear to what extent insular Southeast Asian sailors have also settled down and intermarried with the indigenous population of the Maldives and Minicoy. Marked Southeast Asian phenotypic features have been reported - impressionistically - among the populations of Fuvahmulah (Mohamed 2005:41) and Minicoy (Varadarajan 1998:39). With this in mind, genetic research on these populations could reveal more about their biological lineages and possible Southeast Asian admixture.

Turning to the linguistic implications of contact between Southeast Asia and the Maldives, we may call attention to the export of dried skipjack tuna (Katsuwonus pelamis), a very common Maldivian food staple. Its Dhivehi name is kalu-bila-mas (lit. 'black-bonito-fish') or, in vernacular, komboli-mas (cf. Bell 1882:93). This seafood delicacy was introduced to parts of the Middle East, India and Sri Lanka. It was documented as kulb-al-mās by Ibn Bațūtatä and became known as 'cobily mash' in Indian English (Yule \& Burnell 1903:223-4). The Coromandel Coast became an important centre of re-export to Southeast Asia, as reflected in Tamil

\footnotetext{
81 The text describes the islands where the pao jengki (Lodoicea maldivica) grows (cf. Pelras 1996:75, Manguin 2010:274). This is an extremely rare palm tree, native only to the Seychelles, with enormous bilobed coconuts (coco de mer) that were highly esteemed throughout the Indian Ocean for their presumed medicinal function.
} 
kumpala-mōcu, Malay kəmbal mas and Acehnese kumamaih (cf. Djajadiningrat 1934/1:702). On lexical transmissions in the opposite direction, Nell (1881:121) calls attention to Dhivehi †abaku 'nail'82 (< Malay paku id.) and vali 'knife' (< pisau wali 'a small lancet-like knife used for delicate carving'). The latter, however, presumably does not go back to Malay, but to Tamil vāl 'sword, etc.' or vāli 'swordsman, arrow'. In addition, Gray (1887:190-5) lists Dhivehi kiris 'dagger' (< Malay kəris 'the well-known Malayan dagger') and timara 'tin, lead' (<+tim(ə)rah 'tin', further analysed in Section 3.5). Two more tentative borrowings are proposed in the Etymological Vocabulary of Dhivehi (Maniku 2000): Dhivehi ñamñam 'namnam (Cynometra cauliflora)' (< namnam id.) and kanbali 'sheep, ram, ewe, lamb' (< kambing 'goat'). The last etymology is incorrect; the Dhivehi form goes back to Tamil kampali 'woollen blanket, woollen stuffs, etc.'.

In addition, the following Dhivehi words strike me as Malay loans: addō(i) addōyē 'exclamation, cry of pain' (< Malay aduh adu(ha)i 'exclamation of pain'), Asi`'Aceh' (< Aceh id.), aturanī'arranges in order' (< atur-an 'arrangement, order'), bulibuli 'small glass bowl with lid' (< buli-buli 'a small flask or bottle'), buri 'anus, etc.' (< burit 'buttocks'), danmaru 'torch' (< damar 'dammar'), dolan̆gu 'large, metal tray for food' (< dulang 'wooden tray, base or platter'), fui 'female pudenda' (< puki id.), giligili 'tickling' (<gəli-gəli 'ticklish'), kankun 'water spinach (Ipomoea aquatica)' (< kangkung id.), karā kareak 'watermelon (Citrullus lanatus)' (< kəra(h)i 'a sort of melon or cucumber'), kumunzāni 'incense' (< kəmənyan 'benzoin'), luñbō 'lime fruit (Citrus aurantiifolia)' (< limau 'citrus fruit', further analysed in Section 5.5), nūrī 'k.o. parrot, lory' (< nuri id.), ranbustānu 'rambutan (Nephelium lappaceum)' (< rambut-an id.), riyau riyāa 'sail' (< layar id., further analysed in Section 7.5), sāgu 'sago' (< sagu id.), sunpā 'unlucky, ill-omened' (< sumpah 'oath, ordeal, imprecation') and takatuvā 'cockatoo' (< kakaktua id.). ${ }^{83}$

Even more so than the export of coir, coconuts and dried fish, the early Maldivian economy depended upon its natural abundance of money cowries. Cowries are small sea snails

\footnotetext{
82 The word for 'nail' currently in use in the Maldives is mohoru, while abaku is recorded in earlier sources (cf. Gray 1887/1:179).

${ }^{83}$ Dhivehi ipil-ipil 'white leadtree (Leucaena leucocephala)', known under the same name in Tagalog, must be a relatively recent borrowing, as this plant hails from the New World.
} 
whose shells were used around the world as a currency in pre-monetary economies and, until now, as ornaments throughout the Indo-Pacific region. Of the various cowry species, the money cowry (Monetaria moneta) was regarded highest in rank, followed by the ring cowry $(M$. annulus). Other, cheaper types of cowries were used for less commercial purposes. The Bajau sailors of northern Borneo, for example, use cowries as net weights on their fishing boats (Sather 1997:105). The use of various types of cowry shells was also extensive and widespread in pre-colonial Africa (Hiskett 1966, Mitchell 2005:118-9). ${ }^{84}$ In addition, the use of cowries in prehistoric southern China is documented in the earliest available textual sources (Pelliot 1959:533). Despite a gradual replacement by metal coins during the first mill. BCE, cowries remained an important component of the southern Chinese economy into medieval times (Wicks 1992 passim, Vogel \& Hieronymus 1993). In Northeast India, too, cowries were used into historical times, which obviated the need for various ruling dynasties to issue new coins (Sircar 1983:1). Since southern China originally overlapped with the north of mainland Southeast Asia in terms of culture, history and economy, it has been argued that Chinese bei (贝) 'cowry shell' was taken from a Southeast Asian source (Zhang 1989:90);85 cf. Cham bior

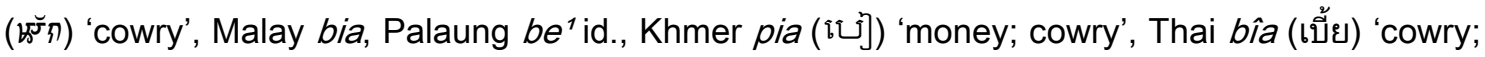
cowry shell money' and Lao bîa (ชั้J) 'cowry shell'. The ultimate origins of this word remain obscure to me. If the Chinese did borrow it from a southern source, the term was later reintroduced into Southeast Asia to refer to a certain Chinese coin, cf. Khmer $p^{/ / a e}$ (ััษั) 'ancient monetary unit', Thai $p æ$ (แปะ) 'a small Chinese coin of low value', Lao bî (Uิ้) 'small coin' and Vietnamese bối 'cowry, precious shell formerly used as money' (Pou \& Jenner 1973:10).

Another word for 'cowry' that spread across linguistic boundaries has been reconstructed as PMP *buliq 'cowry shell', with attestations across insular Southeast Asia and Oceania (Blust 1995 s.v.). Although the most common Malay words for 'cowry' are bia, cungkak and təngkuyung, I have also encountered the vernacular trade name kərang buli (unattested in

\footnotetext{
84 See Hogendorn \& Johnson (1986) on the use of cowries in Africa during the colonial period.

${ }^{85}$ An acquisition in the opposite direction, i.e. from China into Southeast Asia, is favoured by Pelliot (1959:534) and Pou \& Jenner (1973:17).
} 
the dictionaries). In addition, Malay exhibits buli-buli bəbuli 'small stoppered vial or flask of glass or porcelain'. ${ }^{86}$ Based on their translucent qualities, a semantic shift from 'cowry' to 'porcelain' is not difficult to envision. In fact, when the Europeans became acquainted with Chinese porcelain, they too adopted the Italian word porcellana 'cowry' for the new concept. Moving on to the terminology used in the Maldives, we find Dhivehi boli 'cowry', (Huvadhoo Atoll) bōlu id. and Sinhala bolla 'skull; shell, cowry'. ${ }^{87}$ The striking resemblance between the Dhivehi forms and those found in the Malayo-Polynesian languages was first pointed out by Pelliot (1959:555), who refrained from proposing a directionality of transmission. Based on the wide attestation of *buliq reflexes in the Pacific, an eastward dispersal of this term seems excluded. The question then remains why the Maldivians, whose islands are located at the very centre of the trade in money cowries, would adopt an insular Southeast Asian word for an indigenous concept. I would propose that the Maldivians were initially unaware of the great economic value of money cowries. Presumably, merchants from insular Southeast Asia were the first to interlink the Maldives and their wealth in money cowries to the wider trading networks of coastal Asia. As a result, the Maldivians adopted the word of their foreign trading partners for commercial reasons. In any case, the above lexical and cultural transmissions are a clear indicator of direct contact between the Maldives and the Malay World in pre-modern times.

\subsection{The Arabian Sea}

At this stage of knowledge, it is impossible to pinpoint when the first contacts between Southeast Asia and the Middle East were initiated. It has been argued that the 'Ubaid ceramics of Mesopotamia show "Austronesian" characteristics, such as tattooing and skin scarification (Oppenheimer 1998:76-7). In addition, the people of the Tihāmaẗ region of Yemen, based on their physical appearance, have been said to display Malay admixture (Mason 1946:371). I

\footnotetext{
86 The form †buli 'flask' is attested in an older dictionary (Marsden 1812:56). Malay buli-buli has also been borrowed into Dhivehi as bulibuli 'small glass bowl with lid', a doublet of boli 'cowry shell'.

87 On the mid-9th C. CE Tezpur rock inscription of Harjaravarman (written in Sanskrit but awash with regional words and expressions), we encounter the possibly related form butțikā 'one hundred kauris' (Sharma 1978:82-8).
} 
prefer to treat these and other diffusionist approaches with a considerable degree of scepticism until more evidence becomes available. During the better documented Islamic period, the Arabian Peninsula became predominantly a "donor" of culture and remained largely intolerant towards cultural influence from non-Islamic societies. Commercially, however, people in the Middle East had developed a keen interest in novelties from overseas. A substantial settlement of Middle Eastern and Central Asian communities of different ethno-linguistic and religious backgrounds had emerged in Guangzhou during the $8^{\text {th }}$ C. CE (cf. Leslie 1986). By this time, seafaring between the Middle East and China - during which Southeast Asia would have been used as a stopover - became increasingly more frequent. However, the decline of the Tang Dynasty led to increasing xenophobia throughout China and eventually accumulated in the notorious Yangzhou massacre (760) and the Guangzhou massacre (878-879), in which foreign settlers were especially targeted. While the resultant commercial vacuum led to an increase in trade relations between China and Southeast Asia, the role of the Middle East in this part of the world was temporarily suspended.

From antiquity onwards, the Middle East and especially the Arabic world had developed a sophisticated tradition in the use and manufacture of perfumes and other aromatics, constituting an important element of the trans-regional trade. In addition to local aromatics, such as myrrh (Commiphora spp.) and frankincense (Boswellia spp.), the early Arabs also acquired fragrant materials from abroad. Among these were aromatic tree products (see Chapter 6), musk, saffron and ambergris (cf. King 2008). The latter is a gray or blackish biliary secretion from the digestive system of the sperm whale (Physeter macrocephalus), which it regurgitates and which can be found floating on the sea or drifting ashore the coasts of the Indian Ocean, the Pacific and the Caribbean. Although ambergris is believed to be a pathogenic substance, it is characterised by a pleasantly sweet, earthy odour (Burkill 1966/1:130). Ambergris can be found ubiquitously across the Indian Ocean rim, but its esteem and demand have always been highest in the Middle East. The strong Arabic element in the trade in ambergris is reflected by the fact that the majority of the Indian Ocean languages have adopted Arabic 'anbar (originally 
'sperm whale') for 'ambergris', e.g. Farsi 'ambar, Hindi ambar, Tamil ampar, Dhivehi anbaru, Swahili ambari, Malagasy ambary, Thai amban (อำพัน), Malay ambar and Makasar ambara? id. ${ }^{88}$ Presumably, the Arabs were the chief importers of the product, making it effectively an Arab-dominated trade.

Next to these and other commercial networks, the spread of Islam and the Hağğ (pilgrimage to Mecca) greatly strengthened the cultural bonds between the nations of the Middle East, East Africa, Southeast Asia and other Indian Ocean regions. There was a vibrant Southeast Asian community in Mecca known as the Ǧāwä̈ (Bruinessen 1995:41-54, Snouck Hurgronje 2007:470-561). In addition, there is a Southeast Asian element in Yemen as a result of frequent Arab-Malay and Arab-Javanese marriages (Mason 1946:366), evidenced in cuisine, attire and other cultural aspects. As a result of these contacts, trade languages such as Malay (and Swahili) were once widely understood and spoken in certain regions of the Middle East, most notably in the Hadramawt region of Yemen (Ingrams 1936:12). Besides pilgrims, the waters of the Arabian Sea were occasionally visited by Malay freebooters during the colonial period (cf. Nooteboom 1952). Early Islamic sources suggest that this was no different in preand early Islamic times. During the Muslim conquest of Iraq, valuable mercenaries from al-Hind ('India') were employed on police and custodial duties after having embraced Islam (Bosworth 1997:97). After a period of war, these groups appear to have assimilated into the Arabic society, bringing with them the technology of large-scale rice cultivation (Morony 2005:272). One of these groups was known as the Zuțt, identified as the Jāt people from the north-western Indian subcontinent, some of whom migrated into Arabia in pre-Islamic times and were famed as water buffalo herders (Wink 1990:156). The literature closely associates them with the Sayābiğä̈, a group of renowned seafarers and longshoremen. In al-Balāḍri's Kitāb Futūḥ al-Buldān ('Book of the Conquests of the Lands'), it is mentioned that these people inhabited the coasts of the Persian Gulf from pre-Islamic times (Murgotten 1924:106). The name Sayābiğä̈, which is the

88 The word itself does not appear to be inherited and may have come from another source (e.g. Somali nibiri 'whale'), but it is undoubtedly the Arabic 'anbar that was adopted into the other Indian Ocean languages. 
plural of Saybağı'inhabitant of Saybağ, reveals their Southeast Asian ancestry (Goeje 1894:11). As demonstrated in Section 3.3, the name Saybağ, or Zābağ, is the same as Pali Jāvaka and Tamil Cāvakam: a Malay kingdom (and its inhabitants).

These Malay seafarers are quite distinct from their Malagasy colleagues. Medieval Middle Eastern accounts on the geography of the Arabian Sea clearly distinguish between the two. People from Qumr (Madagascar and the Comoros Islands) are reported among the seafaring communities frequenting coastal East Africa and beyond. In his Kitāb Nuzhat alMuštāq fi Intirāq al-Afāq ('Book on the delight of him who desires to get to know countries'), the $12^{\text {th }}$-century Arab geographer al-Idrīsī mentions that people from Qumr and merchants of the country of Mahārāğa (presumably another Sumatran-Malay kingdom - Malay maharaja goes back to Sanskrit mahārāja 'great king') carried out trade in East Africa (Ferrand 1932a:239). The $13^{\text {th }}$-century Kitāb Bast al-Arḍ ('The Book of the Extension of the Land') by al-Magribī describes a migration of Malagasy people to the African mainland (Ferrand 1913-14/2:319-20). Prior to that, they seem to have settled temporarily in Aden, as recounted in Ibn al-Muğāwir's Târīh alMustabșir (Hornell 1934a:313, Hunter 1968:187-8, Smith 2008:137-8). In a 15 th-century nautical manual, Ibn Māğid reports Malagasy voyages as far as the Middle East and western India (Ferrand 1919a/13:484-5).

Southeast Asia was also interlinked with the Middle East through trade in slaves from the Swahili coast. The latter region, known to the Arabs as the Zanğ, features as Azania in the Graeco-Roman accounts, in which it is described as a significant centre for maritime trade. The archaeological record of early iron-working sites in and near the Rufiji Delta in present-day Tanzania supports the historical importance of this region (Chami \& Msemwa 1997, Boivin et al. in press). The term Zanğ is used as a generic word for 'slave' in $7^{\text {th }}$-century Arabic texts, but obtains the more specific meaning of 'East Africa(n)' afterwards (Tolmacheva 1986); the names Zanzibar and Tanzania are derived from this word. Ultimately, it may be of Persian origin, which has zang 'rust, Ethiopia, etc.' and zangī'Egyptian, black person; a savage, etc.'. The latter was borrowed into Hindi as zangī'black person', Dhivehi zangīid., Acehnese dangki 'black person; 
mythical, supernatural creature', Malay janggi ‘East African, black person', Old Javanese jerigi id., Makasar janggi 'giant, supernatural being' and perhaps Angkola-Mandailing Batak jonggi 'name assigned to special things'. ${ }^{89}$ Starting in $813 \mathrm{CE}$, these slaves were occasionally presented as a gift to the Chinese emperor by Javanese envoys (Ferrand 1919a/14:10) and feature in the literature as EMC *səăn-tsi (僧祇). 90 Interestingly, East Africa was referred to as *kun-lun-tshəăn-ki (崑崙層期) when the Chinese started to regularly navigate the Indian Ocean (Hirth \& Rockhill 1912, Ferrand 1919a/13, Needham 1980:495); the first part of this compound refers to 'Southeast Asia', while the second part is another rendering of zangī. Possibly, the Chinese encountered Southeast Asian traders or perhaps even settlers in East Africa. An oftcited passage by al-Idrīsī supports this scenario, as it describes visiting ships from Zābağ into the Zanğ countries. The commercial interaction between these nations was facilitated by the fact that they apparently "understood each other's language" (cf. Ferrand 1932a:239), although we do not know whether they used Malay, Malagasy or Swahili as their lingua franca. The significant degree of lexical influence of Malay on Malagasy (Adelaar 1989, 1995a) would suggest that is was the former. On the Middle East, however, the ancient Malays appear to have asserted very little direct influence.

\subsection{East Africa}

More than 40 years ago, the historian Raymond K. Kent (1970:34) wrote that "the question of human contact between Indonesia and Africa, at least since the first century of our era, constitutes the most interesting historical problem left in this part of the world". While a substantial Southeast Asian presence in Madagascar is beyond doubt, there is much less direct evidence supporting navigations to the East African mainland. If Madagascar was reached via South Asia and East Africa, the settlement of the island may have been a by-product of longdistance trade networks (Shepherd 1982). As demonstrated in the previous section, East Africa

\footnotetext{
${ }^{89}$ Also compare Malay pauh janggi 'legendary tree (Lodoicea maldivica)', Acehnese pawoh junggi, Makasar pao jangki, Bugis pao jengki id.

90 Other renderings are found in Pelliot (1904:289-91, 334-5).
} 
features in the late Graeco-Roman literature as one of the commercial hubs interlinking the Indian Ocean. The Periplus describes the East African coast as a centre for trade in spices, aromatics, ivory, turtle shells and possibly coconuts, while sewn boats and dugout canoes are noted among the watercraft of this region (e.g. Schoff 1912, Huntingford 1980). In addition, Allibert (1999:272) Figure 10: map of coastal East Africa outlines the possibility that East Africa's rich iron deposits were shipped to South and perhaps Southeast Asia for the manufacture of weapons. At present, the dominant Swahili culture of coastal East Africa consists of a Bantu core with considerable Middle Eastern and South Asian influences (cf. Villard 1938, Lodhi 2000, Boivin et al. in press). Contacts

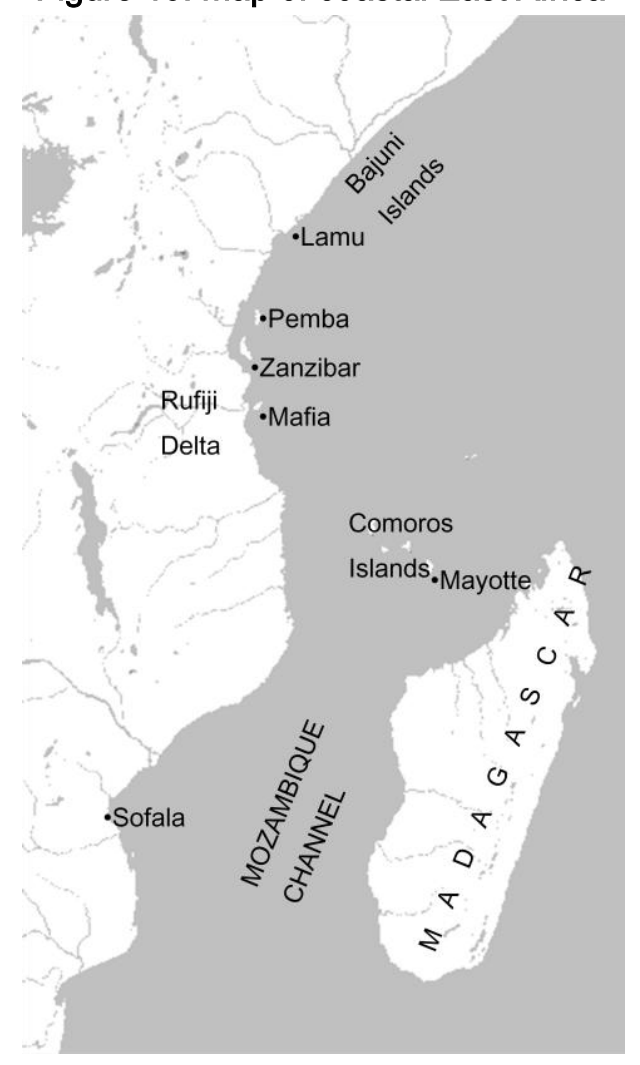
with Southeast Asia appear to have resulted in the introduction of a series of food crops (see Chapter 5) and the adoption of certain boat-building traditions (see Chapter 7).

In addition to the overwhelming amount of linguistic evidence, recent human genetic studies have recently confirmed the Southeast Asian impact on Madagascar (Hurles et al. 2005) and the Comoros (Gourjon et at. 2011, Msaidie et al. 2011). Other fields remain inconclusive about these past encounters. Murdock (1959:216) argues that Southeast Asian (and Chinese) traders were squeezed out of East Africa as a result of the mercantile monopoly of the Muslims from the early $10^{\text {th }}$ C. CE. Far Eastern ceramics known as "Dusun ware", which start to appear in an East African context from the late-8 $8^{\text {th }} / 9^{\text {th }}$ C. BCE (cf. Wilson \& Omar 1997), are hitherto the only unambiguous material evidence for these contacts. ${ }^{91}$ The shell-impressed pottery found in Madagascar and, to a lesser extent, on the East African coast may also hint at Southeast Asian

\footnotetext{
91 There is considerably more evidence for pre-modern contacts between East Africa and China at this period, as evidenced by Chinese textual accounts as well as archaeological findings of Chinese porcelain and coins in East Africa (Needham 1980:494ff.).
} 
influence, but this is less certain (Allibert 2008:10). From Islamic times, the East African culture(s) underwent distinct influences from several Asian regions as a result of expanding commercial and cultural networks. In an exploration of Asian elements in the material culture of Somalia, Grottanelli (1947) lists the presence of cowries, coconut scrapers, coconut vessels, daggers, spears, plaited skull-caps, toe-peg sandals, triton-shell trumpets and bell-mouthed oboes. Others have called attention to the exchange of musical traditions and instruments, especially xylophone types. ${ }^{92}$ Diffusionist theories on the alleged westward spread of metallurgy, the mancala game, the Great Zimbabwe ruins and a rich variety of other cultural elements, however, are less convincing and at times methodologically unsound (e.g. Frobenius 1898, Hornell 1934a, Jones 1964, Dick-Read 2005).

On the other hand, several hypotheses scattered across the literature need to be mentioned here, as they may genuinely hint at transoceanic contacts. Along the same lines as the dispersal of Southeast Asian maritime technology to South Asia and East Africa, some scholars have called attention to a particular turtle-catching method using a sucking-fish or remora (Echeneidae spp.) trained especially for this purpose, a technique found exclusively in East Africa (including Madagascar) and parts of the Pacific Ocean (cf. Gudger 1919, Puccioni 1937:69-71, Hornell 1950:35-8). ${ }^{93}$ While the Malagasy word hamby 'sucking-fish' appears to be related to PMP *gemi *kemi id. (cf. Blust 2002:126), Swahili chazo tazo 'sucking-fish' and

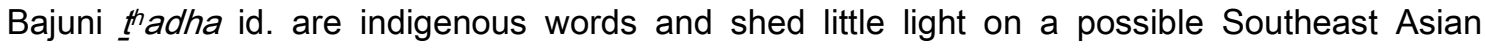
provenance of this turtle-catching method. Equally mysterious is the habit of bat-eating in Pemba, the northern island of Zanzibar, a practice against which neighbouring communities maintain strong taboos (Walsh 2005). This practice, as Walsh points out, is also found in the

\footnotetext{
92 See Blench (1982) for a critical review of the ethno-musicological evidence. Based on the diverse morphology of xylophones in Africa and the uniformity of Southeast Asian types, Blench argues that the latter may have evolved from the former.

${ }^{93}$ Early European accounts of a similar turtle catching technique in use among the indigenous Americans are probably apocryphal and go back to Arabic accounts relating to the Indian Ocean (Wiener 1921). In the Indian Ocean, the shell of the hawksbill sea turtle (Eretmochelys imbricata) and the leatherback sea turtle (Dermochelys coriacea) were among the most expensive trade commodities. The green sea turtle (Chelonia mydas), on the other hand, is only hunted for food (Burkill 1966/1:950-1).
} 
Comoros, Madagascar and several parts of insular Southeast Asia, from which it may have spread to Pemba. Of a quite different nature is the theory that elephantiasis was spread anthropogenically from Southeast Asia or Polynesia to the African continent at some unknown point in history (e.g. Jones 1972, Dick-Read 2005:141-3, Blench 2010:241). Elephantiasis is a tropical disease transmitted by mosquitoes infected with parasitic worms (in most cases Wuchereria bancroft), characterised by gross enlargement of the skin and underlying tissue, and resulting in the swelling of the limbs or male genitals. The idea of a Southeast Asian origin of the disease was first proposed by Laurence (1968:563), whose research on the adaptation of W. bancrofti to a new mosquito vector reveals that elephantiasis can only spread through considerable numbers of infected humans. However, the tentative presence of this disease in ancient Egypt, possibly from the late $3^{\text {rd }}$ mill. BCE (cf. Dean 2001), puts this theory in serious doubt.

Another clue to pre-colonial trade between East Africa and Asia is revealed by a set of Swahili oral histories which mention the legendary Wadiba or Wadebuli people. Some traditions describe these people as the original inhabitants of Zanzibar, who built several wells and fortifications, introduced seaworthy sewn ships (mtepe) with palm leave sails and cultivated coconuts and other plants from Asia (e.g. Lydekker 1919:90-1, Dale 1920:13, Gray 1954:37, Varadarajan 1998:40). In one account, these people are specifically associated with the place names "Diba" (presumably the Maldives) and "Jawa" (Ingrams 1967:125). However, in an exhaustive treatment of the relevant literature, Walsh (2010) concludes that the Wadiba and Wadebuli of the Swahili oral traditions cannot be identified as a single South or Southeast Asian ethnicity. The legends turn out to be of little help for the reconstruction of possible historical scenarios, leaving us unable to determine whether the described visitors were affluent merchants, small-scale fishermen washed ashore, ${ }^{94}$ slave-raiding freebooters or a combination thereof. Equally multi-interpretable are the ancestral claims of several East African communities

${ }_{94}$ Strong sea currents are known to have drifted shipwrecked crews from the central Indian Ocean as far westward as Madagascar (cf. Vérin 1975:179). 
that they derive from shipwrecked "Asian" seafarers (e.g. Lydekker 1919:90-1, Culwick \& Culwick 1936:61, Ingrams 1967:87-8, 125). Nevertheless, these confused accounts represent a glance at a past not otherwise documented, encouraging us to look for further lines of evidence for transoceanic contacts.

In addition to the abovementioned cultural ties, the literary record reveals less peaceful encounters between insular Southeast Asian sailors and the inhabitants of East Africa. Several medieval Middle Eastern authors describe a maritime population known as the Wāqwāq, hailing from a country situated on the fringes of the known world (cf. Ferrand 1907, Mauny 1965:9, Tibbetts 1979:161-77, Tolmacheva 1986-87, Toorawa 2000). ${ }^{95}$ In his Kitāb 'Ağà'íb al-Hind ('The Book of the Marvels of India'), the Persian geographer Bozorg bin Šahriyār describes a largescale raid by Wāqwāq sailors on the Zanğ coast in 945 CE (Ferrand 1907:462-3, Hornell 1934a:307-8, Mauny 1965:7). Among the places reportedly attacked by them are Sufālä̈ (Sofala, in present-day Mozambique) and Qanbaluh, which has been identified as Mkunbuu on Pemba (Ingrams 1967:81). The account further reveals that the Wāqwāq came back peacefully a few years later. When asked, they expressed their interest in ivory, turtle shells, panther skins, ambergris and Zanğ slaves to be transported to their country and to China. Later Arabic, Persian and Turkish authors took their information on the Wāqwāq and their country mainly from al-Mas'ūdī in his Murūğ aḍ-Dahab wa Ma'ādin al-Ǧawahir ('Meadows of Gold and Mines of Gems'), but added several folkloristic elements, such as the presence of a mythical tree bearing humans as fruits, deadly flying scorpions and the phoenix bird (Mauny 1965:9-10, Tolmacheva 1986-87:9-11, Allibert 1991).

In a $14^{\text {th }}$ c. account, the Arab historian Ibn al-Wardī provides his readers with more details, informing them that Nias is part of the Wāqwāq islands, that the people build large ships

\footnotetext{
95 Most accounts situate the Wāqwāq in south-eastern Africa, (South)east Asia or both; in the geographical perception of the authors, these regions were connected by a vast landmass. Several authors distinguish an African and an Asian group of Wāqwāq. According to Tolmacheva (1986-87:12-3), this is based on a misreading of al-Mas'ūdī's original account by later Middle Eastern scholars. In any case, the Wāqwāq were always situated a little beyond the known world (Tibbetts 1979:176-7).
} 
and floating houses, and that gold is abundant in their country (Mauny 1965:9). This is a strong indication that the Wāqwāq country was - by that time - identified with Sumatra and possibly the surrounding islands. While it has been claimed that the term Wāqwāq is related to Malagasy vahoaka 'people (of a country)' (Ferrand 1904b:496-500, Kent 1970:22, Simon 1988:42), the word may ultimately go back to Malay awak-awak 'people, crew' (Mahdi 1994/2:480 n.169). ${ }^{96}$ If this is true, the Wāqwāq may not have been a single ethnicity, but represent rather a group of people of diverse origins forming the crews of Malay (or Malagasy) owned ships. Such a setting would help us to understand why Bozorg bin Šahriyār compares the Wāqwāq to Turks (Devic 1928:150-1), while several other authors describe them as dark-skinned. If the accounts about them contain any element of truth, it would make most sense to see the Wāqwāq as multiethnic crews aboard Malay ships.

Against the backdrop of biological translocations and cultural diffusion from insular Southeast Asia to East Africa, several scholars have identified tentative Malay loanwords in Swahili (Krumm 1940, Teubner 1974, Adelaar 2009c, Walsh forthcoming). There are two major problems in using these data for the purpose of reconstructing transoceanic contacts. First, it is difficult to propose a convincing chronology for these lexical transfers, many of which may very well be of a relatively recent age. Second, most lexical items shared by Malay and Swahili are ultimately derived from a third source, such as Arabic, Farsi or Hindi, from which they would most likely have been borrowed directly, rather than through contact between Southeast Asians and East Africans. In other cases, the path of borrowing is obscure. Farsi sar-'amalä̈'head of workmen', for example, has been borrowed as Malay sorimala 'carpenter', Malagasy soromala, Swahili seremala id. and Comorian sarumá 'craftsman, mason', but we do not know whether the word was borrowed directly from Farsi in all three cases or transmitted via one of the above languages. Swahili mkuta 'stone wall' (cf. Comorian uhura 'brick wall', Malagasy (Mayotte dial.) kòra 'wall') poses a similar problem: is it derived from Malay kota 'fortified place; stronghold' or

${ }^{96}$ Alternative etymologies abound in the literature (cf. Ferrand 1932a:208, Mauny 1965:11, Tibbetts 1979:176, Allibert 1999:269, Dick-Read 2005:218), but strike me as less plausible. 
from an Indo-Aryan reflex of OIA *kōtta 'fort'? A Malay etymology has my preference; most IndoAryan vernaculars of the Indian west coast exhibit the loss of the word-final /a\#/ (cf. Hindi kot 'a fort, castle, stronghold'), a sound law that presumably predated the establishment of regular contacts between Indo-Aryan and Bantu speech communities. In the case of the Swahili attestation kuba guba 'packet of aromatic leaves', too, a transmission via Malay gubah 'wearing in the hair (as a flower or jewelled ornament is worn)' seems most plausible based on the form and meaning (cf. Walsh forthcoming), although the ultimate source of both forms must be OIA *guppha 'something strung together' (cf. Turner 1966 \#4203).

While further research is needed to determine the extent to which Malayo-Polynesian languages have influenced Swahili, Makhuwa and other East African languages, several examples support a scenario of direct contact between insular Southeast Asia and the Swahili Coast. In addition to the insular Southeast Asian impact on East Africa's maritime technology (see Chapter 7), Walsh (1995:17) highlights the possibility that Swahili tupa 'fish poison' is a Southeast Asian borrowing. Indeed, we find reflexes of PMP *tuba 'derris root fish poison' (particularly Derris elliptica) distributed across insular Southeast Asia and Oceania (Blust 1976:21). The word is not found in South Asia, where indigenous types of fish poison are used (cf. Watt 1889-96/iii:80). ${ }^{97}$ The Malay name for 'crocodile' (buaya), also meaning 'scoundrel', appears to have been adopted as Swahili mbuai 'wild, brutal', (Unguja dial.) mbwayi 'savage' and Comorian vwayi 'crocodile' (Walsh 2012). Another example is Swahili tora 'fishing spear', which goes back to Malay torak 'a fish-trident with a loose head' (Adelaar 2009c). We may also call attention to Swahili bakuli 'basin, deep dish, tureen' (> Malagasy bakoly 'bowl', (Sakalava dial.) bakúli 'porcelain, plate', (Mayotte dial.) bakòly 'bowl'), which appears to be related to Malay bakul 'basket (gen.)'. ${ }^{98}$ Of a quite different nature are the Malayo-Polynesian loanwords that entered Swahili varieties through Malagasy. Most of these Malagasy loans are limited to Comorian (cf. Adelaar 2009c), but others have also been adopted into mainstream Swahili (cf.

\footnotetext{
97 We find congeneric Derris species in South Asia, including $D$. robusta, $D$. scandens and $D$. trifoliate. The use of these and other plants for fish-poisoning is especially common in Northeast India (Smith 1976:312).

98 Perhaps ultimately from Arabic, which has būqāl(ä̈) 'vessel without handles, mug'.
} 
Teubner 1974:635, Schadeberg 2009). Malagasy itself displays a profound lexical impact from Malay (Adelaar 1989, 1994a, 1995a, 2009a). In Malagasy, too, some borrowings are limited to specific dialects, e.g. (Mayotte dial.) pòky 'curse, swearword'; mipòky 'to swear, to curse' from Malay puki 'female genitals' (Adelaar 2009a:728). ${ }^{99}$

The biological translocations from Southeast Asia to East Africa and their possible linguistic implications merit particular analysis. Swahili rice terms include mchele '(husked) rice, (cleaned) grain', mpunga 'rice plant, rice in the field' and wali 'cooked rice'. It is tempting to connect mchele with South Asian rice terms (cf. Knappert 1987:78), such as Hindi cāval 'rice (cleared of the husk and not dressed)' or Tamil câli 'a superior species of paddy, growing paddy-crop'. Conversely, Ehret (2011:246 n.8) believes that the Swahili attestation goes back to proto-Mashariki Bantu *sele 'individual grain', itself a noun derivative of *se/ 'to clean'. As for mpunga, he proposes a derivation from Malay bunga 'rice' [recte 'flower'] (Ehret 2011:228). This hypothesis becomes particularly attractive when we compare Swahili upunga 'stage of growth of a plant which is in full flower and just beginning to form fruit; male flowers of the coconut palm'. However, the tentative Malay precursor displays a word-initial voiced bilabial stop /b/ and an intervocalic velar nasal $/ \mathrm{n} /$, whereas the Swahili form has a prenasalised unvoiced bilabial stop $/ \mathrm{mp} /$ and a prenasalised voiced velar stop /ng/ (a velar nasal is written as <ng'> in Swahili). The latter phonemes are unlikely to have evolved out of the former under any known historicophonological process in (proto-)Swahili. That being said, we may call attention once more to the aforementioned Swahili attestation tupa 'fish poison' (< PMP *tuba 'derris root fish poison'), which displays the same enigmatic ${ }^{*} b>p$ innovation. Swahili faithfully maintains the $/ b /$ in all positions with loanwords from Arabic, Farsi, Indian and European languages. Therefore, I am forced to leave this problem open for future studies.

The relation between Swahili wali 'cooked rice' (cf. Comorian melé 'paddy, rice plant') and Malagasy vary 'rice', both also used as a weight unit (Beaujard 2010:366, 2011:177), is well

99 This must be a relatively recent loan, as we would otherwise expect ** pohy based on the historical phonology of Malagasy. 
known. ${ }^{100}$ Recent genetic research by Mather et al. (2010) suggests two introductions of rice into Madagascar: from insular Southeast Asia (Oryza sativa subsp. japonica) and from India (subsp. indica). While the Bantuists Nurse \& Hinnebusch (1993:647) tentatively reconstruct Swahili wali to an earlier stage of Bantu $\left({ }^{*} g a \dot{d} d\right)$, they also call attention to the similarity between Bantu and South Asian attestations. Of the latter, the Dravidian attestations (e.g. Tamil vari 'paddy') resemble the Swahili form closest (cf. Southworth 1988:658-9). However, directly related forms are also found in the Barito region of Borneo, where the Malagasy speech community originated (e.g. Ngaju bari 'cooked rice' and various other forms; cf. Hudson 1967:92, Adelaar 1989:26, Sakiyama 1992:273). We may also compare the Malay compound kadut bari 'dried sticky rice', ${ }^{101}$ Bugis kado? bari 'cooked, sun-dried rice', Toba Batak bari 'foul of taste, e.g. rice', Angkola-Mandailing Batak bari 'stale, spoiled' and Makasar bari 'sour, stale (of food)'. While it is conceivable that all forms ultimately go back to a Dravidian source and denoted some rice cultivar imported from India, I would argue that the direct precursor of the Swahili and Malagasy attestations for '(cooked) rice' is a Bornean source. Rice originally played a minor role in the Barito region in southeast Borneo and the parboiled, dried version of this crop may have been introduced by Malay or Bugis settlers. ${ }^{102}$ This rice variety was soaked in cold water, mixed

\footnotetext{
100 The inherited reflex of Austronesian * pajay 'rice plant, rice in the field' underwent a rather curious semantic shift in Malagasy to fary 'sugarcane', although its original meaning was probably 'rice' (Beaujard 2011:177). This word might be the source of Makhuwa mu-hali 'sugarcane'.

101 The first element of this compound appears to be some sort of small bag made of vegetal fibre, such as the leaves of Corypha spp., in which prepared food was distributed after certain festivities as a present to the guests. It is found in Malay as kadut 'sack-cloth (of local fibre)', Acehnese kadot 'bag, pouch', Toba Batak hajut 'bag made of straw or fur', Bugis ka?do? 'a portion of cooked rice and garniture, to be taken home after weddings etc.' and Makasar ka?do? 'cooked rice, dish; money sent in a letter'. The semantics of this set seem to suggest that the forms ultimately go back to Old Javanese, which has kadut 'a coarse fabric made from the fibre of gəbari-leaves (esp. to wrap something up in)'. Presumably, the original meaning was 'something taken along', cf. the verb dudut 'to take along with one'.

102 Wet rice cultivation is recorded in historical times among the Malayic populations of southeast Borneo, whereas Borneo's inland communities - commonly known as "Dayaks" - traditionally practise dry-land swidden cultivation (cf. Knapen 2001:189ff.). In both cases, rice is traditionally intercropped with tubers, sago, cucurbits and various other vegetables.
} 
with sugar and put under something heavy so that it began to swell and became edible again, serving as a nutritious snack during long journeys (Matthes 1874/1:199). ${ }^{103}$

Moving beyond the dispersal of rice, at least three African tubers have origins in insular Southeast Asia: taro (Colocasia esculenta) and the yam varieties Dioscorea alata and $D$. esculenta (cf. Murdock 1959:222ff.). In general, it may be pointed out that the names of tubers occasionally contain clues to their foreign origins, e.g. Sinhala jāvāle 'yam' from Jāvā 'Malay' (Burkill 1924:171) and Malay ubi bənggala 'potato' from Bənggala 'Bengal'. In the case of East Africa, we may call attention to Swahili ki-azi 'potato' (cf. Comorian shi-hazi 'yam'), which presumably denoted other tubers in the past. It may go back to Malay kəladi 'taro', as does the dialectal Arabic word †kalārī, denoting a certain tuber attested in Yemen (Meinhof 1919-20:150, Krumm 1940:124-5). ${ }^{104}$ If this etymology is correct, the lexical acquisition is relatively early, predating the partial loss of $/ / /$ in Swahili phonology and the pre-Swahili *di $>$ zi innovation (Schadeberg 2009:82). The intervocalic /I/, lost in Swahili, is still reflected in related forms, such as Tete mu-razi 'sweet potato' and Nyanja chi-lazi chi-razi 'yam' (Meinhof 1919-20:151). ${ }^{105}$ The word for 'taro' is completely different in Malagasy (saonjo), suggesting that Swahili obtained the word directly from Malay. Most other African languages, too, display unrelated words for 'taro' with no recognisable Southeast Asian precursors (cf. Burkill 1934, Blench 2006:234). While the first archaeobotanical evidence of taro on the African continent stems from a medieval port excavation at Qușair al-Qadīm on the Red Sea coast (van der Veen 2011:95-7), phylogenetic research may point at a greater antiquity (Grimaldi et al. 2012).

\footnotetext{
${ }^{103}$ Anecdotally, people in the Barito region are still inclined to prepare their rice in a relatively non-sticky way, much to the contempt of more recent Javanese settlers.

${ }^{104}$ According to the medieval Arabic geographer al-Mas 'ūdi, this tuber resembles the qulqās 'taro' of Egypt and Syria. Its exact pronunciation cannot be determined by the spelling $\langle$ s, leaving us with the somewhat unsatisfying reconstruction *k[aiu]lā[drz] (Meinhof 1919-20:150 n.4). The same word is found in several languages of Indonesia (Heyne 1927/1:423), but all forms appear to go back to Malay kəladi 'taro'.

105 Upon further analysis, it becomes clear that the first element of Swahili ki-azi was interpreted as a prefix, hence pl. viazi. This is by no means an isolated case; cf. Swahili ki-labu (< 'club'), pl. vi-labu (Knappert 1970:83) and ki-tabu (< Arabic kitāb 'book'), pl. vi-tabu (Zuckermann 2003:52).
} 
Another tuber name appears to have been introduced into East Africa not through Malay, but through one of the languages of Sulawesi. Swahili kandoro $\sim$ kindoro 'sweet potato' and Bajuni kind'oro 'potato' strikingly resemble Bugis kandora? 'k.o. tuber', Makasar kandora? 'k.o. cassava', and other tuber names attested in Sulawesi (Heyne 1927/2:1421, Mills 1975b/2:724). As the exact botanical identifications of especially the Sulawesi attestations are somewhat vague, there are different possible scenarios: 1) the similarity could be due to chance resemblance, 2) all forms originally referred to one of the two Dioscorea species transmitted from Southeast Asia to Africa in pre-colonial times, or 3) the word denoted a new world tuber, such as the sweet potato (Ipomoea batatas), and the transmission took place during the colonial period. In support of the latter hypothesis, we may also call attention to Sinhala kitala 'k.o. yam', which is evidently from Malay kətela 'sweet potato', reflecting an earlier ubi kastela 'Spanish tuber'. It would also not the only example of a New World crop whose Swahili name is taken from Malay. As pointed out by Teubner (1974:635), the Swahili word karanga kalanga 'peanut (Arachis hypogaea)' goes back to Malay kacang 'pea, bean' (cf. kacang tanah 'peanut'). On the other hand, it is not altogether implausible that sailors from South Sulawesi have reached East Africa. The Malagasy language, too, has borrowed several words from a South Sulawesi source (Adelaar 2009a:725-6, 2009b:166), although these transmissions may have taken place in the Barito region prior to the migration to Madagascar.

The above linguistic data support direct contact between East Africa and the Malay World starting in pre-Islamic times. For influence in the opposite direction, we may call attention to the scale patterns on different xylophone types (Blench 1982) and the transmission of the winged bean (Psophocarpus tetragonolobus) from Africa to Southeast Asia (Harder \& Smartt 1992). As has been argued, contacts between the Malay World and East Africa persisted into the colonial period. In addition to regular interaction during the Hağğ in Mecca, a small number of East Africans found their way to Southeast Asia. A Malay manuscript belonging to the Royal Asiatic Society and compiled during the late $19^{\text {th }}$ C. CE juxtaposes the lexicon of Malay with that of five other languages: Semang Bukit, Semang Paya, Madurese, Tulehu and Makhuwa 
(Maxwell 1899:123, Blagden 1902, 1903). While the first four languages are spoken in the Malay-Indonesian archipelago, the latter occurs in Mozambique. ${ }^{106}$ It is commonly known that Makhuwa slaves were brought to Madagascar, where their descendants formed their own communities (Hébert 1983, Gueunier 2003-04), but no such literature exists about their presence in the Malay World. The presence of Makhuwa speakers in the Malay World is a historical continuation of the Jənggi slaves described in Old Javanese epigraphy and perhaps the slave raids on Sofala by the Wāqwāq, although African slaves were presumably brought to the archipelago by the Portuguese or other Europeans from colonial times. This is a topic that merits further study, drawing on textual, linguistic, anthropological and, possibly, genetic research.

\subsection{Concluding remarks}

In an area as diverse yet interlinked as the Indian Ocean, we have seen that the degree of cultural and lexical impact from insular Southeast Asia, particularly from the Malay World, differs greatly from one region to another. While the languages of the Nicobar Islands display various Malay loans reflecting their receptibility towards trade and interaction with foreigners, those of the Andaman Islands appear devoid of any Malay influence, although a very limited set of words may point to early cultural contact with other Malayo-Polynesian languages. The Nicobarese languages may have also been influenced by Moken, suggesting cultural contact between these now separated societies in an undocumented past. Moving to the South Asian mainland, we see that vocabulary was exchanged widely across linguistic borders since the dawn of commercial interaction across the Bay of Bengal. Sporadically, the literary record offers a timeframe for the acquisition of new vocabulary and its diachronic changes in meaning, but more often we have no means of telling when the cultural contact resulting in such lexical transmissions took place. In several cases, vocabulary attested on both sides of the Bay of Bengal was the result of European colonialism, even though the words may be of local

106 The variety documented in the wordlist appears to be a Rovuma dialect (Charles Kisseberth pers. comm.). 
provenance. This also generally holds true for Sri Lanka, although there is some literary evidence for the presence of Malay loanwords in pre-colonial Sinhala. The Dhivehi data, consisting largely of trade commodities, reveal the nature of contact between the Maldives and insular Southeast Asia. For example, the word for 'money cowry', one of the most valuable products of export, is presumably adopted from a Malayo-Polynesian source, strongly suggesting an insular Southeast Asian element in the commercial networks connecting the Maldives with the wider world. Moving further westward, the early Southeast Asian influence on the Arabic language and society appears to be restricted mostly to a limited corpus of textual attestations of Malay-speaking merchants, freebooters and slave-raiders in the medieval literature. It is conceivable that the local vernaculars of especially the southern Arabian Peninsula would have adopted some Malay vocabulary during the region's trade oriented past, yet such cases have gone undocumented in the literature available to me. As the westernmost region of this study's coverage, the East African coast exhibits some degree of lexical influence from Malayo-Polynesian languages, in particular Malay and Malagasy, which is of direct relevance to a wider understanding of the prehistory of Africa and its position in the Indian Ocean World.

We may conclude that the lexical evidence highlighted in this chapter, especially with regard to East Africa, allows us to reconstruct a past not yet known to a wider readership. In view of the fact that a considerable number of the Malayo-Polynesian loanwords in Swahili and other East African languages are not attested in other languages of the Indian Ocean littoral, the data as they now stand strongly suggest direct contact without intervention of Middle Eastern or South Asian intermediates. Notwithstanding some possible misidentifications in especially Krumm (1940) and Teubner (1974), the lexical data analysed in this study favour a scenario of interaction between speakers of Malay and Swahili. Hopefully, future research on peripheral or substandard languages and dialects in East Africa will reveal more traces of these past encounters. However, in the absence of corroborative data from other disciplines, the datability of "prehistoric" interethnic contact remains highly problematic in the absence of a strong literary 
tradition. Further archaeological and archaeobotanical research on this region may help clarify these issues in the future. To gain a deeper understanding of the interethnic networks and trade commodities outlined in this chapter, the following chapters focus on the transoceanic dispersal of plants, spices and maritime technology respectively. 


\section{Anthropogenic translocations of Southeast Asian plants}

The human impact on landscapes reveals itself in various ways. Human populations and their cultural practices affect their environment, but also adjust to it. The plants traditionally cultivated in a society shape its agricultural systems, village structures, culinary and medicinal traditions, rituals and art. Next to biogeography and linguistics, the study of plant remains from archaeological sites (archaeobotany) can provide us with valuable insights into pre-modern agriculture and cultural contact within a region. This chapter focuses on the anthropogenic dispersal of culturally or economically important plants from Southeast Asia and their distribution across the Indian Ocean, using a combination of archaeobotanical and linguistic evidence. The plants that have travelled eastwards along these trade routes will not be addressed here (but cf. Gonda 1973:322-9, Castillo \& Fuller 2010:95-6). Interdisciplinary research incorporating the most recent archaeobotanical insights has shed new light on agricultural developments and exchanges in the Indian Ocean World (e.g. Boivin et al. 2009, Fuller et al. 2011a, Rangan et al. 2012). To get an image of the time-depth and distances travelled by the early navigators of the Indian Ocean, we may call attention to the introduction of African crops into South Asia and - to a lesser extent - South Asian domesticates travelling in the opposite direction (cf. Knappert 1987:77, Blench 2003, Boivin et al. 2009). This series of agricultural exchanges probably started around 2000 BCE (Fuller 2003). They were followed by long-distance translocations of Southeast Asian cultigens, which are the focus of this chapter.

When examining these biological translocations, one should keep in mind that discontinuous distributions of phylogenetically related species are, if not caused by climate change, strong indicators of anthropogenic dispersal (Asouti \& Fuller 2008:71-4). In the case of the above-mentioned African crops in South Asia, it would be problematic to use historical linguistics to obtain a better picture of these early transmissions, as the time-depth is too great and the linguistic settings of both regions have changed dramatically since the time of the 
translocations. Nevertheless, a small number of early translocations are reflected in the linguistic record and display lexical correspondences in the languages of Africa and South Asia, e.g. the word for 'dates (Phoenix dactylifera)' (Southworth 2005:197) and the word for 'foxtail millet (Setaria italica)' (Witzel 2009:86-7). A longer known instance of long-distance travelling food-stuffs is the ancient introduction of several insular Southeast Asian crops into Africa, including yam varieties (Dioscorea alata and D. esculenta), taro (Colocasia esculenta), banana/plantain (Musa spp.), sugarcane (Saccharum spp.), coconut (Cocos nucifera) and Asian rice (Oryza sativa) (Murdock 1959:222ff., Mitchell 2005:106-8, Boivin et al. in press). In addition, recent mitochondrial DNA analysis reveals a Southeast Asian contribution in the gene pool of East African and Malagasy chicken populations (Razafindraibe et al. 2008, Bjørnstad et al. 2009, Mwacharo et al. 2011). Initially, it was believed that all these agricultural items had reached Africa in the form of a package, which has been named the "Malaysian complex" (Murdock 1959:223-4) or the "Tropical Food Kit" (Blench 2009:364). However, the "package" assumption has become somewhat problematic in the light of more recent findings, as it fails to take into account the wider context of Indian Ocean agricultural and commensal translocations (Fuller \& Boivin 2009, Fuller et al. 2011a, Eager et al. 2012, Boivin et al. in press). ${ }^{107}$

This chapter focuses on the Indian Ocean dispersal of sandalwood, betel chewing, the coconut palm, the banana, citrus cultivars, ginger and related rhizome-propagated plants. I will not address the terminology and early dispersal of taro and yam varieties beyond the discussion in Section 4.6. Previous scholars have shed some light on the rich tuber nomenclature in various regions of the Indian Ocean World (e.g. Burkill 1924, 1938, Sakiyami 1992:739, Blench 2012), but instances of lexical borrowing across the Indian Ocean appear to be extremely rare. Earlier studies on the plant terminologies in the Austronesian languages show that the lexical domain of plant names tends to contain a significant number of phonological irregularities and alternative reconstructions due to frequent borrowing and re-borrowing of plant names between geographically contiguous communities (e.g. Tsuchida 1977, Wolff 1994, Jen-kuei Li 1994). We

107 Instead Fuller \& Boivin (2009:18) employ the safer term “Tropical Trio”, i.e. the banana, taro and yam. 
should be prepared to encounter similar situations in other language families. After all, people use different strategies to name unfamiliar plants, as they do with newly introduced concepts in general. One strategy is to borrow a name from those who already have one, a second is to take a local name originally used for another plant, and a third is to invent a descriptive name. Wild (1970:129) points out that languages can also borrow foreign names for endemic plants, in which case the meaning can become generic, e.g. English 'pine' (< Latin pinus).

\subsection{Sandalwood}

The sandalwood tree (Santalum album) is a 4 to 9 meter high species of the Santalaceae family. This parasitic tree grows best in semi-arid areas and partly draws its nourishment from the roots of other trees. Although the sandalwood tree is easily cultivated, its bark is very delicate and suffers considerably from accidental injuries. The tree is therefore often found in protected areas, such as forests or stony soils (Watt 1889-96/vi.ii:462, Burkill 1966/2:1987). Sandalwood is famous for its fragrance, which develops after its dead wood dries out (Heyne 1927/1:590). In some textual sources, the wood is called 'white sandalwood' to distinguish it from the inferior 'red sandalwood' (Pterocarpus santalinus), a tree native to South India. In South Asian cultures, sandalwood powder was initially used as a cosmetic and subsequently acquired a ceremonial function with the emergence of Brahmanical Hinduism and Buddhism (cf. Burkill 1966/2:1989). In insular Southeast Asia, sandalwood is traditionally made into a porridge known for its aromatic and medicinal properties (Heyne 1927/1:591). The presence of sandalwood in South Asia seems to be of considerable antiquity and its use is deeply rooted in South Asian culture. Sandalwood occurs in various Sanskrit texts, including the Nirukta (by the $7^{\text {th }} / 6^{\text {th }} \mathrm{C}$. BCE grammarian Yāska), Mahābhārata, Rāmāyaṇa and Raghuvamísa (Monier-Williams 1899:386). The identification of sandalwood in the charcoal records at Sanganakallu in southern India suggests that it was used in South Asia by at least 1400-1300 BCE (Fuller 2007:427, Asouti \& Fuller 2008:117, Fuller \& Madella 2009:345). 
In light of the antiquity of sandalwood in South Asia, it is difficult to imagine that this tree might be of foreign origin. Nevertheless, this has been claimed by some early $20^{\text {th }}$-century scholars (Sprague \& Summerhayes 1927, Fischer 1927, 1938) and more recent archaeobotanical work points towards the same conclusion (Harbaugh \& Baldwin 2007). These studies provide several arguments for a non-indigenous origin of the sandalwood tree in South Asia. First, the geographical distribution of species of the genus Santalum shows remarkable discontinuity between Southern India on the one hand and the entire area between Nusa Tenggara, Northern Australia and most of the Pacific region on the other, which, if not caused by massive extirpation in the intervening area, can only be accounted for by anthropogenic dispersal. Second, there is an absence of entirely wild populations in the Indian subcontinent, even though the tree is known for its ability to reproduce quite easily without human intervention. Third, early European sources uniformly identify Nusa Tenggara as an important export centre, whereas they do not mention any South Asian agency in the sandalwood trade. In addition, the Chinese seem to have obtained their sandalwood directly from Southeast Asia, not from India (Laufer 1919:318).

Despite the insular Southeast Asian origin of the tree, the nomenclature for 'sandalwood' is almost entirely of Indo-Aryan derivation. The use of local names is restricted to Nusa Tenggara and adjacent regions, where the tree is found in wild populations (Heyne 1927/1:589). Although Sanskrit has many synonyms to refer to the tree, the most widespread term is candana, itself a borrowing from a Dravidian source (Burrow \& Emenau 1984 \#2448, Zvelebil 1990:80). ${ }^{108}$ This Sanskrit form yielded various reflexes across South Asia (cf. Turner 1966 \#4658), spread westward as Farsi čandan čandal 'sandalwood (Santalum album)'; Aramaic $s^{\varsigma}-n-d-r$, Arabic șandal, Somali sandal 'sandalwood', Swahili †sandali id. and perhaps Comorian msindzanu 'sandalwood powder', and eastward as LMC *tsian-tán (旃檀) ～*thian-tán (填檀)

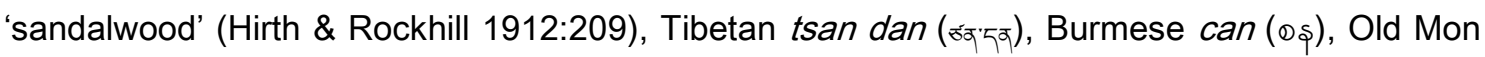

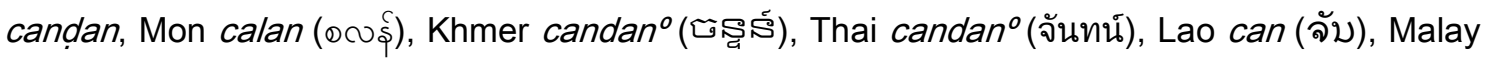


cəndana, Cebuano †sandána 'fragrant tree that yields palina' and Cham candal (ד) (צ') 'sandalwood, saffron'. This word has further been identified as santálina, found in the Periplus (Schrader 1917-23/2:279). In addition, it occurs in $6^{\text {th }}$ C. CE Hellenistic texts as sándanon (Sixteen Books on Medicine) or tzandánē (Topographia Christiana), although these words were later replaced by sántalon (Yule \& Burnell 1903:790, Dalby 2000:31). Thus, throughout the Indian Ocean littoral and beyond, the adopted word for 'sandalwood' was a rendering of Sanskrit candana. ${ }^{109}$ The fact that even the insular Southeast Asian speech communities adopted this word may have been partly trade-related: the Indians made the world aware of the high economic and religious value of the tree. Its important function in Hindu and, later, Buddhist rituals made the use of a Sanskrit name for 'sandalwood' even more plausible.

\subsection{Areca palm and betel pepper}

The addictive habit of betel chewing is found over a vast area around the Indian Ocean and the Pacific. In many of these regions, the tradition plays an important role in social occasions: offering a betel quid to guests is regarded as a sign of hospitality. "To the Indian, the Malay and the Indonesian", as one author puts it, "it is not only his constant companion throughout life, but is there to welcome him into the world, to see him safely married, and to accompany him into the next world. What other object in existence can boast of such devoted service to man? (Penzer 1927:238)" The betel chew mixture generally consists of three ingredients: the "nut" (technically the endosperm of the seed) of the areca palm (Areca catechu), slaked lime (calcium hydroxide, $\mathrm{Ca}(\mathrm{OH})_{2}$, often made from pounded shells) and the leaf of the betel pepper (Piper bet/e). The betel quid is normally spat out after mastication, marking the ground and nearby walls with the unsightly red stains that accompany this habit everywhere it is practiced. The seeds of the areca palm are removed from the husk by boiling or drying them (Burkill 1966/1:225-6). Although the exact origins of the areca palm are somewhat obscure and a

109 Some authors have claimed that the unrelated and poorly attested Indo-Aryan synonym valgu had been borrowed into Biblical Hebrew (Lassen 1847-61/1:538, Müller 1899:189, Miller 1969:62), but these theories were generally received with scepticism and more convincing Semitic etymologies (Schoff 1922a:173, Greenfeld \& Mayrhofer 1967:85). 
deeper phylogenetic examination of Arecinae genera remains to be conducted, our current state of knowledge favours an insular Southeast Asian homeland (Beccari 1919:296, 301, Smith 1976:318, Zumbroich 2007-08:68-9). In support of the early use of areca nuts in insular Southeast Asia, it may be noted that the tree was presumably introduced from the Philippines to the Mariana Islands by the first group of settlers around 1500 BCE (cf. Blust 2000:109), although solid archaeobotanical evidence is lacking. From Southeast Asia, the palm was probably introduced to South Asia around the mid-2nd mill. BCE, together with several other Southeast Asian tree crops (Fuller 2007:427, Fuller et al. 2011a:5-6). In some regions, the areca nut is chewed by itself (Watt 1889-96/i:300, Groot 1894, Heyne 1927/1:395, Burkill 1966/1:224, Zumbroich 2007-08:65-6), although its astringency is usually experienced as unpleasant. Slaked lime is added to make the nut more palatable. The betel leaf, a gentle stimulant and exhilarant, is wrapped around the package to increase its flavour. The betel pepper is a creeper and therefore difficult to cultivate without supporting trees, which is why it is often cultivated together with the areca palm (Heyne 1927/1:518, Burkill 1966/1:230). Parts of Maluku and Nusa Tenggara are home to a subspecies with less tasty leaves ( $P$. betle var. Siriboa), whose peppers are chewed instead (Mahdi 2007:107). Next to these three main ingredients, several other additions can be made to aromatise the betel quid, including spices, tobacco, sugar and rose-water (Watt 1889-96/i:300, Burkill 1966/1:224, 2:2244). In some regions, people also add astringent plant extracts to the quid, including 'cutch' (Acacia spp.) in India and 'gambir' (Uncaria gambir) in the Malay World. The latter is a climbing shrub that grows mainly on plains. The tanniniferous resin from its leaves is added to the betel quid in fresh or extracted form (Heyne 1927/ii:1386-93). In addition, the plant is used for tanning and dye manufacture (Smith 1976:320).

The combination of the areca nut, slaked lime and betel leaf into a single quid was probably invented once and subsequently passed on to neighbouring communities. Although the antiquity of the habit has often been commented on in the wider literature, tentative identifications of areca nuts or betel leaves in the archaeological record do not tell us much 
about whether betel chewing was carried out. Only the study of dental remains can inform us about mastication habits. The so-called "betel stains" on dentitions, either incidental or deliberate for aesthetic reasons, are an important indicator of the use of areca nuts with slaked lime (Zumbroich 2007-08:74-5). The earliest evidence of betel chewing deduced from dentitions is from a burial site in the Duyong Cave on Palawan Island in the southern Philippines, dated to the mid-3rd C. BCE (Fox 1970:60-5, Bellwood 1997:221-2, Barretto-Tesoro 2003:304, Zumbroich 2007-08:75). This raises the question of whether the habit of betel mastication among Southeast Asia's Austronesian-speaking communities was inherited, invented or adopted from pre-existing communities. The practice was followed in Taiwan by at least the early $1^{\text {st }}$ mill. BCE; the $1500-800$ BCE village site of Peinan contains skeletal remains with stained teeth (Lien 1991, Bellwood 1997:217). Betel chewing was also practiced on parts of the island of Madagascar, but the habit was restricted to the Arabised population (Burkill 1966/1:224, Beaujard 2006:424 n.53), making it almost certainly a secondary introduction. The practice is also common in Near Oceania and parts of Micronesia, while it is not traditionally followed in Remote Oceania. Lichtenberk (1998) argues that the first Oceanians chewed betel, since various betel-related terms can be reconstructed to proto-Oceanic. The absence of the habit beyond northern Vanuatu, he argues, is the result of abandonment rather than loss. In these regions, the betel quid has been replaced by a mildly sedative drink prepared from the roots of the kava plant (Piper methysticum), a Piperaceae genus related to the betel pepper. The observation that betel-chewing is rarely found in kava-drinking areas was already made by Penzer (1927:248), who speculated that the areca palm would not grow well on the coral atolls of Remote Oceania.

The Chinese literary records shed some light on the chronology of betel chewing in East Asia. The practice seems to have been introduced during the first centuries of the Common Era, by which time it is still associated with southern non-Han populations (Groot 1894:265ff., Penzer 1927:303, Schafer 1967:175, Mahdi 1998:405, 2010:4). This has changed during the course of the first millennium. We have records of regular import of dried and salted areca nuts from 
Hainan, insular and mainland Southeast Asia into China during the Song Dynasty (Wheatley 1959:68-9). It is less certain when the custom was introduced into South Asia. Remarkably, the Rāmāyaña and Mahābhārata do not mention betel chewing, which suggests that the habit was not yet common in the mid-1st mill. BCE (Mahdi 1998:404). However, the areca nut and betel pepper are mentioned in the Jātakas, in other Pali works and in the Jain scriptures, which suggests familiarity with betel-chewing by the $2^{\text {nd }}$ C. BCE (Penzer 1927:254). Through time, several castes engaged in the cultivation and sale of betel mixtures - such as the Bärujībi and Tãmali of the Bengal region - came into existence. It is unclear when the habit was first introduced into East Africa, but this might have been much later than South Asia and China. The first unambiguous evidence of betel remains on the African continent is a relatively late finding $\left(11^{\text {th }}-15^{\text {th }}\right.$ C. CE) from the site of Qușair al-Qadim (van der Veen 2011:59).

A critical assessment of the linguistic data offers new perspectives on the early dispersal of betel chewing. There is no linguistic evidence that the first speakers of Austronesian languages chewed areca nuts. The Formosan attestations are either borrowings from Chinese (and ultimately from Malay) or terms for species of the genus Pinanga or the Philippine dwarf sugar palm (Arenga tremula) (Tsuchida 1977:114). In insular Southeast Asia and the Pacific, reflexes of PMP *buaq 'fruit' are used to denote areca seeds, perhaps 'the fruit par excellence' (Blust 1995 s.v., Mahdi 1998:406). ${ }^{110}$ In South Asia, we find two sets of lookalikes not explainable in terms of Indo-Aryan or Dravidian

Figure 11: attestations of * $p u ̈(g) a$ 'areca

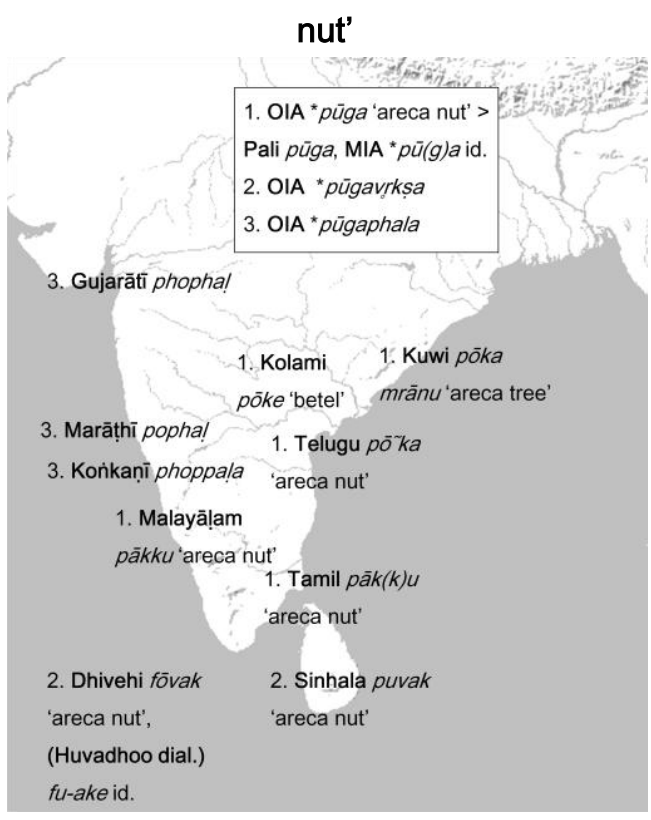
etymology: OIA *pūga (Turner 1966 \#8313) and Dravidian pāk(k)u id. (Burrow \& Emenau 1984 \#4048), as indicated in Figure 11. The relation between the above forms and the Austronesian

\footnotetext{
110 We may also compare Mon sat (๖઼์) and Thai $m a ̄ ’ k$ (หมาก), both words for 'fruit' additionally used for 'areca nut'.
} 
protoform, if any, remains somewhat obscure and is not based on regular sound correspondences. However, we may point out that püga does not occur in any early Sanskrit text except in the Suśruta-Samhita, which may be an introduction into one of the later versions of that work. The form corresponds to MIA *pūa, which resembles PMP *buaq 'fruit' more closely. This becomes more plausible in view of the fact that the sequence / büal is unattested in Indo-Aryan languages and may have become / pūal for phonotactic reasons. If the Indo-Aryan attestations indeed go back to a Malayo-Polynesian form, the form püga must be a backformation. The compounds *pügavrkșa and *pügaphala are further developments. The first consists of püga 'areca nut' and vrkșa 'tree', possibly yielding Sinhala puvak 'areca nut' (< +puvavak, Turner 1966 \#471) and Dhivehi fōvak, (Huvadhoo dial.) fu-ake id. The second consists of püga 'areca nut' and phala 'fruit', which seems to refer specifically to the dried areca nut. This word is reflected on the west coast of India, e.g. Gujarātī phophal, Marāthī pophal, Końkaṇi phoppala id. (Turner 1966 \#1814), from where it has found its way into Baluchi as phophul, Farsi pūpal, Arabic fawfal füfal, Malagasy (Antemoro dial.) foroforo (Ferrand 1904a:112, Beaujard 1998b:159); (Mayotte dial.) pôpô, Swahili popoo (<+popolo) and Comorian vovó id. The adoption of a word for 'dried nut' suggests that the product first reached these regions in its dried form, presumably due to the absence of fresh betel leaves. The Swahili reflex popoo seems to have been borrowed directly from an Indo-Aryan source and not through Arabic. An Indian introduction of betel chewing into East Africa is substantiated by the presence of Swahili terms such as katu 'cutch' (< Sindhī kāthō, Gujarātī kāthōo), pampati 'betel leaf' (< Sindhī panpatī, Gujarātī pān-patțî), patu 'betel box' (< Sindhī pātū 'brass or silver box') and sopari 'areca nut' (< Sindhī sopāri, Gujarātī sopāri) (Lodhi 2000:180, 198, 200, 214). These lexical transmissions, however, may be of relatively late date.

In addition to the lexical data given above, OIA displays the protoform *guvā-ka 'areca nut', mainly attested in Indo-Aryan languages spoken near the Eastern Himalaya region (Turner 1966 \#4219). The word occurs in the late Sanskrit Purāna-Sarvasva (Monier-Williams 1899:360). It resembles several attestations in Tibeto-Burman languages, such as Manipuri gwā 


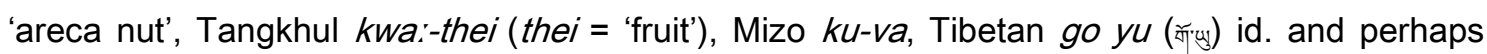
Burmese kvam: ( direction the transmission took place, if not borrowed from a now extinct third source. Santali gəa 'areca nut, betel leaf' and Khasi kwa:j (the devoicing and diphthongisation are regular) also appear to be related. In addition, the Indo-Aryan and Dravidian families display an indigenous protoform - respectively * suppāra (Turner 1966 \#13482) and *ațaikkāy (Burrow \& Emenau 1984 \#88) - which does not resemble anything found in Southeast Asia. The etymology of these protoforms is unknown to me, but reflexes of both also denote male genitals in several Indian languages (Turner $1966 \# 13482$, Subramoniam 2008:267). This may be an allusion to sexual virility or the aphrodisiacal nature of the areca nut. In many parts of Asia, a similar erotic symbolism is applied to the betel leaf, which represents the female

Figure 12: attestations of " guvā-ka 'areca nut'

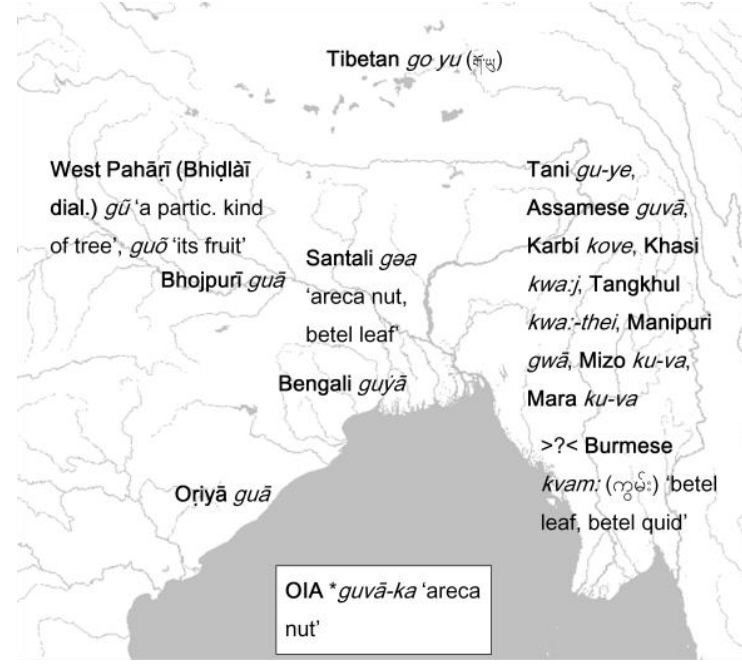
genitals. In Southeast Asia and especially the Malay World, offering betel quids is not only a sign of hospitality, but also a ritualised practice in marriage ceremonies. This is also reflected in idiomatic expressions. The Thai compound khanmā'k (ขันหมาก), for example, denotes the 'betel chewing mixture', but is also used for the 'wedding ceremony'.

As will be argued below, this symbolic relation also transpires from the terminology used in Malayo-Chamic languages, e.g. Malay (buah) pinang 'areca nut' and related forms. This Malayo-Chamic form has been borrowed extensively into the languages of insular Southeast Asia (Heyne 1927/1:393-4, 2:1141, Madulid 2001/2:25, Blust 2010:94, Mahdi 2010:5), mainland Southeast Asia (Davidson 1975:604 n.76, Thurgood 1999:300), East Asia (Tsuchida 
1977:114) $)^{111}$ and the Nicobar Islands, as illustrated in Figure 13. We may also compare Old Javanese k-inan' 'betel quid prepared for chewing' and p-inan' to invite to come'. The corresponding Malay verb məminang means 'to ask in marriage'. A plausible semantic relation

Figure 13: attestations of pinang 'areca nut'

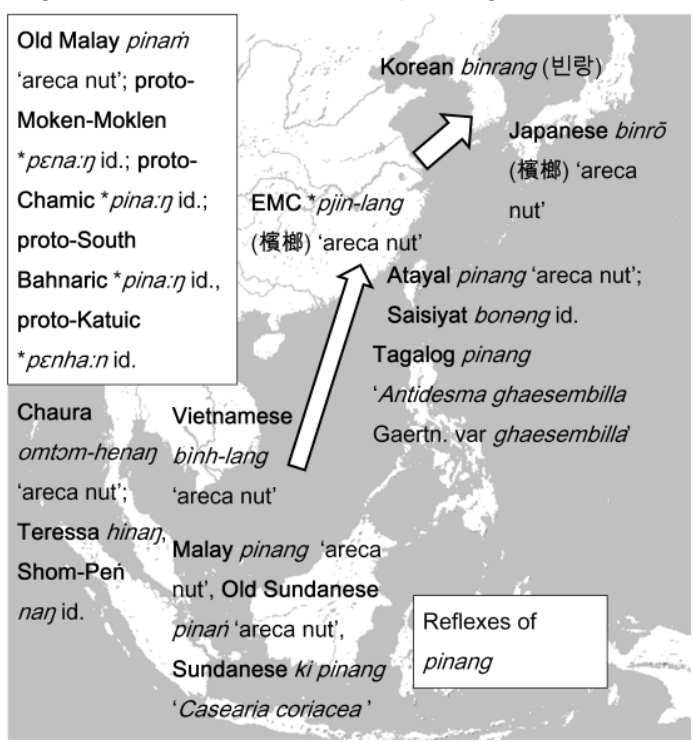

between 'inviting someone' and 'offering a betel quid' leads us to consider an Old Javanese etymology for the Malayo-Chamic reflexes of pinang. Further insights into the dispersal of betel chewing across Asia are provided by the words for 'slaked lime'. Proto-Austronesian has "qapuR 'lime, calcium', reflected from Taiwan to the Pacific (Blust 1995 s.v.). The innovation ${ }^{*} q a p u R>{ }^{+}$kapuR, possibly through a petrified prefix ka- (cf. Wolff 2010/2:958), is reflected in

several west insular Southeast Asian languages, most notably Malay kapur, and has additionally been borrowed as PMK ${ }^{*}$ knpur 'lime';112 Thai pūn (ปูน) 'lime; mortar', Lao pūn (บูบ) 'chalk, lime'; and LMC *kúă-pun (古賁) 'lime (for betel chewing)'. ${ }^{113}$

Moving on to the words used for 'betel leaf', there is no single protoform that can be assigned to proto-Austronesian. Instead, we find different sets of lookalikes, suggesting that people became acquainted with betel mastication after the divergence of proto-Austronesian and the formation of several dialect chains. Insular Southeast Asia displays a complex mosaic of tentative reconstructions for various branches of Malayo-Polynesian (Mills 1975b:633, Pallesen 1977:461, Larish 1991/2:605, Blust 1995 s.v., Lichtenberk 1998, Mahdi 2010:3-4),

\footnotetext{
${ }^{111}$ According to the $6^{\text {th }}$ C. CE Yellow Charts of the Three Regions, the areca palm - known as EMC *pjin-lang (檳榔) was introduced into China following the southward expansions of Han emperor Wŭ in the 2nd c. BCE (Groot 1894:2656, Mahdi 1998:405).

112 Given the scattered distribution of reflexes in Mon-Khmer languages and absence in the Old Mon and pre-Angkorian Khmer literary record, this form probably entered mainland Southeast Asia in a relatively late period, in any case after the break-up of PMK (Mahdi 1999b:217, 2010:7).

113 So called in Plants of the Southern Regions (Groot 1894:266-7), a Chinese botanical treatise traditionally attributed to the 3rd c. CE scholar Ji Hán but presumably of later date (Ma Tai-Loi 1978).
} 
many of which have been borrowed by languages on the Asian mainland (Heyne 1927/1:517-8, Mahdi 1994/2:477 n.155, 2010:4, Shorto 2006 \#1860). ${ }^{114}$ An overview is given in Figure 14. These attestations might also be related to a more general PWMP *bulun 'medicinal herbs'

Figure 14: attestations of *bulu 'betel leaf'

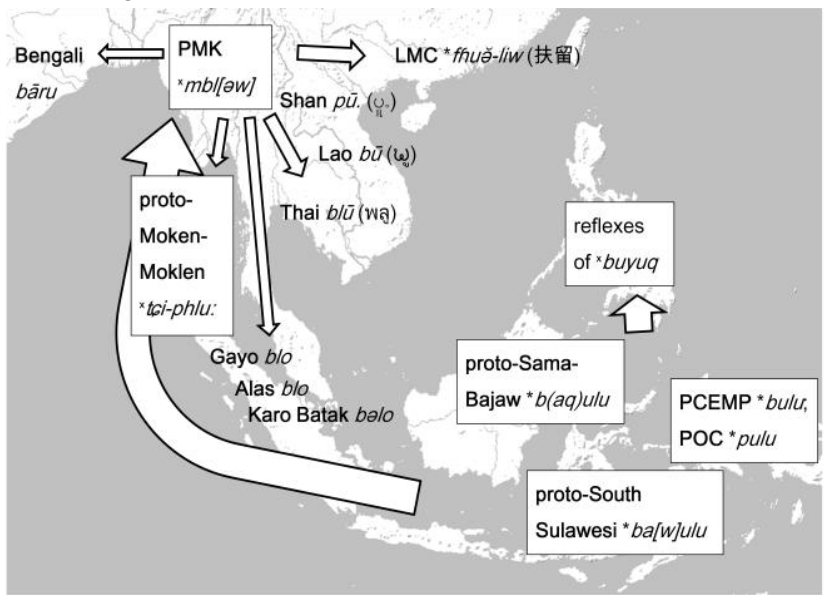

(Blust 1995 s.v.), the meaning of which shifted to 'leaf' in many languages (Mahdi 1994/2:449). Malay and several other geographically contiguous languages display cognates of a completely different form: (daun) sirih 'betel leaf' (Heyne 1927/1:517-8). This form has not been borrowed quite as

extensively as its counterpart pinang 'areca nut. The only instance known to me where this form has been borrowed into a non-Southeast Asian language is Sinhala siribō 'betel variety' (< Malay (dial.) † sirih buah 'a betel variety (Piper betle var. Siriboa)'; see Section 4.3).

Several Indo-Aryan attestations, such as Hindi pān, Bengali pān and Sinhala pānu, go back to *parna, the general Indo-Aryan word for 'leaf'. A more widespread protoform for 'betel leaf' is the OIA doublet *tāmbūlá *tāmbōla (Turner 1966 \#5776), which has been adopted into several Indian Ocean languages (cf. Figure 15). It is difficult to determine whether these forms are related to the reflexes of ${ }^{*}$ bulu listed above. The Indo-Aryan forms are often attributed to an Austro-Asiatic source (cf. Lafeber 1922:144-6, Przyluski 1929). If this were true, both the initial syllable and the word-final vowel would require further explanation. On the other hand, we may consider that $/ \mathrm{u} / \sim / \mathrm{o} /$ fluctuation in Indo-Aryan vocabulary often hints at a Muṇāā etymology (Kuiper 1991:22-3). A more conclusive analysis cannot be given until more is known about betel terminology in Muṇụā languages. Of somewhat less obscure origins are Tamil verr--ilai vell-ilai and Malayālam verr-ila, with possible cognates in other Dravidian languages (Burrow \& Emenau

114 The Plants of the Southern Regions contains the apparent Southeast Asian loanword LMC *ffhü-liw (扶留) 'betel leaf' (Groot 1894:266-7, Mahdi 2010:4). Currently, 'betel leaf' is known as lóuyè (蒌叶) or lăoyè (荖叶). Most Southeast Asian forms do not resemble the Formosan attestations listed in Tsuchida (1977:114). 
1984 \#5515). The second element of this compound means 'leaf', but the meaning of the first element is not clear. There might be a somewhat complex semantic relation with a more generic word for 'creeper' (Sanskrit valli $\sim$ velli, Tamil valli $\sim$ vallı), the ultimate origin of which appears to be Dravidian (Southworth 2005:83). The Sanskrit literature displays several compounds with this element to denote the 'betel pepper', including ahivalli, nāgavall(ar)ī, tāmbülavallī and tāmbülavallikā. ${ }^{115}$ In other words, it seems that Tamil and other Dravidian languages applied a general word for 'creeper' to the betel pepper.

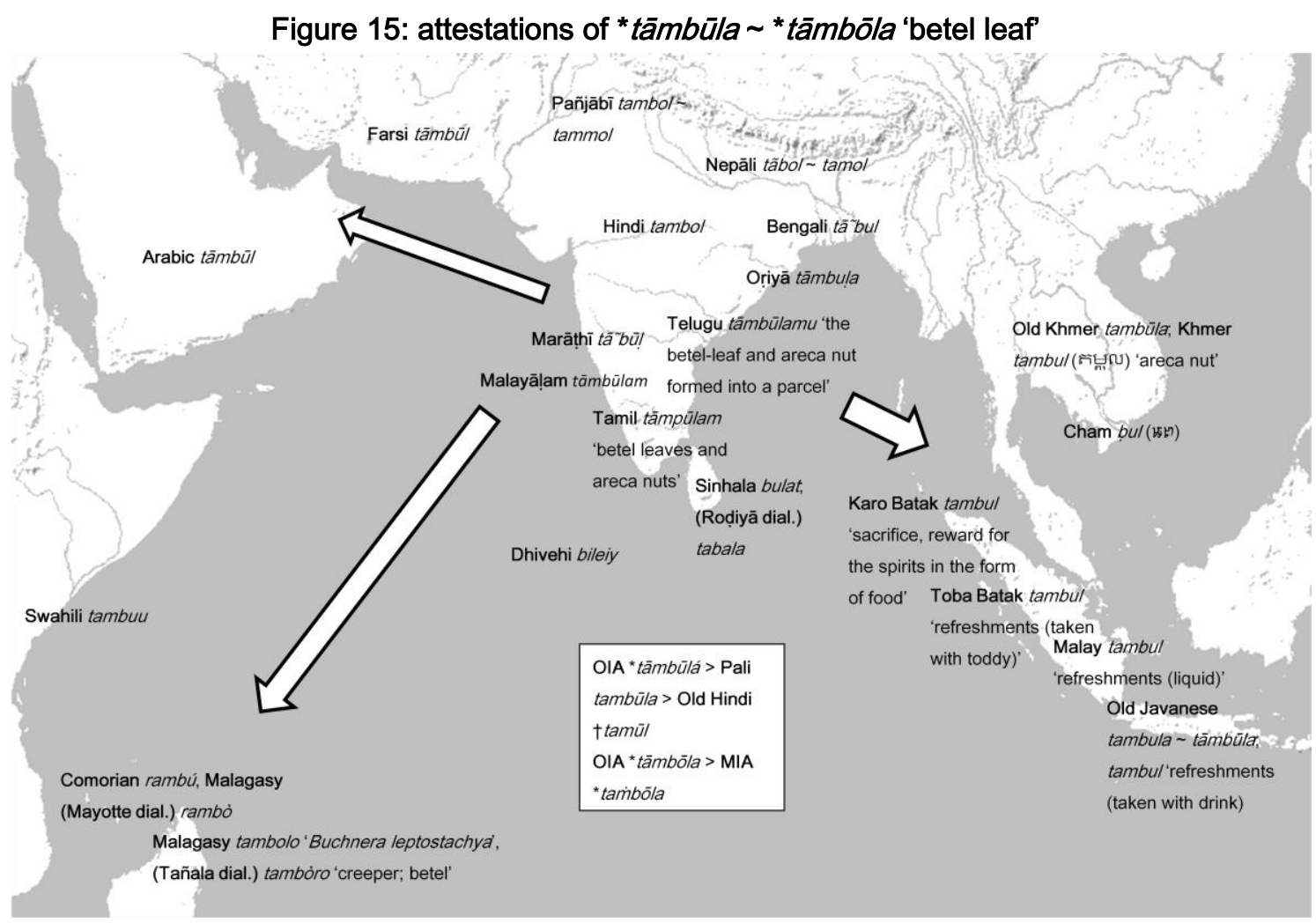

Finally, we find an interesting distribution of the words for 'gambir (Uncaria gambir)', suggesting reciprocal influence between South India and insular Southeast Asia. This was evidently the case during the colonial period, when the plant was imported from Southeast Asia (Watt 188996/vi.iv:211), but we have no archaeobotanical or other evidence of pre-modern gambir cultivation in India. The name of the gambir shrub, which originates from the Thai-Malay Peninsula, Sumatra and several other Indonesian islands, has been borrowed from Malay

115 The form nāgavall(ar)ī would translate as 'Nāga creeper', suggesting another possible connection between these semi-legendary people and the region of Southeast Asia (cf. Section 3.1). 
(gambir) ${ }^{116}$ into Tamil as kampirr. Its synonym katta-k-kāmpu appears to go back to the Malay compound gətah gambir 'gambir sap' (Burkill 1966/2:2293). ${ }^{117}$ Exchange of betel-chewing traditions between Southern India and the Malay World also took place in the opposite direction. At least since colonial times, Indian 'cutch' - used for mastication and as a laxative - was imported into Aceh by the South Indian Kaling community (Djajadiningrat 1934:679). The Tamil word kācu 'cutch' has also been borrowed into Malay (kacu) and several contiguous languages (hence the English 'cachou'). In addition, Malay cuku 'dried gambir root' goes back to Tamil cukku 'dried ginger' (< Sanskrit śușka 'dried'.).

In conclusion, the archaeological and linguistic data favour a scenario in which the habit of betel chewing was invented in insular Southeast Asia and has subsequently spread to South Asia and the Southeast Asian mainland, although knowledge of the separate ingredients of the betel quid might have existed previously. The Indo-Aryan and Dravidian lexical data are somewhat problematic and not unambiguously attributable to an Austro-Asiatic or MalayoPolynesian source. However, their similarity with Southeast Asian attestations, the absence of betel chewing in the earliest Indian literature, and the insular Southeast Asian provenance of both the areca palm and the betel pepper compels us to assume a westward distribution from Southeast Asia into the Indian subcontinent. From South Asia, the habit was propagated further to the west along the trade routes connecting the subcontinent with the Middle East, East Africa and Madagascar.

\subsection{Coconut palm}

The coconut palm (Cocos nucifera) is a large, pinnate-leaved palm with a straight or slightly curved stem. The tree is currently found throughout the tropics, where it is mainly cultivated for its nuts. In addition, practically every other part of the coconut palm can be used, making the

\footnotetext{
116 Cf. Tausug gambia, Cham gamar ( $(\xi 3)) \sim$ gamorr ( 1927/ii:1386).

117 The first element of this Malay compound, gətah 'tree-sap, latex', appears to be a borrowing itself (< Sanskrit $\sqrt{ } k v a t h$ 'to decoct'; hence Hindi kath 'cutch').
} 
tree of high economical value and cultural significance. Its leaves (cadjan) are used for roofthatching, mats or baskets, while the leaf-veins can be bound together to make brooms. In Indonesia, the young pale coconut leaves (janur) are made into ceremonial decorations. The roots of the coconut palm are used medicinally against various illnesses, including dysentery (Heyne 1927/1:400). Its wood, known as "porcupine wood", can be used for house construction and boat-building in the absence of more suitable timbers. The sweet sap of the inflorescence (toddy) can be boiled down to make palm sugar (jaggery) or distilled to make either vinegar or a strong spirit (arrack), although palm species of the Borassus and Arenga genera and sugarcane are preferred for this purpose. ${ }^{118}$ Finally, the haustorial organ or "coconut apple" of a germinating embryonic nut can be eaten raw or pickled (Watt 1889-96/ii:448, Heyne 1927/1:401).

The coconut is characterised by various stages of development. After flowering, a green fruit bud develops. In the Malay World, these young fruits (mumbang) are used medicinally. As the nut ripens, a shell develops within (endocarp), whereas the outer skin (exocarp) and the husk (mesocarp) become harder and darker. An air cavity develops on the inside, allowing the formation of kernel liquid. This substance, commonly known as coconut water, is enjoyed as a refreshing beverage throughout the tropics. At a later stage, the husk gradually becomes drier and the kernel meat (endosperm) develops, at first thin, creamy and transparent and later succulent, firm and white. The coconut meat, also known as desiccated coconut, is used to make coconut milk and other culinary condiments. At the next growing stage, the exocarp becomes brown, the kernel liquid turns bitter and the endosperm becomes harder and thicker, after which the dry nut falls from the tree and sprouts. As is the case with parts of the coconut palm in general, almost all parts of the nut can be used. Coconut shells are used as drinking

\footnotetext{
118 In Old Javanese literature, we find kilari 'a fermented drink made from sugar-cane' (Zoetmulder 1982/1:868), cf. Javanese kilang 'condensed sugar syrup (boiled)', Malay (Sumatra dial.) kilang 'a fermented drink obtained from canesugar or palm-sugar', Gayo kilang 'a sugarcane drink', llokano kílang 'k.o. tree whose bark is used in the fermentation process of sugarcane wine', Cebuano †kilang 'wine from sugarcane'. Presumably, there is a semantic connection with Malay kilang 'mill-stone; roller or crusher; mill', Acehnese kilang 'sewing machine', Gayo kilang id. and perhaps Toba Batak hilang 'deception, dishonesty' and Karo Batak kilang 'fraud, dishonesty, deception'.
} 
beakers, bailers, resonators for musical instruments and coals for goldsmiths (Heyne 1927/1:402, Burkill 1966/1:617, Kapil \& Bhatnagar 1976:451), whereas the coarse fibre from the husks of matured fruits (coir) is manufactured into ropes, mats or mattresses after a process of manual removal (de-husking), beating, soaking and re-drying. Coir ropes play a key role in the boat-building traditions of South Asia (Varadarajan 1998:50-81). The word for 'coir' is taken from Malayāḷam kāyar 'cord' (Yule \& Burnell 1903:233), whose Arabic rendering tqaiyār (قيار) appears to have been misread as †qanbār (قنبار) in the wider literature, hence Swahili kamba 'coir'. The sundried kernel meat (copra), in addition to its nutritional value, can be grated and boiled to produce coconut oil. In India, this oil is traditionally used for lamps, to make soap and to adorn the body (Watt 1889-96/ii:441). The de-oiled residue (poonac) is rich in proteins and is used as fodder for domestic animals. ${ }^{119}$

The coconut palm has a large number of different cultivars, reflecting mankind's continuous attempts to improve its quality, productivity and shape (Foale 2003:21). Recent research on coconut phylogeography points out that there were at least two separate domestication events of the tree, resulting into two highly differentiated genetic subpopulations corresponding to the Pacific and Indian Ocean basins, the latter probably from a South Indian or Sri Figure 16: coconuts for sale (Malé, the Maldives)

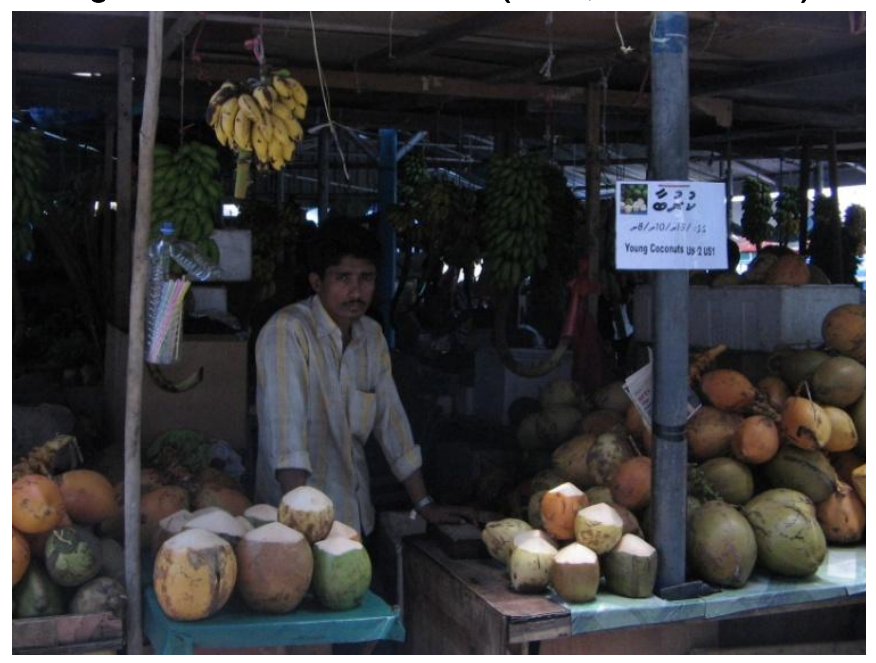
Lankan centre of domestication, with admixture between the two populations occurring in East Africa (Lebrun 1998, Gunn et al. 2011). This dual origin sheds new light on earlier theories of coconut dispersal. Hornell (1920d:221ff.),

\footnotetext{
119 On the given coconut terms in English, Yule \& Burnell (1903:36, 139-40, 233, 254, 446, 927) provide the following etymologies: 'cadjan' from Malay kajang, 'toddy' from Hindi tārī, 'jaggery' from Malayālam cakkara (< Sanskrit śarkarā 'candied sugar'), 'arrack' from Arabic 'arq, 'coir' from Malayālam kāyar 'cord' and 'copra' from Malayālam koppara or Hindi khoprā. In addition, the word 'poonac' is from Tamil punnākku.
} 
for example, correlates the introduction of the coconut - purportedly from Indonesia to Sri Lanka and thence to the mainland - with the migration of certain Sri Lankan palm tree cultivator and toddy-tapper castes known as TIVān, İlavañ or Cānārto coastal South India (Caldwell 1875:110; Iyer 1909:277, Thurston 1909:37-8). This hypothesis, which has found its way into the wider literature, is based on a number of assumptions. The Tamil word for 'coconut', it is argued, is tērikāy, which can be explained as 'fruit from the South', alluding to its presumed insular origins. This etymology, however, is not watertight, as tēnkāy can equally well mean 'sweet fruit'. In further support of an insular origin of the coconut palm, scholars have pointed out that coconut cultivation plays an extremely marginal role in the large corpus of Indian literature prior to the beginning of the Common Era (Kosambi 1965:189, Mahdi 1998:396ff.), suggesting that it was carried out by peripheral, coastal populations but not (yet) by the early Brahmins. Hornell (1920d:232ff.) believes that these coastal populations were of partly Southeast Asian ancestry and cites the results of cranial measurements conducted among several communities to support this claim. In the absence of more solid data supporting this tentative Southeast Asian element, a Sri Lankan origin of the coconut palm in South Asia is the most plausible scenario. In Sri Lanka, the tree may have been domesticated independently.

The dual domestication of the coconut tree corresponds to two main protoforms: PMP *niuR and OIA *nārikēla. PMP *niuR 'coconut tree' is regularly reflected in insular Southeast Asia and the Pacific (but not in Taiwan). OIA ×nārikēla 'coconut tree' has a somewhat unsettled character (cf. Turner 1966 \#7075) suggesting borrowing, although I do not agree with the view that the OIA form is connected to or derived from the Malayo-Polynesian form (pace Chatterji \& Bagchi 1929:xxii, Merrill 1939:123-4, Blench 2008:122). Instead, a Dravidian etymology from *nari 'fibre, rope'120 + "ket-i a u 'tree, bush', as first suggested by Bloch (1930:740) and later reaffirmed by Southworth (2005:82), seems to be more in line with the linguistic data. Either way, the Indo-Aryan form spread throughout South Asia (e.g. Turner 1966 \#7075), from which it was adopted as Farsi nārgì 'coconut palm', Arabic nārağīl, Somali naarajïn, Swahili nazi and

\footnotetext{
120 Also compare Dhivehi nāř̀ 'coconut shell or husk'.
} 
Comorian nadzíid. ${ }^{121}$ In addition, the traditional coconut growing regions of the world display a large amount of specific vocabulary, including terms for different cultivars, parts of the tree, growing stages of the nut and items manufactured from the tree. Although many of these terms are of descriptive nature and vary from one language to another, a small set of terms have been borrowed cross-linguistically. The Malay word kəlapa, referring predominantly to what Burkill (1966/1:607) describes as 'the dry nut which the trader stocks and carries about', seems to be a borrowing from Sanskrit kaläpa 'bundle', alluding to the way in which the nuts were sold. ${ }^{122}$ The word for 'young coconut' has the following three sets of lookalikes:

- Malay kəlambir kərambil 'young coconut'; with many cognates in Sumatra and Java (Heyne 1927/1:398, Clercq 1927:60-1)

- $\quad$ = Tamil kurumpai 'young coconut, for drinking', Malayāḷam kurumba, Kannaḍa kurumbe; from a South Dravidian source > Sinhala kurumbā, Dhivehi kuruñbā kuruñbai id.

- $\quad$ = Swahili urambe-urambe (Sacleux 1939:968) ulambilambi 'coconut with soft flesh' (Madan 1903:400)

Although it is tempting to envision a relation between these forms, there are two main reasons not to do so. First, the three sets cannot be reconciled with each other on phonological grounds: the Dravidian attestations display discrepancy in the second vowel, the Swahili form lacks the word-initial $/ \mathrm{k} /$, and both lack the word-final consonant of the Malay form. Second, all the above attestations are explainable by internal etymologies. The original meaning of the Malay forms is 'soft and swaying', probably on account of the gelatinous structure of the kernel meat in the young coconuts. The Dravidian forms display cognate words denoting 'young' and 'to sprout' (Burrow \& Emenau $1984 \# 1791$ ). The Swahili form has been connected to the root $\sqrt{ }$ lamba 'to lick', hence ulambilambi 'something that can be licked' (Novotna 2000:63). Therefore, I am

121 Presumably also related are the textual attestations argellia (Topographia Christiana) and naúplios (Periplus). The latter is usually emended to nargilios, which resembles its tentative Indo-Aryan precursor even more. Casson (1980:497) disagrees with this view and argues that naúplios refers to a 'little nautilus shell'.

122 To the best of my knowledge, this was first pointed out by Uri Tadmor (2009) in the online database at http://wold.livingsources.org/ (s.v., accessed Mar 2011) 
inclined to attribute the above similarities to chance resemblance. Swahili ki-tamli 'k.o. coconut' also appears to be unrelated to Malay kərambil on account of evident phonological and semantic discrepancy (pace Teubner 1974:635). As suggested by Krain et al. (2002), a likelier precursor of this word is Sinhala tæn̆bili 'king coconut (Cocos nucifera var. aurantiaca)' - cf. Tamil cevvilai id. - a variety bearing yellow, ovoid nuts famous for their sweet juice. In addition, the Malay word kajang 'mat-awning' has found its way into Tamil. In the Malay World, thatching is done with the leaves of several palm species, especially the mangrove palm (Nypa fruticans). This word has been borrowed twice into Tamil: 1) kacanku 'wild date-palm; stalk, as of the dateleaf used in making plaited baskets' and 2) karicaniku 'temporary roof of coconut leaves put up in an Indian raft for protection against inclemencies of weather'. It was also borrowed into several Southeast Asian languages, e.g. Toba Batak hajang 'a cottage in the field to spend the night', Angkola-Mandailing Batak hajang 'k.o. mat, made of pandan etc.', Moken (Myanmar var.) kajang 'roof, cover of boat', Tausug kajang id. and Thai krajǣn (กระแชง) 'removable convex roofing sheet for boat transporting grain'. ${ }^{123}$

Finally, we may call attention to the words for 'palm wine'. Two apparently cognate sets attest to a relatively wide geographical distribution and considerable level of antiquity in insular Southeast Asia (cf. Figure 17), although both sets display a fair amount of irregularity, suggestive of secondary, non-inherited distribution (Heyne 1927/1:324-5, Adelaar 1995a:1630, Blust 2000:119, 2008:109). Of these forms, the Malay reflex tuak has been borrowed into Central Nicobarese (toak) and Malagasy (toaka). Traces of this word also survive in the literary

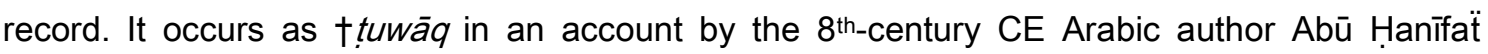
(Ferrand 1913-14/1:295). It has also found its way into the Tamil language, which normally displays kal' 'toddy'. Interestingly, Tamil also exhibits the forms tuvacar 'toddy-sellers, dealers in spirituous liquors' and tuvaca-marikaiyar 'women selling toddy'. The insular Southeast Asian

\footnotetext{
123 The Malay word itself presumably goes back to Javanese kajang 'roof of dried palm leaves'. In Javanese, several words related to the use of vegetal materials for manufacturing purposes contain the element jang, e.g. anjang 'bamboo lattice-work', mbranjang 'wide apart (of woven bamboo etc.)', janjang 'a cluster of coconuts or salak', kranjang 'rattan or bamboo woven basket', ranjang 'bedstead', tanjang 'to intersperse plants with new ones', etc.
} 
provenance of these words seems beyond doubt, although the exact route in which they spread to southern India remains obscure. It is tempting to speculate that some of the toddy-selling castes were of Southeast Asian origin. In that regard, we may also note that Malay nira 'fresh palm-sap' is borrowed from Sanskrit or Tamil nirra 'water; juice, liquor'. The adoption of this South Asian word into Malay is additional evidence suggesting that Malay toddy-sellers once operated in the subcontinent, adopting local terms such as nira and kəlapa. In addition, Beaujard (2010:370, 2011:181) argues that Swahili tembo 'toddy' (> Comorian trembo id.) is derived from Malay təbu 'sugarcane', which would suggest that Malay-speaking toddy-tappers played a similar role in East Africa. As mentioned previously, both sugarcane and palm species are used in the Malay World to produce alcoholic spirits.

Figure 17: attestations of tuba? and tuak 'toddy'

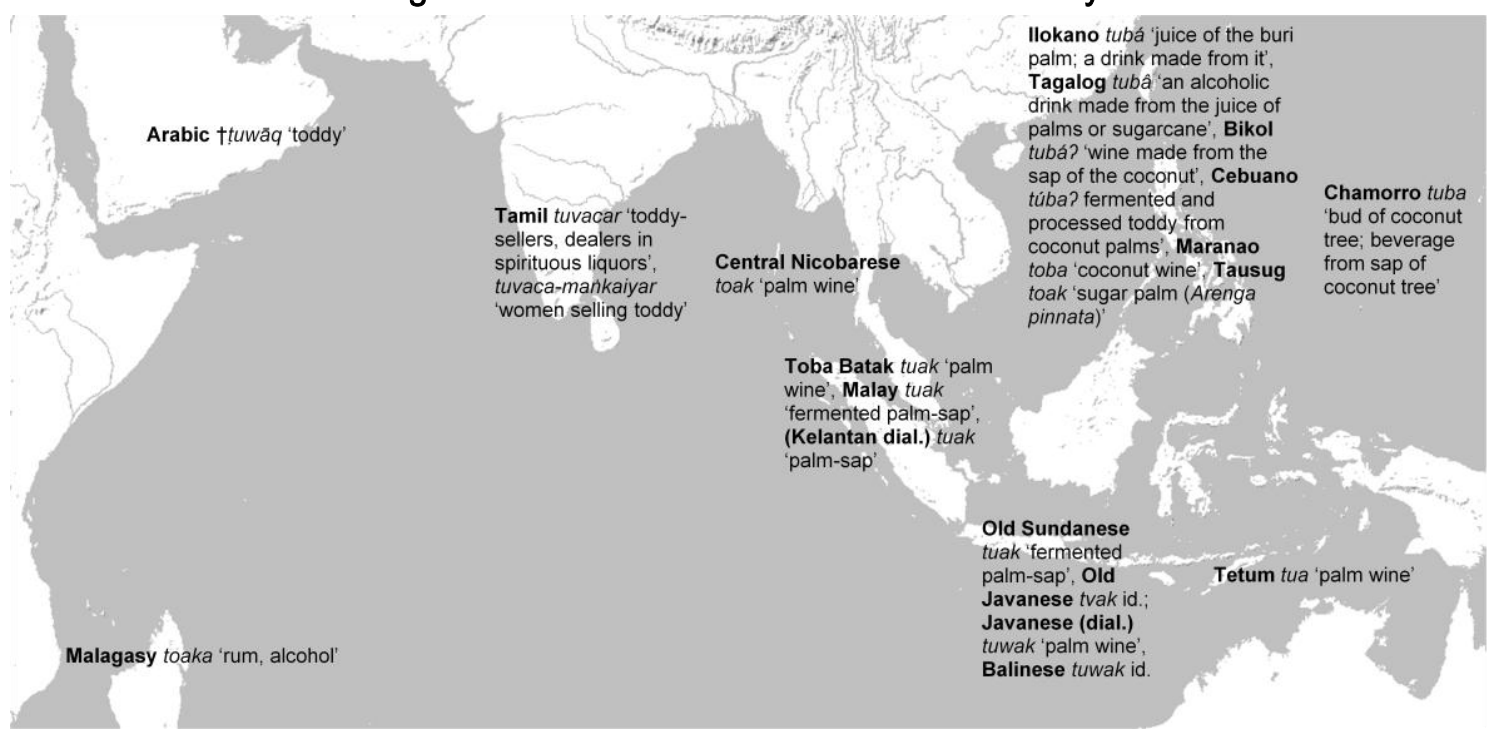

\subsection{Bananas and plantains}

The banana family (Musaceae) has two genera that provide food. Species of the genus Ensete, commonly called "ensets", are cultivated for their fibre, subterranean corm and edible young shoots. In East Africa, the "false banana" (Ensete ventricosum) is the staple for millions. Its fruits are mashed, cooked and eaten as thick porridge or fermented and made into banana beer (Knappert 1987:76). Several species of the taxonomically related genus Musa, found in wild populations across Asia and the Pacific (Fuller \& Madella 2009:334, 337), have edible fruits. 
The starchier cultivars that need to be cooked before consumption are known as "plantains" or "cooking bananas" and the sweet, ready-to-eat cultivars are called "(desert) bananas". In older literature, plantains are referred to as Musa paradisiaca, whereas seedless banana varieties are called M. sapientum, but this classification is no longer regarded as accurate. Plantains are

Figure 18: unripe banana bunch with blossom

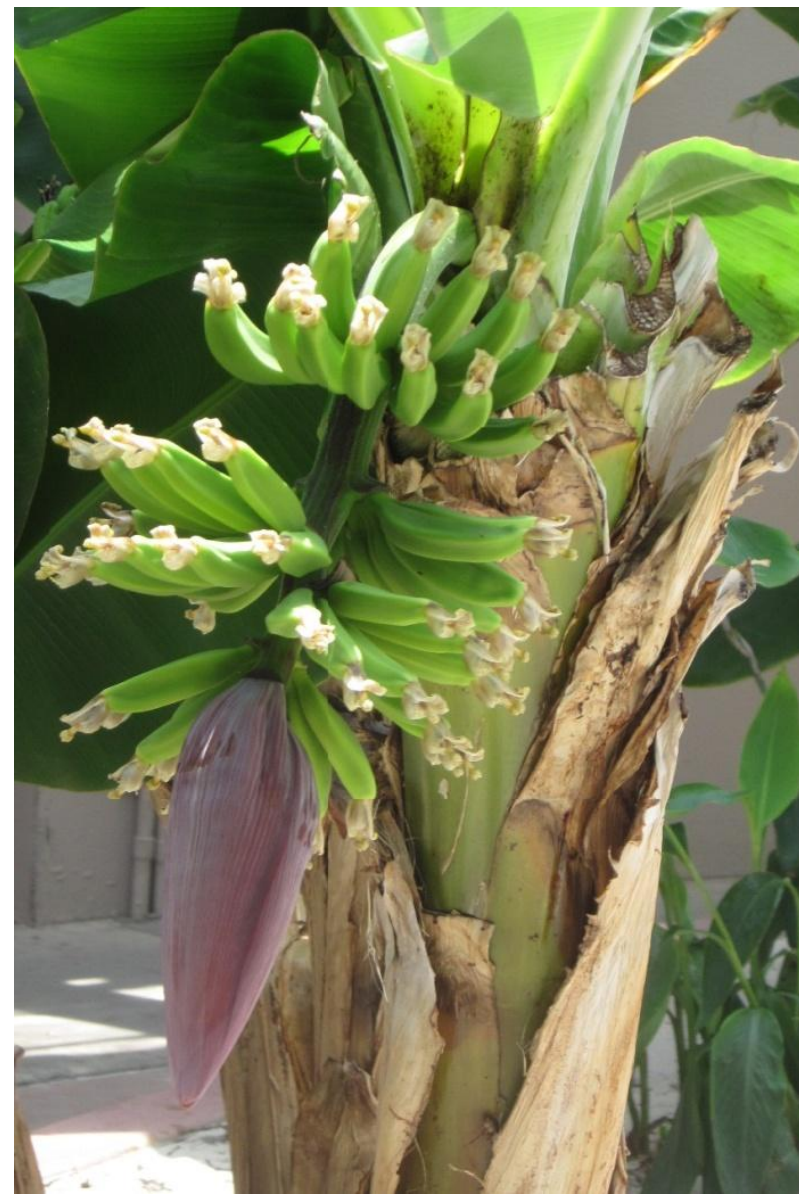

used as staple food in several parts of Africa and the Indo-Pacific (Heyne 1927:465, Fuller \& Madella 2009:335). Together with the recently introduced sweet potato (Ipomoea batatas), the plantain continues to be one of the most widely consumed food-crops in New Guinea and forms the sole staple for several communities (Ross et al. 2008:275). The tender core of the plant's trunk and its inflorescence (flower bud) are consumed raw or cooked in many of the South and Southeast Asian regional cuisines, while the aromatic leaves are used as food containers or packing material. The fibres from the leaf sheaths are used for various purposes, although the fibres of the related Manila hemp (Musa textilis) are preferred in Southeast Asia. Finally, the rhizome and pseudostem are known for their medicinal properties in the Malay World (Heyne 1927/1:464).

The seedless, edible Musa cultivars were probably first domesticated in New Guinea from wild subspecies of Musa acuminata, in some regions cross-bred with subspecies of $M$. balbisiana (Langhe \& de Maret 1999, Carreel et al. 2002, Denham \& Donohue 2009:18). The earliest evidence for banana cultivation is from a site in the Kuk Swamp in highland New Guinea, where banana phytoliths appear by 5000-4500 BCE (Denham et al. 2003). From New 
Guinea, edible banana cultivars were dispersed into the Asian mainland and the Pacific. ${ }^{124}$ The tentative presence of bananas in the pre-Columbian New World is still a matter of controversy (cf. Langdon 1993). Since bananas do not produce seeds, pollen or lignifying tissues, they do not show up easily in the archaeobotanical record. The only direct evidence of bananas in the African continent, for example, comes from a medieval context of the site of Qușair al-Qadim (van der Veen 2011:98-100), where unusually arid conditions resulted in their desiccation hence preservation. The discussion of earlier banana findings, on the other hand, is mainly based on the identification of robust, microscopic silica bodies known as phytoliths. In South Asia, for example, Musa phytoliths have been identified in Koṭ Dijī (Pakistan) in a late $3^{\text {rd }}-$ early $2^{\text {nd }}$ mill. BCE context (Madella 2003). While an increasingly intimate understanding of phytolith and starch residues is becoming instrumental in evaluating early banana findings, some problems remain unresolved. Two oft-cited claims for early bananas in Africa remain subject to controversy. The first was identified in pits at the Nkang site (Cameroon) dated to the $1^{\text {st }}$ mill. BCE (Mbida et al. 2000, 2001, 2006), the second in a geological trench at the Munsa site (Uganda) reported from levels dated to the $4^{\text {th }}$ mill. BCE (Lejju 2005, 2006). In contrast to the ensets, Musa species are not indigenous to Africa. Their tentative early presence in the African archaeobotanical record, therefore, implies anthropogenic introduction and cultivation, which has far reaching implications for our understanding of prehistoric Africa and its agricultural systems. On the other hand, both early African banana claims are based solely on phytolith evidence, arousing concerns about the stratigraphic integrity of the site and the proposed chronology (especially of the Munsa findings) and the possibility of misidentification given the presence of indigenous enset varieties with very similar phytolith morphologies (Mbida 2005, Vansina 2003, Neumann \& Hildebrand 2009). Future research is hoped to clarify these issues.

Not surprising given the abundance of indigenous ensets and wild bananas across the tropics, the linguistic data show a complex picture of banana and plantain terms. West African

124 See Blench (2009:365-7) and Neuman \& Hildebrand (2009:353-4) for an overview and assessment of the relevant literature. 
languages, for instance, have undergone semantic expansion in their terminology, so that terms for pre-existing inedible Musaceae species were applied to more recently introduced edible banana varieties (Blench 2009:368-9). Insular Southeast Asia and the Pacific display a wide variety of banana terms. In these regions, the dispersal of edible bananas from a New Guinean homeland is partly supported by linguistic data: the protoform * $m u k u$, first reconstructed by Verheijen (1984:61), is widely reflected in the Southwest Pacific, Nusa Tenggara and the southern Maluku Islands and is believed to be pre-Austronesian (Denham \& Donohue 2009:21ff). By far the most widespread Austronesian protoform is * puti, reflected in Taiwan, insular Southeast Asia, the north coast of New Guinea and the Pacific (Wolff 2010/2:945-6). This protoform shows one of the clearest cases of transoceanic dispersal. Although the most common Malagasy word for the fruit (akondro) goes back to proto-Bantu *kòndè, inherited reflexes of *puti 'banana' are still attested as (a)fontsy in some of its dialects (Flacourt 1658:119, Simon 1988:283, Berchem 1989-90:63). Speakers of other Malagasy dialects apply this name to the traveller's tree (Ravenala madagascariensis), which physically resembles the banana tree. Two attestations in north-eastern Tanzania, Shambaa huti and Bondei huti, also appear to be derived from this form (Blakney 1963:58-9, Kent 1970:55 n.63, Langhe 1995:8, Beaujard 200304:64 n.14, 2007:37 n.19). ${ }^{125}$ Another hint at the introduction of banana cultivars from Madagascar into coastal East Africa is the Bajuni word ibuki 'plantain', which contains the toponym Buki 'Madagascar'. Madagascar was probably not the only place from which cultivars were introduced. The Swahili word maso 'k.o. banana' ultimately hails from a South Asian source and was presumably acquired via the Middle East through the monsoonal trade routes of the Arabian Sea, cf. Sanskrit mauca moca 'fruit of banana or plantain tree', ${ }^{126}$ Hindi mocā 'banana', Bengali mōcāa 'a cone of the banana'; Aramaic $m-w-z-\bar{a}$ 'banana', Arabic mawz $\sim$ mūz,

\footnotetext{
125 The elision of the initial consonant is not an entirely isolated phenomenon, cf. Malagasy (Tañala dial.) òntsy 'k.o. banana', (Antanosy dial., 17 $7^{\text {th }}$ C. CE) ontsi outsi 'banana' (Beaujard 1998a:524); (Sakalava dial.) ontsy, (Betsileo dial.) otsy (Berchem 1989-90:63); (Mayotte dial.) (h)óntsy, Makasar unti, Bugis utti, Embaloh unti id., Karo Batak uncim 'k.o. banana' (Tuuk 1865:420, Adelaar 1995b:92). Berchem (1989-90:63) suggests that the Swahili form ndizi 'k.o. banana' may also be related, but this etymology is rather weak.

126 Similar looking Dravidian forms refer to the 'plantain flower' (Burrow \& Emenau 1984 \#5138).
} 
Farsi mawz $\sim$ mūz and Somali muus id. Though these isolated examples reflect some of the transoceanic transmissions, most of the African banana terms are not connected to Asian words. ${ }^{127}$

Moving back to Asia, a wide-ranging study of banana terminology has been conducted by Donohue \& Denham (2009), in which it is argued that one of the several Malayo-Polynesian protoforms for 'banana' ("qaRutay) has yielded various Indo-Aryan, Mon-Khmer and Tai-Kadai reflexes - cf. Hindi kelā, Sinhala kehel, Thai klûai(กล้วย), South Nicobarese təlu:iand numerous other forms listed by the authors - via a complicated set of intermediate stages. Earlier scholars have often claimed an Austro-Asiatic etymology for these reflexes following Przyluski (1929:4-5). However, there is no evidence that speakers of Muṇā languages were instrumental in the distribution of banana cultivars. Instead, a comparison of the available linguistic data leads us to believe that they probably obtained their banana terms from Indo-Aryan languages rather than the other way around (Osada 2009:134). Shorto (2006) gives several co-existing Mon-Khmer reconstructions ("t1/uuy[ ] *t1/uəy? 'banana', "priit "priat id. and *kdo? 'plantain bud'). Dravidian protoforms for 'banana', too, differ from one branch to another (Southworth 2005:211, 227 n.27), although it is not clear whether they represent wild or cultivated bananas. The presence of wild bananas in parts of India and Sri Lanka (Kajale 1989, Fuller \& Madella 2009) strongly suggests that people were familiar with the undomesticated fruit, which would explain the observed diversity in banana terminology.

In summary, all regions in which banana cultivation has a sufficient time-depth display a rich and complicated banana terminology, including different protoforms not easily reconciled with each other. Several factors account for this situation. If the identification of New Guinea as a centre of banana dispersal is correct, we are dealing with the world's most diverse region in terms of languages and language families. Since its original domestication, people have used a wide variety of terms for 'banana'. In addition, the presence of ensets and other uncultivated populations of Musaceae genera in several parts of Asia and Africa implies that the banana

127 Pace Blakney $(1963: 59,72)$, who suggests that proto-Bantu *kòndè 'banana' is related to OIA * kadala id. 
concept was already lexicalised in many languages, reducing the need to adopt a foreign word for newly introduced cultivars. In other instances, people used an existing local term to refer to bananas. Hence, several of the protoforms reconstructed for 'banana' may have originally referred to other fruits, in the same way that the banana was known as "fig" by the early Europeans (Yule \& Burnel 1903:715).

\subsection{Citrus cultivars}

Citrus trees are small evergreens known for their acidic fruits. The genus Citrus is believed to originate from the corridor connecting mainland Southeast Asia, Northeast India and Yunnan. At present, citrus fruits are predominantly cultivated for their culinary properties, in particular the sweet orange (C. sinensis), mandarin (C. reticulata) and grapefruit (C. paradisi). Nevertheless, human consumption may have been a relatively late addition to the wide range of functions that people have attributed to citrus fruits. Citric acid can be used as a sanitizer, disinfectant, insecticide, fungicide and medicine for various diseases. Indeed, the first citrus variety introduced into Europe and the Middle East from India was the inedible citron (C. medica), which was used medicinally and in (Jewish) religious ceremonies. Sweet varieties from China and Southeast Asia arrived on the scene much later (Burkill 1966/1:569, Zohary \& Hopf 1994:173). Our understanding of citrus taxonomy is still quite rudimentary. Citrus fruits hybridise easily, accounting for an unclear number of species and difficulties in reconstructing their early phylogeographic dispersal. ${ }^{128}$ The lemon (Citrus limon), for example, is probably a citron-based cultivar (C. medica) with phylogenetic contributions of pummelo ( $C$. maxima) and mandarin ( $C$. reticulata) subspecies (Gulsen \& Roose 2001). Conventional thinking has it that citron cultivation commenced in the area of present-day Northeast India and northern Myanmar. More recently, Gmitter \& Hu (1990) have made a convincing case for origins in Yunnan, South China, where uncultivated citron populations are found in the wild. Other citrus cultivars, such as the

128 It is generally accepted that most citrus genotypes are derived from the pummelo (Citrus maxima), citron (C. medica) and mandarin (C. reticulata). See Tanaka (1954), Mabberley (1997), Woodford (2005), Nicolosi (2007) and Nicolosi et al. (2000) for a detailed treatise of citrus taxonomy. 
mandarin orange (C. reticulata) and the bitter orange ( $C$. aurantium), probably originate from the same region. The round, green citrus varieties known as 'limes' are native to Southeast Asia. The best known lime species are the key lime (C. aurantiifolia) and kaffir lime (C. hystrix).

The global dispersal of citrus cultivars is of particular interest to linguists. The words used for 'lime' - together with a (possibly) related set of words denoting 'lemon' - are among the world's most widespread borrowings. As will be demonstrated below, European languages have obtained their words for both 'lemon' and 'lime' through distinct lines of borrowing from Farsi ( (Iimū vs. lïmūn) through Arabic ( $\lim (a \operatorname{t})$ vs. laymūn). Arabic medieval accounts lead us to believe that the fruits were imported into the Middle East from India, perhaps by Persian merchants (Glidden 1937:381ff., Nicolosi 2007:24-5). Although the linguistic data support this scenario, the word used by early authors may have denoted either 'lemon', 'citron' or 'lime' (Johnson

Figure 19: kaffir lime tree (Citrus hystrix)

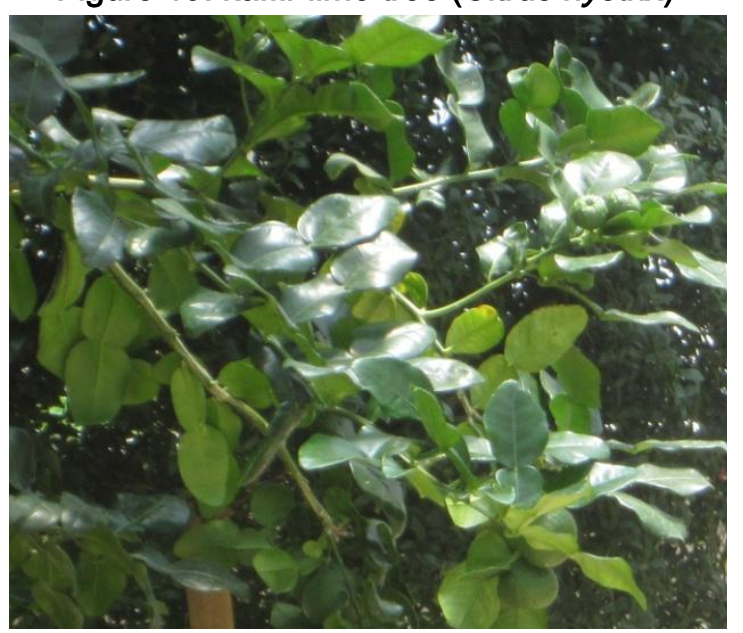

1936:50). The apparently related Sanskrit form ${ }^{*}$ nimbū is not attested in any literature prior to the Rajjanighantu (Glidden 1937:386), a $13^{\text {th }} \mathrm{C}$. CE Sanskrit lexicon on herbs, suggesting that the denoted fruit was an introduced species in the Indian subcontinent as well. A century prior to its earliest attestation in the Indian literary record, we encounter the word in a Chinese botanical account by Fàn Chéngdà as LMC */iaj-məwn (黎朦), after which it recurs in various contexts and renderings throughout the Chinese literature (Laufer 1934:145ff.), cf. modern Mandarin níngméng (橿檬) ‘lemon', hence Vietnamese nịh mông id. Again, it is impossible to determine which variety was meant in these literary sources. The great variation in Chinese transcriptions strongly suggests that the word is borrowed. From southern China, this word was probably propagated westwards by Persian merchants, e.g. Farsi limmūn 'lemon, citron', Arabic laymūn 'lemon' and eventually the European words for 'lemon'. 
It has been pointed out that many Indo-Aryan attestations display fluctuation between /n/ /// and between /e/ /i/ (Mahdi 1998:408, Southworth 2005:215). The level of irregularity in the vernacular attestations and the late occurrence of the literary Sanskrit form put into question the hypothetical reconstruction of OIA ${ }^{x}$ nimbū. Instead, we may consider the possibility of a back-formation from a vernacular term (cf. Hindi limmū 'lime', Nepāli nibu nĩbu, Bengali lēbu id.). Uhlenbeck (1898-99:148) suggests that the hypercorrected form nimbū may have been influenced by OIA *nímba 'neem (Azadirachta indica)', another tree used in traditional Indian medicine. In any case, foreign introduction is the most plausible scenario to account for its late occurrence in the literature. Early scholars have suggested various Austro-Asiatic precursors of the word *nimbū in Indo-Aryan languages. However, the Muṇ̂ā attestations appear to be derived from the Indo-Aryan forms upon closer inspection, rather than the other way around (Osada 2009:136), while Mon-Khmer languages display unrelated reflexes of ${ }^{*} k r u ə c \sim{ }^{*} k r u u c$ 'citrus', cf. proto-Chamic *kruac 'citrus' (Thurgood 1999:324) and Old Chinese kjuĕt (栐) ‘orange' (Shorto 2006 \#846). A Dravidian etymology is equally unlikely based on the form of the Dravidian attestations (cf. Burrow 1945:614-5, Burrow \& Emenau 1984 \#836). ${ }^{129}$ The original precursor of all the Dravidian attestations displayed a word-initial /I/, which subsequently obtained an intrusive /\#i/ or became /n/ for phonotactic reasons (Burrow 1945:614-5). In other words, the forms were probably borrowed into the Dravidian languages as well. Figure 20 gives an overview of these forms.

\footnotetext{
129 Three other Dravidian protoforms for citrus fruits have been reconstructed, although it is difficult to determine which Citrus subspecies or (unrelated) fruit-bearing trees they originally referred to. These reconstructions are *kiccili, *mātulam and *nāram (Burrow \& Emenau 1961 \#1512, \#3653, \#4808). The latter has the widest geographical distribution, yielding various Indo-Aryan reflexes (Turner 1966 \#7073), Farsi nārang, Arabic naranğ and our 'orange'.
} 
Figure 20: attestations of limau 'lime'

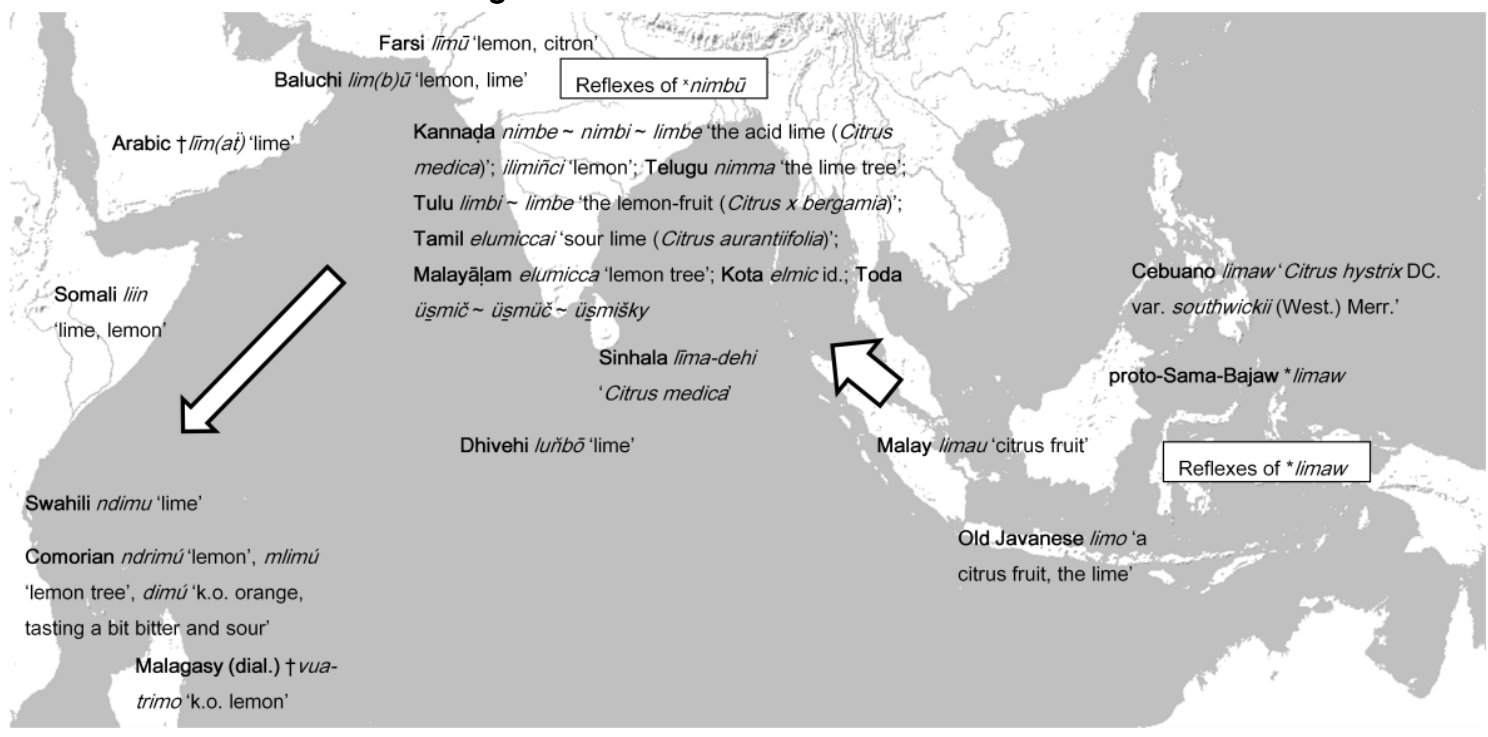

Having discarded the Austro-Asiatic and Dravidian etymologies, let us now explore the terms for citrus fruits in Austronesian languages. Several scholars consider the possibility of an insular Southeast Asian, in particular Malayic, etymology for this word (Bonavia 1890:237-44, Kern 1897:272-3, Uhlenbeck 1898-99:148, Mahdi 1998:407ff., 2008b:322). Indeed, many MalayoPolynesian languages display reflexes of * limaw, apparently a generic name for citrus fruits (cf. Kern 1897:273, Clercq 1927:57, Pallesen 1977:470, Mahdi 1998:408, Madulid 2001/2:71). As mentioned above, this word is also attested in South Asia (Turner 1966 \#7247, Mahdi 1998:408, Southworth 2005:215), the Middle East (Glidden 1937:385) and Madagascar, ${ }^{130}$ as indicated in Figure 20. The presence of endemic limes in insular Southeast Asia might hint at the antiquity of this form. To substantiate the possibility of a Southeast Asian introduction of limes into South Asia, we may also call attention to the more recent trade in citrus fruits from Java to India. As pointed out by Bonavia (1890:30-1), several Indian trade names for citrus fruits are derived from the toponyms 'Ja(ya)karta' and 'Batavia', both referring to the most important harbour of western Java from the mid-2nd mill. CE onwards:

- Malay Ja(ya)karta > Dutch Jacatra > Hindi cakotara 'a fruit of the lime kind, a citron; pompelmoose, shaddock', Marāṭhī cakōtrā cakōtra 'a fruit, pompelmoose or shaddock', Pañjābī cakotrá 'the name of a large fruit of the

130 Cf. Malagasy (dial.) †vua-trimo 'k.o. lemon', attested as < voatrimous in a treatise on various kinds of citrus fruits (Flacourt 1658:125). 
citron kind, the shaddock or pummelo'; Nepāli cakhetro sankkhetro sankkhatra 'pummelo', Bengali †cākhantrā 'orange' (Turner 1961:163)

- Dutch Batavia > Malay Botawi > Tamil vattāyi vattāvi 'Batavian orange', Hindi māhtābī'a sort of muskmelon', Bengali bātābi 'the shaddock, the pompelmoose, the pummelo

If we accept that citrus cultivars - presumably pummelo or lime varieties - were exported from insular Southeast Asia to the Indian subcontinent, we need to examine the antiquity of the tentative precursor *limaw. Many of its reflexes look surprisingly uniform and could be Malay loanwords. Austronesianists have registered different opinions on the antiquity of *limaw, varying from an assignment to proto-Austronesian (Tryon 1994:490) or proto-MalayoPolynesian (Zorc 1994:547) to a relatively late introduction via Portuguese limão 'lemon' (Wolff 1994:532, Jones 2007:183, Blust 2009a:703, contra Mahdi 1998:407-10, 2008b:322). Portuguese agency in the distribution of citrus cultivars across the Indian Ocean is confirmed by the wide adoption of limão 'lemon' across the Indian Ocean, yielding Swahili limau id., Makhuwa

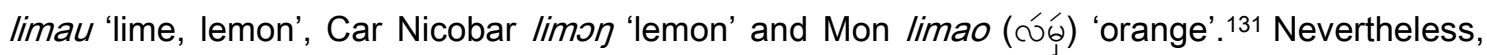
the antiquity of *limaw reflexes in insular Southeast Asia predates the arrival of Portuguese sailors in the Indian Ocean. The form limo has several attestations in Old Javanese literature prior to European contact (Zoetmulder 1982/1:1030). The earliest of these is found in the Javanese Rāmāyaṇa (Kern 1900:89 viii. I. 10, 178 xvi. I. 44), which is dated to the mid-9th C. CE (Jirí Jakl, pers.comm.). The word also occurs on the Keboan Pasar copper plate inscriptions dated to 964 CE (Krom 1913:141 I. Ixiii.1b, 2a). Furthermore, it is found in the Tantri Kāmandaka (Hooykaas 1931:40 I. 24[12]), dated to the mid-15th $C$. CE, and in a later version of that work known as Tantri Kadiri (Soekatno 2009:98). In none of these texts it is clear what kind of citrus variety is denoted by limo, making the above textual attestations of less use for the study of citrus phylogenetics. In the Rāmāyana, however, we may point out that the fruit is

131 Such forms as Chinese limmu் (里木) 'lemon' - in use during the Mongol period (Laufer 1935:151) - Somali liimo 'lime,

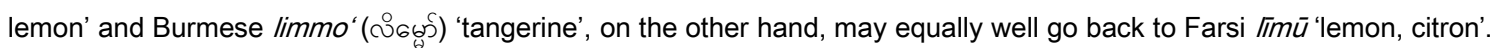


mentioned in the context of a feast, so that the consumption of a sweet pummelo variety would make more sense than that of a sour lime. ${ }^{132}$

A closer look at the geographical distribution of *limaw reflexes across the MalayoPolynesian languages may help us to understand the dispersal of Southeast Asian citrus fruits. To substantiate his claim for an indigenous Southeast Asian origin of *limaw, Kern (1897:273) lists the forms rima, attributed to an undetermined Formosan language (presumably Siraya), and moli, attested in Polynesian languages and purportedly the result of metathesis. I have not

Figure 21: pummelo tree (Citrus maxima)

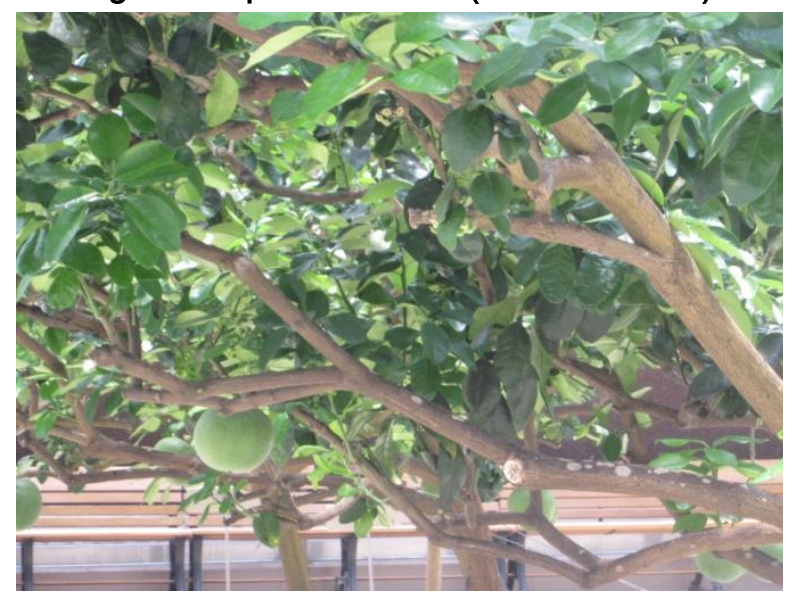

found Kern's Formosan reflex in the literature; its closest resemblances are Pazeh 7arim 'peach' and Favorlang aliem 'all kinds of lemons and citrons' (Tsuchida 1977:110). The Polynesian attestations are also slightly problematic. Although the botanical record implies that all edible citrus species were European introductions

into the Pacific, there is a regular proto-Oceanic reconstruction for 'citrus fruit' ( ${ }^{*}$ moliS), whose reflexes may have originally denoted inedible or barely edible citrus or citrus-like genera (Ross et al. 2008:338-9). ${ }^{133}$ Illustratively, Raluana, a language spoken in the Bismarck Archipelago, displays the inherited term muli 'the native shaddock or large orange (Citrus maxima)' alongside the more recent borrowing nimomo 'lemon or lime'. All things considered, both *limaw and ${ }^{*}$ molis appear to be of considerable antiquity, whether related or not (through metathesis or otherwise). The only other Malayo-Polynesian protoform with a comparable geographical distribution is *muntay 'kind of citrus tree and its fruit' (Clercq 1927:57, Pallesen 1977:470,

\footnotetext{
132 Sweet citrus varieties are also attested in other pre-modern Southeast Asian literature, including limau manis 'sweet citrus fruit' in the Malay Hikayat Bayan Budiman (http://mcp.anu.edu.au/ S.v., accessed Feb 2011) and the toponym Jəruk Manis 'sweet citrus fruit' in the Sundanese Bujangga Manik (Noorduyn \& Teeuw 2006:242).

133 Species such as the wild orange (Citrus macroptera) and the pummelo (C. maxima) were probably present in the Pacific in pre-European times (cf. Bonavia 1890:31-2, Thaman \& Whistler 1996, Walter \& Sam 2002).
} 
Verheijen 1990:201, Blust 1995 s.v., Sakiyama 2009:250, Wolff 2010/2:912), which has been attributed to PAN (Wolff 1994:519) or, more correctly, to PMP (Tryon 1994:490, Blust 2009a:703).

Returning to the discussion on the ultimate etymology of the word for 'lime', it seems that its likeliest source is a Malayo-Polynesian language, in which reflexes of *limaw tend to denote endemic citrus fruits in general. This form was then adopted into South Asian languages, in which it specifically referred to Southeast Asian citrus cultivars. However, since Indo-Aryan and Dravidian languages also display indigenous protoforms for citrus or citrus-like genera, centuries of trade, cross-breeding and hybridisation considerably complicated the citrus terminology in this part of the world. From the subcontinent, the word for 'lime' ended up in the Middle East and reached Europe through Middle Eastern merchants. The relation between insular Southeast Asian reflexes of *limaw 'citrus' and similar looking Chinese names denoting 'lemon' and possibly other citrus species merits further research. Possibly, all forms go back to a now extinct language of southern China.

\subsection{Ginger}

The ginger plant (Zingiber officinale) is a tuber with spicy rhizomes used for human consumption. Ginger is thought to originate from Southeast Asia, although it is not found in a wild state anywhere today (Smith 1976:324, Purseglove et al. 1981/2:447). In the Malay World, at least three different varieties are distinguished: halia bətul ('true ginger'), characterised by its yellowish colour and culinary usage, and halia bara (also known as halia padl) and halia udang, two red, pungent varieties only used medicinally (Holttum 1950:54). The closely related species ləmpoyang 'shampoo ginger (Z. zerumbet)' and bonglai 'cassumunar ginger ( $Z$. montanum)' are also used in Malay medicine. ${ }^{134}$ Ginger is also deeply imbedded in the cultural practices of

134 The name bonglai appears to have been borrowed from a Mon-Khmer source, cf. PMP *bln[iii] 'kind of ginger', cf. Khmer banlai (ตํำ 'cassumunar ginger', borrowed as Thai blai (ไพล) id. It has spread widely across insular Southeast Asia (cf. Heyne 1927/1:474-5), e.g. Minangkabau bolai 'Oroxylum indicum', Sundanese panglay 'ko. plant', Gayo bəngle 
Northeast India (cf. Rahman et al. 2009). The ginger plant is propagated by replanting pieces of its rhizome, rather than its seeds, so that its dispersal typically requires human intervention. Its introduction into South Asia is presumably anthropogenic (Asouti \& Fuller 2008:49). From India, the plant was introduced into the Middle East, Africa and Europe. Prior to Ptolemy, the GraecoRoman authors were unaware of the Asian origin of ginger, as the Middle Eastern traders kept its source a secret (Warmington 1974:184). The Chinese who were familiar with ginger varieties growing in present-

Figure 22: ginger plant in

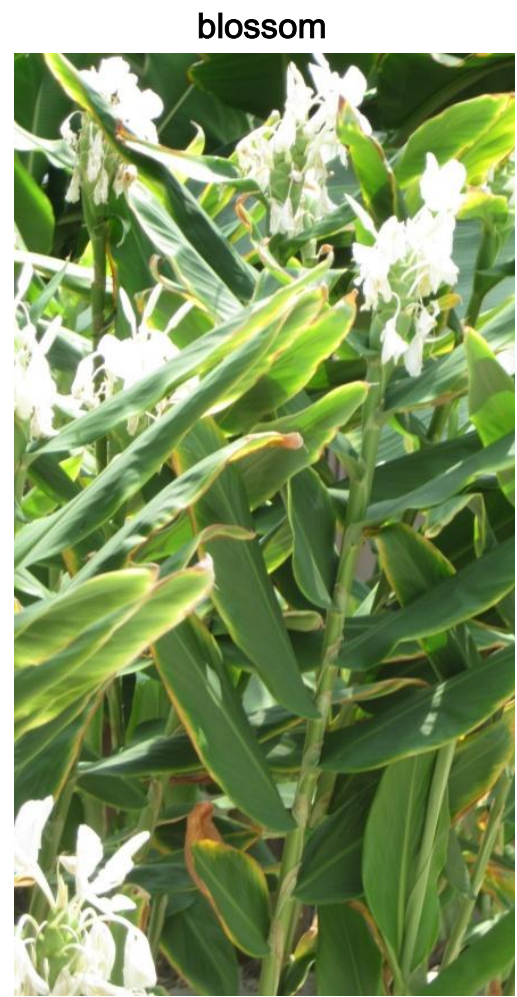
South Asia, the Middle East and Europe, e.g. Sinhala inguru,

Dhivehi ingguru, Farsi šankalil, Arabic zanǧabïl, Somali sinjibiil, Syriac zangebïl, (late) Aramaic

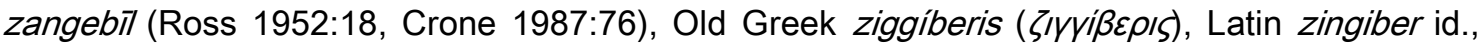
hence our 'ginger'. The form was also borrowed into Swahili as tangawizi, Comorian ntzingiziu and several other East African languages, although these reflexes display irregular sound correspondences and their direct origins remain obscure (Ross 1952:19).

\footnotetext{
'plant whose roots are used as a spice or medicine', Ngaju bangalai 'Curcuma sp.', Javanese bəngle 'Zingiber montanum'; Hanunuo banglay, Mangyan banglayid., Tagalog banglay 'Z. zerumbet (Madulid 2001/2:326).

135 This product is called śonthi in the Sdok Kak Thom inscription (< Sanskrit śunthï'dried ginger', cf. Tamil contii id., Old Javanese (?) sunti 'ginger', Javanese sunti 'k.o. ginger', Acehnese sunti 'dried and salted', Malay sunti 'wart-like excrescence at the root of certain plants; the plants (e.g. ginger) that have this feature'.
} 
Malagasy has not inherited a Malayo-Polynesian reflex for 'ginger' (cf. PMP */aqia), suggesting that the plant was not introduced during the initial colonisation of the island. Instead, the Malagasy word for 'ginger' is sakarivo, cf. Sakalava dial. sákaviru 'ginger sp.; Hedychium flavescens'. In other dialects, too, this word is additionally used for endemic plants of the Hedychium genus (Heckel 1910:340). Whether these Malagasy forms are related to OIA

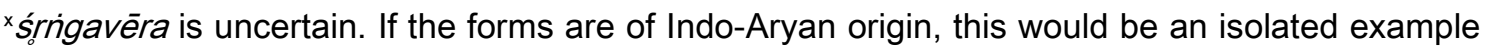
of an Indo-Aryan loanword in Malagasy not paralleled in the languages of Indonesia. ${ }^{136}$ On the other hand, a reflex of śrrigavēra may have existed previously in an obsolete variety of Malay. In any case, the Malagasy attestations, especially sákavíru, represent OIA º́rrngavēra rather faithfully. The latter is almost certainly a back-formation - regardless of folk-etymologies with śrriga 'horn' - consisting of the Dravidian elements iñci 'ginger' and vēr 'root'. ${ }^{137}$ The Dravidian forms reflect an earlier * $\operatorname{cinki}$ (Krishnamurti 2003:5), which is also attested in various other language families in Asia. Although the ultimate origin of the forms is uncertain to me, there are several sets of lookalikes to consider: 138

- $\quad$ Dravidian: Tamil iñci ginger, Malayāḷam iñci, Kota inj, Koḍagu iñji id. (Burrow \& Emenau 1984 \#429)

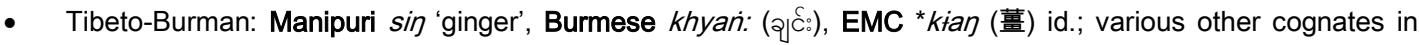
Tibeto-Burman languages spoken in eastern India and Myanmar (Ross 1952:16, Marrison 1967:2/108)

- $\quad$ Austro-Asiatic: Sora $\operatorname{sin(-er)~'ginger',~Khasi~(s)7i\eta ~~~Ji\eta ~'ginger',~Palaung~sian~id.~}$

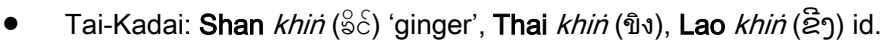

Judging from the attestations listed above, it seems that this protoform for 'ginger' reached South Asia from a north-eastern source through overland trade networks. In addition, OIA displays a protoform with possible Malayic origins: *ārdraka *āllaka 'fresh ginger' (as opposed

\footnotetext{
${ }^{136}$ Conversely, Simon (1988:308, 338 n. 13) suggests that a reflex of OIA ${ }^{*}$ śrngavēra was borrowed into Iban as sənggang, a plant name. However, this name refers to the endemic spindle ginger (Hornstedtia scyphifera) (Sutlive \& Sutlive 2001:1702) and is probably unrelated. On the issue of Sanskrit loanwords in Malagasy, cf. Tuuk (1865:421), Thomas (1905), Ferrand (1908:361-6), Dahl (1951:104-7), Simon (1988:81) and Adelaar (1989, 1994a, 1995a, 2009a). 137 This etymology is quite common in the wider literature (Gundert 1869:352, Yule \& Burnell 1903:374, Hultzsch 1912, 1914, Schrader 1917-23/1:541-2, Burrow 1943:130 n.2, Southworth 2005:83).

138 Jolly \& Thomas (1905:169) and Ross (1952:15-6) give a more detailed treatise of ginger names.
} 
to *sunthr̄'dried ginger'). Burkill (1966/2:2339) was the first to call attention to the resemblance between the South Asian reflexes and Malay halia 'ginger', which goes back to an older */aqia through metathesis (Adelaar 1992b:387). The form *laqia is reflected across insular Southeast Asia and the Pacific and is of considerable antiquity. ${ }^{139}$ At this stage of knowledge, I am inclined to reconstruct the dispersal of the above forms as follows. The Malay form halia 'ginger' spread to India at an early stage, reflected as MIA *allaya 'fresh ginger', hence Marāṭhī ālẽ alẽ 'fresh ginger, ginger plant' and Kōṅkaṇi āllẽ 'ginger'. The subsequent hypercorrection of *allaya, according to regular sound correspondences, to *ällaka is not an isolated example. Smith (1933:216) and Haebler (1965:118-9) demonstrate that the back-formation * $y>k / V \_V$ is also seen in Old Sinhalese, for example lakāra 'sail' from layara (see Section 7.5) and karavika 'to cause to be made' from karaviya. Several Indo-Aryan and Dravidian vernaculars took their words from this back-formation. Through folk-etymology, some speakers associated the resultant form with *ārdra 'wet' and hypercorrected it accordingly, yielding (late) Sanskrit *ārdraka. Compare Figure 23 for an overview of these forms. The Malayo-Chamic form was also borrowed into Bahnar as liā 'ginger' (Thurgood 1999:295).

139 Ross et al. (2008:414) attributes the form to PMP and Tryon (1994:506) to PAN, but the latter is not supported by Formosan reflexes (cf. Jen-kuei Li 1994:262). The form may be a secondary distribution on account of its reflexes in Javanese and Tagalog (Wolff 2010/2:884). 
Figure 23: attestations of halia 'ginger'

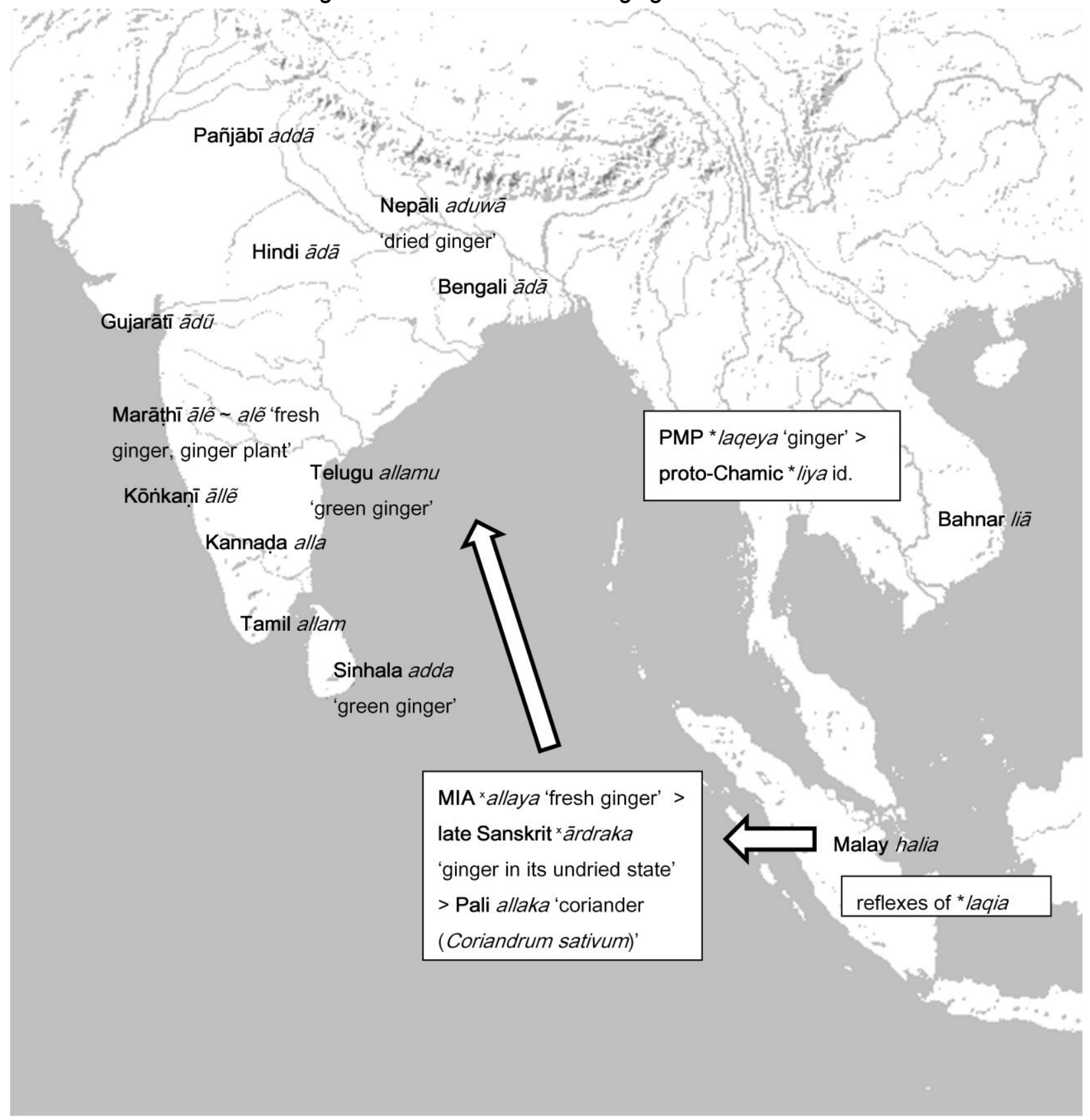

\subsection{Other rhizome-propagated plants}

The galangal (Alpinia galanga) is an herbaceous plant of the family Zingiberaceae, which also encompasses the ginger. Recent molecular phylogenetic analysis of the genus A/pinia indicates that Alpinia galanga is most closely related to $A$. nigra and $A$. conchigera, both native to Southeast Asia (Rangisiruji et al. 2000). The rhizomes of galangal are famed for their culinary and medicinal properties and can be used fresh or in powdered form. Most botanists infer a 
Southeast Asian origin of the galangal, but the plant may have been cultivated in East Bengal and southern India for a long time (Rangisiruji et al. 2000:11). Early colonial sources mention Java as the greatest exporter of the plant. From India and the Middle East, galangal reached Europe in medieval times, where it was valued as a medicine (Dalby 2000:78-9). This diffusion is reflected in the linguistic evidence, cf. late Sanskrit kulañja(na) 'galangal (Alpinia galanga)', Sinhala kalañjana, Hindi kulijan, Dhivehi kolizān, Farsi ḥalanjān, Arabic kulunğān and late Latin galangal id. Miller (1969:52) argues that the Indo-Aryan form probably originates from China, where the plant can be found in the southern regions. ${ }^{140}$ One of its Chinese names is EMC *kaw-lian-kian (高良葍) 'superior ginger', ${ }^{141}$ which denotes the lesser galangal (Alpinia officinarum) and other A/pinia species. Further, we find the (presumably) unrelated forms Tamil

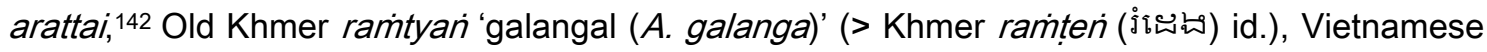
riềng and a set of insular Southeast Asian attestations: Sundanese laja, Makasar laja and Javanese laos (< +laja) 143 id. (Heyne 1927/1:480). Several other attestations in insular Southeast Asia suggest a secondary diffusion of the Javanese term laos, cf. Balinese ka-lawasan, Karo Batak kə-lawas, Simelungun Batak ha-lawas, Lampung lawas, Ternate galiasa id. (Heyne 1927/1:480). This corresponds to early European observations of Java as the main exporter of galangal.

Aromatic ginger (Kaempferia galanga) is another plant of the Zingiberaceae family, found in Southeast Asia, southern China and Northeast India. Its leaves and light yellow rhizomes are used for cooking in some parts of Southeast Asia, in particular in Java. The Javanese and Malays also use the rhizomes for their medicinal function (Heyne 1927/1:494). The presence of borneol in the rhizomes makes the plant interesting for trade. In India, the dried

\footnotetext{
${ }_{140}$ A less convincing etymology explains this form as a South Dravidian root in the meaning of 'esculent or bulbous root' (Dalgado 1919:1/414, cf. Burrow \& Emenau 1984 \#1578).

${ }^{141}$ Alternatively, this name has been interpreted as 'ginger from the (historical) place Gāoliáng Fŭ (高良府) in Guandong province' (Giles 1886:83).

142 Presumably a rendering of Sanskrit rāsnā 'the ichneumon-plant (Curcuma zedoaria); various other plants'.

${ }_{143}$ See Uhlenbeck (1949:93) on the > los\#/ innovation in Javanese. The Malay form longkuas id., which has been borrowed into a number of insular Southeast Asian languages in the meaning of 'galangal' and other Alpinia species (Wolff 1994:522, Madulid 2001/2:18), appears to be related, but the phonological specifics remain unclear.
} 
rhizomes of aromatic ginger are used in perfumery and for poulticing (Burkill 1966/1:724-5). During the colonial period, the roots were imported into South Asia from Chittagong (Watt 188996/iv:561). In the Malay Peninsula, however, the plant is believed to be an Indian import (Holttum 1950:121). Linguistic data contradict this view; the Malay name for this plant (kəncur) appears to have been adopted into several Indian languages. In these languages, the word also came to denote similar looking plants (cf. Turner 1966 \#2828), such as the zedoary (Curcuma aromatica) native to Northeast India and Southeast Asia. The Dutch linguist Abraham Lafeber (1922:141) argued that the late Sanskrit term karcūra 'turmeric' was probably a back-formation from one of these vernacular forms and ultimately from a Southeast Asian source (cf. Figure 24). Most insular Southeast Asian attestations are cognate to or borrowed from Malay kəncur or $c ə(n g) k u r$, two synonyms presumably related through metathesis. Judged from the attestations in neighbouring languages, the former may represent an older Malay ${ }^{*} k \partial c u r$. The forms of Karo Batak kaciwər, Toba Batak hasior and several Philippine attestations (cf. Madulid 2001/2:171) appear to militate against a transmission from India to Southeast Asia. ${ }^{144}$ Therefore, at this stage of knowledge, it is most plausible that the Indian languages adopted a Southeast Asian word for 'aromatic ginger'.

144 Tuuk (1897-1912/1:603) argues that both Batak forms reflect and older *ka-cekur. However, this would leave the Malay from kencur unexplained. 
Figure 24: attestations of $k \theta(n) c u r$ 'aromatic ginger'

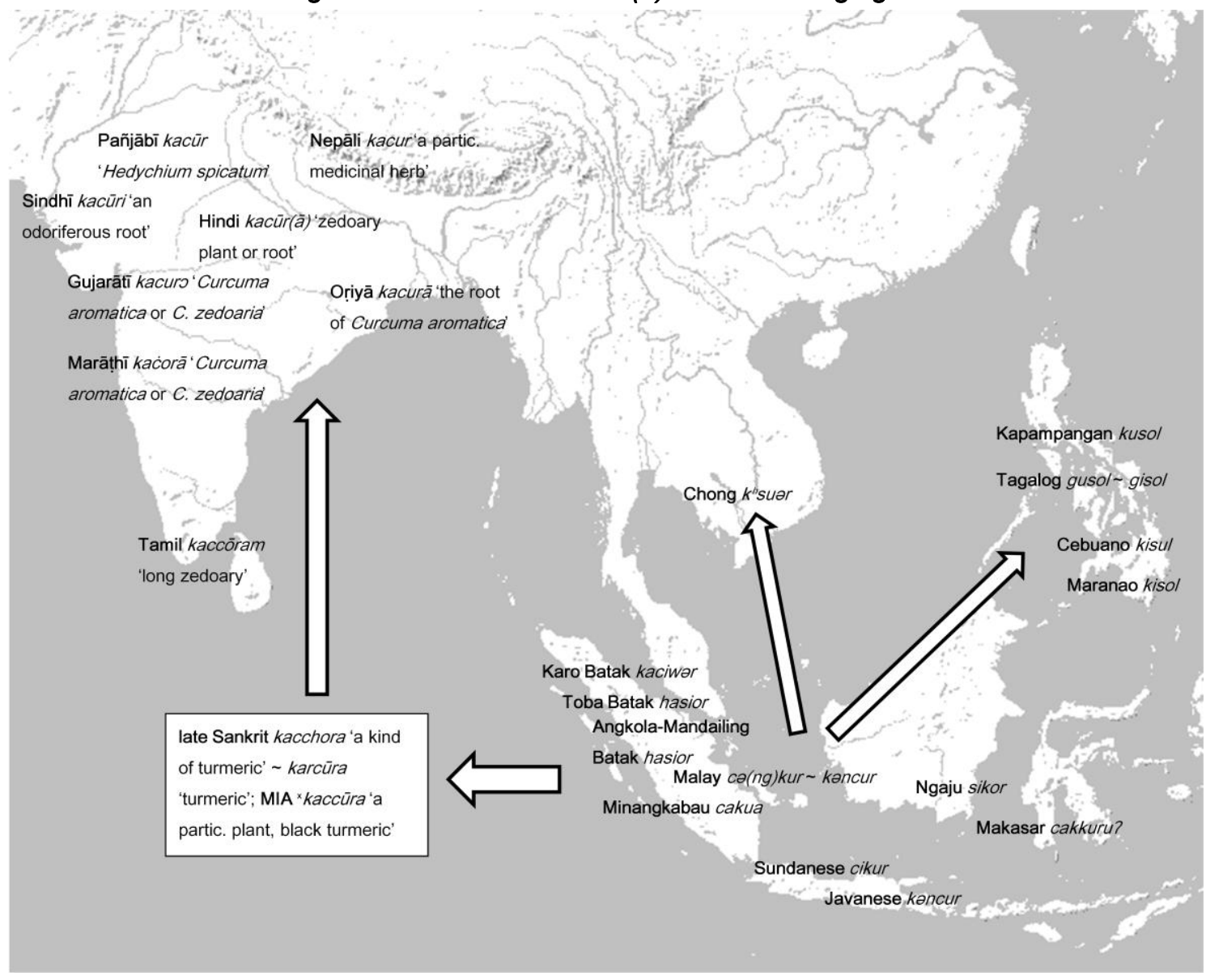

Turmeric (Curcuma longa) has been cultivated in South Asia from antiquity. The plant requires a considerable degree of moisture and is not often attested in a wild state in India, leading some scholars to assume a Southeast Asian provenance (Watt 1889-96/ii:660, Burkill 1966/1:716, Smith 1976:323). The plant is known as kunyit in the Malay World, where it is traditionally used as a dye, medicine and condiment. The Malays also know and employ several closely related species, including təmu pauh 'mango ginger (C. mangga)', təmu hitam 'pink and blue ginger ( $C$. aeruginosa)' and təmu kuning 'zedoary (C. zedoaria)' (Holttum 1950:70-2). Although the Portuguese have made significant contributions to its dispersal across South Asia (cf. Kapil \& Bhatnagar 1976:452), the plant was in use in India from the times of the Mahābhärata and the Suśruta-Samhita (Monier-Williams 1899:1291). It is known as mañcal in Tamil and has cognates in other Dravidian languages, denoting 'turmeric', 'yellow' or both (Burrow \& Emenau 1981 \#4635). One of these forms appears to have ended up in Swahili, which displays the form 
manjano 'turmeric'. ${ }^{145}$ Southeast Asian words for the plant are unrelated, yet display a similar semantic dichotomy: 'turmeric' and 'yellow'. The reconstructed form *kunij 'turmeric', attributed to PMP, is the precursor of various Malayo-Polynesian words for 'yellow' (Kikusawa \& Reid 2007). Indeed, the rhizomes of the plant appear to have been used mainly as a dye in insular

Figure 25: ginger (left), galangal (right),

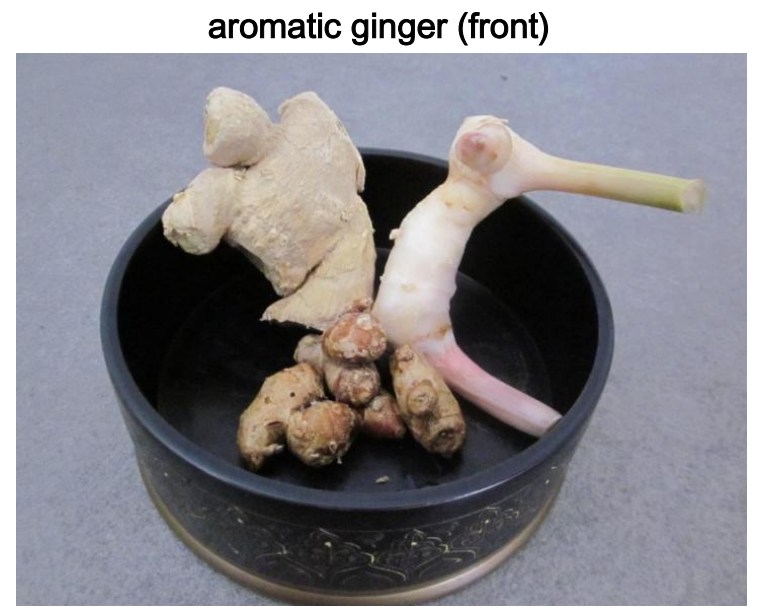

Southeast Asia, while their culinary (turmeric is essential for making curries) and medicinal functions may have been secondary or subsequent developments. In Oceania, where turmeric (POC *yano 'turmeric', cf. *yanoyano 'yellow') grows in the wild and in cultivation, the plant is used for its alleged magical properties, as a medicine and as a dye, but rarely as a condiment (Purseglove et

al. 1981/2:532, Ross et al. 2008:412). Turmeric is also known and used in North Maluku, where local, non-Austronesian languages exhibit semantic shifts between 'turmeric', 'yellow' and 'gold' (cf. Mahdi 1994/1:192). In the Mon-Khmer languages of mainland Southeast Asia, protoforms for 'Curcuma spp.' ('rmiit, " $r$ mit and "rmiət) additionally denote 'yellow', as is the case in Dravidian and Malayo-Polynesian languages. The proto-Muṇāā reconstructions - *sasaク, ${ }^{*}$ sansan and *sisia (Zide \& Zide 1976:1297) - appear to be unrelated. To summarise, the linguistic data do not tell us much about the dispersal of turmeric across ethno-linguistic boundaries, the only recurring pattern being the semantic shift from 'turmeric' to 'yellow' and vice versa.

145 This would not be the only example of a Tamil loan in East Africa. Swahili mronge 'horse-radish tree (Moringa oleifera)' goes back to Tamil murunkai (pronounced /murunge/), ultimately from Sinhala murumgāid. 


\subsection{Early modern translocations}

The translocation of Southeast Asian plants into South Asia persisted into historical times and was in some ways reinforced by the European colonial hegemony over the Indian Ocean. The dispersal of the plants addressed below is believed to be the result of more recent interethnic networks, in which European agents played a significant (but not exclusive) role. One of the most widespread forms is the Malay word for 'bilimbi'. The bilimbi (Averrhoa bilimbi) and carambola ( $A$. carambola), both native to insular Southeast Asia, are closely related species belonging to the Oxalidaceae family. The acidic fruits of both species are of oblong shape and have five to six angles, hence their common nickname 'starfruit'. The ultimate origin of the word examined here is Malay bəlimbing 'ridged longitudinally', denoting both Averrhoa species, various

\section{Figure 26: attestations of belimbing 'bilimbi'}

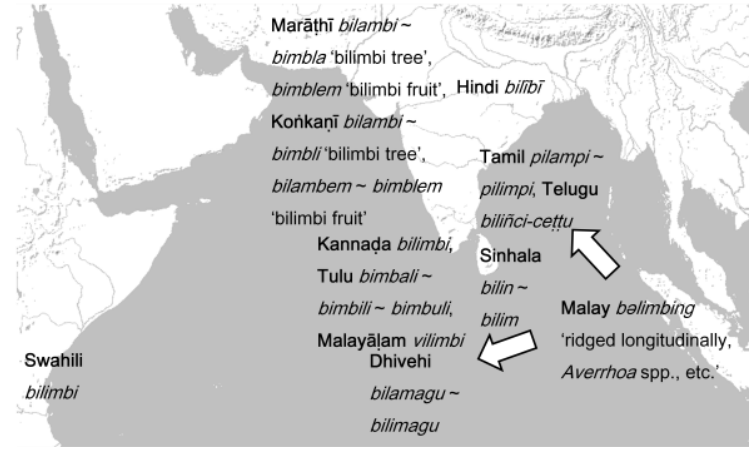
other plants and the leatherback sea turtle (Dermochelys coriacea) on account of its shell (Wilkinson 1932/1:110). This form spread across a wide geographical area, referring to 'Averrhoa spp.' in the languages of Indonesia, 'carambola ( $A$. carambola)' in the languages of the Philippines and 'bilimbi (A. bilimbl)' in the languages of mainland Southeast Asia (Heyne 1927/2:852, Madulid 2001/2:36-7, Blench 2008:134). The fruit has also diffused into South Asia, where its presence was noted by Garcia da Orta (Dalgado 1913:28, 1919:1/127). Indo-Aryan languages display inherited reflexes of OIA *karmaraniga for 'carambola (Averrhoa carambola)' (Turner 1966 \#2895). According to Lévi (1923:37ff.), this word is a rationalisation of Karmaran ga, a Southeast Asian kingdom featuring in Indian literature and apparently known for its bilimbi fruits. In the Tamil Tanjore inscription, he argues, the same kingdom is called Mevilimbangam, ostensibly a rendering of Malay bəlimbing. Figure 26 provides an overview. 
The cajuput tree (Melaleuca cajuputi), also known as the paperbark tree, is found in considerable numbers on the Maluku Islands, where it grows in wild populations. The tree is known for its aromatic oil, which can be distilled from its leaves. Although it has long been used for this purpose in the Maluku Islands, large-scale oil distillation and export was initiated by the Europeans in the early $19^{\text {th }}$ century (Watt 1889-96/v:204, Heyne 1927/2:1199, Burkill 1966/2:1456). The Malay name kayu putih 'cajuput tree (lit. 'white wood')' has spread across the

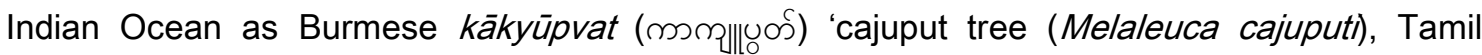
kaiyāppuțai id. and Hindi kāyāpūtī 'cajuput oil'. Another tree product that was introduced into

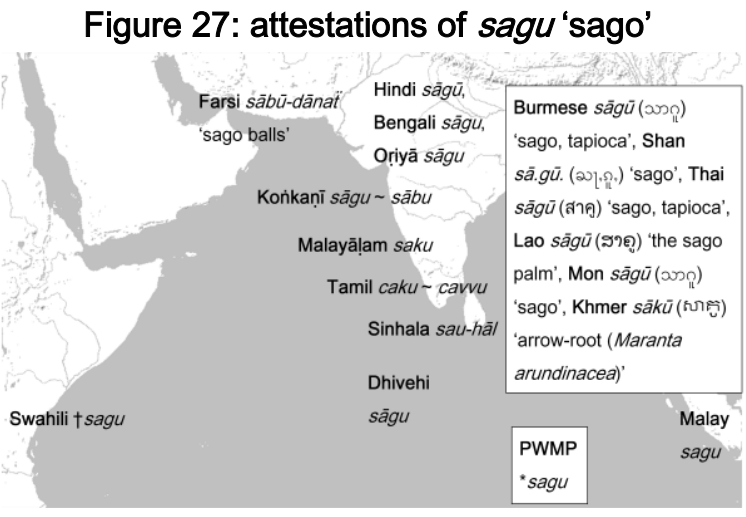
South Asia is sago, a nutritious starch extracted from the pith of palms of the genus Metroxylon. Other trees, such as the sugar palm (Arenga pinnata), also yield varieties of sago. Sago is an important staple food for several communities in insular Southeast Asia, New Guinea and the Pacific (cf. Dutton 1994, Mahdi 2007:147 fn. 172). In the early $19^{\text {th }}$ century, the product was exported to India and China in its granulated form (Crawfurd 1820/iii:348). The Malay word for 'sago' is reflected in a large number of Indian Ocean languages, as shown in Figure 27.

Several Southeast Asian fruits have also found their way across the Indian Ocean. The rambutan (Nephelium lappaceum), a tree of the Sapindaceae family known for its translucent, sweet fruits in a rind covered with soft, hair-resembling spines, is native to Southeast Asia. Its Malay name rambut-an, alluding to something covered with hair (rambut), has been adopted into Sinhala as ran̆butan and Dhivehi ranbustānu ran̆ba id., as well as various MalayoPolynesian languages (Heyne 1927/2:997). The famous durian (Durio zibethinus) also found its way into the wider Indian Ocean World. This tall tree of the Malvaceae family is known for its large, odorous fruits in a thorn-covered husk. In several parts of Asia, the fruits are considered extremely delicious and are also notorious for their virility-enhancing effect. The tree probably 
originates from Borneo, where most of the languages display inherited reflexes (Blust 2010:94). Elsewhere, the Malay word duri-an 'having thorns' (duri = 'thorn') is used, cf. Acehnese duru yan $\sim$ drian 'durian (Durio zibethinus)', Karo Batak durin, Javanese duren, Makasar duriang,

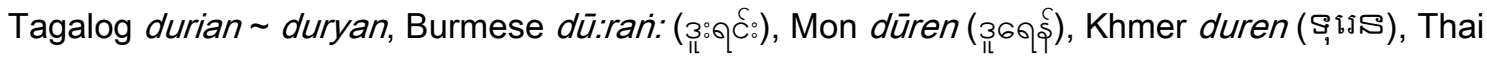
durīan (ทุเรียน), Lao durīan (ขุऽృบ), Vietnamese sầu riêng, Chinese liúlián (榴槤), Sinhala dūriyan and Swahili †doriani †duriani id. The mangosteen tree (Garcinia x mangostana), finally, is a tropical tree of the Clusiaceae family native to Southeast Asia. The edible segments of the endocarp of its fruits are white, fragrant and sweet. The fruit peels are used as a dye (Heyne 1927/2:1090). The tree was introduced into India during the colonial period (Watt 188996/iii:471). Southeast Asian languages display several cognate sets for the tree and its fruit (Heyne 1927/2:1089-90, Madulid 2001/2:141, Blench 2008:136), some of which point to an older Malay †manggus next to its surviving doublet manggis. We further encounter Old Javanese marigista manigusta (Kern 1871a:78) and (Classical) Malay manggista manggusta (Mahdi 2007:142-3), which look rather atypical from an Austronesian point of view. Possibly, they represent hybrid forms between indigenous reflexes of manggus and Sanskrit mañjișthā 'the Indian madder (Rubia cordifolia)', another plant used for its dye. The word-final /n\#/ in several attestations, finally, may have been borrowed through Portuguese mangostão id. Figure 28 presents an overview. 
Figure 28: attestations of 'mangosteen'

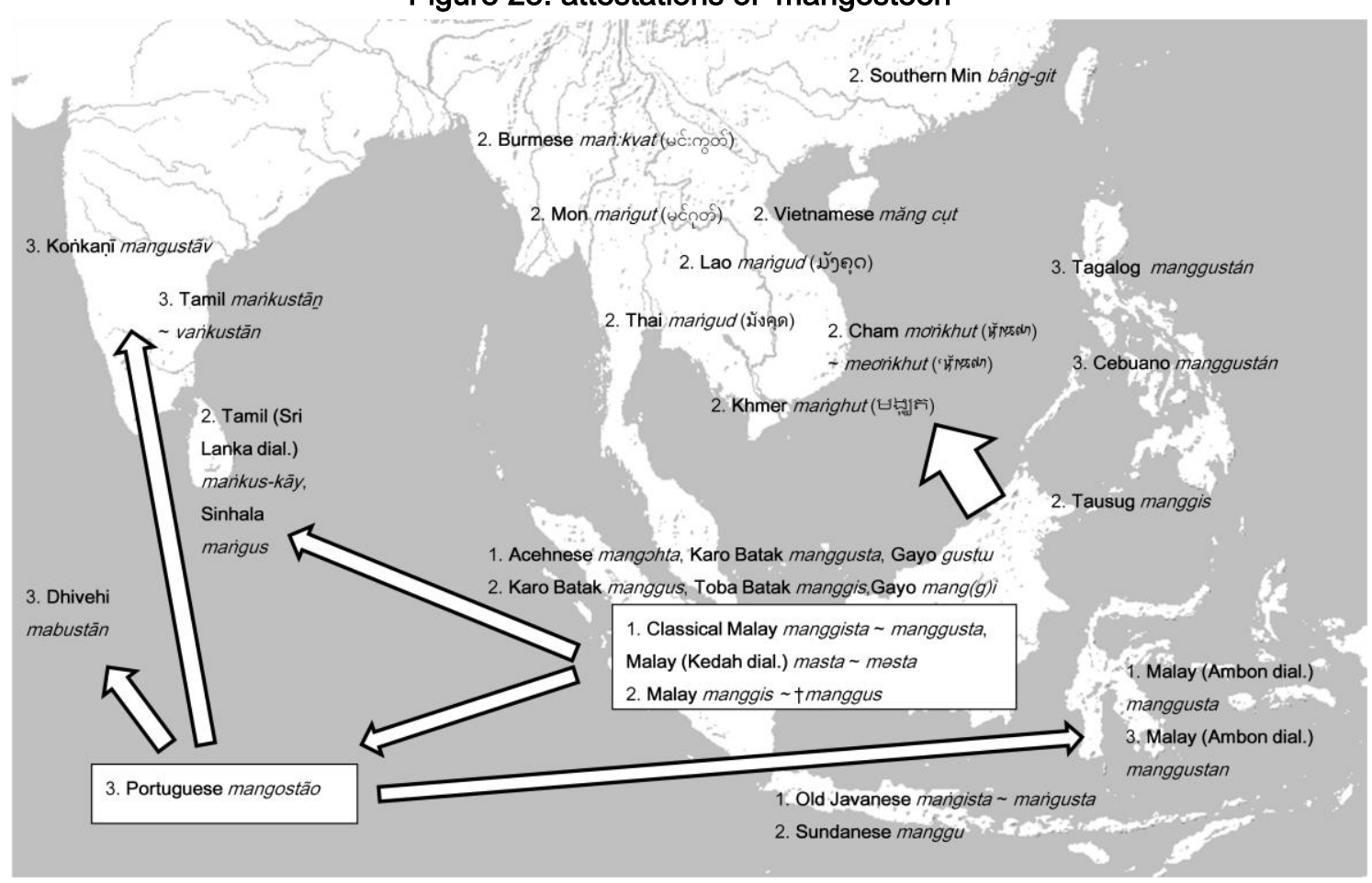

If anything, the plants described in this section demonstrate that, where possible, linguistic data must be analysed alongside evidence from other fields, as the linguistic evidence alone does not provide a clear chronology of transmission. Given the lack of corroborative archaeological and historical evidence, I am inclined to believe that the diffusion of the above products took place during colonial times.

\subsection{Concluding remarks}

Our understanding of the earliest phases of interethnic contact and agricultural exchange in the Indian Ocean is the product of several disciplines. In this chapter, it is argued that numerous plants in the Indian Ocean World have their ultimate origins in insular Southeast Asia. In many cases, the ancient diffusion of plants from Southeast Asia to the Indian subcontinent is supported by linguistic evidence. In other instances, the linguistic data provide contrasting perspectives, encouraging us to find alternative explanations. This chapter demonstrates that the diffusion of plants from South Asia to the Middle East and East Africa is largely reflected by the adoption of Indo-Aryan loanwords in these regions. How these plants reached South Asia is 
often less clear and there is still much work to be done in this field. In the overall picture we get, South Asia played a key role in the east- and westward diffusion of culturally and economically important cultivars from other regions. Many plants already had a long history in South Asia prior to their dispersal to other parts of the Indian Ocean World. The agents in these interethnic networks were probably of diverse ethnic origins and included Middle Eastern, South Asian and Southeast Asian people. In the Bay of Bengal, the linguistic data strongly suggest a key role for Malay-speaking traders. As argued in Chapter 4, several pieces of evidence suggest that these sailors were also active in the western parts of the Indian Ocean. However, this cannot be deduced from the study of plant translocations alone.

Some cultigens, such as ginger, galangal and the betel pepper, may have reached South Asia via overland trade routes, although the introduction of most plants examined here appears to be the result of maritime contacts with insular Southeast Asia. Nevertheless, this chapter does not claim to present a comprehensive overview of transoceanic dispersal of Southeast Asian cultigens. Although the exploration of lexical data can tell us who the cultivators and traders of certain plants were, it remains inconclusive in other instances. Introduced plants that closely resemble indigenous plants are notoriously problematic. It is quite common cross-linguistically to apply the word for an indigenous plant to a similar looking introduced plant. This explains why the Southeast Asian origins of certain tubers do not show up in the linguistic record at all, since people tend to name these new varieties after indigenous tubers, including the Polynesian arrowroot (Tacca leontopetaloides), Asiatic bitter yam (Dioscorea hispida), yellow yam (D. cayennensis) and air potato ( $D$. bulbifera). The limited distribution of Southeast Asian words for 'banana' or 'plantain' across the Indian Ocean may be explained by the same mechanism; people were already acquainted with uncultivated bananas or ensets and did not feel the need to adopt a new word for an existing concept. On the other hand, lexical data for 'ginger', 'aromatic ginger' and 'lime' strongly suggest that these products were introduced by people who spoke Malay or a closely related language. This has been considerably obscured by the tendency of Indo-Aryan languages to create back-formations. In 
the cases of 'sandalwood', 'areca nut' and 'betel leaf', the linguistic data evidence diffusion across the western parts of the Indian Ocean from India. We rely mostly on a growing corpus of genetic data to understand their diffusion from Southeast Asia to India, while the linguistic data remain somewhat ambivalent. The 'coconut' and its numerous cultivars, with distinct Indian Ocean and Pacific gene pools, provide a particularly interesting cross-disciplinary narrative. Although the name adopted across the western Indian Ocean (with the exception of Madagascar) is Indo-Aryan, phylogenetic analyses reveal a considerable admixture from Southeast Asian populations. Therefore, coconut dispersal illustrates clearly the benefits of bringing together data from multiple disciplines: where one field remains silent or inarticulate, another may provide useful contributions to the overall picture. 


\section{Reconstructing the spice trade}

As was pointed out in the previous chapter, the use of imported vegetal products became so embedded in the cultures of the Indian Ocean World that certain socio-economically important plants were moved to regions where they were not endemic. The story of the Indian Ocean spice trade is a different one; most aromatics and other spices were bartered as trade goods for a long period. Some spice-producing plants were eventually translocated to new environments as part of processes of import substitution. The rainforest trees yielding camphor and other resins have never been successfully translocated. This chapter will look more closely at the early trade in Southeast Asian spices in the Indian Ocean. The term "spices" is used in a broad sense, encompassing condiments, pharmacopoeia, odiferous woods and preservatives for food. Many spices can be used in more than one way and their applications and socio-cultural significance differ from one society to another. The historical importance of spices has been the subject of many studies. In fact, textual sources often mention them in the same breath as gold and precious stones (Purseglove et al. 1981/1:1), testimony to their great value in a preindustrialised world where cargo transport over land or sea was often a lengthy, expensive and perilous undertaking. The Romans' desire for luxuries gave the spice trade a considerable boost, in particular through the introduction of significant quantities of metal bullion into the trade exchange (Miller 1969:231ff.). Nevertheless, it was in fact no more than a continuation of much older commercial networks.

The high price people were willing to pay for exotic spices partly explains why they are not easily found in archaeological sites despite their frequent occurrence in classical texts; merchants were careful to avoid spillage of these valuable goods (van der Veen 2011:2). Further reasons include the proportions of spices, which were very low relative to crops, and unfavourable conditions of preservation: macrobotanical remains of spices need to have been charred in order to show up in the archaeological record. For this reason, analysing linguistic 
data and comparing them to the available historical and archaeobotanical evidence is a very useful strategy to increase our understanding of the transoceanic commerce in spices in premodern times. As the geographical centre of the Indian Ocean, South Asia functioned as an important commercial nexus for the transhipment of imported goods and the sale of local produce. Since at least the earliest centuries CE, the Indian elite paid high prices for Southeast

Figure 29: map of North and Central Maluku

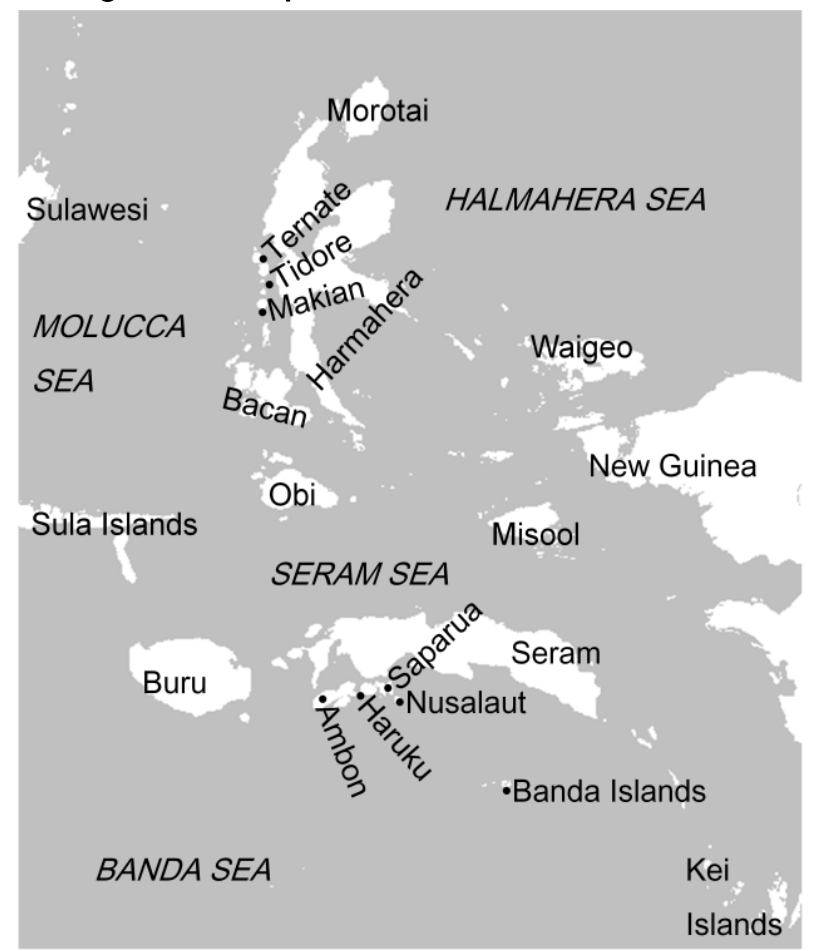

Asian spices, procured from the vast area stretching between the "Spice Islands" of Maluku and the dense rainforests of Sumatra and the Southeast Asian mainland. The Maluku Islands were the only location from which cloves and nutmeg could be obtained until early modern times. Not surprisingly given the location of these islands far to the east, bordering New Guinea, the Indian Ocean was dependent on local, insular Southeast

Asia trade networks and intermediates to obtain these highly valued products. The same was true for the aromatic resins obtained from the gigantic trees deep in the rainforests of Sumatra and Borneo. The import of these products depended on coastal populations, usually Malays, who had, over the centuries, established commercial contacts and patron-client relations with the inland communities throughout the archipelago.

Indian botanists had experience in the various uses of local spices, such as Indian long pepper (Piper longum), black pepper ( $P$. nigrum), true cinnamon (Cinnamomum verum), true cardamom (Elettaria cardamomum) and black cardamom (Amomum subulatum). They became increasingly interested in imported spices at the beginning of the Common Era, when the Āyurvedic medical tradition reached its golden age and excited maritime trade with insular 
Southeast Asia and other spice growing regions (Wolters 1967:69). As was the case with sandalwood, the ceremonial function of aromatic spices in Hindu and Buddhist rituals was adopted by Southeast Asian kings, reshaping the ways in which these products were used and perceived locally. Along the same dynamics, the Roman interest in spices and aromatics was by no means purely attributable to their exorbitant desire for luxuria; these commodities meant much more to them. In ways considerably different from their eastern neighbours, the Romans valued Asian spices and aromatics as medicinal and religious items (Young 2001:16-7). Indeed, the use of spices - in the kitchen, temple and pharmacy - differs greatly from one community to another. Hence, this chapter focuses on the spices and aromatics from Southeast Asia, their usage, nomenclature and pre-modern dispersal across the Indian Ocean. The first two sections deal with the most famous export products of the "Spice Islands": cloves (Syzygium aromaticum) and nutmeg (Myristica fragrans) respectively. The third section examines the Southeast Asian pepper trade, focusing on the transoceanic dispersal of the Java long pepper (Piper retrofractum) and the cubeb ( $P$. cubeba). The fourth section analyses the important and largescale trade in Barus camphor. The fifth section addresses the export of other tropical forest trees of commerce.

\subsection{Cloves}

Cloves are the dried, unopened flower buds of the clove tree (Syzygium aromaticum), an 8-12 meter high member of the Myrtaceae family native to the northern Maluku Islands, especially Ternate, Tidore, Bacan and Makian (cf. Figure 29). The economy of these so-called "Spice Islands" was (and is) largely based on the export of cloves and nutmeg. Although the clove tree has a long pre-bearing period, mature trees can bear flowers each year on the right soil. The flower buds are hand-picked and sun-dried, during which they develop their characteristic aroma. Clove cultivation in parts of East Africa and South Asia is a relatively recent development following a period of Dutch monopoly (Watt 1889-96/ii:203). Prior to this, all cloves were obtained from the northern Maluku Islands. Cloves have presumably reached other places 
in South and Southeast Asia via Malay-speaking traders, as will be argued below. The first historical reference to cloves is found in the Former Han Annals (206 BCE - 25 CE), which mention that courtiers were required to sweeten their breath with clove buds in the Emperor's

Figure 30: half-dried cloves (Neniari Teha, Maluku, Indonesia). Photo courtesy of Nicky Lumatalale

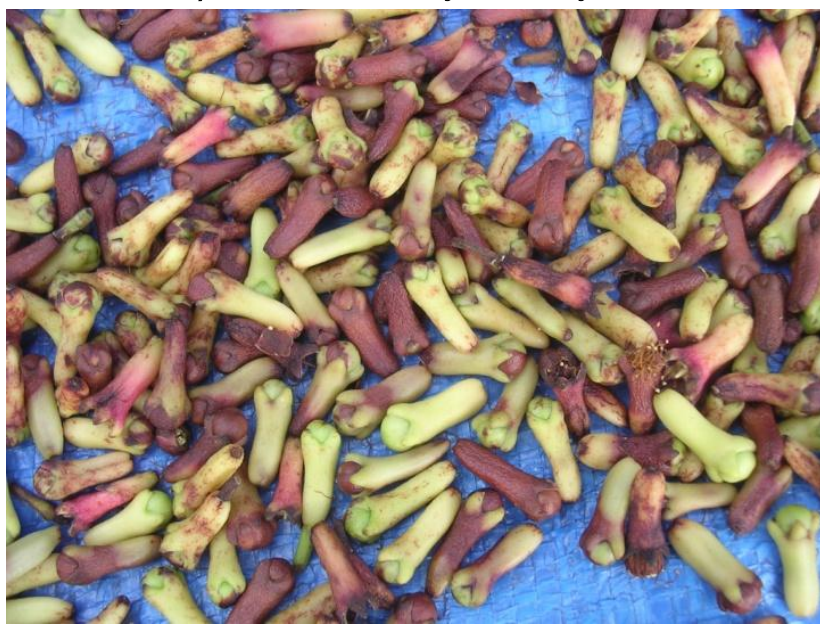

presence (Hirth \& Rockhill 1912:209, Burkill 1966/1:976-7, Purseglove et al. 1981/1:229). The ancient Chinese also used cloves in incense and anaesthetics (Ptak 1993). In South Asian literature, the product is mentioned in (versions of) the Rāmāyana (Gonda 1932:326-9), in Kāvya literature and in the Raghuvamiśa (Monier-Williams 1899:898), suggesting

familiarity with cloves among the Indian peoples by at least the late $1^{\text {st }}$ mill. BCE. Next to their medicinal and aromatic functions, cloves are also widely used as a condiment in South Asia and the Middle East, making it an important part of the culinary traditions of the Indian Ocean World.

It is not known when cloves first spread to the Mediterranean. Pliny's Historia Naturalis, in a rather confused account, describes a fragrant pepper-resembling plant native to India named caryophyllon. This word can be rationalised through Old Greek karyóphyllon 'nut-leave' (Schrader 1917-23/2:111). The supposed Greek and Latin word for 'clove' (garyophyllon caryophyllon) is found in some versions of the Alexandrian Tariff (AD 176-180), a list of commodities subject to import duties at the Alexandrian harbour under Marcus Aurelius (Crawfurd 1820/3:188, 194, Schoff 1912:289, Miller 1969:51). ${ }^{146}$ The same word also refers to the so-called 'gillyflower' or 'clove pink', a sweet-scented carnation of the species Dianthus

\footnotetext{
146 The earliest versions of the Alexandrian Tariff, however, display the more general term aroma indicum 'Indian spice' instead of caryophyllon (Casson 1980:496). This spice could equally well denote a variety of cassia (Cinnamomum cassia).
} 
caryophyllus. Similar looking names in Middle Eastern languages also cover both Dianthus caryophyllus and Syzygium aromaticum, e.g. Arabic qaranful and Farsi qaranful qaranfūl (Harvey 1978:48). We also find lookalikes in South Asia, e.g. Baluchi kalpūr 'cloves', Końkaṇi kālāphul kālāphurid. (Dalgado 1913:66) and Tamil karāmpu 'clove, cinnamon' (cf. Figure 31). These forms are unattested in pre-colonial literature, making a derivation from Portuguese cravo 'cloves' very tempting. The forms may subsequently have been nativised through folketymology. The Tamil form has been explained as 'karām-pū 'pungent flower' (Maloney 1980:119), whereas the Końkaṇī attestation would translate as 'black flower'. All things considered, I see very little evidence to assume wide-ranging familiarity with cloves in classical Europe. Buccellati \& Buccellati (1983) report clove findings in a storage room at the Middle Bronze Age site of Terqa (present-day Syria), in an assemblage of vessels tentatively dated to 1700 BCE. Apart from difficulties in dating these clove remains - if they are indeed cloves and not buds of myrtle (Myrtus spp.) or other similar looking plants - this isolated finding is unable to provide a reliable picture of the earliest distribution of cloves into the Middle East and beyond. More archaeological data are awaited before this matter can be resolved conclusively. 
Figure 31: attestations of 'clove' across the Indian Ocean

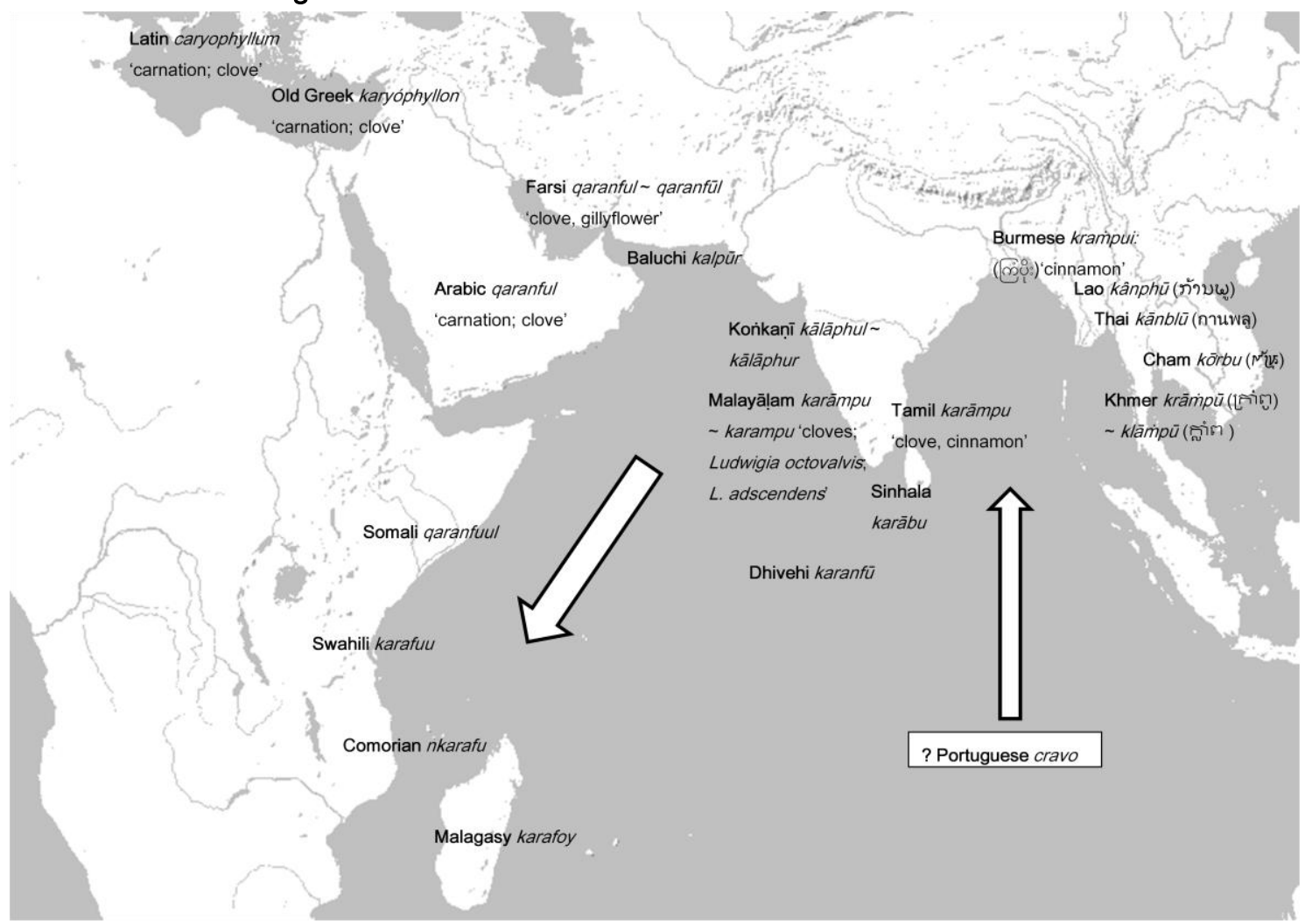

Moving to the linguistic evidence for clove dispersal, we may call attention to the fact that the original North Maluku word for 'clove' (gomods) did not spread much beyond its respective speech area (cf. Heyne 1927/2:1183). Instead, we find a similar word in the Malay World and the Indian subcontinent, as has first been pointed out by Marsden (1812b:xxx). The Dutch linguist H.N. van der Tuuk (1897-1912/3:720) demonstrates that a series of South Asian forms for 'clove, cinnamon' are derived from a west Indonesian word for 'nail'. This is further elaborated upon by Lafeber (1922:144) and Gonda (1932:326-9, 1973:24), who list attestations of this word in several Indonesian languages. ${ }^{147}$ Based on historico-phonological evidence, Mahdi (1994/1:188) demonstrates that the Malay form bunga lawang 'nail flower' stood at the head of this series of borrowings. The form is widely attested across insular Southeast Asia (Heyne 1927/2:1183, Mahdi 1994/1:188ff), South Asia (Dalgado 1913:66, Turner 1966 \#10977)

\footnotetext{
${ }^{147}$ Expanding further on this point, we may compare the following attestations: Toba Batak labang 'nail', Karo Batak labang, Angkola-Mandailing Batak labang, Dairi Batak labang, Alas labang, Gayo labang id., Minangkabau labang 'to hammer, to forge', Iban paku? lawang 'nail', Acehnese labang 'nail, to hammer, to nail down' and perhaps Cham lavak (5LM) 'crook, gaff, hook, harpoon'. The word lawang no longer refers to 'nail' in modern Malay, but an older Malay dictionary displays †labang 'a spike, great nail' (Marsden 1812:295).
} 
and the area in between (cf. Figure 32). The form lavamga has found its way into the $1^{\text {st }}$ mill. CE Sanskrit literature, featuring in the \pm 400 CE Raghuvamiśa by Kālidāsa, possibly in the $1^{\text {st }}$ or $2^{\text {nd }}$ C. CE Caraka-Samihitā and in later texts such as the Pañcatantra, Kathāsaritsāgara and versions of the Rāmāyaṇa and the Uṇādi-sūtras (Monier-Williams 1899:898, Gonda 1932:326, Wolters 1967:66). The difficulty in precisely dating these texts and distinguishing between original versions and later interpolations commands us to be careful in attempting to specify at which point in time the word entered the Indian literature, but its wide distribution in South Asian languages testifies to an ancient dispersal. According to Mahdi (1994/1:215 n.92, 1999b:213ff.), the "as-if" OIA protoform ×lavaniga was probably borrowed from Malay via a Dravidian source. Mahdi argues, based on historico-phonological inferences, that the Sanskrit form would otherwise have resembled ${ }^{* *} / a v a m$. However, late Sanskrit texts additionally display lava 'cloves, nutmeg' (Monier-Williams 1899:898), whereas Tamil exhibits both ilavanikam and ilavam 'clove; true cinnamon (Cinnamomum verum); wild cinnamon (C. iners)'. The intrusive /\#i/ in both forms is indicative of borrowing. In addition, the word occurs in Old Khmer inscriptions as lava(niga) or lava 'cloves' (Chakravarti 1978:210). As seen in the Tamil attestations, the word for 'clove' is additionally used for 'cinnamon' and related plants. A comparable semantic shift has occured in Malay, where the word lawang additionally denotes several other aromatic spices. ${ }^{148}$

\footnotetext{
148 Wilkinson (1932/2:29) gives bunga lawang 'mace' (Myristica fragrans), lawang kəcil 'Indonesian cinnamon (Cinnamomum javanicum)', lawang air 'k.o. tree (Anisophyllea apetala)' and kulit lawang 'lawang tree (Cinnamomum culitlawan)'. In modern Malay, pohon lawang refers to the 'lawang tree (C. culitlawan)' and bunga lawang chiefly denotes 'star anise (Illicium verum)', which is also known under the names adas bintang and pekak, the latter from Southern Min poeh-kak (八角). Iban, a language closely related to Malay, exhibits lawang 'bark of an aromatic tree'. According to Mahdi (1994/1:193-5), the habit of applying the word lawang to local "cinnamic" plants may have started in Central Maluku, where it is pronounced as lawan, homophonous with the local word for 'bark'.
} 
Figure 32: attestations of lawang 'clove'

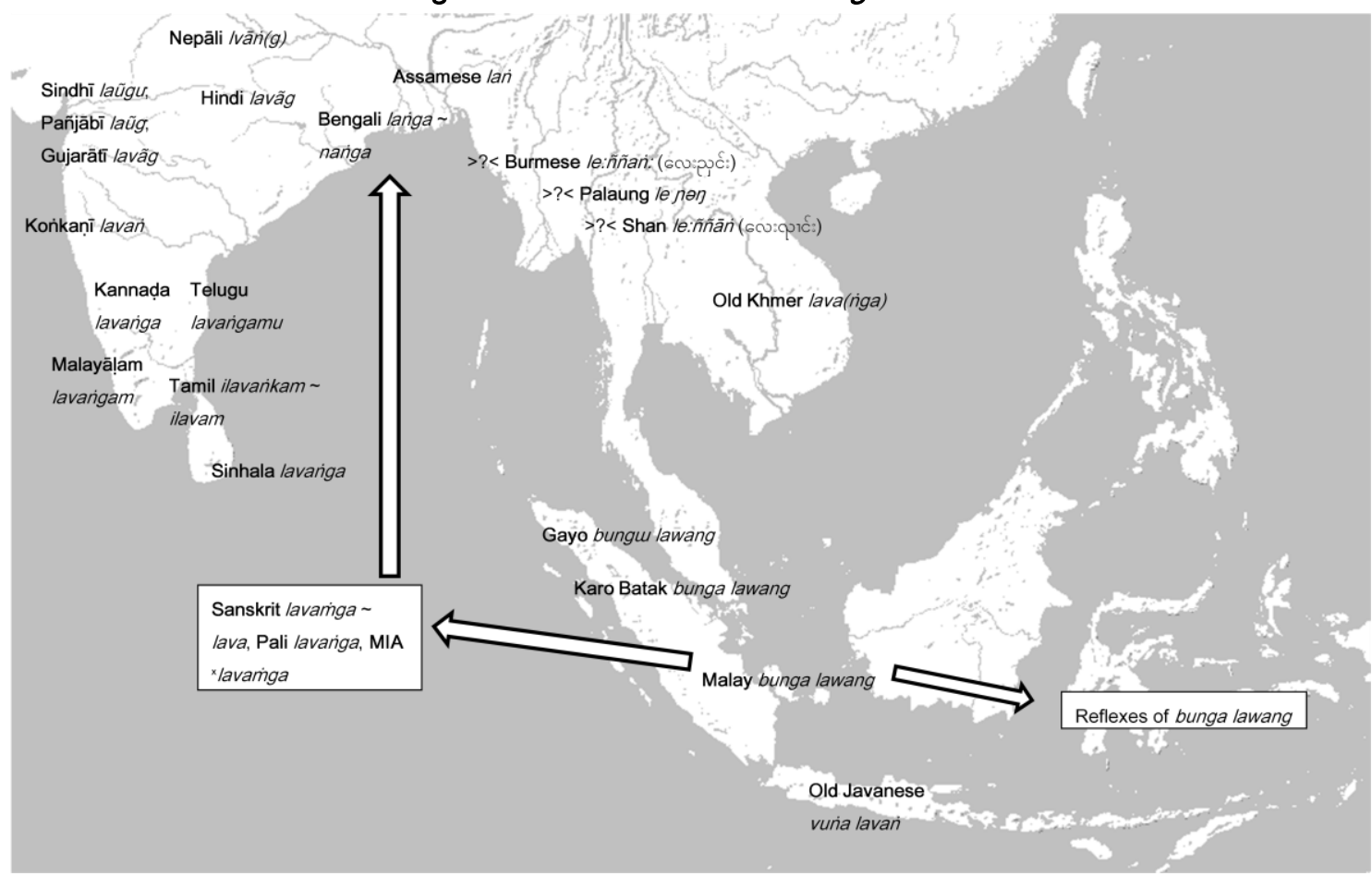

As mentioned, the original Malay word for 'clove' is bunga lawang, ${ }^{149}$ which denotes other aromatic spices in modern usage. In the meaning of 'clove', it has largely been replaced by Malay cingkeh, (Indonesia) cəngkeh, cf. Javanese cəngkeh, Makasar sangki id., Iban sangki cangki 'chilli, red peppers'; Cebuano sangki 'cloves' (Wolff 1976:365); llokano sangkit 'star anise' (Madulid 2001/2:164); Tagalog sangkî sangkê 'a species of spice' and Central Nicobarese fis-tfingi 'cloves'. The Southern Min (Zhangzhou dial.) attestation tsing khik (情客) may also go back to this form. ${ }^{150}$ The word cingkeh occurs in classical Malay literature and was used alongside bunga lawang and the North Maluku form gomode in the early $16^{\text {th }}$ century (Gonda 1938:115, 125). It appears to be a calque of bunga lawang in the vernacular Southern Min dialect spoken by Chinese merchants in Southeast Asia, which they would have pronounced as *teng-gê (丁芽) 'nail-shaped bud or sprout' (Pijnappel 1875:111, Schlegel

\footnotetext{
149 Old Javanese has vuna lavan 'clove', an early borrowing from Malay. It is used alongside lavanga 'clove', which could be a hypercorrection under influence of Sanskrit lavaniga id. Along similar lines, Old Javanese tulanga 'bone' developed out of the original form tulan (Gonda 1973:560).

150 Lafeber (1922:119-20) proposes a transmission in the opposite direction. In Mandarin, qíngkè (情客) is used for a shrub with fragrant, violet-coloured flowers known as the 'early lilac (Syringa oblata)'.
} 
1891:403, Mahdi 2007:71). ${ }^{151}$ Clove terminology thus provides an important illustration of traderelated replacement of pre-existing vocabulary. As Chinese merchants played a leading role in Southeast Asian clove trade, one of the words used by them was adopted into Malay and spread across insular Southeast Asia. In a very similar way, several speech communities in the Indian Ocean have adopted a Portuguese or Spanish loanword for 'clove'. 152

\subsection{Nutmeg}

The nutmeg tree (Myristica fragrans) is a species of the Myristicaceae family indigenous to the Maluku Islands, in particular the Banda Islands. It yields two different trade products: the kernel of the seed (nutmeg) and the dried aril surrounding the seed (mace). In addition, the hull or pericarp is made into sweetmeats (Malay: manisan pala or pala manis) for local consumption. After the arils are removed from the nuts, the former are sundried and crushed, while the latter

Figure 33: fresh nutmeg drying in the sun (Ullath, are dried on gratings over a smoking fire, Maluku, Indonesia). Photo courtesy of Ebed Litaay

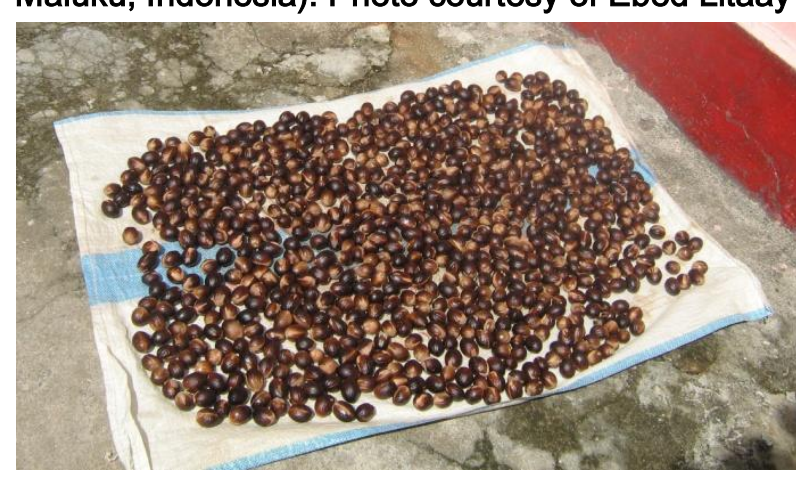
after which they are opened, graded on their quality and covered with slaked lime (Heyne 1927/1:643). Next to its wellknown culinary and aromatic properties, powdered nutmeg has in recent times been used as a recreational drug (Purseglove et al. 1981/1:174). While several islands exported nutmeg in pre-modern times, the Dutch East India Company granted a violently enforced export monopoly to the Banda Islands, making it the most important centre of nutmeg production to date. Nutmeg was used in China by the early $8^{\text {th }}$ C. CE (Hirth \& Rockhill 1912:210-1 n.), although some scholars underline the possibility of an earlier introduction in the $4^{\text {th }}$ C. CE under a different name (Li 1979:18-9, Dalby

\footnotetext{
151 This tentative form is unattested in the Chinese literary corpus. The default Chinese term for 'clove' is dingxiāng ( $丁$ 香) 'nail fragrance', hence Southern Min teng-hiun and Vietnamese đinh hương id.

${ }_{152}$ Cf. Sinhala karābu 'cloves' (< Portuguese cravo id.), Tagalog klabo, Bikol klábo id. and Cebuano klábu 'k.o. aromatic mint' (< Spanish clavo id.).
} 
2000:53). The product was first recorded in Europe in Aëtius of Amida's Sixteen Books on Medicine (Purseglove et al. 1981/1:174), written in the late $5^{\text {th }}-$ early $6^{\text {th }}$ C. CE. The earliest remains of nutmeg in South Asia are from a Kuṣāna fire altar dated to 50-250 CE at Sanghol in the Punjab region, where it was used in combination with sandalwood and black pepper (Saraswat \& Pokharia 1998, Asouti \& Fuller 2008:117). The seeds of the Bombay nutmeg tree (Myristica malabarica), which is endemic to South Asia and somewhat similar in its usage, have been used as an adulterant for true nutmeg by local merchants (Watt 1889-96/v:314, Burkill 1966/2:1550)

Moving to the linguistic attestations for 'nutmeg', we may call attention to a variety of synonyms in the rich corpus of late Sanskrit text, including kośa, kośaphala, jātikośa, jātiphala, jāti, puța(ka), phala, mālatīphala and others. The element jāti has been borrowed as Tibetan

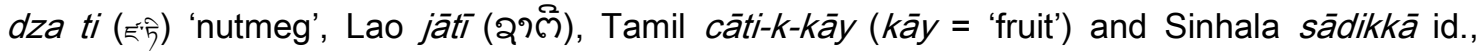
whereas phala occurs as Malay pala 'nutmeg', Javanese polo, Lampung pahlo, Makasar pala id. and various other insular Southeast Asian reflexes. ${ }^{153}$ The compound jātiphala occurs in Old Khmer as jātiphala (Chakravarti 1978:211) and in Burmese as jātipphuil (œ๐ํํำ jātikośa features, in various renderings, in the Aramaic literature (Löw 1881:85). With the exception of some indigenous terms in the Maluku Islands (Heyne 1927/1:485), practically all the South and Southeast Asian names for 'nutmeg' are of Indo-Aryan origin. We have seen similar patterns in the words for 'sandalwood', suggesting that the early Indians played a key role in the import and further diffusion of the product. The spread of the Sanskrit forms across South Asia and back to insular Southeast Asia testifies to the important role of nutmeg in early Hindu rituals and perhaps pharmacopoeia. The adoption of an Indo-Aryan trade name in most of the Southeast Asian languages strongly suggests that nutmeg was mainly an export product and of less significance domestically. This name has not been taken over in Farsi and Arabic,

153 See Heyne (1927/1:680) and Sakiyama (2009:251) for more examples. Also compare Old Mon phalā 'areca nut'. 
which display compounds in the meaning of 'scented nut' (respectively gauz būyā and ğawz at$t i b)$.

The words for 'mace' in several Indian Ocean languages appear to be Arabic borrowings, e.g. Arabic basbās(ä̈) 'mace' (cf. Maghreb dial. basbās(ä̈) 'fennel', Somali basbaas 'chilli, pepper'), Farsi bazbāz 'mace', Swahili †basbasi, Hindi basbāsa, Sinhala vasāvāsi, Dhivehi bazabāzu and Tamil vacuvāci id. The fact that the words for 'mace' are borrowed from Arabic in all these languages suggests that the early Arabs made the most extensive use of this product. Next to its culinary properties, it was an important ingredient for Arab pharmacists, whose expertise must have spread across the Indian Ocean as a result of the Islamic cultural expansion. In summary, we are confronted with an insular Southeast Asian product with an Indo-Aryan name for its nut and an Arabic name for its aril. Indeed, the study of nutmeg terminology illustrates that an analysis of lexical distribution patterns can provide clues about the people who used, introduced or demonstrated the value of certain commodities to other communities.

\subsection{Pepper trade}

From antiquity onwards, the Indian Ocean has formed the stage of a lively trade in pungent pepper varieties. Black pepper (Piper nigrum) and Indian long pepper ( $P$. longum), both native to South Asia, were known and used by the ancient Greeks and Romans (Purseglove et al. 1981/1:11). Black pepper was also introduced into Southeast Asia at an unknown stage of history, where it became an important commodity for export to other regions. The transoceanic diffusion of words for South Asian pepper varieties has already been examined

Figure 34: black pepper plant (Piper nigrum)

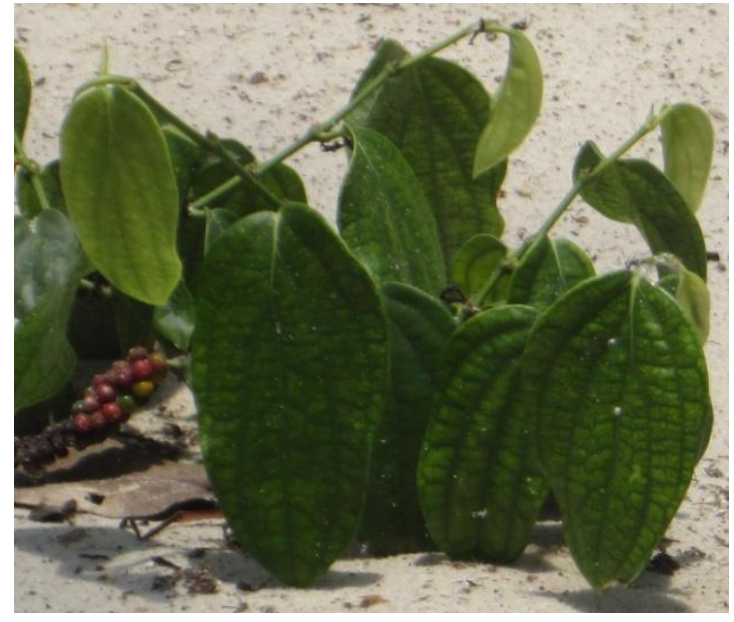
by various scholars (Wheatley 1959:100, Burkill 1966/2:1776, Southworth 2005:209, 216, 
Osada 2009:136). Of relevance to this discussion is the distribution of the OIA word *marica

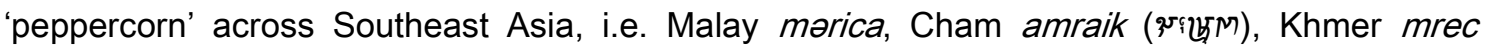

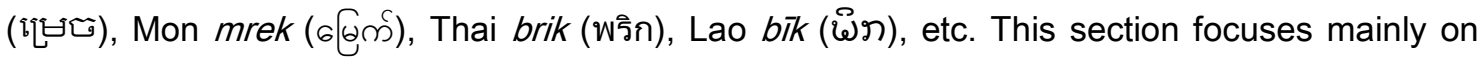
the dispersal of indigenous Southeast Asian peppers. Besides the betel pepper, two Piper species have been of interest for international trade: the Java long pepper (Piper retrofractum) and the cubeb (P. cubeba).

Figure 35: attestations of 'Java long pepper'

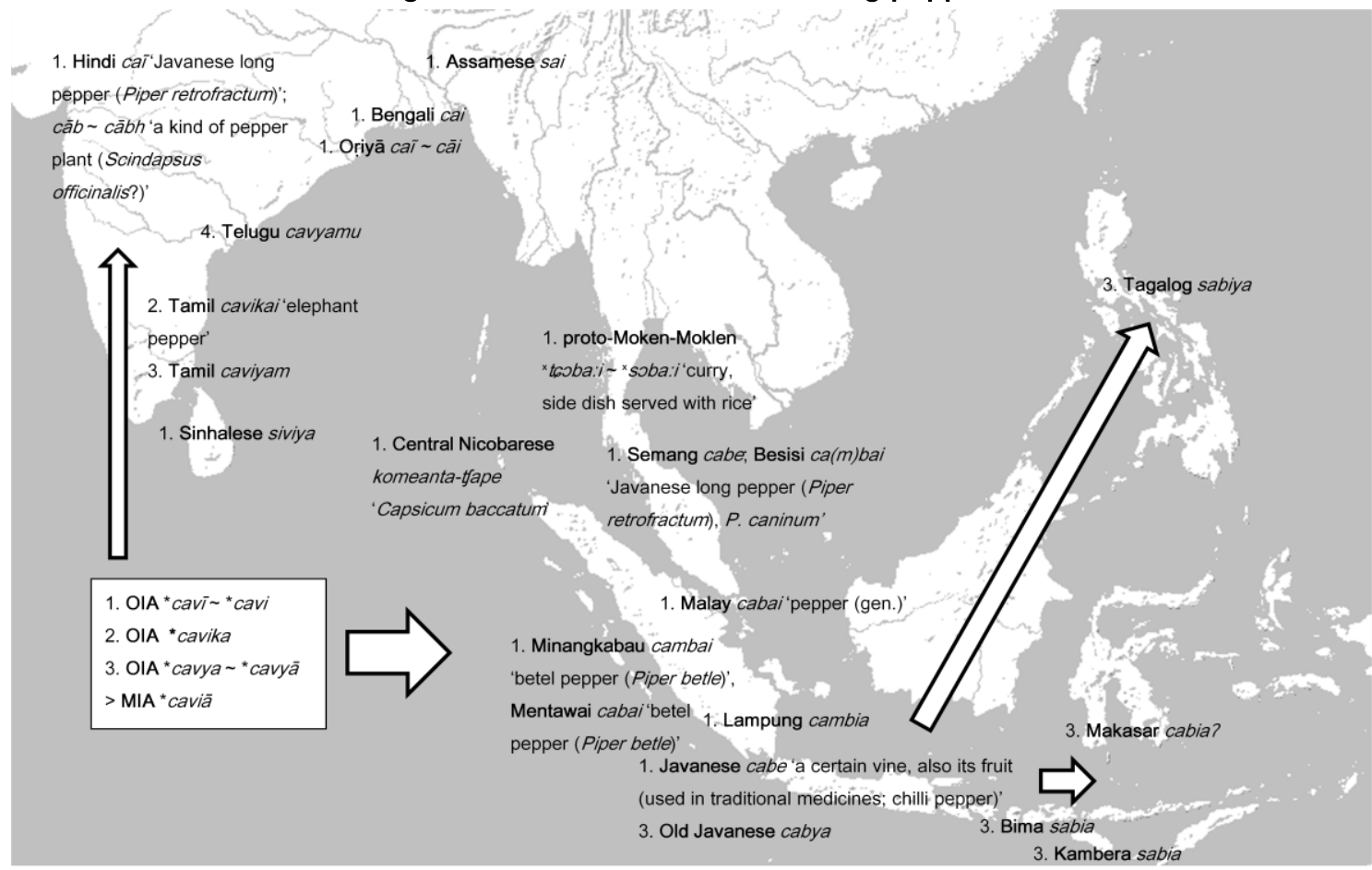

The Java long pepper (Piper retrofractum) is a climber found in the wild in parts of insular Southeast Asia. In Malay, it is known as lada panjang 'long pepper' or cabai jamu 'medicinal pepper', as its unripe spikes (catkins) are harvested and used as seasoning or medicine. The Java long pepper is often confused with the Indian long pepper ( $P$. longum), to which it is closely related. The product is mentioned as one of the export products of a Southeast Asian country named Dżiajia (闍耶), corresponding to Sanskrit and Malay Jaya 'victorious', in a 392 CE Chinese translation of the Sutra of the Life of Säkyamuni to His Twelfth Year (Ferrand 1919b:162, 192 n.2, Sastri 1940:241, Obdeijn 1941a:328). In South Asia, the Java long pepper

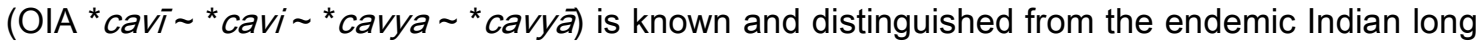


pepper (OIA *pippala). It is sometimes used in betel-chewing when fresh betel leafs are unavailable (Penzer 1927:247). The forms cavya and cavikā are attested in the $3^{\text {rd }}-4^{\text {th }}$ C. CE Suśruta-Samihita and the $11^{\text {th }}$ C. CE Kathāsaritsāgara, while the other attestations only feature in later Sanskrit dictionaries (Monier-Williams 1899:391). Its Indo-Aryan name appears to have become the generic trade name for 'pepper' in some parts of insular Southeast Asia (cf. Figure 35). While Malay cabai and related forms denote different pepper species, if not 'pepper' in general (cf. Heyne 1927/1:517, Burkill 1966/2:1768, 1772, Verheijen 1990:236, Madulid 2001/2:238), all forms seem to go back to the aforementioned Indo-Aryan set of related words. Thus, like the words for 'sandalwood' and 'nutmeg', a "luxury loan" from Sanskrit has replaced indigenous words to denote the valuable, endemic Java long pepper.

The second widely exported Southeast Asian pepper is the cubeb (Piper cubeba), a climber that grows wild on several Indonesian islands, in particular Java (Heyne 1927/1:523, Burkill 1966/2:1773). This pepper is known in Malay as lada bərekor 'tailed pepper' or kəmukus. Due to its abundant wild populations, the plant was never cultivated until recent times (Purseglove et al. 1981/1:13). The stalked, aromatic fruits of the plant are removed at an unripe

Figure 36: cubebs for sale, Hurghada, Egypt

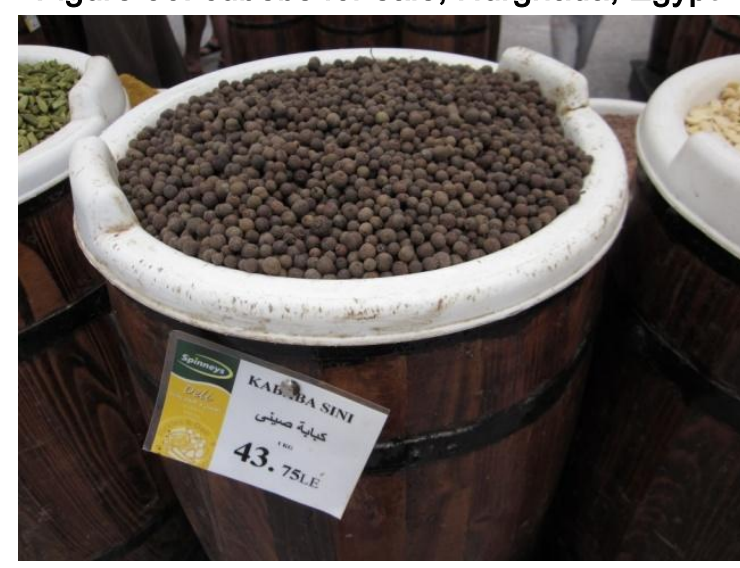

stage and dried. These dried fruits have since long been exported to South Asia, where they were used as a medicine or an adulterant for black pepper intended for the Roman market (Watt 1889-96/vi.i:257-8, Sastri 1944, Dalby 2000:55). Around the early $13^{\text {th }}$ C. CE, a considerable import of cubebs from Śrī Vijaya into China is described in Zhào Rǔguā's

Records of Foreign Peoples. Interestingly, cubebs became known to the Chinese under the Indo-Aryan name vidanga, which also refers to the false black pepper (Embelia ribes), another adulterant for pepper (Hirth \& Rockhill 1912:224, Laufer 1915). The trade in cubebs appears to have been dominated by the Chinese, who used it as a medicine. This is reflected in such 
names as Tamil cinna-milaku 'Chinese pepper' and Hindi kabāb-cīnīid. A second Tamil name for 'cubeb' (vāl-millaku) translates as 'tailed pepper' and is probably a calque of Malay lada bərekor. The second Malay word for 'cubeb' (kəmukus) and several related forms (cf. Heyne 1927/1:523) go back to the root $\sqrt{ }$ kukus 'vapour, steam', so that one might speculate that cubebs were once used as fumigants in the Malay World. Yule (1871:326) suggests that the Malay name might have yielded the insufficiently identified words kömakon in Theophrastus' Enquiry into Plants and comacum in Pliny's Historia Naturalis, but this theory leaves unexplained the absence of related forms in intervening South Asian and Middle Eastern languages.

\subsection{Barus camphor}

Barus camphor, also known as Borneo camphor, was among the most important Southeast Asian export products. It is a white or transparent aromatic resin extracted from the wood of several tropical trees. The most highly regarded type of camphor contains the organic compound borneol $\left(\mathrm{C}_{10} \mathrm{H}_{18} \mathrm{O}\right)$ and is obtained from older trees of the species Dryobalanops sumatrensis, one of the tallest trees of Southeast Asia historically found in Borneo, northern Sumatra, the Thai-Malay Peninsula and the Lingga Archipelago (Heyne 1927/2:1099). In these regions, the product was traditionally used for ceremonial purification of the corpse (Burkill 1966/1:880). As many Dryobalanops trees do not yield camphor, it is extremely difficult to obtain the product in large quantities. Finding suitable trees ("camphor-hunting"), therefore, is intertwined with ritual and Barus camphor is famous both for its high price and religious value (Heyne 1927/2:1102). After the camphor-bearing trees have been located, carvings are made in their bark to collect the crystalline resin, which is then washed and cleaned of wood particles. In other parts of Asia, less highly regarded types of camphor are extracted from other trees, such as Cinnamomum camphora (laurel camphor) and Blumea balsamifera (Blumea camphor). These do not contain borneol, but consist of the chemical compound "camphor" $\left(\mathrm{C}_{10} \mathrm{H}_{16} \mathrm{O}\right)$. Although it is uncertain at which point in time people outside Asia became interested in the use of either type of camphor, this may have been relatively early. The first scientific evidence for 
camphor in the Middle East, identified as Cinnamomum camphora by laboratory analysis, was found in the resin applied onto an Egyptian mummy ${ }^{14} \mathrm{C}$-dated to $170 \mathrm{BCE}$ using linen from the wrappings (Cockburn et al. 1998:77-8). Mahdi (1994/1:190) argues that the camphor used on this mummy was the Indonesian variety, not laurel camphor. The latter is extracted from twigs and wood chips by a process of steam distillation - a technique discovered in China as part of a search for a cheaper alternative to Indonesian camphor - which was probably not available at this time. In addition, Mahdi argues, the borneol in Indonesian camphor is easily transformed into camphor proper over time through the chemical process of oxidation, so that it is nearly impossible to determine which type of camphor had been applied to the mummy. In any case, if the dating of the Egyptian finding is correct, it would suggest that an unspecified type of camphor has already been incorporated into Indian Ocean trade by the late $1^{\text {st }}$ mill. BCE.

It is difficult to determine based on the textual evidence when Barus camphor spread westwards, as for word 'camphor' is used for different tree resins. The product is mentioned in the Sanskrit literature (karpüra) of the $1^{\text {st }}$ mill. CE, but the lack of emphasis it receives in these accounts suggests that is was imported on such a small scale that re-export to the Romans who would have been interested in this exotic luxury - was not feasible (Wolters 1967:68). Possibly, its first attestation in the Graeco-Roman literature is a fragrance called kárpion in the work of Cosmas Indicopleustes (Caldwell 1875:105, Schrader 1917-23/1:557). Camphor spread to the Middle East in the mid-1st mill. CE and is mentioned in the poetry of Imru' al-Qais, the Qur'an and the medical works of contemporaneous Hellenistic writers (Schoff 1922:359, Dalby 2000:58, King 2008:181). ${ }^{154}$ Upon examining further lexical evidence, we may observe that the OIA word for 'camphor' ( $k a r p \overline{\text { 'ra }}$ ) has been borrowed into various Indo-Aryan languages on the South Asian mainland (Turner 1966 \#2880), as well as languages influenced by Sanskrit such as Sinhala kapuru, Dhivehi kafūru; Tamil karppūram (cf. karppurai 'benzoin'), Malayālam karpūram, Kannaḍa karpūra, Tibetan ga bur (ఇ'gुर), Old Javanese ka(r)pura, Old Khmer (pre-

${ }^{154} \mathrm{~A}$ similar word (kōpher) is attested in Old Hebrew, but this probably denotes another aromatic, such as 'spikenard (Nardostachys jatamansl)' (Donkin 1999:46) or 'henna (Lawsonia inermis)'. 
Angkorian) karpūra, Khmer karpūr (๕ุบ่̛̃), Thai kārabūr (การบูร) and Lao kārabūn (ภาธะบูบ) $)^{155}$ id. The word has spread westward as Arabic kāfür, Farsi kāfür, Swahili kafuri, Comorian mkafuru, Syriac kāpūr and Greek kamphorá kaphourá, hence the European reflexes (Schoff 1922:359)

This word has also found its way into the Sanskrit literature, e.g. the Suśruta-Samhita, the Pañcatantra and other works (Monier-Williams 1899:258). In addition, it is mentioned in medieval Chinese accounts as *kiat-phua-la (羯婆羅) ～“kiat-pủə̆-la (羯布 羅) (Gerini 1909:445). ${ }^{156}$ The Sanskrit form is probably a back-formation of MIA *kappūra, ultimately borrowed from a Malayic source. ${ }^{157}$ The common Malay name for 'camphor' is kapur Barus 'lime from Barus'. As we have seen in Section 5.2, the Malay precursor kapur 'chalk, slaked lime' has been borrowed into several insular and mainland Southeast Asian languages (cf. Mahdi 1999b:216ff.). In Malay, this word can also be applied to 'camphor' and several other white or translucent tree resins. ${ }^{158}$ If the above etymology is correct, 'camphor' is one of the most widespread Malay words adopted by the speech communities of the Indian Ocean World. As the name kapur Barus suggests, the most valued camphor was exported from the North Sumatran polity of Barus (see Section 3.3). The topoym Barus is used for camphor from the Dryobalanops sumatrensis in various Southeast Asian languages (Gerini 1909:440, Donkin 1999:85), probably to distinguish it from inferior local kinds of camphor. The same word is

\footnotetext{
155 Lao kārabūn (ภภระบูบ) is used alongside kabūn (ภะบูบ) 'camphor'. The latter may be a direct borrowing from Malay. 156 The modern Chinese terms for 'camphor' are based on its perceived resemblance to 'brains', cf nǎozi (腦子) and lóngnăo (龍腦), also Southern Min chiun-ló (樟腦), Korean jangnoe (장뇌) and Japanese shōnō (樟脳). In addition, Chinese bingpiàn (冰片) 'borneol' (> Southern Min peng-phièn (冰片) 'Barus camphor' and Vietnamese băng phiến 'camphor balls') literally translates as 'icicles'.

157 The similarity between the Indo-Aryan and Malay forms was first noticed by H.N. van der Tuuk (in Klerck 1862:13 n.1), who argued that the form was a Sanskrit loan into Southeast Asia. He later changed this view, proposing a Malay origin (Tuuk 1897-1912/2:291). The latter etymology has found the support of other scholars (e.g. Kern 1871a:81, Yule \& Burnell 1903:151, Fokker 1910:567, Lafeber 1922:142, Schoff 1922:362-3, Gonda 1973:23-4, Mahdi 1994/1:191, 1999b:216ff.). The back-formation of /rp/ from an original /pp/ is a common in Sanskrit (Schoff 1922:363, Kuiper 1991:61).

158 Cf. Malay (Peninsular dial.) kayu kapur 'Indonesian cinnamom (Cinnamomum javanicum)' (Wilkinson 1932/1:510); (Sumatra dial.) kayu kapur 'Barus camphor (Dryobalanops sumatrensis)' (Heyne 1927/2:1099); (Borneo dial.) kayu kapur 'Sabah kapur (D. beccari)' (Heyne 1927/2:1106); Minangkabau kayu kapur 'k.o. tree (Canarium eupteron)' (Wilkinson 1932/1:510).
} 
reflected in the Chinese (Gerini 1909:440, Wolters 1967:361) and Tamil literary record (Obdeijn 1941a:326 fn. 1). Figure 37 presents an overview of Barus-related loanwords. In addition, Watt (1889-96/ii:84) gives baras as the Indian trade name for 'camphor'. This word is no longer used and I have not found it in the dictionaries. However, Indian English has 'baras kapoor', which refers to camphor powder available in pharmacies.

Next to the westward diffusion of camphor names, lexical borrowing also took place in the opposite direction. Reflexes of Sanskrit bhimasena are found in mainland South and Southeast Asia and denote an inferior type of camphor, e.g. Hindi bhïmseñ̄ 'k.o. camphor', Pañjābī bhímsainní, Marāthī bhīmasēnī id.; Burmese phui:masin (ழ̣: camphor', Cham bumsin (via

fragrant flower', Khmer bumsaen

Figure 37: attestations of barus '(camphor from) Barus' (ตุ๊โับธ) 'patchouli (Pogostemon cablin)', Thai phimsēn (พิมเสน) 'refined camphor; purple betony (Stachys officinalis)' and Lao phïmmasēn (๗ீมมะเรบ) 'camphor'. In this regard, mainland Southeast Asian camphor

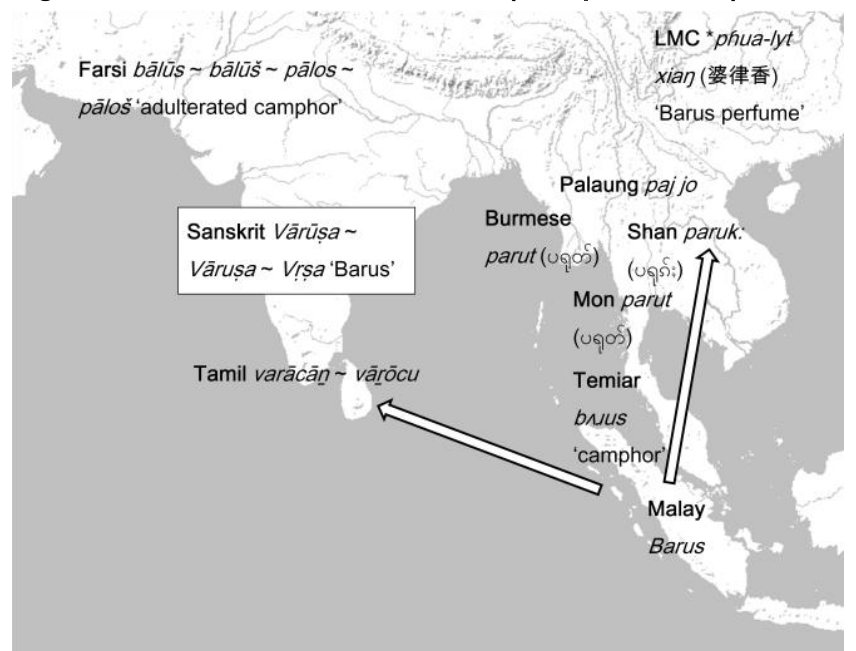
terminology follows the same patterns as other products important in Hindu-Buddhist ritual, such as sandalwood and nutmeg; the Sanskrit word is widely adopted on account of its socio-linguistic prestige. In insular Southeast Asia, however, the indigenous Malay terminology is often preserved and has even spread to other regions of the Indian Ocean World. In light of the possible presence of camphor in the relatively early context of a $2^{\text {nd }}$ C. BCE Egyptian mummy, one might conjecture that the dispersal of this product and its name predated the cult status that Sanskrit developed in the Indian Ocean World. Therefore, it is not entirely surprising that the original Malay name was not replaced by a local neologism, although the back-formation to Sanskrit karpūra did make the word look more indigenous. 


\subsection{Other tropical forest products}

The rainforests of Southeast Asia offer a wealth of natural tree gums. Due to their highly esteemed qualities as dyes, incenses, perfumes and torches, these aromatic wood products

Figure 38: attestations of damar 'dammar'

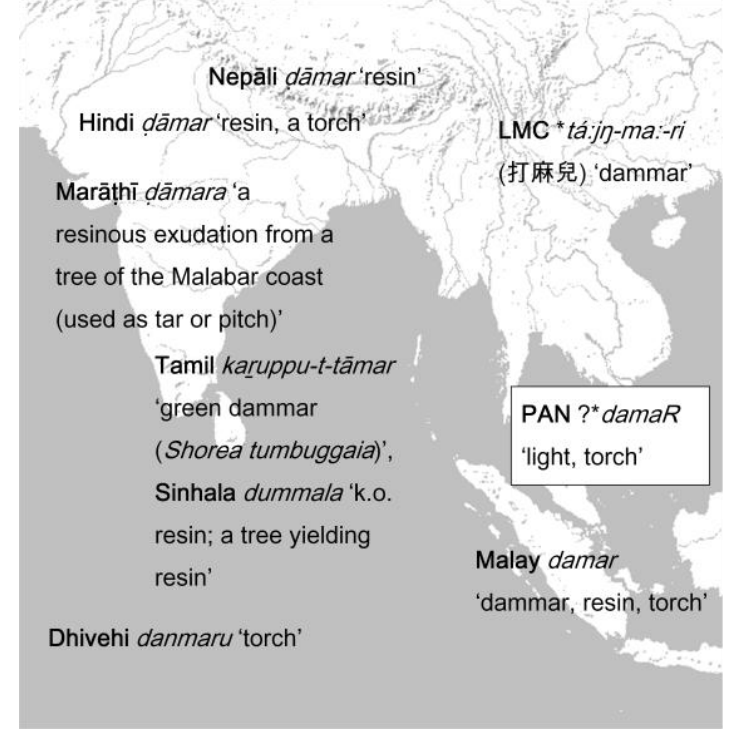

played a role in local and international trade. The various types of resinous exudations from tree bark (dammar) were in demand for their fragrance and applicability in the caulking of boats (putty). A considerable export of dammar from the Malay World to other parts of Asia is evidenced by the linguistic data (cf. Figure 38). The Malay word damar 'dammar, resin, torch', 159 with various Austronesian cognates (Sakiyama 2009:241, Wolff 2010/2:814), was

adopted into several South Asian languages and has also made its way into the Chinese literature as LMC *tá:jp-ma:-ri (打麻兒) ‘dammar’ (Hirth \& Rockhill 1912:200 n.). ${ }^{160}$

Next to this general term for 'aromatic tree bark', several specific trees from the Southeast Asian rainforests were known to the ancient Indians. One of the most important aromatic forest products of Southeast Asia is benzoin, also called gum benjamin, a pathogenic resin obtained by wounding trees of the genus Styrax, particularly Styrax benzoin. Common adulterants for true benzoin were obtained from the aromatic resins of the Sumatran pine (Pinus merkusii) and dragon's blood (Daemonorops draco) (Heyne 1927/1:352, Burkill 1966/1:758, Wolters 1967:106-7). When solidified, the substance that emerges from cuts on the surface of the bark is collected, graded according to its quality and purified (Heyne 1927/2:1257-8). Benzoin is a popular ingredient for incense and perfumes across Asia. There is

\footnotetext{
159 Especially from species of the Shorea and Hopea genera (Heyne 1927/2:1106, Wilkinson 1932:252).

160 It has been claimed that the Malay form also yielded LMC *təwk-nə̀w (篤耨) (Hirth \& Rockhill 1912:200 n., Wheatley 1959:92), but this attestation hardly resembles its alleged Malay precursor.
} 
no evidence of familiarity with benzoin in classical Europe, which is not surprising given the small scale on which it was exported to South Asia (Wolters 1967:68) and the availability of aromatics such as myrrh (Commiphora spp.) and storax (Liquidambar spp.). The linguistic evidence confirms the transmission of an insular Southeast Asian precursor to the Indian subcontinent. As indicated in Figure 39, the Malay word kəmənyan 'benzoin' or a form closely related (cf. Heyne 1927/2:1256, Wilkinson 1932/1:551) appears to have spread to the Southeast Asian mainland (Yamada 1955/2:4, Mahdi 2007:73) and to China, where it was transcribed as LMC * kim-nja:n (金顏) (Hirth \& Rockhill 1912:198-9). In addition, we find reflexes in South Asia. The Arabic word for 'benzoin' is lubān ğāwī 'Malay frankincense', to which Portuguese (†beijoim) and other European languages owe their reflexes (Yule \& Burnell 1903:86-7). ${ }^{161}$ Semantic shifts from one aromatic to another are not unfamiliar crosslinguistically. The Chinese literature, for example, contains the term LMC 7an-siaj xian (安西香) 'Parthian perfume', which originally referred to a variety of the myrrh tree (Commiphora wighti) and was subsequently used for Sumatran benzoin (Hirth \& Rockhill 1912:201-2 n., Laufer 1919:464, Wolters 1967:110).

161 Derived from Arabic /ubān 'frankincense; olibanum' are Malayālam uluvān 'frankincense', Hindi /ubān lobān 'a kind of gum; incense; benzoin (resin)', Farsi lobān 'frankincense; olibanum; benzoin', Somali luubaan 'frankincense', Makhuwa rubani 'incense', Swahili ubani (<+/ubani), Comorian ubani id., Malagasy (Mayotte dial.) obàny 'eastern incense' and possibly Malay (ha)laban 'a tree-name; Vitex spp.' and Toba Batak aloban 'k.o. tree'. 
Figure 39: attestations of kəmənyan 'benzoin'

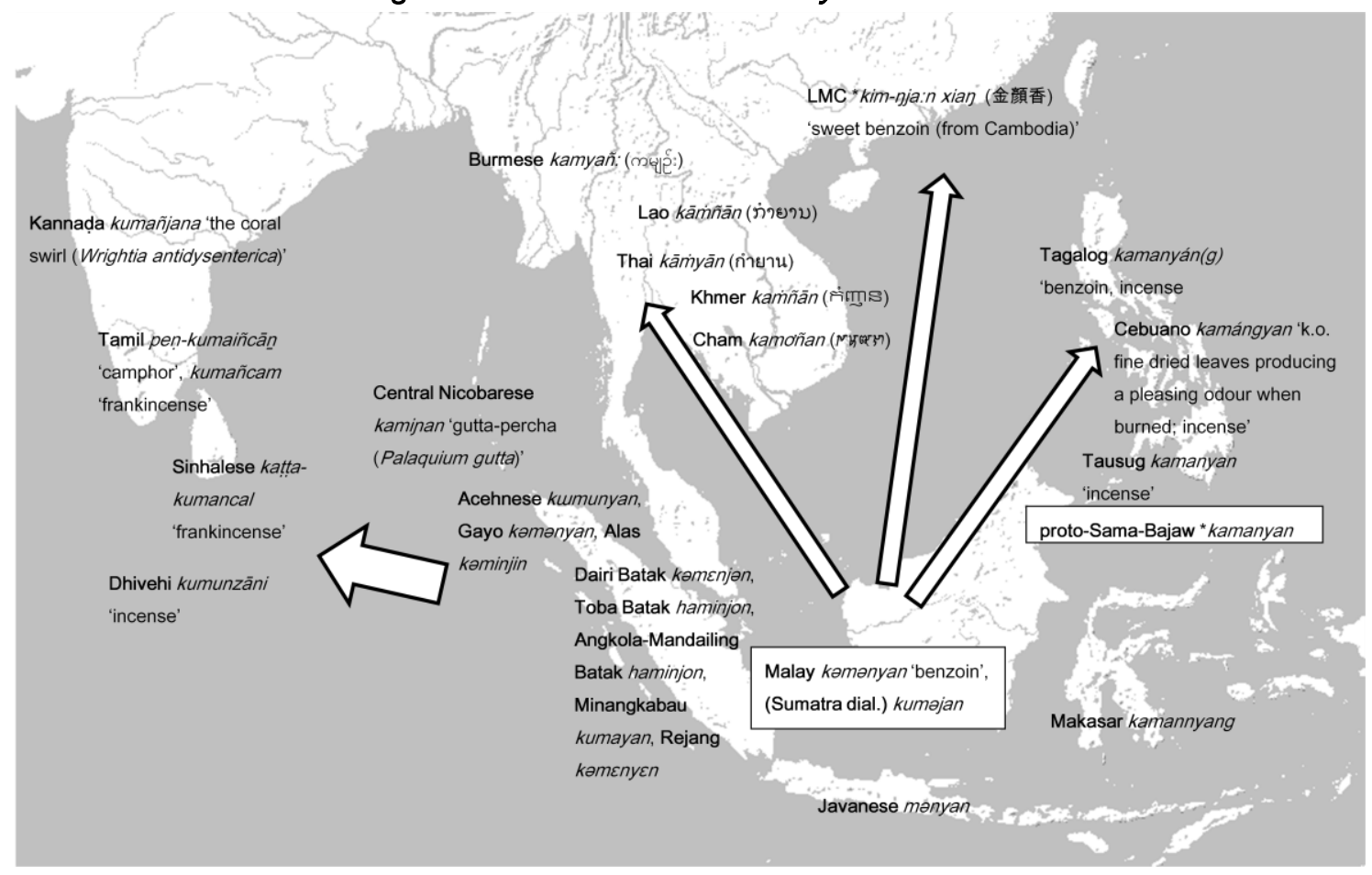

Equally important was agarwood, the resinous heartwood of trees of the genus Aquilaria, in particular Aquilaria malaccensis found in the forests of Southeast Asia and Northeast India (Watt 1889-96/i:279). The wood is also known under the names 'eaglewood', 'agila wood', 'oodh', 'lignum aloes', 'aloe wood', 'aloexylon' and 'garrow wood'. Trees obtain their fragrant resin as a result of infection by a type of parasitic mould. This resin is used as a perfume, incense, cosmetic and breath sweetener (Crone 1987:74). In North Sumatra, the bark is used to make the paper for traditional religious books known as pustaha (< Sanskrit pustaka (manuscript, book'). The olfactory and pharmaceutical properties of the diseased wood made it one of the most popular aromatics in Asian cultures. Nevertheless, tentative claims of agarwood in Dioscorides' Materia Medica (Dalby 2000:70), the Periplus (Miller 1969:86) and even the Old Testament (Rabin 1968) need to be treated with due care, as the bitter, medicinal plants of the Aloe family bear the same name in several languages (cf. Crone 1987:267). We know with more certainty that agarwood was an important incense product in the pre- and early Islamic Middle East, along with myrrh and frankincense (Crone 1987:75, King 2008:180-1). The Chinese and Indians, too, imported it on a considerable scale from the Southeast Asian 
mainland by medieval times (Sastri 1944:27, Wheatley 1959:69). The Portuguese sharply distinguished two different qualities of agarwood (Burkill 1966/1:201): the top-quality wax-like heartwood (calambac) and the heavier, harder variety (pao d'aguila), which is so dense that it sinks in water. The second word yielded (botanical) Latin Aquilaria as well as 'eaglewood', but is in fact no more than a rationalisation of the product's Malayālam name agil, cf. Kannaḍa agil 'fragrance' and Tamil akil 'agarwood' (> Sinhala ayal 'yellow fragrant wood').

These Dravidian forms are related to OIA *agaru ( *aguru) 'agarwood', reflected in Hindi as agar, Bengali aguru id. and many other Indo-Aryan languages (cf. Turner 1966 \#49). This form has also spread beyond the Indian subcontinent, e.g. Farsi agar akar, Tibetan a ga

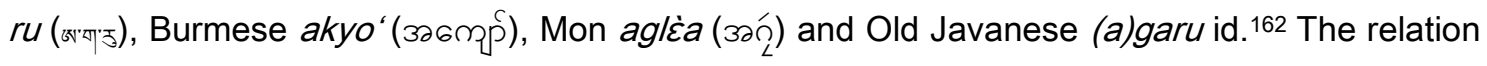

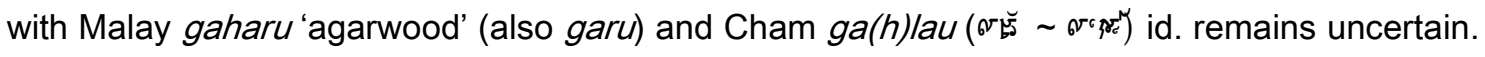
The form is usually explained as an Indo-Aryan compound consisting of a-guru 'not heavy, light' (an apparent contradiction: pao d'aguila is known to be rather dense). If this is true, the shape of Malay gaharu is irregular and would require further explanation. Alternatively, we might argue that the word is a Southeast Asian borrowing into the Indo-Aryan languages (cf. Yule \& Burnell 1903:335), which would compel us to regard the form aguru as the result of folk-etymology. In considering a reverse acquisition, it has been pointed out that the product is also known under the Sanskrit name anāryaja (or anāryaka), denoting a 'product of the country of mlecchas or

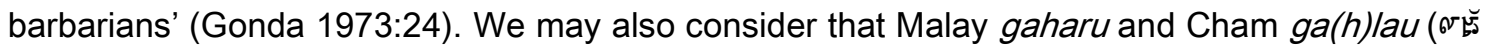
$\sim \mathrm{wros}^{\mathrm{c}}$ ) id. resemble attestations in other mainland Southeast Asian languages, including Pacoh

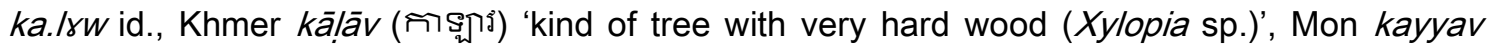
(mu్jం) 'agarwood' and Burmese kayo (mows) 'k.o. creeper'. While the ultimate source of this

\footnotetext{
162 Other languages exhibit descriptive terms for the wood, e.g. Arabic al-'ud 'the wood' and LMC *trhim-xian (沉香) 'sinking perfume' (> Southern Min tîm-hiun (沉香), Vietnamese trầm hương, Japanese jinkō (沈香), Korean ch'imhyang (침향) id.). Such attestations as Khmer krasnā (โกญญ्(), Thai krșanā (กฤษณา), Moken (Myanmar var.) tøana and perhaps Malay karas can be traced back to Old Khmer krșnaguru 'black agarwood' (cf. Chakravarti 1978:209) and ultimately to Sanskrit krșnāaaru id.
} 
word - and the plant it referred to - may have gone lost, a possible Southeast Asian origin is worth considering.

Terms for the resinous 'calambac' variety are restricted to Southeast Asia. The word may be derived from or related to a more general Mon-Khmer term denoting 'heart(wood)', 'pith',

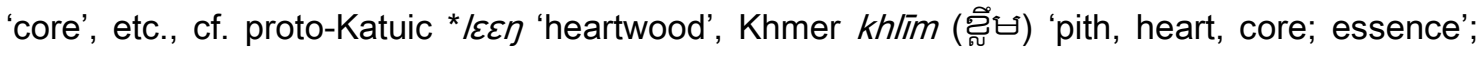
Tampuan khləim 'wood between the bark and heartwood' and Khasi kse? khlen 'resinous pine wood'. ${ }^{163}$ This word presumably yielded such forms as Semang klim 'calambac', Stieng klin (Skeat \& Blagden 1966/2:512); Vietnamese kỳ nam id. (Tana 2002:79-80); Karo Batak alim 'k.o. tree, the bark of which is used to make the paper for pustakas', Toba Batak alim 'Aquilaria sp., a tree, magic books (pustaha) are made from its bark', Angkola-Mandailing Batak alim 'k.o. tree, the bark of which is used to write on', Lampung halim 'agarwood' (Heyne 1927/2:1149), and perhaps Thai (Mae Hong Son dial.) gialīam (เคียะเลี่ยม) 'Malayan spurge tree (Euphorbia antiquorum)'. ${ }^{164}$ The word also occurs in the Chinese accounts on Southeast Asia as LMC *Khia-lam (茄藍～伽藍) id. (Rockhill 1915:86, Mills 1975a:151). It appears to have obtained a

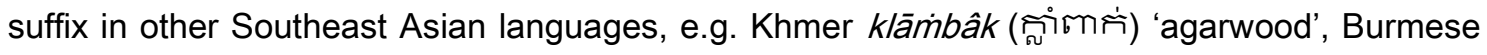
karamak (mфư) $)$ Malay kələmbak kəlambak, Makasar kalamba? id.; Thai (Nakhon Ratchasima dial.) kalāmbak (กะลำพัก) 'Malayan spurge tree (Euphorbia antiquorum)'. ${ }^{165}$ As the Chinese played a major role in the trade in calambac, this additional element is most likely of Chinese origin, cf. colloquial Southern Min bak (木) 'tree' (cf. EMC *mowk). Hence, I would argue that the ultimate origins of calambac wood can be traced back to the Southeast Asian mainland, while the Chinese gave it its more widely distributed trade name. This word was borrowed into Malay in pre-colonial times and is mentioned by Ludovico de Varthema as calampat (Mahdi 2007:3).

\footnotetext{
${ }_{163}$ Burmese kharuin (วด̆c) 'central part of umbrella frame', with an earlier meaning of 'heartwood' (Luce 1959:85), may also be related.

164 (http://www.thaibiodiversity.org/ S.v., accessed Apr 2012).

165 (http://www.thaibiodiversity.org/ S.v., accessed Apr 2012).
} 
Another important trade product is the Indian almond (Terminalia catappa), a large tropical tree found in a wild state in Southeast Asia and the Pacific and in cultivated form all over South Asia (Watt 1889-96 vi/iv:23-4). The tree is famous for the tannin in its leaves and bark, which can be made into a dye. The wood is also used for its timber and edible nut, from which oil is extracted (Burkill 1966/2:2176). Most South Asian languages use a term derived from the word for 'common almond (Prunus amygdalus)' to refer to the tree, e.g. Hindi jarigli bādām 'forest almond' and Orịā Banigalā bādāma 'Bengali almond'. In some cases, the Malay name kətapang has been adopted, ${ }^{166}$ e.g. Malagasy hatafa, (Antankarana dial.) antafa, (Betsimisaraka dial.) antafa(na), Tamil kattāppu and Sinhala koțtambā id. The last two attestations end in an open vowel (as does the botanical name), so that we may assume that the borrowing took place via a third source, e.g. Creole Portuguese katapa id. (Schuchardt 1891a:140, Mahdi 2007:106).

Moving on to the last of valuable Southeast Asian forest products, we conclude with sappan-wood. The sappan tree (Caesalpinia sappan) is a spiny shrub native to Southeast Asia and famous for its medicinal properties and especially for its dye-tincture (Heyne 1927/2:753-4). Together with the closely related species C. violacea, sappan-wood is known as 'Brazilwood' in the early European sources (Burkill 1966/1:390). In Asia, its Malay name (səpang) was borrowed into several languages, e.g. Malagasy (Betsimisaraka dial., Bezanozano dial.) sefana

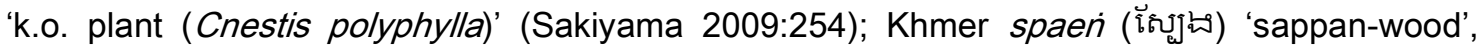
Tamil cappaniki, Malayālam cappaninam and Kannaḍa sappaniga id. ${ }^{167}$ Further, Chinese accounts transcribe this word as LMC *suə̆-fan məwk (蘇枋木) 'sappan-wood' (> Korean sobangmog (소방목), Japanese suou (蘇芳), Vietnamese vang, Thai fān (ฝาง), Lao fān் (๒งๆg)

166 Cf. Tagalog katapang 'k.o. tree (Shorea guiso)' (Dempwolff 1934-38/3:75); Proto-Polynesian *katafa 'bird's nest fern (Asplenium nidus)' (Biggs 2010) and various cognates in Indonesia (Heyne 1927/2:1176, Sakiyama 1992:738).

167 South Asian attestations such as Hindi patang 'sappan-wood', Sinhala petanigi, Dhivehi fatangu and Tamil patarikam id. go back to Sanskrit * pattrānga 'sappan-wood; red sandalwood (Pterocarpus santalinus)', lit. 'silk-dyer' (Turner 1966 \#7707). The etymology of Arabic baqqam (pl. buqūm) is not clear to me, but this word may originally have referred to other dye-yielding plants, cf. Arabic buqaymä̈ 'Solanum armatum, S. forskalii, buqqum 'thorn apple (Datura spp.)', (Yamanī dial.) bugum (تقم) 'Solanum incanum' (Piamanta 1990/1:36). 
id.). ${ }^{168}$ The word does not occur in Sanskrit texts or other early Indian literature that I am aware of.

The insular Southeast Asian origin of various valuable tree products is relatively well reflected in the linguistic data. The donor language was in most, if not all, cases Malay or a Malayic variety. This strongly suggests that Malay-speaking traders were involved in the transport of aromatic resins, possibly all the way to India. Further westwards, we find textual attestations of 'benzoin', 'sappan-wood' and 'agarwood' in Middle Eastern works of medieval times, but the names used for these products were not borrowed from Malay. This does not necessarily imply that the Arabs obtained their supplies of fragrant resins through Indian or other intermediates. Notions of linguistic purism may have compelled Arabic authors to create indigenous names for foreign trade products. Other than the three commodities mentioned above and camphor (cf. Section 6.4), we do not find evidence, textual or other, for Southeast Asian forest products beyond India in pre-modern times. On the whole, the scale on which this exchange took place was relatively small and predominantly restricted to South Asia and the Malay World. The inhabitants of the rainforests, after all, were restricted to a limited amount of tree resins they could sell due to difficulties in finding the right trees at the right time and, possibly, in order to prevent exploiting their valuable natural resources.

\subsection{Concluding remarks}

The many different functions of spices in religion, cuisine, medicine and perfumery made them among the most popular commodities of Indian Ocean trade. Far away from their location of cultivation, local elites in South Asia, the Middle East and Europe were willing to pay exorbitantly high prices for Southeast Asian spices, in particular cloves, nutmeg, pepper species, camphor and benzoin. With the possible exception of sandalwood (cf. Section 5.1), Southeast Asia remained the key source of these spices and resins into historical times. South

168 Later Chinese texts exhibit the abbreviation suə̆-məwk (蘇木) (Hirth \& Rockhill 1912:217 n.). 
Asia, too, exported spices, most notably cinnamon, cardamom and several pepper varieties. The Malay-speaking merchants thus encountered - and were incorporated in the commercial networks of - experienced South Asian spice traders, users and cultivators, who actively interacted with communities to the east and west, all the way to the Roman Empire. The evidence, linguistic and other, presented in this chapter demonstrates that several Southeast Asian spices were chiefly intended for the Indian market. As far as our knowledge reaches, most Southeast Asian spices did not diffuse into the Middle East, Europe and East Africa at any early point in history, barring the tentative identification of clove remains in a Mesopotamian context. Those products that did establish themselves along the shores of the Arabian Sea presumably owe their presence in these regions to Middle Eastern commercial agency of later date, reinforced by the spread of Islam.

As was the case with the translocated plants discussed in the previous chapter, most notably 'sandalwood', the linguistic data contain examples of Indo-Aryan words that spread both east- and westwards across the Indian Ocean. In the cases of the Middle East and East Africa, this strongly suggests that local communities were incorporated into the spice trading networks of Indian merchants. In the case of Southeast Asia - where many of the spices originated from - it appears that Malay-speaking merchants, in due course, have adjusted their lexicon to their customers. The introduction and prevalence of a Sanskrit word for 'nutmeg' and a Chinese word for 'cloves' in the Malay language and, consequently, across insular Southeast Asia attests to the tendency of Malay-speaking merchants to adopt foreign trade names for local products. However, this chapter also demonstrates that a pre-existing Malay term for 'cloves' (lawang) has reached South Asia before the $1^{\text {st }}$ mill. CE. Similar distributions of Malay terms into the Indian subcontinent can be observed in the domain of tropical forest trees. Among these, the word for 'camphor', from Malay kapur Barus 'lime from Barus', is one of the most widespread insular Southeast Asian terms encountered in this study. To illustrate the intricacy of the interethnic networks and commercial exchanges highlighted in this chapter, we may also call attention to the transmission of the Java long pepper. We have seen that an Indo-Aryan 
word (cavī cavya) spread across Southeast Asia to denote a local plant, attesting once more to the social prestige of Sanskrit (as we have seen with the words for 'sandalwood' and 'nutmeg'). At times, the story of the Southeast Asian spice trade proves to be unexpectedly complex. 


\section{The dispersal of Southeast Asian maritime technology}

Seafaring ships are the largest and most important vehicles invented by people. Watercraft has been employed to colonise uninhabited areas, reach otherwise isolated populations, and transport everyday and valuable commodities as well as crops, spices and animals. The history of the Indian Ocean, in particular, is shaped by maritime developments and activities, interaction and cross-fertilisation. To illustrate the interconnectedness of the Indian Ocean and its seafaring traditions, we may call attention to the finding of a shipwreck built in the Arabic tradition, made of African hardwood, carrying $9^{\text {th }}$ C. CE Tang Dynasty ceramics manufactured in China, which was found off the coast of Belitung, an island located east of Sumatra (Flecker 2000, Guy 2006). This chapter focuses on the diffusion of nautical technology and particularly on the contributions from insular Southeast Asia to other regions of the Indian Ocean.

Many cultures of insular Southeast Asia, even those far inland, display an ancient and profound connection with boats - evident in textile and other art forms, in the shape of houses, and in village structures - serving as a constant reminder of their seafaring ancestors (Maxwell 2003:4-7). Even in terms of political organisation, several of insular Southeast Asia's early polities were essentially "shipshape societies" (Manguin 1986). To understand the origins and development of the sophisticated maritime traditions of insular Southeast Asia, it is important to recognise that the earliest inhabitants of this area were oriented towards the sea and frequently undertook sea journeys. At least 40,000 years ago, pre-Neolithic hunter-gatherers were able to transgress the natural barrier between the Eurasian mainland and the Sahul Landmass (the Pleistocene Era continent that joined New Guinea, Australia and Tasmania), presumably helped by favourable winds, methods to calculate tides and sea currents, and patterns of intervisibility between certain island groups (Gosden 1992, Irwin 1992, Allen 1996, O'Connell \& Allen 2004 , O'Connell et al. 2010, Summerhayes et al. 2010). ${ }^{169}$ At all glacial periods, these population

169 Recently, even earlier dates for the initial settlement of Australia have been proposed (Roberts et al. 1990, Chappell et al. 1996, Hesp et al. 1999), though the chronology of Australia's colonisation remains controversial. 
movements required crossing sea straits of at least 90 kilometres, while the settlement of Near Oceania involved even longer voyages (Gibbons \& Clunie 1986:72-5, Irwin 1992:18ff.). In this regard, we may also ask ourselves what kind of maritime technology our predecessor Homo erectus used to reach places as far as Flores and Timor during the late Lower Pleistocene (cf. Verhoeven 1968). In any case, deliberate sea journeys were carried out from this period onwards, presumably with children and food on board to successfully colonise new islands and establish viable populations.

As the small-scale populations of the Pleistocene were forced to look beyond their native territories to exchange staple foods and other trade items, maritime trade and cultural contact has probably prevailed throughout most of insular Southeast Asia and Near Oceania since these regions were first settled. It has been argued that the earliest inhabitants of this region developed genetic famine resistance and cold resistance (to fight hypothermia during prolonged seaborne journeys) over the millennia as a result of their maritime lifestyle (Pearce \& Pearce 2011:31). In addition, archaeological research reveals a distinct maritime orientation of some Pleistocene communities of Southeast Asia as demonstrated by the findings of pelagic fish remains at various recently excavated sites (Lape et al. 2007:240, Barker \& Rabett 2009, O'Connell et al. 2010:60 and the references therein). One of the most important commodities in the Holocene trade networks was obsidian, which was carried over vast distances from the $5^{\text {th }}$ mill. BCE (Bellwood \& Koon 1989, Service 1996, Tykot \& Chia 1997, Chia 1998). Ancient seafarers presumably employed certain types of rafts and bark boats, as is still the case among indigenous Australians (Doran 1981:23, Irwin 1992:25). Given the time-depth and the biodegradability of the materials used, however, it is unlikely that we will ever find the remains of their watercraft.

A different nautical development has led to the prevalence of the dugout canoe, also known as 'monoxylon' or 'logboat'. This boat is made of a single piece of wood, usually a hollowed-out tree trunk. Dugout canoes are found ubiquitously in the waters of insular Southeast Asia and the offshore islands of Taiwan (Nooteboom 1932, Barnes 2002), but very 
rarely on the Taiwanese mainland (Stainton 1999:32-3, Blussé \& Roessingh 1984:70). ${ }^{170}$ On the other hand, a recently excavated dugout canoe at the Kuahuqiao site in south China reveals that this type of watercraft was known in the Lower Yangzi area from at least the $6^{\text {th }}$ mill. BCE (Jiang \& Liu 2005). As a more advanced development, sophisticated rafts consisting of double or multiple dugout hulls have been documented in Oceania (Haddon \& Hornell 1936-38/2:2137). The extent to which these types of watercraft had also been in use in insular Southeast Asia remains uncertain. In East Asia, the earliest types of watercraft were probably bamboo log rafts, still in use amongst Taiwan's indigenous populations and the fishermen of Fujian, Hainan and Vietnam (Hornell 1934:335, Needham 1980:393, Manguin 1985a:321, McGrail 2001:294, 351). It has been argued that these rafts eventually developed into the famous Chinese junks and sampans (Hornell 1934:333-5, Ling 1970:130, 153, Needham 1980:395-6), although alternative scenarios have been proposed in which these ships developed out of double canoes (Hornell 1946:88-9, Gibson 1958:16-7, 32, Mahdi 1992).

From the first centuries CE, Chinese accounts give detailed descriptions of diplomatic missions from several Southeast Asian states, in which large numbers of big animals, slaves and exotica were transported aboard sophisticated watercraft (Pelliot 1925, Manguin 1993:261). These ships were presumably manned by Malay-speaking sailors, who would later play an important role in the maritime transportation of Buddhist pilgrims during the Śrī Vijaya period. By this time, the maritime communities of insular Southeast Asia adeptly produced watercraft with advanced sails, outriggers and sophisticated methods of plank-fastening, at first purely sewn and later fastened with wooden dowels or - rarely - iron nails (Manguin 1985b:17, Horridge 2008:85). Besides Oceania, insular Southeast Asian boat types and maritime technology also spread to northern Australia (Halls 1961) and into the Indian Ocean. In a long list of publications, James Hornell examined and eloquently described the traditional boats of South Asia and East Africa - many of which are currently no longer in use - and argued that several of them were of

170 This may have been different in the more remote past; the archaeological record of Taiwan contains a small amount of boat-shaped ornaments (Wu 2005), although the identification of the depicted watercraft remains problematic. 
insular Southeast Asian provenance. Later, the seaworthiness of traditional Southeast Asian watercraft has been put to the test by such adventurous authors as Bob Hobman (Sarimanok expedition, 1985), Michael Carr (Amanagapa expedition, 1991), Michaël Pitiot (Sao Mai expedition, 1999) and Philip Beale (Borobudur expedition, 2003), who successfully undertook transoceanic journeys in replicas of traditional Southeast Asian ships. To make optimal use of seafaring watercraft, knowledge of sea currents and monsoon winds would have been vital. The monsoon of South Asia blows to the south during the northern hemispherean winter and to the north during the summer, enabling transoceanic journeys from and to any given point in the Indian Ocean within a year (Grimes 1941, Donque 1965). Taking these and other variables into account, the possibility of direct seaborne journeys from the northern tip of Sumatra to Madagascar and back has recently been investigated using computer simulations, the results of which indicate that they were feasible - at least in theory - during several months of the year (Fitzpatrick \& Callaghan 2008).

While our understanding of seafaring in the Indian Ocean is gradually improving, several questions remain unanswered. One particular issue that merits our attention is the way in which people incorporated nautical elements from their neighbours into their own traditions. From antiquity, ship crews consisted of various ethnicities. The early Arabs, for example, initially employed Copts as crew-members at the dawn of their own advanced seafaring tradition and global maritime hegemony (Campbell 1995:10). Similar patron-client relations occurred (and occur) elsewhere. At the time of Portuguese arrival in Southeast Asia, India-bound ships in the harbour of Malacca were normally owned by patrons of the mercantile Kəling community from southern India (Subrahmanyam 1990:21-2). We can only guess at the - presumably diverse origins of their crews; the lives and exploits of the inconspicuous are rarely reflected in historical writing. This chapter addresses how the different seafaring nations that emerged along the coasts of the Indian Ocean influenced one another, highlighting the active participation of Southeast Asian sailors in these interactions. As pointed out in the previous chapters, Malayspeaking seafarers played a major role in the transmission of insular Southeast Asian 
commodities across the Bay of Bengal, while this was much less the case in the regions west of the Indian subcontinent. This chapter explores the extent to which the dispersal of maritime technology displays a similar geographical pattern. It addresses the development and dispersal of various types of watercraft and nautical devices across the Indian Ocean, giving special attention to lexical transmissions. In the first section, the ship-building traditions of the Indian Ocean will be addressed and placed in a historical context. The pre-modern boat and ship types of the Indian Ocean will be treated next, focusing on their names and dispersal from one region to another. This is followed by a closer study of the origins and development of - respectively plank-fastening, the sails of the Arabian Sea, insular Southeast Asian sails, outriggers and other nautical devices, each of which will be addressed in a separate section. By way of conclusion, the dispersal of ship-building technology and terminology across the Indian Ocean will be contextualised and put into a wider framework of ancient cultural contact and diffusion.

\subsection{Nautical traditions across the Indian Ocean}

The Indian Ocean has accommodated seafaring ships from Mesopotamian times (Carter 2003). Unfortunately, we know very little of the watercraft employed by the earliest seafarers of the Near East. While we have a large textual corpus at our disposal on the vessels and nautical technology of China and the Mediterranean, our knowledge of pre-modern Indian Ocean ships is largely based on a limited record of archaeological and iconographic findings, supplemented by ethnographic and ethnohistorical studies on contemporary maritime communities and their material cultures. By combining inferences from all these fields, we can attempt to cast a new light on the watercraft used in the Indian Ocean, albeit in the absence of solid archaeological remains. Such an interdisciplinary analysis has been applied to a now extinct Sri Lankan ship known as yātrā dōni, revealing a hybrid origin and the incorporation of elements from various traditions (Vosmer 1993). From an archaeological perspective, however, we have little solid data on prehistoric Indian Ocean watercraft. Possibly the earliest finding of a complete boat is a dugout canoe found in a river bed near the Kelani Ganga, Sri Lanka, ${ }^{14} \mathrm{C}$-dated to $380 \mathrm{CE} \pm 100$ 
years by the Weizmann Institute, Rehovot, Israel (Kapitän 2009:168-9). After a lull of almost a millennium, the South Indian Kadakkarapally boat, ${ }^{14} \mathrm{C}$-dated to the $11^{\text {th }}-12^{\text {th }} \mathrm{C}$. CE, constitutes one of the few other examples of a pre-colonial South Asian shipwreck (Pedersen 2004, Tomalin et al. 2004).

Several scholars have noted the Middle Eastern influence on South Asian watercraft (Hornell 1924a, Mookerji 1957:22). As mentioned in Section 3.1, cultural contact and commercial interactions between the ancient Middle East and South Asia can be traced back to the Harappan era. However, the somewhat persistent assumption of a one-way directionality of technological diffusion greatly downplays the significance of the South Asian seafaring traditions. Instead, Boivin et al. (2009:25) highlight the likelihood of an indigenous maritime trading culture in this part of the world. In support of this view, we may call attention to the large-scale import of tropical South Asian timbers such as teak (Tectona grandis) and coconut palm (Cocos nucifera) into the Middle East from the mid-1st mill. BCE onwards (Kennedy 1898:267, Hourani 1995:8991). ${ }^{171}$ The directionality of this exchange suggests that Middle Eastern knowledge of shipbuilding and plank-fastening was, at least in part, acquired from the South Asian suppliers of their materials. Although Harappan sites have not yet yielded any datable boat remains, iconographic evidence in the form of graffiti on potsherds, clay models, illustrations on seals and clay amulets points towards a great diversity in types of local watercraft during the $3^{\text {rd }}-2^{\text {nd }}$ mill. BCE (Rao 1993, Deloche 1996, Ray 2003:58-9). However, it is uncertain whether the depicted vessels were sea- or river-faring boats. The tentative finding of a tidal dock at the archaeological site of Lothal would favour a maritime orientation (cf. Rao 1993), but this remains controversial at our present stage of knowledge. Nonetheless, many archaeological sites along the South Asian coast reveal a distinct maritime orientation (Sila Tripati et al. 2004). The prevalence of maritime activity is also supported by the literary corpus; many of the earliest Indian texts demonstrate an awareness of seafaring, which was, however, often discouraged and associated with impurity in the Brahmanical śāstras (Subrahmanian 1977:11, Dhal 1999, Ray

171 Teakwood is still imported from India to Socotra to manufacture the traditional hawārīboats (Rensburg 2010). 
1994:2-3, 153, Bayly 2004:720). Nevertheless, as has been pointed out in Section 3.2, there is clear evidence of Brahmanical proselytism in Southeast Asia during the first centuries CE, suggesting that actual practise was considerably different from that advocated in the religious scriptures. Particularly since the rise of Buddhism, seafaring and maritime contacts with Southeast Asia radically changed the maritime history of the Indian Ocean (Ray 1994:124). With this in mind, we may safely assume that seafaring was known and frequently carried out in the waters of the Indian subcontinent throughout much of the region's prehistory.

Various Graeco-Roman texts, too, mention long-distance maritime contacts in those parts of the Indian Ocean known to them. In his Historia Naturalis, Pliny the Elder describes the 'cave-dwellers' ( Troglodytæ) who import "cinnamomum or cinnamum" into the Horn of Africa on "rafts, which are neither steered by rudders, nor drawn or impelled by oars or sails". Despite the alleged absence of sails, these bold merchants "choose the winter season, about the time of the equinox, for their voyage, for then a south easterly wind is blowing" (Bostock \& Riley 1892:138). This account has obtained a prominent place in the wider literature as one of the first known textual references to the use of seasonal monsoon winds to facilitate interregional trade. Pliny's "cinnamon-traders" have frequently been interpreted as maritime communities of at least partly Southeast Asian ancestry (Miller 1969:156-7, Marschall 1980:19, Mahdi 1999a:156-7, DickRead 2005:28-30, Blench 2010:241). However, the ambiguous nature of this isolated account and the lack of corroborative evidence compel us to treat such inferences as conjecture rather than actual historical fact. ${ }^{172}$ In response, several other authors favour an East African provenance for the troglodytes (Murray \& Warmington 1967, Gray 1970:221, Raschke 1978:652-5, Crone 1987:259). Another oft-cited Graeco-Roman reference to Indian Ocean seafaring comes from the Perip/us, which mentions the local names of two types of watercraft in use in the Bay of Bengal (Schoff 1912:46-7). The first term, sángara ( $\sigma \alpha ́ y \gamma \alpha \rho \alpha)$, denotes a raft

\footnotetext{
172 On a related note, the implausible notion that the word for 'cinnamon' - cf. Latin cinnamomum, Old Greek kinnámōmon, Hebrew qinnāmōn, (late) Aramaic qunimon - would be derived from Malay kayu manis 'cinnamon (lit. 'sweet wood')' displays an unfortunate tendency to resurface in the wider literature, despite having been refuted as early as the mid-19th century (Lassen 1847-61/1:280-1 n.2).
} 
made of wooden logs and can be identified with a still existing South Indian type of double canoe called caninātam in Malayālam and canikātam in Tamil. ${ }^{173}$ The second word, colandia

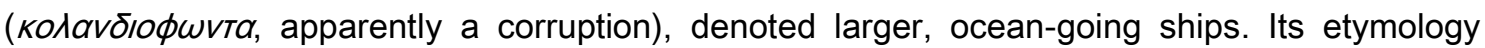
presents more difficulties. Some scholars have attempted to relate the word to Indian boat names (Cœdès 1910:xvii fn.1, Hornell 1920d:215-6, Meile 1940-41:91), whereas others have explained it as a corruption of the Chinese name *Kun-Iun baijk (崑崙舶) for 'Southeast Asian ships' (Stein 1947:64, Christie 1957:345, Miller 1969:186-7). There is, however, little evidence that Chinese seafarers frequented the Indian coast at the time the Perip/us was written (Manguin 1985a:335). A Chinese etymology of colandia, therefore, is rather far-fetched and phonologically irreconcilable withal.

On the East African coast, the Periplus describes sewn boats ( $\dot{\rho} a m t \hat{\omega} v$ ) (Huntingford 1980:158-9), implying that the populations of East Africa had a maritime tradition from at least the first centuries CE. This is supported by archaeological findings on the Swahili Coast (e.g. Chami \& Msemwa 1997, Boivin et al. in press). The presence of indigenous Swahili words for nautical terms such as 'mast' and 'sail' (Prins 1959:207) suggests that these seafaring skills were not simply adopted from Middle Eastern or Asian sailors. On the other hand, a strong Asian element in the boat- and ship-building traditions of eastern Africa is beyond doubt. According to Hornell (1944/2), all traditional dugout canoes of East Africa evolved from a single prototype, the main characteristics of which are the presence of broad, plank-shaped double outriggers, connective pegs to join the outrigger floats to crossbeams, plank-fastening through continuous lashings and the use of organic materials for caulking. There is little doubt that this boat type originated in insular Southeast Asia. The introduction of Southeast Asian boat-building traditions into East Africa must be understood against the backdrop of regular journeys made by Southeast Asian sailors to the East African coast (see Section 4.6). Most of the watercraft of coastal East Africa and the Comoros Islands have also been influenced by Middle Eastern

173 This word presumably goes back to Sanskrit samghāta 'fitting and joining of timber, joinery, carpentry' (Caldwell 1875:95). 
nautical traditions, such as the introduction of the lateen sail and the lashed stern-mounted rudder, or have been replaced completely by Middle Eastern or South Asian ship types. Watercraft in Mayotte and Madagascar, on the other hand, generally remain closer to the prototype (Hornell 1944/2:175).

Figure 40: single outrigger boat (front) and lateen-rigged dhow (background), Mafia Island, Tanzania. Photo courtesy of Ania Kotarba-Morley

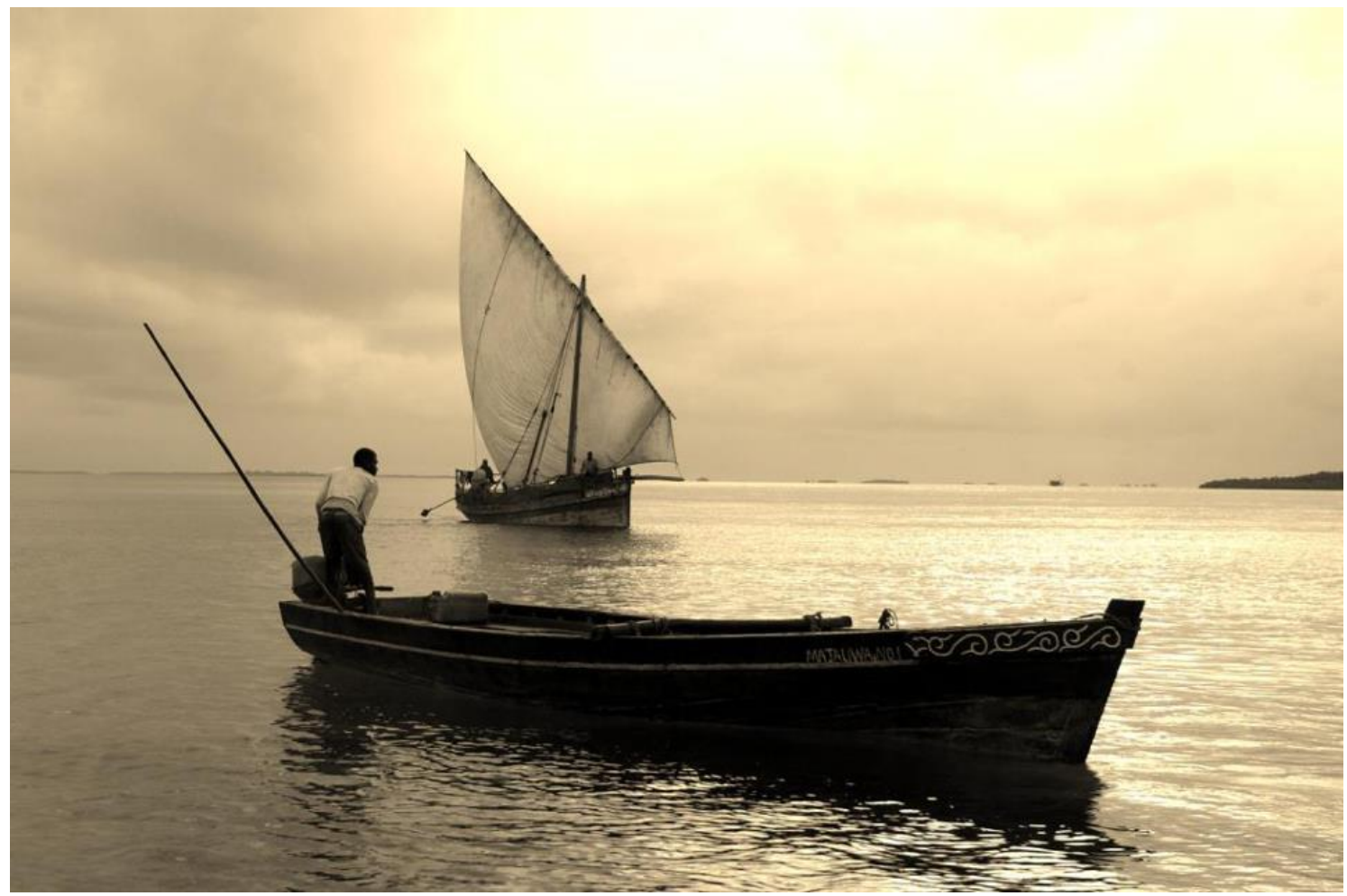

Moving on to the Asian continent, textual references to maritime activities abound in the Sanskrit, Pali and Tamil canonical literature (Sastri 1944, Mookerji 1957:13-21, Pandian 1989:124). However, most of these texts only inform us matter-of-factly that ocean-borne voyages and maritime trade were known and carried out. Consequently, Indian nationalists and regionalists have repeatedly cited such texts, some of which list extremely large numbers of people aboard ships, to applaud the early seafaring skills of their ancestors. Nevertheless, the absence of detailed technical descriptions and the lack of corroborative archaeological evidence urge the objective scholar not to see too much in these literary accounts. In fact, the only Indian texts giving more detailed information on different types of watercraft and plank-fastening techniques are of much later date, in particular the $11^{\text {th }}$ C. CE Yuktikalpataru (Chaudhuri 1976). 
The Chinese literary corpus, on the other hand, provides us with meticulous descriptions of seafaring and ship-building. Manguin (1985a:335) argues that the Han Chinese did not develop a merchant navy and the related seafaring skills until the end of the $1^{\text {st }}$ mill. CE. Although the Chinese had large ships, these were mainly used for riverine and lake transportation (Manguin 1993:269). Before the Chinese developed their own seafaring tradition, various references to large foreign ships occur in the literature. From the $3^{\text {rd }} \mathrm{C}$. CE, textual accounts mention the word *baijk *bs:jk (舶 艊) 'ocean-going junk' (Pelliot 1925, Needham 1980:449ff., Porée-Maspero 1986:85). The descriptions in these texts strongly suggest that this watercraft was of Southeast Asian provenance, yielding several tentative Southeast Asian etymologies of this word (Christie 1957, Manguin 1980:276, Porée-Maspero 1986, Mahdi 1994/2:458, 1999:163-5, 2009:82-3). In the $3^{\text {rd }}$ C. CE Account of Remarkable Objects in the Southern Provinces by Wàn Zhèn, we find descriptions of large foreign ships with up to four sails, set obliquely to use the maximal amount of wind (Manguin 1993:262). Another detailed account is given in the early $9^{\text {th }}$ C. CE Sounds and Meanings in the Vinaya by Huì-lín, which describes large sailing ships displaying several layers of planks fastened through vegetal fibres (Manguin 1993:262). These accounts appear to provide accurate descriptions of contemporaneous Southeast Asian watercraft.

As a general note, a factor not to be overlooked in the evolution of nautical technology is the availability of suitable construction materials. From the mid-1st mill. BCE, when Middle Eastern ship-builders started importing timbers from India (Kennedy 1898:267, Hourani 1995:89-91), ship-builders have often made use of materials not native to their region. This notion offers interesting perspectives on the hybridity of the maritime traditions in the Indian Ocean World. In East Africa, for example, we can observe the use of plantain fibre for caulking (Hornell 1943:15-6) and coconut shells to make bailers (Morgan 1940:31), while river-faring vessels in India incorporate elements such as areca wood and plantain stems (Hornell 1924a:182; McGrail 2001:263). All these materials were presumably introduced into these regions from Southeast Asia as a result of transoceanic trade. In addition, we may call attention to a description of a boat initiation ritual on India's east coast, in which "flowers, betel and 
plantains are laid on the plank as an offering and cooked rice is distributed. Incense sticks are burned and prayers said, while a coconut is broken over the plank. [...] On the sheer strake near the bow, or on the stem post, a smear of milk, sandalwood paste and turmeric is made [...] The owner has plantains, betel and sweets distributed. [...] Finally, a coconut is broken over the bow and the boat will be launched for a symbolic (rather than a fish-catching) journey (Kentley 2003:135-6)." The plantain tree (Musa sp.), the areca nuts (Areca catechu), the betel pepper (Piper betle), the sandalwood tree (Santalum album) and possibly the incense used in the ritual have their origins in insular Southeast Asia and the observation that these products play such important roles points towards a significant cultural contribution from Southeast Asian seafarers, who perform very similar rituals. Moreover, the manufacture of most types of Indian Ocean watercraft would be extremely difficult if not impossible without the introduction of the coconut palm, which provides oil for plank-bending and caulking, leaves for the sail-matting, timber for several specific parts, kernel fibre for threads and nutrition for long seaborne journeys. Since the East African coconut palm population shows considerable Southeast Asian admixture (Lebrun 1998, Gunn et al. 2011), we have ample reason to believe that the introduction of the coconut tree and the transoceanic dispersal of insular Southeast Asian maritime technology were closely interrelated.

\subsection{The ships of the Indian Ocean}

Triggered by the scarcity of archaeological evidence for South and Southeast Asian watercraft, earlier scholars were compelled to focus predominantly on iconographic data to gain an idea of the types of ships used for ocean-faring journeys. In this regard, they have frequently called attention to the reliefs of the $8^{\text {th }}-9^{\text {th }}$ C. CE Borobudur temple in Central Java, which depict several large ships rigged in Southeast Asian tradition (Erp 1923, Heide 1928, Nooteboom 1950-51, Manguin 1980:273, 1985b:12, McGrail 2001:202-3). The Indian nationalist Radha Kumud Mookerji (1957) compares these ships to the watercraft depicted on the Ajanta reliefs and the Coromandel coins, pointing out that all three ship types had several masts, a bowsprit 
and lateral steering oars positioned at the sides of the hull (quarter rudders). This shared set of features was conveniently defined as the result of Indian influence on Southeast Asia. Later scholars demonstrated that the Borobudur ships are primarily part of a Southeast Asian tradition with several distinctive characteristics, such as compound tripod masts, canted rectangular sails and outriggers (Nooteboom 1950-51:126, Manguin 1980:273). Nevertheless, the iconographic evidence tells us little about the origins, crew, manufacturers and geographical distribution of the depicted ships. In other words, it is difficult to determine to what extent the Borobudur ships belong to a local or hybrid, trans-regional tradition. The finding of the aforementioned Kadakkarapally boat favours a scenario of cultural cross-fertilisation between South and Southeast Asia by at least medieval times, if not earlier. Although manufactured from local materials, the keel shape of this boat resembles that of Chinese boats while the lugs through which its planks are fastened belong to the Southeast Asian tradition (Pedersen 2004, Tomalin et al. 2004). In the light of these observations, it seems that Manguin (1996:191) was right when he proposed that the Bay of Bengal may have developed a unique hybrid ship-building tradition, in the same way as had happened in the Arabian Sea and in the South China Sea.

To get an idea of the intensity of contact between insular Southeast Asian ship-builders and their colleagues from other regions, we will now examine the names of several types of vessels. Two Austronesian protoforms for watercraft display a wide distribution: *banka? 'boat' and 'qaban 'boat for travelling' (Wolff 2010/2:756, 947). ${ }^{174}$ The two forms might be related through metathesis or otherwise - or commonly derived from an earlier precursor (Mahdi 1994/2:480-1 fn.177, Benedict 1975:407). The element * ban that both forms share is similar to proto-Kadai * 7 baa ${ }^{\AA}$ 'boat' (Benedict 1975:407) and several attestations in the Chinese literature (Ling 1970:115-7, Mahdi 1994/2:456), suggesting that prehistoric Austronesian-

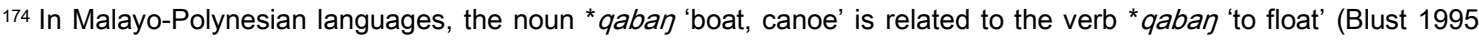
s.v.). Isolated reflexes of * qaban and *banka? are also found in Formosan languages (Ling 1970:130, 153, Pawley \& Pawley 1994:337, Jen-keui Li 1995:964), but these may be secondary introductions from Malayo-Polynesian languages based on phonological irregularities (Mahdi 1994/2:455, Wolff 2010/2:947). Formosan languages additionally exhibit reflexes of * qacu 'boat' (Jen-kuei Li 1995:964).
} 
speaking communities asserted a certain amount of influence on the Asian mainland. The protoform * $q a b a \eta$ is regularly reflected as Moken kaba:ク 'houseboat', 175 from which it has been borrowed into several Mon-Khmer (cf. Old Mon kban 'ship, boat') and Tibeto-Burman languages and, in some cases, underwent a semantic shift to 'coffin' (Mahdi 1994/2:458-9, 1999:165-9, Shorto 2006 \#633). In addition, Mahdi (2009:82-3) argues that another reflex of * qaban was the precursor of the aforementioned EMC attestation *baijk *bc:jk (舶) 'ocean-going junk', presumably through a now-extinct Malayic dialect in which the innovation ${ }^{*} \eta>k / \_\#$ took place. Upon exploring the distribution of the protoform *banka?, it has been pointed out that regular reflexes are only found in Oceania and eastern insular Southeast Asia, whereas attestations in western insular Southeast Asia and Taiwan are probably secondary introductions (Mahdi 1994/2:455, Blust 2009:48-9). The word is distinct from Malay wangkang 'Chinese junk', another type of vessel recorded across insular Southeast Asia. ${ }^{176}$ As was first pointed out by Kern (1915:5), one reflex of *banka? found its way across the Bay of Bengal. In literary Tamil, the word vankkam refers to a large sailing boat used in river transport, warfare and intercontinental trade (Raj \& Rajamanickam 1988:10). This word is already recorded in the Maturaikkāñci poems (Manguin 1996:192), which implies that the boat was known in southern India from at least the first centuries CE. The form varikam also occurs in other works of the Canikam literature (cf. Lehmann 1992:382), but the exact meaning of these attestations remains unclear.

\footnotetext{
175 The regularly inherited Malay reflex of this form is hawang, found in the obsolete compound tpu-hawang 'shipmaster', cf. puhāvami in the Old Malay Sabokingking Naga inscription (Casparis 1956:20). The same word occurs in Old Javanese literature (e.g. in the Harivamśa and the Smaradahana) as (da)puhavan (Kern 1877:142, Zoetmulder 1982/2:1432) and in the Old Sundanese Bujangga Manik as puhavan (Noorduyn \& Teeuw 2006:260). The word was presumably used as an honorary title. The History of the Song Dynasty, in the context of a late $10^{\text {th }}$-century CE voyage to Java, mentions a person known as phut-he-yan ' (勃荷王), evidently the same word (Damais 1956:25-9). Also related are the name Dampu Awang (†dang is an obsolete honorific title in Malay) - belonging to a mythical seafaring hero in several insular Southeast Asian oral histories (cf. Manguin 1986:197) - and Malay pawang 'expert in any art believed to need the use of magic', Acehnese pawang id. and Karo Batak puang 'title for a sultan'.

176 The name wangkang is presumably a Chinese borrowing. The word appears in early Portuguese sources as vancão bancão (Wicki 1971 n.62). Dempwolff (1934-38/3:164) erroneously connects it with reflexes of *banka?, while Varier (1988:54) proposes a rather unconvincing etymology from Tamil. Schlegel (1891:404-5) proposes an etymology from Chinese fénggāng (艂舡), which would correspond to the EMC pronunciation *buawn-kaiwn, whereas Yuanzhi (2005:235) and Jones (2009:172) derive the form from huánggāng (艎舡), i.e. EMC * ywan-kaiwn.
} 
A specific type of ship, documented in early European accounts as parau paró (Wicki 1971 n.44, Mahdi 2007:223, 226-8) and in English sources as 'proa', was found and documented ubiquitously in the Indian Ocean when the Europeans first entered its waters. As shown in Figure 41, this word is reflected in the languages of insular Southeast Asia (cf. Blust 1995 s.v., Mahdi 1999a:171-2) and South Asia (cf. Burrow \& Emenau 1984 \#3838, Sivashanmugan \& Rajamanickam 1988:38). ${ }^{177}$ The first occurrence of parahu in Southeast Asian literature is in an 896 CE Balinese inscription (Manguin 1996:192 fn. 34). Attestations in early Tamil literature include pațavu in the Periya-Purānam and the Tiruvilaiyātạ-Purānam (Raj \& Rajamanickam 1988:12) and pațaku in the Sri Lankan Tamil-Brahmi inscriptions (Rajan 2002:92). The word is attested once in the Islamic Sorabe literature of Madagascar (Beaujard 2003-04:112), presumably as a result of contact with Malay-speaking seafarers. However, this is an isolated occurrence and none of the present-day Malagasy dialects display cognate forms. In insular Southeast Asia and Near Oceania, the word usually refers to a medium-sized sailing boat, as opposed to the small dugout canoes known by reflexes of * banka?. Mahdi (1994/2:462, 1999:171-2) demonstrates, based on historico-phonological evidence, that most of the Southeast Asian attestations go back to either Malay †padau or Old Javanese parahu (borrowed into Malay as pərahu).

Malay-speaking sailors seem to have played a particularly important role in the dispersal of the word for 'proa', although it has not been conclusively demonstrated whether it spread from Southeast to South Asia or vice versa. Tentative reflexes are found as far eastward as Near Oceania with attestations in Raluana, Nissan and other languages of the Bismarck Archipelago (Friederici 1928:33-4, Haddon \& Hornell 1936-38/3, Blust 1995 s.v., Mahdi 1999a:170), which would make an insular Southeast Asian origin plausible (but not irrefutable). Dempwolff (1934-38/3:113) and Wolff (1974:82, 2010/2:880) assume a relation between the name of this boat type and a set of similar looking attestations in Remote Oceania, including

177 The similarity between the South and Southeast Asian attestations has not gone undocumented in the wider literature (cf. Marsden 1812b:xxx, Tuuk 1897-1912/4:159, O'Sullivan 1901:72, Yule \& Burnell 1903:733, Kern 1915:5, Dalgado 1919:2/171, Wilkinson 1932/2:249, 268, Blust 1983-84:90, Zorc 1994:545, Mahdi 1994/2:462, 1999:171-2). 
Fijian (Bau dial.) volau 'canoe shed' and proto-Polynesian * folau 'sea travel, navigation, canoe shed, fleet of vessels'. Pawley \& Pawley (1994:358-9), again connecting the Oceanic forms with their suspected West Indonesian counterparts, proposes the reconstruction of pa-laSud 'go down to the sea or coast', consisting of the elements * pa 'locative marker' and *laSud 'sea'. The inclusion of the Oceanic attestations in this reconstruction, however, is problematic, as protoAustronesian pa-laSud would result into proto-Oceanic *palaur, whose word-final $/ \mathrm{r} /$ is not reflected in the available data (Blust 1995 s.v., Mahdi 1999a:171). If the two sets of forms are at all related, we must instead reconstruct * $p[ə a] D a H u$ '(sailboat for) long-distance navigation' (Mahdi 1999a:169-74), reflected as Malay †padau, Old Javanese parahu and the aforementioned Oceanic attestations (but surprisingly little regularly inherited reflexes in the area between West Indonesia and Remote Oceania). This reconstructed protoform bears a striking resemblance to the literary Tamil attestations patavu and pataku, especially since the intervocalic $<k>$ is pronounced as $/ x /$ in some varieties of colloquial Tamil (cf. Ramaswami 1997:69), while the intervocalic <t> in (literary) Tamil is typically pronounced as /d/ the in colloquial varieties of South India. ${ }^{178}$ On phonological grounds, there are two plausible scenarios to account for the similarity in form and meaning between the Indo-Aryan, Dravidian and Malayo-Polynesian attestations: 1) the Indian attestations go back to a Malayo-Polynesian reflex of * $p[ə a] D a H u$ '(sailboat for) long-distance navigation', or 2) the form ${ }^{*} p[ə a] D a H u$ was borrowed from Tamil at a very early stage, predating the sound changes ${ }^{*} D>d$ (Malay) and ${ }^{*} D>$ $r$ (Javanese). This would also imply that the forms are unrelated to the Oceanic reflexes, since the time depth of the ethnologuistic dispersal of Oceanic speech communities is too early to

\footnotetext{
178 Illustratively, Asher \& Annamalai (2002) give colloquial forms such as ooqu 'to run', paaqu 'to sing' and equ 'to take', corresponding to literary Tamil ōtu- (ஓடு), pātu- (பாடு) and eț- (எடு) respectively. The shape of Tamil loanwords in Southeast Asian languages demonstrates that this sound change is not restricted to modern parlance, cf. pāvātai 'cloth or carpet spread on the ground for persons of distinction to walk on' > Malay puadai 'a cloth or mat used as a seat for royalty', Javanese puwade 'dais on which the bridal couple sits'; Tamil katalai 'chickpea (Cicer arietinum); Indian rhododendron (Melastoma malabathricum)' > Malay kədəlai 'mung-bean; soy-bean', Javanese kəộle 'soybean'; Tamil kōti 'a score, as in counting precious stones, silk, etc.' > Malay kodi 'corge; (roughly) score', Javanese kodi 'a score (counting term used in the marketplace)'. Whether or not these and other Javanese attestations have been borrowed through Malay requires further research; we are starting to realise that Javanese exhibits numerous Tamil loans unattested in Malay (cf. Gomperts forthcoming).
} 
account for contacts across the Bay of Bengal. At this stage of knowledge, a Malayo-Polynesian rather than an Indo-Aryan or Dravidian origin of the word is favoured. If this is true, several South Asian languages have adopted a foreign, insular Southeast Asian word for a specific kind of sailing boat. Either way, its distribution in South and Southeast Asia is in all likelihood the result of a hybrid ship-building tradition in which both Indian and Malay-speaking seafarers played a role.

Figure 41: attestations of " $p[ə a] D a H u$ '(sailboat for) long-distance navigation'

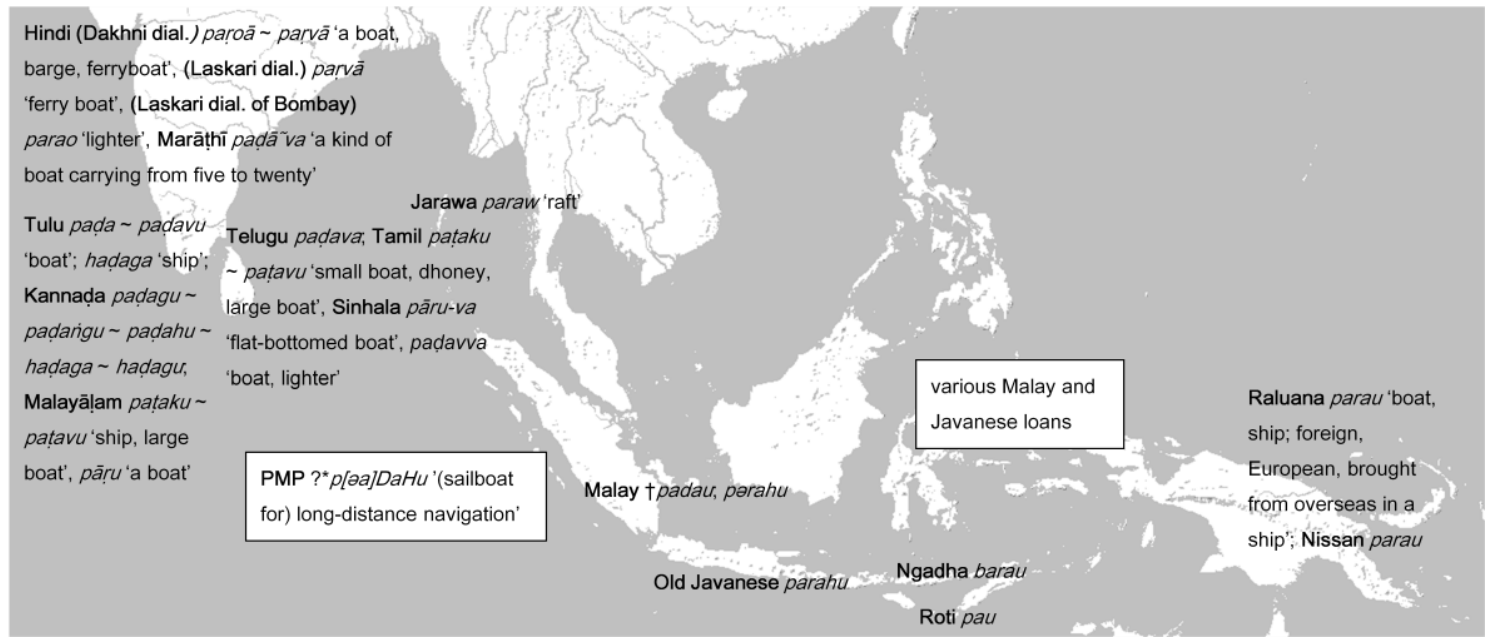

Another clear indication of a shared nautical tradition in the pre-colonial Indian Ocean is the distribution of a large sailing ship known as the 'junk'. The earliest European navigators often commented on this big, plank-built boat rendered junco by the Portuguese and jonk by the Dutch (Yule \& Burnell 1903:472, Manguin 1980:266). Their descriptions mention wooden dowels, the absence of iron, multiple rudders and sails made of woven rattan (Manguin 1980:272). This set of features is typical for Southeast Asian watercraft. When the Portuguese made their entry into Indian Ocean commerce, this Southeast Asian vessel type was already declining in importance due to ongoing competition from highly organised Chinese, Gujarati and Tamil seafarers equipped with advanced watercraft (Manguin 2012:613). In more recent times, the term 'junk' became predominantly associated with Chinese ships (Hornell 1934), although it continued to be attested in the waters of Bangladesh into the 1950s (Greenhill 1957:204). On account of the $/ \mathrm{\eta k \# /}$ cluster in the European attestations, it seems likely that the Portuguese obtained the word from Arabic †ğunk (Mahdi 2007:37-9). Various etymologies of the word have 
been proposed, from Farsi (Tuuk 1864:39) to a Malayo-Polynesian source (Kern 1889b:1219-20, 1915:4-5). Its presence in insular Southeast Asia is of considerable antiquity; Old Javanese jor

Figure 42: attestations of 'junk'

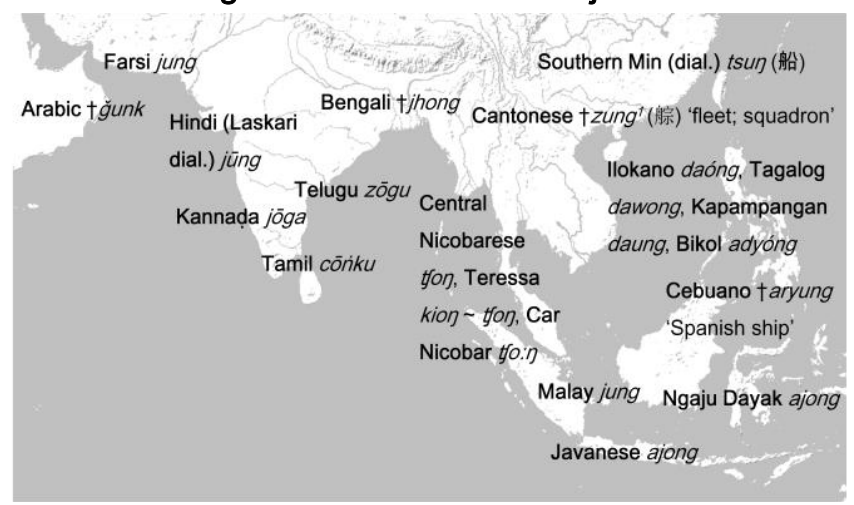
'(sea-going) ship' is first attested in a late $1^{\text {st }}$ mill. BCE copper plate inscription (Brandes 1889:51). The Malay equivalent jung id. features in pre-colonial literature, such as the late $14^{\text {th-century }}$ Hikayat Raja Pasai. 179 An old dictionary of

Cebuano attests the word as †aryung 'Spanish ship' (Mentrida 1841:30). See Figure 42 for an overview of the attestations of 'junk' in the Indian Ocean.

None of the attestations found in the Indian Ocean can be regularly reconstructed to an inherited protoform or is otherwise explainable in terms of internal etymologies. Instead, the word might be an early borrowing from a Chinese source. Needham (1980:380) derives the insular Southeast Asian forms from Chinese chuán (船) 'boat, junk, ship, canoe'. PoréeMaspero (1986:65) discards this etymology on the base of the word-final $/ \mathrm{n \# /}$ in most Chinese dialects. However, a word-final velar nasal $/ \mathrm{n} \# /$ is attested in some Chinese dialects, ${ }^{180}$ making this etymology considerably more plausible. Alternatively, the form has been connected to a Chinese word pronounced in Cantonese as $z u n g^{1}$ (䑸), which is found in the medieval literary corpus (Porée-Maspero 1986:65). This term specifically refers to a fleet or squadron (Needham 1980:380 fn. a), making it a somewhat less likely precursor of the Southeast Asian attestations. Instead, Zhang (1989:94) proposes a reverse acquisition in which the latter reached the Chinese literature via a Southeast Asian source, itself borrowed from a Southern Min dialect. This scenario of borrowing and re-borrowing corresponds with the frequent interaction between Chinese and Southeast Asian ship-builders in and around the South China Sea, occasionally

\footnotetext{
179 http://mcp.anu.edu.au/ (s.v., accessed Feb 2011).

180 Cf. EMC * ${ }^{*}$ wian > LMC * shyan > Chinese (Ningbo) jöñ, (Fuzhou) sun (Giles 1892:282); (Southern Min dial.) tsun (Zhang 1989:94); hence Vietnamese thuyên id.
} 
resulting in hybrid nautical traditions. If the word is indeed of Chinese origin, its adoption into the Malay language must have taken place fairly early, as it was regarded as a native Malay word in a $15^{\text {th }}$-century Chinese-Malay dictionary (Edwards \& Blagden 1931:734, Jones 2009:125).

An even more widespread boat type is the sambook, in modern usage generally denoting a small, flat-bottomed boat used for fishing and transportation. Glidden (1942:71) argues that this word originates from Farsi. However, the form is not attested in Middle Persian and does not appear in early epigraphy, which suggests that it is not a native word. It seems more plausible to assume that the word sambook is connected to a Southeast Asian type of boat known as Old Malay sāmvau, which is first mentioned in the Kedukan Bukit inscription (682 CE) as a vessel used in military expeditions (Cœdès 1930). ${ }^{181}$ The same word occurs in Old Khmer inscriptions as samivo (pre-Angkorian) or sambau samihveva 'large ocean-going junk' and in Burmese inscriptions as saniphaw (Luce 1969:20, 20 fn. 63). In addition, it is attested in languages spoken across the area stretching between Sulawesi - cf. Binongko sambo 'k.o. boat' (Liebner 1988:11) - and East Africa - cf. Swahili (Kingozi dial.) sambu 'boat' (Simon 1988:309). The fact that sambook and sāmvau both denote flat-bottomed watercraft used for transportation makes an etymological connection between the two words tempting, although the direction of borrowing and the sound correspondences remain obscure. Yajima (1976:25, 29 fn. 15) and Porée-Maspero (1986) connect these forms to yet another type of watercraft documented in the waters of South and Southeast Asia known as 'sampan'. Early European travellers rendered this word as ch(i)ampana (Yule \& Burnell 1903:789, Wicki 1971:146, Mahdi 2007:228), probably on account of Tamil campān 'skiff'. As shown in Figure 43, attestations of this ship type are found throughout South and Southeast Asia.

Hornell (1934:334) describes sampans as "open skiffs, bluntly wedge-shaped in plan, shallow, keelless and very broad in the beam at the after end; here on each side the gunwale rail is continued beyond the stern as an upwardly curved projection, endowing the craft with great horns, facing astern." In a description of the watercraft of the Chittagong area of modern-

181 A rather unconvincing etymology from Sanskrit śambūka 'bivalve shell' is proposed by Yule \& Burnell (1903:788). 
day Bangladesh, Greenhill (1957:213) calls the sampan "[...] a short, high-sided vessel and her general form, particularly her high transom stern with the twin horns rising above it, suggests Chinese influence." Both descriptions strongly suggest a Chinese provenance of these ships, even though they were once very common in southern India (e.g. Wicki 1971:146). In insular Southeast Asia, the meanings of 'sampan' can be quite variable, being applied to different types of watercraft across regions. The word is usually thought to be derived from the Chinese compound sānbăn (三板) 'three planks' (LMC *sam-pha:n), although such a form remains unattested in the early Chinese literature. ${ }^{182}$ Nonetheless, the term could have been in use among peripheral communities with a maritime lifestyle, whose nautical vocabulary would have gone largely undocumented by lexicographers (Needham 1980:380 fn. b). As mentioned previously, Porée-Maspero (1986) takes a different stance and sees both sāmvau and sampan as compound forms hailing from a mainland Southeast Asian source. The second syllable of both forms is believed to be related to EMC *baijk ${ }^{*} b \varepsilon$ :jk 'ocean-going junk'. Although this etymology remains rather speculative, it offers interesting perspectives on the interconnectivity of Southeast Asian and Chinese ship-building traditions by at least the first centuries CE. Illustratively, the partial replacement of insular Southeast Asian watercraft with ribs and thwarts by larger vessels with bulkheads may be connected to influence from the mainland (cf. Horridge 1982:57). While the exact etymology of sambook, sāmvau and sampan remains obscure, the development and presumable interrelatedness of these broad, flat-bottomed types of watercraft is best understood against a backdrop of regular contacts between maritime communities of diverse ethnolinguistic affiliation in the South China Sea and the Indian Ocean.

\footnotetext{
182 The word features in medieval and later Chinese literature (Péri 1919, Aurousseau 1922). Several renderings are given in Giles (1886:206-7) and Aurousseau (1922:139), cf. Chinese (Ningbo dial.) sæn-pæn' (杉舨) 'boat' (Morrison 1876:48).
} 
Figure 43: attestations of 'sambook', 'sāmvau' and 'sampan'

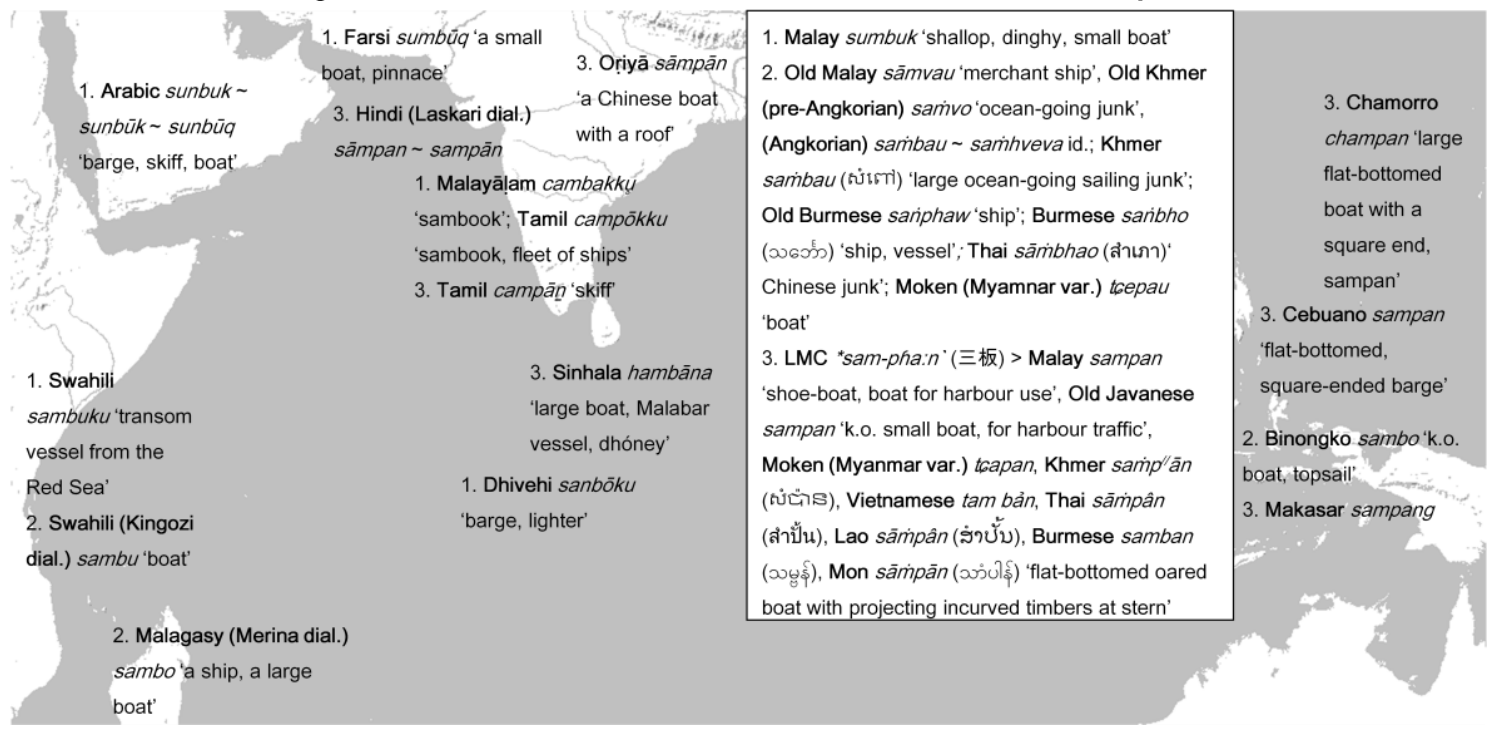

Finally, some vessel types have only spread over a limited area of the Indian Ocean. A well known example is the Tamil form kappal 'ship, sailing vessel', which appears to have been adopted into Southeast Asia as Malay kapal 'decked ship' and related attestations (cf. Figure 44) and even into Southern Min as kap-pán (䑪舨 舺舨) 'foreign square-rigged ship or vessel' (Schlegel 1891:394, Douglas 1899:196, 358). This distribution probably took place in relatively recent times; the term kappal does not occur in Tamil literature prior to the $17^{\text {th }}$ century (Raj \& Rajamanickam 1988:13), although it is attested in Malay and Portuguese accounts of earlier date. ${ }^{183}$ The western half of the Indian Ocean also experienced a considerable amount of cultural cross-fertilisation, which was reinforced by the Islamic expansion. In the western Indian Ocean, seafarers of Arabic, Persian, Swahili and Baluchi ancestry spoke a now extinct pidgin language known as 'Abbāsī (Sheriff 2010:100-1). A Hindustani based pidgin known as Laskari fulfilled a similar role during colonial times. Further, the degree and directionality of these contacts are partly revealed by the Middle Eastern textual accounts, from which we may deduce a considerable Persian element in the Arab nautical tradition (Ferrand 1924, Sheriff 2010:110). As can be observed in the literature (e.g. Johnstone \& Muir 1964), numerous Persian nautical terms spread across the Indian Ocean. The Farsi word nāhudā 'captain', for example, was

183 The word kapal is first mentioned in surviving copies of the Hikayat Bayan Budiman, Hikayat Amir Hamzah and Hikayat Raja Pasai, the original texts of which are dated to the late $14^{\text {th }}$ C. CE (http://mcp.anu.edu.au/ s.v., accessed Mar 2011). 
borrowed as Swahili nahodha, Malagasy nahoda, Tamil nakutā, Hindi nāhudā, Bengali nākhōdā nākhudā and Malay nakhoda id., whereas Farsi bandar 'harbour' was borrowed as Swahili bandari, Hindi bandar, Dhivehi ban̆daru

Figure 44: attestations of kappal 'ship' and Malay bandar. The linguistic data strongly suggest that ship-builders from various regions of the Arabian Sea maintained intensive contact into historical times. As a result, various vessel names are shared by their languages; the dinghy, dhow, mashua, kotia, hori and balam are attested in East Africa, the Middle East and South Asia. When the Portuguese first entered the waters of the Indian Ocean, many of their ship features, including those of the batelão, baixel, galleota and pinaça (pinnace), were also incorporated into existing ship-building traditions. The Portuguese were also keen to learn from the traditions of the Indian Ocean. After encountering ships larger than theirs, they quickly learned to have their ships built locally, resulting in the development of hybrid types of watercraft (Mathew 1988:276, Subrahmanyam 1988, Manguin 1993:266).

\subsection{Methods of plank-fastening}

In contrast to the Mediterranean and East Asian traditions of plank-fastening through iron nails or clamps, plank-sewing was the most common technique throughout the Indian Ocean until modern times. This technique is mentioned in Graeco-Roman sources, including Strabo's Geōgraphiká, Pliny's Historia Naturalis and the Periplus (cf. Ray 2003:59-60). It can be deduced from the Indian and Middle Eastern literature on ship-building that the use of iron nails for plankfastening was known, but not favoured (Gopal 1999:91, Khan 2001:60). Although plank-nailing on Indian Ocean ships is often attributed to European influence, recent archaeological and historical research reveals that it is most likely the result of contact with Chinese or Arabian ship-builders in pre-colonial times (Manguin 1985b:10-1, 2012:606-8, Varadarajan 1998:37, 
Tomalin et al. 2004:258-9). Nevertheless, early European travellers such as Marco Polo and Vasco da Gama exclusively mention sewn-plank watercraft, testifying to the prevalence of this technique throughout the Indian Ocean. Sewn vessels continue to be mentioned by European authors of later periods, not infrequently followed by some sort of derogatory remark on their apparent fragility (Manguin 1985b:4). However, European type iron-nailed boats did not supersede the indigenous plank-sewn types until centuries later. In fact, the tropical waters of Southeast Asia were detrimental to the iron fits of European and Chinese plank-nailed watercraft, which would normally last only 2-3 years (Horridge 1982:59). Therefore, the reluctance of ship-builders across the Indian Ocean to use iron nails or clamps was presumably not a cultural reflex nor the result of a superstitious fear of magnetic rocks (pace Chaudhuri 1976:139-40, Varadarajan 1994:174), but simply the most cost-efficient and effective technique. A variety of other studies on sewn-plank watercraft suggest that this was no different in other parts of the world (Kentley 1985, 1996, Manguin 1985a, Prins 1986, McGrail 1996, McCarthy 2005).

Let us now examine the tradition of plank-sewing in more detail. The planks of Indian Ocean watercraft are traditionally fastened prior to the attachment of the supporting frames (shell-built), whereas European watercraft is usually constructed in the reverse order (skeletonbuilt). Throughout the Indian Ocean, the planks are generally fastened edge-to-edge (flush-laid), although there are some local traditions in which the planks overlap (cf. Deloche 1994:166-70). The term 'sewing' refers to a method of plank-fastening in which threads are passed through holes or lugs carved out of the planks. The latter is known as the lashed-lug design and has been documented in the Philippines, Nusa Tenggara, Maluku, Sulawesi, North Borneo, Botel Tobago, the Solomon Islands and the Maldives (Horridge 1982, Manguin 2000). Although sewnplank boats developed independently in other parts of the world, such as Scandinavia and the Americas, the technique has probably spread across the Indian Ocean as a result of cultural contact and diffusion. According to Prins (1986:160-3), in his pioneering work on sewn-plank boats, the Bay of Bengal generally exhibits a tradition of discontinuous sewing (stitching) with 
stitches kept inside the planks, whereas most traditional boats of the Arabian Sea display continuous sewing (lacing) with threads showing on the outer side of the hull. These threads are usually made of coarse coconut fibre (coir), although the use other organic materials such as sugar palm bark (Arenga pinnata) and dried marsh grass (Spartina spp.) is also recorded (Kentley 1985:305, Manguin 1993:259, 1996:184). Various substances are used to make the hull of a boat watertight - a process known as caulking or, more correctly, luting - including coir fibre, plantain fibre, lime and various oils, resins and dammars (Hornell 1941:62, 1943:15-6, Varadarajan 1994:169, Beckerleg 2002:273, Kapitän 2009:175). In South Asia, these mixtures are known as gala, an Indo-Aryan word (< OIA $\sqrt{ } g a l$ 'dripping') which was adopted into Malay (through reduplication) as gala, gəgala and gala-gala 'a mixture of dammar and pitch used for caulking boats'. The latter was presumably re-borrowed from Malay into Hindi, which displays the word galgal 'a mixture of lime and linseed oil forming a kind of mortar impenetrable to water' (cf. Galgal 1886:100), and Marāthī galagala 'the viscous matter obtained from certain plants (from Cordia myxa etc.)'. The tentative Malay etymology of these forms lies in the fact that noun reduplication is much more common in Malayo-Polynesian languages than in Indo-Aryan languages. ${ }^{184}$ We may also call attention to late Sanskrit kalakala the resinous exudation of Shorea robusta', although, if derived from or related to the Malay form, the $/ \mathrm{k} /$ instead of expected $/ g /$ requires further explanation.

${ }^{184}$ Alternatively, the form may go back to a set of onomatopoeia in Indo-Aryan languages used to designate a dripping sound (cf. Dakshi 2003:127). 
Figure 45: attestations of gala(-gala) 'pitch'

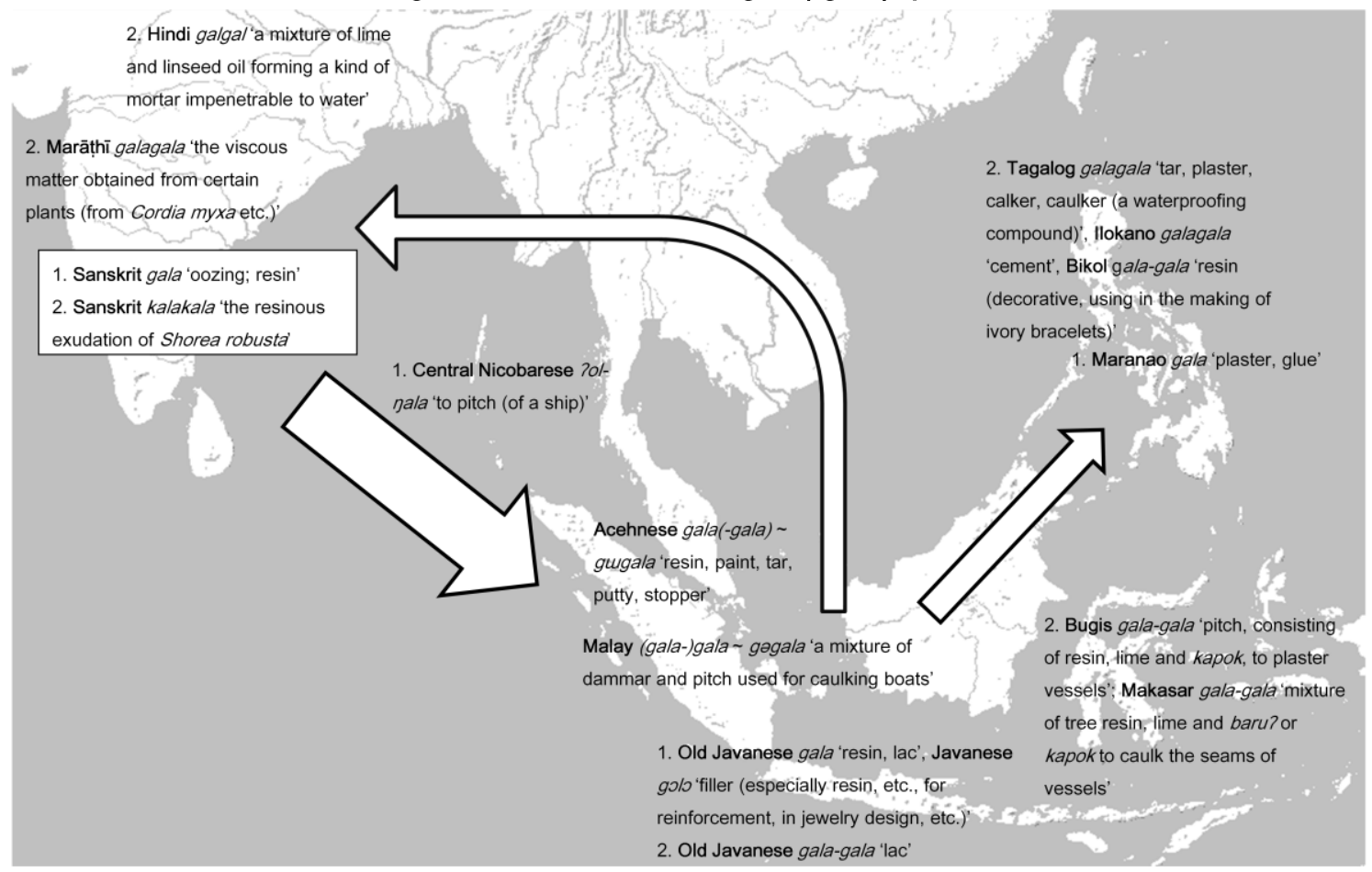

A more sophisticated strategy of plank-fastening is the insertion of holes into the edges of the planks, after which the planks are fastened through internal dowel pins. These dowels are made from hard timbers, such as sappan-wood (Caesalpinia sappan) or bullet-wood (Mimusops elengl) (Horridge 1987:32). At the expense of earlier sewn or stitched traditions, fully edgedowelled methods of plank-fastening gradually gained popularity among insular Southeast Asian ship-builders in the first centuries CE. The adoption of the edge-dowelling method is probably connected to the introduction and prevalence of iron in Southeast Asia, since an iron tool is required to drill holes into the edges of the planks. ${ }^{185}$ Therefore, the development of large ocean-going vessels cannot be seen in isolation from advances in metallurgy (see Section 3.4). Several shipwrecks in Southeast Asia dated to the $1^{\text {st }}$ mill. CE represent an intermediate stage between sewn and edge-dowelled traditions (Manguin 1985a:339, 1993, McGrail 2001:297-302). A list of Southeast Asian shipwrecks exhibiting this type of plank-fastening is presented in Manguin (1996:186). The lepa boats currently in use among the Bajau communities in northern Borneo and the southern Philippines, which display a combination of wooden dowels and

185 In the Solomon Islands, however, pieces of flint and sharp-pointed shells have been used for this purpose (Horridge 1982:1). 
stitches through lugs, can be seen as a remnant of this tradition (Peralta 1995). The transition from sewn to fully dowelled watercraft also took place in South Asia. Traditional purely sewn vessels are found in parts of India, the Laccadives and the Arabian Sea, while edge-dowelled types occur in the Maldives, Minicoy and Sri Lanka (Prins 1986:162-3, Varadarajan Figure 46: edge-dowelled planks (Kota Kinabalu, 1994). According to Manguin $(2000,2012)$ and Selvakumar (2011), boat types with dowelled plank edges have been introduced into these regions by insular Southeast Asian ship-builders. We do not know whether the Harappan boats used dowels, but if they did, plank-dowelling

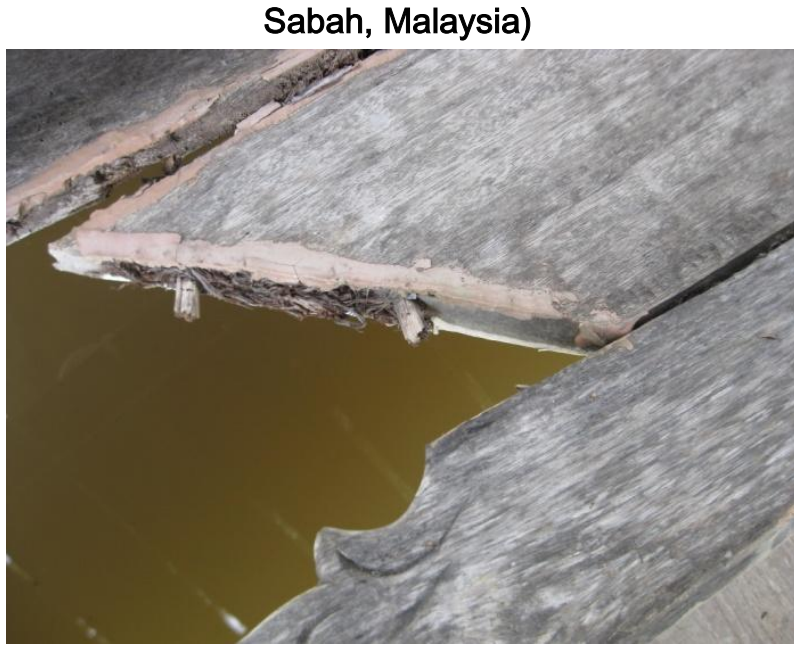
must have been a much more widespread practice. However, the earliest solid evidence for this plank-fastening method in South Asia thus far is found on the Kadakkarapally boat dated to the $11^{\text {th }}-12^{\text {th }}$ C. CE (Pedersen 2004, Tomalin et al. 2004), by which time contacts between South and Southeast Asian ship-builders were well established. Research on traditional Maldivian watercraft has revealed more links to Southeast Asian traditions, such as the aforementioned lashed-lug technique and the use of thwart beams (Millar 1993:10-1). The following sections elaborate on additional similarities in sail and outrigger types.

\subsection{Western Indian Ocean sails}

Since people learned how to navigate primitive types of watercraft, they understood the benefits of using the wind. In favourable winds, one man standing on a raft could act as a sail, as was practiced by the indigenous Australians into modern times (McCarthy 2005:6 fig. 2). On the other end of the spectrum, long ocean-borne voyages required an advanced knowledge of rigging. Recent archaeological research reveals that early sail types were used in Mesopotamia and Egypt from the $4^{\text {th }}$ mill. BCE (Carter 2006, Ward 2006). At some point in time, the ancient 
Egyptians learned how to use sails to assist, and later replace, the efforts of paddles and rowers on galleys. Lionel Casson (1994:14ff., 36ff.) argues that the first true Egyptian sails were made of leaves or woven reeds set on a vertical mast, a construction that probably evolved out of the leafy fronds fastened to the bows of small river boats. From the iconographic evidence, Casson reconstructs several stages of sail evolution. The earliest sails used on the Nile were rectangular, rather vertical sails with a yard and a boom. ${ }^{186}$ Around $2000 \mathrm{BCE}$, when the Egyptians started to regularly navigate the sea, their sails became wider to handle the stronger winds that seafaring imposes on watercraft. The reliefs at Dayr al-Bahrī, for example, contain ships with broad sails and booms (Steffy 1994:29 fig. 3-6). The prototypical Egyptian sails were furled by letting the yard down until it rested on the boom. A new type of sail emerged during the last centuries of the $2^{\text {nd }}$ mill. BCE and replaced the more archaic types (Hornell 1939-40/2:136, Casson 1994:39ff.). These quadrilateral rigs, commonly known as 'square sails', did not have a boom (loose-footed) and were taken in with brails. They were adopted by the Greeks and Phoenicians and became the prevailing sails throughout the Mediterranean until the introduction of the lateen sail.

Egyptian quadrilateral sails with booms have only survived on certain traditional boats in present-day Sudan, such as the markab and the nuggār (نقار), which are mainly used for Nile transportation (Hornell 1939-40). Their rectangular sails can be canted to make more effective use of the wind, very similar to the way this is done in Southeast Asia and Near Oceania, leading several scholars to suggest the possibility of Indonesian influence on the rigs of these river boats (Brindley 1926:21, Hornell 1939-40/2:136-7, Mahdi 1999a:158). Others, however, propose that the diffusion of this sail type took place in the opposite direction (Bowen 1953:199, Needham 1980:588ff.). I would argue that rectangular sails with booms were much more widespread in the past. This diversity of Indian Ocean sail types was subsequently obscured by the introduction of the lateen sail. Nonetheless, sails with booms have survived in the Bay of

186 Here and elsewhere, I will use the term 'yard' for the spar supporting the head of the sail and 'boom' for the spar connected to the foot of the sail. 
Bengal (Smyth 1906:325, 333ff., 359ff, Piétri 1949 passim, Bowen 1953:110-1, 192, Deloche 1994:151 fig. 28a, 182 fig. 38b, Kentley 1996:252 fig. 3, Pohl 2007:393-5). The traditional Moken communities of the Andaman Sea occasionally tilt these sails to catch more wind (Sopher 1965a:189), a practice that might also have been known to sailors in other parts of the Indian Ocean. Given the fact that the Egyptians abandoned the booms on their sails fairly early, their role in introducing this particular rig into the Indian Ocean would have been limited.

Perhaps the populations of the Near East played a more important role in the transoceanic dispersal of the quadrilateral sail with boom. A potsherd of a painted 'Ubaid bowl dated to the second half of the $6^{\text {th }}$ mill. BCE contains a two-masted ship (Carter 2006:53), which arguably makes the Neolithic Arabians the earliest known seafarers. Unfortunately, we have little details regarding the sail types used by them. Artefacts identified with the Harappan Civilisation, which with the Middle Eastern populations maintained commercial relations, display a variety of sailing vessels (Deloche 1996, Ray 2003:58-9, Rajamanickam 2004:8). In all likelihood, the earliest transoceanic distribution of sail types and other maritime technology took place against the backdrop of these early interethnic contacts. It is unclear what the first sails were made of. Animal skins, woven reeds or other crude materials would have sufficed for rudimentary, small sails. Sophisticated sail types that required be furled or otherwise manipulated were made of palm fibre, papyrus (Cyperus papyrus), flax (Linum usitatissimum), hemp (Cannabis sativa) or other grasses. Sail remains on shipwrecks are not easily found back due to oxidative degeneration, extraction of component parts of the fibre by metals (leaching) or destruction by micro-organisms (Black \& Samuel 1991:224). In other cases, the identification can be problematic. The linen wrappings of a Thebes mummy dated to $50 \pm 100$ BCE have been tentatively identified as sailcloth (Rougé 1987), while the matting found near an 8000-year-old dugout canoe at Kuahuqiao (China) could have been remains of a sail, if not of roofing attached to the canoe (Jiang \& Lui 2005).

The relatively straighforward concept of a quadrilateral sail is fairly easy to grasp and might have been invented independently in different parts of the world. However, this type of 
sail has its inherent limitations. Watercraft with a simple, quadrilateral sail rigged perpendicular to the keel are impossible to navigate into the wind without the very time-consuming process of casting off the sail, changing the direction of the bow and re-securing the sail. The development of more sophisticated sail types, on the other hand, requires a considerable degree of nautical experience and several stages of testing on different hull shapes. In many cases, their distribution is the result of diffusion, although the hulls of the boats often remain indigenous (cf. Bowen 1953:82-3). In general, a significant improvement in maritime transport is the innovation of setting the sail along the line of the keel (fore-and-aft) rather than perpendicular to it, enabling navigation closer to the wind and in lighter winds. The best-known strategy to come about to windward is to point the sail into the wind, let it go slack and move it to the other side while changing tack by angling the bow, then reset the sail and let the wind fill it again (tacking). To successfully tack or "zigzag" into the wind, a true fore-and-aft rig is required. Another way to navigate to windward is to point the sail into the wind, loosen it and move it to the other side while changing tack by looping away from the wind direction and letting the wind pass astern, then resetting the sail and moving further on the opposite tack (wearing). A third method is to loosen the sail, take it along the side of the vessel and reset it in the opposite direction, enabling the vessel to continue navigating in reverse position (shunting). This technique requires a special type of reversible boat with interchangeable bow and stern (double-ended), a centrally positioned or unfixed mast and an outrigger, which has to be kept on the windward continuously in order not to plough into the ocean. ${ }^{187}$

Upon first European contact, the most prevalent sail in the Indian Ocean was the lateen sail, which was used all over the Arabian Sea (McGrail 2001:278) and was reported as far east as Sumatra in colonial times (Nooteboom 1952 fig. 2). The triangular shape of this sail and its aslant position enable easier control from the deck and more efficient use of the wind. Indeed, the lateen sail was soon taken over by European ship-builders, eventually enabling the "discovery" of the New World and other distant continents. The lateen sail of the western Indian

\footnotetext{
187 Mahdi (1999a:147 fig. 5.2) offers an illustration of these three manoeuvres.
} 
Ocean represents an intermediate stage of development between the traditional square sail and the fully developed fore-and-aft sail. Although it can be set along the line of the keel, it is not a true fore-and-aft rig, since it is supported by a yard preventing it to be effectively shifted around the mast (Bowen 1953:83 n.2). Unlike the triangular lateen sails of the Mediterranean, the western Indian Ocean lateens are technically quadrilateral since they do not have a fore-part that ends in a foot. The sail is also known as the 'quasi-lug lateen', 'Arab lateen', 'eastern lateen', 'Arabian Sea lateen' and 'settee'. It has been argued that lateen sails developed from a specific type of canted, fore-and-aft set rectangular sail known as the dipping lugsail (Bowen 1953:187-9, Hourani 1995:102-5). Alternatively, they may have evolved out of square sails brailed in a triangular shape (Casson 1971:49-51). Either way, both the textual and iconographic evidence suggest a large-scale replacement of square sails by lateen sails during the Byzantine era (Brindley 1926:9-11, Hourani 1995:103).

The most common explanation for the large-scale adoption of the lateen sail throughout the Indian Ocean and the Mediterranean is that it is an Arab invention disseminated during the Islamic expansion. Indeed, several sail types recorded in the Arabian Sea represent

Figure 47: attestations of 'yard' across the Indian Ocean

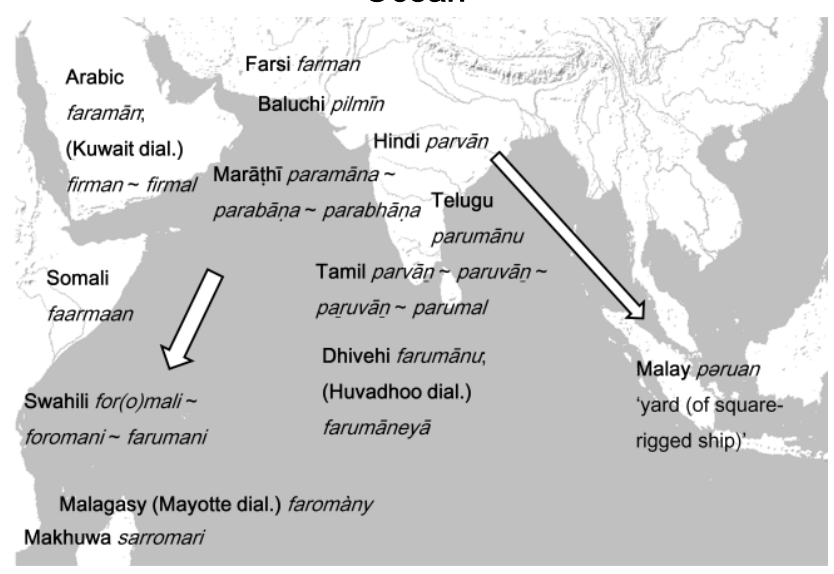

intermediate stages of development from a dipping lugsail to a true lateen sail (Bowen 1953:192). On the other hand, there is scattered iconographic evidence for the presence of lateen sails in the Mediterranean prior to the Islamic expansion, such as the sail depicted on a $2^{\text {nd }}$ C. CE relief on the tombstone of

Alexander of Miletus (Casson 1991 plate 49 ), the late $5^{\text {th }}-$ early $6^{\text {th }}$ C. CE Kelenderis ship mosaic, and the early $7^{\text {th }}$ C. CE Kellia ship graffito (Whitewright 2009:98f.). This could mean that the lateen sail was invented independently in the Mediterranean and in the Indian Ocean. It could also mean that the sail was an introduction into both regions, for instance from the Red 
Sea. In any case, I would argue that the Arabs did not obtain their lateen sail from the Mediterranean. Instead, an eastern origin of the sail is supported by the fact that most of the words for 'lateen yard' (also known as antena) in the Indian Ocean - cf. Arabic faramān id. (Glidden 1942:71), (Kuwait dial.) firman firmal (Johnstone \& Muir 1964:316), Swahili for(o)mali $\sim$ foromani farumani, etc. - appear to be related to a Dravidian root for 'to spread out' (Maloney 1980:67, Burrow \& Emenau 1984 \#3949). ${ }^{188}$ Figure 47 presents a tentative overview. We are less certain about the types of sails in use in the waters of South Asia before the introduction of the lateen sail. Archaeological data are lacking and the iconographic record is rather unclear. While the $15^{\text {th }}$-century Arabic navigator Ibn Māğid makes mention of al-qulu' alHindīyyaẗ 'Indian sails', is it difficult to say what kind of sails were being referred to (e.g. Khan 2001:63).

Traditionally, the large-scale adoption of the lateen sail at the expense of quadrilateral sail types has been explained along the lines of the presumed higher speed and better windward performance of the former. The extent to which this was the main reason for adopting a new rig can be questioned. According to Julian Whitewright (2010), the "need" to sail to windward has, quite unjustly, obtained a prominent place in the wider literature. Instead, he correlates the increase of lateen sails at the expense of square sails to developments in hull forms. He argues that the overall performance of square-rigged watercraft in long-distance voyages was not markedly inferior to that of lateen-rigged watercraft. Starting from the early $5^{\text {th }}$ c. BCE, square-rigged Greek ships were generally equipped with a small foremast (artemōn) on which a spritsail was set to enhance their manoeuvrability (Casson 1994:45-6). The ships depicted on the Ajanta and Borobudur reliefs - albeit belonging to a quite different tradition also display rectangular sails in combination with a foremast, which suggests that foremasts spread across the ancient Indian Ocean as a result of the Graeco-Roman activity in these

188 Presumably unrelated are Malayālam parimaram 'yard of a ship' and the series Malay pəbahu 'yard', Old Sundanese babahon, Bugis pambauang, Javanese pambaon, Madurese pəmbaon, Makasar bau id. (cf. Horridge 1981:86-9, Liebner 1993:39, Noorduyn \& Teeuw 2006:260), presumably related to Malay bahu 'shoulder' (< Sanskrit bāhu 'arm, shoulder'). 
waters. I would argue that the first lateen-rigged watercraft served quite different purposes than conventional square-rigged ships. A lateen sail would definitely increase a boat's manoeuvrability on rivers and narrow waters, which is why it was initially rigged on relatively small, single mast watercraft (Manguin 1985b:7). On larger ships, however, square sails seem to have been preferred until medieval times on account of the stability they offer. Eventually, lateen sails were also adopted on larger, two-masted galleys in the Mediterranean (Steffy 1994:92 fig. 4-17, 94 fig. 4-18), possibly on account of developments in hull shapes.

In classical times, quadrilateral sails, triangular sails and other sail types coexisted, as can be seen in pre-medieval Mediterranean iconography (Casson 1991:195). Analogously, lateens have never completely replaced the loose-footed rectangular sails in the waters of the western Indian Ocean (Smyth 1906:306, Bowen 1953:186, Prins 1982:86, Manguin 1985b:8,

Figure 48: sails of the western Indian Ocean

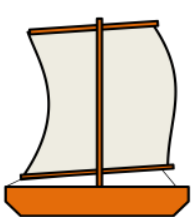

square sail with lower boom

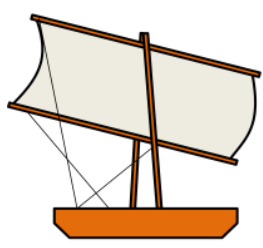

canted rectangular lugsail

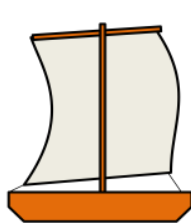

loose-footed square sail

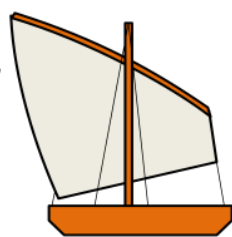

western Indian Ocean lateen sail

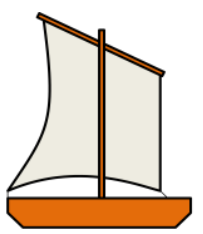

dipping lugsail

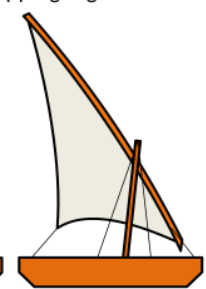

lateen sail 2012:604-5, Khan 2001:63-4). This coexistence, too, is substantiated by iconographic evidence: the $1237 \mathrm{BCE}$ alHarīīi ship (Hourani 1995:100-1, pl. 7) and the medium-sized Arabo-Indian ship depicted on a $16^{\text {th }}$-century $\mathrm{BCE}$ fresco in the Tiruppuțaimarutūr temple (Deloche 1983 fig.1) both exhibit square sails. In this regard, the main generalisation seems to be that a new

sail type was only adopted when it would significantly advance the purpose for which the boat or ship was designed. Only large commercial ships would have profited from the adoption of sophisticated rigs, while this would not be a worthwhile investment for small-scale fishermen. Even today, traditional fishermen do not travel far and fair-wind sailing is often a sufficient 
method to sustain their livelihood. ${ }^{189}$ Therefore, it is not surprising that their fishing boats tend to stick to more primitive sails.

\subsection{Insular Southeast Asian sails}

Despite the prevalence of lateen rigs on the boats of the Arabian Sea, which frequently visited the ports of the eastern Indian Ocean, the rectangular sail with boom survived throughout the Bay of Bengal and insular Southeast Asia, while rectangular sails without booms were preferred in Bangladesh (e.g. Greenhill 1957:122 fig. 14, 15, 133 fig. 21). These rectangular sails with boom spread remarkably far eastward. A recent study on yet to be dated rock paintings in Tutuala, present-day East Timor, exclusively shows rectangular sails on the several depicted plank-built ships (Lape et al. 2007:247-8). To date, traditional medium-sized watercraft exhibit a specific type of canted rectangular sail with boom throughout insular Southeast Asia and Near Oceania (Brindley 1926:16, Haddon \& Hornell 1936-38/1:52-4, Bowen 1953:205 fig. 28b, Doran 1981:40, 82 fig. 46). With the exception of the aforementioned Nile boats, this type of rigging is not documented in the western Indian Ocean corridor. Richard LeBaron Bowen (1953:200-1, 208), therefore, argues that this sail was probably invented in the waters of Indonesia. On the other hand, the tradition of using fixed masts is found ubiquitously in the Indian Ocean, but not traditionally in Oceania. Thereupon, Mahdi (1999a:159) proposes a scenario in which the rectangular sail was dispersed into insular Southeast Asia and eventually into Near Oceania through several stages of cultural contact.

If such a secondary diffusion indeed took place, it shows a remarkable geographical parallel with the presence of double outriggers and the distribution of the aforementioned pərahu sailing boat (and its name). The hypothesis of prehistoric cultural contact between insular Southeast Asia and Near Oceania is also supported by the finding of a bronze artefact in

\footnotetext{
189 The traditional prawn-fishers in western Sri Lanka, for example, sail northwards with the morning land breezes and return with the afternoon sea breezes (Kapitän 2009:180). Even larger ships have used this technique. The commercial yātrā dōṇi watercraft of Sri Lanka undertook voyages to the Maldives during the southwest monsoon and returned homewards during the northeast monsoon (Vosmer 1993:39).
} 
the Admirality Islands north of Papua New Guinea dated to \pm 150 BCE (Ambrose 1988), which suggests that ideas and commodities were exchanged over vast distances much earlier than previously realised. An exhaustive study on Malay and other loanwords in the languages of Near Oceania could further clarify this issue. From an impressionistic glance through a dictionary of the Raluana language spoken in the Bismarck Archipelago (Lanyon-Orgill 1960), it would seem that there was indeed a certain degree of contact at a yet to be determined time period. This is demonstrated by the following tentative Malay loanwords in that language, none of which can - to the best of my knowledge - be attributed to a mutually ancestral protolanguage: Raluana alir 'to float; etc.' (< Malay alir 'to flow along'), băl(i) 'repay, replace; punish, revenge; etc.' (< balik 'reversal, going back'), libur 'to play, amuse oneself, etc.' (< libur 'vacation, holiday, leave, time off'), padi 'maize' (< padi 'rice (as unhusked grain)'), păret 'trench' (< parit 'groove; cutting; moat'), (Duke of York dial.) piră 'money from Mioko Island' (< perak 'silver, coin'), tamăn 'the clear piece of ground around a house, etc.' (< taman 'garden, pleasure-ground'), tarik 'to tear' (< tarik 'to draw, to pull'), taŭn 'season, time, period' (< tahun 'year') and urat 'sinew, tendon, etc.' (< urat 'nerve, vein, sinew, etc.'). The inclusion of a word for 'maize', if not caused by a semantic shift, seems to suggest that the contact continued into colonial times. The periodisation of these lexical transmissions, however, remains problematic. In any case, the fascinating topic of possible Malay influence as far as Near Oceania merits a study on its own. ${ }^{190}$

While the distribution of rectangular sails on fixed masts may be the result of a wider Indian Ocean tradition, the use of unfixed sprit spars to hold up the sail is certainly an indigenous insular Southeast Asian invention (Campbell 1995:12). These sails can easily be set fore-and-aft or perpendicular to the keel, depending on the wind conditions. The famous Oceanic spritsail - also known as the 'triangular spritsail' or 'Polynesian Oceanic rig' - is one of the most prevalent traditional sails in insular Southeast Asia and Oceania. This sail is traditionally made of matting from rattan (Calameae spp.), pandan (Pandanus spp.), corypha

\footnotetext{
190 See Seiler (1982) on Malay influence on the languages of Papua New Guinea in historical times.
} 
palm (Corypha utan) or coconut palm leaf (Cocos nucifera). It is supported by two spars, the forward ends of which are connected at the tack and fitted into a socket at the bow, giving the sail its characteristic V-shape. The leech of the sail is supported by the aft sprit and the peak is attached to the aft end of the forward sprit, which functions as a mast. The sail is occasionally hoisted from a true mast, which is rarely more than a short, unfixed spar positioned at the bow of the boat. Boats rigged with the Oceanic spritsail are able to come about to windward in a course of minimally $60^{\circ}$ to $65^{\circ}$ (Doran $1981: 36$ ). Figure 49: sails of the eastern Indian Ocean In parts of insular Southeast Asia and Oceania, a further development to this sail is the addition of a supportive prop, making the spars essentially a yard and a boom (Cotterell \&

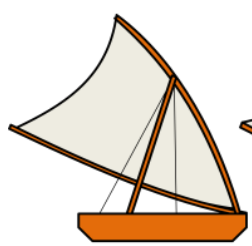

Oceanic spritsail with supportive prop

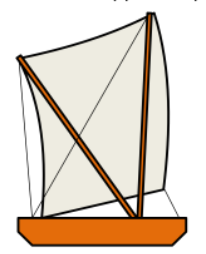

Madagascar double spritsail

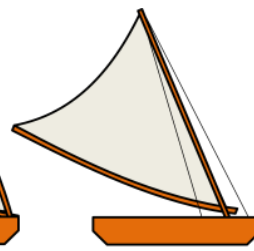

Oceanic spritsail

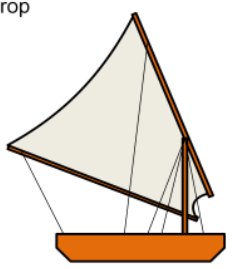

trapezoid lugsail

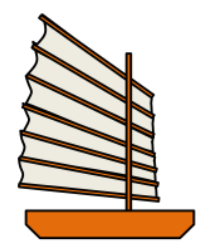

battened lugsail

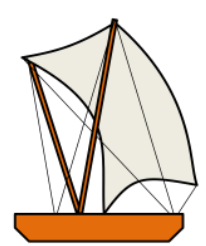

Sri Lankan double spritsail

Kamminga 1990:251-2, Campbell 1995:13-4). This type of rig is also known as the 'Oceanic lateen'. Finally, insular Southeast Asia is home to a type of sail hoisted from a V-aligned bifid mast. This sail is documented as the 'Indian Ocean double spritsail', 'bifid-mast spritsail' or 'proto-Oceanic spritsail'. It is found in somewhat different but clearly related forms in Sumatra, Sri Lanka, the Maldives, Madagascar and the Gulf region (Haddon 1920:52, Bowen 1952:216 fig. 13, 1953:82ff., Doran 1981:81). Bowen (1953:87, 110 fig. 13) argues that this sail was the predecessor of the Oceanic spritsail, whereas Horridge (2008:102-3) suggests that it was a relatively late development. The latter possibility is more plausible in view of the fact that the Sri Lankan double spritsail is always used in combination with a single outrigger, 'double-ended' hull and centrally positioned twin mast, allowing the vessel to shunt into the wind. This set of characteristics is unique to Sri Lankan watercraft and appears to be an adaptation to specific local circumstances. The double spritsail appears to be a local adaptation of the Oceanic spritsail, intended for short-distance fishing journeys. 
The western Indian Ocean lateen sail and the Oceanic spritsail share some similarities in form, leading several scholars to consider scenarios in which one sail evolved out of or was influenced by the other (Brindley 1932:308f., Cotterell \& Kamminga 1990:251-2, Hourani 1995:105, Horridge 2008:102, Mahdi 1999a:157-9). One region where the two rigging styles have evidently been brought together into a hybrid tradition is the east coast of India, where we see V-shaped sails with booms and short masts stepped forward like the Oceanic spritsail, but with a typically Middle Eastern short luff (Bowen 1953:110-1, 192, Kentley 1996:252 fig. 3, Pohl 2007:393-5), making it essentially a trapezoid lugsail. This prevalence of short masts stepped far forward is also seen on watercraft in Bangladesh (Greenhill 1957:204). In a wider context, however, Bowen (1953:110-211) and Campbell (1995:17) convincingly demonstrate that the western Indian Ocean lateen sail and the Oceanic spritsail work in essentially different ways. Based on their findings, we can summarise the following major functional differences: 1) the lateen sail has no boom, whereas the aft sprit of the Oceanic spritsail functions as a boom connected to the stern by a foot-rope, 2) the lateen sail is supported by a long, fixed mast, positioned close to the centre of the keel and held in place by a rope, whereas the Oceanic spritsail has no mast or is supported by a short, canted, moveable mast, positioned far forward and held in place by a supportive prop and a mast-shore, 3) the western Indian Ocean lateen sail has a short luff on the forward edge of the sail so that the head of the sail is larger than the foot, whereas the Oceanic spritsail has no luff and its head and foot are equilateral, 4) the foot of the lateen sail is fastened by a rope, whereas the tack of the Oceanic spritsail is fitted into a socket at the forward end of the hull, and 5) the western Indian Ocean lateen sail is quadrilateral with a vertical leech, whereas the Oceanic spritsail is triangular with an apex of the fore and aft sprit at the tack.

In addition to these functional differences, I would argue that the absence of outriggers on Middle Eastern watercraft is another important argument against any significant Southeast Asian influence on the existing boat-building practices. As upwind sailing inherently entails the danger of capsizing, one would expect that the Middle Eastern sailors would have adopted this 
stability device, as was the case in East Africa and South Asia. Even though it is not entirely impossible that the form of the western Indian Ocean lateen sail was, in some regions, influenced by Southeast Asian sail types, at this stage of knowledge it seems likelier that both traditions developed without considerable mutual influence. Consequently, Southeast Asian and

Figure 50: Oceanic spritsail (Pulau Sapondan, Sulawesi, Indonesia)

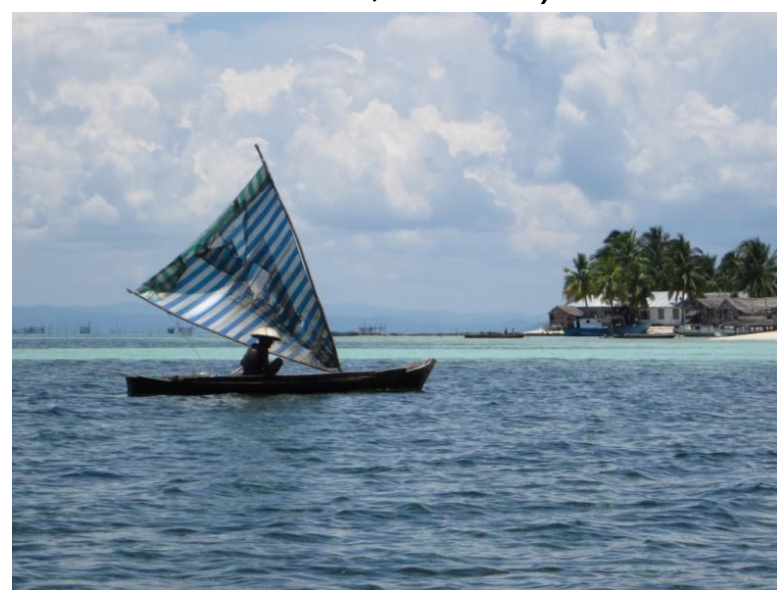

Middle Eastern watercraft are navigated in completely different ways. It is true that the lateen sail offers greater manoeuvrability, but this has impacted little on the fact that upwind sailing has never been popular among Middle Eastern sailors (Campbell 1995:18-9). Technically, tacking into the wind is possible on a vessel rigged with a western Indian Ocean lateen sail, although

it is somewhat inefficient. Apart from the risk of capsizing, resetting the sail requires large crews and clear decks. In addition, the yard of a lateen sail extends both fore and aft the mast, so that a part of the sailcloth would back against the mast on the new tack (Bowen 1953:189, Campbell 1995:19). The sail would be aback but still drawing (a "bad tack"), as its design allows it to catch a considerable amount of wind in any position.

Figure 51: Oceanic spritsail (left) and western Indian Ocean lateen sail (right)

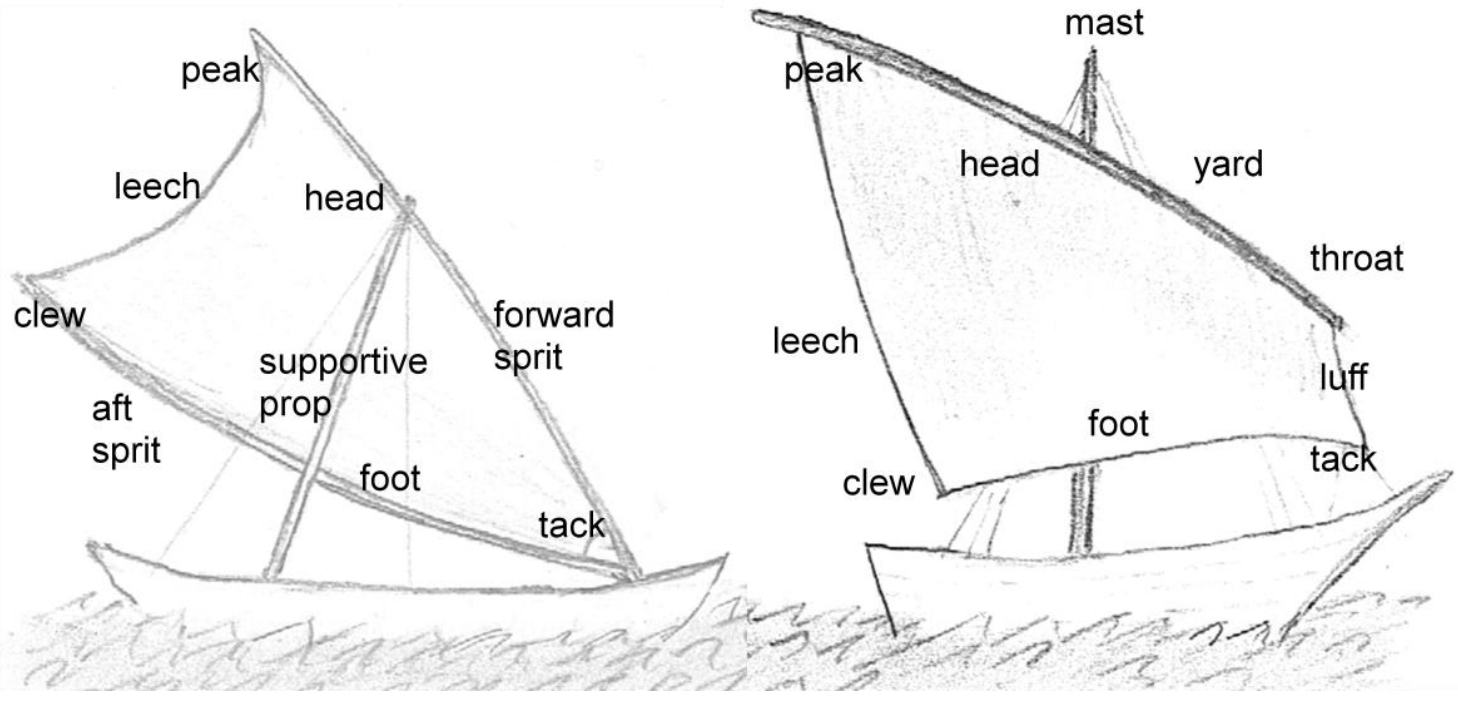


Having argued that the Indian Ocean double spritsail and the Oceanic spritsail have their origins in insular Southeast Asia, let us now examine the extent to which this is reflected in the linguistic data. The word for 'sail' can be reconstructed to PMP *layaR, regular reflexes of which are found in insular Southeast Asia and Oceania (Pawley \& Pawley 1994:350, Wolff 2010/2:886). Its attestations in several Formosan languages are irregular and may be the result of borrowing from a Malayo-Polynesian source (Wolff 2010/2:886). Through Moken layan 'sail', reflexes of this protoform appear to have been adopted into several mainland Southeast Asian languages spoken around the Bay of Bengal, e.g. Mon hlayā ( $\jmath_{L}$ (s)), Burmese lañ:yañ ( (น์์: presumably via Malay layar 'sail'. Smith (1933:216) demonstrates that Sinhala ravala (pl. ruval) 'sail' (Dhivehi riyau riyāi id.) goes back to the Malay precursor through metathesis. According to known sound correspondences, the same word was hypercorrected to lakāra in Pali. ${ }^{191}$ Other Indo-Aryan attestations for sail are derived from OIA * palla 'cloth' (Turner 1966 \#7967) and thus postdate the introduction of Southeast Asian sail types into the subcontinent, since cloth sails unattested in the earliest texts - are probably a relatively recent development in South (and Southeast) Asia; late Sanskrit texts display such terms as marutpața and vātapața, designating a 'wind-cloth'. The reconstructed form OIA *sidha * síta 'sail' is not attested in the classical literature (cf. Turner $1966 \# 13397$ ), but resembles Arabic širā' 'sail; tent'. The direction of borrowing, if not due to chance resemblance or acquisition from a thirds source, remains obscure. The Dravidian words for 'sail' - e.g. Tamil pāy, Malayālam pāy, Kannaḍa hāy - are semantically linked with 'spreading, extension, mat' (Burrow \& Emenau 1984 \#4088). Along similar lines, there might be a connection between the Swahili words tanga 'sail' (Comorian trangá id.) and tangaa 'to spread'.

\footnotetext{
191 The innovations *aya > uva/C_C, * $\mathrm{V} r \mathrm{r}>\mathrm{rVI} /(\mathrm{V}) \_\mathrm{V},{ }^{*} \overline{\mathrm{a}}>\mathrm{a} / \mathrm{C} \_\mathrm{C}$ and ${ }^{*} \mathrm{k}>\mathrm{y} / \mathrm{V} \_\mathrm{V}$ are regular in proto-Sinhala (cf. Haebler 1965:118-9). Turner (1966 \#10964) indeed reconstructs OIA ×layara but acknowledges its ultimate Indonesian etymology. The meaning of Pali lakāra has erroneously been interpreted as 'anchor' (see Section 7.7). The form occurs in the Visuddhimaga, Milindapañho, Silānisamisa Jātaka and other texts (cf. De 1906-07:173, Haebler 1965:113-4).
} 
As argued above, the concept of a fixed mast was probably a later introduction into the maritime traditions of insular Southeast Asia, resulting from cross-fertilisation with traditions from other parts of the Indian Ocean. If this is indeed the case, it is probably not reflected in the linguistic data. The only attestations for 'mast' in Southeast Asia that resemble South Asian words are found around the island of Buton, where we find the word kokumbu (Liebner 1993:38), reminding us of Tamil kūmpu and Malayālam kümbu. ${ }^{192}$ On account of the absence of cognates elsewhere, I would argue that this is due to chance resemblance. Either way, at some point in time a ship-building tradition with elaborated tripod masts emerged in southern China, Myanmar and insular Southeast Asia (Hornell 1920d:221). Based on textual evidence from Chinese accounts, the Southeast Asians were using multiple fixed masts from at least the early $1^{\text {st }}$ mill. CE (Manguin 1996:189). One of the words for 'mast' used in these descriptions of Southeast Asian and (later) Chinese ships was *tshian (樯) (Needham 1980:462). I would argue that the Chinese obtained this word from a Malayo-Polynesian source, presumably Malay tiang 'mast, pole'. ${ }^{193}$ The Malay reflex goes back to proto-Austronesian *tiSan 'pole' (Wolff 2010/2:1010-1), which makes a reverse acquisition unlikely. Consequently, the linguistic data suggest that Malay-speaking seafarers played a pioneering role in the dispersal of the characteristic tripodmasted ships plying the Southeast Asian waters into historical times. At one point, these cultural contacts between Southeast Asian and Chinese ship-builders converged into a hybrid tradition that flourished during the $10^{\text {th }}$ C. CE Song Dynasty (Manguin 1993:270-4, 2012:613ff.). ${ }^{194}$

The adoption of fixed masts on Southeast Asian ships probably coincided with the availability of superior materials to produce sails. As mentioned above, Southeast Asian sail types were originally made of woven vegetal materials. We may ask ourselves when textile sails have started to replace the former. In China, cloth sails were used at least from the first

\footnotetext{
192 Cf. Burrow \& Emenau (1984 \#1895) and OIA * kūpa(-ka) 'mast', Sinhala kun̆ba-ya, Dhivehi kun̆bu.

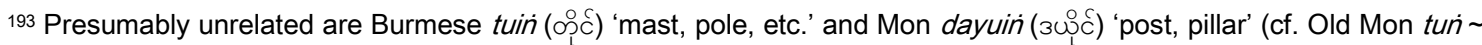

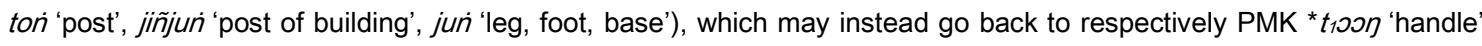

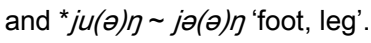

194 We may also call attention to the fact that Malay and other Southeast Asian boat-builders occasionally adopted Chinese battened lugsails on their watercraft (cf. Smyth 1906:336ff., Piétri 1949 passim).
} 
centuries CE (cf. Needham 1980:600). The Z/Z-spun cottons found at the Red Sea shipping port Berenike ( $3^{\text {rd }} \mathrm{C} . \mathrm{BCE}-3^{\text {rd }} \mathrm{C}$. CE) have been identified as sailcloth and reinforcing strips, probably for local ships (Wild \& Wild 2000, 2001). These textiles were presumably imported from India, as were numerous other items at the site, including Indian teak (Tectona grandis), black peppercorn (Piper nigrum), coconuts (Cocos nucifera), beads, fine-ware pottery and precious stones (Wild \& Wild 2000:271-2 and the references therein). It is not known whether the ancient Indians also used cotton sails on their own ships. Although cotton sails were more efficient to use and would not lose as much wind through pores between the threads, they are relatively difficult to weave and susceptible to rot and mould (Black \& Samuel 1991:222). Middle Eastern seafarers popularised cloth sails - cotton, linen or other - at the expense of woven palm sails throughout the Indian Ocean in Islamic times (Bowen 1953:82, Hourani 1995:100). This transition may have been concomitant with the spread of the lateen sail. The linguistic evidence points towards a Persian origin and distribution of sailcloth technology (cf. Farsi dāman 'sheet, sailcloth') across the Indian Ocean (cf. Glidden 1942:71), adopted as Arabic damān, Swahili demani, Malagasy (dial.) demany, Hindi dāmān, Tamil tāmān ('lower back rope of a dhoney sail, back clew line'), Malayālam tammān ('the large sail of native vessels'), Telugu ḍamānu ('sail') and Malay daman. The adoption of cloth sails on Southeast Asian ships implies that Southeast Asian ship-builders, although playing a significant role in the dispersal of maritime technology across the Indian Ocean, were equally ready to incorporate foreign elements into their nautical corpus if these were regarded as technological or cost-efficient improvements. During the colonial period, this tendency was reinforced by the large-scale local production of ships under European patronage, resulting in the adoption of various Portuguese, Dutch and English nautical terms into the languages of Southeast Asia (Liebner 1993:37-9, Mahdi 2007:232-6). 


\subsection{The outrigger device}

The previous sections have demonstrated how innovations in rigging have enhanced the speed and manoeuvrability of Southeast Asian watercraft, but also increased the risk of capsizing. Boat-builders across the world have come up with different strategies to improve the seaworthiness of their watercraft, including the addition of outboard thwart poles or planks (balance boards), lateral bamboo compartments and deck platforms connecting one canoe hull to another. The most widespread balance device is without doubt the outrigger, found throughout the Indo-Pacific waters. An outrigger can be defined as a small hull, usually made of bamboo or buoyant timbers, connected to the main hull with transverse poles (crossbeams). The outrigger device is designed to improve the buoyancy and increase the resistance to capsizing (roll stability) of an inherently unstable dugout canoe or small boat. The device is especially useful in combination with comparatively large sail types. Boats can be equipped with single or double outriggers. In the former case, the boat is generally sailed with the outrigger on the windward to prevent it from capsizing under strong winds.

Despite their many benefits and wide geographical distribution, outriggers are by no means indispensable to Southeast Asian watercraft. Although several of the depicted Borobudur ships display outriggers, it appears from contemporaneous textual sources that the largest Southeast Asian ships were not equipped with this device. Indeed, the smaller sea-boats equipped with outriggers were normally not designed for transoceanic voyages (with the exception of Remote Oceania). None of the known Chinese accounts, which tend to accurately describe Southeast Asian watercraft, call attention to the presence of outriggers (Manguin 1980:276). Neither is the device visibly depicted in other iconographic sources of the region, such as the Đông Sơn drums or the Tutuala rock paintings. Nevertheless, outriggers were definitely in use at the time these textual and iconographic sources were produced. The earliest archaeological evidence for the use of outriggers is probably the aforementioned Kelani Ganga boat of Sri Lanka (380 CE \pm 100 ), which shows an outrigger connective mechanism to the main 
hull (Kapitän 2009:168-9). ${ }^{195}$ This early date is relevant to the periosidation of the transoceanic diffusion of maritime technology.

Outriggers are different from the so-called 'balance boards' found on several South and Southeast Asian boats (Kiehl 1877:361-2, Hornell 1920d:260, 1946:225ff., 260, Paris 1955:45, 46-7, Deloche 1994:183, Blue et al. 1998:63, 64 fig. 19). When a boat is under high wind pressure, the crew can fasten or temporarily rig out planks to the windward, on which they stand

Figure 52: double outrigger canoe (Tuktuk, Sumatra,

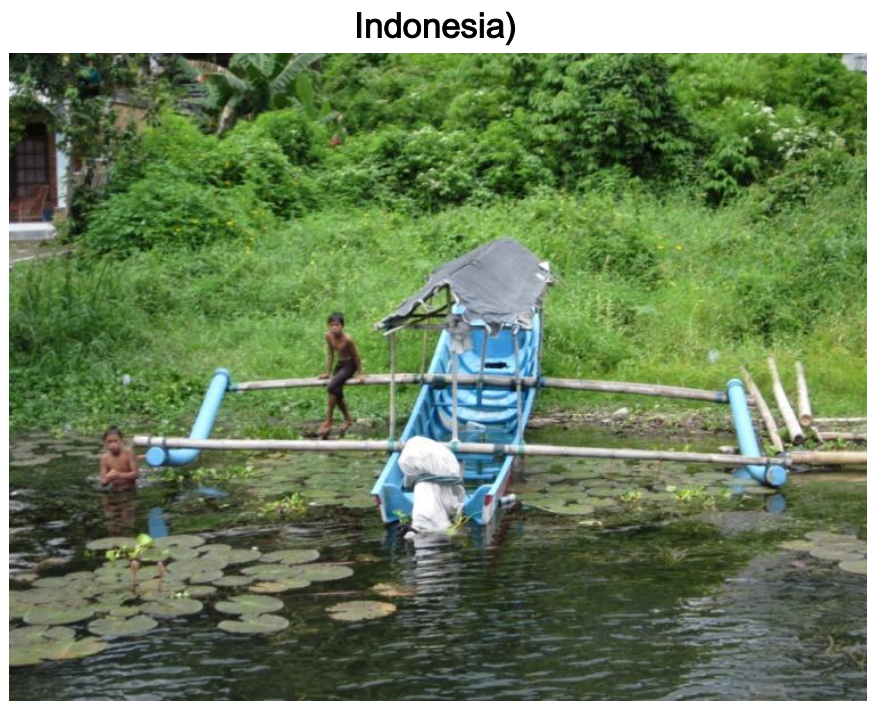

or put ballast to obtain an effective counterweight and prevent water from coming over the lee gunwale. Balance boards do not possess floats to contribute to the boat's buoyancy. In fact, the two devices can complement each other, as is demonstrated by fishermen in Karachi who fasten a single outrigger on the leeward side and two balance boards

on the windward side of their lateen-rigged ekdār horā watercraft (Greenhill 1971:125). Also different are the lateral bamboo compartments known as 'aerial non-floating outriggers' or 'sponsons' found on south Chinese and mainland Southeast Asian river boats (Smyth 1906:316, Paris 1955:48, Needham 1980:385 n.). Although these supportive bamboo poles render the boats nearly unsinkable, they also heavily impede their speed and manoeuvrability. Some scholars have argued that outrigger boats evolved from these river boats (Heine-Geldern 1932, Paris 1941:356, Ling 1970:15), but it seems more likely that the former developed out of asymmetric double canoes used in the open waters of insular Southeast Asia (Brindley 1932:308, Doran 1981:93, Mahdi 1999a:145).

195 Conversely, no such mechanism was found on the $6^{\text {th }}$ mill. BCE Kuahuqiao boat (Jiang \& Liu 2005), so I see little reason to assume that this early canoe was equipped with an outrigger, as is suggested by the authors. 
Outside insular Southeast Asia, outrigger boats have been documented in the seas of the Pacific, New Guinea, northern Australia, the Andaman Islands, the Nicobar Islands, Sri Lanka, the South Asian mainland, the Maldives, the Comoros Islands, Madagascar and East Africa (Hornell 1920d:180, 1944, Brindley 1932:311, Haddon \& Hornell 1936-38/3:85, Prins 1959:206, Greenhill 1971:157, Doran 1981, Kapitän 2009). The fully developed outrigger device is fairly complex in structure and use and is frequently found in combination with insular Southeast Asian sail types. This militates against spontaneous ab initio invention in the above regions and favours a scenario in which its presence throughout the Indian Ocean is the result of introduction or stimulus from Southeast Asia. Indeed, the Malayo-Polynesian speaking regions display the greatest diversity of outrigger designs, probably reflecting a considerable degree of antiquity and various stages of development. Despite some scattered accounts of outriggers fastened to Middle Eastern watercraft (Crossland 1918:167, Varadarajan 1994:171), the device was generally not adopted by boat-builders from this region. The Middle East already possessed an advanced seafaring tradition and their sophisticated plank-built watercraft did not suffer greatly from instability. Therefore, there was no need to adopt outriggers; even Arabinfluenced boat types in insular Southeast Asia (Hornell 1920c:105) and eastern Africa were constructed without the device. The only outriggers typically present on Arab vessels are those fastened to the nuggär (نقار) boats of present-day Sudan. These outriggers serve to assist the boatmen in increasing the propulsive force of their sweeps and were probably invented independently (Hornell 1938, 1939-40). Claims of outriggers in Central Africa (Torday 1918), West Africa (Jones 1964:189ff.), Scandinavia (Hallström 1925), the eastern Arctic (Brindley 1932:308) and Colombia (Hornell 1928) are poorly documented and, if true, probably unrelated to maritime networks in the Indian Ocean.

In most parts of insular Southeast Asia, the Comoros Islands and coastal East Africa there is a predominance of double outrigger boats, whereas the sailors of South Asia, the Pacific, New Guinea and northern Australia generally prefer single outrigger boats. Both types have been documented in Madagascar, the Philippines, parts of Indonesia and northwest New 
Guinea (Hornell 1920c:89, 105, Patanñe 1977:717). There has been a fair amount of debate as to which type preceded the other. The most likely order of succession seems to be that the single outrigger canoe developed out of an asymmetric double canoe and the double outrigger was a later development, also reflected by its smaller geographical distribution (Brindley 1932:308, Doran 1981:93, Mahdi 1999a:145). In Madagascar, however, the single outrigger appears to have superseded the double outrigger (Hornell 1920a, 1920b). Nonetheless, I see little reason to doubt the overall picture.

Figure 53: small single-outrigger boat (Baotere, Instead, I would argue that the transition from one type to another depended on specific local circumstances, such as the presence or absence of sheltered bays and the nature of monsoon winds and sea currents. Since outriggers are often boomlashed to the hull, attaching and detaching

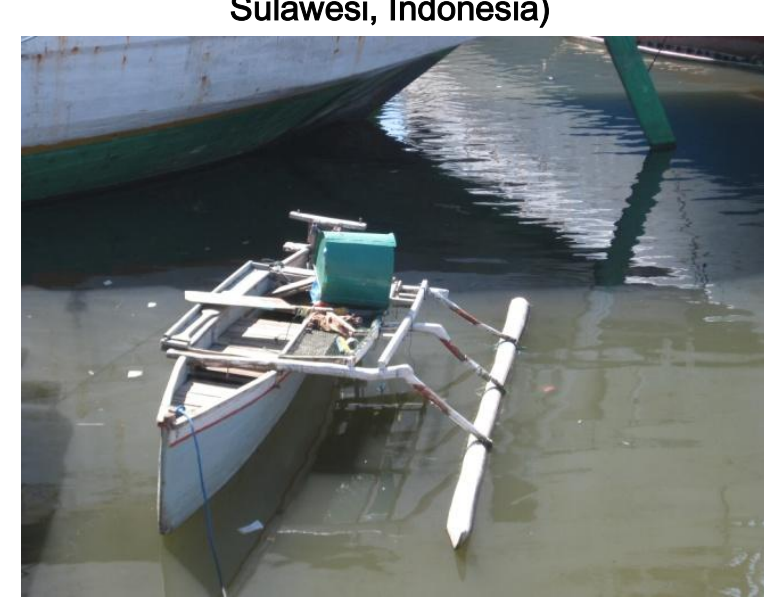
them is not extremely problematic and is occasionally done on small watercraft (e.g. Vosmer 1993:39). Depending on the purpose of the sea journey, both the single and the double outrigger have advantages and disadvantages. Boats with double outriggers are less likely to capsize - especially when sailing into the wind and allow for more accommodation in the cabin, whereas those equipped with single outriggers can move closer to the wind and have better manoeuvrability in general; there are only two points of contact with the water and therefore less drag. Illustratively, in the Philippines we see a clear distinction between relatively big and seaworthy boats equipped with double outriggers versus smaller vessels used for river and port navigation with single outriggers, usually on the port side to permit rowing with the right arm (Patanñe 1977:717).

Upon closer examination of the lexical data for 'outrigger', not a single protoform can be unambiguously attributed to proto-Malayo-Polynesian. Reflexes of * $k a t i R$ and ${ }^{*}$ saRiman are the most widely dispersed, but their geographical distribution is fairly restricted. The form * $k a t i R$ 
seems to have originally referred to a 'canoe hull' or 'small outrigger canoe' - a meaning it still has in some languages in Near Oceania - and has obtained the meaning 'outrigger float' in a limited set of languages in the Philippines and West Indonesia (Pawley \& Pawley 1994:339). ${ }^{196}$ The form *saRiman 'outrigger float' (Wolff 2010/2:794) or *(cs)a(R)man id. (Pawley \& Pawley 1994:347) is predominantly found in East Indonesia and Oceania and may have moved westward from that area. This would suggest that the outrigger device was invented and dispersed after the divergence of proto-Malayo-Polynesian. The fact that one of the original meanings of *katiR was 'canoe hull' supports the hypothesis that the single outrigger canoe developed out of an asymmetric double canoe. Alternatively, the outrigger device may have been invented by and taken over from pre-Austronesian communities, many of which appear to have had a distinctly maritime orientation.

\section{Figure 54: attestations of 'outrigger' across the Indian Ocean}

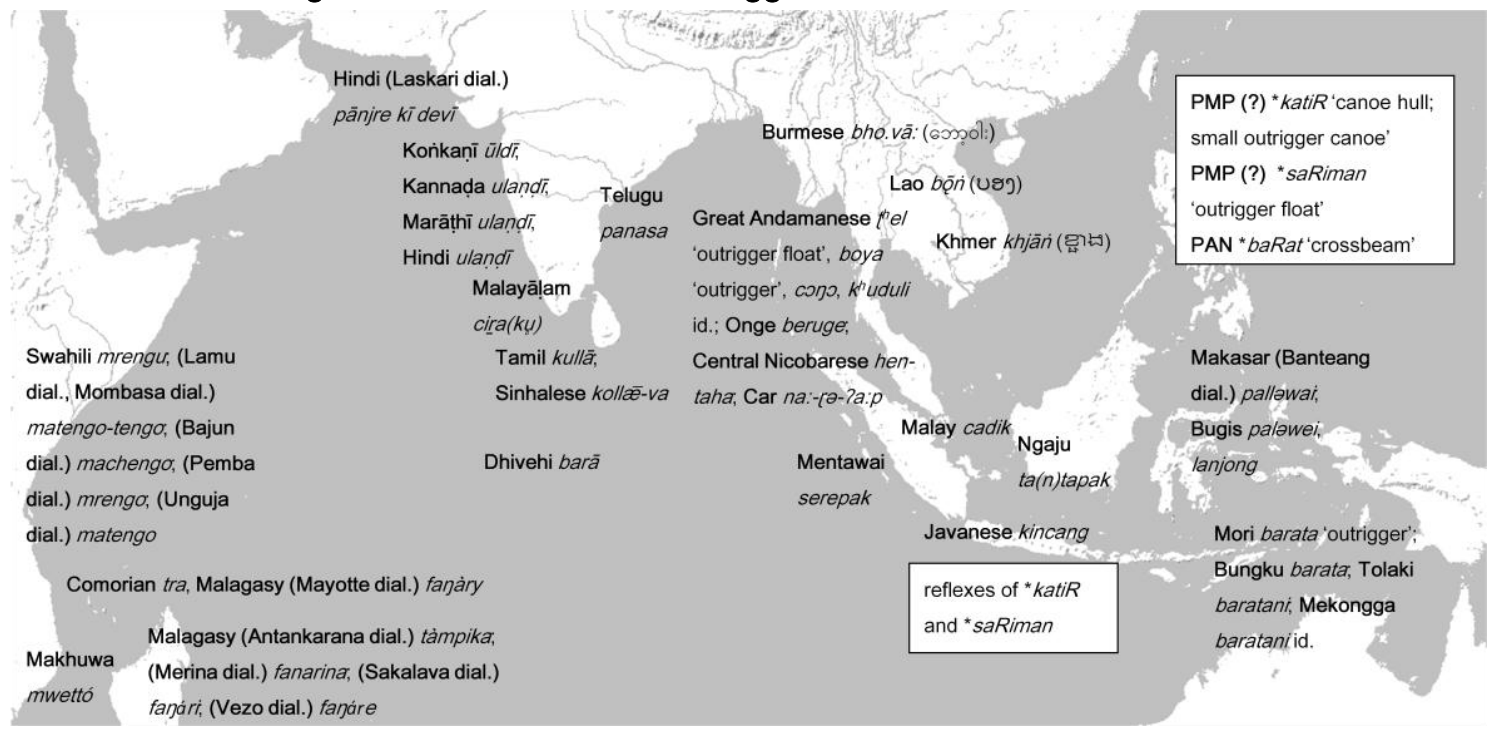

Moving beyond this, the lexical data on outrigger terms across the Indian Ocean are extremely diverse (cf. Figure 54) and only two attestations have been connected to terms found in insular Southeast Asia. Blevins (2007:197) suggests that the Onge (Little Andaman Island) word

\footnotetext{
196 Reflexes of protoform * $k a t i R$ may also have been adopted into southern China. Manuel (1948:75-8) lists a term allegedly derived from the Southern Min elements 'to tie' and 'bamboo'. The characters are not given, but we might reconstruct this form as *kat tek (結竹). Such a compound is not attested in any dictionary that I am aware of and might be a borrowing from a Philippine language (cf. Tagalog katig 'outrigger') subsequently rationalised through the given etymology. We know that Filipino seamen reached the Fujian coast from the late $12^{\text {th }}$ C. CE (Scott 1980:18, 23-4). Further research is needed to clarify this issue.
} 
beruge 'outrigger' has been borrowed from a West-Malayo-Polynesian reflex of ?*bilug 'type of boat (dugout with outrigger)', which seems legitimate on phonological grounds. ${ }^{197}$ Other Great Andamanese terms for outrigger appear to be completely unrelated, cf. thel 'outrigger float', boya 'outrigger', cono, $k^{h} u d u l i$ id. The attempt by Dick-Read (2005:92-3) to connect the Swahili root (ma-)tengo 'outrigger' to a somewhat obscure term for 'outrigger connective piece' documented in a single language of South Sulawesi (to wit: Makasar (Konjo dial.) tengko) is considerably less convincing. None of the authors concerned with the issue have, to the best of my knowledge, analysed the word for 'outrigger' in Dhivehi (barä). Although Maldivian boatbuilders have stopped manufacturing their traditional boat type consisting of a dugout hull, lashed lugs, sewn planks and an outrigger (Hornell 1920:180, Maloney 1980:114, Millar 1993:15), this term is still known by some consultants. I would argue that it goes back to a reflex

Figure 55: attestations of *baRat '(outrigger) crossbeam'

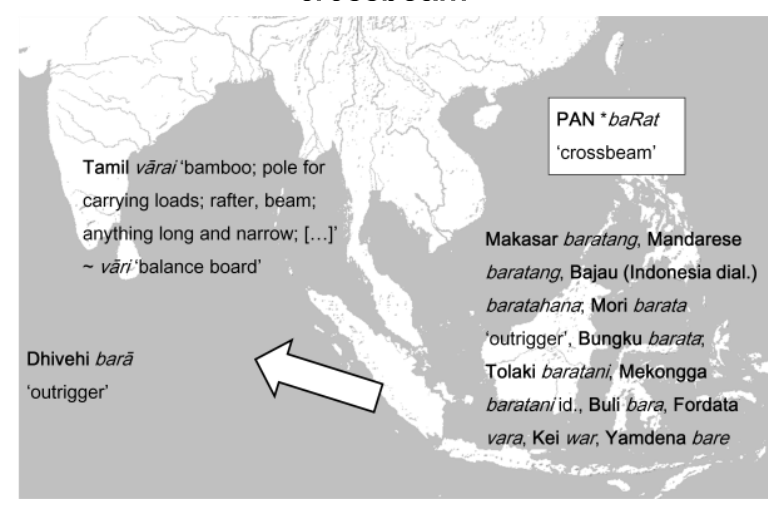

of proto-Austronesian *baRat 'crossbeam' (Blust 1995 s.v.) 'be athwart' (Wolff 2010/2:747). This form yielded several Malayo-Polynesian reflexes in the meaning of 'outrigger crossbeam' (cf. Friederici 1912:235-315, Haddon \& Hornell 193638/2:137, Horridge 1981:86-9, Blust 1995 s.v.) or, around south-eastern Sulawesi, 'outrigger' (Stokhof 1984:12, 52, 68, 85). The word may also have been borrowed into Tamil as vārai 'bamboo; pole for carrying loads; rafter, beam; anything long and narrow; [...]' vāri 'balance board', although this is less certain (cf. Figure 55). Finally, there appears to be a relation between Khmer khjāin (록ํㄱ) 'outrigger' and Javanese kincang id., although the direction of borrowing remains uncertain.

\footnotetext{
197 On the other hand, a relation between the PWMP ?*bilug 'type of boat (dugout with outrigger)' and PMK * $d u u k \sim$ * $d u k$ 'boat, canoe' may be premature (pace Shorto 2006 \#336). More convincingly, Pou \& Jenner (1973:36) propose a Chinese etymology for this Mon-Khmer protoform, cf. EMC * $d \partial^{h}$ (渡) 'ferry'.
} 
In general, the archaeological, linguistic and ethnohistorical data show that the introduction of the outrigger across the Indian Ocean was a secondary distribution adopted as a result of cultural contact, not inheritance or independent invention. The outrigger device was probably invented somewhere in insular Southeast Asia, from which it diffused westwards. In most cases, however, the name was not borrowed along with the device. This is not to say that contacts between Southeast Asian sailors and their colleagues from other Indian Ocean regions were of serendipitous nature. It does, however, imply that sailors noticed straight away the benefits of outriggers on small watercraft in terms of buoyancy and seaworthiness, grasped the relatively self-explanatory concept, and adopted the device without any active teaching process by Southeast Asian boat-builders. This explains why the technical details in terms of fastening the outrigger to the hull, often involving rather complex constructions of sticks and rods, are quite different from one region to another (cf. Haddon 1920). Arguably, this discrepancy was also a result of specific regional and cultural circumstances, as sailors and shipwrights from different backgrounds use different materials to manufacture outrigger boats and benefit from them in different ways. This is demonstrated by the entirely different outrigger constructions of Malay sport racers (FitzGerald 1939:156), Sri Lankan prawn-fishers (Kapitän 2009:180) and Lamalera whale hunters (Barnes 1996:294), just to mention a few.

\subsection{Other nautical devices}

The smallest types of watercraft require no elaborate steering apparatus and can be propelled by paddles or oars. Oars are defined as bladed wooden implements connected to the vessel, whereas paddles are hand-held. The words for 'paddle' and 'oar' in the languages across the Indian Ocean are predominantly inherited reflexes. Nevertheless, the linguistic data also reveals that a specific type of paddle from insular Southeast Asia was adopted into other regions of the Indian Ocean. The paddle in question "[...] is the short, broad paddle, scull or oar, not connected to the vessel but held with the hands at the shaft, with which the islanders of the Pacific propel their canoes, but [which is] also very much in use among the peoples of the 
Indian Archipelago [...]". ${ }^{198}$ This Southeast Asian paddle is known as Malay pəngayuh 'oar, paddle (n.)' (from kayuh 'single-bladed paddle'), (Sumatra dial.) pəngayong id., (Ambon dial.) panggayo 'single bladed paddle' and Makasar panggayong 'long oar'. It was regarded as a particularly efficient means of propulsion, as illustrated by a Dutch observer in the late $19^{\text {th }}$ century: "as heavy as the native finds rowing, he could propel a pəngayuh all day long." 199 We find this Southeast Asian word for paddle reflected in South Asia as Malayālam panigāyam 'paddle' and Hindi (Laskari dial.) pangae id., in addition to its (apparently unrelated) adoption in several European languages, such as Dutch pagaai, French pagaie and Spanish pagaya. European authors recorded a strikingly similar word on the East African coast and the waters of South Asia (Gray 1887/1:53, Yule \& Burnell 1903:668), where it referred to a specific type of small watercraft. In one of these early descriptions, we can read how people made use of "[...]certain boats, called pangaios, [...] made of light wood, and sewn together with cords, without having a single iron nail."200 This boat name still survives as Końkaṇi pangay 'k.o. boat' (Dalgado 1913:120) and Makhuwa pangaya pangayo 'Indian boat, with mat sails'. It has been suggested that the adoption of this word is the result of semantic reinterpretation from 'paddle' to a 'small boat propelled by a paddle' (Kern \& Terpstra 1955:24 n.8). Since Malay pəngayuh can mean both 'paddle' and 'paddler', such a shift in meaning is not as far-fetched as it may seem at first glance.

Whereas paddles suffice to propel small watercraft, larger ships require a more sophisticated system of configuration, normally the addition of one or more rudders. The Indian Ocean displays two traditional rudder types: the quarter rudder and the stern-mounted rudder. Quarter rudders are essentially lateral steering oars positioned at the sides of the hull (trunk-

\footnotetext{
198 My translation from the original Dutch "[...] is de korte, breede, niet op het vaartuig rustende, maar aan een kruk met de handen vastgehouden roeiriem, schepriem, of roeischop, waarmede de eilanders der Stille Zuidzee hunne kano's voortstuwen, maar die ook zeer veel gebruikt wordt bij de volken van den Indischen Archipel [...] (Veth 1889:294)" 199 "Zoo zwaar als een inlander het roeien valt, het scheppen met een pagaai houdt hij wel een heelen dag vol. (Clercq 1890:41)"

200 "[...]seeckere schuyten, ghenaemt pangajos, [...] ghemaeckt van licht hout, ende aen malcanderen ghenaeyt met coorden, sonder eenen yseren naghel te hebben. (Kern \& Terpstra 1955:24)"
} 
ways). These are the most archaic rudders and can be found on traditional watercraft in the Bay of Bengal, insular Southeast Asia and Oceania. Watercraft of the Arabian Sea (as well as Chinese ships) are generally equipped with stern-mounted rudders, lashed to or otherwise suspended on the ship's stern. These lashed stern-mounted rudders were either independently invented or modified from an earlier stern-mounted rudder tradition, presumably by the Arabs. The linguistic data reflects the Arabic origin of the most widespread Indian Ocean word for

Figure 56: lateral steering oar on a fishing vessel known as mādæl-pāru 'large net boat' (Negombo,

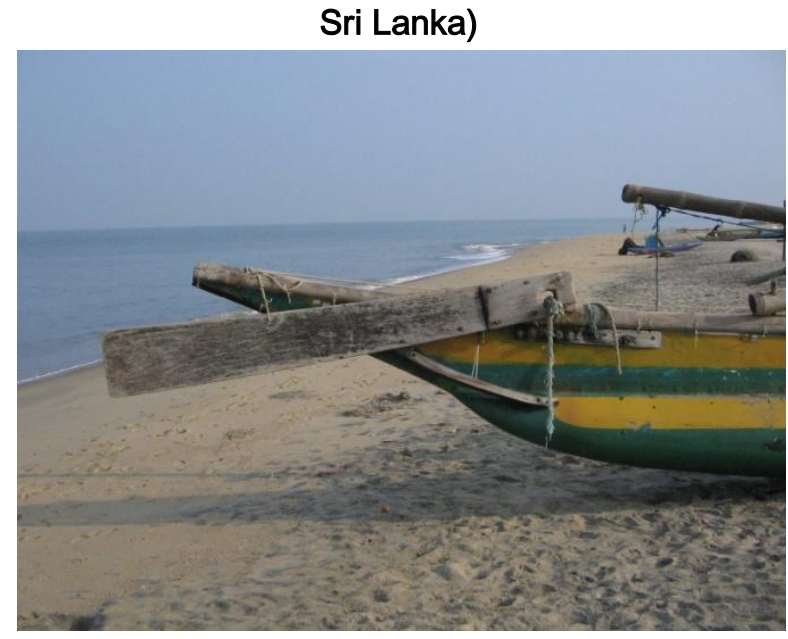

'rudder' (sukkān), e.g. Farsi sukkān,

Somali shukaan, Swahili sukani, Makhuwa sukani, Comorian usukani, Malagasy (Mayotte dial.) sokàny, Hindi sukkān, Marāțīi sukāṇa sukānūu, Tamil cukkān, Malayālam cukkān, Kannaḍa cukkaṇa and Sinhala (coll.) sukkānama id. The first depiction of a stern-mounted rudder in a South Asian context dates from the $12^{\text {th }} \mathrm{c}$. $\mathrm{CE}$, predating the first known European

median rudders (Deloche 1996:208). A more recent innovation on Indian Ocean watercraft is the pintle-and-gudgeon rudder, installed on some ship types as a result of European influence. The adoption of a loanword for 'tiller' may be coeval with the spread of this rudder type; the Portuguese term cana (do leme) 'tiller (of a rudder)' has been borrowed as Arabic kānaẗ 'tiller', Tamil kānā and Swahili kana id. (cf. Johnstone \& Muir 1964:318 n.93, Manguin 1985b:7). Cognate forms in some Dravidian languages, such as Malayālam karṇam 'rudder' and Kannaḍa karna id., appear to go back to OIA *kárna 'ear, handle of a vessel' upon first inspection, but this is probably due to back-formation.

In his important work on the development of the rudder, Mott (1996) makes the point that the replacement of quarter rudders by stern-mounted rudders on European and Middle Eastern watercraft is not exclusively a matter of superior technology. Although the stern- 
mounted rudder is potentially a stronger device, it is also more complex and requires radical changes in hull design before it can be used effectively. This might help us to understand why the stern-mounted rudder was much less readily adopted into the ship-building traditions of the Bay of Bengal and beyond. The Malayo-Polynesian speaking regions traditionally exhibit double quarter rudders, designated by reflexes of PMP *qulin (Pawley \& Pawley 1994:352, Wolff 2010/2:970). The (unrelated) Malay form kəmudi 'rudder (gen.)' is the only word that spread across the Indian Ocean, where it has been borrowed as Malagasy (Antankarana dial.) hamory 'rudder'. This form was also adopted in neighbouring languages, e.g. Toba Batak hamudi, Makasar kamudi, Tausug kamudi and Ngaju kamburi kambudi. Etymologically, Malay kəm-udi can be explained as 'that which is behind', implying that the word originally denoted a sternmounted rudder, as opposed to the conventional lateral rudders for which reflexes of PMP *qulin were used. We also come across the term kamudi Kaling '(South) Indian rudder' in the $16^{\text {th }}$ C. AD Sundanese poem Bujangga Manik (Noorduyn \& Teeuw 2006:243), but it is unclear how this specific rudder differed from indigenous rudder types.

Another example of the transoceanic dispersal of nautical technology is the spread of anchor types. The simplest anchors are essentially heavy objects or sea-floor tackles connected to the vessel with a rope to prevent it from drifting away. These may have been invented independently in various places. A further development from these simple mooring stones is an implement which grips the sea bottom, through plugs, flukes or otherwise. Through various intermediate stages of development, advanced stone-shank grapnels and stock anchors evolved in the classical Mediterranean, presumably independent from the sophisticated wooden stock anchors found in East Asia (Votruba 2010). While the evolution of different anchor types is relatively well documented for the Mediterranean (cf. Moll 1927, Nouhuys 1951, Kapitän 1984), much less is known about the Indian Ocean and East Asia. European style iron anchors were taken over by Indian Ocean ship-builders in historical times (Nouhuys 1951:46, Qaisar 1982:27). Prior to that, the boat-builders of the Indian Ocean presumably employed several types of pierced stone-slab anchors and grapnels. 
A closer look at the linguistic data reveals several transmission patterns. According to Burrow (1945:614 fn. 1), all South Asian words for 'anchor' go back to Old Greek ánkyra (áyKupa), which obtained an intrusive word-initial /\#n/ in the Dravidian languages (cf. Tamil nanikuram and Malayālam naniguram, hence Sinhala nærigurama, Dhivehi nagili and possibly Makhuwa nànkura). On linguistic grounds, however, the precursor of the Dravidian attestations might equally well have been Portuguese âncora. This is substantiated by the fact that nanikuram 'anchor' only entered the Tamil literature during the colonial period, while the device was previously called cinnior kal (Rajamanickam \& Raj 1994:37). The word kal, with the primary meaning 'stone', occurs in the Maturaikkāñci and presumably refers to a rudimentary type of mooring stone or pierced stone-slab anchor. The Tamil word cinni, which remains unattested in the earliest literature, refers to a 'wooden anchor made heavy with stones' (cf. Malayālam cinni 'an anchor, grapnel'). This word might be derived from the Arabic sini - attested in the compounds hağar șin̄i and anğar șin̄ī - presumably denoting a 'Chinese anchor' (Yajima 1976:29 n.13). The same word features as sinn 'killick' in modern Arabic and as șiniyaẗ in the work of Ibn Māğid (Tibbetts 1981:529). Indeed, the Chinese nautical corpus exhibits several advanced types of wooden stock anchors, some of which, based on the tentative transmission of the above word, may have been adopted by other seafaring communities operating in the Indian Ocean. In the waters of Southeast Asia, contact with Chinese seafarers resulted in the development of hybrid Chinese-Southeast Asian anchor types (Nouhuys 1925:19-21). We may tentatively date these acquisitions to the late $1^{\text {st }}$ mill CE or later, when the Han Chinese started to regularly undertake ocean-faring journeys.

Several other words for 'anchor' are attested in South Asian languages prior to Portuguese contact. The Pali form laggana-ka lakana-ka 'ship's anchor', attested in the Milindapañho (Trencker 1908:112 fn. 16, Geiger 1916:57), appears to go back to the root $\sqrt{\text { lag }}$ 'to adhere, to cling on to'. The unrelated Pali form lakāra (lanikāra in Burmese texts) has also been interpreted as 'anchor' (Cowell 1895:78 fn. 2, Andersen 1979:221), but a closer look at the Pali literature reveals that this device was connected to the use of wind energy during sea 
journeys (De 1906-07:173, Haebler 1965:113-4), making the meaning of 'sail' far more plausible (see Section 7.5). Also unrelated is late Sanskrit nāngara, found in the $8^{\text {th }} \mathrm{C} . \mathrm{CE}$ Samarāiccakahā and the $11^{\text {th }} \mathrm{C}$. CE Tilakamañjarī, believed to refer to an anchor made of rock (Gopal 1999:92-3). The same form is reflected as Marāṭī nā(ni)gara langara 'anchor, plough', Gujarātī nā̃̃ar 'anchor', Hindi (Laskari dial.) langar nangar and Bengali nōniara id. The resemblance to Tamil nankuram and related forms is presumably fortuitous, judged from the observed discrepancy in the second vowel. As the Marāthī form suggests, this set of attestations may be influenced by or ultimately derived from OIA */ā'ngala 'plough' (Dalgado 1913:10 fn. 1, Turner 1966 \#11006). Indeed, a stock anchor resembles a plough in almost every detail (much more so than a grapnel). As yet, however, the absence of corroborative archaeological data renders premature any speculation that these pre-modern anchors were modified ploughs. Forms like Kannaḍa narigal 'anchor', Tulu nangaru nangalu, Farsi langar, Baluchi nagar, Balinese manggah, Bajau (Indonesian dial.) manggar, Swahili nanga and Comorian nangá also appear to go back to these Indo-Aryan forms, although the exact sound correspondences remain unexplained. 201

Reflexes of this word appear to have been reintroduced into India along with later types of anchors used by Middle Eastern sailors. Several languages spoken in the vicinity of the Arabian Sea additionally exhibit anchor terms derived from Farsi langar, cf. Hindi langar, Tamil lańkar, Malayālam lanigar, Tulu laṅgarụ, Telugu lańgaru and Arabic (Kuwait dial.) anğar id. (Johnstone \& Muir 1964:301).202 A recent archaeological study indeed points to Middle Eastern influence on several Indian Ocean anchors - all made of granite with square holes for wooden pegs - found off the Kerala coast, Goa and Mogadishu (Sila Tripati et al. 2005). The lexical data, however, remain insufficient to provide a complete picture. The dictionaries rarely account for

201 The Swahili and Comorian forms appear to go back to Gujarātī nã̃gar. The word-initial /\#m/ in the Balinese and Bajau attestations remain unexplained. The irregular initial vowel of Malay jangkar 'anchor' could be a borrowing from English the anchor (Dalgado 1913:10), if not the result of folk-etymology through association with jangkar 'air roots'. Certainly of European origin (English or Dutch) are Sinhala ankara-ya 'anchor' and Malay †angker. 202 The word-initial /\#l/ was perceived as part of the Arabic article and therefore dropped (Hourani 1995:99). Malay †anjar 'anchor' appears to be a borrowing from the same Arabic form. 
the differences in meaning between word pairs such as Tamil nankkuram vs. lankkar and Malayālam nariguram vs. lanigar, so that we can only speculate which specific anchor type each term designated upon its adoption into the language. The aforementioned Persian term langar forms a welcome exception: the Miftāh-ul Fuzālä̈, a mid $15^{\text {th }}$-century wordlist, defines langar as a 'boat stone' (sang-i-kištt), leaving little doubt to its identification as a pre-modern type of stone anchor, not a wooden stock anchor (cf. Qaisar 2002:20). Along similar lines, we know that the grapnel described in medieval Arabic texts was made of iron, as the device was known under the name hadid 'iron' (Khan 2001:65). In general, however, considerably more archaeological data is needed to gain a better picture of pre-modern anchor types and their dispersal across the Indian Ocean.

\subsection{Concluding remarks}

Defying the forces of nature in a wooden sailing vessel, even in the relatively predictable waters of the Indian Ocean, requires skill and courage. The seafarers of this highly interconnected area were keen to learn from each other and proved able to benefit from the technological advantages that had evolved in different maritime traditions over the centuries. Several of the Indian Ocean's boat- and ship-building traditions have adopted and modified Southeast Asian elements, including various types of vessels, methods of plank-fastening, rigging traditions, the outrigger device and a specific type of paddle. Meanwhile, Southeast Asian sailors also demonstrate a willingness to incorporate ideas from other maritime traditions into their corpus of nautical technology, often resulting in unique hybrid traditions. In general, insular Southeast Asian influence has been stronger in the Bay of Bengal, while it was much less profound in the Arabian Sea. Judged from widely distributed and commonly shared names of ship types and other nautical vocabulary, the Bay of Bengal appears to have developed a hybrid maritime tradition, to which both (South) Indians and Southeast Asians have actively contributed. From the perspective of maritime archaeology, however, much remains to be done. Our lack of data 
on the vessels used by the famous Cōla navy, for example, compels us to continue working on this area.

Regular contact between seafarers and shipwrights from different backgrounds led to familiarisation with each other's shipping technology. Like the Bay of Bengal, the western parts of the Indian Ocean have developed a shared ('Arabo-Indian') maritime tradition. This tradition dates back to the earliest days of cultural contact between the Arabian Peninsula and the Indian subcontinent and has been greatly reinforced by the Islamic expansion. In this regard, several shared innovations in the Arabian Sea, such as the lateen rig and the stern-mounted rudder, were probably relatively late developments superseding all previous technology. Those regions of East Africa in which Arabo-Indian seafaring did not fully replace the pre-existing diversity, in particular Madagascar and Mayotte, reveal an evident insular Southeast Asian substrate. The presence of outriggers on small fishing boats along the East African coast is testimony to this underlying layer of Southeast Asian elements, which was largely overshadowed by AraboIndian technology during the Islamic period. This marks a clear contrast with the distribution of Southeast Asian plants and spices, both of which exhibit much less unquestionable evidence for direct contact between Southeast Asia and the African mainland.

In several cases there is a clear correlation between the diffusion of nautical technology and the corresponding lexical items. Occasionally we are able to pin down the origin and dispersal of certain types of watercraft and technical devices. More often, however, the situation turns out to be complicated. The sailors of the Indian Ocean have adopted various elements from insular Southeast Asian nautical traditions, but the original names did not always travel along with the items. While the dispersal of the double spritsail from insular Southeast Asia to Sri Lanka and possibly the Maldives is reflected in the linguistic data, outriggers seem to have spread across the Indian Ocean mostly without carrying with them their specific terminology. The stability and buoyancy of outriggers are relatively straightforward and the device might have been adopted simply by observing Southeast Asian watercraft, while its specific benefits in combination with Southeast Asian sail types may not always have been understood or taken 
over by the recipient societies. In general, seafaring fishing boats used outriggers, whereas large cargo ships designed for ocean-born journeys often did not. It is important to underline that all types of watercraft have evolved and keep developing in a rational way, conforming to the local ports, rivers, bays, seas and natural harbours in which they are navigated. Differences in boat forms, after all, are a reflection of the unique pathways of evolutionary change experienced and put into practice by different maritime societies. 


\section{Conclusion}

Contrary to the impression to be gained from much scholarship, several decisive developments in world history took place in the maritime instead of terrestrial sphere. The development of ocean-going watercraft, the maritime diffusion of new agricultural practices, the spice trade and the spread of religions (in part a maritime process) have all impacted and radically changed the cultures and societies of the Old World. Great civilisations such as Mesopotamia, ancient Egypt, the Indus Valley, the Roman Empire and China were all interconnected through the Indian Ocean. This ocean formed the single most important axis of world history, and - with the rising power of China, the wealth of the Middle East, the natural resources of Africa and Central Asia, the vibrant democracies of India and Indonesia, and the problematic states of Pakistan and Myanmar - will continue to play a decisive, all-encompassing role in the present century. Over water, ideas about agriculture, metallurgy, urbanisation, maritime technology and religion have spread faster than they could ever have done overland. While many pre-modern societies looked partly seawards for their livelihood, some communities depended on it entirely. In insular Southeast Asia and Oceania, such communities practiced a predominantly maritime lifestyle until modern times. The advanced technological knowledge and material culture that interethnic contact and maritime trade had conferred upon them provided these communities with numerous advantages over their inland-oriented neighbours. Indeed, political hegemony in Southeast Asia was always achieved by controlling the seas, as was the case in other archipelagic regions in the world.

This study has brought forth new evidence for the pre-modern presence and significance of insular Southeast Asian seafarers and traders in the Indian Ocean World. It is important to realise that transoceanic commerce was a continuation of small-scale regional trade, in which affluent cosmopolitan merchants were cleverly tapping into well established local networks. The expansion and interconnectivity of these networks eventually facilitated the transoceanic diffusion of various cultural processes. While our overall picture of the prehistory 
of this part of the world remains spotty, we see that such developments as urbanisation, metallurgy and the spread of religions took place almost simultaneously in several parts of the Indian Ocean littoral, following very similar patterns across the regions in contact. Commodities, concepts and people moved from the centre (South Asia) to the periphery (Southeast Asia and East Africa), but also in the opposite direction. Several plants, spices and boat-building techniques adopted from Southeast Asia revolutionised the cultural landscapes and seascapes of the Indian Ocean. It is clear that Southeast Asians did not play a passive role in this process, a persistent image constructed in colonial and early post-colonial historiography. Instead, the last decades saw a revolution in the field of Southeast Asian archaeology and it is now beyond doubt that social complexity and ancient traditions in metallurgy, agriculture and semiurbanisation existed prior to the better-documented period of "Indianisation".

In some cases, the Southeast Asian influence on the Indian subcontinent is quite tangible. Tin from Myanmar and the Thai-Malay Peninsula was in high demand in India and bronze artefacts with a high tin content appear abundantly in the archaeological record of particularly India's south coast and Sri Lanka. The Malayic name for this metal was adopted into late Sanskrit and other Indian languages, substantiating the role of Malay-speaking communities in these commercial interactions. Gold was another important export product, with Southeast Asia featuring as the semi-mythical "Golden Land" of Indian literature. Pre-existing Southeast Asian traditions in bronze production notwithstanding, Indian experts have significantly impacted on and reshaped the art of metallurgy in this part of the world. Numerous lexical transmissions from Sanskrit and Tamil suggest that new metal-working techniques, alloys and possibly the profession of 'blacksmith' were Indian introductions. One of the claims made in Section 3.4 is that Malay and related languages adopted an Indian word for 'iron'. This has significant implications for our understanding of the history of ferrous metallurgy in insular Southeast Asia. While the region appears to have obtained its iron-working tradition from the Southeast Asian mainland, based on the use of identical piston bellows and the presence of similar archaeological assemblages, contact with India has stimulated the manufacture of iron 
tools among especially the Malayo-Chamic populations. The lexical data further imply a particularly important role for the Tamil-speaking metal-workers, artisans and traders of South India. In various locations across Southeast Asia, in particular North Sumatra, they had established their own trading guilds. We must also place the socio-cultural process of "Indianisation" in the context of regular contact across the Bay of Bengal. South and Southeast Asia were gradually becoming part of the same world.

Meanwhile, the seafaring Malay communities inhabiting the coasts of Borneo, the ThaiMalay Peninsula and especially Sumatra began asserting different degrees of influence on their neighbours. The introduction of new concepts, techniques and ideas across Southeast Asia, possibly as far as Near Oceania, took place through the efforts of Malay-speaking sailors. These people also ventured beyond their archipelago and interacted with trade-oriented communities of the Indian Ocean World. The strong commercial relations between Malay traders and the Nicobarese stood in stark contrast with the deliberate self-isolation of the Andamanese, living only $300 \mathrm{~km}$ to the north of the Nicobar Islands. In India, Sri Lanka and the Maldives, we have encountered various examples of Malay loanwords adopted into local languages. However, much more textual research is needed to determine which of these words occur in the pre-colonial literary record of the languages involved and which were transmitted during the colonial period. Further westwards, the Malay influence diminishes, in some regions, to the point of virtual absence. Nevertheless, certain textual sources allude to the presence of rogue freebooters and slave-raiders from beyond the fringes of the known world, visiting the coasts of the Middle East and East Africa. If these people were from insular Southeast Asia, which the evidence suggests, we may assume that their presence had later been overshadowed by Indo-Arabian Muslims across the entire western Indian Ocean save Madagascar. A limited set of Malayo-Polynesian loanwords in Swahili appears to substantiate these ancient contacts between Southeast Asia and the African east coast. In order to reach East Africa and Madagascar from the island of Sumatra, it seems plausible that the Maldives 
were frequented and used as stepping stones. We find that this archipelago, situated at the very centre of the Indian Ocean, indeed displays several Malay loanwords.

The quantity of lexical influence from Malayo-Polynesian languages in South Asia and East Africa compel us to envision a more active role for insular Southeast Asian seafarers in the ancient Indian Ocean World than previously recognised. Their presence in the South Asian harbours has led to the exchange of vegetal products and other commodities across the Bay of Bengal. Against the backdrop of early contact networks, an important set of trees and other plants - including sandalwood, the areca palm, the betel pepper, banana and citrus cultivars, ginger and galangal - is believed to have been introduced from Southeast Asia to India and from there to the Middle East, East Africa and Europe. The spice trade, too, featured active Southeast Asian participants. Several valuable spices and aromatics, such as cloves, nutmeg and camphor, were produced exclusively in relatively isolated regions of present-day Indonesia. Therefore, the Indian Ocean was dependent on local intermediates for its supplies in these commodities. Often, mercantile Malay-speaking coastal populations appropriated this role, enhancing the wealth, status and prestige of their overlords and incorporating the latter's polities into more cosmopolitan, long-distance networks. The isolated communities responsible for the harvest of these spices and tree resins, too, depended on Malay and other coastal populations to ship and sell their produce abroad. As I have argued, the adoption of Sanskrit cultural elements by local elites fits well within the wider framework of cultural convergence - if not early globalisation - in this part of the world.

A further issue addressed in this study is the question of how people, crops and trade items were transported over the vast sea lanes connecting Southeast Asia with the wider Indian Ocean World. In the domain of ship-building, insular Southeast Asians contributed to the rich tradition of maritime transport that shaped the history of the Indian Ocean (and, therefore, of Eurasia). It has long been argued that seaworthy outrigger boats with sails hoisted from sprit spars have evolved in the waters of Southeast Asia and spread across the Indian Ocean as a result of interethnic contact. It now seems plausible that larger commercial vessels, constructed 
of edge-dowelled planks, were also invented in insular Southeast Asia and played important roles in the ancient commercial activities in the South China Sea and the Bay of Bengal. In both seas, local nautical traditions inspired, influenced and enriched each other. The active role of Malay (or more correctly: Malay-speaking) and other insular Southeast Asian seafarers in these dynamic processes of cross-fertilisation is reflected in the lexical data. Several languages of the Bay of Bengal, for example, adopted a Malay or Moken word for 'sail'. In other cases, lexical data are less capable of revealing cultural contact. The outrigger canoes of Madagascar and East Africa are almost identical in their design, but the specific terminology for parts of these vessels is almost entirely different in Malagasy and Swahili - as well as most other parts of the Indian Ocean World. It has become clear that the study of maritime vocabulary has its limitations. While historical linguistics can help us reconstruct the dispersal of nautical technology, cultural contact is by no means consistently reflected in the vocabularies of each speech community involved.

We are without conclusive evidence as to when Southeast Asian sailors started to ply the waters of the Indian Ocean. The presence of Southeast Asian tree crops and spices in the still sparse archaeological record of South Asia suggests that they were regularly crossing the Bay of Bengal by the $1^{\text {st }}$ mill. BCE. The attestation of cloves and sandalwood in the Sanskrit literature and the tentative finding of Sumatran camphor applied to an Egyptian mummy suggest an intensification of westward voyaging by the end of the $1^{\text {st }}$ mill. BCE. However, South Asia was not the end point for Southeast Asian sailors. They reached the island of Madagascar and settled there long before any of the world's better known civilisations could successfully undertake transoceanic journeys of comparable distance. It is not known whether they preferred to sail directly to Madagascar, stopping perhaps on the Maldives to obtain fresh supplies, or took the coastal route connecting South Asia, the Middle East and East Africa. The latter scenario is far from implausible in the light of their undeniable impact on each of these regions through the cultural, lexical and technological transmissions highlighted in this study. The strategically situated southern coast of India and the island of Sri Lanka functioned as important 
transit-marts, uniting east and west. Coastal South Asia - due to its wealth in local export products and access to trade communities from classical Europe, the Middle East, Southeast Asia and China - became the prime bustling hub of Indian Ocean commerce. As a result, commercial contacts with South Asia left a deep cultural impact on the first large-scale civilisations of Southeast Asia. Along the trading routes came religion, ritual, architecture, language and literature, disseminating Indian cultural elements across an area stretching from Central Asia to Indonesia.

The influence of insular Southeast Asian sailors and merchants in the Indian Ocean is widely reflected in the linguistic data. As we have seen, several loanwords from MalayoPolynesian languages are found in the languages of the Nicobar Islands, India, Sri Lanka, East Africa and, possibly, the Andaman Islands. These borrowings encompass the domains of maritime technology, agriculture, spices and trade commodities. Relatively little evidence has been found of lexical borrowing for economic commodities with a pan-Indian Ocean usage and distribution, such as corals, ivory, rhinoceros horns and sea cucumbers. In general, people would use inherited lexicon, rather than foreign loans, to refer to such well-known, endemic concepts. We have also seen that the Malay language was by far the most influential means of communication in Southeast Asia - as it is today - and that many cultural items not native to the region were disseminated through Malay-speaking people. Consequently, the Southeast Asian concepts dispersed across South Asia and other parts of the Indian Ocean were transmitted through Malays or sailors who used Malay as a lingua franca. Other insular Southeast Asian speech communities left their mark as well. We do not know whether they ventured into the Indian Ocean independently, although it seems likely that a large portion of the non-Malay communities were sailing under Malay patronage. We find several isolated examples of lexical transmissions from Malayo-Polynesian languages other than Malay in the Indian Ocean World, encouraging us to look for more. Swahili, for instance, has been influenced by Malagasy, whereas a small set of words in both languages may go back to the languages of South Sulawesi. Several speech communities of the Bay of Bengal display a modicum of loanwords 
transmitted through Moken, suggesting that the ancestors of this nowadays rather peripheral, maritime oriented speech community played an important role in the ancient trade networks between coastal and inland populations.

In several cases, the linguistic data tell us something about the relation between the donor and the recipient languages. If the latter adopts a loanword for a new concept, it is often taken from those who introduced it into the speech community. In the case of highly specialised items, such as nautical technology, there might have been an active teaching process involved. In an area as interconnected as the Indian Ocean, people have often learned from their neighbours, patrons or vassals to improve their own skills. Sailing technology, for example, seems to have spread from insular Southeast Asia to parts of the Southeast Asian mainland, Sri Lanka and the Maldives, an inference based in part on the distribution of words for 'sail'. If, on the other hand, the terminology in the recipient society is of a descriptive character, the donor culture may have stimulated local imitations or innovations without such a teaching process. It has also been pointed out that some languages are markedly hostile towards lexical borrowing, which obscures the degree of cultural contact. In addition, we have encountered cases where the presence of an indigenous word whose meaning can be stretched to cover the meaning of a new concept obviates the need to adopt a loanword. Consequently, the foreign acquisition of some cultural items remains unnoticed by the linguist. These factors make it especially difficult to shed light on the diffusion of tubers, plantains and other foodstuffs across the Indian Ocean in the absence of archaeobotanical evidence, since speech communities would very often use the name of a similar looking familiar plant.

By analysing how different languages treat their foreign vocabulary, we are able to increase our understanding of the socio-linguistic nature of speech communities. Returning to the main research question of this study, how historical linguistics can help us to reconstruct the presence of ancient Southeast Asian seafarers in the Indian Ocean, several important notions need to be borne in mind. Some languages of the Indian Ocean World have been very receptive of lexical borrowing, whereas others have not. The Malay language was (and is) 
spoken by many people from different ethno-linguistic backgrounds. Its role as a trade oriented lingua franca triggered the large-scale adoption of external vocabulary. Sometimes, this process has even led to the replacement of indigenous vocabulary denoting local concepts by foreign loans, as we have seen with the words for 'gold', 'sandalwood', 'clove', 'nutmeg' and 'Java long pepper'. The opposite tendency can be observed in Tamil and Arabic, which tend to prefer an indigenous neologism over a loanword, even if the concept referred to is undoubtedly introduced. The Sanskrit language occasionally permits loanwords alongside inherited vocabulary or indigenous creations, possibly because its literary and poetical ambitions require a high degree of synonymy. Nevertheless, we have seen that Sanskrit and other Indian languages often "correct" their foreign vocabulary to make the words look more indigenous. The examples we have come across in this study are listed in Table 5:

Table 5: OIA back-formations

\begin{tabular}{|c|c|c|c|}
\hline literary form & earlier form & source & original meaning \\
\hline ārdraka & allaya & halia (Malay) & 'ginger' \\
\hline karcūra & kaccūra & $k \partial(n) c u r$ (Malay) & 'aromatic ginger' \\
\hline karṇa (Malayālam, Kannaḍa) & kānā & cana (Portuguese) & 'tiller' \\
\hline karpūra & kappūra & kapur (Malay) & 'camphor' \\
\hline lakāra (Pali) & layara & layar(Malay) & 'sail' \\
\hline nimbū & $? \operatorname{limū}$ & limau (Malay) & 'lime’ \\
\hline pūga & pūa & *buaq (Malayo-Polynesian) & 'areca nut' \\
\hline rājāvarta & ?rājuvarta & lāžuward (Farsi) & 'lapis lazuli' \\
\hline śrnigavera & singivēra & ${ }^{*}$ cinki + * vēr(Dravidian) & 'ginger' \\
\hline $\operatorname{ti}(v) r a$ & ?timara & $\operatorname{tim}(\partial)$ rah (Malay) & 'tin' \\
\hline
\end{tabular}

A general methodological caveat has manifested itself through the juxtaposition and comparison of lexical data from unrelated languages: the danger of relying solely and uncritically on hypothetical reconstructions. Occasionally, linguists attribute high degrees of antiquity to cultural vocabulary on account of perceived regular sound correspondences between attestations in genetically related languages. Subsequently, a hypothetical protoform is reconstructed, erroneously pushing these words back to the remotest common linguistic ancestors of the speech communities involved. If such chronological inferences are recklessly taken over by historians or archaeologists, they risk piling one questionable assumption on top 
of another. After comparing a large number of specific lexical items in unrelated language families and demonstrating connections between these attestations in form and meaning, it becomes clear that lexical borrowing and back-formation are possible scenarios even if a word exhibits all the historico-phonological characteristics of an indigenous form. If the transmission took place at an early stage of language development, the resultant forms would display the exact same regular sound correspondences attested in inherited vocabulary. Therefore, hypothetical reconstructions are exactly what they are: hypotheses that can be disproven based on linguistic and, occasionally, extra-linguistic lines of evidence.

Another important contribution towards a better understanding of the speech communities inhabiting the ancient Indian Ocean World is found in the domain of sociolinguistics. Ever since the spread of Hinduism beyond its northwest Indian homeland, the social attitudes towards Sanskrit in South and Southeast Asia became similar to those towards Latin in medieval Europe or Arabic in the Islamic World. The interethnic trade networks of the Indian Ocean became inseparable from religion and ritual, as is illustrated by the transoceanic incense trade and the diffusion of the Sanskrit words for 'sandalwood', 'nutmeg', 'Java long pepper' and other products. More generally, speech communities were keen to adopt vocabulary from "high" languages with extensive literary-religious traditions, such as Sanskrit and Arabic, as this was perceived to be enrichment to their mother tongue. Loanwords from "low", unwritten trade languages, on the other hand, were often regarded as corruptions. This explains why people did not always adopt a vernacular word for a concept introduced by insular Southeast Asian (or East African) merchants and preferred an indigenous creation instead. Nevertheless, it is very likely that the colloquial languages and dialects of South Asia, the Middle East and East Africa adopted more Malay and other insular Southeast Asian loanwords than could be documented in this study and in previous scholarship. At a time when contact with insular Southeast Asia was still regular, the quantity of loanwords - and perhaps even regional pidgin languages - in South Asia, East Africa and perhaps the Middle East must have been much higher. This explains why we have encountered a Malay swearword adopted into at 
least three Indian Ocean languages. Similar examples may have been lost through time, since the words of illiterate sailors would have rarely made it into the dictionaries and other textual accounts of literate societies. Even at present, the extensive maritime vocabularies of our remaining sea- and coast-dwelling populations tend to be poorly documented.

It makes sense to assume that certain crops, products and techniques travelled together. To my knowledge, previous authors did not detect or analyse this important aspect of biological vis-à-vis cultural diffusion sufficiently. As has been pointed out in Chapter 7, traditional watercraft incorporated various timbers and vegetal products that potentially moved around the Indian Ocean as a package. The coconut tree was especially important, as its fibres were used for plank-sewing, its fruits would provide nutrition during long seaborne journeys and practically every other part of the tree could be manufactured into something useful. Other trees may have been translocated chiefly for their timber. The dispersal of cotton and other textiles may be related to the adoption of cloth sails (and, of course, developments in attire), replacing the more rudimentary palm leaf sails. For obvious reasons, local rulers and others in power were particularly interested in these technological innovations and often possessed the capital to implement them. This explains why commercial and/or state-owned sailing ships tend to be bigger and more advanced than small-scale fishing craft, which is normally more traditional in design. For the same reason, isolated regions irrelevant for global trade are often technologically less developed - an observation that still holds true in our modern world.

This study has demonstrated that the introduction of Southeast Asian spices, food stuffs, maritime technology, and trade commodities has revolutionised the societies of the Indian Ocean World. Conversely, contact with South Asia, China and other regions enabled Southeast Asian seafaring populations, in particular the Malay-speaking communities, to gain substantial economical surpluses, manufacture better ships, improve metallurgical and agricultural practices and establish efficiently structured harbour polities. Their new-found hegemony was often consolidated through a new religion. Both Hinduism and Buddhism were more cosmopolitan and provided access to wider networks than any of the pre-existing local 
religions. Similar developments took place elsewhere in the Indian Ocean. The Swahili coast, for example, seems to have functioned as an entrepôt between the Middle East and the African hinterland from antiquity onwards. The fact that East African slaves made their way to the Chinese court from at least the mid-1st C. CE - typically transported aboard insular Southeast Asian ships - demonstrates the interconnectedness of the Indian Ocean by that time. Next to the commerce in spices and precious metals, slave trade appears to have been one of the most profitable enterprises in the ancient Indian Ocean. We can see people of diverse ethnolinguistic backgrounds participate in it.

This study has called attention to several linguistic and extra-linguistic clues to ancient Southeast Asian elements in the Indian Ocean World. Inevitably, numerous questions remain unanswered at this stage of knowledge. Ongoing and future archaeobotanical research is hoped to shed more light on the arrival of Southeast Asian food crops in East Africa and the Asian mainland, especially on the time depth of translocation. In this regard, phylogenetic data on tubers and banana cultivars will provide more solid evidence about the dispersal patterns of these crops than linguistic data could do. After all, as has been pointed out in Chapter 5, many languages use the names of endemic plants to refer to similar looking introduced cultivars. The archaeological record of especially the East African coast and Madagascar is still fragmentary and incomplete, although this is slowly starting to change. The extent to which various Indian Ocean island groups, such as the Seychelles (including the Amirantes), the Mascarenes (including Mauritius and Réunion) and the Chagos Islands, have been used as stopover points on the way to Madagascar is still an open question. Archaeological and other research has failed so far to confirm the possibility of human impact on these islands predating their European discovery, but future research may perhaps do so.

This study has cast considerable light on the impact of insular Southeast Asia on other societies in the Indian Ocean World and its methodology can be used to (re-)examine the impact of other communities on their neighbours. New perspectives on the relations between South India and various parts of Southeast Asia, for example, remain to be elucidated through 
an exhaustive lexical analysis of Tamil and other South Indian loanwords in mainland and insular Southeast Asian languages, such as Khmer, Thai, Javanese and the Batak languages of North Sumatra. The serendipitous encounters of such borrowings throughout the present study encompass the domains of plants, animals, technological items and cultural vocabulary. Further analysis lies beyond its scope, but much more can be done in the future. I hope to be able to make contributions to this exciting field from this time forth. A study of plants and plant names that travelled from South to Southeast is particularly long overdue. The strategies employed in this study can equally well be applied to bolster our knowledge of possible Malay and Philippine influence on the indigenous languages of Taiwan. In addition, it has been beyond the purview of this study to clarify the role of land-based communities in the dispersal of plants, trade commodities and material culture between South Asia, Southeast Asia and China. New and comparative insights into the poorly documented languages of Northeast India, Myanmar and Yunnan are a prerequisite to addressing these issues. In this regard, positive developments in the democratisation of Myanmar and the relative stability in Northeast India will hopefully provide better opportunities to understand the prehistory of this part of the world in the foreseeable future. Finally, a thorough study on the remaining languages of the Andamanese, Nicobarese and Moken groups in the Bay of Bengal is of utmost scientific urgency to gain insights into some of the most unique and threatened cultures of the Indian Ocean. Each of these endeavours will present us with additional puzzle pieces to reconstruct our world's long and exciting history of maritime activity, interethnic communication and cultural contact. 


\section{Appendix 1: Linguistic data}

Table 6: Malay loanwords across the Indian Ocean

\begin{tabular}{|c|c|c|}
\hline borrowed word & attestations & notes \\
\hline $\begin{array}{l}\text { Old Malay sāmvau } \\
\text { 'merchant ship' }\end{array}$ & $\begin{array}{l}\text { Binongko sambo 'k.o. boat, topsail';203 Malagasy } \\
\text { sambo 'a ship, a large boat'; Swahili (Kingozi dial.) } \\
\text { sambu 'boat'204 }\end{array}$ & $\begin{array}{l}\text { cf. Old Khmer (pre- } \\
\text { Angkorian) samivo 'ocean- } \\
\text { going junk', (Angkorian) } \\
\text { sambau saṁhveva id. }\end{array}$ \\
\hline $\begin{array}{l}\text { Malay (dial.) † sirih buah } \\
\text { 'betel variety (Piper betle } \\
\text { var. Siriboa)' }\end{array}$ & Sinhala siribō 'betel variety' & $\begin{array}{l}\text { Transmission probably } \\
\text { during colonial period }\end{array}$ \\
\hline $\begin{array}{l}\text { Malay †Jawa 'Jawa (name of } \\
\text { a Sumatran Malay polity)' }\end{array}$ & 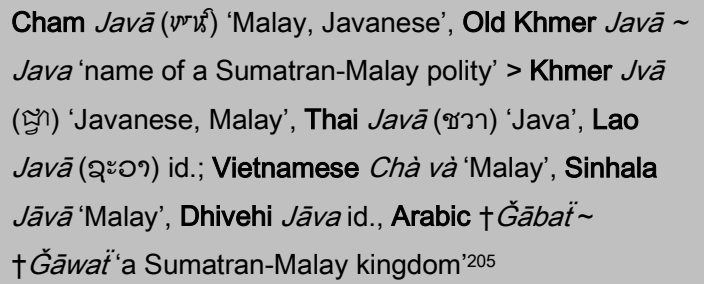 & $\begin{array}{l}\text { Ultimately from OIA * yáva } \\
\text { 'barley (Hordeum vulgare)', } \\
\text { MIA *java id. }\end{array}$ \\
\hline $\begin{array}{l}\text { Malay † manggista } \\
\text { manggusta 'mangosteen } \\
\text { tree (Garcinia } x \\
\text { mangostana)' }\end{array}$ & $\begin{array}{l}\text { Malay (Ambon dial.) manggustan, Tamil manikustān } \\
\text { vañkustān, Dhivehi mabustān, Końkaṇi mangustãv } \\
\text { id. }{ }^{206}\end{array}$ & $\begin{array}{l}\text { (Mahdi 2007:142-3); } \\
\text { probably through Portuguese } \\
\text { mangostão id. }\end{array}$ \\
\hline $\begin{array}{l}\text { Malay †manggus } \\
\text { 'mangosteen tree (Garcinia } x \\
\text { mangostana)' }\end{array}$ & 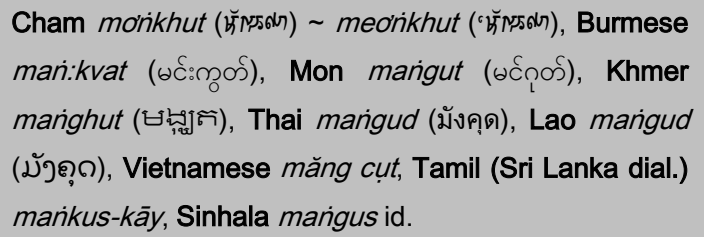 & $\begin{array}{l}\text { Tamil (Sri Lanka dial.) } k a ̄ y= \\
\text { 'fruit' }\end{array}$ \\
\hline Malay †tim(ə)rah 'tin' & $\begin{array}{l}\text { Sanskrit } t i(v) r a \text { 'tin, steel, iron', Sinhala tīvra 'tin'; } \\
\text { Dhivehi timara 'tin, lead' }\end{array}$ & $\begin{array}{l}\text { (cf. Lafeber 1922:138, Mills } \\
\text { 1975a/2:901) }\end{array}$ \\
\hline $\begin{array}{l}\text { Malay Aceh (name of an } \\
\text { area in North Sumatra) }\end{array}$ & Dhivehi $A s \bar{l}$, Tamil $A c c i$ id. & \\
\hline $\begin{array}{l}\text { Malay aduh adu(ha)i } \\
\text { 'exclamation of pain' }\end{array}$ & Dhivehi $\operatorname{add} \bar{o}(i) \sim$ addōyē 'exclamation, cry of pain' & \\
\hline $\begin{array}{l}\text { Malay aturan 'arrangement, } \\
\text { order' }\end{array}$ & Dhivehi aturani 'to arrange in order' & \\
\hline Malay ayam 'chicken' & Teressa haijom 'chicken', Car Nicobar haijam id. & \\
\hline Malay bakul 'basket (gen.)' & $\begin{array}{l}\text { Swahili bakuli 'basin, deep dish, tureen' > Malagasy } \\
\text { bakoly 'bowl', (Sakalava dial.) bakúli 'porcelain, plate', } \\
\text { (Mayotte dial.) bakòly 'bowl' }\end{array}$ & $\begin{array}{l}\text { Possibly from Arabic } \\
\text { būqäl(ä̈) 'vessel without } \\
\text { handles, mug' }\end{array}$ \\
\hline $\begin{array}{l}\text { Malay Bangka (name of an } \\
\text { island famous for its tin) }\end{array}$ & $\begin{array}{l}\text { Tamil vanikam 'lead, tin, zinc, etc.' > late Sanskrit } \\
\text { vaniga 'tin or lead', Malayālam vanigam 'lead, tin, } \\
\text { tincal', Kannaḍa vaniga 'tin, lead', Sinhala vaniga 'tin', } \\
\text { Hindi bang 'calx of tin given internally as an } \\
\text { aphrodisiac' }\end{array}$ & (Obdeijn 1943:707) \\
\hline
\end{tabular}

\footnotetext{
203 Liebner (1988:11).

204 Simon (1988:309).

205 Laffan (2005).

206 Dalgado (1913:103).
} 


\begin{tabular}{|c|c|c|}
\hline borrowed word & attestations & notes \\
\hline $\begin{array}{l}\text { Malay Barus 'Barus (place } \\
\text { famous for its camphor)' }\end{array}$ & 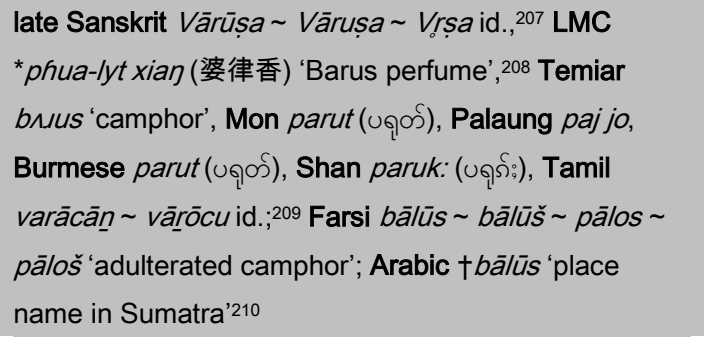 & LMC *xiaク (香) 'perfume' \\
\hline Malay bawang 'onion' & 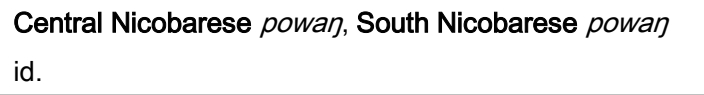 & \\
\hline $\begin{array}{l}\text { Malay bəbingka 'cake made } \\
\text { of rice flour, coconut-milk, } \\
\text { egg and palm-sugar' }\end{array}$ & Końkaṇ̄ bebinka 'k.o. layered pudding' & $\begin{array}{l}\text { Transmission during colonial } \\
\text { period }\end{array}$ \\
\hline $\begin{array}{l}\text { Malay bəlacan 'shrimp- } \\
\text { paste' }\end{array}$ & 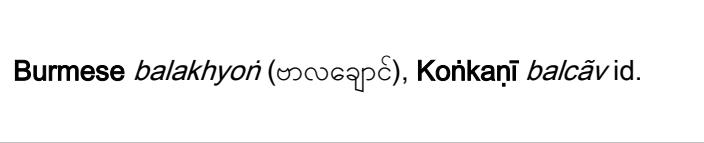 & $\begin{array}{l}\text { (Dalgado 1913:19); probably } \\
\text { through Portuguese } \\
\text { bal(i)chão 'shrimp-paste' }\end{array}$ \\
\hline $\begin{array}{l}\text { Malay bəlimbing 'ridged } \\
\text { longitudinally, Averrhoa spp., } \\
\text { etc.' }\end{array}$ & $\begin{array}{l}\text { Tamil pilampi pilimpi 'bilimbi (Averrhoa bilimbi)', } \\
\text { Malayālam vilimbi, Kannaḍa bilimbi, Telugu biliñci- } \\
\text { cețtu, Tulu bimbali bimbili bimbuli, Hindi bilībī, } \\
\text { Marāțhī bilambi bimbla 'bilimbi tree', bimblem 'bilimbi } \\
\text { fruit', Końkaṇī bilambi bimbli 'bilimbi tree', bilambem } \\
\text { bimblem 'bilimbi fruit',;11 Sinhala bilin bilim 'bilimbi', } \\
\text { Dhivehi bilamagu bilimagu, Swahili bilimbi id. }\end{array}$ & $\begin{array}{l}\text { Transmission possibly during } \\
\text { colonial period, cf. } \\
\text { Portuguese bilimbi }(m) \text { id.; } \\
\text { Telugu cettu = 'tree' }\end{array}$ \\
\hline Malay Botawi (Batavia) & $\begin{array}{l}\text { Tamil vattāyi vattāvi 'Batavian orange', Hindi māhtābi } \\
\text { 'a sort of muskmelon', Bengali bātābi 'the shaddock, } \\
\text { the pompelmoose, the pummelo', Dhivehi batāvi } \\
\text { 'Javanese' }\end{array}$ & $\begin{array}{l}\text { (cf. Bonavia 1890:30-1); } \\
\text { Hindi form due to folk- } \\
\text { etymology through } \\
\text { association with mahtāb-ī } \\
\text { 'like the moon'; transmission } \\
\text { during colonial period; < } \\
\text { Dutch Batavia }\end{array}$ \\
\hline $\begin{array}{l}\text { Malay buaya 'crocodile; } \\
\text { scoundrel', Malagasy voay } \\
\text { 'crocodile' }\end{array}$ & $\begin{array}{l}\text { Swahili mbuai 'wild, brutal', (Unguja dial.) mbwayi } \\
\text { 'savage', Comorian vwayi 'crocodile' }\end{array}$ & (Walsh 2012) \\
\hline $\begin{array}{l}\text { Malay buli-buli 'a small flask } \\
\text { or bottle' }\end{array}$ & Dhivehi bulibuli 'small glass bowl with lid' & \\
\hline
\end{tabular}

207 Obdeijn (1941a), Prakash (1964:85), Paranavitana (1966a:19ff.), Wolters (1967:186).

208 Gerini (1909:440), Wolters (1967:361).

209 Obdeijn (1941a:326 fn. 1).

210 Only attested in the Kitāb al-Masālik w'al-Mamālik ('Book of Roads and Kingdoms') by lbn Hordādbeh and later works based thereon (Tibbetts 1979:141-3).

211 Dalgado (1913:28). 


\begin{tabular}{|c|c|c|}
\hline borrowed word & attestations & notes \\
\hline Malay bunga lawang 'cloves' & 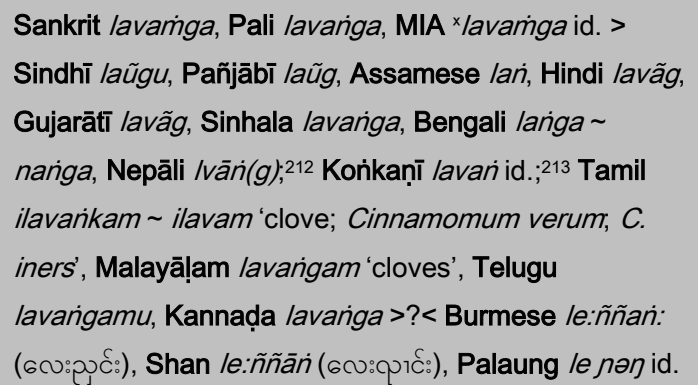 & $\begin{array}{l}\text { (cf. Tuuk 1897-1912/3:720, } \\
\text { Lafeber 1922:144, Gonda } \\
\text { 1932:326-9, 1973:24, Mahdi } \\
\text { 1994/1:188); Malay bunga = } \\
\text { 'flower' }\end{array}$ \\
\hline Malay burit 'buttocks' & Dhivehi buri 'anus, etc.' & \\
\hline Malay cabai 'pepper' & $\begin{array}{l}\text { Central Nicobarese komeanta-tfape 'Capsicum } \\
\text { baccatum' }\end{array}$ & $\begin{array}{l}<\text { OIA }{ }^{\times} \text {cavī } \sim \text { 'cavi 'Java long } \\
\text { pepper (Piper retrofractum)'; } \\
\text { Central Nicobarese } \\
\text { komeanta = 'chilli' }\end{array}$ \\
\hline Malay cəngkeh 'cloves' & $\begin{array}{l}\text { Central Nicobarese fis-tfingi, Southern Min (Zhangzhou } \\
\text { dial.) tsîng khik (情客) id. }{ }^{214}\end{array}$ & $\begin{array}{l}\text { Probably from a Chinese } \\
\text { source; perhaps Southern } \\
\text { Min (?) teng-gê (丁芽) 'nail- } \\
\text { shaped bud or sprout' } \\
\text { (Pijnappel 1875:111, } \\
\text { Schlegel 1891:403, Mahdi } \\
\text { 2007:71) }\end{array}$ \\
\hline $\begin{array}{l}\text { Malay damar'dammar, } \\
\text { resin, torch' }\end{array}$ & 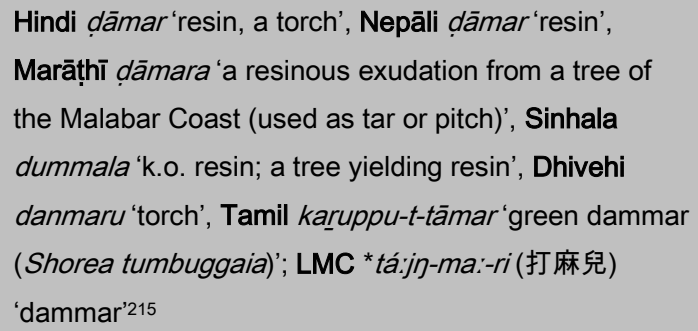 & $\begin{array}{l}\text { Tamil karuppu = 'blackness, } \\
\text { ambergris, ebony' }\end{array}$ \\
\hline $\begin{array}{l}\text { Malay dodo/ 'toffee-like } \\
\text { sweetmeat' }\end{array}$ & Końkaṇi dodol, Sinhala dodo/id. & $\begin{array}{l}\text { Transmission during colonial } \\
\text { period }\end{array}$ \\
\hline $\begin{array}{l}\text { Malay duit 'copper coin, } \\
\text { money' }\end{array}$ & Central Nicobarese rut' 'copper, copper coin' & $\begin{array}{l}\text { Transmission during colonial } \\
\text { period; < Dutch duit 'type of } \\
\text { coin' }\end{array}$ \\
\hline
\end{tabular}

212 Turner (1966 \#10977).

213 Dalgado (1913:66).

${ }^{214}$ Lafeber (1922:119-20).

215 Hirth \& Rockhill (1912:200 n.). 


\begin{tabular}{|c|c|c|}
\hline borrowed word & attestations & notes \\
\hline $\begin{array}{l}\text { Malay dulang 'wooden tray, } \\
\text { base or platter' }\end{array}$ & $\begin{array}{l}\text { Acehnese dulang 'twisted flat wooden dish on pedestal } \\
\text { (used as a tray or a table for the processing of silver } \\
\text { thread)', Karo Batak dulang 'circular pedestal made of } \\
\text { rattan or metal', Javanese dulang 'round wooden tray', } \\
\text { Balinese dulang 'a wooden tray on which to put dishes } \\
\text { or cups', Sundanese dulang 'a hollowed wooden bowl', } \\
\text { Tagalog †dolang 'to remove metal from the mines; low } \\
\text { dining table', Cebuano dúlang 'round wash basin dug } \\
\text { out from a single piece of wood', Dhivehi dolan̆gu } \\
\text { 'large, metal tray for food' }\end{array}$ & 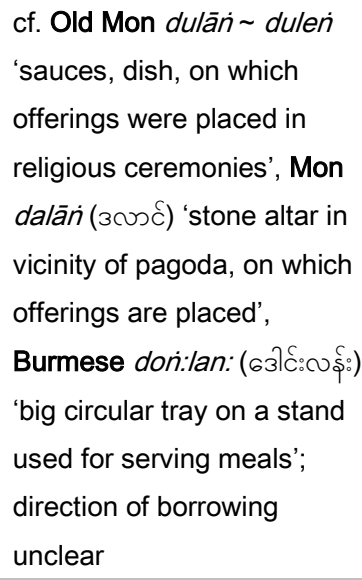 \\
\hline $\begin{array}{l}\text { Malay durian 'durian (Durio } \\
\text { zibethinus)' }\end{array}$ & 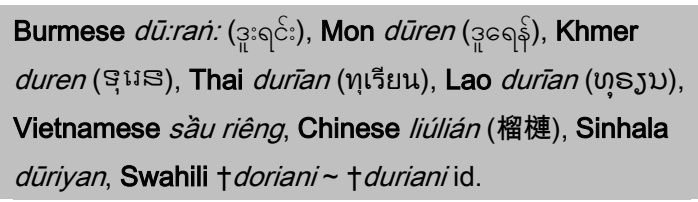 & \\
\hline $\begin{array}{l}\text { Malay gadis 'marriageable } \\
\text { girl' }\end{array}$ & Sinhala gætissi 'young girl' & (Jayasuriya 2002:54-7) \\
\hline $\begin{array}{l}\text { Malay gala-gala 'a mixture of } \\
\text { dammar and pitch used for } \\
\text { caulking boats' }\end{array}$ & $\begin{array}{l}\text { Hindi galgal'a mixture of lime and linseed oil forming a } \\
\text { kind of mortar impenetrable to water', Marāțhī galagala } \\
\text { 'the viscous matter obtained from certain plants (from } \\
\text { Cordia myxa etc.)' >?< late Sanskrit kalakala 'the } \\
\text { resinous exudation of Shorea robusta' >?< Central } \\
\text { Nicobarese 2ol-nala 'to pitch (of a ship)' }\end{array}$ & $\begin{array}{l}\text { < Sanskrit gala 'oozing; } \\
\text { resin' }\end{array}$ \\
\hline $\begin{array}{l}\text { Malay gambir 'gambir } \\
\text { (Uncaria gambir)' }\end{array}$ & Tamil kampīrid. & \\
\hline Malay gəli-gəli 'ticklish' & Dhivehi giligili 'tickling' & \\
\hline $\begin{array}{l}\text { Malay gətah gambir 'gambir } \\
\text { sap' }\end{array}$ & Tamil katta-k-kāmpu id. & (Burkill 1966/2:2293) \\
\hline $\begin{array}{l}\text { Malay gubah 'wearing in the } \\
\text { hair (as a flower or jewelled } \\
\text { ornament is worn)' }\end{array}$ & Swahili kuba guba 'packet of aromatic leaves' & $\begin{array}{l}\text { (Walsh forthcoming); } \\
\text { ultimately from OIA * guppha } \\
\text { 'something strung together' }\end{array}$ \\
\hline Malay gudang 'warehouse' & 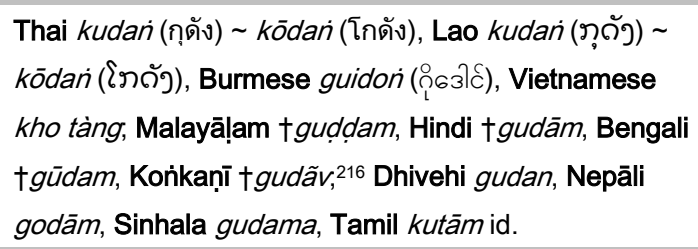 & $\begin{array}{l}\text { Transmission during colonia } \\
\text { period; probably ultimately } \\
\text { from a Dravidian source (cf. } \\
\text { Burrow \& Emenau } 1984 \\
\# 1525 \text { ) }\end{array}$ \\
\hline Malay gula-gula 'sweets' & Hindi gulgulā 'sweet cakes fried in butter' & \\
\hline
\end{tabular}

${ }^{216}$ Dalgado (1913:87). 


\begin{tabular}{|c|c|c|}
\hline borrowed word & attestations & notes \\
\hline Malay halia 'ginger' & $\begin{array}{l}\text { MIA *allaya 'fresh ginger' > Marāțhī ālẽ alẽ 'fresh } \\
\text { ginger, ginger plant', Kōnikan̄i āllẽ 'ginger';217 Kannaḍa } \\
\text { alla, Tamil allam id., Telugu allamu 'green ginger'; > } \\
\text { late Sanskrit *ārdraka 'ginger in its undried state' > Pali } \\
\text { allaka 'coriander (Coriandrum sativum)'; Pañjābī addāa } \\
\text { 'ginger', Nepāli aduwā 'dried ginger', Bengali ādā } \\
\text { 'ginger', Hindi ādā, Gujarātĩ ādũ id.;218 Sinhala adda } \\
\text { 'green ginger' }\end{array}$ & $\begin{array}{l}\text { Sanskrit attestation the result } \\
\text { of back-formation }\end{array}$ \\
\hline Malay hanyut 'type of coat' & $\begin{array}{l}\text { Central Nicobarese kafut 'coat', South Nicobarese } \\
\text { kanut, Car Nicobar enut, Chaura hanut id. }\end{array}$ & $\begin{array}{l}\text { Cf. Malay baju hanyut } \\
\text { 'frogged coat worn loosely } \\
\text { (i.e. unbuttoned) by Chinese' }\end{array}$ \\
\hline $\begin{array}{l}\text { Malay hulu 'head, upper } \\
\text { portion' }\end{array}$ & Sinhala olu-va 'head' & $\begin{array}{l}\text { (Gunasékara 1962:382, } \\
\text { Jayasuriya 2002:54-7) }\end{array}$ \\
\hline $\begin{array}{l}\text { Malay Ja(ya)karta (the } \\
\text { modern "Jakarta") }\end{array}$ & $\begin{array}{l}\text { Hindi cakotara 'a fruit of the lime kind, a citron; } \\
\text { pompelmoose, shaddock', Marāṭ̂̄ cakōtrā cakōtra 'a } \\
\text { fruit, pompelmoose or shaddock', Pañjābī cakotrá 'the } \\
\text { name of a large fruit of the citron kind, the shaddock or } \\
\text { pummelo'; Nepāli cakhetro sanikhetro sanikhatra } \\
\text { 'pummelo', Bengali †cākhantrā 'orange'219 }\end{array}$ & $\begin{array}{l}\text { (cf. Bonavia 1890:30-1); } \\
\text { presumably via Dutch } \\
\text { Jacatra }\end{array}$ \\
\hline Malay jarum 'needle' & $\begin{array}{l}\text { Central Nicobarese tfarum, South Nicobarese tfadup, } \\
\text { Teressa kiarum, Car Nicobar tfarum, Chaura tfarum id. }\end{array}$ & \\
\hline Malay jung 'sea-going ship' & 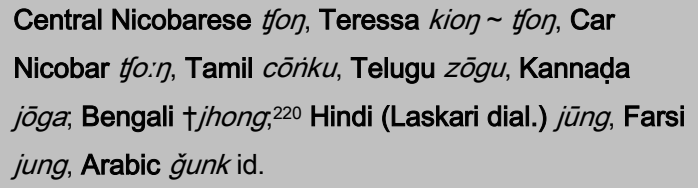 & $\begin{array}{l}\text { Probably ultimately from a } \\
\text { Chinese source }\end{array}$ \\
\hline Malay kacang 'pea, bean' & $\begin{array}{l}\text { Swahili karanga kalanga 'peanut (Arachis } \\
\text { hypogaea)' }\end{array}$ & $\begin{array}{l}\text { Transmission during colonial } \\
\text { period (Teubner 1974:635) }\end{array}$ \\
\hline $\begin{array}{l}\text { Malay kajang 'mat-protection } \\
\text { against rain; mat-awning' }\end{array}$ & $\begin{array}{l}\text { Toba Batak hajang 'a cottage in the field to spend the } \\
\text { night', Angkola-Mandailing Batak hajang 'k.o. mat, } \\
\text { made of pandan etc.', Moken (Myanmar var.) kajang } \\
\text { 'roof, cover of boat', Tausug kajang id., Thai krajǣin } \\
\text { (กระแชง) 'removable convex roofing sheet for boat } \\
\text { transporting grain', Tamil kacariku 'wild date-palm; } \\
\text { stalk, as of the date-leaf used in making plaited } \\
\text { baskets'; karicaniku 'temporary roof of coconut leaves } \\
\text { put up in an Indian raft for protection against } \\
\text { inclemencies of weather' }\end{array}$ & $\begin{array}{l}\text { Presumably from Javanese } \\
\text { kajang 'roof of dried palm } \\
\text { leaves' }\end{array}$ \\
\hline Malay kakaktua 'cockatoo' & $\begin{array}{l}\text { Thai kratûa (กระตั้ว), Bengali kākātuỹā, Hindi kākātūā, } \\
\text { Oṛiyā kākatuā, Marāṭī kākākavvā, Tamil kākkattuvān̄, } \\
\text { Dhivehi takatuvāid. }\end{array}$ & \\
\hline
\end{tabular}

217 Turner (1966 \# 1341).

218 Turner (1966 \# 1341).

219 Turner (1961:163).

220 Greenhill (1957:204). 


\begin{tabular}{|c|c|c|}
\hline borrowed word & attestations & notes \\
\hline $\begin{array}{l}\text { Malay kangkung 'water } \\
\text { spinach (Ipomoea aquatica)' }\end{array}$ & Sinhala kankun, Dhivehi kankun id. & \\
\hline Malay kapur 'lime, calcium' & $\begin{array}{l}\text { PMK ×knpur 'lime', Shom-Pen kabeu id., Thai pūn (ปูน) } \\
\text { 'lime; mortar', Lao pūn (ปูบ) 'chalk, lime'; LMC *kúə̆- } \\
\text { pun (古賁) 'lime (for betel chewing)'221 }\end{array}$ & (Mahdi 1999b:217, 2010:7) \\
\hline $\begin{array}{l}\text { Malay kapur Barus } \\
\text { 'camphor' }\end{array}$ & $\begin{array}{l}\text { Lao kabūn (ภะบูบ), MIA ×kappūra > late Sanskrit } \\
\text { karpūra id. }\end{array}$ & $\begin{array}{l}\text { (cf. Tuuk 1897-1912/2:291, } \\
\text { Kern 1871a:81, Yule \& } \\
\text { Burnell 1903:151, Fokker } \\
\text { 1910:567, Lafeber 1922:142, } \\
\text { Schoff 1922:362-3, Gonda } \\
\text { 1973:23-4, Mahdi } \\
\text { 1994/1:191, 1999b:216ff.); } \\
\text { Malay Barus = 'Barus (place } \\
\text { famous for its camphor)'; late } \\
\text { Sanskrit attestation } \\
\text { presumably a back-formation }\end{array}$ \\
\hline $\begin{array}{l}\text { Malay kayu putih 'cajuput } \\
\text { tree (Melaleuca cajuputi)' }\end{array}$ & 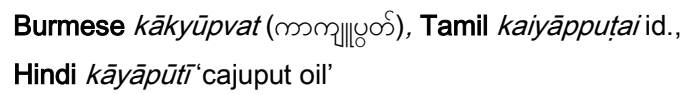 & \\
\hline Malay kəladi 'taro' & $\begin{array}{l}\text { Arabic †kalārī'a certain tuber', Swahili ki-azi 'potato', } \\
\text { Comorian shi-hazi 'yam', Tete mu-razi 'sweet potato', } \\
\text { Nyanja chi-lazi chi-razi 'yam' }\end{array}$ & $\begin{array}{l}\text { (Meinhof 1919-20:150-1, } \\
\text { Krumm 1940:124-5) }\end{array}$ \\
\hline $\begin{array}{l}\text { Malay kəncur 'aromatic } \\
\text { ginger (Kaempferia galanga)' }\end{array}$ & 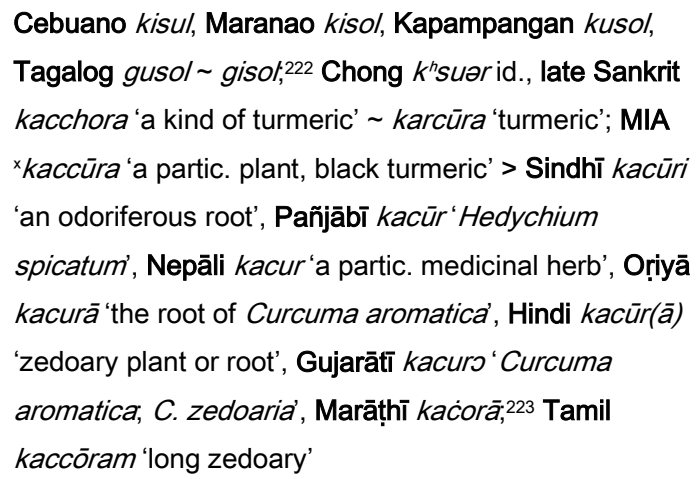 & (cf. Lafeber 1922:141-2) \\
\hline $\begin{array}{l}\text { Malay } k \text { ra(h)i 'a sort of } \\
\text { melon or cucumber' }\end{array}$ & Dhivehi karā kareak 'watermelon (Citrullus lanatus)' & \\
\hline Malay kərbau 'water buffalo' & Central Nicobarese kapo 'cow', Teressa krebo id. & $\begin{array}{l}\text { Ultimately from a Mon-Khmer } \\
\text { source }\end{array}$ \\
\hline Malay kəris 'k.o. dagger' & 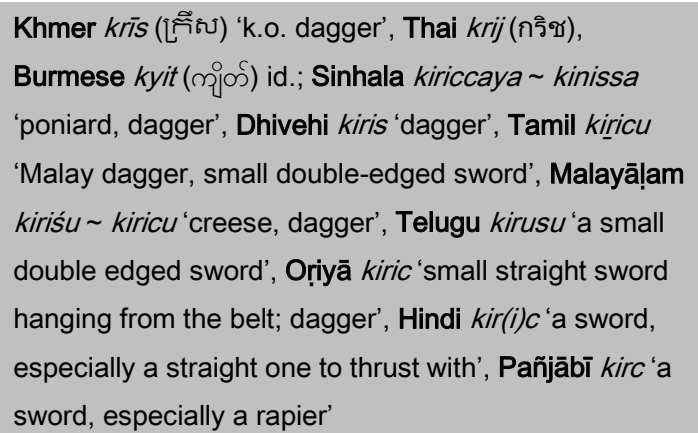 & \\
\hline
\end{tabular}

221 Groot (1894:266-7).

222 Madulid (2001/2:171).

223 Turner (1966 \#2828). 


\begin{tabular}{|c|c|c|}
\hline borrowed word & attestations & notes \\
\hline $\begin{array}{l}\text { Malay kətapang 'Indian } \\
\text { almond ( Terminalia } \\
\text { catappa)' }\end{array}$ & $\begin{array}{l}\text { Malagasy hatafa, (Antankarana dial.) antafa, } \\
\text { (Betsimisaraka dial.) antafa(na), Tamil kattāppu, } \\
\text { Sinhala kotțambāid. }\end{array}$ & $\begin{array}{l}\text { Borrowing into Tamil and } \\
\text { Sinhala presumably through } \\
\text { Creole Portuguese katapa id. } \\
\text { (cf. Schuchardt 1891a:140, } \\
\text { Mahdi 2007:106) }\end{array}$ \\
\hline $\begin{array}{l}\text { Malay kətela 'sweet potato } \\
\text { (Ipomoea batatas)' }\end{array}$ & Sinhala kitala 'k.o. yam' & $\begin{array}{l}\text { (Sannasgala 1976:104-5); } \\
\text { transmission during colonial } \\
\text { period < Malay ubi kastela } \\
\text { 'Spanish tuber' }\end{array}$ \\
\hline $\begin{array}{l}\text { Malay kota 'fortified place; } \\
\text { city' }\end{array}$ & $\begin{array}{l}\text { Javanese kuțo 'surrounding wall, fort; town, city'; } \\
\text { Tagalog †kúta 'fortress', Cebuano †kota, Toba Batak } \\
\text { huta 'village, city', Swahili mkuta 'stone wall', Comorian } \\
\text { kura 'boundary, border, limitation, fence', uhura 'brick } \\
\text { wall', Malagasy (Mayotte dial.) kòra 'wall' }\end{array}$ & < OIA *kōtta 'fort' \\
\hline Malay kucing 'cat' & Central Nicobarese kotfin, Shom-Pen tị id. & \\
\hline Malay labu 'gourd' & Central Nicobarese lapu 'pumpkin' & $\begin{array}{l}\text { Transmission during colonial } \\
\text { period; ultimately from } \\
\text { Sanskrit alābu 'the bottle- } \\
\text { gourd' }\end{array}$ \\
\hline Malay lada 'pepper' & $\begin{array}{l}\text { Central Nicobarese lara 'black pepper', South } \\
\text { Nicobarese lara id., Sinhala lādā 'betel pepper (Piper } \\
\text { betle)' }\end{array}$ & (cf. Rigg 1844:244-6) \\
\hline $\begin{array}{l}\text { Malay lada bərekor'cubeb } \\
\text { (Piper cubeba)' }\end{array}$ & Tamil vāl-millaku id. & Loan translation? \\
\hline Malay layarid. & $\begin{array}{l}\text { Pali lakāra, Sinhala ravala (pl. ruva), Dhivehi riyau } \\
\text { riyā id. }\end{array}$ & $\begin{array}{l}\text { Sinhala and Dhivehi } \\
\text { attestations through } \\
\text { metathesis (cf. Smith } \\
\text { 1933:216, Haebler 1965, } \\
\text { Turner 1966 \#10964); Pali } \\
\text { attestation probably a } \\
\text { hypercorrection }\end{array}$ \\
\hline Malay malung 'conger eel' & Tamil malaŕku 'true eel', Malagasy amalona 'an eel' & (Allibert 1984:191) \\
\hline $\begin{array}{l}\text { Malay manggis 'mangosteen } \\
\text { tree (Garcinia X } \\
\text { mangostana)' }\end{array}$ & Southern Min bâng-git id. & \\
\hline Malay mangkuk 'small bowl' & Central Nicobarese monko 'cup' & \\
\hline Malay Məlayu 'Malay' & $\begin{array}{l}\text { Central Nicobarese Malaju id., LMC *Muâ-lâ-iäu (摩羅 } \\
\text { 游) 'a Sumatran kingdom', Tamil †Malaiyūrid. }\end{array}$ & $\begin{array}{l}\text { Tamil attestation presumably } \\
\text { a rationalisation of malai } \\
\text { 'mountain' + } \bar{u} r \text { 'city' }\end{array}$ \\
\hline $\begin{array}{l}\text { Malay namnam 'namnam } \\
\text { (Cynometra cauliflora)' }\end{array}$ & Sinhala namnam, Dhivehi ñamñam id. & (Maniku 2000) \\
\hline Malay nangka 'jackfruit' & Central Nicobarese nanka id. & \\
\hline $\begin{array}{l}\text { Malay - } n d a \text { (suffix used to } \\
\text { address kinship members) }\end{array}$ & Sinhala - $n d a$ id. & \\
\hline
\end{tabular}




\begin{tabular}{|c|c|c|}
\hline borrowed word & attestations & notes \\
\hline Malay nuri luri 'parrot, lory' & 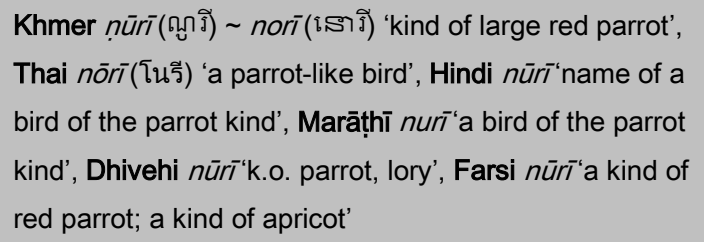 & \\
\hline Malay paku 'nail' & Dhivehi †abakuid. & (Nell 1881:121) \\
\hline $\begin{array}{l}\text { Malay pəngayuh 'oar, } \\
\text { paddle', (Sumatra dial.) } \\
\text { pəngayong id., (Ambon dial.) } \\
\text { panggayo 'single bladed } \\
\text { paddle', cf. Makasar } \\
\text { panggayong 'long oar' }\end{array}$ & $\begin{array}{l}\text { Malayālam pañgāyam 'paddle', Hindi (Laskari dial.) } \\
\text { pangae id.; Końkaṇi pangay 'k.o. boat',224 Makhuwa } \\
\text { pangaya pangayo 'Indian boat, with mat sails' }\end{array}$ & $\begin{array}{l}\text { Semantic shift from 'paddle' } \\
\text { to a 'small boat propelled by } \\
\text { a paddle'? }\end{array}$ \\
\hline Malay pənyu 'turtle' & Car Nicobar penut id. & \\
\hline $\begin{array}{l}\text { Malay pikul 'to carry a load } \\
\text { on the shoulder, a weight } \\
\text { equal to } 133 \text { pounds' }\end{array}$ & Tamil pikkal'a weight unit' & via English 'pecul' \\
\hline Malay pinggan 'plate' & Car Nicobar pinã:/id. & $\begin{array}{l}\text { Ultimately from Farsi pingān } \\
\text { 'dish, plate' }\end{array}$ \\
\hline Malay pisau 'knife' & Sinhala piha-ya 'knife, chopper' & (Gunasékara 1962:382) \\
\hline $\begin{array}{l}\text { Malay pukas 'nudity, } \\
\text { improper or indecent } \\
\text { exposure' }\end{array}$ & Sinhala puka 'anus' & (Sannasgala 1976:104-5) \\
\hline Malay puki 'female genitals' & $\begin{array}{l}\text { Sinhala pukkī'indecent word for females';225 Dhivehi } \\
\text { fui 'female genitals'; Malagasy (Mayotte dial.) pòky } \\
\text { 'curse, swearword'; mipòky 'to swear, to curse'226 }\end{array}$ & $\begin{array}{l}\text { Transmission presumably } \\
\text { recent }\end{array}$ \\
\hline Malay pulau pulo 'island' & Teressa pulo id. & $\begin{array}{l}\text { cf. Dhivehi Fölavahi 'Chagos } \\
\text { Archipelago' (Gray } \\
\text { 1887/1:296, Maloney } \\
\text { 1980:113) }\end{array}$ \\
\hline $\begin{array}{l}\text { Malay rambutan 'rambutan } \\
\text { (Nephelium lappaceum)' }\end{array}$ & Sinhala ran̆butan, Dhivehi ranbustānu rañba id. & \\
\hline Malay rupiyah 'rupee' & Central Nicobarese rupia, Car Nicobar rupiə id. & $\begin{array}{l}\text { < Sanskrit rūpya 'well- } \\
\text { shaped; silver; rupee' }\end{array}$ \\
\hline Malay sagu'sago' & 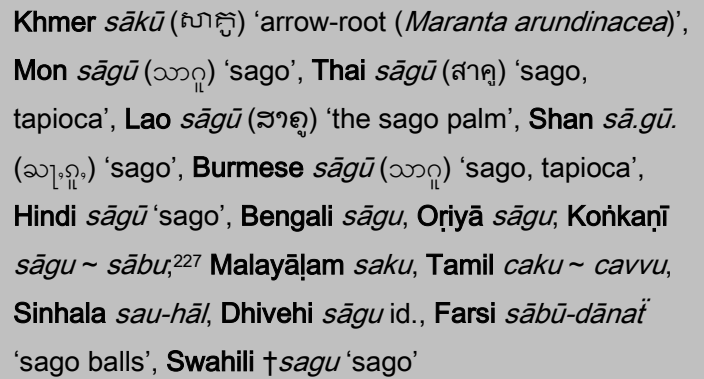 & $\begin{array}{l}\text { Transmission during colonial } \\
\text { period; Sinhala hāl= } \\
\text { '(unboiled) rice', Farsi dānä̈ } \\
\text { = 'grain' }\end{array}$ \\
\hline
\end{tabular}

224 Dalgado (1913:120).

225 Sannasgala (1976:104-5), Jayasuriya (2002:54-7).

226 Adelaar (2009a:728).

227 Dalgado (1913:139). 


\begin{tabular}{lll}
\hline borrowed word & attestations & notes \\
\hline $\begin{array}{l}\text { Malay sambal 'chilli-based } \\
\text { spicy sauce or paste' }\end{array}$ & Tamil cāmpal, Sinhala sambōla id.228 & $\begin{array}{l}\text { Transmission during colonial } \\
\text { period }\end{array}$ \\
$\begin{array}{ll}\text { Malay sampan 'shoe-boat, } \\
\text { boat for harbour use' }\end{array}$ & $\begin{array}{l}\text { sampān 'skiff', Hindi (Laskari dial.) sāmpan } \\
\text { a roof', Sinhala hambāna 'large boat, Malabar vessel, } \\
\text { dhóney' }\end{array}$ & pha:n' (三板) 'three planks'
\end{tabular}

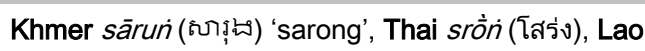

Malay sarung 'the typical salö̀n (వโล่ง) id.; Sinhala saroma 'native dress made of

Malay long kilt or skirt' cloth the ends of which are joined together';229 Tamil

(Sri Lanka dial.) cāram 'sarong'

Malay səmbərani
səmburani 'legendary horse'

Tamil cāmpirāni 'benzoin; region famous for its horses, etc.', Malayālam sāmbrāṇi 'benzoin, olibanum', Telugu sāmrāṇi 'benzoin; a steed, a fine horse'

$<$ Tamil cem-purani 'redskinned' (cf. Ronkel 1905); re-borrowing?

\section{Malagasy (Betsimisaraka dial., Bezanozano dial.)}

sefana 'k.o. plant (Cnestis polyphylla)';230 Khmer spaer

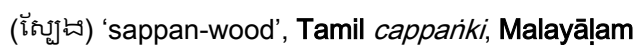

Malay səpang 'sappanwood'
$\mathrm{LMC}$ * $\operatorname{mowk}($ 木 $)=$ 'wood' (蘇枋木) id. > Korean sobangmog (소방목), Japanese suou (蘇芳), Vietnamese vang, Thai fär (ฝาง), Lao fär (๘) ) id.

\begin{tabular}{l|l}
$\begin{array}{l}\text { Malay sərai 'citronella grass, } \\
\text { Cymbopogon spp.' }\end{array}$ & $\begin{array}{l}\text { Sinhala sēra 'vegetable plant used especially with } \\
\text { beef' }\end{array}$
\end{tabular}
Malay sumpah 'oath, ordeal, imprecation'

Dhivehi sunpā ‘unlucky, ill-omened'

Malay sumpitan 'blowgun' $\quad \begin{aligned} & \text { Malayālam tūmbitān, Tamil cerikuttāñ, Arabic } \\ & \text { zabațānaẗ, Farsi zabtānaẗid. }\end{aligned}$

Malay təbu 'sugarcane' Swahili tembo 'toddy' $>$ Comorian trembo id.

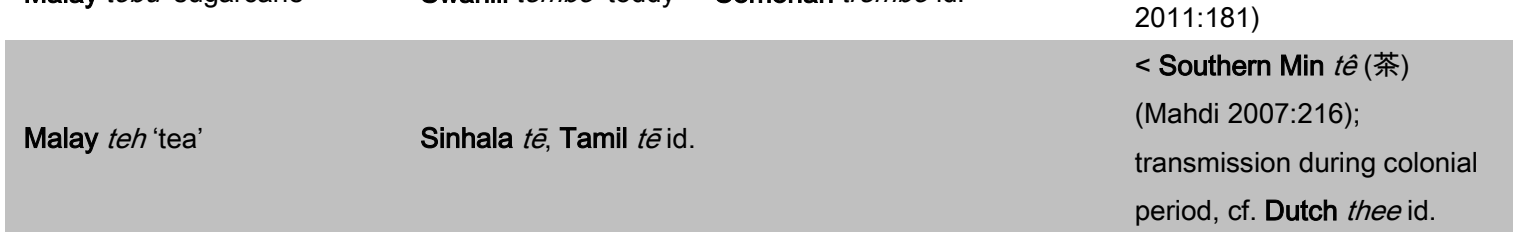

Malay təmbaga 'copper'

Tagalog tumbaga 'copper-gold alloy' > Spanish tumbaga, Portuguese †tambaca, English 'tombac', Arabic tambāk id.

\begin{tabular}{l} 
Malay təmbikai təmekai \\
'water melon' \\
Malay təngah(an) 'half' \\
Malay tiang 'mast, pole' \\
\hline 228 Jayasuriya (2002:54-7). \\
229 Jayasuriya (2002:54-7). \\
230 Sakiyama (2009:254). \\
231 Needham (1980:462).
\end{tabular}

\section{Central Nicobarese tamikaj 'melon'}

(Yule \& Burnell 1903:795, Hornell 1924b:326, 334)

(Beaujard 2010:370,

2011:181

< Southern Min tê (茶)

(Mahdi 2007:216); period, cf. Dutch thee id.

< MIA; cf. Sanskrit tāmraka 'copper' (Blust 1992:443); transmission during colonial period

< Tamil kommatti-kāy 'a small water-melon' (Lafeber 1922:79); the Malay doublet (kə)məndikai represents this precursor more faithfully

(Kern 1894) 


\begin{tabular}{|c|c|c|}
\hline borrowed word & attestations & notes \\
\hline Malay timun 'cucumber' & Central Nicobarese temon, Car Nicobar timun id. & \\
\hline $\begin{array}{l}\text { Malay tong 'tub, tun, cask, } \\
\text { etc.' }\end{array}$ & Central Nicobarese toๆ 'wooden bucket' & $\begin{array}{l}<\text { Chinese tǒng (桶) 'bucket, } \\
\text { tub, etc.', Southern Min } \\
\text { thóng (桶) 'cask, barrel, tub, } \\
\text { etc.', (coll.) tháng id. }{ }^{232}\end{array}$ \\
\hline $\begin{array}{l}\text { Malay torak 'a fish-trident } \\
\text { with a loose head' }\end{array}$ & Swahili tora 'fishing spear' & (Adelaar 2009c) \\
\hline $\begin{array}{l}\text { Malay tuak 'fermented palm- } \\
\text { sap' }\end{array}$ & $\begin{array}{l}\text { Central Nicobarese toak 'palm wine', Malagasy toaka } \\
\text { 'rum, alcohol'; Arabic †țwāa 'fermented palm sap';233 } \\
\text { Tamil tuvacar 'toddy-sellers, dealers in spirituous } \\
\text { liquors', tuvaca-mankaiyar 'women selling toddy' }\end{array}$ & Tamil mańkaiyar 'women' \\
\hline $\begin{array}{l}\text { Malay tuba 'derris root fish } \\
\text { poison' }\end{array}$ & Swahili tupa 'fish poison' & (Walsh 1995:17) \\
\hline
\end{tabular}

Table 7: other Malayo-Polynesian loanwords across the Indian Ocean

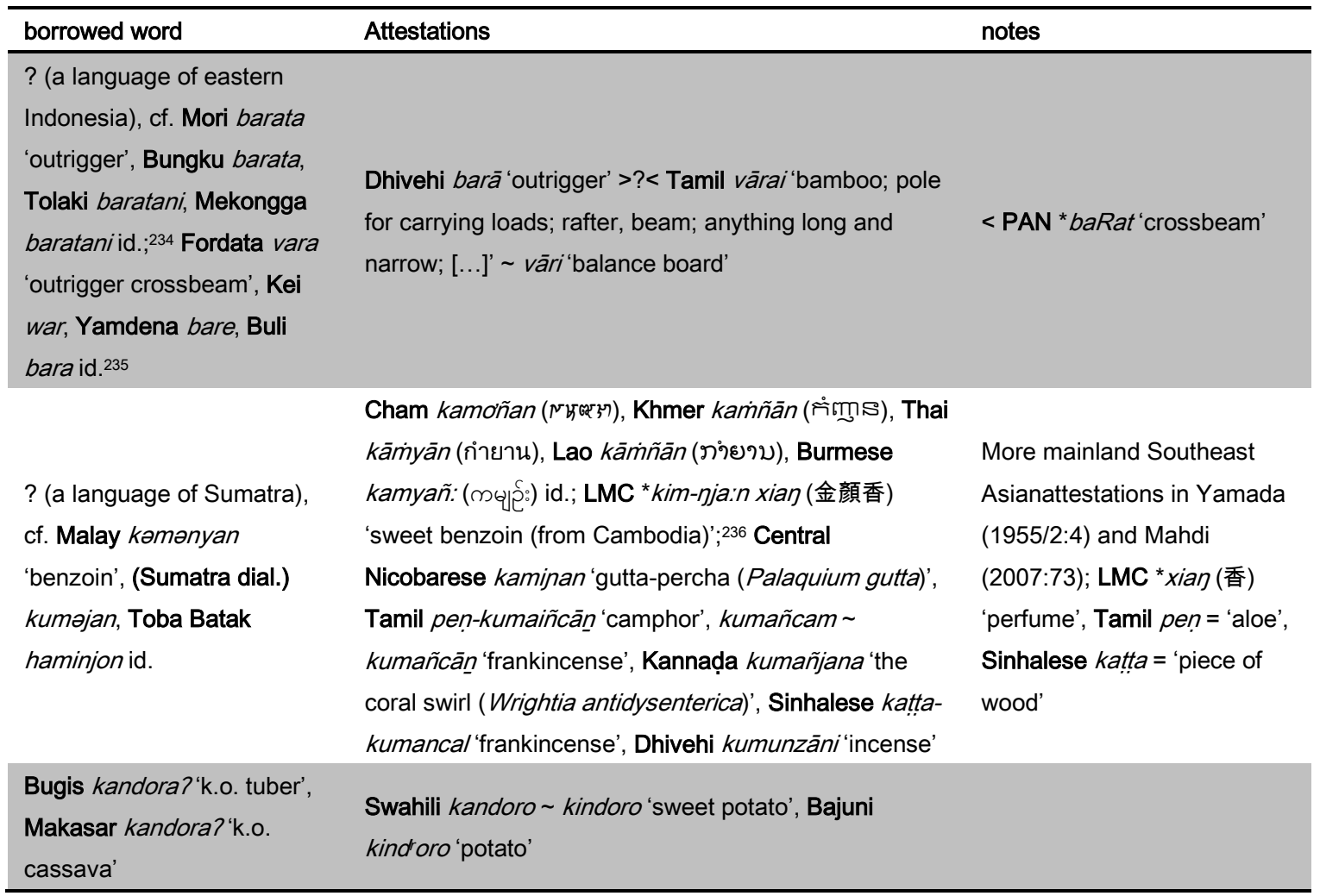

${ }^{232}$ Cf. Moken (Myanmar var.) tung 'bailing place (or bucket) of a boat', Khmer thāmin (ธึ่นุ) 'pail, wooden basket, bucket, tub', Thai thanं (ถัง) 'bucket, pail, tub, etc.', Vietnamese thùng 'barrel, box, bucket'.

233 Ferrand (1913-14/1:295).

234 Stokhof $(1984: 52,68,12,85)$.

235 Blust (1995 s.v.).

236 Hirth \& Rockhill (1912:198-9). 


\begin{tabular}{|c|c|c|}
\hline borrowed word & Attestations & notes \\
\hline Bugis tamara? 'tin' & $\begin{array}{l}\text { Sanskrit tamara id. > Tamil takaram 'tin, white lead, } \\
\text { etc.', Malayālam takaram 'tin, tinned iron plate', } \\
\text { Kannaḍa tagara } \sim \text { tamara } \sim \text { tavara 'tin', Tulu tamarů } ~ \\
\text { tamara tavara, Telugu tagaramu tamaramu } \sim \\
\text { tavaramu id. }\end{array}$ & $\begin{array}{l}\text { Intervocalic velar stop in } \\
\text { Dravidian attestations may } \\
\text { be under influence of } \\
\text { Sanskrit tagara 'borax'. }\end{array}$ \\
\hline Cham basəi $\left(v_{\nu}{ }^{2}\right)$ 'iron' & Mon basai (৫ગ̀) 'iron; nail, spike' & $\begin{array}{l}\text { Possibly also the precursor } \\
\text { of PWMP * wasay 'axe' }\end{array}$ \\
\hline $\begin{array}{l}\text { Javanese bațik 'k.o. textile } \\
\text { fabric', Malay batik, } \\
\text { Acehnese pate?id. }\end{array}$ & $\begin{array}{l}\text { Thai pāté (ปาเต๊ะ), Burmese pātit(טીڤ๐oß); Sinhala bațik } \\
\sim \text { batik id.237 }\end{array}$ & \\
\hline Javanese bocah 'child' & Sinhala $b \bar{o} c \bar{a} \sim ~ b u \bar{c} c \bar{a}$ 'appellation for little child' & (Sannasgala 1976:104-5) \\
\hline Javanese jaran 'horse' & Makasar jarang id., Tamil cārañ 'a breed of horse' & $\begin{array}{l}\text { Transmission probably } \\
\text { recent; < Old Javanese ajar- } \\
\text { an 'horse'; more East } \\
\text { Indonesian attestations in } \\
\text { Verheijen (1967:100) }\end{array}$ \\
\hline Javanese mənyan 'benzoin' & $\begin{array}{l}\text { Sinhala mæliyam 'gum, glue, any glutinous substance } \\
\text { exuding from trees or plants on incision' }\end{array}$ & (cf. Rigg 1844:244-6) \\
\hline $\begin{array}{l}\text { Karo Batak dua 'two', Malay } \\
\text { dua id. }\end{array}$ & Tamil (Jaffna; slang) tuvā-, (India; slang) tō- id. & (cf. Kern 1894) \\
\hline $\begin{array}{l}\text { Karo Batak əmpat'four', } \\
\text { Malay əmpat id. }\end{array}$ & $\begin{array}{l}\text { Tamil (Jaffna; slang) pāttu, (India; slang) pātt- pāttu } \\
\text { id. }\end{array}$ & (cf. Kern 1894) \\
\hline Karo Batak pitu 'seven' & Tamil (India; slang) piccu id. & (cf. Kern 1894) \\
\hline Karo Batak (sə)puluh 'ten' & Tamil (India; slang) puli- pulu id. & $\begin{array}{l}\text { (cf. Kern 1894); the } \\
\text { innovation *u\# > i is regular } \\
\text { in colloquial Tamil } \\
\text { (Ramaswami } 1997: 80 \text { ) }\end{array}$ \\
\hline $\begin{array}{l}\text { Karo Batak sə- 'one', cf. } \\
\text { Malay (early) sa- id. }\end{array}$ & Tamil (Jaffna; slang) sā-, (India; slang) śā- id. & (cf. Kern 1894)) \\
\hline Karo Batak siwah 'nine' & Tamil (India; slang) tāyā- tāyāñ id. & (cf. Kern 1894) \\
\hline $\begin{array}{l}\text { Karo Batak tə/u 'three', Old } \\
\text { Malay } t / u \text { id. }\end{array}$ & Tamil (Jaffna; slang) tilu, (India; slang) tiru- tilu id. & (cf. Kern 1894) \\
\hline Karo Batak waluh 'eight' & Tamil (India; slang) vali- valu id. & $\begin{array}{l}\text { (cf. Kern 1894); the } \\
\text { innovation *u\# > i\# is regular } \\
\text { in colloquial Tamil } \\
\text { (Ramaswami } 1997: 80 \text { ) }\end{array}$ \\
\hline Makasar tumbera 'lead' & Sinhala tuňba id. & Uncertain \\
\hline Malagasy fary 'sugarcane' & Makhuwa mu-hali id. & Uncertain \\
\hline $\begin{array}{l}\text { Malagasy (Tañala dial.) } \\
\text { ontsy'k.o. banana', } \\
\text { (Sakalava dial.) ontsy, } \\
\text { (Mayotte dial.) (h)òntsy, }\end{array}$ & Shambaa huti 'banana', Bondei huti id. & $\begin{array}{l}\text { (cf. Blakney 1963:58-9, Kent } \\
\text { 1970:55 n.63, Langhe } \\
\text { 1995:8, Beaujard 2003-04:64 } \\
\text { n.14, 2007:37 n.19) }\end{array}$ \\
\hline
\end{tabular}

237 Sannasgala (1976:104-5), Jayasuriya (2002:54-7). 


\begin{tabular}{|c|c|c|}
\hline borrowed word & Attestations & notes \\
\hline Malagasy vary 'rice' & $\begin{array}{l}\text { Swahili wali 'cooked rice', Comorian melé 'paddy, rice } \\
\text { plant' }\end{array}$ & $\begin{array}{l}\text { (cf. Beaujard 2010:366); } \\
\text { ultimately from Tamil vari } \\
\text { 'paddy' through a language } \\
\text { of Borneo (cf. Hudson } \\
\text { 1967:92, Adelaar 1989:26, } \\
\text { Sakiyama 1992:273) }\end{array}$ \\
\hline $\begin{array}{l}\text { Minangkabau girek-girek } \\
\text { 'areca nut pounder' }\end{array}$ & $\begin{array}{l}\text { Sinhala gira-ya } \sim \text { girē 'k.o. knife used especially for } \\
\text { cutting areca nuts' }\end{array}$ & (Sannasgala 1976:104-5) \\
\hline $\begin{array}{l}\text { Moken (Myanmar var.) pewa } \\
\text { 'oar, paddle' }\end{array}$ & $\begin{array}{l}\text { Central Nicobarese powah 'a paddle', South } \\
\text { Nicobarese pawwə, Car Nicobar paijuə id. }\end{array}$ & (Lewis 1960:93) \\
\hline Moken kabān 'houseboat' & Old Mon kḅan' 'ship, boat' & $\begin{array}{l}\text { Also several attestations in } \\
\text { Mon-Khmer and Tibeto- } \\
\text { Burman languages (Mahdi } \\
\text { 1994/2:458-9, 1999:165-9, } \\
\text { Shorto 2006 \#633) }\end{array}$ \\
\hline Moken layan 'sail' & 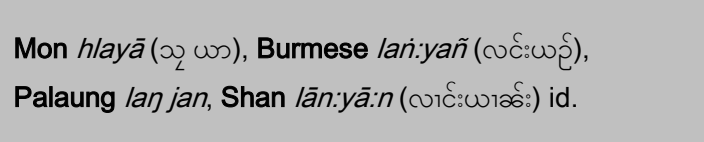 & $\begin{array}{l}\text { The Mon attestation possibly } \\
\text { through folk-etymological } \\
\text { association with } h / a\left(v_{L}\right) \text { 'leaf' }\end{array}$ \\
\hline PMP *banka?'boat' & Tamil vanikam 'ship' & (Kern 1915:5) \\
\hline PMP *buaq 'fruit, areca nut' & $\begin{array}{l}\text { MIA * pūa 'areca nut' > Sanskrit * pūga, Pali pūga; } \\
\text { Tamil pāk(k)u, Malayāḷm pākku, Telugu pō̌ka id., } \\
\text { Kolami pōke 'betel', Kuwi pōka mrānu 'areca tree'238 }\end{array}$ & $\begin{array}{l}\text { Possibly a back-formation; } \\
\text { Sinhala puvak 'areca nut', } \\
\text { Dhivehi fōvak, (Huvadhoo } \\
\text { dial.) fu-ake id. < OIA } \\
\text { *pūgavrrsșa 'areca tree'; Kuwi } \\
\text { mrānu = 'tree' }\end{array}$ \\
\hline PMP *buliq 'cowry shell' & $\begin{array}{l}\text { Dhivehi boli, (Huvadhoo Atoll dial.) bōlu id., Sinhala } \\
\text { bolla 'skull; shell, cowry' }\end{array}$ & (cf. Pelliot 1959:555) \\
\hline $\begin{array}{l}\text { PMP *kuluR 'breadfruit } \\
\text { (Artocarpus altilis) }\end{array}$ & Jarawa kulu 'jackfruit (A. heterophyllus)' & $\begin{array}{l}\text { (cf. Blevins 2009); Wolff } \\
\text { (2010/2:875) reconstructs } \\
{ }^{*} \text { kulu id., a secondary } \\
\text { borrowing that spread } \\
\text { westwards from Oceania }\end{array}$ \\
\hline $\begin{array}{l}\text { PMP ?* } p[ə a] D a H u \text { '(sailboat } \\
\text { for) long-distance } \\
\text { navigation' > Malay (early) } \\
\text { †padau 'boat' }\end{array}$ & 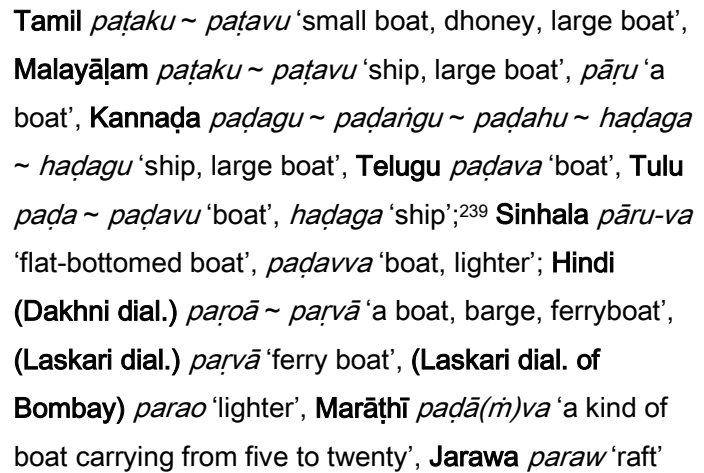 & $\begin{array}{l}\text { (cf. Blust } 1995 \text { s.v., Mahdi } \\
\text { 1999a:171-2); Malay layar } \\
\text { padau = 'storm sail'; } \\
\text { directionality of borrowing } \\
\text { uncertain }\end{array}$ \\
\hline
\end{tabular}

${ }^{238}$ Burrow \& Emenau (1984 \#4048).

239 Burrow \& Emenau (1984 \#3838), Sivashanmugan \& Rajamanickam (1988:38). 


\begin{tabular}{|c|c|c|}
\hline borrowed word & Attestations & notes \\
\hline $\begin{array}{l}\text { proto-Chamic * pina: } \eta \text { 'areca } \\
\text { nut'; Old Malay pinam }> \\
\text { Malay pinang id. }\end{array}$ & 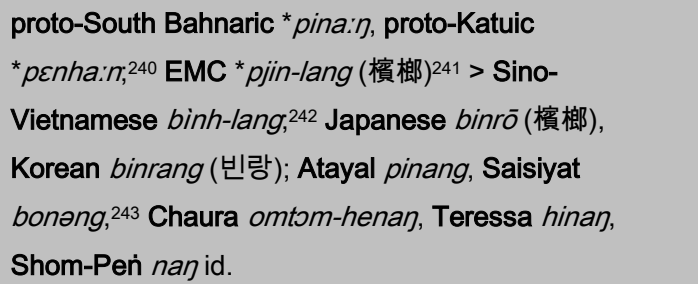 & $\begin{array}{l}\text { (cf. Mahdi } 1999 \mathrm{~b}: 217, \\
2010: 7 \text { ); presumably related } \\
\text { to Old Javanese } k \text {-inan 'betel } \\
\text { quid prepared for chewing', } \\
\text { p-inan' 'to invite to come' }\end{array}$ \\
\hline $\begin{array}{l}\text { proto-South Sulawesi } \\
{ }^{*} b a[\text { W]ulu 'betel leaf', proto- } \\
\text { Sama-Bajaw * } b(a q) u l u \text {, } \\
\text { PCEMP * bulu, } 244 \text { POC * pulu } \\
\text { id. }{ }^{245}\end{array}$ & 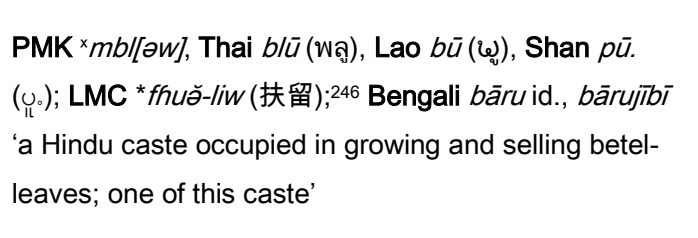 & $\begin{array}{l}\text { (cf. Mahdi 2010:3-4); Bengali } \\
\text {-jībī'practicing for livelihood', } \\
\text { relation with OIA *tāmbūlá } \\
\text { *tāmbōla 'betel leaf' remains } \\
\text { uncertain }\end{array}$ \\
\hline $\begin{array}{l}\text { PWMP ?*limaw'citrus fruit', } \\
\text { Malay limau id. }\end{array}$ & 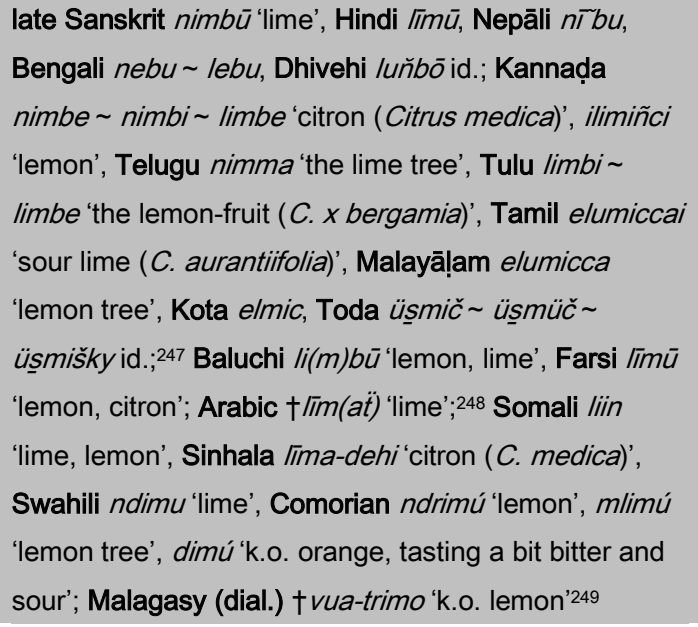 & $\begin{array}{l}\text { (Kern 1897:273, Mahdi } \\
\text { 1998:408); more Indo-Aryan } \\
\text { attestations in Turner (1966 } \\
\text { \#7247); late Sanskrit form } \\
\text { presumably a back- } \\
\text { formation; Sinhala dehi = } \\
\text { 'citrus fruit', Malagasy vua = } \\
\text { 'fruit' }\end{array}$ \\
\hline $\begin{array}{l}\text { PWMP ?* bilug 'type of boat } \\
\text { (dugout with outrigger) }\end{array}$ & $\begin{array}{l}\text { Onge beruge 'outrigger' }>\text { ? }<\text { Great Andamanese bil(I)u } \\
\text { 'ship' }\end{array}$ & \\
\hline
\end{tabular}

Table 8: South Asian mineral and metal terms in Southeast Asia

\begin{tabular}{lll}
\hline South Asian precursor & Southeast Asian attestations & notes \\
\hline $\begin{array}{l}\text { Farsi horāsān̄'from the } \\
\text { Khorasan region' }\end{array}$ & $\begin{array}{l}\text { Malay kərsani' 'iron from Khorasan', Old Javanese } \\
\text { purasani 'a kind of iron', Javanese purosani 'high- } \\
\text { quality iron or steel used for making kərises, royal } \\
\text { carriage etc.' }\end{array}$ & (cf. Tuuk 1897-1912/4:99) \\
\hline
\end{tabular}

\footnotetext{
240 Thurgood (1999:300), proto-Katuic * penha:n not in Sidwell (2005).

241 Groot (1894:265-6).

242 Davidson (1975:604 n.76).

243 Tsuchida (1977:114).

244 Mahdi (2010:3).

245 Lichtenberk (1998).

246 Groot (1894:266-7).

247 Burrow (1945:614-5), Burrow \& Emenau (1984 \#836).

248 Glidden (1937:385).

249 Flacourt (1658:125).
} 


\begin{tabular}{|c|c|c|}
\hline South Asian precursor & Southeast Asian attestations & notes \\
\hline $\begin{array}{l}\text { Hindi } P a \bar{a} \text { de, Bengali } P a \bar{a} r e, \\
\text { Orịā Pānḍa 'a class of } \\
\text { Brahmins' }\end{array}$ & $\begin{array}{l}\text { Old Javanese pande panday 'skilled worker, smith, } \\
\text { goldsmith, etc.', Malay pandai 'artist-craftsman, expert, } \\
\text { specialist', Balinese pande 'skilled in craftwork; smith', } \\
\text { Acehnese pande 'blacksmith', Toba Batak pande, Karo } \\
\text { Batak pande, Makasar panre, Tagalog pandayid., } \\
\text { Cebuano panday 'blacksmith, carpenter' }\end{array}$ & $\begin{array}{l}\text { (cf. Gonda 1973:170-1, } \\
\text { Casparis 1988:61); < MIA } \\
\text { “pamidia 'learned, clever', } \\
\text { OIA * panḍitá id.; } \\
\text { alternatively, the form may } \\
\text { be related to Tamil panțai } \\
\text { 'knowledge, learning' }\end{array}$ \\
\hline $\begin{array}{l}\text { Hindi patrī'a narrow slip of } \\
\text { iron, etc.' }\end{array}$ & 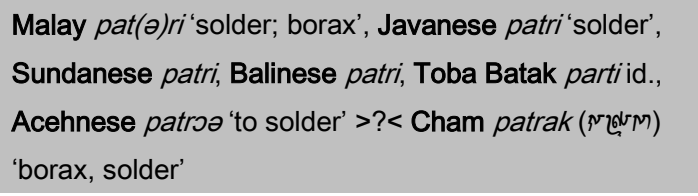 & (cf. Gonda 1973:139) \\
\hline $\begin{array}{l}\text { Malayālam Malayāla } \\
\text { 'Malabar Coast' }\end{array}$ & $\begin{array}{l}\text { Old Javanese malyāla 'a country in South India and its } \\
\text { people; steel (a partic. kind of steel)', Javanese malelo } \\
\text { 'steel', Sundanese malela 'shining (steel)', Malay } \\
\text { məlela 'dark, undamasked steel', Balinese malela } \\
\text { 'steel', Acehnese mulila, Toba Batak malela id., Karo } \\
\text { Batak malela 'a word often used in mantras' }\end{array}$ & \\
\hline MIA ?*tamba-ka 'copper' & $\begin{array}{l}\text { Old Javanese tambaga, Javanese təmbəgo, } \\
\text { Sundanese tambaga id., Balinese təmbaga 'red } \\
\text { copper', Malay təmbaga 'copper', Acehnese tumaga } \\
\text { id., Toba Batak tombaga 'copper, brass', Karo Batak } \\
\text { təmbaga 'copper', Makasar tambaga 'red copper', } \\
\text { Tagalog tumbaga 'copper-gold alloy', Cebuano } \\
\text { tumbága 'copper, copper alloy' }\end{array}$ & $\begin{array}{l}\text { (Casparis 1988:63-4, Blust } \\
\text { 1992:443); < Sanskrit tāmra- } \\
\text { ka 'copper' }\end{array}$ \\
\hline $\begin{array}{l}\text { MIA ?* vajja 'thunderbolt; } \\
\text { steel' }\end{array}$ & $\begin{array}{l}\text { Malay baja 'steel', Iban baja, Old Javanese vaja, } \\
\text { Javanese woj, Sundanese baja, Karo Batak baja, } \\
\text { Bugis baja?, Makasar baja?id. }\end{array}$ & $\begin{array}{l}\text { (cf. Rigg 1862:364); } \\
\text { ultimately from OIA * vájra } \\
\text { 'thunderbolt; diamond' }\end{array}$ \\
\hline $\begin{array}{l}\text { OlA * vā 'śi 'sharp pointed } \\
\text { knife or adze', Pali vāsi } \\
\text { 'sharp knife, adze', Bengali } \\
\text { bāsi 'axe' }\end{array}$ & 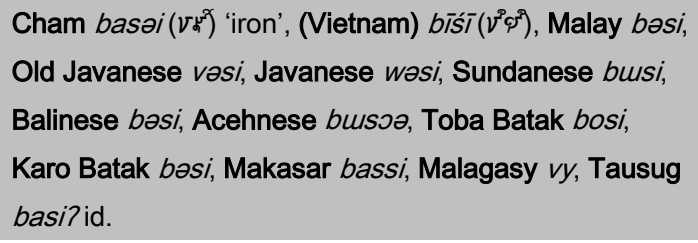 & \\
\hline Sanskrit ayaskāra 'smith' & Khmer ayaskār (ร-ษณุก) id. & \\
\hline Sanskrit galū 'sort of gem' & $\begin{array}{l}\text { Malay tgaluh 'silver, gem', Old Javanese galuh 'jewel', } \\
\text { Javanese galuh 'diamond, jewel', Sundanese Galuh 'a } \\
\text { place name' }\end{array}$ & \\
\hline $\begin{array}{l}\text { Sanskrit gulikā 'globule; } \\
\text { pearl' }\end{array}$ & $\begin{array}{l}\text { Malay guliga 'talismanic or curative bezoar; snake- } \\
\text { stone', Acehnese guliga guliga 'magic stone', } \\
\text { Makasar guliga id. }\end{array}$ & \\
\hline Sanskrit hïra 'diamond' & 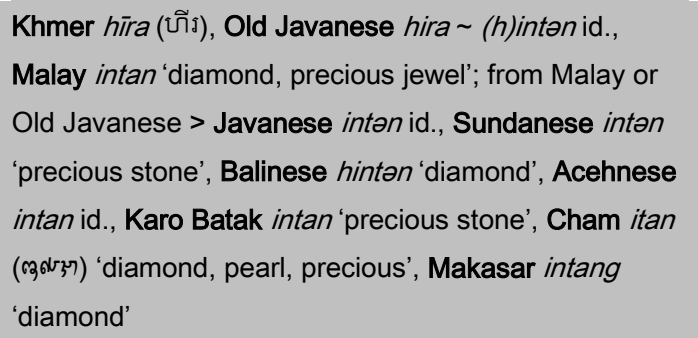 & $\begin{array}{l}\text { See Adelaar (1992a:52 fn. } \\
\text { 95) on the innovation *ira\# > } \\
\text { intan\# in Malay; this } \\
\text { innovation is also common in } \\
\text { (Old) Javanese. }\end{array}$ \\
\hline
\end{tabular}




\begin{tabular}{|c|c|c|}
\hline South Asian precursor & Southeast Asian attestations & notes \\
\hline Sanskrit kāca 'glass' & $\begin{array}{l}\text { Malay kaca 'glass, mirror', Old Javanese kaca, } \\
\text { Javanese koco, Sundanese kaca, Balinese kaca, } \\
\text { Acehnese kaca id., Makasar kaca '(drinking) glass', } \\
\text { Tagalog †kasá 'bracelet of green and blue stones', } \\
\text { Cebuano †katya 'glass' >?< Thai kracak (กระจก) } \\
\text { 'mirror; plate of glass; lens', Lao kacok (クะจ์ }) \text { 'mirror, } \\
\text { glass' }\end{array}$ & \\
\hline $\begin{array}{l}\text { Sanskrit kamala 'rose- } \\
\text { coloured' }\end{array}$ & $\begin{array}{l}\text { Malay kəmala 'luminous bezoar', Old Javanese } \\
\text { komala 'a kind of precious stone', Javanese kumolo } \\
\text { 'jewel, diamond', Sundanese kumala 'k.o. precious } \\
\text { stone', Balinese kumala 'diamond', Karo Batak kumala } \\
\text { 'sign, omen, bright light, ray of light in the evening (as } \\
\text { a sign that a village will burn down)' }\end{array}$ & \\
\hline $\begin{array}{l}\text { Sanskrit kamsa 'brass, bell- } \\
\text { metal, etc.' }\end{array}$ & $\begin{array}{l}\text { Malay gangsa 'bronze', Old Javanese ganisa 'bell- } \\
\text { metal', Javanese gongso 'bronze, musical instrument', } \\
\text { Sundanese gangsa 'k.o. bell metal', Balinese gangsa } \\
\text { 'bell-metal', Toba Batak hangsa 'ore, alloy, bronze', } \\
\text { Karo Batak kangsa 'bell metal, alloy' }\end{array}$ & $\begin{array}{l}\text { More reflexes in Nicolas } \\
\text { (2011) }\end{array}$ \\
\hline Sanskrit kañcana 'gold' & $\begin{array}{l}\text { Khmer kañcan (โฺฺฺs) id., Lao kāncanā (ภาบจะบๆ) } \\
\text { 'gold; silver; asset', Malay kəncana 'gold', Old } \\
\text { Javanese kāñcana, Sundanese kancana, Balinese } \\
\text { kancana id. }\end{array}$ & \\
\hline $\begin{array}{l}\text { Sanskrit kauśala 'skilfulness, } \\
\text { cleverness, experience' }\end{array}$ & $\begin{array}{l}\text { Old Javanese guśali 'blacksmith', Javanese gusali id., } \\
\text { Balinese hasta kosali 'title of a book of measurements } \\
\text { for houses', Sundanese gosali 'smithy', Lampung } \\
\text { †kasali id., Nias osali 'council, church', Bugis †gosali } \\
\text { 'cemetery, residence of the deceased', Tagalog gusali } \\
\text { 'building' }\end{array}$ & $\begin{array}{l}\text { (cf. Tuuk 1897-1912/2:199, } \\
\text { 4:733, Lafeber 1922:135-6, } \\
\text { Gonda 1973:548, Casparis } \\
\text { 1988:58); Balinese hasta = } \\
\text { 'hand' }\end{array}$ \\
\hline Sanskrit kundala 'ear-ring' & $\begin{array}{l}\text { Old Javanese gondala, Old Khmer kuṇdala, Thai } \\
\text { kuṇdal(กุณฑล) id. }\end{array}$ & \\
\hline Sanskrit lohakāra 'smith' & $\begin{array}{l}\text { Old Javanese lohakāra, Khmer lohākār (เณบบกกา), } \\
\text { Lao Iōhakān (โลขระภาบ) id. }\end{array}$ & \\
\hline $\begin{array}{l}\text { Sanskrit makuț ( mukuța) } \\
\text { 'crown, diadem' }\end{array}$ & $\begin{array}{l}\text { Old Khmer makuța, Thai makuț (มกุฎ) manikut } \\
\text { (มงกุฎ), Lao morikud (ม๊ๆฺุด), Old Javanese makuța, } \\
\text { Malay mahkota, Sundanese makuta, Balinese makuta, } \\
\text { Toba Batak †bahota, }{ }^{250} \text { Makasar makotta id. }\end{array}$ & \\
\hline $\begin{array}{l}\text { Sanskrit mani 'a jewel, gem, } \\
\text { pearl', Tamil mani 'gem, } \\
\text { precious stone' }\end{array}$ & 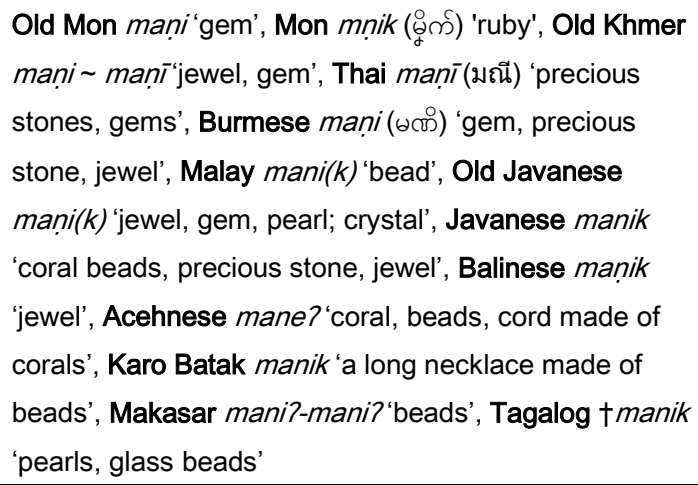 & \\
\hline
\end{tabular}

250 Parkin (1978:103). 


\begin{tabular}{|c|c|c|}
\hline South Asian precursor & Southeast Asian attestations & notes \\
\hline $\begin{array}{l}\text { Sanskrit māṣa 'a bean; } \\
\text { weight of gold }\end{array}$ & 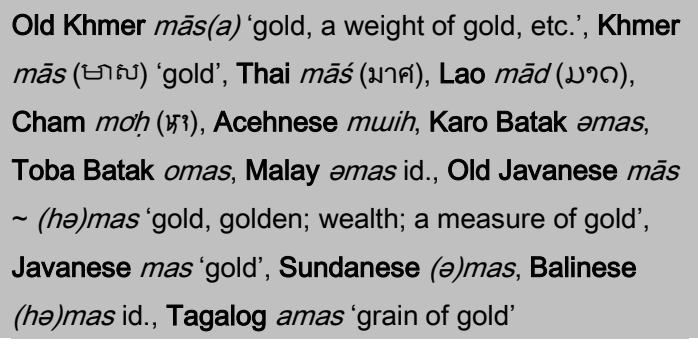 & \\
\hline Sanskrit mutya 'pearl' & $\begin{array}{l}\text { Malay mutia, Old Javanese mutya id., Balinese mute } \\
\text { 'glass beads', Toba Batak mutiha 'pearl', Tagalog } \\
\text { mutyâ 'amulet; pearl', Cebuano †motya †mutya } \\
\text { 'pearl, bead' }\end{array}$ & \\
\hline $\begin{array}{l}\text { Sanskrit (?) mutyahāra 'a } \\
\text { string of pearls' }\end{array}$ & $\begin{array}{l}\text { Malay mutiara 'pearl', Old Javanese mutya(hā)ra } \\
\text { mutəara, Javanese mutiyoro, Sundanese mutiyara, } \\
\text { Balinese mutyara id., Makasar muttiara 'oyster, pearl' }\end{array}$ & $\begin{array}{l}\text { (cf. Gonda 1973:493); cf. Old } \\
\text { Khmer muktihāra 'string of } \\
\text { pearls, pearl necklace' }\end{array}$ \\
\hline $\begin{array}{l}\text { Sanskrit paramatā 'highest } \\
\text { position or rank' }\end{array}$ & $\begin{array}{l}\text { Old Javanese p(a)ramata 'gem, jewel', Malay pormata } \\
\text { 'jewel', Sundanese pərmata 'precious stone, jewel', } \\
\text { Makasar paramata 'precious stone, stone in ring', } \\
\text { Tagalog palamata 'bracelets of glass' }\end{array}$ & \\
\hline Sanskrit rājasa 'tin' & $\begin{array}{l}\text { Malay rəjasa id., Javanese rəjoss 'solder (mixture of tin } \\
\text { and gluga)' }\end{array}$ & \\
\hline $\begin{array}{l}\text { Sanskrit rājāvarta 'lapis } \\
\text { lazuli; a kind of diamond or } \\
\text { other gem' }\end{array}$ & $\begin{array}{l}\text { Old Javanese rājāvarta 'a kind of diamond or other } \\
\text { gem', Javanese rojowərdi 'bluish enamel used for } \\
\text { jewelry', Malay rajawardi 'lapis lazuli; pale blue } \\
\text { enamel', Acehnese rajawarudi'glaze, enamel' }\end{array}$ & $\begin{array}{l}\text { See Gonda (1973:427-30) } \\
\text { and Casparis (1988:53) on } \\
\text { the innovation }{ }^{*} \mathrm{Ca \#} \mathrm{>} \mathrm{Ci \# ;} \\
\text { ultimate source presumably } \\
\text { Farsi lāžuwardid. }\end{array}$ \\
\hline $\begin{array}{l}\text { Sanskrit rasa 'mercury, } \\
\text { quicksilver' }\end{array}$ & $\begin{array}{l}\text { Khmer rasa (โ乞), Malay rasa, Javanese banyu roso, } \\
\text { Sundanese rasa, Makasar rasa id. }\end{array}$ & Javanese banyu = 'water' \\
\hline $\begin{array}{l}\text { Sanskrit ratna 'a jewel, gem, } \\
\text { precious stone') }\end{array}$ & 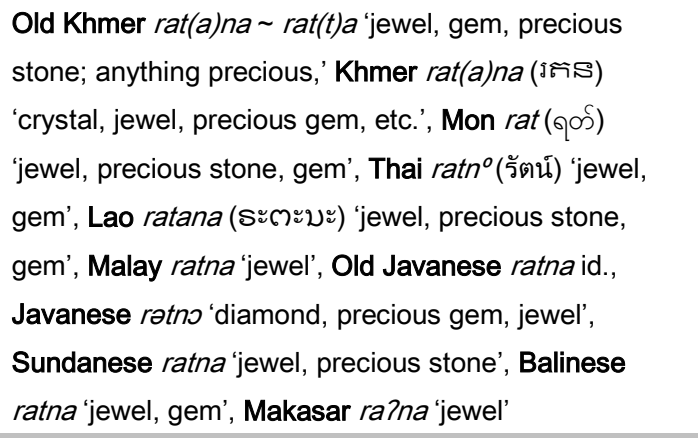 & \\
\hline $\begin{array}{l}\text { Sanskrit riti 'yellow or pale } \\
\text { brass, bell-metal' }\end{array}$ & $\begin{array}{l}\text { Malay (?) †riti 'brass, bronze', Old Javanese riti' 'certain } \\
\text { metal (brass, bronze?)' }\end{array}$ & $\begin{array}{l}\text { Malay form unattested, but } \\
\text { adopted into various East } \\
\text { Indonesian languages } \\
\text { (Mahdi 1994/1:181) }\end{array}$ \\
\hline $\begin{array}{l}\text { Sanskrit rūpya 'well-shaped; } \\
\text { silver; rupee' }\end{array}$ & $\begin{array}{l}\text { Khmer rūpiya (รูป̂ษษ) 'money, currency; silver', Malay } \\
\text { rupiyah 'k.o. coin', Javanese rupiyah, Sundanese } \\
\text { rupiyah, Toba Batak rupia, Karo Batak rupia, Makasar } \\
\text { rupia id. }\end{array}$ & \\
\hline $\begin{array}{l}\text { Sanskrit śalākā 'chip, } \\
\text { splinter, etc.' }\end{array}$ & $\begin{array}{l}\text { Old Javanese salaka 'silver', Javanese sloko, Malay } \\
\text { səlaka, Sundanese salaka, Balinese salaka səlaka, } \\
\text { Makasar (Salayar dial.) salaka id. }\end{array}$ & (cf. Mahdi 1994/1:185-6) \\
\hline
\end{tabular}




\begin{tabular}{|c|c|c|}
\hline South Asian precursor & Southeast Asian attestations & notes \\
\hline $\begin{array}{l}\text { Sanskrit sindūra 'red lead, } \\
\text { minium, vermilion' }\end{array}$ & $\begin{array}{l}\text { Lao sindhūra (ฐิบขูऽะ) 'vermilion, cinnabar red', Malay } \\
\text { sindura 'minium, red-lead', Old Javanese sindūra 'red } \\
\text { lead, minium, vermilion' }\end{array}$ & \\
\hline $\begin{array}{l}\text { Sanskrit sphatika 'crystal, } \\
\text { quartz' }\end{array}$ & $\begin{array}{l}\text { Old Javanese sphatika pastika 'a (powerful) gem' > } \\
\text { a-mastika 'like a pastika', Javanese musțiko 'bezoar; } \\
\text { jewel', Sundanese mustika 'prime jewel, the best thing, } \\
\text { etc.', Malay məstika 'bezoar (esp. when endowed with } \\
\text { talismanic properties)', Balinese mustikan 'a magic } \\
\text { jewel' }\end{array}$ & (cf. Gonda 1973:493) \\
\hline $\begin{array}{l}\text { Sanskrit svaccha 'an alloy or } \\
\text { amalgam of silver and gold' }\end{array}$ & $\begin{array}{l}\text { Malay suasa 'gold alloyed with copper', Javanese } \\
\text { suwoso 'pinchbeck, a gold-coloured copper-zinc alloy', } \\
\text { Sundanese suasa 'alloy of two parts of gold and one } \\
\text { part of red copper, pinchbeck', Balinese suwasa 'an } \\
\text { alloy of gold and copper', Toba Batak suasa 'alloy of } \\
\text { gold, copper and silver; bronze', Karo Batak suasa } \\
\text { 'alloy of gold and copper', Makasar suasa 'alloy of gold } \\
\text { and a large quantity of copper and silver; k.o. } \\
\text { pinchbeck' }\end{array}$ & $\begin{array}{l}\text { Alternative etymologies in } \\
\text { Maxwell (1882:15), Ronkel } \\
\text { (1902:109), Gonda } \\
\text { (1973:136-7 fn. 26) and } \\
\text { Jones (2007:300); cf. Old } \\
\text { Javanese nāgasvāsa } \\
\text { nagasosa'an alloy of gold } \\
\text { and copper (a kind of } \\
\text { pinchbeck)' }\end{array}$ \\
\hline $\begin{array}{l}\text { Sanskrit vaidūrya 'a cat's- } \\
\text { eye gem' }\end{array}$ & 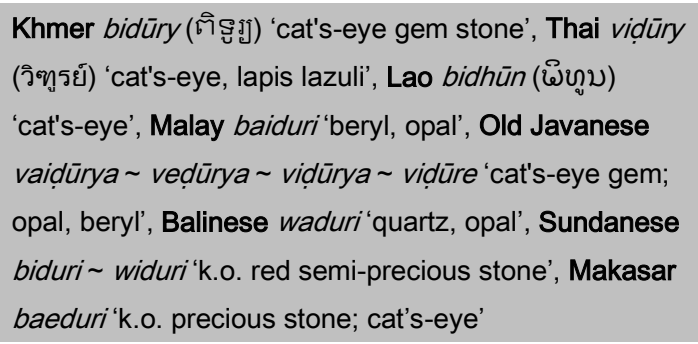 & \\
\hline $\begin{array}{l}\text { Sanskrit vajra 'thunderbolt, } \\
\text { diamond, etc.' }\end{array}$ & 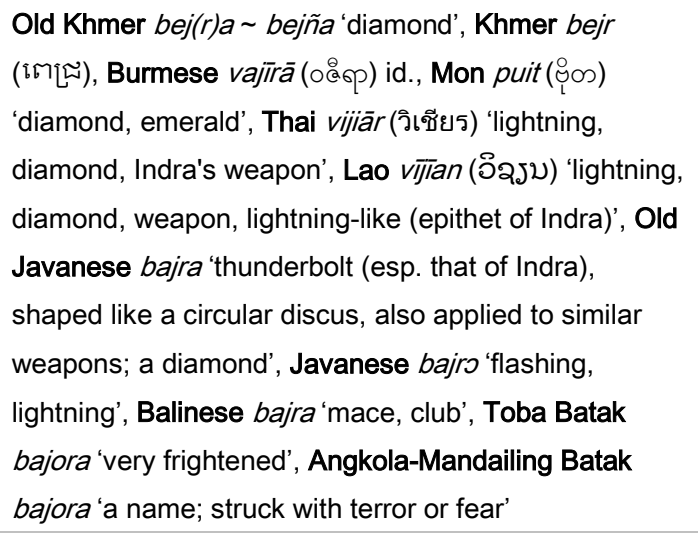 & \\
\hline Sanskrit valaya 'bracelet' & $\begin{array}{l}\text { Old Javanese valaya, Old Khmer vala(i)ya, Thai valai } \\
\text { (วลัย) id. }\end{array}$ & \\
\hline $\begin{array}{l}\text { Sanskrit vardhaki } \\
\text { 'carpenter', Pali vaḍdhaki id. }\end{array}$ & 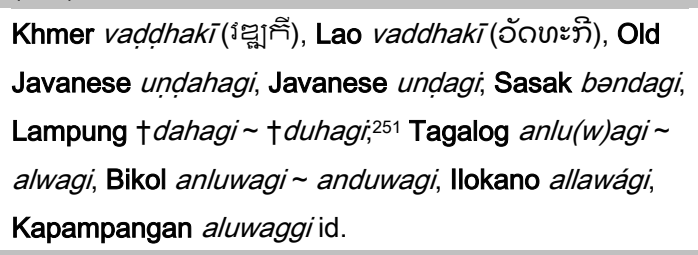 & $\begin{array}{l}\text { (cf. Tuuk 1897-1912/1:35, } \\
\text { Casparis 1988:64-5) }\end{array}$ \\
\hline Sanskrit vyokāra 'smith' & Khmer byokār (เตูกตาง) id. & \\
\hline
\end{tabular}

251 Tuuk (1897-1912/1:35). 


\begin{tabular}{|c|c|c|}
\hline South Asian precursor & Southeast Asian attestations & notes \\
\hline $\begin{array}{l}\text { Tamil cātilinkam 'vermilion, } \\
\text { red sulphurate of mercury, } \\
\text { etc.' }\end{array}$ & $\begin{array}{l}\text { Malay sədəlinggam 'minium; red-lead', Acehnese } \\
\text { sudalinggam sidalinggam 'minium, vermilion' }\end{array}$ & \\
\hline $\begin{array}{l}\text { Tamil kalluli 'stone-cutter's } \\
\text { chisel' }\end{array}$ & Malay kəluli 'steel' & $\begin{array}{l}\text { Cf. Tamil kalluli-y-urukku'a } \\
\text { kind of very hard steel used } \\
\text { for cutting stones' }\end{array}$ \\
\hline Tamil lōkam 'metal' & Malay logam, Toba Batak logam, Karo Batak logam id. & \\
\hline $\begin{array}{l}\text { Tamil māṇikkam 'ruby, } \\
\text { carbuncle' }\end{array}$ & $\begin{array}{l}\text { Malay manikam 'precious stone', Javanese manikəm } \\
\text { 'jewel', Sundanese manikəm 'precious stone, jewel', } \\
\text { Acehnese ma(7)nikam 'ruby, precious stone', Makasar } \\
\text { mannikang 'precious stone' }\end{array}$ & \\
\hline Tamil muttu 'pearl' & Malay mutu, Acehnese mutu, Makasar muttu id. & \\
\hline Tamil nilam 'sapphire' & $\begin{array}{l}\text { Malay nilam, Sundanese niləm, Acehnese nilam, } \\
\text { Makasar nillang id. }\end{array}$ & \\
\hline $\begin{array}{l}\text { Tamil pañcalōkam 'the five } \\
\text { kinds of metal' }\end{array}$ & $\begin{array}{l}\text { Malay pancalogam 'multicoloured or "composite" metal } \\
\text { or stone', Acehnese pancalugam 'consisting of } \\
\text { different metals' }\end{array}$ & \\
\hline $\begin{array}{l}\text { Tamil pavalam 'red coral, } \\
\text { stony axis of the stem of a } \\
\text { gorgonian' }\end{array}$ & $\begin{array}{l}\text { early Malay †pawalam 'coral'; } 252 \text { Malay pualam } \\
\text { 'marble', Makasar pawallang 'bracelet made of beads' }\end{array}$ & \\
\hline $\begin{array}{l}\text { Tamil poti 'dust; magical } \\
\text { powder; small gem' }\end{array}$ & $\begin{array}{l}\text { Malay podi 'the dust of gems; very small gems } \\
\text { mounted in large numbers to make a glittering show', } \\
\text { Javanese podi 'loose, not set (precious stones)', } \\
\text { Balinese podi 'a sort of small precious stone, } \\
\text { amethyst', Acehnese pudjə pudi 'a mixture of metal } \\
\text { grit and borax (to solder gold and silver), diamond grit, } \\
\text { gemstones', Karo Batak podi 'gold filing; silver pulp } \\
\text { mixed with borax' }\end{array}$ & \\
\hline $\begin{array}{l}\text { Tamil turuci turucu 'blue } \\
\text { vitriol' }\end{array}$ & $\begin{array}{l}\text { Malay tərusi 'copper vitriol; copper sulphate; } \\
\text { bluestone', Javanese trusi prusi 'verdigris; an } \\
\text { ointment made from verdigris for healing sores', } \\
\text { Sundanese trusi 'green mineral, verdigris', Balinese } \\
\text { trusi 'green vitriol (iron sulphate)', Acehnese turusi } \\
\text { 'copper vitriol' }\end{array}$ & \\
\hline $\begin{array}{l}\text { Tamil tuttam 'a prepared } \\
\text { arsenic, vitriol, sulphate of } \\
\text { zinc or copper' }\end{array}$ & Malay tutam cutam 'niello' >?< Thai tham (ถม) id. & \\
\hline Tamil vācci 'adze' & $\begin{array}{l}\text { Malay baji '(splitting) wedge', Acehnese baci 'axe } \\
\text { (small type)', Gayo baji 'wedge', Toba Batak baji } \\
\text { 'splitting wedge', Makasar banci 'a tool to cut stones' }\end{array}$ & $\begin{array}{l}\text { (cf. Ronkel 1902:103, } \\
\text { Lafeber 1922:98) }\end{array}$ \\
\hline Tamil vairam 'diamond' & $\begin{array}{l}\text { Thai bairāmm (ไพรำ) 'gem, jewel; precious stone', Lao } \\
\text { bairām (ใ๒ธ่ง) 'diamond; precious stone, gem', Malay } \\
\text { †beram 'red diamond', Acehnese biram 'red diamond', } \\
\text { Sundanese burum 'red' }\end{array}$ & \\
\hline
\end{tabular}

252 Edwards \& Blagden (1931:745). 


\begin{tabular}{|c|c|c|}
\hline South Asian precursor & Southeast Asian attestations & notes \\
\hline $\begin{array}{l}\text { Tamil vați 'sharpness', } \\
\text { Telugu vāọi 'sharpness of } \\
\text { weapons or instruments' }\end{array}$ & $\begin{array}{l}\text { Old Javanese (?) kadivadi 'splinted open'; }{ }^{253} \text { Malay } \\
\text { badik 'k.o. dagger' > Sundanese badi(-badi) 'k.o. cut- } \\
\text { and-thrust weapon (from Sumatra)', Acehnese bade? } \\
\text { 'k.o. knife', Makasar badi? 'k.o. thrusting weapon', } \\
\text { Cebuano bari 'k.o. sickle' >?< Thao bálie 'iron, metal', } \\
\text { Kavalan balís 'nail (iron)' }\end{array}$ & $\begin{array}{l}\text { See Mahdi (1994/1:171-5) } \\
\text { and Blust (1995 s.v.) for } \\
\text { more Malayo-Polynesian } \\
\text { attestations }\end{array}$ \\
\hline $\begin{array}{l}\text { Tamil vayira-mani 'bead of } \\
\text { gold; diamond' }\end{array}$ & $\begin{array}{l}\text { Malay biramani 'coral beads', Acehnese untuə? } \\
\text { biramani 'a necklace consisting of gold beads in the } \\
\text { form of biramaniflowers' }\end{array}$ & $\begin{array}{l}\text { Acehnese untuə? = } \\
\text { 'necklace of gold beads' }\end{array}$ \\
\hline
\end{tabular}

253 Presumably a corrupted form (Kern 1901:51 n. 31). 


\section{Appendix 2: Botanical names}

Alocasia macrorrhizos (L.) G. Don

Alpinia conchigera Griff.

Alpinia galanga (L.) Sw.

Alpinia nigra (Gaertn.) B. L. Burtt

Alpinia officinarum Hance

Amomum subulatum Roxb.

Anacardium occidentale L.

Anisophyllea apetala Scort. ex King

Antidesma ghaesembilla Gaertn.

Aquilaria malaccensis Lam.

Arachis hypogaea L.

Areca catechu L.

Arenga pinnata (Wurmb) Merr.

Arenga tremula (Blanco) Becc.

Artocarpus altilis (Parkinson) Fosberg

Artocarpus heterophyllus Lam.

Asplenium nidus L.

Averrhoa bilimbi L.

Averrhoa carambola L.

Azadirachta indica A. Juss.

Blumea balsamifera (L.) DC.

Borassus flabellifer $\mathrm{L}$.

Buchnera leptostachya Benth.

Caesalpinia sappan L.

Caesalpinia violacea (Mill.) Standl.

Calotropis gigantea (L.) Dryand.

Canarium eupteron Miq. syn. Santiria oblongifolia Blume

Cannabis sativa $\mathrm{L}$.

Capsicum baccatum L.

Casearia coriacea Vent.

Cicer arietinum $\mathrm{L}$.

Cinnamomum camphora (L.) J.Presl

Cinnamomum cassia (Nees \& T.Nees) J.Presl

Cinnamomum culitlawan (L.) J.Presl

Cinnamomum iners Reinw. ex Blume

Cinnamomum javanicum Blume

Cinnamomum verum J.Presl 
Citrullus lanatus (Thunb.) Matsum. \& Nakai

Citrus $\times$ bergamia Risso \& Poit. syn. Citrus $\times$ limon (L.) Osbeck

Citrus aurantiifolia (Christm.) Swingle

Citrus aurantium $\mathrm{L}$.

Citrus hystrix DC.

Citrus limon (L.) Burm. f.

Citrus maxima (Burm.) Osbeck

Citrus medica L.

Citrus paradisi Macfad.

Citrus reticulata Blanco

Citrus sinensis (L.) Osbeck

Cnestis polyphylla Lam.

Cocos nucifera L.

Coix lacryma-jobi L.

Colocasia esculenta (L.) Schott

Commiphora wightii (Arn.) Bhandari

Cordia myxa L.

Coriandrum sativum $\mathrm{L}$.

Corypha utan Lam.

Curcuma aeruginosa Roxb.

Curcuma aromatica Salisb.

Curcuma longa $\mathrm{L}$.

Curcuma mangga Valeton \& Zijp

Curcuma zedoaria (Christm.) Roscoe

Cynometra cauliflora L.

Cyperus papyrus $\mathrm{L}$.

Daemonorops draco (Willd.) Blume

Derris elliptica (Wall.) Benth.

Derris robusta (DC.) Benth.

Derris scandens (Roxb.) Benth.

Derris trifoliata Lour.

Dianthus caryophyllus $\mathrm{L}$.

Dioscorea alata L.

Dioscorea bulbifera L.

Dioscorea cayennensis Lam.

Dioscorea esculenta (Lour.) Burkill

Dioscorea hispida Dennst.

Dryobalanops beccarii Dyer

Dryobalanops sumatrensis (J.F.Gmel.) Kosterm.

Durio zibethinus L. 
Elettaria cardamomum (L.) Maton

Embelia ribes Burm.f.

Ensete ventricosum (Welw.) Cheesman

Euphorbia antiquorum L.

Garcinia × mangostana L.

Gossypium arboreum L.

Hedychium flavescens Carey ex Roscoe

Hedychium spicatum $\mathrm{Sm}$.

Hordeum vulgare L.

Hornstedtia scyphifera (J.König) Steud.

Illicium verum Hook. f.

Ipomoea aquatica Forssk.

Ipomoea batatas (L.) Poir.

Kaempferia galanga $\mathrm{L}$.

Lawsonia inermis $\mathrm{L}$.

Leucaena leucocephala (Lam.) de Wit

Linum usitatissimum $\mathrm{L}$.

Lodoicea maldivica (J.F.Gmel.) Pers.

Ludwigia adscendens (L.) H. Hara

Ludwigia octovalvis (Jacq.) P.H.Raven

Macrotyloma uniflorum (Lam.) Verdc.

Maranta arundinacea L.

Melaleuca cajuputi Powell

Melastoma malabathricum L.

Mimusops elengi L.

Moringa oleifera Lam.

Musa acuminata Colla

Musa balbisiana Colla

Musa textilis Née

Musa $\times$ paradisiaca $\mathrm{L}$.

Myristica fragrans Houtt.

Myristica malabarica Lam. syn. Palala malabarica Kuntze

Nardostachys jatamansi(D. Don) DC.

Nephelium lappaceum $\mathrm{L}$.

Nypa fruticans Wurmb

Oroxylum indicum (L.) Kurz

Oryza sativa L.

Palaquium gutta (Hook.) Burck

Phoenix dactylifera $\mathrm{L}$.

Pimenta racemosa var. racemosa 
Pinus merkusii Jungh. \& de Vriese

Piper betle L.

Piper caninum Blume

Piper cubeba L.f. syn. Cubeba cubeba H.Karst. syn. C. officinalis Raf. syn. C. pipereta Raf.

Piper longum L.

Piper methysticum L.f. syn. Macropiper methysticum Hook. \& Arn. syn. Methysticum esculentum Raf. syn. M. methysticum (G.Forst.) A.Lyons

Piper nigrum $\mathrm{L}$.

Piper retrofractum Vahl

Planchonia valida (Blume) Blume

Pogostemon cablin (Blanco) Benth.

Prunus amygdalus Stokes

Psidium guajava $\mathrm{L}$.

Psophocarpus tetragonolobus (L.) DC.

Pterocarpus santalinus L.f.

Ravenala madagascariensis Sonn.

Rubia cordifolia L.

Saccharum officinarum $\mathrm{L}$.

Salacca wallichiana Mart.

Santalum album L.

Scindapsus officinalis (Roxb.) Schott

Sesamum indicum $\mathrm{L}$.

Setaria italica (L.) P.Beauv.

Shorea guiso Blume syn. Anisoptera guiso (Blanco) A.DC. syn. Dipterocarpus guiso Blanco syn. Mocanera guiso Blanco

Shorea robusta Gaertn.

Shorea tumbuggaia Roxb.

Solanum armatum Forssk.

Solanum forskalii Dunal

Solanum incanum $\mathrm{L}$.

Solanum melongena $\mathrm{L}$.

Sorghum bicolor (L.) Moench

Stachys officinalis (L.) Trevis.

Styrax benzoin Dryand syn. Benzoin officinale Hayne syn. Benzoina vera Raf. syn. Cyrta dealbata Miers syn. Styrax benjuifer Stokes

Syringa oblata Lindl.

Syzygium aromaticum (L.) Merr. \& L.M.Perry

Syzygium cumini (L.) Skeels

Syzygium jambos (L.) Alston

Syzygium malaccense (L.) Merr. \& L.M.Perry 
Tacca leontopetaloides (L.) Kuntze

Tamarindus indica $\mathrm{L}$.

Tectona grandis L.f.

Terminalia catappa L.

Uncaria gambir (Hunter) Roxb.

Vigna radiata (L.) R.Wilczek

Wrightia antidysenterica (L.) R.Br.

Zingiber montanum (J.König) Link ex A.Dietr.

Zingiber officinale Roscoe

Zingiber purpureum Roxb.

Zingiber zerumbet (L.) Roscoe ex Sm. 


\section{References}

Abbi, Anvita, 2009. 'Is Great Andamanese genealogically and typologically distinct from Onge and Jarawa?', Language Sciences 31:791-812.

2012. Dictionary of the Great Andamanese language: English - Great Andamanese - Hindi. Delhi: Ratna Sagar.

Adelaar, K. Alexander, 1989. 'Malay influence on Malagasy: linguistic and culture-historical implications.' Oceanic Linguistics 28/1:1-46.

1992a. Proto-Malayic: the reconstruction of its phonology and parts of its lexicon and morphology. Canberra: Australian National University.

1992b. 'The relevance of Salako for Proto-Malayic and for Old Malay epigraphy.' Bijdragen tot de Taal-, Land-en Volkenkunde 148/3-4:381-408.

1994a. 'Malay and Javanese loanwords in Malagasy, Tagalog and Siraya (Formosa).' Bijdragen tot de Taal-, Land- en Volkenkunde van NederlandschIndië 150/1:50-65.

1994b. 'The history of thing, animal, person and related concepts in Malay.' In: A.K. Pawley \& M.D. Ross (eds.), Austronesian terminologies: continuity and change (Canberra: Pacific Linguistics Series C-127):1-20.

1995a. 'Bentuk pinjaman Bahasa Melayu dan Jawa di Malagasi.' In: Ismail Hussein, A. Aziz Deraman, Abd. Rahman al-Ahmadi (eds.), Tamadun Melayu. Jilid empat (Kuala Lumpur: Dewan Bahasa dan Pustaka):1621-40.

1995b. 'Borneo as a cross-roads for comparative Austronesian Linguistics.' In: Peter Bellwood, James J. Fox \& Darrell Tyron (eds.), The Austronesians: historical and comparative perspectives (Canberra: Australian National University):75-95.

2009a. 'Loanwords in Malagasy.' In: Martin Haspelmath \& Uri Tadmor (eds.), Loanwords in the world's languages: a comparative handbook (The Hague: De Gruyter Mouton):717-46

2009b. 'Towards an integrated theory about the Indonesian migrations to Madagascar.' In: P.N. Peregrine, I. Peiros \& M. Feldman (eds.), Ancient human migrations: an interdisciplinary approach (Salt Lake City, Utah: University of Utah Press):149-72.

2009c. 'Malagasy morphosyntax: Austronesian or Bantu?' Presented at the Special study day on the history of Madagascar, its peoples, languages, plants and music, 9 October 2009, Tervuren, Belgium

Ahmed-Chamanga, Mohamed, 1992. Lexique Comorien (shindzuani) - Français. Paris: I'Harmattan.

Akbar, Osra M., Syech Ahmaddin \& Hasanuddin Mardjo, 1985. Kamus Alas-Indonesia. Jakarta: Pusat Pembinaan dan Pengembangan Bahasa

Albada, Rob van \& Th. Pigeaud, 2007. JavaansNederlands woordenboek. Leiden: KITLV Uitgeverij.

Allen, Jim, 1996. 'The pre-Austronesian settlement of island Melanesia: implications for Lapita archaeology.' Transactions of the American Philosophical Society (new series) 86/5:11-27.

Allibert, Claude, 1984. Mayotte, plaque tournante et microcosme de l'océan indien Occidental. Paris: Anthropos.

1999. 'The archaeology of knowledge: Austronesian influences in the western Indian Ocean.' In: Roger Blench \& Matthew Spriggs (eds.), Archaeology and language III: artefacts, languages, and texts (London \& New York: Routledge):268-76.

2008. 'Austronesian migration and the establishment of the Malagasy civilization: contrasted readings in linguistics, archaeology, genetics and cultural anthropology.' Diogenes 218:7-16.

Altehenger-Smith, Sherida, 1990. Language change via language planning: some theoretical and empirical aspects with a focus on Singapore. Hamburg: Buske.

Ambrose, W.R., 1988. 'An early bronze artefact from Papua New Guinea.' Antiquity 62/236:483-91.

Andaya, Leonard Y., 2002. 'The trans-Sumatra trade and the ethnicization of the Batak' Bijdragen tot de Taal-, Land- en Volkenkunde 158/3:367-409.

2008. Leaves of the same tree: trade and ethnicity in the Straits of Melaka. Honolulu: University of Hawai'i Press.

Andersen, Dines, 1979. A Pāli glossary: Pāli reader and of the Dhammapada. Vol. II. New Delhi: Award Publishing House. Reprint.

Annandale, N., 1906. 'The meaning and origins of the phrase "Nuri Muhammad" among the Malays of the Patani States.' Journal \& Proceedings of the Asiatic Society of Benga/ 2/7:334-5.

Anshari, Gusti, A. Peter Kershaw, Sander van der Kaars \& Geraldine Jacobsen, 2004. 
'Environmental change and peatland forest dynamics in the Lake Sentarum area, West Kalimantan, Indonesia.' Journal of the Quaternary Science 19/7:637-55

Ardika, I. W. \& Peter Bellwood, 1991. 'Sembiran: the beginnings of Indian contact with Bali.' Antiquity 65/247:221-32.

Ariokaswamy, Celine W.M., 2000. Tamil influences in Malaysia, Indonesia and the Philippines. Manila: [s.n.].

Ariyapala, M.B., 1956. Society in mediaeval Ceylon: the state of society in Ceylon as depicted in the Saddharma-ratnāvaliya and other literature of the thirteenth century. Colombo \& Kandy: K.V.G. de Silva.

Asher, R.E. \& E. Annamalai, 2002. Colloquial Tamil: the complete course for beginners. London \& New York: Routledge.

Asouti, Eleni \& Dorian Q. Fuller, 2008. Trees and woodlands in South India: archaeological perspectives. Walnut Creek: Left Coast Press.

Aurousseau, L., 1922. 'Le mot sampan est-il chinois?' Bulletin de l'Ecole française d'Extrême-Orient 22:139-42.

Aymonier, Étienne \& Antoine Cabaton, 1906. Dictionnaire Čam-Français. Paris: Ernest Leroux.

Balfour, Henry, 1907. 'The fire-piston.' In: W.H.R. Rivers, R.R. Marett \& Northcote W. Thomas (eds.), Anthropological essays presented to Edward Burnett Tylor in honour of his $75^{\text {th }}$ birthday Oct. 2 1907 (Oxford: Clarendon Press):16-49.

Banerjee, N.R., 1965. The Iron Age in India. Delhi: Munshiram Manoharlal.

Baradat, R., 1941. Les dialectes des tribus sâmrê. Paris: Ecole Française d'Extrême-Orient. Unpublished manuscript. Accessed via http://sealang.net/ (2010-11)

Barber, Charles Clyde, 1979. Dictionary of Balinese English. Aberdeen: University of Aberdeen. Aberdeen University Library Occasional Publications No. 2.

Barker, Graeme \& Ryan Rabett, 2009. 'Late Pleistocene and early Holocene forager mobility in Southeast Asia.' Presented at the $19^{\text {th }}$ Congress of the Indo-Pacific Prehistory Association (IPPA), 29 Nov - 5 Dec 2009, Hanoi, Vietnam.

Barnes, Robert H., 1996. Sea hunters of Indonesia: fishers and weavers of Lamalera. Oxford: Clarendon Press.
2002. 'Yami boats and boat building in a wider perspective' In: David Parkin \& Ruth Barnes, Ships and the development of maritime technology in the Indian Ocean (New York: RoutledgeCurzon):291314.

Barretto-Tesoro, G., 2003. 'Burial goods in the Philippines: an attempt to quantify prestige values.' Southeast Asian Studies 41/3:299-315.

Bastin, Yvonne \& Thilo Schadeberg, 1998. Bantu Lexical Reconstructions 3. (http://www.metafro.be/blr/ accessed 08/11)

Bayard, D. T., 1972. 'Early Thai bronze: analysis and new dates.' Science 176:1411-12.

Bayly, Susan, 2004. 'Imagining 'Greater India': French and Indian visions of colonialism in the Indic mode.' Modern Asian Studies 38/3:703-44.

Beaujard, Philippe, 1998a. Dictionnaire MalgacheFrançais. Dialecte Tañala, Sud-Est de Madagascar. Avec recherches étymologiques. Paris: I'Harmattan.

2003-04. 'Les arrivées austronésiennes à Madagascar: vagues ou continuum?' Études Océan Indien 35-36:59-147.

2006. 'Le pèlerinage septennal sur le tombeau de l'ancêtre des aristocrates anteoñy (pays antemoro, Sud-Est de Madagascar).' In: Sophie Blanchy, Jean-Aimé Rakotoarisoa, Philippe Beaujard, Chantal Radimilahy (eds.), Les dieux au service du peuple. Itinéraires religieux, médiations, syncrétisme à Madagascar (Paris: Éditions Karthala):403-53.

2007. 'L'Afrique de l'Est, les Comores et Madagascar dans le système-monde avant le XVIe siècle.' In: Didier Nativel et Faranirina V. Rajaonah (eds.), Madagascar et l'Afrique: entre identité insulaire et appartenances historiques (Paris: Karthala):29-102.

2010. 'Les plantes cultivées apportées par les premiers migrants austronésiens à Madagascar.' In: Chantal Radimilahy \& Narivelo Rajaonarimanana (eds.), Civilisations des mondes insulaires (Madagascar, îles de canal de Mozambique, Mascareignes, Polynésie, Guyanes). Mélanges en l'honneur du Professor Claude Allibert (Paris: Karthala):357-86.

2011. 'The first migrants to Madagascar and their introduction of plants: linguistic and ethnological evidence.' Azania 46/2:169-89.

Beccari, O., 1919. 'The palms of the Philippine Islands. Philippine Journal of Science 14:295-362. 
Beckerleg, Susan, 2002. 'Continuity and adaptation by contemporary Swahili boatbuilders in Kenya.' In: David Parkin \& Ruth Barnes (eds.), Ships and the development of maritime technology in the Indian Ocean (New York: RoutledgeCurzon):259-77.

Bell, H.C.P., 1882. The Máldive Islands: an account of the physical features, climate, history, inhabitants, productions, and trade. Colombo: Frank Luker.

Bellina, Bérénice, 2003. 'Beads, social change and interaction between India and South-east Asia' Antiquity 77/296:285-97.

2007. Cultural exchange between India and Southeast Asia: production and distribution of hard stone ornaments (VI C. $B C-V I$ c. $A D)$. Paris: Éditions de la Maison des sciences de l'homme, Éditions Épistèmes.

Bellwood, Peter, 1979. Man's Conquest of the Pacific: the prehistory of Southeast Asia and Oceania. New York: Oxford University Press.

1991. 'The Austronesian dispersal and the origin of languages.' Scientific American 265/1:88-93.

1995. 'Austronesian prehistory in Southeast Asia: homeland, expansion and transformation.' In: Peter Bellwood, James J. Fox \& Darrel Tryon (eds.), The Austronesians: historical \& comparative perspectives. Canberra, Australia: The Australian National University.

1997. Prehistory of the Indo-Malaysian Archipelago. Honolulu: University of Hawai'i. Revised Edition.

2002. 'Farmers, foragers, languages, genes: the genesis of agricultural societies.' In: Peter Bellwood \& Colin Renfrew (eds.), Examining the farming / language dispersal hypothesis (Oxford: Oxbow Books):17-28.

Bellwood, Peter \& Colin Renfrew (eds.), 2003. Examining the farming / language dispersal hypothesis Cambridge: McDonalds Institute Monographs.

Bellwood, Peter \& Eusebio Dizon, 2008. 'Austronesian cultural origins: Out of Taiwan, via the Batanes Islands, and onwards to Western Polynesia.' In: Sanchez-Mazas, Alicia, Roger Blench, Malcolm D. Ross, Ilia Peiros \& Marie Lin (eds.), Past human migrations in East Asia: matching archaeology, linguistics, and genetics (London \& New York: Routledge):23-39.

Bellwood, Peter \& Jared Diamond, 2003. 'Farmers and their languages: the first expansions.' Science 300:597-603.
Bellwood, Peter \& P. Koon, 1989. "Lapita colonists leave boats unburned!' The question of Lapita links with Southeast Asia.' Antiquity 63/240:613-22.

Bemmelen, R.W. van, 1949. The geology of Indonesia. Vol II: economic geology. The Hague: Martinus Nijhoff.

Benedict, Paul K., 1975. Austro-Thai language and culture: with a glossary of roots. New Haven: Hraf Press.

Benfey, Theodor, 1840. 'Indien.' In: J.S. Ersch \& J.G. Gruber (eds.), Allgemeine Encyclopädie der Wissenschaften und Künste (Leipzig: F.U. Brodhaus):2/17:1-356.

Bentley, Jerry H., 1996. 'Cross-cultural interaction and periodization in world history.' The American Historical Review 101/3:749-70.

Berchem, Jörg, 1989-1990. 'Sprachbeziehungen im Bereich des Kulturwortschatzes zwischen den Bantusprachen und dem Malagasy.' SUGIA: Sprache und Geschichte in Afrika 10-11:9-189.

Biggs, Bruce, 2010. Polynesian Lexicon Project Online. Accessed through http://pollex.org.nz/ (2010-11)

Biswas, Sailendra, 2000. Samsad Bengali-English dictionary. Calcutta: Sahitya Samsad. Third edition. Accessed through http://dsal.uchicago.edu/ (201011)

Bjørnstad, Gro, Han Jianlin, Zhao Shenguo \& Olivier Hanotte, 2009. 'Phylogeographic study of chicken mitochondrial DNA reveals ancient Old world maritime and terrestrial trading routes.' Presented at the Ancient Indian Ocean Corridors, 7-8 November 2009, Oxford, United Kingdom.

Black, Eve \& David Samuel, 1991. 'What were sails made of?' The Mariner's Mirror 17:217-26.

Blagden, C. Otto, 1902. 'A comparative vocabulary of Malayan dialects.' Journal of the Royal Asiatic Society of Great Britain and Ireland (July 1902):557-66.

1903. 'Further notes on a Malayan comparative vocabulary.' Journal of the Royal Asiatic Society of Great Britain and Ireland (January 1903):167-79.

Blakney, Charles P., 1963. On "banana" and "iron", linguistic footprints in African history. Auburndale, Mass.: The Hartfort Seminary Foundation. Thesis.

Blench, Roger, 1982. 'Evidence of the Indonesian origins of certain elements of African culture: a review, with special reference to the arguments of A.M. Jones.' African Music: Journal of the International Library of African Music 6/2:81-93. 
2003. 'The movement of cultivated plants between Africa and India in prehistory.' In: Katharina Neumann, Ann Butler \& Stefanie Kahlheber (eds.), Food, fuel and fields: progress in African archaeobotany (Köln: Heinrich-Barth-Institut):27392.

2006. Archaeology, language, and the African past. Lanham, etc.: Altamira Press.

2008. 'A history of fruits on the Southeast Asian mainland.' In Toshiki Osada \& Akinori Uesugi (eds.), Occasional Paper 4: Linguistics, archaeology and the human past (Kyoto: Indus Project, Research Institute for Humanity and Nature):115-37.

2009. 'Bananas and plantains in Africa: reinterpreting the linguistic evidence.' Ethnobotany Research \& Applications 7:363-80.

2010. 'Evidence for the Austronesian voyages in the Indian Ocean.' In: Atholl J. Anderson, James H. Barrett \& Katherine V. Boyle (eds.), The global origins and development of seafaring (Cambridge: McDonald Institute for Archaeological Research):239-48.

2012. 'Vernacular names for taro in the Indo-Pacific region and their possible implications for centres of diversification.' In: Matthew Spriggs, David Addison \& Peter J. Matthews (eds.), Irrigated taro (Colocasia esculenta) in the Indo-Pacific: biological, social and historical perspectives (Osaka: Minpaku):21-43.

Blench, Roger \& Matthew Spriggs (eds.), 1997. Archaeology and Language I: theoretical and methodological orientations. London \& New York: Routledge.

1998. Archaeology and Language II: archaeological data and linguistic hypotheses. London \& New York: Routledge.

1999a. Archaeology and Language III: artefacts, languages, and texts. London \& New York: Routledge.

1999b. Archaeology and Language IV: language change and cultural transformation. London \& New York: Routledge.

Blevins, Juliette, 2007. 'A long lost sister of ProtoAustronesian? Proto-Ongan, mother of Jarawa and Onge of the Andaman Islands.' Oceanic Linguistics 46:154-98.

2009. 'New Austronesian-Ongan comparisons.' International Conference on Austronesian Linguistics 11, 22-26 Jun 2009, Aussois.
Bloch, Jules, 1930. 'Some Problems of Indo-Aryan Philology Forlong Lectures for 1929.' Bulletin of the School of Oriental Studies 5/4:719-56.

Blue, Lucy, Eric Kentley \& Seán McGrail, 1998. 'The vattai fishing boat and related frame-first vessels of Tamil Nadu.' South Asian Studies 14:41-74.

Blussé, Leonard \& Marius P.H. Roessingh, 1984. 'A visit to the past: Soulang, a Formosan village anno 1623.' Archipe/27:63-80.

Blust, Robert, 1976. 'Austronesian culture history: some linguistic inferences and their relations to the archaeological record.' World Archaeology 8/1:1943.

1982. 'An overlooked feature of Malay historical phonology.' Bulletin of the School of Oriental Studies 45/2:284-99.

1983-84. 'Austronesian etymologies: II.' Oceanic Linguistics 22-23/1-2:29-149.

1992. 'Tumbaga in Southeast Asia and South America.' Anthropos 87:443-57.

1995. Austronesian comparative dictionary. Honolulu: University of Hawai'i. Accessed through http://trussel2.com/ACD/ (2012)

1999. 'Linguistics versus archaeology: early Austronesian terms for metals.' In: Roger Blench \& Matthew Spriggs (eds.), Archaeology and Language III: artefacts, languages, and texts (London \& New York: Routledge):127-43.

2000. 'Chamorro historical phonology.' Oceanic Linguistics 39/1:83-122.

2002. 'The history of faunal terms in Austronesian languages.' Oceanic Linguistics 41/1:89-139.

2005. 'Borneo and iron: Dempwolff's *besi revisited”.' Bulletin of the Indo-Pacific Prehistory Association 25/3:31-40.

2007. 'On datus, ancient and modern.' In: Loren Billings \& Nelleke Goudswaard (eds.), Piakandatu ami Dr. Howard P. McKaughan (Manila: SIL Philippines):36-51.

2008. 'Is there a Bima-Sumba subgroup?'Oceanic Linguistics 47/1:45-113.

2009a. The Austronesian languages. Canberra: Pacific Linguistics Series 602.

2009b. 'The position of the languages of Eastern Indonesia: a reply to Donohue and Grimes.' Oceanic Linguistics 48/1:36-77.

2010. 'The greater North Borneo hypothesis.' Oceanic Linguistics 49/1:44-118. 
Boeles, J.J., 1966. 'A note on Tamil relations with South Thailand and the identification of Ptolemy's Tacola.' The Journal of the Siam Society LIV/1:221-30.

Boivin, Nicole, Roger Blench \& Dorian Q. Fuller, 2009. 'Archaeological, linguistic and historical sources on ancient seafaring: a multidisciplinary approach to the study of early maritime contact and exchange in the Arabian Peninsula.' In: M. Petraglia \& J. Rose (eds.), The evolution of human populations in Arabia (New York: Springer):1-44.

Boivin, Nicole, Alison Crowther, Richard Helm \& Dorian Q. Fuller, in press. 'East Africa and Madagascar in the Indian Ocean world.' Journal of World Prehistory.

Bonavia, Emanuel, 1890. The cultivated oranges and lemons etc. of India and Ceylon with researches into their origin and the derivation of their names, and other useful information. London: W.H. Allen.

Bosch, F.D.K., 1956. 'C.C. Berg and ancient Javanese history.' Bijdragen tot de Taal-, Land- en Volkenkunde van Nederlandsch-Indië 112:1-24.

1961. 'The problem of the Hindu colonisation of Indonesia.' In: F.D.K. Bosch, Selected Studies in Indonesian Archaeology (The Hague: Martinus Nijhoff):3-22.

Bostock, John \& Henry Thomas Riley (eds.), 1892. The natural history of Pliny. Volume 3. London: G. Bell and sons.

Bosworth, C.E., 1997. 'Sayābidja.' In: C.E. Bosworth, E. van Donzel, W.P. Heinrichs \& G. Lecomte (eds.), The Encyclopaedia of Islam: Volume IX (Leiden: Brill):97-8.

Bowen, Richard LeBaron, 1952. 'Primitive watercraft of Arabia.' The American Neptune 12/3:186-221.

1953. 'Eastern sail affinities.' The American Neptune 13/1:81-117, 185-211.

Braine, Jean Critchfield, 1970. Nicobarese grammar (Car dialect). Berkeley: University of California. $\mathrm{PhD}$ dissertation.

Brindley, H.H., 1926. 'Early pictures of lateen sails.' The Mariner's Mirror 12:9-22.

1932. 'Primitive craft - evolution or diffusion.' The Mariner's Mirror 18:303-17

Braginsky, Vladimir, 1998. 'Two eastern Christian sources on medieval Nusantara.' Bijdragen tot de Taal-, Land- en Volkenkunde 154/3:367-96.

Brandes, J., 1889. 'De koperen platen van Sĕmbiran (Boeleleng, Bali), oorkonden in het Oud-
Javaansch en het Oud-Balineesch'. Tijdschrift voor Indische Taal-, Land- en Volkenkunde 33:16-56.

Brown, C.C., 1952. 'Sějarah Mělayu or 'Malay Annals'.' Journal of the Malayan Branch of the Royal Asiatic Society 25/2-3:6-270.

Brown, Charles Philip. 1903. A Telugu-English dictionary. Madras: Promoting Christian Knowledge. Second edition. Accessed through http://dsal.uchicago.edu/ (2010-11)

Bruinessen, Martin van, 1995. Kitab Kuning: pesantren dan tarekat. Tradisi-tradisi Islam di Indonesia. Bandung: Penerbit Mizan.

Buccellati, G. \& M.K. Buccellati, 1984. 'Terqa: the first eight seasons.' Annales Archéologiques Arabes Syriennes 33/2:47-67.

Buenaobra, Nita P., 2004. Bokabularyong traylingguwal: Kapampangan Filipino English. San Miguel: Komisyon sa Wikang Filipino.

Burkill, I.H., 1924. 'A list of oriental vernacular names of the genus Dioscorea.' The Gardens' Bulletin, Straits Settlements 3/4-6:121-244.

1938. 'The contact of the Portuguese with African food-plants which gave words such as 'yam' to European language.' Proceedings of the Linnean Society of London 150/2:84-95.

1966 [1934]. A dictionary of the economic products of the Malay Peninsula. Kuala Lumpur: Ministry of Agriculture and Co-operatives. Two volumes.

Burrow, T., 1943. 'Dravidian Studies III.' Bulletin of the School of Oriental and African Studies 11/1:12239.

1945. 'Dravidian Studies V.' Bulletin of the School of Oriental and African Studies 11/3:595-616.

1948. 'Dravidian Studies VII.' Bulletin of the School of Oriental and African Studies 12/2:365-96.

2001 [1955]. The Sanskrit language. Delhi: Motilal Banarsidass. Reprint.

Burrow, T. \& M.B. Emenau, 1984. Dravidian etymological dictionary. Oxford: Clarendon Press. Second edition.

Caldwell, Robbert, [1856] 1875. A comparative grammar of the Dravidian of South-Indian family of languages. London: Trübner. Second edition, revised and enlarged.

Campbell, A., 1899. A Santali-English dictionary. Pokhuria, Manbhum: The Santal Mission Press.

Campbell, I.C., 1995. 'The lateen sail in world history.' Journal of World History 6/1:1-23. 
Campbell, Lyle, 2004. Historical linguistics: an introduction. Edinburgh: Edinburgh University Press.

Carreel, F., D. Gonzalez de Leon, P. Lagoda, C. Lanaud, C. Jenny, J.P. Horry \& H. Tezenas du Montcel, 2002. 'Ascertaining maternal and paternal lineage within Musa chloroplast and mitrochondrial DNA RFLP analyses.' Genome 45:679-92.

Carter, R., 2006. 'Boat remains and maritime trade in the Persian gulf during the sixth and fifth millennia BC.' Antiquity 80/307:52-63.

Casparis, J.G. de, 1950. Prasasti Indonesia I. Bandung: A.C. Nix.

1956. Prasasti Indonesia II. Bandung: Masa Baru.

1961. 'New evidence on cultural relations between Java and Ceylon in ancient times.' Artibus Asiae 24/3-4:241-8.

1983. India and maritime South East Asia: a lasting relationship. Kuala Lumpur: University of Malaya.

1988. 'Some notes on words of 'Middle-Indian' origin in Indonesian languages (especially Old Javanese).' In: Luigi Santa Maria, Faizah Soenoto Rivai \& Antonio Sorrentino (eds.), Papers from the III European Colloquium on Malay and Indonesian Studies, Naples, 2-4 June, 1981 (Naples: Instituto Universitario Orientale):51-69.

Casson, Lionel, 1971. 'The origin of the lateen.' The American Neptune 31:49-51.

1980. 'Periplus Maris Erythraei: three notes on the text.' The Classical Quarterly (new series) 30/2: 495-7.

1991. The ancient mariners: seafarers and sea fighters of the Mediterranean in ancient times. Princeton, New Jersey: Princeton University Press. Second edition.

1994. Ships and seafaring in ancient times. London: British Museum Press.

Castillo, Christina \& Dorian Q. Fuller, 2010. 'Still too fragmentary and dependent upon chance? Advances in the study of early Southeast Asian archaeobotany.' In: Bérénice Bellina, Elisabeth A. Bacus, Thomas Oliver Pryce \& Jan Wisseman Christie (eds.), 50 years of archaeology in Southeast Asia: essays in honour of lan Glover (Bangkok: River Books):91-110.

Cense, A.A., 1979. Makassaars-Nederlands woordenboek. 's-Gravenhage: Martinus Nijhoff. In collaboration with Abdoerrahim.
Chakrabarti, Dilip, 1976. 'The beginning of iron in India.' Antiquity 50/197:114-24.

Chakravarti, Adhir, 1978. The Sdok Kak Thom Inscription. Part I: A study in Indo-Khmèr civilization. Calcutta: Sanskrit College.

Chami, Felix A. \& Paul J. Msemwa, 1997. 'A new look at culture and trade on the Azanian Coast.' Current Anthropology 38/4:673-7.

Chang, Kwang-chih, 1969. Fengpitou, Tapenkeng, and the prehistory of Taiwan. New Haven: Yale University.

1970. 'The beginnings of agriculture in the Far East.' Antiquity 44/175:175-85.

Chappell, J., J. Head \& J. Magee, 1996. 'Beyond the radiocarbon limit in Australian archaeology and Quaternary research.' Antiquity 70/269:543-52.

Chatterji, S.K. \& Bagchi, P.C., 1929. 'Some more Austric words in Indo-Aryan.' In: Sylvain Lévi, Jean Przyluski \& Jules Bloch (eds.), Pre-Aryan and preDravidian in India ([Calcutta:] University of Calcutta; translation Prabodh Chandra Bagchi):ixxxix.

Chaudhuri, Mamata, 1976. 'Ship-building in the Yuktikalpataru and Samarangana Sutradhara.' Indian Journal of History of Science 11:137-47.

Chhabra, B.Ch. (ed.), 1956-57. Department of Archaeology annual report on Indian epigraphy for 1956-57. Delhi: Government of India Press.

Chia, Stephen, Ming Soon, 1998. 'The obsidian industry at Bukit Tengkorak, Sabah, Malaysia.' Presented at the $16^{\text {th }}$ Congress of the Indo-Pacific Prehistory Association, 1-8 July 1998, Melaka, Malaysia.

Christie, Anthony, 1957. 'An obscure passage from the

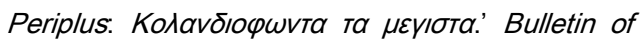
the School of Oriental and African Studies 29:34553.

Christie, Jan Wisseman, 1998. 'The medieval Tamillanguage inscriptions in Southeast Asia and China.' Journal of Southeast Asian Studies 29:239-68.

Clercq, Frederick Sigismund Alexander de, 1876. Het Maleisch der Molukken. Lijst der meest voorkomende vreemde en van het gewone Maleisch verschillende woorden, zooals die gebruikt worden in de residentiën Manado, Ternate, Ambon met Banda en Timor Koepang, benevens eenige proeven van aldaar vervaardigde pantoens, prozastukken en gedichten. Batavia: W. Bruining. 
1890. Bijdragen tot de kennis der Residentie Ternate. Leiden: E.J. Brill

1927. Nieuw plantkundig woordenboek voor Nederlandsch-Indië. Amsterdam: J.H. de Bussy. Second edition. Edited by A. Pulle.

Cleuziou, S. \& M. Tosi, 1994. 'Black boats of Magan.' In: A. Parpola \& P. Koskikallio (eds.), South Asian Archaeology 1993. Voll. // (Helsinki: Soumalainen Tiedakatemia):745-61.

Clough, B., 1892. Sinhalese-English dictionary. Colombo: Wesleyan Mission Press, Kollupitiya.

Cockburn, Aidan, Robin A. Barraco, William H. Peck \& Theodore A. Reyman, 1998 [1980]. 'A classic mummy: PUM II.' In: Aidan Cockburn, Eve Cockburn \& Theodore A. Reyman (eds.), Mummies, disease \& ancient cultures (Cambridge: Cambridge University Press):69-90. Second edition.

Codrington, Humphrey William, 1994 [1929]. A short history of Ceylon. New Delhi / Madras: Asian Education Services. Reprint.

Cœdès, George, 1910. Textes d'auteurs grecs et latins relatifs a l'Extrême-Orient depuis le IVe siècle av. J.-C. jusqu'au XIVe siècle. Paris: Ernest Leroux.

1918. 'Le royaume de Çrivijaya.' Bulletin de l'Ecole française d'Extrême-Orient 18/1:1-36.

1927. 'A propos de la chute du royaume de Çrîvijaya.' Bijdragen tot de Taal- Land- en Volkenkunde 83:459-72.

1930. 'Les inscriptions malaises de Çrīijaya.' Bulletin de l'École Française d'Extrême Orient 30:29-80

1961. Recueil des Inscriptions du Siam, Deuxième Partie: Inscriptions de Dvāravati, de Çrivijaya et de Lāvo. Bangkok: The Siam Society.

1968. The Indianized states of Southeast Asia. Honolulu: East-West Center Press. Edited by Walter F. Vella. Translated by Susan Brown Cowing.

Collett, N.A., 1986. A grammar, phrase book and vocabulary of Baluchi (as spoken in the Sultanate of Oman). Camberley: N.A. Collett. Second edition. Accessed through http://dsal.uchicago.edu/dictionaries/ (2010-11)

Cooke, Michael, 1988. 'Makassar and Northeast Arnhem Land: missings links and living bridges.' Indonesian Studies: Bulletin of the Indonesian Cultural and Educational Institute 5/1:17-27.
Coolsma, S., 1913. Soendaneesch-Hollandsch woordenboek. Leiden: A.W. Sijthoff. Second edition.

Cotterell, Brian \& Johan Kamminga, 1990. Mechanics of pre-industrial technology: an introduction to the mechanics of ancient and traditional material culture. Cambridge: University of Cambridge.

Cowell, E.B. (ed.), 1895. The Jātaka or stories of the Buddha's former births. Vol. II. Cambridge: University Press. Translated by W.H.D. Rouse.

Crawfurd, John, 1820. History of the Indian Archipelago: containing an account of the manners, arts, languages, religions, institutions, and commerce of its inhabitants. Edinburgh: Archibald Constable. Three volumes.

Crone, Patricia, 1987. Meccan trade and the rise of Islam. Oxford: Basil Blackwell.

Crossland, Cyril, 1918. 'Notes on the East African outrigger canoe.' Man 18:166-7.

Crowley, James Dale, Vay Tieng \& Wain Churk, 2007. Tampuan Khmer English dictionary: with English Khmer Tampuan glossary. Cambodia: EMU International \& National Language Institute of the Royal Academy of Cambodia. Accessed through http://sealang.net/ (2010-11)

Culwick, A.T. \& Culwick G.M., 1936. 'Indonesian echoes in Central Tanganyika.' Tanganyika notes and records 2:60-6.

Cushing, J.N., 1881. Shan-English Dictionary. Rangoon: American Baptist Mission Press. Accessed through http://sealang.net/ (2010-11)

Dahl, Otto Christian, 1951. Malgache et Maanjan. Oslo: Egede-Instituttet.

Dakers, C.H., 1939. 'The Malay coins of Malacca.' Journal of the Malayan Branch of the Royal Asiatic Society 17/1:1-12.

Dakshi, A., 2003. 'Onomatopeia in Bengali in comparison with Oriya and Hindi.' International journal of Dravidian linguistics 32:123-36.

Dalby, Andrew, 2000. Dangerous tastes: the story of spices. London: British Museum Press.

Dale, Godfrey, 1920. The peoples of Zanzibar: their customs and religious beliefs. Westminster: the Universities' Mission to Central Africa.

Dalgado, Sebastião Rodolfo, 1913. Influência do vocabulário Português em línguas Asiáticas (abrangendo cêrca de cinqúenta idiomas). Coimbra: Imprensa da Universidade.

1919. Glossário Luso-Asiático. Coimbra: Imprensa da Universidade. Two volumes. 
Damais, Louis-Charles, $1960 . \quad$ 'Études sinoindonésiennes: quelques titres javanais de l'époque de Song.' Bulletin de l'Ecole française d'Extrême-Orient 50/1:1-35.

Dames, Mansel Longworth, 1922. A text book of the Balochi language: consisting of miscellaneous stories, legends, poems and Balochi-English vocabulary. Lahore: Printed by the Superintendent, Govt. Print., Punjab.

Das, Sarat Chandra, 1902. A Tibetan - English dictionary with Sanskrit synonyms. Calcutta: Bengal Secretariat Book Depôt.

Das, A.R., 1977. A study on the Nicobarese language. Calcutta: Anthropological Survey of India. Access through http://sealang.net/

Dasgupta, D. \& S.R. Sharma, 1982. A hand book of Onge language. Calcutta: Anthropological Survey of India.

David, Irrigaray, 1952. Lexiques des dialectes du Nord de Madagascar. Toliary: Velonandro. Accessed via www.malagasyworld.org (2010-11)

Davidson, Jeremy H.C.S., 1975. 'A new version of the Chinese-Vietnamese vocabulary of the Ming Dynasty_II.' Bulletin of the School of Oriental and African Studies 38/3:586-608.

De, Harinath,1906-07. 'A note on the word 'lankāro'.' Journal of the Pâli Text Society (1906-07):173.

Dean, Malcolm, 2001. Lymphatic filariasis - The quest to eliminate a 4000 year old disease. Hollis $\mathrm{NH}$ : Hollis Publishing Company.

Deloche, Jean, 1983. 'Études sur la circulation en inde: III. Le bateau de Tiruppuțaimarutūr.' Bulletin de l'École Française d'Extrême-Orient 71:1-11.

1994. Transport and communications in India prior to steam locomotion. Volume II: Water transport. Dehli: Oxford University Press. Translated by James Walker.

1996. 'Iconographic evidence on the development of boat and ship structures in India ( $2^{\text {nd }}$ C. B.C. $-15^{\text {th }}$ c. A.D.). A new approach.' In: Himanshu Prabha Ray \& Jean-François Salles (eds.), Tradition and archaeology: early maritime contacts in the Indian Ocean (New Dehli: Manohar):199-224.

Dempwolff, Otto, 1934-38. Vergleichende Lautlehre des Austronesischen Wortschatzes. Berlin: Dietrich Reimer. Three volumes.

Denham, T.P., S.G. Haberle, C. Lentfer, R. Fullagar, J. Field, M. Therin, N. Porch \& B. Winsborough, 2003. 'Origins of agriculture at Kuk Swamp in the highlands of New Guinea.' Science 301:189-93.
Denham, Tim \& Mark Donohue, 2009. 'PreAustronesian dispersal of banana cultivars West from New Guinea: linguistic relics from Eastern Indonesia.' Archaeology in Oceania 44:18-28.

Devic, L., Marcel (translator), 1928. The book of the Marvels of India. London: George Routledge \& Sons. Translated into English by Peter Quennell.

Dhal, U.N., 1999. 'Indian maritime activities: Vedic, Epic and Purānic sources.' In: K.S. Behera (ed.), Maritime history of India (New Delhi: Aryan Books International):11-4.

Dick-Read, Robert, 2005. The phantom voyagers: evidence of Indonesian settlement in Africa in ancient times. Winchester: Thurlton publishing.

Diffloth, Gérard, 2005. 'The contribution of linguistic palaeontology to the homeland of Austro-Asiatic.' In: Laurent Sagart, Roger Blench \& Alicia Sanchez-Mazas (eds.), The peopling of East Asia: putting together archaeology, linguistics and genetics (New York: RoutledgeCurzon):77-80.

Disanayaka, J.B., 1978. 'In search of a "lost language": some observations on the complex origins of Sinhala.' The Ceylon historical journal 25:51-7.

Djajadiningrat, Hoesein, 1934. Atjèhsch-Nederlandsch woordenboek. Batavia: Landsdrukkerij. Two volumes.

Donkin, R.A., 1999. Dragon's brain perfume: an historical geography of camphor. Leiden, Boston, Köln: Brill.

2003. Between East and West: the Moluccas and the traffic in spices up to the arrival of Europeans. Philadelphia: American Philosophical Society.

Donohue, Mark \& Tim Denham, 2009. 'Banana (Musa spp.) domestication in the Asia-Pacific region: Linguistic and archaeobotanical perspectives.' Ethnobotany Research \& Applications 7:293-332.

Donque, Gérald, 1965. 'Le contexte océanique des anciennes migrations: vents et courants dans l'Océan Indien.' Taloha 1:43-59.

Doran, Edwin, 1981. Wangka: Austronesian canoe origins. [s.I.:]Texas A\&M University Press.

Douglas, Carstairs, 1899. Chinese-English dictionary of the vernacular or spoken language of Amoy, with the principal variations of the Chang-chew and Chin-chew dialects. London: Publishing office of the Presbyterian Church of England. New edition.

Drakard, Jane, 1989. 'An Indian Ocean port: sources for the earlier history of Barus.' Archipe/37:53-82. 
Ducourneau, Axel, 2010. 'Approche phylogéographique du peuplement de l'océan Indien occidental.' In: Chantal Radimilahy \& Narivelo Rajaonarimanana (eds.), Civilisations des mondes insulaires (Madagascar, îles de canal de Mozambique, Mascareignes, Polynésie, Guyanes). mélanges en l'honneur du Professor Claude Allibert (Paris: Karthala):855-71.

During Caspers, E.C.L., 1965. 'Further evidence for cultural relations between India, Baluchistan, and Iran and Mesopotamia in early dynastic times.' Journal of Near Eastern Studies 24/1-2:53-6.

Dutton, Tom, 1994. 'Sago and related items in early Austronesian vocabulary.' In: A.K. Pawley \& M.D. Ross (eds.), Austronesian terminologies: continuity and change (Canberra: Australian National University, Pacific Linguistics Series C 127):10125.

Dyen, Isidore, 1946. 'Malay tiga 'Three'.' Language 22/2:131-7

1952. 'Malay tiga "Three”: a further note.' Language 28:465-72.

1965. A lexicostatistical classification of the Austronesian languages. Baltimore: Waverly Press. Indiana University publications in anthropology and linguistics, Memoir 19.

Eager, Heidi, Jeremy Searle, Alexandra Trinks, Greger Larson, Keith Dobney \& Nicole Boivin, 2012. 'Commensal small mammal translocations as a proxy for human trade and contact in ancient East Africa.' Presented at the East Africa in the Indian Ocean World I/ workshop, 22-23 March 2012, Oxford.

Edwards McKinnon, E., 1996. 'Mediaeval Tamil involvement in northern Sumatra, c11-c14 (the gold and resin trade).' Journal of the Malaysian Branch of the Royal Asiatic Society 69/1:85-99.

2011. 'Continuity and change in South Indian involvement in northern Sumatra: the inferences of archaeological evidence from Kota Cina and Lamreh.' In: Pierre-Yves Manguin, A. Mani \& Geoff Wade (eds.), Early interactions between South and Southeast Asia: reflections on cross-cultural exchange (Singapore: Institute of Southeast Asian Studies):137-60.

Edwards, E.D. \& C.O. Blagden, 1931. 'A Chinese vocabulary of Malacca Malay words and phrases collected between A.D. 1403 and 1511 (?).' Bulletin of the School of Oriental Studies 6/3:71549.
Eggink, H.J., 1936. Angkola- en Mandailing-Bataksch - Nederlandsch woordenboek.Bandoeng: A.C. Nix.

Ehret, Christopher, 2011. History and the testimony of language. Berkeley \& Los Angeles: University of California Press.

Eliot, Charles, 1998. Hinduism and Buddhism: an historical sketch, Volume 1. Richmond: Curzon Press. Reprint.

Erp, Th. van, 1923. Voorstellingen van vaartuigen op de reliefs van den Boroboedoer. 's-Gravenhage: Ādi-Poestaka.

Evans, Nicholas, 1992. 'Macassan loanwords in Top End languages.' Australian Journal of Linguistics 12:45-91.

Ferlus, Michel, 2010. 'The Austroasiatic vocabulary for rice: its origin and expansion.' Journal of the Southeast Asian Linguistics Society 3/2:61-76.

Ferrand, M. Gabriel, 1904a. Un texte ArabicoMalgache du XVIe siècle: transcrit, traduit et annote d'après les mss 7 et 8 de la Bibliothèque nationale. Paris: Imprimerie Nationale. Notices et extraits des manuscrits de la Bibliothèque nationale et autres bibliothèques 38 .

1904b. 'Madagascar et les iles Uâq-Uâq.' Journal Asiatique 3 (10 $10^{\text {th }}$ series):489-503.

1907. 'Les îles Râmny, Lâmery, Wâkwâk, Komor des géographes arabes, et Madagascar.' Journal Asiatique 10/1:433-566.

1908. 'L'origine africaine des malgaches.' Journal Asiatique (10 th series) $11: 353-500$.

1910. 'Les voyages des javanais à Madagascar.' Journal Asiatique (10 ${ }^{\text {th }}$ series) $15: 281-330$.

1913-14. Relations de voyages et textes géographiques arabes, persans et turks relatifs a l'Extrême-Orient du VIIle au XVIIle siècles. Paris: Ernest Leroux. Two volumes.

1918. 'Malaka, le Malāyu et Malāyur.' Journal Asiatique (11 th series) $11: 391-484$.

1919a. 'Le K'ouen-Louen et les anciennes navigations interocéaniques dans les mers du sud.' Journal Asiatique (1 $11^{\text {th }}$ series) $13: 239-333,431-92$, 14:5-68, 201-41.

1919b. 'Comptes rendus.' Journal Asiatique (11 th series) 14:149-200.

1924. 'l'Élément persan dans les textes nautiques arabes des XVe et XVle siècles.' Journal Asiatique (11 th series) 204:192-257.

1932a. 'Le Wāḳwāḳ. Est-il le Japon?' Journal Asiatique (11 $1^{\text {th }}$ series) $220: 193-243$. 
1932b. 'Quatre textes éphigraphiques malayosanskrits de Sumatra et de Banka.' Journal Asiatique (11th series) 221:271-326

Ferrell, Raleigh, 1969. Taiwan aboriginal groups: problems in cultural and linguistic classification. Nankang, Taipei: Academia Sinica. Institute of Ethnology Academia Sinica Monograph 17.

1982, Paiwan Dictionary. Canberra: Pacific Linguistics C-73.

Ferrer, Alicia S., 2003. Diksyunaryo Filipino - English. Manilla: MECS Publishing House.

Fischer, C.E.C., 1927. 'Santalum album in India.' Bulletin of miscellaneous information (Royal Gardens, Kew) 5:200-2.

1938. 'Where did the sandalwood tree (Santalum album Linn.) evolve?' Journal of the Bombay Natural History Society 40:458-66.

FitzGerald, R.T.D., 1939. 'The jong (جوغ)), a model boat with an outrigger from Malaya.' Man 39:156-7.

Fitzpatrick, Scott M. \& Richard Callaghan, 2008. 'Seafaring simulations and the origin of prehistoric settlers to Madagascar.' In: Geoffrey Clark, Foss Leach \& Sue O'Connor (eds.), Islands of inquiry. colonisation, seafaring and the archaeology of maritime landscapes (Canberra: ANU E Press):4758.

Flacourt, Étienne de, 1658, Histoire de la grande isle Madagascar. Paris: Alexandre Lesselin.

Flecker, M., 2000. 'A 9th-century Arab or Indian shipwreck in Indonesian waters.' The International Journal of Nautical Archaeology 29/2:199-217.

Foale, Mike, 2003. The coconut odyssey: the bounteous possibilities of the tree of life. Canberra: Australian Centre for International Agricultural Research.

Fokker, A.A., 1910. 'Quelques mots espagnols et portugais d'origine orientale, dont l'étymologie ne se trouve pas ou est insuffisamment expliquée dans les dictionnaires.' Zeitschrift für romanische Philologie 34:560-8.

Forbes, Andrew D.W., 1981. 'Southern Arabia and the Islamicisation of the central Indian Ocean archipelagoes.' Archipe/21:55-92.

Forbes, R.J., 1971. Studies in ancient technology. Volume VIII. Leiden: E.J. Brill. Second edition.

Fox, R.B., 1970. The Tabon caves: archaeological explorations and excavations on Palawan island, Philippines. Manila: National Museum.

Freeman-Grenville, G.S.P., 1962. The medieval history of the coast of Tanganyika with special reference to recent archaeological discoveries. London / New York / Toronto: Oxford University Press.

Friederici, George, 1912. Wissenschaftiche Ergebnisse einer amtlichen Forschungsreise nach dem Bismarck-Archipel im Jahre 1908. II. Beitrage zur Völker- und Sprachekunde von DeutschNeuguinea. Berlin: Ernst Siegfried und Sohn. Ergänzungsheft Nr. 5 der Mitteilungen aus den Deutschen Schutzgebieten.

1928. 'Die vorkolumbischen Verbindungen der Südsee-Völker met Amerika.' Mitteilungen aus den Deutschen Schutzgebieten 36:27-51.

Frobenius, Leo, 1898. Der Ursprung der afrikanischen Kulturen. Berlin: Gebrüder Borntraeger.

Fuller, Dorian Q., 2003. 'African crops in prehistoric South Asia: a critical review.' In: Katharina Neumann, Ann Butler \& Stefanie Kahlheber (eds.), Food, fuel and fields: progress in African archaeobotany (Köln: Heinrich-Barth-Institut):23971.

2007. 'Non-human genetics, agricultural origins and historical linguistics in South Asia.' In: M.D. Petraglia \& B. Allchins (eds.), The evolution and history of human populations in South Asia: interdisciplinary studies in archaeology, biological anthropology, linguistics and genetics (New York: Springer Press):393-443.

Fuller, Dorian Q. \& Marco Madella, 2009. 'Banana cultivation in South Asia and East Asia: a review of the evidence from archaeology and linguistics.' Ethnobotany Research \& Applications 7:333-51.

Fuller, Dorian Q., Nicole Boivin \& Ravi Korisettar, 2007. 'Dating the Neolithic of South India: new radiometric evidence for key economic, social and ritual transformations.' Antiquity 81/312:755-78.

Fuller, Dorian Q. \& Nicole Boivin, 2009. 'Crops, cattle and commensals across the Indian Ocean: current and potential archaeobiological evidence.' Études Océan Indien 42-43:13-46.

Fuller, Dorian Q., Nicole Boivin, Robin Allaby \& Tom Hoogervorst, 2011a. 'Across the Indian Ocean: prehistoric movements of plants and animals.' Antiquity 85/328:544-58.

Fuller, Dorian Q, Jacob van Etten, Katie Manning, Cristina Castillo, Eleanor Kingwell-Banham, Alison Weisskopf, Ling Qin, Yo-Ichiro Sato \& Robert J Hijmans, 2011b. 'The contribution of rice agriculture and livestock pastoralism to prehistoric methane levels: an archaeological assessment.' 
The Holocene [special issue for August 2011]:1-17. DOI: 10.1177/0959683611398052.

Galgal, 1886. 'Galgal.' Notes and queries of the Straits Branch of the Royal Asiatic Society (Singapore: Government Printing Office):100.

Ganguly, Pranab, 1966. 'Vocabulary of the negritos of Little Andaman with grammatical notes and materials.' Bulletin of the Anthropological survey of India 15/1-4:1-30.

Garris, A.J., T.H. Tai, J. Coburn, S. Kresovich \& S. McCouch, 2005. 'Genetic structure and diversity in Oryza sativa L.' Genetics 169:1631-8.

Geest, Peter de, 2006. 'The discovery and protection of one of the most important ancient metropolitan cave sites of the Middle-East: Hoq Cave on Soqotra Island, Yemen.' Presentation at the 14th International Karstological School "Classical Karst", Postojna, Slovenia, June-July 2006.

Geiger, Wilhelm, 1916. Pāli Literatur und Sprache. Strassburg: Verlag von Karl J. Trübner.

1941. An etymological glossary of the Sinhalese language. Colombo: The Royal Asiatic Society, Ceylon Branch.

1953. Cülavamsa, being the more recent part of the Mahāvamsa. Colombo: Ceylon Government Information Department. Two volumes.

Gerini, G.E., 1897. 'Notes on the early geography of Indo-China.' Journal of the Royal Asiatic Society of Great Britain and Ireland (July 1897):551-77.

1909. Researches on Ptolemy's Geography of Eastern Asia (Further India and Indo-Malay Archipelago). London: Royal Asiatic Society \& Royal Geographic Society.

Gibbons, John R.H. \& Fergus G.A.U. Clunie, 1986. 'Sea level changes and Pacific prehistory: new insight into early human settlement of Oceania.' The Journal of Pacific History 21/2:58-82.

Gibson, Charles E., 1958. The Story of the ship: from the earliest days to the present. London \& New York: Abelard-Schuman.

Giles, Herbert A., 1886. A glossary of reference on subjects connected with the Far East. Hongkong: Lane, Crowford \& Co, Shanghai \& Yokohama: Kelly \& Walsh, London: Bernard Quaritch. Second edition.

1892. A Chinese-English dictionary. London: Bernard Quaritch.

Glidden, Harold W., 1937. 'The lemon in Asia and Europe.' Journal of the American Oriental Society 57/4:381-96.
1942. 'A comparative study of the Arabic nautical vocabulary from Al-'Aqabah, Transjordan.' Journal of the American Oriental Society 62/1:68-72.

Glover, I.C., 1996. 'Recent archaeological evidence for early maritime contacts between India and SE Asia.' In: Himanshu Prabha Ray \& Jean-François Salles (eds.), Tradition and archaeology: early maritime contacts in the Indian Ocean (New Dehli: Manohar):129-51.

(forthcoming). 'The Bronze Age to Iron Age transition in Southeast Asia - a comparative perspective.'

Gmitter, Frederick G. \& Xulan Hu, 1990. 'The possible role of Yunnan, China, in the origin of contemporary citrus species (Rutaceae).' Economic Botany 44/2:267-77.

Goeje, M.J. de, 1894. 'De Sajâbidja.' In: Feestbunde/ van taal-, letter-, geschied- en aardrijkskundige bijdragen ter gelegenheid van zijn tachtigsten geboortedag aan Dr. P.J. Veth, oud-hoogleraar, door eenige vrienden en oud-leerlingen aangeboden (Leiden: E.J. Brill):10-2.

Gomperts, Amrit, forthcoming. Javano-Sanskrit and Old Javanese: an analysis of technical texts. Leiden: University of Leiden. PhD dissertation.

Gonda, J., 1932. 'Etymologica.' Acta Orientalia 10:326-35.

1938. 'Pigafetta's vocabularium van het "MolukkenMaleisch".' Bijdragen tot de Taal-, Land- en Volkenkunde van Nederlandsch-Indië 97:101-24.

1941. 'Enkele opmerkingen over woordvorming.' Bijdragen tot de Taal- Land- en Volkenkunde van Nederlandsch-Indië 100:127-72.

1973. Sanskrit in Indonesia. New Dehli: International Academy of Indian Culture. Second edition.

Gopal, Lallanji, 1999. 'Indian shipping in early mediaeval period.' In: K.S. Behera (ed.), Maritime history of India (New Delhi: Aryan Books International):90-106.

Goris, R. 1960. 'The position of the blacksmiths.' In: A. van Marle (ed.), Bali: studies in life, thought and ritual (The Hague \& Bandung: W. van Hoeve):28999.

Gosden, Chris, 1992. 'Production systems and the colonization of the western Pacific.' World Archaeology 24/1:55-69.

Gourjon, G., G. Boëtsch \& A. Degioanni, 2011. 'Gender and population history: sex bias revealed by studying genetic admixture of Ngazidja 
population (Comoro Archipelago).' American Journal of Physical Anthropology 144/4:653-60.

Gray, Albert (ed.), 1887. The voyage of François Pyrard of Laval to the East Indies, the Maldives, the Moluccas and Brazil. London: Hakluyt Society. Two volumes.

Gray, E.W., 1970. 'Review [The Spice Trade of the Roman Empire 29 B.C.-A.D. 641 by J. I. Miller]. The Journal of Roman Studies 60:222-4.

Gray, John, 1954. 'The Wadebuli and the Wadiba.' Tanganyika notes and records 36:22-42.

Greenfeld, Jonas C. \& Manfred Mayrhofer, 1967. 'The 'algummīm/almuggīm-problem reexamined.' Supplements to Vetus Testamentum 17:83-9.

1971. Boats and boatsmen of Pakistan. Newton Abbot: David \& Charles.

Greenhill, Basil, 1957. 'The boats of East Pakistan: a preliminary study.' The Mariner's Mirror 43/2:10634, 43/3:203-15.

Greeshmalatha, A.P. \& Victor G. Rajamanickam, 1995. 'The ship building technology: as practised in Beypore, Kerala.' Proceedings of the International Seminar on Shipbuilding, Navigation and Intercultural Movements in the Indian Ocean Regions (A.D. 1400-1800), 6-10 Feb 1995, Pondicherry.

Grimaldi, Ilaria, Robin Allaby \& Nicole Boivin, 2012. 'Evaluating early African connections using Colocasia esculenta (L.) Schott history and genetics: preliminary results.' Presented at the East Africa in the Indian Ocean World I/ workshop, 22-23 March 2012, Oxford.

Grimes, A., 1941. 'The journey of Fa-Hsien from Ceylon to Canton.' Journal Malayan Branch Royal Asiatic Society xix/ii:76-92.

Groeneveldt, W.P., 1880. 'Notes on the Malay Archipelago and Malacca, compiled from Chinese sources.' Verhandelingen van het Bataviaasch Genootschap van Kunsten en Wetenschappen 39:1-144

Groot, J.J.M. de, 1894. 'lets naders omtrent de verbreiding en de geschiedenis van het betelkauwen.' In: Feestbundel van taal-, letter-, geschied-, en aardrijkskundige bijdragen ter gelegenheid van zijn tachtigsten geboortedag aan Dr. P.J. Veth, oud-hoogleraar, door eenige vrienden en oud-leerlingen aangeboden (Leiden: Brill):265-72.

Grottanelli, Vinigi L., 1947. 'Asiatic influences on Somali culture.' Ethnos 13:153-81.
Gudger, 1919. 'On the use of the sucking-fish for catching fish and turtles: studies in Echeneis or Remora.' The American Naturalist 53/627:289-311, 628:446-67, 629:515-25.

Guermonprez, Jean-François. 1987. Les pandé de Bali: laformation d'une <<caste>> et la valeur d'un titre. Paris: École Française d'Extrême-Orient.

Gueunier, Noël Jacques, 1986. Lexique du dialecte malgache de Mayotte (Comores). Paris: Institut National des Langues et Civilisations Orientales. Études Océan Indien 7.

2003-04. 'Documents sur la langue makhuwa à Madagascar et aux Comores (fin XIXe - début XXe siècles) avec un lexique du makhuwa de Madagascar et des Comores.' Études Océan Indien 35-36:149-223.

Gulsen, O. \& M.L. Roose, 2001. 'Lemons: diversity and relationships with selected citrus genotypes as measured with nuclear genome markers.' Journal of the American Society for Horticultural Science 126:309-17.

Gunasékara, Abraham Mendis, 1962 [1891]. A comprehensive grammar of the Sinhalese language. Colombo: Sri Lanka Sahitya Mandalaya. Reprint.

Gunawardana, R.A.L.H., 1967. 'Ceylon and Malaysia: a study of professor S. Paranavitana's research on the relations between the two regions.' University of Ceylon Review 25/1-2:1-64.

Gundert, H., 1869. 'Die dravidischen Elemente im Sanskrit.' Zeitschrift der Deutschen Morgenländischen Gesellschaft 23:517-30.

1962. A Malayalam and English dictionary. Kottayam: Sahitya Pravarthaka. Second edition.

Gunn, Bee F., Luc Baudouin, Kenneth M. Olsen, 2011. 'Independent origins of cultivated coconut (Cocos nucifera) in the Old World tropics'. PLOS ONE 6/6:e21143.

Gupta, Sunil, 2005. 'The Bay of Bengal interaction sphere (1000 BC - AD 500).' Bulletin of the IndoPacific Prehistory Association 25:21-30.

Guy, John, 2006. 'Early ninth-century Chinese export ceramics and the Persian Gulf connection: the Belitung shipwreck evidence.' Taoci 4:9-20.

2011. 'Tamil merchants and the Hindu-Buddhist diaspora in early Southeast Asia.' In: Pierre-Yves Manguin, A. Mani \& Geoff Wade (eds.), Early interactions between South and Southeast Asia: reflections on cross-cultural exchange (Singapore: Institute of Southeast Asian Studies):243-62. 
Haas, Mary, 1951-. Thai Dictionary Project. Accessed through http://sealang.net/ (2010-11)

Haddon, A.C., 1920. 'The outriggers of Indonesian canoes.' Journal of the Royal Anthropological Institute of Great Britain and Ireland 50:69-134.

Haddon, A.C. \& James Hornell, 1936-38. Canoes of Oceania. Honolulu: Bishop Museum Press. Three volumes.

Haebler, Claus, 1965. 'Ein nautischer Ausdruck im Pāli (Pā. lakāra-).' Zeitschrift für vergleichende Sprachforschung auf dem Gebiete der indogermanischen Sprachen 79:112-22.

Halls, C., 1961. 'The origin and distribution of the dugout canoe in Australia.' Mariner's Mirror 47:208-9.

Hallström, Gustaf, 1925. 'Utriggade kanoter i Sverige?' Fornvännen 20:50-70.

Hamidy, Badrul Munir \& Azis Wahab, M. Yusuf Yacub, Sjafruddin, Zamal Hakim, 1985. Kamus Rejang Indonesia. Jakarta: Pusat Pembinaan dan Pengembangan Bahasa.

Hamilton, A.W., 1919. 'Hindustani, Tamil, Sanskrit and other loan words in Malay.' Journal of the Straits Branch of the Royal Asiatic Society 80:29-38.

Harbaugh, D.T. \& B.G. Baldwin, 2007. Phylogeny and biogeography of the sandalwoods (Santalum, Santalaceae): repeated dispersals throughout the Pacific. Annals of Botany 94:1028-40.

Hardeland (ed.), 1859. Dajaksch-Deutsches Wörterbuch. Amsterdam: Frederik Muller.

Harder, Daniel K. \& Joseph Smartt, 1992. 'Further evidence on the origin of the cultivated winged bean, Psophocarpus tetragonolobus (L.) DC. (Fabaceae): chromosome numbers and the presence of a host-specific fungus.' Economic Botany 46/2:187-91.

Harrison, Simon, 1995. 'The commerce of cultures in Melanesia.' Man (new series) 28/1:139-58.

Hartmann, John, 1996. 'Bioforms and biophilia in Thai poetry and the extinction of experience.' MonKhmer Studies 25:161-89.

Harvey, John H., 1978. 'Gilliflower and carnation.' Garden History 6/1:46-57.

Hassan, Irene U., Nurhadan Halud, Seymour A. Ashley \& Mary L. Ashley, 1994. Tausug-English dictionary: kabtangan iban maana. Manilla: Summer Institute of Linguistics.

Hayden, Brian, 2003. 'Were luxury foods the first domesticates? Ethnoarchaeological Perspectives from Southeast Asia.' World Archaeology 34/3:458-69.
Haynes, T.H., 1885-86. 'English, Sulu and Malay vocabulary.' Journal of the Straits Branch of the Royal Asiatic Society 16:321-84, 18:193-239.

Hazarika, Manjil, 2006. 'Neolithic culture in Northeast India: a recent perspective on the origin of pottery and agriculture.' Ancient Asia 1:25-43.

Hazeu, G.A.J., 1907. Gajōsch-Nederlandsch woordenboek met Nederlandsch-Gajōsch register. Batavia: Landsdrukkerij.

Headley, Robert K., Rath Chim \& Ok Soeum, 1997. Cambodian-English Dictionary. Kensington: Dunwoody Press. Accessed through http://sealang.net/ (2010-11)

Hébert, Jean-Claude, 1983. 'Documents sur les razzias malgaches aux lles Comores et sur la côte orientale africaine (1790-1820).' Études Océan Indien 3:5-60.

Heckel, Édouard, 1910. 'Les plantes utiles de Madagascar.' Annales du Musée Colonial de Marseille (second series) 8:5-372.

Heide, G.J. Van der, 1928. 'De samenstelling van Hindoe-vaartuigen. Uitgewerkt naar beeldwerken van den Boroboedoer.' Nederlandsch Indië: oud \& nieuw, maandblad gewijd aan bouwkunst, archæologie, land- en volkenkunde, kunstnijverheid, handel en verkeer, cultures, mijnbouw, hygiëne 13:343-57.

Heine-Geldern, Robert, 1932. 'Urheimat und früheste Wanderungen der Austronesier.' Anthropos 27:543-619.

Henley, David, 2004. 'Rizification revisited: reexamining the rise of rice in Indonesia with special reference to Sulawesi.' In: Peter Boomgaard \& David Henley (eds.), Smallholders and stockbreeders: history of foodcrop and livestock farming in Southeast Asia (Leiden: KITLV Press):107-38.

Hesp, Patrick A., Colin V. Murray-Wallace \& C. E. Dortch, 1999. 'Aboriginal occupation on Rottnest Island, Western Australia, provisionally dated by aspartic acid racemisation assay of land snails to greater than 50 ka.' Australian Archaeology 49:712

Hewitt, J.F., 1888. 'Notes on the early history of Northern India.' Journal of the Royal Asiatic Society of Great Britain and Ireland 20:321-63.

Heyne, K., 1927. De nuttige planten van Nederlandsch Indië. Buitenzorg: Departement van Landbouw, Nijverheid en Handel. Three volumes. 
Higham, Charles \& Thomas Higham, 2009. 'A new chronological framework for prehistoric Southeast Asia, based on a Bayesian model from Ban Non Wat.' Antiquity 83/319:125-44.

Hill, A.H., 1960. 'Hikayat Raja-Raja Pasai.' Journal of the Malayan Branch of the Royal Asiatic Society 33/2:3-215

Hirth, Friedrich, 1888. 'The Andaman cannibals in Chinese literature.' Journal of the China Branch of the Royal Asiatic Society (new series) 22:103-4.

1896. 'Chao Ju-kua's ethnography: table of contents and extracts regarding Ceylon and India, and some articles of trade.' Journal of the Royal Asiatic Society of Great Britain and Ireland (Juli 1896):477-507.

Hirth, Friedrich \& W.W. Rockhill, 1912. Chau Ju-Kua: his work on the Chinese and Arab trade in the twelfth and thirteenth centuries, entitled Chu-fanchï. St. Petersburg: Imperial Academy of Sciences.

Hiskett, M., 1966. 'Materials relating to the cowry currency of the Western Sudan--II: Reflections on the provenance and diffusion of the cowry in the Sahara and the Sudan.' Bulletin of the School of Oriental and African Studies 29/2:339-66.

Hoffer, Bates L., 2005. 'Language borrowing and the indices of adaptability and receptivity.' Intercultural Communication Studies XIV/2:53-72.

Hogendorn, Jan \& Johnson, Marion, 1986. The shell money of the slave trade. Cambridge: Cambridge University Press. African Studies Series 49.

Holttum, R.E., 1950. 'The Zingiberaceae of the Malay peninsula.' Gardens' Bulletin Singapore 13/1:1250.

Hoogervorst, Tom G., 2012. 'Ethnicity and aquatic lifestyles: exploring Southeast Asia's past and present seascapes.' Water History 4:1-21.

Hooykaas, C., 1931. Tantri Kāmandaka: een Oudjavaansche Pañtjatantra-bewerking in tekst en vertaling. Bandoeng: A.C. NIX \& Co.

Hornell, James, 1920a. 'Les pirogues à balancier de Madagascar et de l'Afrique orientale.' La Géographie 34:1-23.

1920b. 'The common origin of the outrigger canoes of Madagascar and East Africa.' Man 20:134-9.

1920c. 'The outrigger canoes of Indonesia.' Madras Fisheries Bulletin 12:43-114.

$1920 \mathrm{~d}$. 'The origins and ethnological significance of Indian boat designs.' Madras Fisheries Bulletin 7/3:139-256. 1924a. 'The boats of the Ganges.' Madras Fisheries Bulletin 8/3:171-98.

1924b. 'South Indian blow-guns, boomerangs, and crossbows.' The Journal of the Royal Anthropological Institute of Great Britain and Ireland 54:316-46.

1928. 'South American balanced canoes: stages in the invention of the double outrigger.' Man 28:12933.

1934a. 'Indonesian influence on East African culture.' Journal of the Royal Anthropological Institute of Great Britain and Ireland 64:305-32.

1934b. 'The origin of the junk and sampan.' The Mariner's Mirror 20:331-7.

1938. 'The outrigger-nuggar of the Blue Nile.' Antiquity 12/47:354-9.

1939-40. 'The frameless boats of the Middle Nile.' The Mariner's Mirror 25/4:417-32, 26/2:125-44.

1941. 'The sea-going mtepe and dáu of the Lamu Archipelago.' The Mariner's Mirror 27:54-68

1943. 'The sewn canoes of Victoria-Nyanza: construction and origin.' Tanganyika notes and records 15:7-24.

1944. 'The outrigger canoes of Madagascar, East Africa and the Comoro Islands.' The Mariner's Mirror 30/1:3-18, 30/4:170-84.

1946. Water transport: origins \& early evolution. Cambridge: University Press.

1950. Fishing in many waters. London \& New York: Cambridge University Press.

Horridge, Adrian, 1978. Design of planked boats of the Moluccas. Greenwich, London: National Maritime Museum. Maritime Monographs and Reports No. 38.

1979. The Konjo boatbuilders and the Bugis prahus of South Sulawesi. Greenwich, London: National Maritime Museum. Maritime Monographs and Reports No. 40.

1981. The prahu: traditional sailing boat of Indonesia. Kuala Lumpur e.a.: Oxford University Press.

1982. The lashed-lug boat of the eastern archipelagoes, the Alcina MS and the Lomblen whaling boats. Greenwich, London: National Maritime Museum. Maritime monographs and reports 54 .

1987. Outrigger canoes of Bali and Madura, Indonesia. Honolulu: Bishop Museum Press.

Horton, M.C, 1996. 'Early maritime settlement and trade along the coasts of East Africa.' In: J. Reade 
(ed.), The Indian Ocean in Antiquity (London: Kegan Paul International):439-60.

1997. 'Mare Nostrum - A new archaeology in the Indian Ocean?' Antiquity 71/273:753-5.

Hourani, George F., 1995. Arab seafaring in the Indian Ocean in ancient and early medieval times. Princeton Un iversity Press. Renewed edition. Huang Shiqiang (黃士強), 1984. 臺北芝山箃遺址發掘 報告. Taipei: Taipei City Archives.

Hudson, Alfred B., 1967. The Barito isolects of Borneo: a classification based on comparative reconstruction and lexicostatistics. Ithaca, New York: Cornell University. Data Paper 68. Southeast Asia Program.

Hultzsch, E., 1912. 'Ginger.' Journal of the Royal Asiatic Society of Great Britain and Ireland (April 1912):475-6.

1914. 'Ginger.' Journal of the Royal Asiatic Society of Great Britain and Ireland (January 1914):93-7.

Hunter, Frederick Mercer, 1968 [1877]. An account of the British settlement of Aden in Arabia. London: Frank Cass.

Huntingford, G.W.B. (ed.), 1980. The Perip/us of the Erythraean Sea. London: The Hakluyt Society.

Hurles, M., B. Sykes, M. Jobling \& P. Forster, 2005. 'The dual origin of the Malagasy in island Southeast Asia and East Africa: evidence from maternal and paternal lineages.' American Journal of Human Genetics 76:894-901.

Hussein, Asiff, 2001. The lion and the sword: an ethnological study of Sri Lanka, Volume 1. Colombo: s.n.

Hyde, William Peter, 2008. A new Vietnamese-English dictionary. Kensington: Dunwoody Press. Accessed through http://sealang.net/ (2010-11)

Indrapala, K., 1967. 'Book reviews: Ceylon and Malaysia. S. Paranavitana, Colombo 1966.' Journal of the Ceylon Branch of the Royal Asiatic Society (new series) 11:101-6.

Ingrams, W.H., 1936. A report on the social, economic and political condition of the Hadhramaut. London: H.M. Stationery Office.

1967. Zanzibar: its history and its people. London: Frank Cass. Second edition.

Irwin, Geoffrey, 1992. The prehistoric exploration and colonisation of the Pacific. Cambridge: Cambridge University Press.

Issawi, Charles, 1967. 'European loan-words in contemporary Arabic writing: a case study in modernization.' Middle Eastern Studies 3/2:110-33.
Ivanoff, Jacques, 1989. Moken: les naufrages de l'histoire; une société de nomades marins de l'archipel de Mergui. Ecole des Hautes Etudes en Sciences Sociales. PhD Thesis.

Jayasuriya, Shihan de Silva, 2002. 'Sri Lankan Malay: a unique creole.' In: Uri Tadmor (ed.), Studies in Malay dialects. Part III (Badan Penyelenggara Seri NUSA; Universitas Katolik Indonesia Atma Jaya, NUSA Vol. 50):43-57.

Jen-kuei Li, Paul, 1994. 'Some plant names in Formosan languages'. In: A.K. Pawley \& M.D. Ross (eds.), Austronesian terminologies: continuity and change (Canberra: Pacific Linguistics Series C-127):241-66.

1995. 'Formosan vs. non-Formosan features in some Austronesian languages in Taiwan.' In: Paul Jen-kuei Li, Cheng-hwa Tsang, Dah-an Ho, Yingkuei Huang, Chiu-yu Tseng (eds.), Austronesian studies relating to Taiwan (Taipei: ROC):651-82.

Jenner, Phillip, 2009. Dictionary of pre-Angkorian Khmer and dictionary of Angkorian Khmer. Canberra: Pacific Linguistics Series 597. Accessed through http://sealang.net/ (2010-11)

Jenner, Phillip \& Saveros Pou, 1980-81. 'A lexicon of Khmer morphology.' The Mon-Khmer Studies Journal 9-10:1-517.

Jiang, Leping \& Li Liu, 2005. 'The discovery of an 8000-year-old dugout canoe at Kuahuqiao in the Lower Yangzi River, China.' Antiquity 79/305:(Project Gallery) http://antiquity.ac.uk/projgall/liu/index.html (2011)

Johnson, Helen M., 1936. 'The lemon in India.' Journal of the American Oriental Society 56/1:47-50.

Johnstone, T.M. \& J. Muir, 1964. 'Some nautical terms in the Kuwaiti dialect of Arabic.' Bulletin of the School of Oriental and African Studies 27/2:299332.

Jolly, J. \& F. W. Thomas, 1905. 'Ginger.' Journal of the Royal Asiatic Society of Great Britain and Ireland (1905):167-70.

Jones, A.M., 1964. Africa and Indonesia: the evidence of the xylophone and other musical and cultural factors. Leiden: E.J. Brill.

1972. 'Elephantiasis and music.' African Music 5/2:46-9.

Jones, Russel (ed.), 1978. Arabic loan-words in Indonesian: a check-list of words of Arabic and Persian origin in Bahasa Indonesia and traditional Malay, in the Reformed Spelling. London: School 
of Oriental and African Studies; Paris: Cahier d'Archipel.

2007. Loan-words in Indonesian and Malay. Leiden:

KITLV Press. Compiled by the Indonesian Etymological Project.

2009. Chinese loan-words in Malay and Indonesian. Kuala Lumpur: University of Malaya Press.

Joustra, M., 1902. 'Mededeelingen omtrent, en opmerkingen naar aanleiding van het "pĕk oewaloeh" of het doodenfeest der mĕrga Simbiring.' Tijdschrift voor Indische Taal-, Land- en Volkenkunde XLV:541-56.

Juleff, Gill, 1996. 'An ancient wind-powered iron smelting technology in Sri Lanka.' Nature 379:60-3.

Kajale, M.D., 1989. 'Mesolithic exploitation of wild plants in Sri Lanka: archaeobotanical study at the cave site of Beli-Lena.' In: D.R. Harris \& G.C. Hillman (eds.), Foraging and farming: the evolution of plant exploitation (London: Routledge):269-81.

Kanakasabhai, V., 1904. The Tamils eighteen hundred years ago. Madras \& Bangalore: Higginbotham.

Kapil, R.N. \& A.K. Bhatnagar, 1976. 'Portuguese contributions to Indian botany.' Isis 67/3:449-52.

Kapitän, Gerhard, 1984. 'Ancient anchors - technology and classification.' The International Journal of Nautical Archaeology and Underwater Exploration 13/1:33-44

2009. Records of traditional watercraft from South and West Sri Lanka. Oxford: Archaeopress. BAR International Series 1931.

Karafet, Tatiana M., J.S. Lansing, Alan J. Redd, Joseph C. Watkins, S.P.K. Surata, W.A. Arthawiguna, Laura Mayer, Michael Bamshad, Lynn B. Jorde \& Michael F. Hammer, 2005. 'Balinese Y-chromosome perspectives on the peopling of Indonesia: genetic contributions from pre-Neolithic hunter-gatherers, Austronesian farmers, and Indian traders.' Human Biology 77/1:93-111.

Kennedy, J., 1898. 'The early commerce of Babylon with India - 700-300 B.C.' Journal of the Royal Asiatic Society of Great Britain and Ireland (Apr. 1898):241-88.

Kent, Raymond K., 1970. Early kingdoms in Madagascar, 1500-1700. New York: Holt, Rinehart and Winston.

Kentley, Eric, 1985. 'Some aspects of the Masula surf boat.' In: Seán McGrail \& Eric Kentley (eds.), Sewn Plank Boats: archaeological and ethnographic papers based on those presented to a conference at Greenwich in November, 1984 ([Oxford:] B.A.R., BAR International Series 276):303-17.

1996. 'The sewn boats of India's East Coast.' In: Himanshu Prabha Ray \& Jean-François Salles (eds.), Tradition and archaeology: early maritime contacts in the Indian Ocean (New Dehli: Manohar):247-60.

2003a. 'The masula - a sewn plank surf boat of India's eastern coast.' In: McGrail, Seán (ed.), Boats of South Asia (London \& New York: RoutledgeCurzon):120-66.

Kern, J.H.C., 1869a. 'Bijdrage ter verklaring van eenige uitdrukkingen in de wayang-verhalen Palasara en Pandu.' Bijdragen tot de Taal- Landen Volkenkunde van Nederlandsch-Indië 16:1-23.

1869b. 'Java en het Goudeiland volgens de oudste berichten.' Bijdragen tot de Taal-, Land- en Volkenkunde van Nederlandsch-Indië 16:638-48.

1871a. 'Korte opmerkingen over Balineesch en Kawi (medegedeeld uit brieven van Dr. H.N. van der Tuuk.).' Bijdragen tot de Taal-, Land- en Volkenkunde van Nederlandsch-Indië 18:77-92.

1871b. 'De naamsoorsprong van Java.' Bijdragen tot de Taal-, Land- en Volkenkunde van Nederlandsch-Indië 18:116-20.

1877. 'Mengelingen.', Bijdragen tot de Taal-, Landen Volkenkunde 25/1:137-58.

1889a. 'Taalkundige gegevens ter bepaling van het stamland der Maleisch-Polynesische Volken.' Verslagen en Mededeelingen der Koninklijke Akademie van Wetenschappen (Afdeeling Letterkunde, 3e reeks) 6:270-87.

1889b. 'Critisch overzicht.' De Indische Gids 11/2a:1210-23.

1894. 'Over de herkomst van eenige telwoorden in 't Bargoensch der Zuidindische kooplieden.' In: Feestbundel van taal-, letter-, geschied- en aardrijkskundige bijdragen ter gelegenheid van zijn tachtigsten geboortedag aan Dr. P.J. Veth, oud-hoogleraar, door eenige vrienden en oudleerlingen aangeboden (Leiden: E.J. Brill):199-200. 1896. 'Twee krijgstochten uit den Indischen archipel tegen Ceilon.' Bijdragen tot de Taal-, Land- en Volkenkunde van Nederlandsch-Indië 46:240-5.

1897. 'Limoen.' Tijdschrift voor Nederlandsche Taalen Letterkunde 16:271-3.

1900. Râmâyaṇa. Oudjavaansch heldendicht. 'sGravenhage: Martinuf Nijhoff. 
1903. 'Drawidische volksnamen op Sumatra.' Bijdragen tot de taal-, land- en volkenkunde van Nederlandsch-Indië 55:358-62.

1915. 'Georg Friederici, Beiträge zur Völker- und Sprachenkunde von Deutsch-Neuguinea. - Ders.: Untersuchungen über eine melanesische Wanderstraße.' Göttingische gelehrte Anzeigen unter der Aufsicht der königlichen Gesellschaft zu Wissenschaften 177/1:1-12.

Kern, H. \& H. Terpstra (eds.), 1955. Jan Huyghen van Linschoten, Itinerario, voyage ofte schipvaert naer Oost ofte Portugaels Indien 1579-1592. Den Haag: Martinus Nijhoff. Second edition.

Kerr, Allen, 1972. Lao-English Dictionary. Washington: Catholic University Press. With the assistance of Sing Bourommavong, Houmphent Phetmongkhonh, Samreung Singhavara and Somsangouane loungsisomkham. Accessed through http://sealang.net/ (2010-11)

Khan, Iftikhar Ahmad, 2001. 'Arabian sea ships and navigation before Vasco da Gama.' Quarterly Journal of the Pakistan Historical Society 49/3:5970.

Kiehl, A.H., 1877. 'Notes on the Javanese.' The Journal of the Anthropological Institute of Great Britain and Ireland 6:346-64.

Kikusawa, Ritsuko \& Lawrence A. Reid, 2007. 'Proto who utilised turmeric, and how?' In: Jeff Siegel, John Lynch \& Diana Eades (eds.), Language description, history and development (Amsterdam I Philadelpia: John Benjamins Publishing Company):341-54.

King, Anya, 2008. 'The importance of imported aromatics in Arabic culture: illustrations from preIslamic and early Islamic poetry.' Journal of Near Eastern Studies 67/3:175-89.

Kirch, Patrick V., 1997. The Lapita peoples: ancestors of the Oceanic World. Cambridge, Mass. \& Oxford: Blackwell.

Kittel, F., 1894. A Kannaḍa-English Dictionary. Mangalore: Basel Mission Book \& Tract Depository.

Klerck, A.W. de, 1862. Lassen's geschiedenis van den Indischen Archipel. Utrecht: C. van der Post jr.

Knapen, Han, 2001. Forests of fortune? The environmental history of Southeast Borneo, 16001880. Leiden: KITLV Press.

Knappert, Jan, 1970. 'Contribution from the study of loanwords to the cultural history of Africa.' In:
David Dalby (ed.), Language and history in Africa (London: Frank Cass):78-88.

1987. East Africa: Kenya, Tanzania \& Uganda. New Delhi: Vikas Publishing House.

Koechlin, Bernard, 1975. Les Vezo du sud-ouest de Madagascar: contribution à l'étude de l'écosystème de semi-nomades marins. Paris, The Hague: Mouton.

Kosambi, D.D., 1965. The culture and civilization of ancient India in historical outline. London: Routledge and Kegan Paul.

Krain, E., J.A. Issa, A. Kullaya, M. Schuiling \& H.C. Harries, 2002. 'The natural and economic history of the coconut in Zanzibar.' The Palm Enthusiast (Journal of the South African Palm Society) 19/2:720.

Krishnamurti, Bhadriraju, 2003. The Dravidian languages. Cambridge: Cambridge University Press.

Krishnan, M.S., 1951. Mineral resources of Madras. Calcutta: Memoirs of the Geological Survey of India 80.

Krom, Nicolaas Johannes, 1913. 'Oud-Javaansche oorkonden. Nagelaten transcripties van wijlen Dr. J.L.A. Brandes.' Verhandelingen van het Bataviaasch Genootschap van Kunsten en Wetenschappen 60.

1931. Hindoe-Javaansche geschiedenis. 'sGravenhage: Martinus Nijhoff. Second edition.

Krumm, Bernhard, 1940. Words of oriental origin in Swahili. London: The Sheldon Press.

Kuhn, E., 1883. 'On the oldest Aryan element of the Sinhalese vocabulary.' The Indian Antiquary 12:53-70.

Kuiper, F.B.J. 1948. Proto-Munda words in Sanskrit. Amsterdam: Noord-Hollandsche Maatchappij.

1962. 'A Malay word in Tamil.' Indo-Iranian Journal 5/3:237-41.

1991. Aryans in the Rigveda. Amsterdam / Atlanta: Rodopi. Leiden Studies in Indo-European 1.

Kulke, Hermann, 1990. 'Indian colonies, Indianization or cultural convergence? Reflections ono the changing image of India's role in South-East Asia.' In: H. Schulte Nordholt (ed.), Onderzoek in Zuidoost-Azië: Agenda's voor de jaren negentig (Leiden: Rijksuniversiteit te Leiden):51-62.

Kulke, Hermann, K. Kesavapany \& Vijay Sakhuja (eds.), 2009. Nagapattinam to Suvarnadwipa: reflections on the Chola naval expeditions to 
Southeast Asia. Singapore: Institute of Southeast Asian Studies.

Kunst, J., 1973. Music in Java: its history, its theory and its technique. The Hague: Martinus Nijhoff. Third edition.

Kusuba, Takanori \& David Pingree, 2002. Arabic astronomy in Sanskrit: al-Birjandī on Tadhkira II, Chapter 11 and its Sanskrit translation. Leiden I Boston / Köln: Brill.

Lafeber, Abraham, 1922. Vergelijkende klankleer van het Niassisch. 's-Gravenhage: Hadi Poestaka.

Laffan, Michael, 2005. Finding Java: Muslim nomenclature of insular Southeast Asia from Śrivijaya to Snouck Hurgronje. Asia Research Institute Working Paper Series No. 52.

Lahiri, Nayanjot, 1992. The archaeology of Indian trade routes upto c. 200 BC: resource use, resource access and lines of communication. Delhi: Oxford University Press.

Lamb, Alistair, 1960. 'Report on the excavation and reconstruction of Chandi Bukit Batu Pahat, central Kedah.' Federation Museums Journal (new series) 5. Museums Department, Federation of Malaya. Kuala Lumpur.

Langdon, Robert, 1993. 'The banana as a key to early American and Polynesian history.' Journal of Pacific History 28/1:15-35.

2001. 'The bamboo rafts as a key to the introduction of the sweet potato in prehistoric Polynesia.' Journal of Pacific History 36:51-76.

Langhe, Edmond de, 1995. 'Banana and plantain: the earliest fruit crops?' INIBAP Annual Report 1995:6-8.

Langhe, Edmond de \& P. de Maret, 1999. 'Tracking the banana: its significance in early agriculture.' In: C. Gosden \& J. Hather (eds.), The prehistory of food: appetites for change (London: Routledge):377-96.

Lansing, J.S., A.J. Redd, T.M. Karafet, J. Watkins, I.W. Ardika, S.P.K. Surata, J.S. Schoenfelder, M. Campbell, A.M. Merriwether, M.F. Hammer, 2004. 'An Indian trader in ancient Bali?' Antiquity 78/300:287-93

Lanyon-Orgill, Peter A., 1960. A dictionary of the Raluana language. Victoria, B.C., Canada: published by the author.

Lape, Peter V. \& Sue O'Connor, Nick Burningham, 2007. 'Rock art: a potential source of information about past maritime technology in the South-east
Asia-Pacific region.' The International Journal of Nautical Archaeology 36/2:238-53.

Larish, Michael D., 1999. The position of Moken and Moklen within the Austronesian language family. An Arbor: UMI. PhD dissertation. Two volumes.

Lassen, Christian, 1847-61. Indische Alterthumskunde. Leipzig: Verlag von L.A. Kittler / London: Williams \& Norgate. Four volumes.

1867. Indische Alterthumskunde: Erster Band. Geographie, Ethnographie und älteste Geschichte. Leipzig: Verlag von L.A. Kittler / London: Williams \& Norgate. Second edition.

Laufer, B., 1915. 'Vidanga and cubebs.' T'oung Pao (second series) 16/2:282-8.

1919. Sino Iranica. Chinese contributions to the history of civilization in ancient Iran with special reference to the history of cultivated plants and products. Chicago: Field Museum of Natural History.

1934. 'The lemon in China and elsewhere.' Journal of the American Oriental Society 54/2:143-60.

Laurence, B.R., 1968. 'Elephantiasis and Polynesian origins.' Nature 219/5154:561-3.

Leach, Helen, 2003. 'Did East Polynesians have a concept of luxury foods?' World Archaeology 34/3:442-57.

Lebrun, P., Y.P. N'cho, M. Seguin, L. Grivet \& L. Baudouin, 1998. 'Genetic diversity in coconut (Cocos nucifera L.) revealed by restriction fragment length polymorphism (RFLP) markers.' Euphytica 101:103-8.

Legrand, F., 1954. 'Tamil loan words in Greek.' Tamil Culture 3/1:36-45.

Lehmann, Thomas \& Thomas Malten, 1992. A word index of Old Tamil Carikam literature. Stuttgart: Franz Steiner Verlag.

Lejju, J.B., D. Taylor \& P. Robertshaw, 2005. 'LateHolocene environmental variability at Munsa archaeological site, Uganda: a multicore, multiproxy approach.' The Holocene 15:1044-61.

Lejju, J.B., P. Robertshaw \& D. Taylor, 2006. 'Africa's earliest bananas?' Journal of Archaeological Science 33:102-13.

Leslie, Donald, 1986. Islam in traditional China: a short history to 1800. Canberra: Canberra College of Advanced Education.

Leur, Jacob Cornelis van, 1934. Eenige beschouwingen betreffende den ouden Aziatischen handel. Middelburg: G.W. den Boer. 
Lévi, M. Sylvain, 1923. 'Pré-aryen et pré-dravidien dans I'Inde.' Journal Asiatique (July-September 1923):1-57.

1925. 'Ptolomée, le Niddesa et la Bṛhatkathâ.' In: G. van Oest (ed.), Études Asiatiques publiées à l'occasion du vingt-cinquième anniversaire de l'École Française d'Extrême-Orient ([s.l.:] l'École Française d'Extrême-Orient. Two volumes):2/1-55.

1931. 'Kouen Louen et Dvîpântara.' Bijdragen tot de Taal-, Land- en Volkenkunde van NederlandschIndië 83:621-7.

Lévi, M. Sylvain, Jean Przyluski \& Jules Bloch, 1929. Pre-Aryan and pre-Dravidian in India. [Calcutta:] University of Calcutta. Translation Prabodh Chandra Bagchi.

Lewis, J.P., 1890. 'Slang of Tamil castes.' Indian Antiquary 19:160.

Lewis, M. Blanche, 1960. 'Moken texts and word-list: a provisional interpretation.' Federation Museums Journal (new series) 4. Museums Department, Federation of Malaya. Kuala Lumpur.

Leyden, J., 1808. 'On the languages and literature of the Indo-Chinese nations.' Asiatic Researches 10:158-289.

Li, Hui-Lin, 1970. 'The origin of cultivated plants in Southeast Asia.' Economic Botany 24/1:3-19.

1979. Nan-fang ts'ao-mu chang: a fourth century flora of Southeast Asia. Hong Kong: the Chinese University Press.

Lichtenberk, Frantisek, 1998. 'Did speakers of Proto Oceanic chew betel?' Journal of the Polynesian Society 107/4:335-63.

Liebner, Horst, 1993. 'Remarks on the terminology of boatbuilding and seamanship in some languages of southern Sulawesi.' Indonesia Circle 59-60:1844.

Lien, Chaomei, 1991. 'The Neolithic archaeology of Taiwan and the Peinan excavations.' Bulletin of the Indo-Pacific Prehistory Association 11:339-52.

Ling, Shun-Sheng, 1970. A study of the raft, outrigger, double, and deck canoes of ancient China, the Pacific, and the Indian Oceans. Nankang, Taipei: Academica Sinica. Monograph no. 16.

Lodhi, Abdulaziz, 2000. Oriental influences in Swahili: a study in language and culture contact. Göteborg: Acta Universitatis Gothoburgensis. PhD dissertation.

Logan, J.R., 1848. 'Customs common to the hill tribes bordering on Assam and those of the Indian
Archipelago.' Journal of the Indian Archipelago and Eastern Asia 2:229-36.

Lorrain, Arthur, 1951. Grammar and dictionary of the Lakher or Mara language. Shillong: Assam Government Press.

Lorrain, James Herbert, 1910. A dictionary of the Abor-Miri language, with illustrative sentences and notes. Shillong: Eastern Bengal and Assam Secretariat.

1940. Dictionary of the Lushai language. Calcutta: Asiatic Society.

Löw, Immanuel, 1881. Aramæische Pflanzennamen. Leipzig: Verlag von Wilhelm Engelmann.

Lubotsky, Alexander, 1997. A Rgvedic word concordance. Part I: $A-N$. New Haven, Connecticut: American Oriental Society.

Luce, Gordon H., 1959. 'Old Kyaukse and the coming of the Burmans.' Journal of the Burma Research Society 42/1:75-112.

1969. Old Burma: Early Pagán. Locust Valley, New York: New York University. Artibus Asiae Supplementum 25

Lukas, Helmut, 2003. 'Theories of Indianization exemplified by selected case studies from Indonesia (insular Southeast Asia).' In: Proceedings of papers. "Sanskrit in Southeast Asia: the harmonizing factor of cultures" (Bangkok: Mahachulalongkornrajavidyalaya Press):82-107.

Luling, Virginia, 1987. Somali-English dictionary. Wheaton, MD: Dunwoordy Press.

Lydekker, C.J.W., 1919. 'The "mtepe" dhau of the Bajun Islands.' Man 19 (June):88-92.

Ma Tai-Loi (馬泰來), 1978. 'The authenticity of the "Nan-Fang Ts'ao-mu Chuang" 南方草木狀.' T'oung Pao (second series) 64/4-5:218-52.

Mabberley, D.J., 1997. 'A classification for edible Citrus (Rutaceae).' Telopea 7/2:167-72.

Madan, Arthur Cornwallis, 1903. Swahili-English dictionary. Oxford: Oxford Clarendon Press.

Madella, M., 2003. 'Investigating agriculture and environment in South Asia: present and future contributions from opal phytoliths.' In: S. Weber \& W. Belcher (eds.), Indus ethnobiology: new perspectives from the field (Lanham: Lexington Books):199-249.

Madulid, Domingo A., 2001. A dictionary of Philippine plant names. Makati City: Bookmark. Two volumes.

Mahalingam, T.V., 1965. The Nagas in Indian history and culture. Madras: G.S. Press. 
Mahdi, Waruno, 1992. 'Zur Ontogenese des austronesischen und malaiischen Schiffes.' Poster presentation at the Tagung des Südostasienarbeitskreises, 3-5 July 1992, Königstein im Taunus.

1994. 'Some Austronesian maverick protoforms with culture-historical implications.' Oceanic Linguistics 33/1:167-229, 33/2:431-90.

1995. 'Wie hießen die Malaien, bevor sie "Malaien" hießen?' In: A. Bormann, A. Graf, M. Meyer \& M. Voss (eds.), Südostasien und wir: Grundsatzdiskussion und Fachbeiträge (Münster, Hamburg: LIT):162-76.

1998. 'Linguistic data on transmission of Southeast Asian cultigens to India and Sri Lanka.' In: Roger Blench \& Matthew Spriggs (eds.), Archaeology and Language II: archaeological data and linguistic hypotheses (London \& New York: Routledge):390-415.

1999a. 'The dispersal of Austronesian boat forms in the Indian Ocean.' In: Roger Blench \& Matthew Spriggs (eds.), Archaeology and Language III: artefacts, languages, and texts (London: Routledge):144-79.

1999b. 'Linguistic and philological data towards a chronology of Austronesian activity in India and Sri Lanka.' In: Roger Blench \& Matthew Springs (eds.), Archaeology and Language IV: language change and cultural transformation (London \& New York: Routledge):160-242.

2007. Malay words and Malay things: lexical souvenirs from an exotic archipelago in German publications before 1700. Harrassowitz Verlag. Wiesbaden.

2008a. 'Yavadvipa and the Merapi Volcano in West Sumatra' Archipe/75:111-43.

2008b. 'Review of Jones (2007).' Archipe/ 76:318-22. 2009. 'In search of an historical Sea-People Malay dialect with -aba.' In: Alexander Adelaar \& Andrew Pawley (eds.), Austronesian historical linguistics and cultural history: a festschrift for Robert Blust (Canberra: Pacific Linguistics Series 601):73-90.

2010. 'The protohistorical linguistic, ethnic, and political situation around the Gulf of Thailand in the light of borrowing between Malayo-Chamic and Eastern Austroasiatic languages.' Presented at the $13^{\text {th }}$ International Conference of the European Association of Southeast Asian Archaeologists, 27 Sep - 01 Oct 2010, Berlin.
Majumdar, R.C., 1963 [1944]. Hindu colonies in the Far East. Calcutta: Firma K.L. Mukhopadhyay.

Maloney, Clarence, 1975. 'Archaeology in South India: accomplishments and prospects.' In: Burton Stein (ed.), Essays on South India ([s.I.]: University of Hawaii):1-40.

1980. People of the Maldive Islands. Bombay, etc.: Orient Longman.

Man, Edwin Horace, 1888-89. A dictionary of the Central Nicobarese language (English Nicobarese and Nicobarese-English). Dehli: Sanskaran Prakashak. Accessed through http://sealang.net/ (2010-11)

Manguin, Pierre-Yves, 1980. 'The Southeast Asian ship: an historical approach.' Journal of Southeast Asian Studies 11:266-76.

1985a. 'Sewn-plank craft of South-East Asia: a preliminary survey.' In: Seán McGrail \& Eric Kentley (eds.), Sewn Plank Boats: archaeological and ethnographic papers based on those presented to a conference at Greenwich in November, 1984 ([Oxford:] BAR International Series 276):319-43.

1985b. 'Late Medieval Asian shipbuilding in the Indian Ocean: a reappraisal.' Moyen Orient \& Océan Indien 2/2:1-30.

1986. 'Shipshape societies: boat symbolism and political systems in insular Southeast Asia.' In: David G. Marr \& A.C. Milner (eds.), Southeast Asia in the $9^{\text {th }}$ to $14^{\text {th }}$ centuries (Singapore: Institute of Southeast Asian Studies / Canberra: Australian National University):187-214.

1993. 'Trading ships of the South China sea: shipbuilding techniques and their role in the history of the development of Asian trade networks.' Journal of the Economic and Social History of the Orient 36/3:253-80.

1996. 'Southeast Asian shipping in the Indian Ocean during the first millennium A.D.' In: Prabha Ray, Himanshu \& Jean-François Salles (eds.), Tradition and archaeology: early maritime contacts in the Indian Ocean (New Dehli: Manohar):181-98.

2000. 'Les techniques de construction navale aux Maldives originaires d'Asie du Sud-Est.' Techniques \& Culture 35-36:21-47.

2010. 'The Maldives connection: pre-modern Malay World shipping across the Indian Ocean.' In: Chantal Radimilahy \& Narivelo Rajaonarimanana (eds.), Civilisations des mondes insulaires (Madagascar, îles de canal de Mozambique, 
Mascareignes, Polynésie, Guyanes). Mélanges en l'honneur du Professor Claude Allibert (Paris: Karthala):261-84.

2012. 'Asian ship-building traditions in the Indian Ocean at the dawn of European expansion.' In: Om Prakash \& D. P. Chattopadhyaya (eds.), History of science, philosophy and culture in Indian Civilization. Volume III, part 7: the trading world of the Indian Ocean, 1500-1800 (Delhi, Chennai, Chandigarh: Pearson):597-629.

Manhitu, Yohanes, 2007. Kamus Indonesia-Tetun Tetun-Indonesia. Jakarta: Penerbit PT Gramedia Pustaka Utama.

Manickavasagom, M.E., 1986. Dravidian influence in Thai culture. Thanjavur: Tamil University.

Manik, Tindi Radja, 1977. Kamus Bahasa Dairi Pakpak-Indonesia. Jakarta: Pusat Pembinaan dan Pengembangan Bahasa.

Maniku, Hassan Ahmed, 2000. A concise etymological vocabulary of Dhivehi language. Colombo: The Royal Asiatic Society of Sri Lanka.

Männer, A., 1886. Tulu-English dictionary. Mangalore: Basel Mission Press.

Manoharan, S., 1989. A descriptive and comparative study of Andamanese language. Calcutta: Anthropological survey of India.

Manuel, E. Arsenio, 1948. Chinese elements in the Tagalog language. Manila: Filipiniana Publications.

Marrison, Geoffrey Edward, 1967. The classification of the Naga languages of north-east India. London: SOAS. PhD dissertation. Two volumes.

Marschall, Wolfgang, 1980. 'Indonesia in Indian Ocean culture history.' Indonesia Circle: School of Oriental and African Studies Newsletter 21:15-23.

Marsden, William, 1812a. A dictionary of the Malayan language; to which is prefixed a grammar, with an introduction and praxis. London: Cox \&Baylis.

1812b. A grammar of the Malayan language with an introduction and praxis. London: Cox and Baylis.

Marshall, Yvonne \& Alexandra Maas, 1997. 'Dashing dishes.' World Archaeology 28/3:275-90.

Masica, Colin P., 1979. 'Aryan and non-Aryan elements in Northern Indian agriculture.' In: M.M. Deshpande \& P.E. Hook (eds.), Aryans and nonAryan in India (Ann Arbor: Centre for South and Southeast Asian studies, University of Michigan):55-151.

Mason, K. (dir.), 1946. Western Arabia and the Red Sea. [s.l.:] Naval Intelligence Division.
Maspéro, Georges, 1928. Le royaume de Champa. Paris \& Bruxelles: Van Oust.

Mather, K.A., J. Molina, J. Flowers, S. Rubinstein, B. Rauh, A. Lawton-Rauth, A. Caicedo, K. McNallys \& M. Purugannan, 2010. 'Migration, isolation and hybridization in island crop populations: The case of Madagascar rice.' Molecular Ecology 19:4892905.

Mathew, K.M., 1988. History of the Portuguese navigation in India. Delhi: Mittal Publications.

Mathur, L.P., 1968. History of the Andaman and Nicobar Islands (1756-1966). Jullundur \& Dehli: Sterling Publishers.

Matthes, B.F., 1874. Boegineesch-Hollandsch woordenboek met Hollandsch-Boegineesche woordenlijst en verklaring van een tot opheldering bijgevoegden ethnographischen atlas. 's Gravenhage: M. Nijhoff. Two volumes.

Mauny, Raymond, 1965. 'The Wakwak and the Indonesian invasion in East Africa in 1945 A.D.' Revista Studia 15:7-16.

Maxwell, C.N., 1921. Malayan fishes. Singapore: Methodist Publishing House.

Maxwell, Robyn, 2003. Sari to sarong: five hundred years of Indian and Indonesian textile exchange. Canberra: National Gallery of Australia.

Maxwell, William Edward, 1882. A manual of the Malay language with an introductory sketch of the Sanskrit element in Malay. London: Trübner \& Co., Ludgate Hill.

Mayrhofer, Manfred, 1956. Kurzgefaßtes etymologisches Wörterbuch des Altindischen. Heidelberg: Carl Winter. Three volumes.

Mazumdar, Bijaychandra, 1927. The history of the Bengali language. Calcutta: University of Calcutta. Second edition.

Mbida, C., E. De Langhe, L. Vrydaghs, H. Doutrelepont, Ro Swennen, W. Van Neer \& P. de Maret, 2006. 'Phytolith evidence for the early presence of domesticated banana (Musa) in Africa.' In: M.A. Zeder, D.G. Bradley, E. Emshwiller \& B.D. Smith (eds.), Documenting domestication: new genetic and archaeological paradigms (University of California Press, Berkeley):68-81.

Mbida, C., H. Doutrelepont, L. Vrydaghs, R.L. Swennen, H. Beeckman, E. De Langhe \& P. de Maret, 2001. 'First archaeological evidence of banana cultivation in central Africa during the third 
millennium before present.' Vegetation History and Archaeobotany 10:1-6.

Mbida, C., H. Doutrelepont, L. Vrydaghs, R.O. Swennen, Ru Swennen, H. Beeckman, E. De Langhe \& P. de Maret, 2005. 'The initial history of bananas in Africa: a reply to Vansina.' Azania 40:128-35.

Mbida, C., W. van Neer, H. Doutrelepont \& L. Vrydaghs, 2000. 'Evidence for banana cultivation and animal husbandry during the first millennium B.C. in the forest of southern Cameroon.' Journal of Archaeological Science 27:151-62.

McCarthy, Michael, 2005. Ships' fastenings: from sewn boat to steam ship. College Station, Texas: TAMU Press.

McGrail, Seán, 1996. 'The study of boats with stitched planking.' In: Himanshu Prabha Ray \& JeanFrançois Salles (eds.), Tradition and archaeology: early maritime contacts in the Indian Ocean (New Dehli: Manohar):225-38

2001. Boats of the world: from the Stone Age to Medieval times. Oxford: University Press.

McKaughan, Howard \& Batua Al-Macaraya, 1996. A Maranao dictionary. Manilla: De La Salle University \& the Summer Institute of Linguistics. Accessed through http://sealang.net/ (2010-11)

Means, Natalie, 1998. Temiar-English, English-Temiar Dictionary. Minnesota: Hamline University Press. Accessed through http://sealang.net/ (2010-11)

Meile, Pierre, 1940-41. 'Les Yavanas dans I'Inde Tamoule.' Journal Asiatique (11 ${ }^{\text {th }}$ series) 232:85123.

Meinhof, Karl, 1900. 'Semitische Spuren in Südafrika: Ndalama = Geld.' Globus: Illustrierte Zeitschrift für Länder- und Völkerkunde 78/13:203-5.

1919-20. 'Afrikanische Worte in orientalischer Literatur.' Zeitschrift für Eingeborenen-Sprachen 10:147-52.

Mentrida, Alonso de, 1841. Diccionario de la lengua Bisaya, Hiligueina y Haraya de la Isla de Panay. [Manila]: Impremeria de D. Manuel y de D. Felis S. Dayot.

Merrill, E.D., 1937. 'On the significance of certain Oriental plant names in relation to introduced species.' Proceedings of the American Philosophical Society 78/1:111-46.

Meulen, W.J. van der, 1974. 'Suvarnadvîpa and the Chrysê Chersonêsos.' Indonesia 18:1-40.
Meyer, C., J.M. Todd \& K. Beck, 1991. 'From Zanzibar to Zagros: a copal pendant from Eshunna.' Journal of Near Eastern Studies 50/4:289-98.

Millar, Karen, 1993. 'Preliminary reports on observations made into the techniques and traditions of Maldivian shipbuilding.' Bulletin Australian Institute for Maritime Archaeology 17/1:9-16.

Miller, J. Innes, 1969. The spice trade of the Roman Empire. Oxford: Clarendon Press.

Mills, J.V.G., 1937. 'Malaya in the Wu-Pei-Chih charts.' Journal of the Malayan Branch of the Royal Asiatic Society 15/3:1-48.

Mills, J.V.G., 1975a. 'Ma Huan's Contribution to the "Hobson-Jobson" of Yule and Burnell.' T'oung Pao (second series) 61/1-3:148-60.

Mills, Roger Frederick, 1975b. Proto South Sulawesi and proto Austronesian phonology. Michigan: University of Michigan. PhD dissertation. Two volumes.

Milne, Leslie, 1931. A dictionary of English-Palaung and Palaung-English. Rangoon: Government Printing and Stationary. Accessed through http://sealang.net/ (2010-11)

Mintz, Malcolm W., 2004. Bikol dictionary diksionáriong Bíkol. Volume II. Bikol - English dictionary: diksionáriong Bíkol - Inglés. Perth: Indonesian / Malay texts and resources.

Mitchell, Peter, 2005. African connections: an archaeological perspective on Africa and the wider world. Walnut Creek, etc.: Altamira Press.

Mohamed, Naseema, 2002. 'Pre-Islamic Maldives.' Man and Environment 27/1:109-15.

2004. 'Seafaring in early Maldives.' In: Naseema Mohamed (ed.), Essays on early Maldives (Male': National Centre for Linguistic and Historical Research):63-84.

Mohring, H., 1973. 'The word anito and its associations: a remark about etymological research.' In: Andrew B. Gonzalez (ed.), Parangal kay Cecilio Lopez: essays in honor of Cecilio Lopez on his seventy-fifth birthday (Quezon City: Linguistic Society of the Philippines. Philippine Journal of Linguistics Special Monograph 4):15-37.

Molesworth, James Thomas, 1857. A dictionary, Marathi and English. Bombay: Bombay Education Society's press. Second edition. Accessed through http://dsal.uchicago.edu/ (2010-11)

Moll, F., 1927. 'The history of the anchor.' The Mariner's Mirror 13:293-332. 
Monier-Williams, Monier, 1899. A Sanskrit-English dictionary: etymologically and philologically arranged with special reference to cognate IndoEuropean languages (Oxford: Clarendon Press).

Mookerji, Radha Kumud, 1957. Indian shipping: a history of the sea-borne trade and maritime history of the Indians from the earliest times. Bombay \& Calcutta \& Madras: Orient Longmans. Second edition (revised).

Morgan, J.C., 1940. 'The Ngalawa of the Kilwa Coast.' Tanganyika notes and records 9:27-36.

Morony, Michael G., 2005. Iraq after the Muslim conquest. Piscataway, NJ: Gorgias Press.

Morrison, W.T., 1876. An Anglo-Chinese vocabulary of the Ningpo dialect. Shanghai: American Presbyterian Mission Press.

Mott, Lawrence V., 1996. The development of the rudder: a technological tale (London: Chatham Publishing).

Mouat, Frederic J., 1863. Adventures and researches among the Andaman Islanders. London: Hurst and Blackett.

Moussay, Gérard, 1995. Dictionnaire Minangabau Indonesien - Français. Paris: I'Harmattan. Two volumes.

Msaidie, S., A. Ducourneau, G. Boëtsch, G. Longepied, K. Papa, C. Allibert, A.A. Yahaya, J. Chiaroni \& M. Mitchell, 2011. 'Genetic diversity on the Comoros Islands shows early seafaring as major determinant of human biocultural evolution in the Western Indian Ocean.' European Journal of Human Genetics 19:89-94.

Muhly, James D., 1985. 'Sources of tin and the beginnings of bronze metallurgy.' American Journal of Archaeology 89/2:275-91.

Müller, F. Max, 1899. The science of language. Vol. I. London \& Bombay: Longmans, Green, and Co.

Murdock, George Peter, 1959. Africa: its peoples and their culture history. New York \& Toronto \& London: McGraw Hill.

Murgotten, Francis Clark, 1924. The origins of the Islamic State. Part II. New York: Columbia University.

Murray, G.W. \& E.H. Warminton, 1967. 'Trogodytica: the Red Sea littoral in Ptolemaic times.' The Geographical Journal 133/1:24-33.

Muss-Arnolt, W., 1892. 'On Semitic words in Greek and Latin.' Transactions of the American Philological Association 23:35-156.
Mwacharo, J.M., G. Bjørnstad, V. Mobegi, K. Nomura, H. Hanada, T. Amano, H. Jianlin \& O. Hanotte, 2011. 'Mitochondrial DNA reveals multiple introductions of domestic chicken in East Africa.' Molecular Phylogenetics and Evolution 58:374-82.

Myanmar, 1993. Myanmar-English Dictionary. Kensington: Dunwoody Press. Republication. Accessed through http://sealang.net/ (2010-11)

Needham, Joseph, 1965. Science and civilisation in China. Volume 4: Physics and physical technology. Part II: Mechanical engineering. Cambridge: Cambridge University Press.

1980. Science and civilization in China. Volume 4. Physics and physical technology. Part III. Civil engineering and nautics. Cambridge: Cambridge University Press.

Neighbor, R. E., 1878. A vocabulary in English and Mikir: with sentences illustrating the use of words. Calcutta: Baptist mission press.

Nell, L., 1881. 'A hūniyam image.' Journal of the Ceylon Branch of the Royal Asiatic Society 6/2:116-24

Neumann, J.H, 1926. 'Bijdrage tot de geschiedenis der Karo-Batakstammen.' Bijdragen tot de Taal- Land en Volkenkunde van Nederlandsch-Indië 82:1-36.

Neumann, Katharina \& Elisabeth Hildebrand, 2009. 'Early bananas in Africa: the state of the art.' Ethnobotany Research \& Applications 7:353-62.

Nicholas, C.W. \& S. Paranavitana, 1961. A concise history of Ceylon: from the earliest times to the arrival of the Portuguese in 1505. Colombo: Ceylon University Press.

Nicolas, Arsenio 2011, 'Early musical exchange between India and Southeast Asia.' In: PierreYves Manguin, A. Mani \& Geoff Wade (eds.), Early interactions between South and Southeast Asia: reflections on cross-cultural exchange (Singapore: Institute of Southeast Asian Studies):347-69.

Nicolosi, Elisabetta, 2007. 'Origin and taxonomy.' In: Iqrar Khan (ed.), Citrus genetics, breeding and biotechnology (Wallingford: CABI):19-43.

Nicolosi, Elisabetta, Z.N. Deng, A. Gentile, S. La Malfa, G. Continella, E. Tribulato, 2000. 'Citrus phylogeny and genetic origin of important species as investigated by molecular markers.' Theoretical and Applied Genetics 100:1155-66.

Nixdorff, Heide, 1971. Zur Typologie und Geschichte der Rahmentrommeln. Berlin: Verlag von Dietrich Reimer. Baessler-Archiv Beiträge zur Völkerkunde (new series) 7 . 
Noceda, P. Juan de \& P. Pedro de Sanlucar, 1860. Vocabulario de la lengua Tagala. Manila: Ramirez y Giraudier.

Noorduyn, J. \& A. Teeuw, 2006. Three Old Sundanese poems. Leiden: KITLV Press.

Nooteboom, C., 1932. De boomstamkano in Indonesie. Leiden: N.V. Boekhandel en drukkerij voorheen E.J. Brill.

1950-51. 'Sumatra en de zeevaart op de Indische Oceaan.' Indonesië 4:119-27.

1952. 'Galeien in Azië (met platen).' Bijdragen tot de Taal-, Land-en Volkenkunde 108/4:365-80.

Nouhuys, J.W. van, 1925. In en om het Oostersche ankerpark. Rotterdam: Museum "Prins Hendrik". Reprint.

1951. 'The anchor.' The Mariner's Mirror 37:17-47.

Novotna, Jana, 2000. 'Reduplication in Swahili.' In: Rose-Marie Beck, Lutz Diegner, Thomas Geider \& Werner Graebner (eds.), Swahili Forum VII (Köln: Institut für Afrikanistik, Afrikanistische Arbeitspapiere 64):57-73.

Nurse, Derek, 2009. 'Lexicon for Ki-Bajuni = Ki-Gunya $=$ Ki-Thikhuu.' Unpublished wordlist. Accessed through

www.ucs.mun.ca/ dnurse/bajuni_database/wordlis t.pdf (2012)

Nurse, Derek \& Thomas J. Hinnebusch, 1993. Swahili and Sabaki: a linguistic history. Berkeley / Los Angeles / London: University of California Press. University of California publications in linguistics 121.

O'Connell, James F. \& J. Allen, 2004. 'Dating the colonization of Sahul (Pleistocene Australia - New Guinea): a review of recent research.' Journal of Archaeological Science 31:835-53.

O'Connell, James F., Jim Allen \& Kristen Hawkes, 2010. 'Pleistocene Sahul and the origins of seafaring.' In: A. Anderson, J. Barrett \& K. Boyle (eds.), The global origins and development of seafaring (Cambridge: McDonald Institute for Archaeological Research):57-68.

O'Sullivan, W.A., 1901. 'The relations between southern India and the Straits Settlements.' Journal of the Straits Branch of the Royal Asiatic Society 36/67-74.

Obdeijn, V., 1941a. 'Zuid-Sumatra volgens de oudste berichten. II. De goud- en specerij-eilanden.' Tijdschrift van het Koninklijk Nederlandsch Aardrijkskundig Genootschap (second series) 58:322-41. 1941b. 'Zuid-Sumatra volgens de oudste berichten. III. (Slot) Taprobane.' Tijdschrift van het Koninklijk Nederlandsch Aardrijkskundig Genootschap (second series) 58:476-502.

1943. 'Volk en taal der oude Maleise rijken in ZuidSumatra.' Tijdschrift van het Koninklijk Nederlandsch Aardrijkskundig Genootschap (second series) 60:706-23.

Oemar, Faqir, 1896. Bastaardwoorden in de Maleische taal en Oosterlingen in de Nederlandsche taal. Batavia: H.M. van Dorp.

Omar, Asmah binte Haji, 1966. 'The natural of Tamil Ioan words in Malay.' Proceedings of the First International Conference of Tamil Studies, Kuala Lumpur. Vol. I/ (Kuala Lumpur: International Association of Tamil Research):534-58.

Oppenheimer, Stephen, 1998. Eden in the East: the drowned continent of Southeast Asia. London: Weidenfeld and Nicolson.

Osada, Toshiki, 2009. 'How many Proto-Munda words in Sanskrit? With special reference to agricultural vocabulary.' In: Toshiki Osada (ed.), Linguistics, archaeology and human past in South Asia (New Dehli: Manohar):127-46.

Oudheidskundig, 1912. Oudheidskundig verslag 1912. Weltevreden: Albrecht \& Co / 's Hage: M. Nijhoff.

Pallesen, Alfred Kemp, 1977. Cultural contact and language convergence. Berkeley: University of California. PhD dissertation

Pandian, Pichai Pillai, 1989. Cāttanār's Mañimēkalai. Tinnevelly: The South India Saiva Siddharta Works Publishing Society.

Pandit, Natesa Sastri, 1894. 'Traders' slang in Southern India.' The Indian Antiquary 23:49-52.

Paranavitana, Senarat, 1960. 'Ceylon and Malaysia in mediaeval times.' Journal of the Ceylon Branch of the Royal Asiatic Society (new series) 7/1:1-42.

1966a. Ceylon and Malaysia. Colombo: Lake House. 1966b. 'Ceylon and Śrī Vijaya.' In: Ba Shin, Jean Boisselier \& A.B. Griswold (eds.), Essays offered to $G$. H. Luce by his colleagues and friends in honour of his seventy-fifth birthday. Volume 1: Papers on Asian history, religion, languages, literature, music folklore, and anthropology (Ascona, Switzerland: Artibus Asiae. Supplementum, Vol. 23):205-12.

1973. 'Pan̆duvasnuvara pillar-inscription of the reign of Udaya II.' Epigraphia Zeylanica 6/1:12-20. 
Paris, Pierre, 1941. 'Les bateaux des bas-reliefs khmèrs.' Bulletin de l'École Française d'Extrême Orient 41/1:335-61.

1955. Esquisse d'une ethnographie navale des peuples annamites. Rotterdam: Museum voor Land- en Volkenkunde \& Maritiem Museum "Prins Hendrik".

Parkin, H., 1978. Batak fruit of Hindu thought. Madras: Christian Literature Society.

Patanñe, E.P., 1977. 'The outrigger in the maritime scene.' In: Alfredo R. Roces (ed.), Filipino heritage: the making of a nation. The age of trade and contacts: visitors from across many seas (Manila: Lahing Pilipino Publishing):716-8.

Patterson, William L. \& Mario E. Severino, 1995. LaoEnglish dictionary. Kensington: Dunwoody Press. Accessed through http://sealang.net/ (2010-11)

Pawley, Andrew \& Medina Pawley, 1994. 'Early Austronesian terms for canoe parts and seafaring.' In: A.K. Pawley \& M.D. Ross (eds.), Austronesian terminologies: continuity and change (Canberra: Pacific Linguistic Series C-127):329-61.

Pawley, Andrew, 2002. 'The Austronesian dispersal: languages, technologies and people.' In: Peter Bellwood \& Colin Renfrew (eds.), Examining the farming / language dispersal hypothesis (Oxford: Oxbow Books):251-73.

Paz, Victor, 2002. 'Island Southeast Asia: spread or friction zone.' In: Peter Bellwood \& Colin Renfrew (eds.), Examining the farming / language dispersal hypothesis (Oxford: Oxbow Books):272-85.

Pearce, Charles E.M. \& Frances M. Pearce, 2011. Oceanic migration: paths, sequence, timing and range of prehistoric migration in the Pacific and Indian Oceans. Dordrecht, etc.: Springer.

Pedersen, Ralph K., 2004. 'The shipwreck in the coconut grove: the Kadakkarapally boat.' The Institute of Nautical Archaeology Quarterly 31/2:39.

Pelliot, M. Paul, 1904. 'Deux itinéraries de Chine en Inde a la fin du VIIIe siècle.' Bulletin de l'École Française d'Extrême Orient 4:131-413.

1925. 'Quelques texts chinois concernant l'Indochine Hindouisée.' In: G. van Oest (ed.), Études Asiatiques publiées à l'occasion du vingtcinquième anniversaire de l'École Française d'Extrême-Orient ([s.l.:] l'École Française d'Extrême-Orient. Two volumes):2/243-63.

1959. Notes on Marco Polo 1. Paris: Imprimerie Nationale.
Pelras, Christian, 1996. The Bugis. Oxford: Blackwell. Penzer, N.M., 1927. The Ocean of Story: being C.H. Tawney's translation of Somadeva's Kathā Sarit Sāgara (or Ocean of Streams of Story). Vol . VIII. Delhi, Varanasi, Patna: Motilal Banarsidass.

Peralta, J.T., 1995. 'Prehistoric links of the Sama lepa of Tawi-Tawi province, Philippines.' Paper presented at the International Conference on Bajau/Sama Community "Bajau - Meniti Zaman" (Progress through the ages), 24-28 June 1995, Kota Kinabalu, Malaysia.

Péri, Nöel, 1919. 'A propos du mot sampan.' Bulletin de l'Ecole française d'Extrême-Orient 19:13-9.

Perret, Daniel \& Heddy Surachman, 2009. 'Introduction'. In: Daniel Perret \& Heddy Surachman (eds.), Histoire de Barus Sumatra III. Regards sur une place marchande de l'Océan Indien (XIIe-milieu du XVIIe s.) (Paris: Association Archipel / Ecole Française d'extrême-Orient):11-24. Cahier d'Archipel 38.

Petraglia, Michael D. \& Bridget Allchin (eds.), 2007. The evolution and history of human populations in South Asia: inter-disciplinary studies in archaeology, biological anthropology, linguistics and genetics. Dordrecht: Springer.

Pettigrew, W., 1918. Tāngkhul Nāga grammar and dictionary (Ukhrul dialect) with illustrative sentences. Shillong: printed at the Assam Secretariat office.

Piamenta, Mosha, 1990. A dictionary of post-classical Yemeni Arabic. Leiden: E.J. Brill. Two volumes.

Piétri, J.B., 1949. Voiliers d'Indochine. Saigon: S.I.L.I.

Pijnappel, Jan, 1875. Maleisch-Hollandsch woordenboek. Haarlem: Enschedé, Amsterdam: Muller. Second edition.

Pinnow, Heinz-Jürgen, 1959. Versuch einer historischen Lautlehre der Kharia-Sprache. Wiesbaden: Otto Harrassowitz.

Pohl, Henrik, 2007. 'From the kattumaram to the fibreteppa - Changes in boatbuilding traditions on India's East Coast.' International Journal of Nautical Archaeology 36/2:382-408.

Pollock, Sheldon, 2006. The language of the gods in the world of men. Berkeley etc.: University of California.

Poonyarit, M., D.J. Mackhill \& B.S. Vergara, 2002. 'Genetics of photoperiod sensitivity and critical day length in rice.' Crop Science 29:647-52.

Porée-Maspero, Eveline, 1986. 'Jonques et po, sampou et sampān.' Archipe/32:65-85. 
Portman, M.V., 1899. A history of our relations with the Andamanese. Vol. I. Calcutta: Office of the Superintendent of Government Printing.

Pou, Saveros \& Philip N. Jenner, 1973. 'Some Chinese loanwords in Khmer.' Journal of Oriental Studies (東方文化) 11/1:1-90

Poumailloux, Pascal, 1999. 'Le <<mtepe>>, bateau cousu des Swahili, suivi d'un glossaire technique.' Études Océan Indien 27-28:227-327.

Praharaj, G.C., 1931-40. Purnnachandra Ordia bhashakosha. Cuttack: Utkal Sahitya Press. Accessed through http://dsal.uchicago.edu/dictionaries/ (2010-11)

Prakasar, Gnana S., 1999. An etymological and comparative lexicon of the Tamil language. Chennai: International Institute of Tamil Studies.

Prakash, Buddha, 1964. India and the world: researches in India's policies, contacts, and relationships with other countries and peoples of the world. Hoshiarpur: Vishveshvaranand Vedic Research Institute.

Prata, A. Pires, 1990. Dicionário Macua-Português. Lisboa: Instituto de Investigação Científica Tropical.

Primrose, A.J., 1888. A Manipuri grammar, vocabulary and phrasebook: to which are added some Manipuri proverbs and specimens of Manipuri correspondence. Shillong: Assam Secretariat Press.

Prins, A.H.J., 1959. 'Uncertainties in coastal cultural history: The "ngalawa" and the "mtepe".' Tanganyika notes and records 53:204-13.

1970. A Swahili nautical dictionary. Dar es Salaam: Chuo cha Uchunguzi wa Lugha ya Kiswahili. Preliminary studies in Swahili lexicon 1.

1982. 'The mtepe of Lamu, Mombasa and the Zanzibar Sea.' Paideuma 28:85-100.

1986. A handbook of sewn boats: the ethnography and archaeology of archaic plank-built craft. Greenwich, London: Trustees of the National Maritime Museum. Maritime Monographs and Reports 59.

Prinst, Darwin, 2002. Kamus Karo-Indonesia. Medan: Penerbit Bina Media.

Pryce, Thomas Oliver \& S. Natapintu, 2010. 'Smelting iron from laterite: technical possibility or ethnographic aberration?' Asian Perspectives 48/2:249-64.

Pryce, Thomas Oliver, Mark Pollard \& Ernst Pernicka, 2011. 'Southeast Asia's first isotopically defined prehistoric copper production system: when did extractive metallurgy begin in the Khao Wong Prachan Valley of Central Thailand.' Archaeometry 53/1:146-63.

Przyluski, Jean, 1925. 'La princesse à l'odeur de poisson et la nāgī dans les traditions de l'asie orientale.' In: G. van Oest (ed.), Études Asiatiques publiées à l'occasion du vingt-cinquième anniversaire de l'École Française d'ExtrêmeOrient ([s.l.:] l'École Française d'Extrême-Orient. Two volumes):2/265-84.

1929. 'Non-Aryan loans in Indo-Aryan.' In: Sylvain Lévi, Jean Przyluski \& Jules Bloch (eds.), PreAryan and pre-Dravidian in India ([Calcutta:] University of Calcutta. Translated by Prabodh Chandra Bagchi):3-34.

Ptak, Roderich, 1993. 'China and the trade in cloves, circa 960-1435.' Journal of the American Oriental Society 113/1:1-13.

1998. 'Possible Chinese references to the Barus area (Tang to Ming).' In: Claude Guillot (ed.), Histoire de Barus: Sumatra. Le site de Lobu Tua. I: Études et documents (Paris: Association Archipel):119-47.

Puccioni, Nello, 1937. Le popolazioni indigene della Somalia Italiana. Bologna: Licinio Capelli.

Pulleyblank, Edwin G., 1991. Lexicon of reconstructed pronunciation of early Middle Chinese, late Middle Chinese, and early Mandarin. Vancouver: UBC Press.

Purseglove, J.W., E.G. Brown, C.L. Green \& S.R.J. Robbins, 1981. Spices. London \& New York: Longman. Two volumes.

Qaisar, Ahsan Jan, 1982. The Indian response to European technology and culture (AD 1498-1707). New Delhi: Oxford University Press.

2002. 'The Miftah-ul Fuzala'. a study of an illustrated Persian lexicon.' In: A. Jan Qaisar \& S.P Verma (eds.), Art and culture, painting and perspective (New Delhi: Abhinav Publications):17-32.

Rabin, Chaim, 1968. 'Loanword evidence in Biblical Hebrew for trade between Tamil $\mathrm{Nadu}$ and Palestine in the first millennium B.C.' In: R.E. Asher (ed.), Proceedings of the Second International Conference Seminar of Tamil Studies. Volume one (Madras: International Association of Tamil Research):432-40.

1994. 'Lexical borrowings from Indian languages as carriers of ideas and technical concepts.' In: Hananya Goodman (ed.), Between Jerusalem and 
Benares: comparative studies in Judaism and Hinduism (Albany: State University of New York):25-32.

Radhakrishnan, R., 1981. The Nancowry word, phonology, affixal morphology and roots of a Nicobarese language. Carbondale, Illinois \& Edmonton, Alberta: Linguistic research. Current Inquiry Into Language and Linguistics 37.

Raffles, Thomas Stamford, 1978. The history of Java. Kuala Lumpur: Oxford University Press. Reprint. Two volumes.

Raghavan, M.D., 1935. 'The fire-piston in South India.' Man 35:104-6.

Raghunatha Rao, B. \& B. Sasisekaran, 1997. 'Guttur: an Iron Age industrial centre in Dharmapuri District.' Indian Journal of History of Science 32/4:347-59.

Rahman, H., R. Karuppaiyan, K. Kishore \& R. Denzongpa, 2009. 'Traditional practices of ginger cultivation in Northeast India.' Indian Journal of Traditional Knowledge 8/1:23-8.

Raj, V.S. Arul \& G. Victor Rajamanickam, 1988a. 'Traditional boats in Tamil literature.' In: G. Victor Rajamanickam \& Y. Subbarayalu (eds.), History of traditional navigation (Thanjavur: Tamil University):7-18.

1988b. 'Maritime activities of Keralites (as gleaned from Malayalam literature).' In: G. Victor Rajamanickam \& Y. Subbarayalu (eds.), History of traditional navigation (Thanjavur: Tamil University):19-36.

Rajamanickam, G. Victor, 2004. Traditional Indian ship building: memories, history, technology. Dehli: New Academic Publishers.

Rajamanickam, G. Victor \& V.S. Arul Raj, 1994. Maritime history of South India: indigenous traditions of navigation in Indian Ocean. Thanjavur: Tamil University.

Rajan, K., 2002. 'Maritime trade in early historic Tamil Nadu.' Man and Environment 27/1:83-98.

2011. 'Emergence of early historic trade in peninsular India.' In: Pierre-Yves Manguin, A. Mani \& Geoff Wade (eds.), Early interactions between South and Southeast Asia: reflections on crosscultural exchange (Singapore: Institute of Southeast Asian Studies):177-96.

Ramaswami, N., 1997. Formal and informal Tamil. Mysore: Central Institute of Indian Languages.

Rangan, Haripriya, Judith Carney \& Tim Denham, 2012. 'Environmental history of botanical exchanges in the Indian Ocean World.' Environment and History 18:311-42.

Rangsiruji, A., M.F. Newman \& Q.C.B. Cronk, 2000. 'Origin and relationships of Alpinia galanga (Zingiberaceae) based on molecular data.' Edinburgh Journal of Botany 57:9-37.

Rankin, Daniel J., [1886]. Arab tales in the Túgulu dialect of the Mákua language together with comparative vocabularies of five dialects of the Mákua language. London: Society for promoting Christian knowledge.

Rao, S.R., 1993. 'Missing links in the history of boat building technology of India.' Marine Archaeology 4:60-7.

Raschke, Manfred G., 1978. 'New studies in Roman commerce with the East.' In: Hildegard Temporini (ed.), Aufstieg und Niedergang der Römischer Welt (New York: De Gruyter):604-1378.

Rathnavel, L.K., 1973. 'The Indian circumnavigators of the past.' Journal of Tamil Studies 4:24-32.

Ratnagar, S., 1981. Encounters: the westerly trade of the Harappa Civilisation. Oxford: Oxford University Press.

Ray, Himanshu Prabha, 1986. Monastery and guild: commerce under the Sātavāhanas. Oxford: Oxford University Press.

1989. 'Early maritime contacts between South and Southeast Asia.' Journal of Southeast Asian Studies 20/1:42-54.

1994. Winds of change: Buddhism and the maritime links of early South Asia. Delhi: Oxford University Press.

2003. The archaeology of seafaring in ancient South Asia. Cambridge: Cambridge University Press.

Razafindraibe, H., V.A. Mobegi, S.C. Ommeh, J. Rakotondravao, G. Bjørnstad, O. Hanotte \& H. Jianlin, 2008. 'Mitochondrial DNA origin of indigenous Malagasy chicken: implications for a functional polymorphism at the Mx gene.' Animal Biodiversity and emerging disease: annals of the New York Academy of Sciences 1149:77-9.

Rea, Alexander, 1915. Catalogue of the prehistoric antiquities from Ādichanallūr and Perumbāir. Madras: Government Press.

Reid, Lawrence A., 1994. 'Morphological evidence for Austric.' Oceanic Linguistics 33/2:323-44.

Renfrew, Colin, 1987. Archaeology and language: the puzzle of Indo-European origins. Cambridge: Cambridge University Press. 
Rensburg, Julian Jansen van, 2010. 'The Hawārī of Socotra, Yemen.' The International Journal of Nautical Archaeology 39/1:99-109.

Reynolds, Christopher, 2003. A Maldivian dictionary. London \& New York: RoutledgeCurzon.

Rhys Davids, T.W. \& William Stede (eds.), 1966. The Pali Text Society's Pali-English dictionary. London: Luzac, 1966. Reprint.

Richards, Anthony, 1981. An Iban-English dictionary. Oxford: Clarendon Press.

Richardson, James, 1885. A new Malagasy-English dictionary. Antananarivo: The London Missionary Society. Accessed through www.malagasyworld.org/ (2010-11)

Rigg, Jonathan, 1844. 'Bespiegelingen over de Maleijers.' Tijdschrift voor Neêrlandsch Indië 6/2:222-46.

1862. A dictionary of the Sunda language. Batavia: Lange \& Co.

Roberts, R.G., R. Jones \& M.A. Smith, 1990. 'Thermoluminescence dating of a 50,000-year-old human occupation site in northern Australia.' Nature 345:153-6.

Robson, Stuart \& Singgih Wibisono, 2002. Javanese English dictionary. Singapore: Periplus.

Rockhill, W.W., 1915. 'Notes on the relations and trade of China with the Eastern Archipelago and the coast of the Indian Ocean during the fourteenth century. Part II.' T'oung Pao (second series) 16/1:61-159.

Röepstorff, F.A. de, 1875. Vocabulary of dialects spoken in the Nicobar and Andaman Isles: with a short account of the natives, their customs and habits, and of previous attempts at colonization. Calcutta: Office of the Superintendent of Government Printing. Second edition.

1884. A dictionary of the Nancowry dialect of the Nicobarese language. Calcutta: Home Department Press.

Ronkel, Ph.S. van, 1902. 'Het Tamil-element in het Maleisch.' Tijdschrift voor Indische Taal- Land- en Volkenkunde 45:97-119.

1903. 'Een Maleisch telwoord in het Teloegoe?' Tijdschrift voor Indische Taal- Land- en Volkenkunde 46:568.

1905. 'Koeda sĕmbĕrani.' Bijdragen tot de TaalLand- en Volkenkunde van Nederlandsch-Indië 53:483-8.
1918. 'Drawidische volksnamen op Sumatra.' Bijdragen tot de taal-, land- en volkenkunde van Nederlandsch-Indië 74:263-6.

1933. 'Sporen van Dravida-Bataksche betrekkingen?' In: Verslag van het zevende congres gehouden te Leiden op 13-15 september 1933 (Leiden: E.J. Brill):40-3.

Ross, Alan S.C., 1952. Ginger: a loan-word study. Oxford: Basil Blackwell.

Ross, Malcolm, Andrew Pawley, Meredith Osmond, 2008. The lexicon of Proto Oceanic: the culture and environment of ancestral Oceanic society. 3: Plants. Canberra: Pacific Linguistics 599.

Rouffaer, G.P., 1905. 'Oudste ontdekkingstochten tot 1497.' In: Joh. F. Snelleman (ed.), Encyclopædie van Nederlandsch-Indië. Vierde deel: SoekapoeraKolot - Zijdeplanten ('s Gravenhage: Martinus Nijhoff / Leiden: E.J. Brill):363-95.

Rougé, J., 1987. 'La Momie, contenait-elle les fragments d'une voile?' Nouvelles archives $d u$ Muséum d'Histoire Naturelle de Lyon 25:91-6.

Roux, C.C.F.M. le, 1935. 'Boegineesche zeekaarten van den Indischen Archipel.' Tijdschrift van het Koninklijk Nederlandsch Aardrijkskundig Genootschap (second series) 52:687-714.

Rubino, Carl Ralph Galvez, 2000. Ilocano dictionary and grammar: Ilocano-English, English-Ilocano. [s.l.:] University of Hawai'i Press.

Sacleux, Ch., 1939. Dictionnaire swahili-français. Paris: Musée de l'Homme.

Sagart, Laurent, 2003. 'The vocabulary of cereal cultivation and the phylogeny of East Asian languages.' Bulletin of the Indo-Pacific Prehistory Association 23:127-36.

Sagart, Laurent, Roger Blench \& Alicia SanchezMazas (eds.), 2005. The peopling of East Asia: putting together archaeology, linguistics and genetics. New York: RoutledgeCurzon.

Sakiyama, Osamu (崎山理), 1992. ‘マダガスカルの民 族移動と言語形成民俗語彙・植物名称の意味的变 遷から (Migrations to Madagascar and formation of the language of Madagascar: a comparative study on the folk-vocabularies and plant names).' マダガスカルの民族移動と言語形成 16/4:715-62. 2009. ‘マダガスカルにおけるオーストロネシア系言 語由来の植物名称の意味变化 (Austronesian etymologies and semantic change of plant names in Madagascar).'国立民族学博物館研究報告 33/2:227-64. 
Sanchez-Mazas, Alicia, Roger Blench, Malcolm D. Ross, Ilia Peiros \& Marie Lin (eds.), 2008. Past human migrations in East Asia: matching archaeology, linguistics, and genetics. London \& New York: Routledge.

Sannasgala, P.B., 1976. A study of Sinhala vocables of Dutch origin with appendices of Portuguese and Malay/Javanese borrowings. Colombo: University of Sri Lanka.

Saraswat K.S. \& A.K. Pokharia, 1998. 'On the remains of botanical material used in the fire-sacrifice ritualized during Kushana Period at Sanghol (Punjab).' Pragdhara 8:149-81.

Sarkar, Himansu Bhusan, 1970. Some contributions of India to the ancient civilisation of Indonesia and Malaysia. Calcutta: Punthi Pustak.

Sastri, K.A. Nilakanta, 1932. 'A Tamil merchant-guild in Sumatra.' Tijdschrift voor de Indische TaalLand-en Volkenkunde 72:314-27.

1937. 'Śrīijaya, Candrabhānu and Virra-Pāṇdya.' Tijdschrift voor Indische Taal-, Land- en Volkenkunde 77:251-68.

1938. 'Southern India, Arabia and Africa.' New Indian Antiquary 1/1:24-36.

1940. 'I. Sri Vijaya.' Bulletin de l'Ecole française d'Extrême-Orient 40/2:239-313.

1944. 'The Tamil land and the Eastern Colonies.' The Journal of the Greater India Society 11:26-8.

1949. 'Takuapa and its Tamil inscription.' Journal of the Malayan Branch of the Royal Asiatic Society 22/1:25-30.

1962. 'Ceylon and Sri Vijaya.' Journal of the Ceylon Branch of the Royal Asiatic Society (new series) 8/1:125-40.

Sâstrî, Surendranath Majumdar, 1927. McCrindle's ancient India as described by Ptolemy. Calcutta: Chuckervertty, Chatterjee \& Co.

Sather, Clifford A., 1997. The Bajau Laut: adaptation, history, and fate in a maritime fishing society of South-eastern Sabah. Kuala Lumpur: Oxford University Press.

Sayce, A.H., 1887. Lectures on the origin and growth of religion as illustrated by the religion of the ancient Babylonians. London \& Edinburgh: Williams and Norgate.

Schadeberg, Thilo C., 2009. 'Loanwords in Swahili.' In: Martin Haspelmath \& Uri Tadmor (eds.), Loanwords in the world's languages: a comparative handbook (Berlin: de Gruyter Mouton):76-10.
Schafer, Edward H., 1967. The vermilion bird: T'ang images of the South. Berkeley \& Los Angeles: University of California Press.

Schlegel, Gustav, 1891. 'Chinese loanwords in the Malay language.' T'oung pao 1/5:391-405.

1899. 'Geographical Notes. X. To-ho-lo 墮和國 or Tok-ho-lo 獨和羅, Takōla or Takkōla.' T'oung Pao 10/2:155-8

Schliemann, Henry, 1881. The city and country of the Trojans: the results of researches and discoveries on the site of Troy and through the Troad in the years 1871-72, 73, 78-79. New York: Harper \& Brothers.

Schmidt, Wilhelm, 1906. 'Die Mon-Khmer-Völker, ein Bindeglied zwischen Völkern Zentralasiens und Austronesiens.' Archiv für Anthropologie 33:59106.

Schnitger, F.M., 1937. The archaeology of Hindoo Sumatra. Leiden: E.J. Brill.

Schoff, Wilfred H., 1912. The Periplus of the Erythræan Sea: travel and trade in the Indian Ocean by a merchant of the first century. New York, London, Bombay, Calcutta: Longmans, Green, and Co.

1922a. 'Aloes.' Journal of the American Oriental Society 42:171-85.

1922b. 'Camphor.' Journal of the American Oriental Society 42:355-70.

Schoterman, J.A., 1986. Indonesische sporen in Tibet. Leiden: E.J. Brill.

Schrader, O., 1917-23. Reallexicon des indogermanischen Altertumskunde: Grundzüge einer Kultur- und Völkergeschichte Alteuropas. Berlin \& Leipzig: Walter de Gruyter. Second edition. Two volumes.

Schuchardt, Hugo, 1891a. 'XII. Kreolische Studien. IX. Über das malaioportugiesische von Batavia und Tugu.' Sitzungsberichte der kaiserlichen Akademie der Wissenschaften in Wien (philosophischhistorische Classe) 122:1-255.

1891b. 'Miscellen. II: Beiträge zur Kenntnis des englischen Kreolisch. III: Das Indo-Englische.' Englische Studien 15:286-305.

Scott, Charles Payson Gurley, 1897. 'The Malayan words in English.' Journal of the American Oriental Society 18:49-124.

Scott, William Henry, 1980. Boat building and seamanship in classic Philippine society. Manila: National Museum. Anthropological papers 9. 
Seiler, Walter, 1982. 'The spread of Malay to Kaiser Wilhelmsland.' In: Rainer Carle, Martina Heinschke, Peter W. Pink, Christel Rost \& Karen Stadtlander (eds.), Gawa': studies in Austronesian languages and cultures dedicated to Hans Kähler (Berlin: Dietrich Reimer Verlag):67-85. Veröffentlichungen des Seminars für Indonesische und Südseesprachen der Universität Hamburg 17.

Selvakumar, V., 2011. 'Contacts between India and Southeast Asia in ceramic and boat building traditions.' In: Pierre-Yves Manguin, A. Mani \& Geoff Wade (eds.), Early interactions between South and Southeast Asia: reflections on crosscultural exchange (Singapore: Institute of Southeast Asian Studies):197-220.

Sen, Sri Probhat Kumar, 1962. Land \& people of the Andamans. Calcutta: Sri G.R. Bhattacharyya.

Service, Robert F., 1996. 'Rock chemistry traces ancient traders.' Science (new series) 274/5295:2012-3.

Shakespear, John, 1834. A dictionary, Hindustani and English: with a copious index, fitting the work to serve, also, as a dictionary of English and Hindustani. London: J.L. Cox and Son. Third edition. Accessed through http://dsal.uchicago.edu/ (2010-11)

Sharma, Mukunda Madhava, 1978. Inscriptions of ancient Assam. Assam: Gauhati University.

Shepherd, Gill, 1982. 'The making of the Swahili: a view from the southern end of the East African Coast.' Paideuma 28:129-48.

Sheriff, Abdul, 2010. Dhow cultures of the Indian Ocean: cosmopolitanism, commerce and Islam. London: Hurst \& Company. Zanzibar Indian Ocean Research Institute.

Shorto, Harry L., 1962. Dictionary of modern spoken Mon. Oxford. Oxford University Press. Accessed through http://sealang.net/ (2010-11)

1971. A dictionary of the Mon inscriptions from the sixth to the sixteenth centuries. London: Oxford University Press.

2006. A Mon-Khmer comparative dictionary (Canberra: Pacific Linguistics Series 579). Main editor: Paul Sidwell, assisting editors: Doug Cooper \& Christian Bauer.

Shrimali, K.M., 1976. 'The significance of the metal content of the Pancala coins.' Proceedings of the Indian History Congress 37:87-91.

Sidwell, Paul, 2005. The Katuic languages: classification, reconstruction and comparative lexicon. München: Lincom Europa. Accessed through http://sealang.net/ (2010-11)

Sila Tripati, A., 2005. 'An Indo-Arabian type of stone anchor from Kannur, Kerala, west coast of India' The International Journal of Nautical Archaeology 34/1:131-7.

Sila Tripati, A., A.S. Gaur \& Sundaresh, 2004. 'Marine archaeology in India.' Man and Environment 29/1:28-41.

Simon, Pierre, 1988. Ny fiteny fahizany: reconstitution et périodisation du malgache ancien jusqu'au XVIe siècle. Paris: Institut des langues et civilisations orientales. Travaux et documents 5. Série langues et littérature.

Singh, Maya, 1895. The Panjabi dictionary. Lahore: Munshi Gulab Singh \& Sons. Accessed through http://dsal.uchicago.edu/ (2010-11)

Singh, U. Nissor, 1906. Khasi / English dictionary. Shillong: Eastern Bengal and Assam Secretariat Press. Accessed through http://sealang.net/ (2010-11)

Sircar, D.C., 1983. 'Money in pre-Ahom Assam and its neighbourhood.' In: Jai Prakash Singh \& Nisar Ahmad (eds.), Coinage and economy of north eastern states of India (Varanasi: The Numismatic Society of India):1-6.

Sirisena, W.M., 1971. 'The Kalinga Dynasty of Ceylon and the theory of its South-East Asian origin.' The Ceylon Journal of Historical and Social Studies (new series) 1/1:11-47.

1978. Sri Lanka and South-East Asia: political, religious and cultural relations from A.D. C. 1000 to c. 1500. Leiden: E.J. Brill.

Sivashanmugam, C. \& G.V. Rajamanickam, 1988. 'History of traditional navigation in Karnataka.' In: G. Victor Rajamanickam \& Y. Subbarayalu (eds.), History of traditional navigation (Thanjavur: Tamil University):37-49.

Skeat, Walter William \& Charles Otto Blagden, 1966. Pagan races of the Malay Peninsula. London: Frank Cass \& Co. Two volumes.

Slamet-Velsink, Ina E., 1995. Emerging hierarchies: processes of stratification and early state formation in the Indonesian archipelago: prehistory and the ethnographic present (Leiden: KITLV Press). Verhandelingen van het Koninklijk Instituut voor Taal-, Land- en Volkenkunde 166.

Small, George, 1882. A Laskari dictionary or AngloIndian vocabulary of nautical terms and phrases in English and Hindustani. London: W.H. Allen. 
Smith, G. Rex, 2008. A traveller in thirteenth-century Arabia: Ibn al-Mujāwir's Tārīkh al-Mustabșir. London: the Hakluyt Society.

Smith, Helmer, 1933. 'Cinghalais ruval <<la voile>>.' Bulletin de la Société de Linguistique 34/2:216-7.

Smith, Monica L., 1999. "Indianization" from the Indian point of view: trade and cultural contacts with Southeast Asia in the early first millennium C.E.' Journal of the Economic and Social History of the Orient 42/1:1-26.

Smith, P.M, 1976. 'Minor crops.' In: N.W. Simmonds (ed.), Evolution of crop plants (London \& New York: Longman):301-24.

Smyth, H. Warington, 1906. Mast and sail in Europe and Asia. London: John Murray.

Snouck Hurgronje, Christiaan, 2007. Mekka in de tweede helft van de negentiende eeuw: schetsen uit het dagelijks leven. Amsterdam/Antwerpen: Uitgeverij Atlas. Translated by Jan Just Witkam.

Soekatno, Revo Arka Giri, 2009. Kidung Tantri Kediri. Kajian filologis sebuah naskah Jawa pertengahan. Leiden: University of Leiden. PhD dissertation.

Solheim, Wilhelm G. II, 1968. 'Early bronze in northeastern Thailand.' Current Anthropology 9/1:59-62.

1980. 'Neue Befunde zur späten Prähistorie Südostasiens und ihre Interpretation.' Saeculum: Jahrbuch für Universalgeschichte 31/3:275-317, 31/4:319-44.

Solheim, Wilhelm G. II \& S. Deraniyagala, 1972. Archaeological survey to investigate Southeast Asian prehistoric presence in Ceylon. Colombo: Department of Archaeology. Occasional paper 1.

Sopher, David E., 1965a. The sea nomads: a study based on the literature of the maritime boat people of Southeast Asia. [s.l.:] Syracuse University. Memoirs of the National Museum 5.

Sopher David E., 1965b. 'Indian boat types as a cultural geographic problem.' Bombay Geographical Magazine 13/1:5-19.

Southworth, Franklin C., 1988. 'Ancient economic plants of South Asia: linguistic archaeology and early agriculture.' In: Mohammad Ali Jazayery \& Werner Winter (eds.), Languages and cultures: studies in honor of Edgar C. Polomé (Berlin, New York, Amsterdam: Mouton de Gruyter):649-68.

2005. Linguistic archaeology of South Asia. London \& New York: RoutledgeCurzon.
Sprague, T.A. \& V.S. Summerhayes, 1927. 'Santalum, Eucarya, and Mida.' Bulletin of Miscellaneous Information (Royal Gardens, Kew) 5:193-9.

Spriggs, 2007. 'The Neolithic and Austronesian expansion within Island Southeast Asia and into the Pacific.' In: Scarlett Chiu \& Christophe Sand (eds.), From Southeast Asia to the Pacific: archaeological perspectives on the Austronesian expansion and the Lapita cultural complex (Taipei: Centres for Archaeological Studies Research):104-25.

Srinivasan, Sharada, 1994. 'Wootz crucible steel: a newly discovered production site in South India.' Papers from the Institute of Archaeology 5:44-59.

Stainton, Michael, 1999. 'The politics of Taiwan aboriginal origins.' In: Murray A. Rubinstein, Taiwan: a new history. Expanded edition (New York: An East Gate Book):27-44.

Starostin, Sergei, Anna Dybo \& Oleg Mudrak, 2003. Etymological dictionary of the Altaic languages. Leiden / Bosten: Brill. Two volumes.

Steffy, J. Richard, 1994. Wooden ships building and the interpretation of shipwrecks. College Station: Texas A\&M University Press.

Stein, Burton, 1965. 'Coromandel trade in medieval India.' In: John Parker (ed.), Merchants and scholars: essays in the history of exploration and trade (Minneapolis: University of Minnesota):49-62.

Stein, R.A., 1947. 'Le Lin-Yi: sa localisation, sa contribution a la formation du Champa et ses liens avec la Chine.' Han-Hieu: Bulletin de centre d'études sinologiques de Pékin II:1-336.

Steingass, Francis Joseph, 1892. A comprehensive Persian-English dictionary, including the Arabic words and phrases to be met with in Persian literature. London: Routledge \& K. Paul. Accessed through http://dsal.uchicago.edu/ (2010-11)

Stokhof, W.A.L. (ed.), 1984. Holle lists: vocabularies in languages of Indonesia vol.7/3: central Sulawesi, south-west Sulawesi (Canberra: Pacific Linguistics Series D-62).

1985. Holle lists: vocabularies in languages of Indonesia vol.7/4: south-east Sulawesi and neighbouring islands. West and north-east Sulawesi (Canberra: Pacific Linguistics Series D66).

Stonor, Charles, 1975. 'The blacksmith and his forge in the mountains of North-East India.' Anthropos 70:833-8. 
Subramaniam, T.N., 1957. South Indian temple inscriptions. Volume III. Part II. Madras: Government Oriental Manuscripts Library.

Subrahmanian, N., 1977. 'Cultural contacts between Tamilnadu and South East Asia.' Journal of Tamil Studies 11:11-23.

Subrahmanyam, Sanjay, 1988. 'A note on Narsapur Peta: a "syncretic" shipbuilding centre in South India, 1570-1700.' Journal of the Economic and Social History of the Orient 31/3:305-11.

1990. Improvising empire: Portuguese trade and settlement in the Bay of Bengal 1500-1700. Delhi: Oxford University Press.

Subramoniam, V.I. (director), 2008. Dialect maps of Malayalam. Thiruvananthapuram: International School of Dravidian Linguistics.

Summerhayes, Glen R., Matthew Leavesley, Andrew Fairbairn, Herman Mandui, Judith Field, Anne Ford \& Richard Fullagar, 2010. 'Human adaption and plant use in highland New Guinea 49,000 to 44,000 years ago'. Science 330:78-81.

Sunderman, H., 1905. Niassisch-Deutsches Wörterbuch. Moers: J.W. Spaarmann.

Sutlive, Vinson H. \& Joanne Sutlive, 2001. Encyclopaedia of Iban Studies: O-Z. Kuching: Tun Jugah Foundation.

Tadmor, Uri, 2009. 'Loanwords in Indonesian.' In: Martin Haspelmath \& Uri Tadmor (eds.), Loanwords in the world's languages: a comparative handbook (Berlin: de Gruyter Mouton):686-716

Takakusu, J., 1896. A record of the Buddhist religion as practised in India and the Malay archipelago (A.D. 671-695) by I-Tsing. Oxford: Clarendon Press.

Tamil, 1924-36. Tamil Lexicon. [Madras:] University of Madras. Six volumes. Accessed through http://dsal.uchicago.edu/dictionaries/ (2010-11)

Tana, Li, 2002. Nguyễn Cochinchina: southern Vietnam in the seventeenth and eighteenth centuries. Ithaca, NY: Cornell University. Second print.

Tanaka, T., 1954. Species problem in Citrus (revisio aurantiacearum, $(X)$. Ueno, Tokyo: Japanese Society for Promotion of Science.

Terrell, John Edward (ed.), 2001. Archaeology, language and history: essays on culture and ethnicity. Westport, Connecticut \& London: Bergin \& Garvey.
Teubner, Johann Karl, 1974. 'Altaisches, Fernöstliches und Malaiisches Wortgut im Suaheli.' Zeitschrift der Deutschen Morgenländischen Gesellschaft (Supplement II) XVIII:629-36.

Tewari, Rakesh, 2003. 'The origins of iron working in India: new evidence from the central Ganga plain and the eastern Vindhyas.' Antiquity 77/297:53644.

Thaman, R.R. \& W.A. Whistler. 1996. A review of uses and status of trees and forests in land-use systems in Samoa, Tonga, Kiribati and Tuvalu with recommendations for future action. Suva: South Pacific Forestry Development Programme.

Thomas, George, 1991. Linguistic purism. London \& New York: Longman.

Thomas, R.P., 1905. 'l'Origine des noms de mois à Madagascar: notes de philologie comparée.' Bulletin de l'Académie Malgache 4:17-36.

Thomas-Fattier, Dominique, 1982. Le dialecte Sakalava du nord-ouest de Madagascar: phonologie - grammaire - lexique. Paris: Selaf.

Thurgood, Graham, 1999. From Ancient Cham to modern dialects: two thousand years of language contact and change. With an appendix of Chamic reconstructions and loanwords. Honolulu: University of Hawai'i Press.

Thurston, Edgar, 1909. Castes and tribes of Southern India. Volume VII - T to Z. Madras: Government Press.

Tibbetts, G.R., 1979. A study of the Arabic texts containing material on South-East Asia. Leiden \& London: E.J. Brill.

1981. Arab navigation in the Indian Ocean before the coming of the Portuguese: being a translation of Kitāb al-Fawā'id fị ușūl al-baḥr wa'l-qawā'id of Ahmad b. Mājid al-Najdī together with an introduction on the history of Arab navigation, notes on the navigational techniques and on the topography of the Indian Ocean, and a glossary of navigational terms. London: the Royal Asiatic Society of Great Britain and Ireland.

Tideman, J., 1936. Hindoe-invloed in noordelijk Batakland. Amsterdam: De Valk.

Tolmacheva, Marina, 1986. 'Toward a definition of the term Zanj.' Azania 21:105-13.

1986-87. 'The African Wāq-Wāq: some questions regarding the evidence', Fontes Historiae Africanae, Bulletin d'Information 11-12:9-15.

Tomalin, Victoria, V. Selvakumar, M.V. Nair \& P.K. Gopi, 2004. 'The Thaikkal-Kadakkarappally boat: 
an archaeological example of medieval shipbuilding in the western Indian Ocean.' The International Journal of Nautical Archaeology 33/2:253-63.

Toorawa, Shawkat M., 2000. 'Wâq al-wâq: fabulous, fabular, Indian Ocean (?) island(s)...' Emergences 10/2:387-402.

Topping, Donald M., Pedro M. Ogo, Bernadita C. Dungca, 1980. Chamorro-English dictionary. Honolulu: University Press of Hawaii.

Torday, E., 1918. 'Outrigger canoes in the Congo.' Man 18:72

Trencker, V, 1908. 'Critical and philological notes to the first chapter (Bāhirakathā) of the MilindaPañha.' Journal of the Pali Text Society (1908):102-51. Revised and edited by Dines Andersen.

Trigger, B.G., 1989. A history of archaeological thought. Cambridge: Cambridge University Press.

Tryon, Darrell, 1994. 'Oceanic plant names.' In: A.K. Pawley \& M.D. Ross (eds.), Austronesian Terminologies: continuity and change (Canberra: Pacific Linguistics Series C-127):481-509.

Tsang, Cheng-hwa, 2005. 'Recent discoveries at a Tapenkeng cultural site in Taiwan: implications for the problem of Austronesian origins.' In: Laurent Sagart, Roger Blench \& Alicia Sanchez-Mazas (eds.), The peopling of East Asia: putting together archaeology, linguistics and genetics (New York: RoutledgeCurzon):63-73.

Tsuchida, Shigeru, 1977. 'Some plant names in Formosan languages.' Computational Analyses of Asian \& African Languages 7:79-119.

Turner, Ralph Lilley, 1961. A comparative and etymological dictionary of the Nepali language. London: Routledge.

1966. A comparative dictionary of the Indo-Aryan languages. London: Oxford University Press.

Tuuk, Herman Neubronner van der, 1862. Taalkundige aanteekeningen en bladwijzer, vertaalde stukken en inhoudsopgave tot de drie stukken van het Bataksche leesboek. Amsterdam: Frederik Muller.

1864. Tobasche Spraakkunst. Amsterdam: Frederik Muller.

1865. 'Outlines of a grammar of the Malagasy language.' Journal of the Royal Asiatic Society of Great Britain and Ireland (new series) 1:419-46.

1866. 'Short account of the Malay manuscripts belonging to the Royal Asiatic Society.' The
Journal of the Royal Asiatic Society of Great Britain and Ireland (new series) 2:85-135.

1881. 'Notes on the Kawi language and literature.' Journal of the Royal Asiatic Society of Great Britain and Ireland (new series) 13/1:42-58.

1894. Eene aanvulling der Maleische woordenboeken. 's Gravenhage: Martinus Nijhoff.

1897-1912. Kawi-Balineesch-Nederlandsch woordenboek. Batavia: Landsdrukkerij. Four volumes.

Tykot, R.H. \& Stephen Ming Soon Chia, 1997. 'Longdistance obsidian trade in Indonesia.' In: $P$. Vandiver, J. Druzik, J. Merkel \& J. Stewart (eds.), Materials issues in art and archaeology $V$ (Warrendale: Materials Research Society):175-80.

Uhlenbeck, C.C., 1898-99. Kurzgefasstes etymologisches Wörterbuch der altindischen Sprache. Amsterdam: Johannes Müller.

Uhlenbeck, E.M., 1949. De structuur van het Javaanse morpheem. Bandoeng: A.C. Nix.

van der Veen, Marijke, 2003. 'When is food a luxury?' World Archaeology 34/3:405-27.

2011. Consumption, trade and innovation: exploring the botanical remains from the Roman and Islamic ports at Quseir al-Qadim, Egypt. Frankfurt: Africa Magna Verlag.

van Driem, George, 2001. Languages of the Himalayas: an ethnolinguistic handbook of the Greater Himalayan region containing an introduction to the symbiotic theory of language. Leiden / Boston / Köln: Brill.

2012. 'The ethnolinguistic identity of the domesticators of Asian rice.' Comptes Rendus Palevol 11:117-32.

Vansina, J., 2003. 'Bananas in Cameroon c. 500 B.C.E? Not proven.' Azania 38:174-6.

Varadarajan, Lotika, 1994. 'Indian boat building traditions: the ethnological evidence.' In: MarieFrançoise Boussac \& Jean-François Salles (eds.), Athens, Aden, Arikamedu: essays on the interrelations between India, Arabia and the eastern Mediterranean (New Dehli: Manohar):16792.

1998. Sewn boats of Lakshadweep. [s.I.:] National Institute of Oceanography.

2010. 'Pre-Portuguese maritime crafts of India: the ethnological evidence.' In: [India International Centre], Water: Culture, politics and management (Noida, India: Dorling Kindersley):69-81. 
Varier, M.R. Raghava, 1988. 'Marine technology in ancient Tamilakam.' In: G. Victor Rajamanickam \& Y. Subbarayalu (eds.), History of traditional navigation (Thanjavur: Tamil University):51-62.

Vavilov, Nicolai Ivanovitch, 1926. 'Studies on the origin of cultivated plants. 'Bulletin of Applied Botany and Plant-Breeding 16/2:139-248.

1927. 'Geographical regularities in the distribution of the genes of cultivated plants.' Bulletin of Applied Botany and Plant-Breeding 17/3:411-28.

Verheijen, Jilis A.J., 1967. Kamus Manggarai I: Manggarai-Indonesia. 's-Gravenhage: Martinus Nijhoff.

1984, Plant names in Austronesian linguistics. Jakarta: Badan Penyelenggara Seri NUSA. NUSA Linguistic Studies of Indonesian and Other Languages in Indonesia 20.

1990. Dictionary of plant names in the Lesser Sunda Islands (Canberra: Pacific Linguistics Series D-83).

Verhoeven, Theodor, 1968. 'Vorgeschichtliche Forschungen auf Flores, Timor und Sumba.' In: Anthropica: Gedenkschrift zum 100. Geburtstag von P. W. Schmidt (Studia Instituti Anthropos No. 21):393-403.

Veth, Pieter Johannes, 1889. Uit Oost en West: verklaring van eenige uitheemsche woorden. Arnhem: P. Gouda Quint.

Villard, Ugo Monneret de, 1938. 'Note sulle influenze asiatiche nell'Africa orientale.' Revista degli studi orientali 17:303-49.

Vogel, Hans Ulrich \& Sabine Hieronymus, 1993. 'Cowry trade and its role in the economy of Yünnan: from the ninth to the mid-seventeenth century.' Journal of the Economic and Social History of the Orient 36/3:211-52, 4:309-53.

Vosmer, Tom, 1993. 'The yatra dhoni of Sri Lanka.' Bulletin Australian Institute for Maritime Archaeology 17/1:37-42.

Votruba, Gregory, 2010. 'Ships' anchors of the ancient world.' Presented at the Oxford University Archaeological Society Lectures, 10 May 2010, Oxford.

Wackernagel, Jakob, 1903. 'Prakritismen im altindischen.' In: Otto von Böhtlingk (ed.), AlbumKern: opstellen geschreven ter eere van Dr. $H$. Kern, hem aangeboden door vrienden en leerlingen op zijn zeventigsten verjaardag (Leiden: E.J. Brill):149-52.
Walker, Alan \& R. David Zorc, 1981, 'Austronesian loanwords in Yolngu-Matha of northeast Arnhem Land.' Aborginal History 5/2:109-34.

Walsh, Martin, 1995. 'Eating bats on Pemba Island: a local innovation or borrowing?' Mvita: Newsletter of the Regional Centre for the Study or Archaeology in Eastern and Southern Africa 6:158.

2010. 'Deep memories of symbolic statements? The Diba, Debuli, and related traditions of the East African coast.' In: Chantal Radimilahy \& Narivelo Rajaonarimanana (eds.), Civilisations des mondes insulaires (Madagascar, îles de canal de Mozambique, Mascareignes, Polynésie, Guyanes): mélanges en l'honneur du professor Claude Allibert (Paris: Karthala):453-76.

2012. 'The crocodiles of Azania and the prehistory of the western Indian Ocean.' Presented at the workshop East Africa in the Indian Ocean World II, 22-23 March 2012, Oxford.

Walter, A. \& C. Sam. 2002. Fruits of Oceania. Canberra: Australian Centre for International Agricultural Research. ACIAR Monograph 85. Translated by P. Ferrar.

Ward, C.A., 2006. 'Boat-building and its social context in early Egypt: interpretations from the First Dynasty boat-grave cemetery at Abydos.' Antiquity 80/307:118-29.

Warminton, E.H., 1974. The commerce between the Roman Empire and India. London: Curzon Press I New York: Octagon Books. Second edition.

Warneck, Joh., 1977. Toba-Batak - Deutsches Wörterbuch. Den Haag: Martinus Nijhoff.

Watson, Richard, 2009. Pacoh lexicon. Unpublished manuscript. Accessed through http://sealang.net/ (2010-11)

Watt, George, 1889-96. A dictionary of the economic products of India. Calcutta: Department of Revenue and Agriculture. Six volumes.

Webster, Hutton, 1948. Magic: a sociological study. Stanford: Stanford University Press \& London: Geoffrey Cumberlege / Oxford University Press.

Weerakkody, D.P.M., 1997. Taprobanê: ancient Sri Lanka as known to Greeks and Romans. Turnhout: Brepols.

Wehr, Hans, 1976. A dictionary of modern written Arabic. Ithaca, New York: Spoken language services. Third edition.

Weinreich, Uriel, 1974. Languages in contact: findings and problems. The Hague / Paris: Mouton. 
Wheatley, Paul, 1959. Geographical notes on some commodities involved in sung maritime trade. Singapore: Tien Wah Press. Journal Malayan Branch Royal Asiatic Society 32/2.

1961. The Golden Khersonese: studies in the historical geography of the Malay Peninsula before A.D. 1500. Kuala Lumpur: University of Malaya Press.

1983. Nāgara and commandery: origins of the Southeast Asian urban traditions. Illinois: University of Chicago.

Whitehead, G., 1925. Dictionary of the Car-Nicobarese language. Rangoon: American Baptist Mission Press. Accessed through http://sealang.net/ (2010-11)

Whitewright, Julian, 2009. 'The Mediterranean lateen sail in late antiquity.' The International Journal of Nautical Archaeology 38/1:97-104.

2010. 'The potential performance of ancient Mediterranean sailing rigs' The International Journal of Nautical Archaeology 40/1:1-16.

Wicki, J., 1971. 'Lista des moedas, pesos e embarcações do Oriente, composta por Nicolau Perreira S.J. por 1582.' Revista Studia 33:137-48.

Wicks, Robert S., 1992. Money, markets, and trade in early Southeast Asia: the development of indigenous monetary systems to $A D$ 1400. Ithaca, New York: Cornell University.

Wiener, Leo, 1921. 'Once more the sucking-fish.' The American Naturalist 55/637:165-74.

Wijesekera, N.D., 1949. The people of Ceylon. Colombo: M.D. Gunasena.

Wild, J.P., 1970. 'Borrowed names for borrowed things?' Antiquity 44/174:125-30.

Wild, Felicity C. \& John P. Wild, 2001. 'Sails from the Roman port at Berenike, Egypt.' The International Journal of Nautical Archaeology 30/2:211-20.

Wild, John P. \& Felicity C. Wild, 2000. 'Textiles.' In: Steven E. Sidebotham \& Willemina Z. Wendrich (eds), Berenike 1998: report of the 1998 excavations at Berenike and the survey of the Egyptian Eastern Desert, including excavations at Wadi Kalalat (Leiden: Research School of Asian, African, and Amerindian Studies):251-76.

Wilkinson, R.J., 1932. A Malay-English dictionary (romanised). Mytilene: Salavopoulos and Kinderlis. Two volumes.

Williams, Robert Orchard, 1949. The useful and ornamental plants in Zanzibar and Pemba. London: St. Ann's Press.
Wilson, Thomas H. \& Athman Lali Omar, 1997. 'Archaeological investigations at Pate.' Azania 32/1:31-76

Wink, André, 1990. Al Hind: the making of the IndoIslamic world. Volume 1: Early medieval India and the expansion of Islam $7^{\text {th-1 }} 11^{\text {th }}$ centuries. Leiden: E.J. Brill.

Winstedt, R.O., 1920. Hikayat Bayan Budiman atau Chěrita Khojah Maimun. Singapore: Methodist Publishing House.

Witzel, Michael, 1999. 'Early sources for South Asian substrate languages.' Mother Tongue (extra number 1999):1-70.

2009. 'South Asian agricultural terms in Old IndoAryan.' In: Toshiki Osada (ed.), Linguistics, archaeology and human past in South Asia (New Dehli: Manohar):79-100.

Wolff, John U., 1972. A dictionary of Cebuano Visayan. Manila: The Linguistic Society of the Philippines.

1974. 'Proto-Austronesian ${ }^{*} r$ and *d.' Oceanic Linguistics 3/1-2:77-121.

1976. 'Malay borrowings in Tagalog.' In: C.D. Cowan \& O.W. Wolters (eds.), Southeast Asian history and historiography: essays presented to D.G.E. Hall (Ithaca \& London: Cornell University Press):345-67.

1994. 'The place of plant names in reconstructing proto Austronesian' In: A.K. Pawley \& M.D. Ross (eds.), Austronesian terminologies: continuity and change (Canberra: Pacific Linguistics Series C127):511-40.

2010. Proto-Austronesian phonology with glossary. Ithaca, NY: Cornell Southeast Asia Program Publications. Two volumes

Wolters, O.W., 1960. 'The "Po-ssŭ” pine trees.'Bulletin of the School of Oriental and African Studies 23/2:323-50.

1967. Early Indonesian commerce: a study of the origins of Śrivijaya. Ithaca, New York: Cornell University Press.

1979. 'Studying Śrivijaya.' Journal of the Malaysian Branch of the Royal Asiatic Society 52/2:1-32.

Woodford, R. C., 2005. Citrus classification. Delhi: Biotech Books.

Wu I-lin (吳意琳), 2005. ‘史前臺灣的交通與「船」.’發 現一史前館電子報. Accessed through http://www.nmp.gov.tw/enews/no66/page_02.html (October 2012) 
Yajima, Hikoichi, 1976. The Arab dhow trade in the Indian Ocean: preliminary report. Tokyo: Tokyo Gaikokugo Daigaku.

Yamada, Kentaro, 1955. A study on the introduction of an-hsi-hsiang in China and that of gum benzoin in Europe. II. [s.I.]: the Kinki University. Reports of the Institute of World Economics No. 7.

Young, Gary Keith, 2001. Rome's eastern trade: international commerce and imperial policy, 31 BC - $A D$ 305. London \& New York: Routledge.

Yuanzhi, Kong, [2005]. Silang budaya Tiongkok Indonesia. [s.I.:] PT Bhuana IImu Populer.

Yule, Henry, 1871. The book of Ser Marco Polo: concerning the kingdoms and marvels of the east. Volume 2. London: John Murray.

Yule, Henry \& A.C. Burnell, 1903. Hobson-Jobson: a glossary of colloquial Anglo-Indian words and phrases, and of kindred terms, etymological, historical, geographical and discursive. London: John Murray. New edition edited by William Crooke.

Zhang, Yongyan (张永言), 1989. '汉语外夹词杂谈.' 语 言文字学 9:90-8.

Zide, Arlene R.K. \& Norman H. Zide, 1976. 'ProtoMunda cultural vocabulary: evidence for early agriculture'. In: P.N. Jenner, L.C. Thompson \& S. Starosta (eds.), Austroasiatic Studies // ([s.I.:] University Press of Hawaii i):1295-334.

Zide, Norman \& Vishvajit Pandya, 1989. 'A bibliographical introduction to Andamanese linguistics.' Journal of the American Oriental Society 109/4: 639-51.

Zoetmulder, P.J., 1982. Old Javanese-English dictionary. 's-Gravenhage: Martinus Nijhoff. Two volumes.

Zohary, Daniel \& Maria Hopf, 1994. Domestication of plants in the Old World: the origin and spread of cultivated plants in West Asia, Europe, and the Nile Valley. Oxford: Clarendon Press. Second edition.

Zorc, R. David Paul, 1994. 'Austronesian cultural history through reconstructed vocabulary (an overview).' In: A.K. Pawley \& M.D. Ross (eds.), Austronesian terminologies: continuity and change (Canberra: Pacific Linguistics Series C-127):54194.

Zuckermann, Ghil'ad, 2003. Language contact and lexical enrichment in Israeli Hebrew. Houndmills, Basingstoke, Hampshire: Palgrave MacMillan.

Zumbroich, Thomas J., 2007-08. 'The origin and diffusion of betel chewing: a synthesis of evidence from South Asia, Southeast Asia and beyond.' Electronic Journal of Indian Medicine 1:63-116.

2009. 'Teeth as black as a bumble bee's wings': the ethnobotany of teeth blackening in Southeast Asia.' Ethnobotany Research \& Applications 7:381-98.

Zvelebil, Kamil Veith, 1990. Dravidian linguistics: an introduction. Pondicherry: Pondicherry Institute of Linguistics and Culture. 


\section{Index}

'Abbāsī, 217

Abhayagiri, 99

Abū Hanīfä̈, 145

Account of Remarkable Objects in the

Southern Provinces, 207

Aceh, 66, 72

Admirality Islands, 230

Aëtius of Amida, 181

agarwood, 195

agriculture, 23, 27, 49, 67, 74, 127, 252, 253, 257

Ajanta caves, 208, 227

al-Balāduri, 111

Alexander of Miletus, 226

Alexandrian Tariff, 175

al-Harīīi ship, 228

al-Idrīsī, 112, 113

al-Maǵribī, 112

al-Mas'ūdī, 100, 117

ambergris, 87, 110, 117

anchor, 34, 38

Andaman Islands, 87, 90, 124, 239, 257

areca nut, 48, 131-40, 171, 208, 255

aromatic ginger, 162, 170

Aśoka, 52, 56

Atîsa, 58

Axum, 55

Āyurvedic medicine, 173

back-formation, 39, 93, 135, 153, 160, 163,

170, 187, 188, 260

Bajau people, 105, 108, 221

Bālarāmāyaṇa, 93

Bali, 54, 81

banana, 27, 42, 48, 128, 146-51, 170, 208,

255, 258, 262

Banda Islands, 180

Bangka, 76, 78

Barus, 66, 102, 187, 196 beads, $54,57,92,93,236$

benzoin, 59, 189, 195

Berenike, 236

betel leaf, $27,53,128,131-40,170,171,207$, 208, 255

bilimbi, 166

Bismarck Archipelago, 156, 211, 230

blacksmith (metallurgy), 82

blowgun, 95

Bodhisattvāvadāna Kalpalatā, 52

Borneo, 71, 72, 73, 96, 108, 121, 168, 173, $185,219,221,254$

borneol, 162, 185, 187

Borobudur, 201, 208, 209, 227, 237

Bozorg bin Šahriyār, 117, 118

Brahmi inscriptions, 55, 58, 211

Brahmins, 54, 56, 57, 58, 143, 204

Brhatkathā-Śloka-Sanigraha, 62

bronze, 48, 66, 68, 69, 75, 80, 229

Buddhism, 22, 47, 52, 53, 55, 58, 62, 99, 105, 129, 131, 174, 200, 204, 261

Bujangga Manik, 156, 210, 246

Butsarana, 104

cajuput tree, 167

calambac, 192, 193

calque, 36, 38, 179, 185

camphor, 66, 92, 174, 185-88, 196, 255, 256

Cańkam literature, 78, 210

Caraka-Samhitā, 178

cardamom, 173, 196

ceramics, 42, 43, 48, 54, 66, 99, 109, 114, 198 , 236

Chagos Islands, 25, 85, 106, 262

Chandrabhānu, 100

Chén Cángqì, 65

chicken, 128

China, 22, 24, 27, 46, 47, 58, 65, 66, 75, 76, $96,99,108,117,133,152,157,162,167$. 
180, 184, 186, 190, 200, 202, 209, 214, 216,

235, 241, 252, 257, 261, 263

cinnamon, 99, 173, 176, 177, 196, 204

citron, 151, 152

citrus fruits, 151-57

cloves, 22, 34, 38, 66, 92, 101, 174-80, 196,

255, 256, 259

cockatoos, 94

coconut (palm), 48, 104, 115, 128, 140-46,

171, 203, 207, 208, 220, 231, 236, 261

coins, 67, 75, 77, 108, 208

coir, 107, 142, 220

Cōlas, 58, 83, 250

Comoros Islands, 112, 114, 116, 205, 239

copper, 46, 67, 68, 75

Cosmas Indicopleustes, 186

cotton, 49, 236, 261

cowries, 108, 109, 115, 125

cubeb (pepper), 174, 184, 185

Cūlavamisa, 96, 100

cutch, 132, 135, 140

dammar, 189, 220

Dayr al-Bahrī̄, 223

Description of Cities, Indian and Persian, 63

Dioscorides, 158, 191

Đông Sơn, 68, 70, 76, 237

dowels, 200, 213, 221

Duarte Barbosa, 105

durian, 34, 167

Dvāravatī, 53, 90

East Africa, 20, 25, 46, 48, 50, 86, 111, 112, 113-24, 125, 134, 135, 140, 142, 146, 149 169, 174, 196, 200, 205, 207, 215, 218, 233, 239, 250, 254, 255, 256, 257, 260, 262

Egypt, 46, 112, 116, 122, 186, 188, 222, 223, 224, 252, 256

elephantiasis, 116

Enquiry into Plants, 185

ensets, 146, 148, 150, 170

epigraphy, 53, 94, 100, 124, 125, 215
Fàn Chéngdà, 152

Făxiăn, 99

fish poison, 119, 120

Flores, 199

folk-etymology, 39, 77, 160, 176, 192, 248

Former Han Annals, 66, 175

foxtail millet, 62, 128

frankincense, 110, 190, 191

Fujian, 200, 241

galangal, 161, 162, 170, 255

gambir, 132, 139

Garcia da Orta, 166

genetics, 21, 54, 114, 121, 124, 142, 199

Geōgraphiká, 218

ginger, 42, 128, 157-61, 163, 170, 255

godown, 97

gold, 67, 68, 69, 74, 75, 78, 83, 118, 172

Hağğ, 111, 123

Hainan, 134, 200

Han Dynasty, 66

Harappan civilisation, 48, 50, 203, 222, 224

Harivamiśa, 210

Hikayat Amir Hamzah, 217

Hikayat Bayan Budiman, 97, 156, 217

Hikayat Raja Pasai, 214, 217

Hinduism, 52, 53, 129, 131, 174, 181, 260, 261

Historia Naturalis, 175, 185, 204, 218

History of the Song Dynasty, 75, 210

horses, 58, 59, 60

Huì-lín, 207

hypercorrection, 179, 245

I la Galigo, 106

Ibn al-Muǧāwir, 112

Ibn al-Wardī, 117

Ibn Batțūțä̈, 106

Ibn H_ordādbeh, 265

Ibn Māğid, 112, 227, 247

Imru' al-Qais, 186

Indian almond, 194 
Indianisation, 26, 53, 56, 69, 84, 254

iron, 67-74, 75, 77, 78, 79, 83, 87, 96, 112,

114, 200, 213, 218, 221, 246

Islam, 84, 105, 111, 196

Isthmus of Krā, 64

jackfruit, 91

Jaffna, 60, 61, 100

Jātpeople, 111

Jātakas, 134

Jatāvarman Vîra Pāndya, 100

Java, 60, 62, 66, 99, 154, 162, 174, 184, 208

Java long pepper, 183, 196

Ji Hán, 137

Job's tears, 59

junk, 207, 210, 213, 216

Kadakkarapally boat, 203, 209, 222

Kālidāsa, 178

Kalingga, 81, 100, 140, 246

Kathāsaritsāgara, 66, 178, 184

Kāvya literature, 175

Keboan Pasar inscriptions, 155

Kedukan Bukit inscription, 215

Kelani Ganga boat, 202, 237

Kelenderis ship mosaic, 226

Kellia ship graffito, 226

kəris, 96

Khao Sam Kaeo, 54

Kiṣkindhākānḍa, 62

Kitāb 'Ağā'ib al-Hind, 117

Kitāb al-Masālik w’al-Mamālik, 265

Kitāb Bast al-Arọ, 112

Kitāb Futūh al-Buldān, 111

Kitāb Nuzhat al-Muštāq fi Iṇtirāq al-Afāq, 112

Kot Dịīi, 148

Kșemendra, 52

Kuahuqiao boat, 200, 224, 238

Kuala Selinsing, 68

Kuñjarakarṇa, 72

Laskari, 217 lateen sail, 206, 225-28, 229, 231, 232, 233, 238,250

lemon, 151, 152, 155, 156, 157

lime (fruit), 92, 128, 157, 170, 255

lime (material). See slaked lime

linguistic purism, 37, 195

Ludovico de Varthema, 193

Mǎ Huān, 105

mace, 180, 182

Madagascar, 24, 25, 71, 86, 104, 106, 112, $113,114,115,116,121,123,124,133,140$, 149, 154, 171, 201, 206, 211, 231, 239, 240 , 254, 256, 262

Mahābhārata, 129, 134, 164

Mahāvamisa, 52

Malacca, 76, 201

Maldives, 28, 29, 86, 104-9, 116, 219, 222, 229, 231, 239, 250, 254, 256, 258

Maluku, 93, 101, 132, 149, 165, 167, 173, 174, $177,179,180,181,219$

mango, 37, 42, 49

mangosteen, 168

Marco Polo, 63, 219

Marcus Aurelius, 175

mast (ship), 205, 223, 225, 226, 228, 231, 232 , 233, 235

Materia Medica, 191

Maturaikkāñci, 210, 247

Mayotte, 25, 206, 250

Mediterranean, 175, 202, 218, 223, 226, 228, 246

megalithic traditions, 27,48

Mesopotamia, 48, 109, 196, 202, 222, 252

metallurgy, 21, 26, 47, 49, 67-74, 76, 79, 81, $82,115,221,252,253$

metathesis, 156, 160, 163, 209, 234

Middle East, 20, 25, 26, 46, 47, 65, 66, 76, $104,106,109-13,140,149,151,152,154$, $157,158,162,169,175,176,186,191,195$, 
196, 203, 207, 218, 224, 239, 254, 255, 256, 260, 262

Miftāh-ul Fuzālä̈, 249

Milindapañho, 62, 234, 247

Minicoy, 104, 106, 222

Moken people, 90, 124, 210, 224, 258, 263

Murūğ ad-Dahab wa Ma'ādin al-Ǧawahir, 117

Myanmar, 52, 76, 86, 151, 235, 253, 263

Nāgā populations (Tibeto-Burman), 52

Nāgas, 51, 52, 139

Nālandā monastery, 58

nautical technology, 198, 202, 207, 246, 249, 250, 258

neem, 153

neologism, 29, 36, 188, 259

New Guinea, 41, 93, 147, 149, 150, 167, 173, 198, 230, 239

Nias, 63, 117

Nicobar Islands, 86-91, 124, 137, 239, 257

Nicolò Ponti, 63

Niddesa, 62

Nirukta, 129

North Sumatra, 51, 58, 60, 83, 254, 263

Northeast India, 27, 48, 52, 71, 96, 108, 119, 151, 158, 162, 163, 191, 263

nuggār boats, 223, 239

numerals, 60

Nusa Tenggara, 48, 130, 132, 149, 219

nutmeg, 22, 174, 180-82, 184, 188, 196, 197, $255,259,260$

obsidian, 199

Óc Eo, 54

Oceania, 24, 48, 108, 119, 133, 199, 200, 210, $211,212,223,229,230,234,237,241,245$, 252

orange, $48,151,153,155,156$

outriggers, 25, 45, 91, 99, 200, 202, 205, 209, $222,225,231,232,237-43,249,250$

paddle types, 68, 90, 243, 244, 249

Pañcatantra, 178, 187
Paraiyar community, 60

Parākramabāhu II, 100

parrots, 93, 94

peanut, 123

Peinan, 133

Pemba, 115, 117

pepper species, $99,170,173,174,175,181$, 195, 196, 236

Periplus, 55, 114, 131, 144, 191, 204, 205, 218

Periya-Purānam, 211

Philippines, 42, 69, 72, 132, 133, 166, 219, 221, 239, 241

Phoenicians, 75, 223

phonology, 38, 122

piracy, 52, 86, 87, 90, 116

piston bellows, 70, 73, 253

plank-sewing, 218, 219, 261

plantain. See banana

Plants of the Southern Regions, 137, 138

Pliny the Elder, 77, 158, 175, 185, 204, 218

pottery. See ceramics

Ptolemy, 62, 66, 158

pummelo, 151, 156

Purāna-Sarvasva, 135

Pyrard de Laval, 105

Qur'an, 158, 186

Qușair al-Qadìm, 122, 134, 148

Raghuvamíá, 129, 175, 178

Rājanighantu, 152

Rājaśekhara, 93

Rāmāyaṇa, 62, 129, 134, 155, 156, 175, 178

rambutan, 34, 167

Ratu Baka inscription, 99

Records of Foreign Peoples, 184

Rg Veda, 52

rice, $26,42,49,62,98,99,111,120,121,122$, 128,208 
Romans, 22, 46, 47, 75, 84, 99, 112, 114, 158, 172, 174, 182, 184, 186, 196, 204, 218, 227. 252

rudder types, 206, 244, 245, 246, 250

Sabokingking Naga inscription, 210

Saddharma-Ratnāvaliya, 104

sago, 167

sail types, 102, 160, 205, 206, 208, 222-36, 237, 239, 250, 255, 258

Śailendra Dynasty, 63

Samarāiccakahā, 248

sambook, 215, 216

sampan, 215, 216

sandalwood, 22, 30, 47, 128, 129-31, 171,

174, 181, 184, 188, 195, 196, 197, 208, 255 , 256, 260

sappan-wood, 194, 195, 221

Sayābiğä̈, 111

Seychelles, 25, 85, 106, 262

Sī̄nisamisa Jātaka, 234

silver, 69, 75, 77, 78, 83, 92

Sixteen Books on Medicine, 131, 181

skipjack tuna, 106

slaked lime, 132, 137, 180, 196, 220

slave trade, $86,105,112,113,116,117,124$, $125,200,254,262$

Smaradahana, 210

Socotra, 55, 203

Sofala, 117,124

Solomon Islands, 221

Somalia, 115

Song Dynasty, 93, 134, 235

Sorabe literature, 211

sorghum, 42, 49, 62

Sounds and Meanings in the Vinaya, 207

South India, 48, 51, 59, 60, 61, 71, 72, 74, 76,

79, 83, 96, 99, 129, 139, 143, 254, 262

spice trade, 172-97, 252, 260

spritsail, 227, 230-33, 250
Sri Lanka, 28, 45, 56, 76, 86, 101, 104, 106, $125,143,150,203,222,229,231,237,239$, 250, 254, 256, 257, 258

Śrī Vijaya, 53, 58, 63, 100, 183, 184, 200

steel, 77,79

Strabo, 218

sugar palm, 134, 167, 220

sugarcane, 42, 121, 128, 146

Sulawesi, 51, 63, 123, 215, 219, 242, 257

Sumatra, 25, 58, 59, 61, 62, 66, 72, 74, 76, 86, 99, 105, 112, 118, 139, 173, 185, 198, 201, $225,231,254$

Supplement to Materia Medica, 65

Suśruta-Samihita, 135, 164, 184, 187

Sutra of the Life of Sākyamuni to His Twelfth Year, 183

Taiwan, 23, 41, 42, 44, 71, 72, 133, 137, 143, 149, 199, 200, 210, 263

Tākū`a Pā’, 64

tambourine, 101

Tang Dynasty, 198

Tanjore inscription, 100, 166

Tantri Kaḍiri, 155

Tantri Kāmandaka, 155

Tārīh al-Mustabșir, 112

taro, 42, 122, 128

teak, 203, 236

Terqa, 176

Tezpur rock inscription, 109

Thailand, 54, 68

Thai-Malay Peninsula, 64, 68, 74, 75, 76, 100, 139, 185, 253, 254

Theophrastus, 185

Tilakamañjarī, 248

Timor, 199, 229

tin, 48, 53, 68, 69, 75, 76, 77, 78, 253

Tirupputaimarutūr temple, 228

Tiruvịlaiyātar-Purānam, 211

toddy, 141, 143, 145

Tomé Pires, 105 
Topographia Christiana, 131, 144

troglodytes, 204

turmeric, 163, 164, 165, 208

turtle, 99, 114, 115, 117, 166

Tutuala rock paintings, 229, 237

Unādi-sūtras, 178

urbanisation, 49, 50, 252, 253

Vasco da Gama, 219

Vietnam, 54, 55, 68, 200

Visuddhimaga, 234

Võ-cạnh inscription, 54

Wadebuli, 116

Wadiba, 116

Wàn Zhèn, 207

Wāqwāq, 117, 124 wootz, 79

xylophone types, 115, 123

yam, 27, 42, 122, 123, 128

Yāska, 129

Yellow Charts of the Three Regions, 137

Yemen, 111, 122

Yijìng, 58, 81

Yuktikalpataru, 206

Yunnan, 71, 151, 263

yūpa stone inscriptions (Kutai), 54

Zābağ, 63, 100, 112, 113

Zanğ, 112, 113, 117

Zanzibar, 112, 115, 116

zedoary, 163, 164

Zhào Rǔguā, 100, 184 